The copyright of this thesis vests in the author. No quotation from it or information derived from it is to be published without full acknowledgement of the source. The thesis is to be used for private study or noncommercial research purposes only.

Published by the University of Cape Town (UCT) in terms of the non-exclusive license granted to UCT by the author. 


\title{
Mesoscale Convective Complexes over southern Africa
}

\author{
By Ross C. Blamey
}

Supervisor:

Prof. Chris J. C. Reason

\section{Thesis Presented for the Degree of DOCTOR OF PHILOSOPHY}

In the Department of Oceanography

Faculty of Science

University of Cape Town

June 2012 


\section{$\sim$ Declaration}

I hereby declare that all the work presented in this thesis is my own, except where otherwise stated in the text. This thesis has not been submitted in whole or in part for a degree at any other university.

\section{Ross Campbell Blamey}

11 November 2011 .

Date

\section{Publications:}

Blamey R. C. and C. J. C. Reason, 2012: Mesoscale Convective Complexes over Southern Africa. Journal of Climate, 25, 753-766.

Blamey R. C. and C. J. C. Reason, 2012: The role of Mesoscale Convective Complexes in southern Africa summer rainfall. Submitted to Journal of Climate.

Blamey R. C. and C. J. C. Reason, 2012: An analysis of three mesoscale convective complexes over southern Africa. In Prep. 


\section{Abstract}

A combination of numerous factors, including geographic position, regional orography and local sea surface temperatures, ensures that subtropical southern Africa experiences considerable spatial and temporal variability in rainfall and is prone to both frequent flooding and drought events. One system that may contribute to rainfall variability in the region is the mesoscale convective complex (MCC). Defined as a large, long-lived, quasi-circular convective system, MCCs have been found to be beneficial in various regions around the world in that they can make a large contribution to the seasonal rainfall totals. However, most research on these systems and the rainfall they produce has been focused outside of Africa, with southern Africa in particular receiving little attention.

Through the use of an objective and automated tracking method, a detailed climatology of 70 MCCs that occur during the austral summer months over southern Africa for the 1998-2006 period is presented in this thesis. Most MCCs are clustered along the eastern regions of southern Africa, adjacent to the warm waters of the Mozambique Channel and Agulhas Current. It is also found that a few infrequent systems develop in Namibia and Botswana. The systems are found to predominantly occur during the months of November - February, with maximum activity occurring in November and December. Although fewer in number ( $\sim 9$ per season) compared to MCC populations in other regions, the systems do tend to follow the nocturnal lifecycle as documented elsewhere. The results also suggest that there is variability in MCC frequency on monthly and seasonal timescales.

An analysis on the synoptic environments in which MCC develop over southern Africa reveal that moisture transport and instability of the atmosphere are more 
favourable during the core summer months as compared to the transition seasons of October and March. Additionally, the transition from a more midlatitude dominated circulation to a tropical circulation over the region during the late summer leads to an uncharacteristic (compared to MCC behaviour elsewhere) equatorward migration of MCC distribution then. Consistent with MCC populations elsewhere, the systems over southern Africa are found to develop in a wide variety of large-scale environments. Three MCC case studies are presented, with each indicating that these systems evolve in an environment that contains significant moisture transport and is convectively unstable for long periods of time. In all cases, the moisture appeared to originate from the neighbouring southwest Indian Ocean.

Due to southern Africa being mainly a data sparse region, with no dense raingauge network being available post-1999, the Tropical Rainfall Measuring Mission (TRMM) Multi-satellite Precipitation Analysis 3B42 version 6 dataset (TMPA) are used for the rainfall analysis. Most of the rainfall associated with MCCs is found to occur over central Mozambique and extending southwards to eastern South Africa. High precipitation totals associated with these systems also occur over the neighbouring ocean, particularly off the northeast coast of South Africa. MCCs are found to contribute up $20 \%$ of the total summer rainfall (November - March) in parts of the eastern region of southern Africa. If the month of March is excluded from the analysis, then the contribution increases up to $24 \%$. Over the western interior, in places such as Botswana and Namibia, the MCC contribution is much less (about 6\%). The analysis also indicates that El Niño-Southern Oscillation (ENSO) may influence MCC rainfall over the region, with systems contributing more (less) during La Niña (El Niño) years. 


\section{Acknowledgments}

This thesis would not have been possible without the financial assistance provided by the National Research Foundation (NRF), UCT Postgrad Funding Office and the Marine Research Institute (Ma-Re). I would also like to thank the American Metrological Society (AMS), the World Meteorological Organisation (WMO) and Institute de recherche pour le développement (IRD) for providing funding to attend international conferences during my studies.

Secondly, projects such as these require datasets from various organisations. So thank you to EUMETSAT (www.eumetsat.int) for the satellite data and their technicians who provided assistance. The NCEP data is provided by the NOAA/Earth Systems Research Laboratory Physical Sciences Division (ESRL:PSD), Boulder, Colorado, from their website http://www.cdc.noaa.gov/. The CFSR data was developed by NOAA's National Centers for Environmental Prediction (NCEP). The data for this study are from NOAA's National Operational Model Archive and Distribution System (NOMADS) which is maintained at NOAA's National Climatic Data Center (NCDC). The TMPA rainfall data used in this effort were acquired as part of the activities of NASA's Science Mission Directorate, and are archived and distributed by the Goddard Earth Sciences (GES) Data and Information Services Center (DISC).

Thank you also to Dr. Leila Carvalho and Dr. Charles Jones for allowing me to use the MASCOTTE program and to Dr. Daniel Parades for the technical assistance with it. For all the other technical assistance over the years, thank you to Chris Jack, Christo Whittle and Neil Hart.

To the staff and students of the Oceanography Department, thank you for all your support over the years, which is something I will always appreciate. It had to be one of the best working environments (there won't be too many other places where the postgrad students are allowed to play corridor golf). In particular, to Bus, Jane, Burly, Ten, Heks, Bjorny, Canada and Jen-ni-fer, thank you!!! Being in the "PhD boat" all together was a great adventure and full of laughs.

To my family, Mum and Dad, thank you for giving me the opportunity to study what I love and enjoy doing. There are no words that can express how appreciative I am of the support and guidance you have given me throughout my life. Laura, you may have beaten me to the PhD finish line, but it was never a race (ok it was). I could not have asked for a better sibling rivalry. Thank you for all the guidance and encouragement over the years, as well as all the discussions and arguments. To my younger sister, Jo, although you been a million miles 
away for the last few years, you were always there with messages of support and have always been there when needed. Tom thanks for always reminding me of the simple things in life...live life, play hard and laugh along the way.

Finally, to my supervisor, Prof. Chris Reason, thank you for all your hard work, support and time that you put in to help me achieve my goals. The supervisor is central to any students $\mathrm{PhD}$ and I was very fortunate enough to have you guiding me through it. Thank you! 


\title{
$\sim$ Table of Contents
}

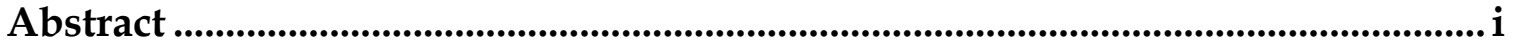

Acknowledgements ............................................................................................... ii

List of Tables and Figures ..................................................................................... ix

List of Acronyms .............................................................................................. xxiii
\end{abstract}

Chapter One - Introduction and Thesis Overview ................................................ 1

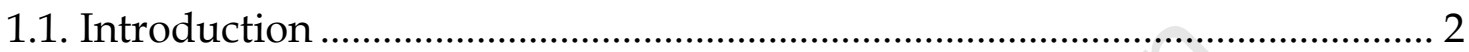

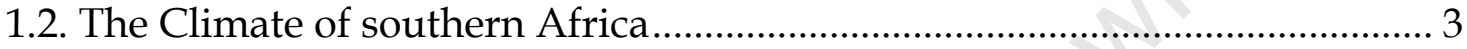

1.2.1. Characteristics of the southern African Climate .................................... 4

1.2.2. Atmosphere Circulation Patterns ............................................................ 5

1.2.3. Mean Precipitation Patterns ............................................................... 7

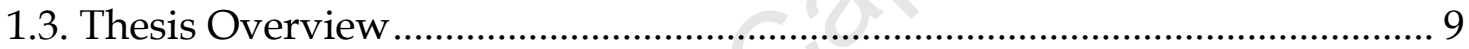

Chapter Two - Literature Review .............................................................................. 16

2.1. The Mesoscale Convective Complex.......................................................... 17

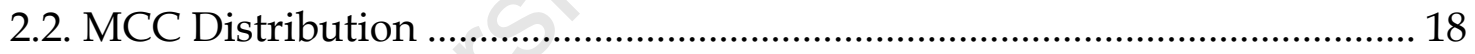

2.3. The MCC Life Cycle.................................................................................. 20

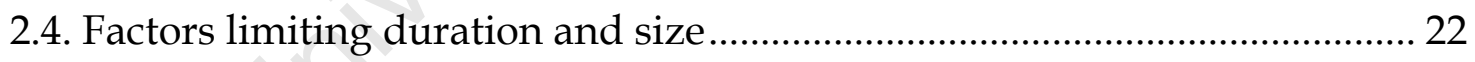

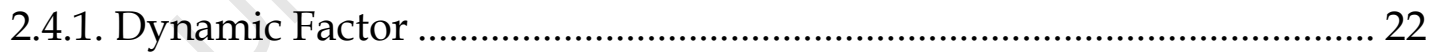

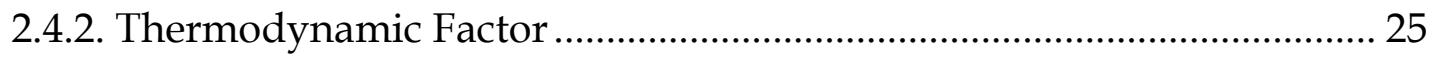

2.5. Favourable Synoptic and Mesoscale Environments .................................. 26

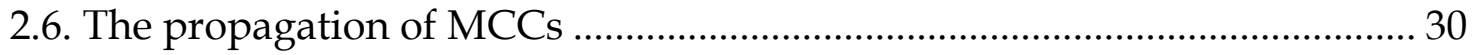

2.7. MCC Precipitation Characteristics ............................................................ 32

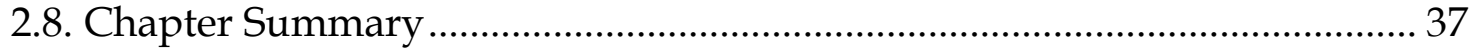

Chapter Three - Satellite Tracking Methods and MASCOTTE ............................... 44

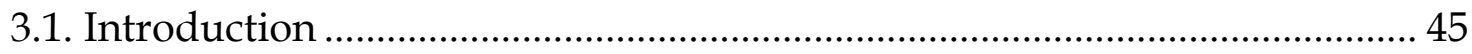


3.2. Maximum Spatial Correlation Technique (MASCOTTE) ........................... 48

3.3. South African Adaptation of MASCOTTE ................................................. 52

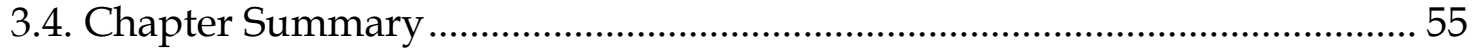

Chapter Four - Mesoscale Convective Complexes over southern Africa..............59

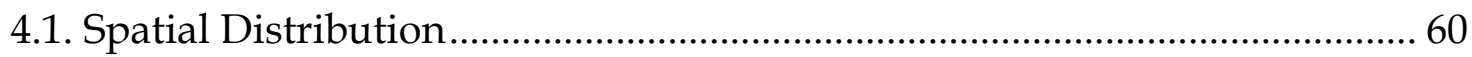

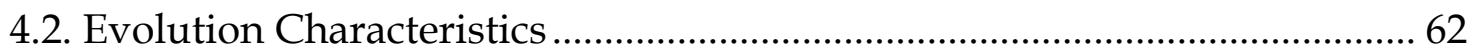

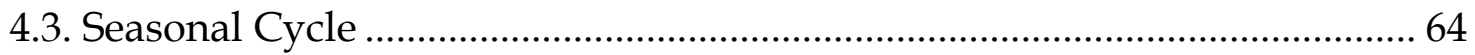

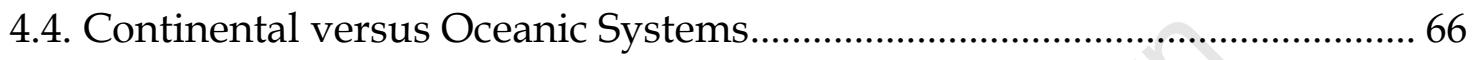

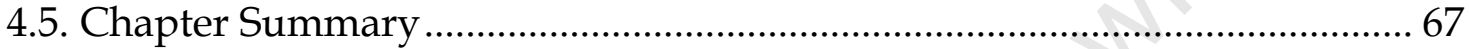

Chapter Five - Monthly mean large-scale environments over southern Africa .. 79

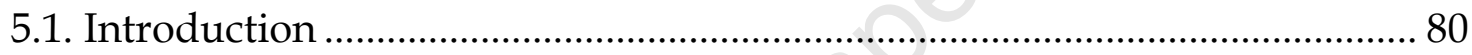

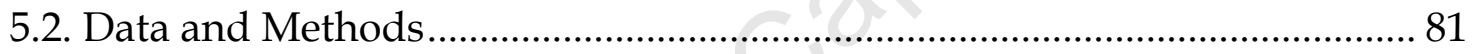

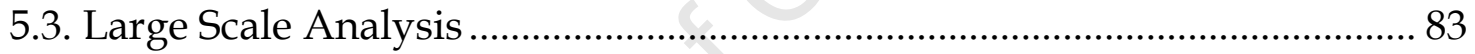

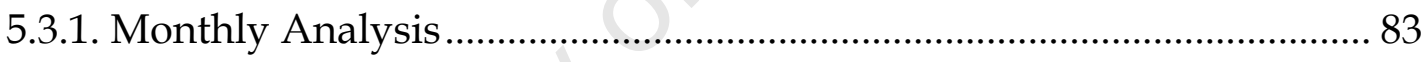

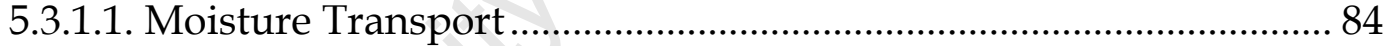

5.3.1.2. Thermodynamic and Kinematic Aspects ...................................... 87

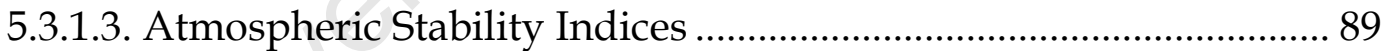

5.3.1. The Influence of ENSO, SSTs and Atmospheric Circulation................. 92

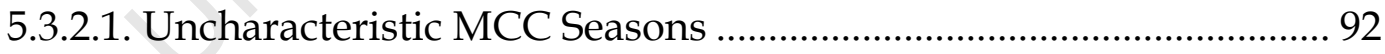

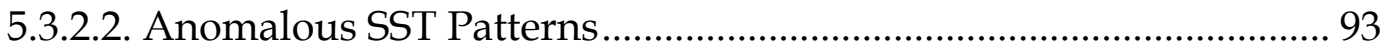

5.3.2.3. Circulation Changes associated with SST Anomalies .................... 95

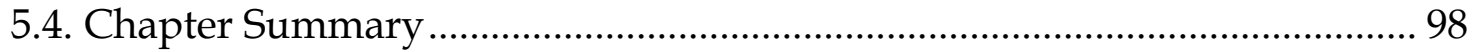

Chapter Six - MCCs and southern Africa Summer Rainfall ............................... 124

6.1. Introduction to Satellite-Derived Rainfall ............................................... 125

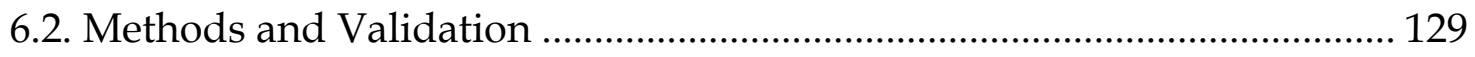

6.3. MCC Rainfall over Southern Africa ......................................................... 132 


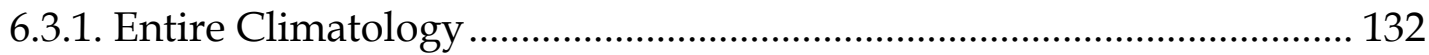

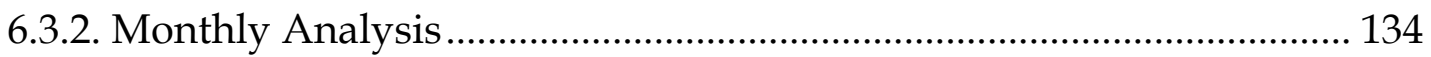

6.3.3. Seasonal Analysis ..................................................................................... 135

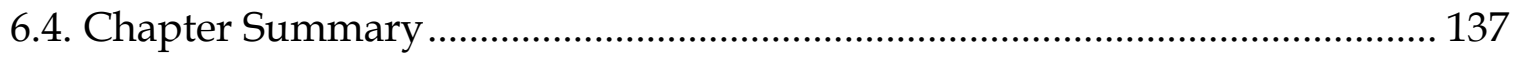

Chapter Seven - Case studies of MCCs over southern Africa............................... 156

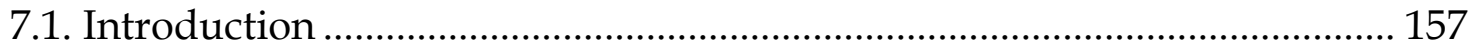

7.2. Case Study I: 04 - 05 February 2001.............................................................. 158

7.2.1. Overview of Storm and Precipitation ................................................... 158

7.2.2. Synoptic Setting and Moisture Transport .............................................. 159

7.2.3. Favourable Convective Environment ................................................... 161

7.3. Case Study II: 05 - 06 February 2003 ................................................................. 163

7.3.1. Overview of Storm and Precipitation ..................................................... 163

7.3.2. Synoptic Setting and Moisture Transport ............................................... 164

7.3.3. Favourable Convective Environment ...................................................... 166

7.4. Case Study III: 09 - 10 February 2006 …………………………………....... 168

7.4.1. Overview of Storm and Precipitation ..................................................... 168

7.4.2. Synoptic Setting and Moisture Transport ............................................. 169

7.4.3. Favourable Convective Environment ………………………………..... 170

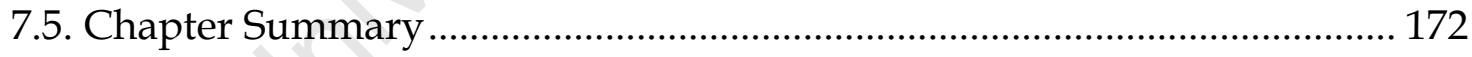

Chapter Eight - Discussion and Conclusions ............................................................. 219

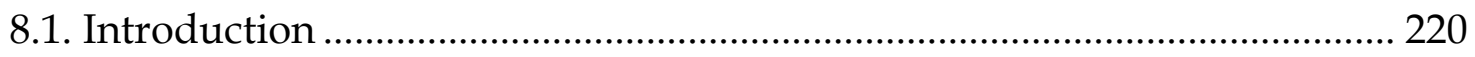

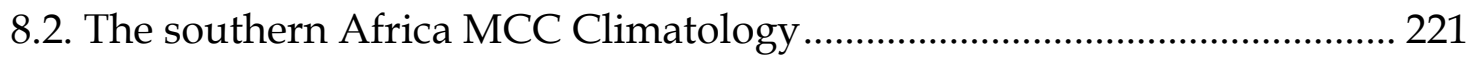

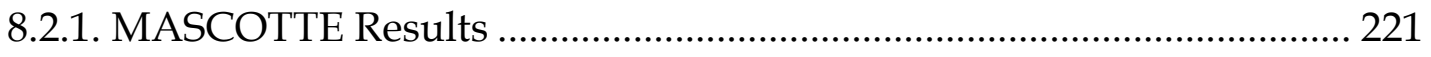

8.2.2. Subjectivity in MCC Identification ........................................................... 223

8.3. Synthesis of Environments Conducive to MCC development.................... 226

8.3.1. The Importance of Moisture Availability ............................................... 226

8.3.2. ENSO, the SICZ and MCCs .................................................................. 228 
8.4. Satellite-derived MCC Rainfall over southern Africa................................ 239

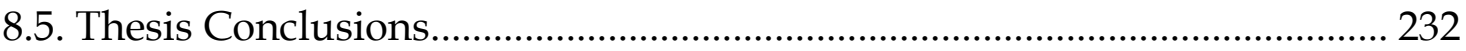

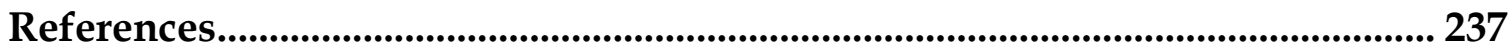

Appendix A - MCCs over southern Africa .................................................................. 267

Appendix B - Basic Severe Weather Parameters .......................................................... 271

Appendix C - Supplementary Figures.................................................................... 275

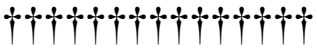




\section{$\sim$ List of Tables and Figures}

Table 2.1: The original MCC criteria defined by Maddox (1980). Note there are two size and two cloud shield temperature thresholds in this definition. 40

Table 7.1: $\mathrm{MCC}$ precipitation characteristics for four different regions, which include systems from this study, Sahelian Africa (Laing et al. 1999), subtropical South America (Durkee et al. 2009) and the United States ( ${ }^{1}$ Kane et al. 1987; ${ }^{2}$ McAnelly and Cotton, 1989).

Figure 1.1: AVHRR $4 \mathrm{~km}$ sea surface temperatures surrounding southern Africa (shaded, $3^{\circ} \mathrm{C}$ interval) for January 2000 . Countries referred to in the text are also labelled.... 13

Figure 1.2: Topography of southern Africa (shaded, $500 \mathrm{~m}$ intervals). The eastern escarpment is highlighted in the figure.

Figure 1.3: Schematic showing the common surface synoptic features that influence the weather and climate of southern Africa. These include: the subtropical anticyclones positioned over the oceans, westerly wave and low to the south, easterly wave and low to the south, easterly wave and low to the north and the Angola low (red circle). Also shown is the common position of tropical-temperate troughs (grey clouds) over the continent during summer months. Surface shading over land is the average normalised difference vegetation index (NDVI; $1^{\circ}$ resolution) for the region for the 1982-2001 period

Figure 1.4: Average annual rainfall, in millimetres, over South Africa for the period 1961-1990 (from Kruger 2007).

Figure 2.1: The global distribution of MCCs, based on satellite imagery. Small squares indicate location of MCC at time of maximum extent (from Laing and Fritsch 1997).... 41 
Figure 2.2: The distribution of MCC populations, elevated terrain and the prevailing mid-level flow (from Laing and Fritch 1997).

Figure 2.3: Illustration of infrared radiant energy absorbed and received at different levels in the atmosphere (From Cotton 2000). Left panel (a) illustrates a cloud-free atmosphere, while the right panel (b) illustrates a stratiform-anvil cloud layer. Length of arrows is proportional to the amount of radiant energy per unit area.

Figure 2.4: Regions where LLJ are known or suspected to regularly occur (dark shading) and the global location of frequent warm season MCC activity (square boxes). This figure is taken from Stensrud (1996a).

Figure 2.5: Tracks of MCCs during January-March 1986 (left) and January-March 1987 (right) over Africa (from Laing and Fritsch 1993b).

Figure 3.1: The domain of MASCOTTE over southern Africa is represented here by the area covered by the IR satellite data (brightness temperature overlaid; ${ }^{\circ} \mathrm{C}$ ). Included in this figure is an example of an MCC positioned off the east coast of South Africa on the 26 November 1999 at 0100 LST.

Figure 4.1: MCC tracks (red lines) and origin points (x) for the October-March period, 1998-2006. Also shown is the topography of the region (shaded, 500m intervals). "N" is equal to the number of systems during this period (bottom left corner). 71

Figure 4.2: The origin or trigger locations of MCCs in southern Africa. The figure is created by clustering the MCC origins found in Fig. 4.1 into $4^{\circ}$ blocks. 71

Figure 4.3: Monthly mean outgoing longwave radiation (OLR, W.m ${ }^{-2}$ ) over southern Africa. Monthly means created using the dataset described in Liebmann and Smith (1996). 
Figure 4.4: Same as Fig. 4.2, but now for all stages of the MCC evolution. The grid spacing is at $1^{\circ}$ resolution.

Figure 4.5: The key stages of the MCC lifecycle as described in the text, as well as an addition of "last track", which refers to the last time the evidence of the system is tracked in the program. The times have been binned into three-hourly time slots for ease of reading and are in local standard time. 73

Figure 4.6: The initiating times of the first storms of MCCs (shaded bars, left y-axis) and the number of images containing an MCC (line graph, right y-axis) in the half-hourly Meteosat-7 images.

Figure 4.7: Bar graph of warm season MCC duration. The percentage contribution of each category is shown at the top of each bar. The average duration is included in the top right hand corner.

Figure 4.8: Same as Fig. 4.7, but for maximum size. Note that the size here refers to the maximum extent of the $-52^{\circ} \mathrm{C}$ cloud shield.

Figure 4.9: The $70 \mathrm{MCCs}$ divided up into the months in which they occurred (' $\mathrm{x}$ ' denotes origin and red line denotes the track). The month is given in the bottom left corner of each panel, while the number of systems for that month is in the bottom right.

Figure 4.10: Box plots of the latitudinal distribution of MCCs during each month. Each box is drawn between the $25^{\text {th }}$ and $75^{\text {th }}$ percentiles of the data in Fig. 4.9, while the line in the middle is the median. Whiskers extend to extreme data points, while outliers are denoted by a black star. 76 
Figure 4.11: Same as Fig. 4.9, but for the eight warm seasons and the entire period (bottom right). The season is given in the bottom left corner of each panel, while the number of systems in the season is in the bottom right.

Figure 4.12: The distribution of MCCs at maximum extent (centre of circle), with the circles representing the cloud shield size $\left(\mathrm{km}^{2}\right)$.

Figure 5.1: Monthly mean $850 \mathrm{mb}$ moisture flux $\left(\mathrm{g} \cdot \mathrm{kg}^{-1} \mathrm{~m} \cdot \mathrm{s}^{-1}\right)$ over Africa, south of the equator. Months are given at the top left corner of each panel and the red boxes in some of the panels depict the region where the most MCC activity took place for that month.

Figure 5.2: Same as Fig. 5.1, except for South America and only December has a red box depicting the main region of MCC activity (determined from Durkee and Mote 2009).

Figure 5.3: Same as Fig. 5.1, except now illustrating precipitable water $\left(\mathrm{kg} \mathrm{m}^{-2}\right)$

Figure 5.4: Same as Fig 5.2, except now illustrating precipitable water $\left(\mathrm{kg} \mathrm{m}^{-2}\right)$.

Figure 5.5: Monthly mean precipitable water $\left(\mathrm{kg} \mathrm{m}^{-2}\right)$ over Australia. Months are given at the top left corner of each panel. The red box in (d) refers to the study domain used by Perrin and Reason (1997), which extended to $45^{\circ} \mathrm{S}$.

Figure 5.6: Same as Fig. 5.5, but for monthly mean $850 \mathrm{mb}$ moisture flux $\left(\mathrm{g} \cdot \mathrm{kg}^{-1} \mathrm{~m} \cdot \mathrm{s}^{-1}\right)$.

Figure 5.7: Vertical cross-section taken along $25^{\circ} \mathrm{E}$ showing the zonal moisture flux $\left(\mathrm{g} . \mathrm{kg}^{-1} \mathrm{~m} \cdot \mathrm{s}^{-1}\right)$. Easterly flux is shaded with a dash contour, while westerly flux contains just solid contours. 107 
Figure 5.8: Monthly mean moisture convergence (shaded; $x 10^{-5}$ g.kg. $\mathrm{s}^{-1}$ ) and moisture flux (vector, $\mathrm{g} . \mathrm{kg}^{-1} \mathrm{~m} . \mathrm{s}^{-1}$ ) at the $850 \mathrm{hPa}$ level. Moisture convergence is negative, while divergence is positive. Scale of moisture flux is given above the top right hand corner of each panel. 108

Figure 5.9: Monthly mean sea level pressure (hPa), temperature $\left({ }^{\circ} \mathrm{C}\right)$ and wind $\left(\mathrm{m} . \mathrm{s}^{-1}\right)$ at $1000 \mathrm{hPa}$. Scale of vector wind is given above the top right hand corner of each panel..

Figure 5.10: Monthly mean geopotential height (solid contours, m), wind vectors (vectors, $\mathrm{m} . \mathrm{s}^{-1}$ ) and mixing ratio (shaded, only values greater than $10 \mathrm{~g} \mathrm{~kg}^{-1}$ are shown) at $850 \mathrm{hPa}$

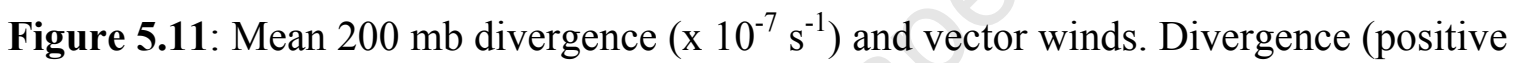
values) is shaded with solid contours (interval $5 \times 10^{-7} \mathrm{~s}^{-1}$ ), while convergence (negative values) is depicted by grey dashed contours.

Figure 5.12: Mean vertical motion (omega, $\mathrm{Pa}_{\mathrm{s}} \mathrm{s}^{-1}$ ). Upward vertical motion is shaded and dashed contours (interval 0.01 $\mathrm{Pa}_{\mathrm{s}} \mathrm{s}^{-1}$ ), while downward motion is depicted by grey solid contours

Figure 5.13: Shear vectors (arrows) and shear magnitude (solid lines, $\mathrm{m} . \mathrm{s}^{-1}$ ) in the 1000$700 \mathrm{mb}$ layer.

Figure 5.14: Mean monthly CAPE (shaded with solid contours, J.kg-1).

Figure 5.15: The number of days per month at $12 \mathrm{~h} 00$ UTC that contain CAPE $>1500$ $\mathrm{J} . \mathrm{kg}^{-1}$

Figure 5.16: Mean monthly K-Index (shaded with dashed contours). 
Figure 5.17: NDJF sea surface temperature (SST) anomalies $\left({ }^{\circ} \mathrm{C}\right)$ during a) 1999/2000 and b) $2002 / 2003$.

Figure 5.18: Same as Fig. 5.17, but for outgoing longwave radiation (OLR, W.m $\left.{ }^{-2}\right) \ldots 118$

Figure 5.19: Same as Fig. 5.17, but for surface latent heat flux (W.m²)

Figure 5.20: Same as Fig. 5.17, but for moisture flux (vectors, g. $\mathrm{kg}^{-1} \mathrm{~m} . \mathrm{s}^{-1}$ ) and moisture convergence (shaded; $x 10^{-5} \mathrm{~g} \cdot \mathrm{kg}^{-1} \mathrm{~s}^{-1}$ ) at $850 \mathrm{hPa}$.

Figure 5.21: Same as Fig. 5.17, but for geopotential height at $500 \mathrm{hPa}$ (shaded; m)... 121

Figure 5.22: Same as Fig. 5.17, but for omega $\left(\mathrm{Pa} . \mathrm{s}^{-1}\right)$ and vector winds (vector; $\left.\mathrm{m} . \mathrm{s}^{-1}\right)$ at $700 \mathrm{hPa}$ 122

Figure 5.23: Same as Fig. 5.17, but for divergence $\left(\times 10^{-7} \mathrm{~s}^{-1}\right)$ and vector winds (vector arrow; $\mathrm{m} . \mathrm{s}^{-1}$ ) at $200 \mathrm{hPa}$.

Figure 6.1: Satellite images (cloud top temperature shaded from $-52^{\circ} \mathrm{C}$ to $-80^{\circ} \mathrm{C}$ ) at 2 hour intervals (time, in UTC, and date in bottom right-hand corner) for the MCC that took place along the east coast of South Africa during 26-27 November 1999. 140

Figure 6.2: The process used to identify the rainfall produced by each system. This particular figure is for the MCC that occurred during the 26-27 November 1999 (see Fig. 6.1). The process is a) first identify the spatial extent of the cloud shield and produce polygon, b) convert polygon into a convex hull and overlay on the TMPA 3 hourly rainfall and c) extract only the rainfall occurring within the cloud shield. 141

Figure 6.3: Mean DJF rainfall over southern Africa using TMPA data for the period January 1998 - December 2007. SAWS station locations are marked with an "X"..... 142 
Figure 6.4: Mean monthly rainfall totals for a few SAWS weather stations (see Fig. 6.3 for locations) and the TMPA data (averaged over a $1^{\circ} \times 1^{\circ}$ ).

Figure 6.4 (cont): Mean monthly rainfall totals for SAWS weather stations (see Fig. 6.3 for locations) and the TMPA data (averaged over a $1^{\circ} \times 1^{\circ}$ grid) 144

Figure 6.5: Mean spatial distribution of TMPA monthly rainfall (months in bottom left hand corner) for the period 1998-2007. 145

Figure 6.6: Core summer (DJF) rainfall totals for the SAWS weather stations used in Fig. 6.3 and the TMPA data (averaged over a $1^{\circ} \times 1^{\circ}$ ) for the period 1998-2007. 146

Figure 6.6 (cont): Core summer (DJF) rainfall totals for the SAWS weather stations used in Fig. 6.3 and the TMPA data (averaged over a $1^{\circ} \times 1^{\circ}$ ) for the period 1998-2007. 147

Figure 6.7: DJF rain totals determined from the TMPA data. 148

Figure 6.8: DJF Anomalies using the mean of the TMPA data for the period 1998-2007.

Figure 6.9: Spatial distribution of MCCs during October - March for the period 19982006. The frequency is determined by the adding the cloud shield polygons discussed in the methods and validation section. 149

Figure 6.10: a) Total MCC rainfall for the 1998-2006 period and b) Spatial distribution of the mean MCC contribution (shaded, 2\% interval) to the total summer (NovemberMarch) rainfall over the region and c) same as Fig. 6.10b, but for November-February. 
Figure 6.11: Spatial distribution of the mean MCC contribution to monthly rainfall. The month is indicated in bottom left hand corner and number of systems ("N") in bottom right.

Figure 6.12: Mean contribution of MCCs to rainfall over three month periods, which are a) October - December, b) November - January, c) December - February and d) January - March.

Figure 6.13: MCC contribution to the individual warm season (November - March) precipitation.

Figure 6.14: NDJF rain anomalies (\%).

Figure 7.1: Meteosat-7 IR images showing cloud top temperature $\left({ }^{\circ} \mathrm{C}\right)$ of the $\mathrm{MCC}$ that took place during 04-05 February 2001. Times shown are in UTC (LST - 2). 176

Figure 7.2: Rainfall (mm) derived by the 3 hourly TMPA data from 12h00 UTC 04 February through to 06h00 UTC 05 February. 177

Figure 7.3: South African Weather Service (SAWS) synoptic charts for the 04 February 2001 (top) and 05 February 2001 (bottom) 178

Figure 7.4: Mean sea level pressure (solid contours; $4 \mathrm{hPa}$ interval), temperature (grey dashed contours, $2{ }^{\circ} \mathrm{C}$ interval) and vector winds $\left(\mathrm{m}^{-1}{ }^{-1}\right.$, proportion of wind speed to arrow length given above top right corner) at the $1000 \mathrm{hPa}$ level.

Figure 7.5: Geopotential height (solid contours; $20 \mathrm{~m}$ interval), vector winds $\left(\mathrm{m} . \mathrm{s}^{-1}\right.$, proportion of wind speed to arrow length given above top right corner) and temperature (dashed contour; units in ${ }^{\circ} \mathrm{C}$ ) for the $500 \mathrm{hPa}$ level. 
Figure 7.6: Moisture flux (g. $\mathrm{kg}^{-1} \mathrm{~m} \cdot \mathrm{s}^{-1}$, both arrow and contours) at the $1000 \mathrm{hPa}$ level.

Figure 7.7: The average 6 hourly moisture flux (vector, g. $\mathrm{kg}^{-1} \mathrm{~m} . \mathrm{s}^{-1}$ ) and moisture

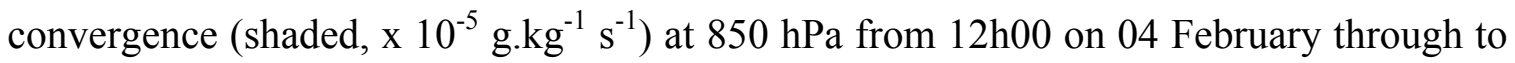
06 h00 on 05 February. Note that for clarity, moisture divergence is not shown.

Figure 7.8: Equivalent potential temperature (shaded; units are ${ }^{\circ} \mathrm{K}$ ), geopotential height

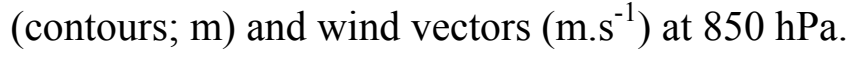

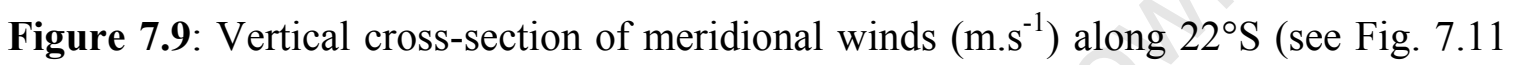
for location). Southerly winds are shaded, while northerly winds are depicted with contours

Figure 7.10: Divergence (shaded, $\left.x 10^{-5} \mathrm{~s}^{-1}\right)$ and vector winds $\left(\mathrm{m} . \mathrm{s}^{-1}\right)$ at $200 \mathrm{hPa}$. 185

Figure 7.11: Omega (shaded with contours, $\mathrm{Pa} / \mathrm{s}$ ) and vector winds $\left(\mathrm{m}_{\mathrm{s}} \mathrm{s}^{-1}\right)$ at $700 \mathrm{hPa}$. Note that only upward motion is plotted. Red line denotes latitude of which the crosssection Fig. 7.12 is based.

Figure 7.12: Cross section of omega (shaded with contours, $\mathrm{Pa} / \mathrm{s}$ ) along $22^{\circ} \mathrm{S}$ (see Fig. 7.11 for location). Also shown are vector winds $\left(\mathrm{m} . \mathrm{s}^{-1}\right)$.

Figure 7.13: The K-Index (shaded) and vector winds $\left(\mathrm{m} . \mathrm{s}^{-1}\right)$ at $850 \mathrm{hPa}$. 188

Figure 7.14: Surface convective available potential energy (shaded, ${\mathrm{J} . \mathrm{kg}^{-1}}$ ).

Figure 7.15: Low level shear $(1000-700 \mathrm{hPa})$ in $\mathrm{m} . \mathrm{s}^{-1}$ 190

Figure 7.16: Meteosat-7 IR images showing cloud top temperature $\left({ }^{\circ} \mathrm{C}\right)$ of the $\mathrm{MCC}$ that took place during 05-06 February 2003. Times shown are in UTC (LST - 2). 191 
Figure 7.17: Rainfall (mm) derived by the 3 hourly TMPA during the duration of the event.

Figure 7.18: South African Weather Service synoptic charts for the 05 February 2003 (top) and 06 February 2003 (bottom).

Figure 7.19: Mean sea level pressure (solid contours; $4 \mathrm{hPa}$ interval), temperature (grey dashed contours, $2^{\circ} \mathrm{C}$ interval) and vector winds $\left(\mathrm{m}^{-1} \mathrm{~s}^{-1}\right.$, proportion of wind speed to arrow length given above top right corner) at the $1000 \mathrm{hPa}$ level. 194

Figure 7.20: Average moisture convergence (shaded; $x 10^{-5} \mathrm{~g} \cdot \mathrm{kg}^{-1} \mathrm{~s}^{-1}$ ) and moisture flux (vector arrow; g. $\mathrm{kg}^{-1} \mathrm{~m} . \mathrm{s}^{-1}$ ) at $1000 \mathrm{hPa}$ (top) and $850 \mathrm{hPa}$ (bottom) from $12 \mathrm{~h} 00$ UTC on 05 February through to 06 h00 UTC on 06 February 2003. Only moisture convergence is shown. 195

Figure 7.21: Geopotential height (solid contours; $20 \mathrm{~m}$ interval), vector winds $\left(\mathrm{m} . \mathrm{s}^{-1}\right.$, proportion of wind speed to arrow length given above top right corner) and temperature (dashed contour; units in ${ }^{\circ} \mathrm{C}$ ) for the $500 \mathrm{hPa}$ level.

Figure 7.22: Omega (shaded with contours, Pa.s $\left.{ }^{-1}\right)$ and vector winds $\left(\mathrm{m} . \mathrm{s}^{-1}\right)$ at $700 \mathrm{hPa}$. Note that only upward motion is plotted. Red line denotes latitude of which the crosssection Fig. 7.23 is based.

Figure 7.23: Cross section of omega (shaded with contours, Pa.s ${ }^{-1}$ ) along $26^{\circ} \mathrm{S}$ (see Fig. 7.22 for location). Also shown are vector winds $\left(\mathrm{m} . \mathrm{s}^{-1}\right)$. 198

Figure 7.24: Moisture flux (g. $\mathrm{kg}^{-1} \mathrm{~m} \cdot \mathrm{s}^{-1}$, both arrow and contours) at the $1000 \mathrm{hPa}$ level.

Figure 7.25: Surface convective available potential energy (shaded, ${\mathrm{J} . \mathrm{kg}^{-1}}^{-}$. 200 


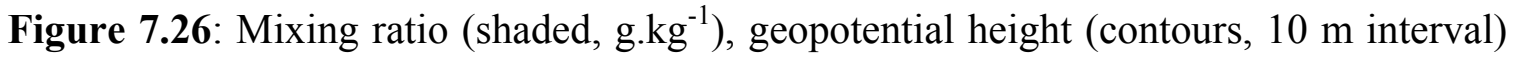
and vector winds $\left(\mathrm{m} . \mathrm{s}^{-1}\right)$ at $850 \mathrm{hPa}$.

Figure 7.27: The K-Index (shaded) and vector winds $\left(\mathrm{m} . \mathrm{s}^{-1}\right)$ at $850 \mathrm{hPa}$. 202

Figure 7.28: Low level shear $\left(\mathrm{m} . \mathrm{s}^{-1}\right)$ between the 1000-700 hPa layer. 203

Figure 7.29: Meteosat-7 IR images showing cloud top temperature $\left({ }^{\circ} \mathrm{C}\right)$ of the $\mathrm{MCC}$ that took place during 09-10 February 2006. Times shown are in UTC (LST - 2). 204

Figure 7.30: Rainfall (mm) derived by the 3 hourly TMPA during the duration of the event. The stations of Charters Creek, Mbazwana Airfield and Richards bay are denoted by 'C', 'M' and ' $R$ ', respectively. Open grey circles identify the station location. ....... 205

Figure 7.31: South African Weather Service synoptic charts for the 09 February 2006 (top) and 10 February 2006 (bottom). 206

Figure 7.32: Mean sea level pressure (solid contours; $4 \mathrm{hPa}$ interval) and vector winds $\left(\mathrm{m} . \mathrm{s}^{-1}\right.$, proportion of wind speed to arrow length given above top right corner) at the 850 $\mathrm{hPa}$ level. Times indicate here are UTC. 207

Figure 7.33: Geopotential height (solid contours; $20 \mathrm{~m}$ interval), vector winds $\left(\mathrm{m} . \mathrm{s}^{-1}\right.$, proportion of wind speed to arrow length given above top right corner) and temperature (dashed contour; units in ${ }^{\circ} \mathrm{C}$ ) for the $500 \mathrm{hPa}$ level. 208

Figure 7.34: Daily outgoing longwave radiation (shaded with contours, units are W. $\mathrm{m}^{-2}$ ) for 09 - 10 February 2006. Dataset described in Liebmann and Smith (1996). 209

Figure 7.35: Same as Fig. 7.33, except for $200 \mathrm{hPa}$ and temperature is not shown. .... 210 
Figure 7.36: Moisture flux (g.kg $\mathrm{kg}^{-1} \mathrm{~s}{ }^{-1}$, both arrow and contours) at the $1000 \mathrm{hPa}$ level.

Figure 7.37: Average moisture flux (vector, g. $\mathrm{kg}^{-1} \mathrm{~m} \cdot \mathrm{s}^{-1}$ ) and convergence (shaded, $\mathrm{x} 10^{-5}$ g. $\mathrm{kg}^{-1} \cdot \mathrm{s}^{-1}$ ) at $850 \mathrm{hPa}$ between $12 \mathrm{~h} 00 \mathrm{UTC}$ on 09 February and $06 \mathrm{~h} 00 \mathrm{UTC}$ on 10 February 2006. Note that for clarity, moisture divergence is not shown.

Figure 7.38: Omega (shaded with contours, Pa.s $\left.{ }^{-1}\right)$ and vector winds $\left(\mathrm{m}_{\mathrm{s}} \mathrm{s}^{-1}\right)$ at $700 \mathrm{hPa}$. Note that only upward motion is plotted. Red line denotes latitude of which the crosssection Fig. 7.39 is based.

Figure 7.39: Cross-section of omega (shaded with contours, $\mathrm{Pa} . \mathrm{s}^{-1}$ ) along $29^{\circ} \mathrm{S}$ (see Fig. 7.38 for location). Also shown are vector winds $\left(\mathrm{m} . \mathrm{s}^{-1}\right)$.

Figure 7.40: Equivalent potential temperature (shaded; units are ${ }^{\circ} \mathrm{K}$ ), geopotential height (contours; $\mathrm{m}$ ) and wind vectors $\left(\mathrm{m}^{-\mathrm{s}^{-1}}\right)$ at $850 \mathrm{hPa}$.

Figure 7.41: Mixing ratio (shaded, $\mathrm{g} \cdot \mathrm{kg}^{-1}$ ), geopotential height (contours, $10 \mathrm{~m}$ interval) and vector winds $\left(\mathrm{m} . \mathrm{s}^{-1}\right)$ at $850 \mathrm{hPa}$.

Figure 7.42: Surface convective available potential energy ( shaded, ${\mathrm{J} . \mathrm{kg}^{-1}}$ ). 217

Figure 7.43: Low level shear $(1000-700 \mathrm{hPa})$ in $\mathrm{m}_{\mathrm{s}} \mathrm{s}^{-1}$ 218

Figure 8.1: Tracks (red lines) and origin points (o) of systems that were not included in the climatology. Also shown is the topography of the region (shaded, $500 \mathrm{~m}$ intervals). $\mathrm{N}$ is equal to the number of systems during this period 235

Figure 8.2: A flow diagram depicting the process used to determine the contribution by MCCs to southern Africa summer rainfall. 236 
Figure A5.1: Vertical cross-section taken along $30^{\circ} \mathrm{E}$ showing the zonal moisture flux $\left(\mathrm{g} . \mathrm{kg}^{-1} \mathrm{~m} \cdot \mathrm{s}^{-1}\right)$. Easterly flux is shaded with a dash contour, while westerly flux contains just solid contours.

Figure A5.2: Same as Fig. A5.1, but now taken along $35^{\circ} \mathrm{E}$. 276

Figure A5.3: Mean $500 \mathrm{mb}$ divergence ( $\mathrm{x} 10^{-7} \mathrm{~s}^{-1}$ ) and vector winds. Divergence (positive values) is shaded with solid contours, while convergence (negative values) is depicted by grey dashed contours.

Figure A5.4: Mean monthly potential instability of the 925-500 $\mathrm{hPa}$ layer (only positive values are shaded with contours; units are $10^{-3} \mathrm{~K} \mathrm{~m}^{-1}$ ). Positive values indicate potentially unstable regions. 278

Figure A5.5: The number of days per month at $12 \mathrm{~h} 00$ UTC that contain CAPE $>1000$ $\mathrm{J} . \mathrm{Kg}^{-1}$ 279

Figure A5.6: NDJF $850 \mathrm{hPa}$ vector winds anomalies (m.s ${ }^{-1}$ ) during a) 1999/2000 and b) $2002 / 2003$. 280

Figure A5.7: Same as Fig. A5.6, but for mean sea level pressure (hPa). 281

Figure A5.8: Same as Fig. A5.6, but now showing surface precipitable water $\left(\mathrm{kg} \cdot \mathrm{m}^{-2}\right)$. 282

Figure A5.9: Same as Fig. A5.6, but for omega $\left(\mathrm{Pa}_{\mathrm{s}} \mathrm{s}^{-1}\right)$ and vector winds (vector; $\left.\mathrm{m} . \mathrm{s}^{-1}\right)$ at $500 \mathrm{hPa}$. 283

Figure A7.1: Divergence (shaded, x $\left.10^{-5} \mathrm{~s}^{-1}\right)$ and vector winds $\left(\mathrm{m} . \mathrm{s}^{-1}\right)$ at $500 \mathrm{hPa} \ldots \ldots .284$

Figure A7.2: Divergence (shaded, $\left.x 10^{-5} \mathrm{~s}^{-1}\right)$ and vector winds $\left(\mathrm{m} . \mathrm{s}^{-1}\right)$ at $200 \mathrm{hPa} . \ldots . .285$ 
Figure A7.3: Equivalent potential temperature (shaded; units are ${ }^{\circ} \mathrm{K}$ ), geopotential height

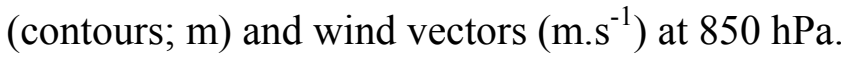

Figure A7.4: Potential instability (shaded, $\mathrm{K} \mathrm{m}^{-1}$ ) calculated between 925 and $500 \mathrm{hPa}$ using equivalent potential temperature and height between the two layers.

Figure A7.5: Meteosat-7 IR images showing cloud top temperature $\left({ }^{\circ} \mathrm{C}\right)$ of the $\mathrm{MCS}$ that took place on 10 February 2006. Times shown are in UTC (LST - 2) 288

Figure A7.6: Horizontal convergence (shaded, $10^{-5} \mathrm{~s}^{-1}$ ) and vector winds $\left(\mathrm{m} . \mathrm{s}^{-1}\right)$ at 850 $\mathrm{hPa}$. Note that only convergence is shown. 289

Figure A7.7: Divergence (shaded, $10^{-5} \mathrm{~s}^{-1}$ ) and vector winds $\left(\mathrm{m}^{-1} \mathrm{~s}^{-1}\right)$ at $200 \mathrm{hPa}$. 290

Figure A7.8: Moisture flux (vector arrows; units are g. $\mathrm{kg}^{-1} \mathrm{~m} . \mathrm{s}^{-1}$ ) at $850 \mathrm{hPa}$. 291

Figure A7.9: Temperature ( shaded; $^{\circ} \mathrm{C}$ ), geopotential height (contours; $\mathrm{m}$ ) and wind vectors $\left(\mathrm{m} . \mathrm{s}^{-1}\right)$ at $850 \mathrm{hPa}$

Figure A7.10: Temperature advection (shaded; $\mathrm{K} \mathrm{s}^{-1}$ ), geopotential height (contours; $\mathrm{m}$ ) and wind vectors $\left(\mathrm{m} . \mathrm{s}^{-1}\right)$ at $850 \mathrm{hPa}$.

Figure A7.11: The $K$-Index (shaded) and vector winds $\left(\mathrm{m} . \mathrm{s}^{-1}\right)$ at $850 \mathrm{hPa}$. 294

Figure A7.12: Meridional wind speed along $29^{\circ} \mathrm{S}$ (see Fig. 7.38 for location). Positive shaded values indicate equatorward moving air, while negative contoured values indicate poleward moving air. 295 


\title{
$\sim$ List of Acronyms
}

\begin{abstract}
AMIP-II - Second Atmospheric Model Intercomparison Project
AVHRR - Advanced Very High Resolution Radiometer

CS - Convective Systems

CC - Convective Clusters
\end{abstract}

CAPE - Convective Available Potential Energy

CFSR - Climate Forecast System Reanalysis

CT - Cross Totals

DOE - Department of Energy

DJF - December, January and February

EL - Equilibrium Level

ENSO - El Niño - Southern Oscillation

EOF - Empirical Orthogonal Function

EUMETSAT - European Organisation for the Exploitation of Meteorological Satellites

GOES - Geostationary Operational Environmental Satellite

GPCP - Global Precipitation Climatology Project

IDL - Interactive Data Language

IOD - Indian Ocean Dipole

IR - Infrared

ITCZ - Intertropical Convergence Zone

JFM - January, February and March

KI - K-Index

KZN - KwaZulu-Natal

LFC - Level of free convection

LI - Lifted Index

LLJ - Low Level Jet 
LST - Local Standard Time (UTC + 2)

MASCOTTE - Maximum Spatial Correlation Technique

MBE - Meso- $\beta$-scale Convective Elements

MCC - Mesoscale Convective Complex

MCS - Mesoscale Convective System

MCV - Mesoscale Convective Vortex

MSG - Meteosat Second Generation

NCAR - National Center for Atmospheric Research

NCEP - National Centers for Environmental Prediction

NDJF - November, December, January and February

NDVI - Normalised Difference Vegetation Index

OISST - Optimally Interpolate Sea Surface Temperature

OLR - Outgoing Longwave Radiation

OND - October, November and December

R1 -Reanalysis one

R2 -Reanalysis two

SACZ - South Atlantic Convergence Zone

SALLJ - South America Low Level Jet

SAWS - South African Weather Service

SICZ - South Indian Convergence Zone

SIOD - Subtropical Indian Ocean Dipole

SPCZ - South Pacific Convergence Zone

SST - Sea Surface Temperature

SWEAT - Severe Weather Threat Index

SWIO - southwest Indian Ocean

$\mathbf{T}_{B}$ - Brightness Temperature

TMI - TRMM Microwave Imager

TMPA - TRMM Multi-satellite Precipitation Analysis 
TRMM -Tropical Rainfall Measuring Mission

TTT - Tropical Temperate Trough

U.S. - United States of America

UTC - Coordinate Universal Time

UTWV - Upper-Tropospheric Water Vapour

VT - Vertical Totals 


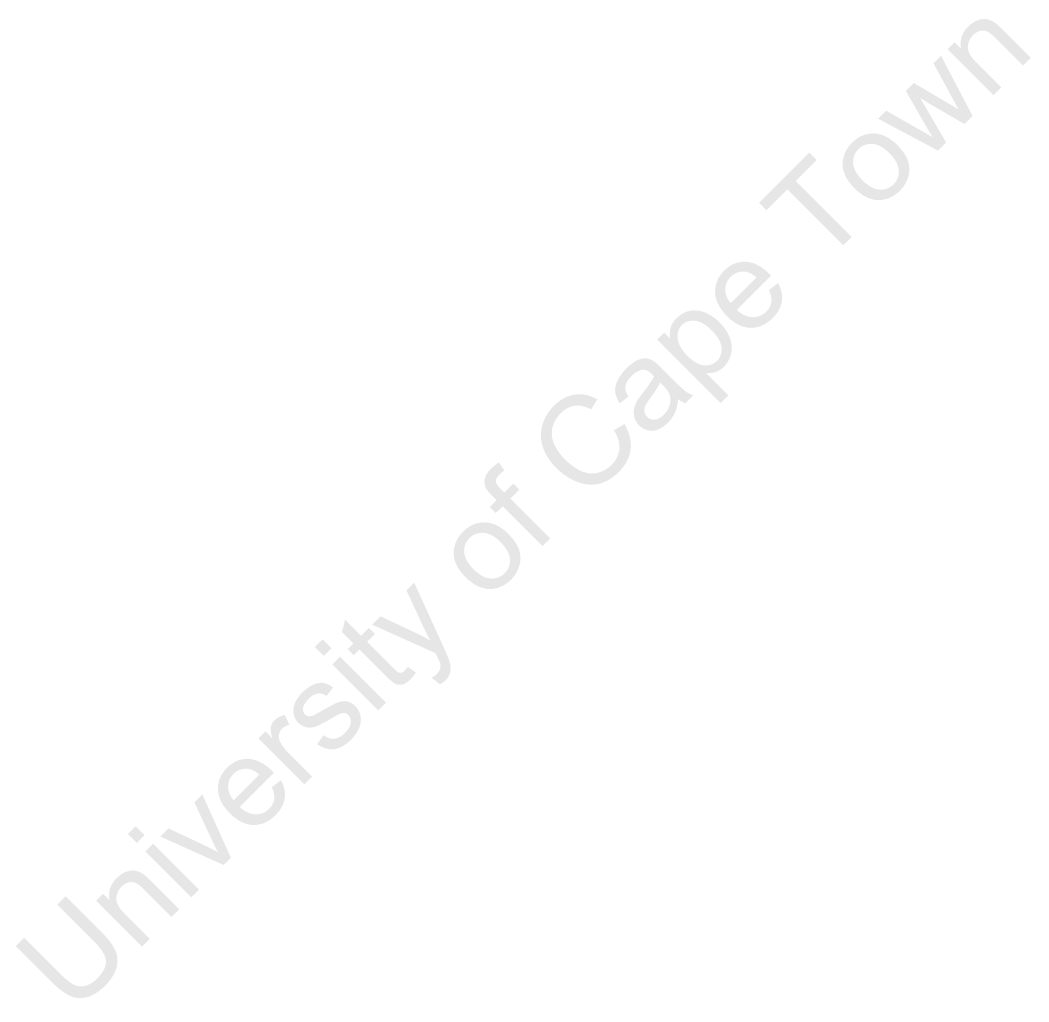

- xxvi - 


\section{Chapter One}

Introduction and Thesis Overview 


\subsection{Introduction}

Subtropical southern Africa, defined here as Africa south of $18^{\circ} \mathrm{S}$, experiences considerable spatial and temporal variability in climate and is susceptible to a wide range of weather phenomena. Severe weather producing systems over the region include cut-off lows (e.g., Singleton and Reason 2006, 2007), thunderstorm systems, ranging from single cell storms through to mesoscale convective systems (e.g., Laing and Fritsch 1993b; Tyson and Preston-Whyte 2000; Blamey and Reason 2009), and tropical cyclones in the southwest Indian Ocean, which occasionally make landfall over Madagascar or Mozambique (Dyson and van Heerden 2001; Reason and Keibel 2004). Studies focusing on the global distribution of favourable severe weather environments (e.g., Brooks et al. 2003) or global distribution of intense thunderstorms (e.g., Zipser et al. 2006) have identified eastern and southeastern southern Africa (including the adjacent warm ocean) as a convective hotspot. The severe weather phenomena that are produced by convective systems, such as flooding, hail, tornadoes, lightning and strong wind bursts, not only pose safety problems to society, but can also result in damage to agriculture, transportation, communications and infrastructure. These impacts are likely to be enhanced in environmentally and socio-economically vulnerable regions. However, another perspective is that the same severe weather producing systems often provide much of the all important rainfall, very significant to a semi-arid country, such as South Africa. Thus, it is vital to have a better understanding of these systems whether damaging or beneficial to society.

One such severe weather producing system that may contribute to the intense convective activity over subtropical southern Africa is the mesoscale convective complex (MCC). The MCC, defined by Maddox (1980), is identified as convective cloud system that is large, long-lived and exhibits a quasi-circular cloud shield. They are among the largest of the mesoscale convective systems (MCSs), typically extending more than $350,000 \mathrm{~km}^{2}$ in area and lasting longer than 10 hours (Laing and Fritsch 1997). MCCs are of great research interest because they typically lead to considerable damage via flash flooding, hail, lightning and sometimes even via tornadoes. Although MCCs may often be associated with severe weather, they are beneficial in that they frequently make a large 
contribution to the seasonal rainfall total in some regions, such as the United States of America (U.S.) (Tollerud and Collander 1993; Ashley et al. 2003), South America (Durkee et al. 2009) and West Africa (Laurent et al. 1998).

From the global research, it has become evident that some key patterns emerge for these systems, ranging from the regions over which they develop to the life cycles they display, which is discussed in more detail in the subsequent chapter. However, rather little research has been done on African MCCs and this work is mainly focused on systems located in the Sahel (e.g., Laurent et al. 1998; Laing et al. 1999; Mathon et al. 2002), which can influence hurricane development in the tropical Atlantic (e.g., Sall et al. 2005). Apart from the limited attempt of Laing and Fritsch (1993b), there is no evidence of any other climatological studies of MCCs over subtropical southern Africa. There have however been some attempts to provide a general description of MCSs in the region (Garstang and Tyson 2000) and analyses of individual case studies of large MCSs (e.g., de Coning et al. 1998; Blamey and Reason 2009). Similarities in the properties of MCC environments worldwide (Laing and Fritsch 2000) suggest that subtropical southern Africa contains a favourable setting for these systems to develop.

\subsection{The Climate of southern Africa}

Positioned in the ocean dominated Southern Hemisphere, subtropical southern Africa (hereafter referred to as southern Africa) could be considered to be a semi-arid region, which contains high rainfall variability. The spatial and seasonal distribution of rainfall is linked to numerous complex factors, ranging from the geographic position of the region to the interaction of the surrounding oceans with that of the general atmospheric circulation. Not only do these factors influence the spatial distribution of southern Africa rainfall, but also have an affect on the inter- and intra-seasonal variability. However, the extent to which these features impact the regional climate is not completely understood and is part of ongoing research. The aim in this section is to provide a concise synopsis of the current understanding of the climate of southern Africa, with particular focus on 
summer rainfall variability over the region. For a full description of subtropical southern African climate, the reader is referred to Tyson and Preston-Whyte (2000).

\subsubsection{Characteristics of the southern African Climate}

Located at the southern tip of the continent, the region is unique in terms of contrasting gradients (Reason 2006). Possibly the most evident contrast is that of the surrounding sea surface temperatures (SSTs), where the west coast is bounded by the cold Benguela Current, which is a region of strong ocean upwelling, while the east coast is bounded by the warm Agulhas Current (Fig. 1.1 ${ }^{\dagger}$ ). This warm current is perceived to be an influential feature in South African weather patterns. Evidence has been presented that it not only has an influence on the summer rainfall and severe weather events in the region (e.g., Jury et al. 1993; Crimp and Mason 1999; Rouault et al. 2002; Blamey and Reason 2009), but also on regional atmospheric circulation patterns (Reason 2001b). This is likely due to the close proximity of the core of the Agulhas Current, which has been shown to not only result in high latent heat fluxes of several hundred watts per square meter, but also transfer more moisture to the atmosphere than the surrounding waters (Rouault et al. 2003b).

The topography is also thought to play a crucial role in the weather and climate of the region (Tyson and Preston-Whyte 2000). As documented by Kruger (2007), there is a clear relationship between rainfall and elevation within South Africa. The coastal regions of South Africa are separated from the elevated plateau (approximately 1-2 km above sea level) by a well-defined escarpment that extends above $3 \mathrm{~km}$ in certain places within the Drakensberg mountain range in KwaZulu-Natal (KZN) and the Lesotho Maluti Mountains (Fig. 1.2). The interaction between the topography of the northeastern escarpment with that of westerly waves propagating across the southern tip of Africa has been shown to assist in the development of convective storms in the region (Garstang et al. 1987). The eastern escarpment has also previously been linked to the development of MCCs (as an initiating mechanism) in the region (Laing and Fritsch 1993b). The local

\footnotetext{
${ }^{\dagger}$ All figures are found at the end of each chapter
} 
coastal topography is known to play a major role in promoting the ascent of moist air, blocking the propagation of synoptic systems, such as cut-off lows (e.g., Singleton and Reason 2007), and in the trapping of mesoscale coastal lows (Gill 1997; Reason and Jury 1990).

In addition to strong SST and orographic gradients, southern Africa is also unique in terms of other influential gradients, such as the spatial distributions of soil moisture and vegetation type and cover, with the west coast very much drier than the east coast (Fig. 1.3). These factors, in conjunction with the geographical position of the region, result in southern Africa having a diverse climate that is influenced by numerous precipitating systems.

\subsubsection{Atmosphere Circulation Patterns}

The day to day weather of the southern Africa is effectively determined by synoptic and small-scale disturbances, whereas the general mean circulation controls the climate of the region (Tyson and Preston-Whyte 2000). Due to the location of southern Africa, the climate and rainfall variability is influenced by circulation features in both the tropics and midlatitudes. The most prominent features are the semi-permanent anticyclonic systems associated with the high-pressure belt encircling the Southern Hemisphere around $30^{\circ} \mathrm{S}$ (Fig. 1.3).

The South Indian anticyclone, positioned to the east of southern Africa, plays a crucial role in advecting moisture into the region. This moisture is advected from the Indian Ocean, which has often been portrayed as one of the major moisture sources for southern Africa (Mason 1995; Reason and Godfred-Spenning 1998; Landman and Mason 1999; Reason and Mulenga 1999; Reason 2001a and others). Anomalous SST conditions within this ocean basin are thought to influence atmospheric circulation patterns, which then play a crucial role in enhancing or weakening the moisture advected into the region. The subtropical Indian Ocean dipole (SIOD; Behera and Yamagata 2001; Reason 2001a) is one such SST pattern, with a positive (negative) SIOD being characterized by warm 
(cool) SST anomalies in the southwest Indian Ocean, cool (warm) SSTs in the southeast and above (below) average rainfall over parts of southern Africa.

Off the west coast, the south-easterly / southerly winds associated with the South Atlantic anticyclone play a pivotal role in the west coast upwelling systems during the summer in South Africa and throughout the year in Namibia. In addition, the South Atlantic anticyclone often ridges around the south of the continent, producing onshore flow along the south and southeast coast. Although most literature has identified the Indian Ocean as a dominant regional moisture source, evidence has been accumulating regarding the Atlantic Ocean has another important moisture source (Rouault et al. 2003a; Reason et al. 2006; Vigaud et al. 2009). Furthermore, SST patterns off the Namibian / Angolan coastline are thought to have a strong influence on heavy rainfall events along the west coast (Muller et al. 2008; Jury 2010).

Not only is the regional circulation strongly influenced by the neighbouring oceans, but also through SST variability in the Pacific Ocean. Summer circulation patterns and rainfall over southern African has also been linked to the El Niño-Southern Oscillation (ENSO) (e.g., Lindesay 1988; Rocha and Simmonds 1997; Reason et al. 2000; Tyson and Preston-Whyte 2000; Richard et al. 2000; Cook 2001). The relationship is thought to be fairly consistent with warm (cold) phase ENSO producing drier (wetter) conditions over much of southern Africa. The mechanism thought to be responsible for modulating these rainfall patterns is the global shift in the position of the zonal Walker Circulation (Cook 2001). During El Niño, the African cell of the Walker Circulation shifts farther eastwards and is positioned over the western Indian Ocean. This results in unfavourable precipitation conditions, through a reduction in moisture convergence, uplift and instability, over the continent. However, reduced rainfall over southern Africa during an El Niño does not always occur (e.g., 1997/98 El Niño). Thus, the relationship between ENSO and southern African rainfall is complex and is subject of ongoing research. 


\subsubsection{Mean Precipitation Patterns}

In an analysis of South African rainfall, Kruger (2007) identified that the highest rainfall ( $>2000 \mathrm{~mm}$ ) occurs along the mountainous areas of the eastern escarpment and southwestern Cape, while the lowest $(<50 \mathrm{~mm})$ were along the west coast near the South Africa / Namibia boarder. Rainfall amounts generally decrease from east to west, with the highest amounts in the east averaging $800 \mathrm{~mm}$ per year, with amounts less than $200 \mathrm{~mm}$ per year occurring in the west (Fig. 1.4). Overall, South Africa can be divided up into the following rainfall regions: west coast and immediate hinterland is an austral winter rainfall region, the south coast, which may receive considerable rainfall throughout the year, and the east coast and most of the interior, which are predominantly summer rainfall regions.

It should be noted that most of the summer rainfall produced over the interior of the country and along the eastern coastal regions is of convective origin (Tyson and PrestonWhyte 2000). These authors suggest that the degree of convectivity over South Africa is determined not only by the diurnal heating cycle of the near surface air, but also by the prevailing dynamics of particular synoptic conditions and by mesoscale and local effects. The precipitating systems are often produced by disturbances in the general circulation in both the tropics to the north and the midlatitudes to the south. Makarau and Jury (1997) noted that in subtropical southern Africa, most rain-producing systems in the early summer take the form of baroclinic westerly waves, while the late summer rains are more tropical and barotropically structured. In addition, Tennant and Hewitson (2002) found that parts of summer rainfall region could also be divided into areas that are influenced more so by tropical weather systems and rainfall that is controlled by local forcing (e.g., northeastern South Africa), compared to other areas that more dependent on organised synoptic-scale weather systems (e.g., central interior).

A common synoptic-scale feature over southern Africa during the austral summer months are cloudbands evolving from tropical-extratropical interactions. These cloudbands, locally known as tropical-temperate troughs (TTT), typically extend diagonally from the 
northwest to the southeast over both the continent as well as the adjacent southwest Indian Ocean (see Fig 1.3) (Harrison 1984; Lyons 1991; Todd and Washington 1999; Washington and Todd 1999). Not only are these cloudbands responsible for a large portion of the South African summer rainfall (Harrison 1984; Diab et al. 1991; Todd et al. 2004), they are also known to produce heavy rainfall events (Hart et al. 2010). A common circulation feature that assists in the development of these cloud bands, through sustained moisture transport into southern Africa, is the Angola low (Todd and Washington 1999; Hart et al. 2010). The Angola low is defined as heat low and is positioned in southern Angola only during the summer months (see Fig. 1.3) (Reason et al. 2006). The circulation around the low and the interaction with the local topography is also thought to also create favourable conditions for precipitation in the region (Monaghan et al. 2010).

Cook (2000) describes this region over southern Africa/ southwest Indian Ocean where tropical-extratropical interaction takes place as the South Indian convergence zone (SICZ). The SICZ displays similarities to the two other Southern Hemisphere convergence zones, the South Pacific convergence zone and South Atlantic convergence zone (SPCZ and SACZ, respectively), but it exhibits higher synoptic variability and only occurs during the austral summer. Essentially, the SICZ reflects the aggregated expression of the synoptic cloudband events, which tend to prefer to be located here rather than further west. The global distribution of MCCs (Laing and Fritsch 1997) often coincide with these three convergence zones, thus suggesting one may find MCCs embedded in the cloud bands or that processes favouring cloudband development may also facilitate MCC production.

Harrison (1984) also noted that subtropical cyclones (i.e., cut-off lows) were another major contributor to the rainfall over the interior, while the summer rainfall over the coastal regions were also produced via cyclonic or frontal disturbances. Similar results were obtained by Diab et al. (1991), where these authors found that 4 synoptic types, namely the tropical-temperate trough, westerly wave, ridging high and east coast low, accounted for 81 percent of the rainfall over the east coast of South Africa for the 1971- 
85 period. However, it should be kept in mind that due to the subtropical location of the region, it is possible that a diverse range of precipitating systems could influence the annual rainfall.

In terms of extreme rainfall, the major flooding events over South Africa tend to be associated with cut-off lows, where precipitation totals in excess of $300 \mathrm{~mm}$ within 24 hours are not uncommon (Singleton and Reason 2006, 2007). Tropical cyclones, although infrequent, are another extreme rainfall producer over the region, but they are restricted to the northeastern and eastern parts, such as Dominia and Eline in 1984 and 2000, respectively (Dyson and van Heerden 2001; Reason and Keibel 2004). A variety of thunderstorms, ranging from single-cells storms through to the larger mesoscale convective systems are also present over South Africa, predominantly during the austral summer months (Laing and Fritsch 1993b; Garstang and Tyson 2000; Tyson and PrestonWhyte 2000). The impact these convective storms have on the region is evident by the large precipitation totals produced over a short period of time. Individual South African case studies have shown that a single MCS event may produce over a $100 \mathrm{~mm}$ of rainfall within 6 hours, thereby making a sizeable contribution to the seasonal rainfall (de Coning et al. 1998; Blamey and Reason 2009). Some of these individual events have even been linked to regions experiencing above average summer rainfall, with Blamey and Reason (2009) documenting an MCS that produced almost two thirds of the monthly rainfall total at some stations in eastern South Africa. This occurrence again highlights the importance of a better understanding of such systems.

\subsection{Thesis Overview}

A vast amount of the literature is dedicated to aspects of southern African rainfall due to the high spatial and temporal variability of rainfall in the region. Most studies based on summer rainfall patterns have focused on the precipitation produced by all forms of convective systems and not individual types or have just focused on the synoptic patterns associated with the precipitation. Furthermore, the research in the region pertaining to 
individual precipitating systems has often focused on the larger cut-off low systems (e.g., Singleton and Reason 2007), tropical-temperate troughs (e.g., Hart et al. 2010) or infrequent tropical cyclones (e.g., Reason and Keibel 2004). The current understanding of the role MCCs play in South African summer rainfall patterns is not completely understood. Garstang and Tyson (2000) suggest that MCSs, including MCCs, may contribute substantially to the annual summer rainfall in South Africa, but they do not quantify to what extent. This warrants for further investigation on these large precipitation producers in southern Africa.

An important first step is to build a climatology of these systems based on a longer period of data than that developed by Laing and Fritsch (1993b), which only used two years (1986-1987). By so doing, we will be able to determine how important such systems are for rainfall production in the region, as well as been able to identify any environmental precursors leading to their development. However, in terms of surface-based weather observation platforms (i.e., rain-gauges, radar, etc), southern Africa could be described as a data sparse region, which generates a problem for monitoring these mesoscale systems and their precipitation characteristics. Furthermore, over the last few decades there has been a steady decrease in the number of radiosondes released over the region. As stated by Maddox et al. (1986), the detailed structure of MCCs and the environments in which they develop requires special data sets that can only be obtained during intensive field efforts that are specifically designed to probe the life cycles of numerous systems. Not only are there issues with spatial availability of data, but the data is further limited due to the lack of quality control. These issues are not confined to the region, but are problematic worldwide. Despite the limited data available in southern Africa, more knowledge about MCCs is required in order to understand the role they play in regional climate variability.

Essentially, it is the development in satellite technology that has resulted in much improved observations of weather features around the world, which is due to these instruments being able to cover a very large range of space and timescales. To date, nearly all MCC climatologies have been constructed based on data provided by the 
various geostationary satellites (e.g., Maddox 1980; Velasco and Fritsch 1987; Miller and Fritsch 1991; Laing and Fritsch 1993a, 1993b; Durkee and Mote 2009 and others). Using Meteosat-7 infrared (IR) satellite data and a hybrid automated/manual tracking method, a MCC climatology over southern Africa is developed here for the 1998-2006 period. The automated method utilized in this study is the MAximum Spatial COrrelation TEchnique (MASCOTTE), developed by Carvalho and Jones (2001). The process is based on IR images converted into brightness temperature $\left(\mathrm{T}_{B}\right)$ as input, where systems are identified based on a set of predefined criteria. This method has been successfully applied to cases in South America (Carvalho and Jones 2001), as well as Spain (García-Herrera et al. $2005 \mathrm{~b}$ ). It has also been shown to have higher detection ability than visually inspecting satellite images (García-Herrera et al. 2005b).

Not only have satellites been useful in detecting MCCs and monitoring the evolution of such large systems, but they have also provided another way in which to estimate the precipitation they produce. In this study, Tropical Rainfall Measuring Mission (TRMM) Multi-satellite Precipitation Analysis (TMPA) 3B42 version 6 data (Huffman et al. 2007; Huffman et al. 2010) is used to document the precipitation produced by MCCs over southern Africa. The advantage of using this data is that it provides quasi-global $\left(50^{\circ} \mathrm{S}-\right.$ $50^{\circ} \mathrm{N}$ ) precipitation rate estimates over a $0.25^{\circ} \times 0.25^{\circ}$ spatial resolution and contains a temporal resolution of 3 hours. The data has also already successfully been used in MCC rainfall variability studies in South America (Durkee et al. 2009) and global tropical cyclones precipitation patterns (Jiang and Zipser 2010).

In summary, the main objectives of this dissertation are twofold, with the first relating to the development of the MCC climatology and the second being to obtain a better understanding of the role MCCs play in South African summer rainfall. In addition, an attempt is made to identify what synoptic and mesoscale features are important for the regional development of these systems. It should be taken into consideration that even though a large amount of global research has been dedicated to MCCs and their associated severe weather, there still remain several gaps in the literature regarding the evolution of these systems and the environment in which they develop. There is not only 
a lack of understanding of MCCs, but also not much skill in predicting these types of systems worldwide (Zeigler 2000). Ultimately, the results here will not only benefit the local understanding of these systems, but will hopefully contribute to the global knowledge on MCCs.

The thesis contains the following sections. Chapter Two provides a brief overview of MCCs and looks at what makes these systems unique. The intent is to provide enough description of MCCs in order to allow for an informed analysis and discussion of the results presented in later chapters. Chapter Three provides an introduction to the use of satellite tracking methods and discusses the satellite tracking method used to build the climatology for this study. It should be noted that the data and methods used to investigate the precipitation produced by the systems is not included in Chapter Three, but instead provided in a later chapter. The results for the MCC climatology is analysed in Chapter Four. Chapter Five provides some insight into the large-scale environment that favours the development of MCCs over southern Africa. In Chapter Six, the satellitederived rainfall used in this study is introduced, as well as an analysis of the role MCCs play in South African precipitation patterns. Chapter Seven presents three case studies of MCCs that occurred over southern Africa using a high resolution reanalysis dataset. The aim of the chapter is to highlight some of the synoptic and mesoscale features (precursors) that are often associated with the development of such systems in the region. The discussion and conclusions from this thesis are found in Chapter Eight. 


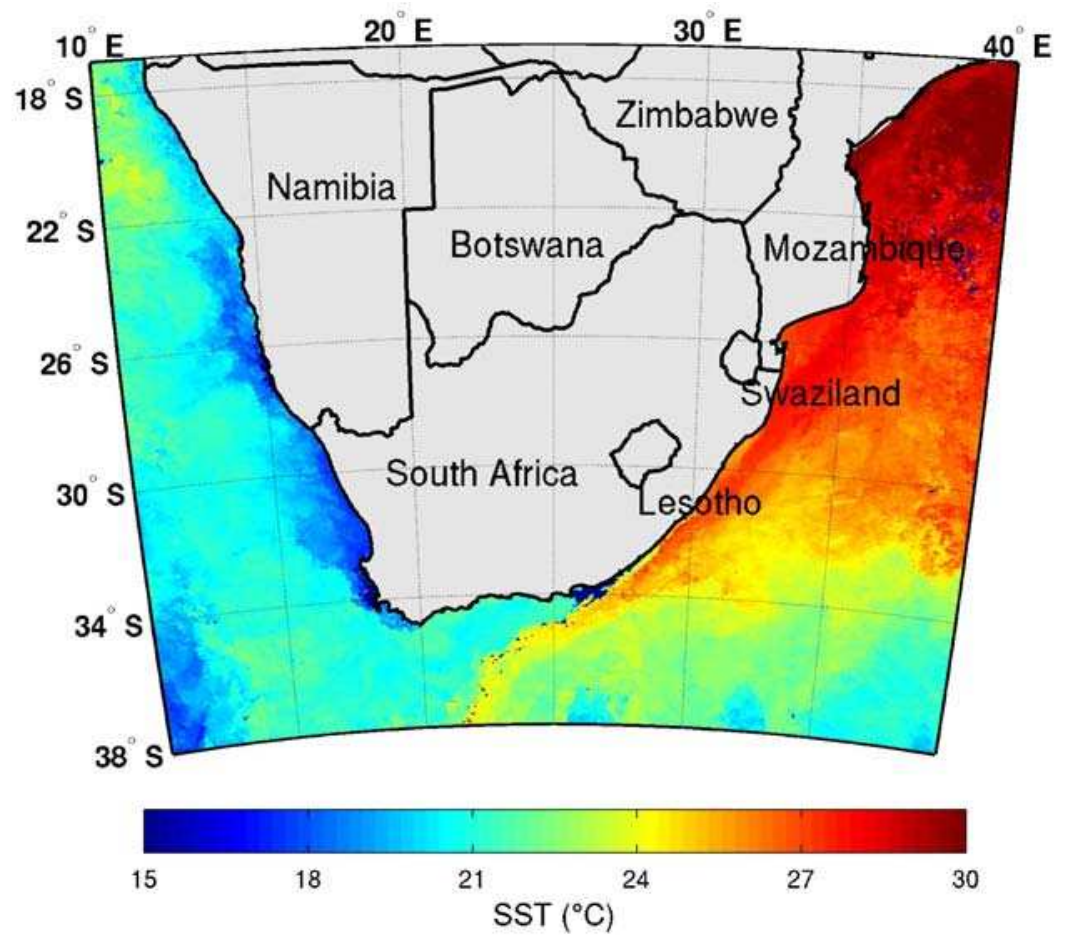

Figure 1.1: AVHRR $4 \mathrm{~km}$ sea surface temperatures surrounding southern Africa (shaded, $3^{\circ} \mathrm{C}$ interval) for January 2000. Countries referred to in the text are also labelled.

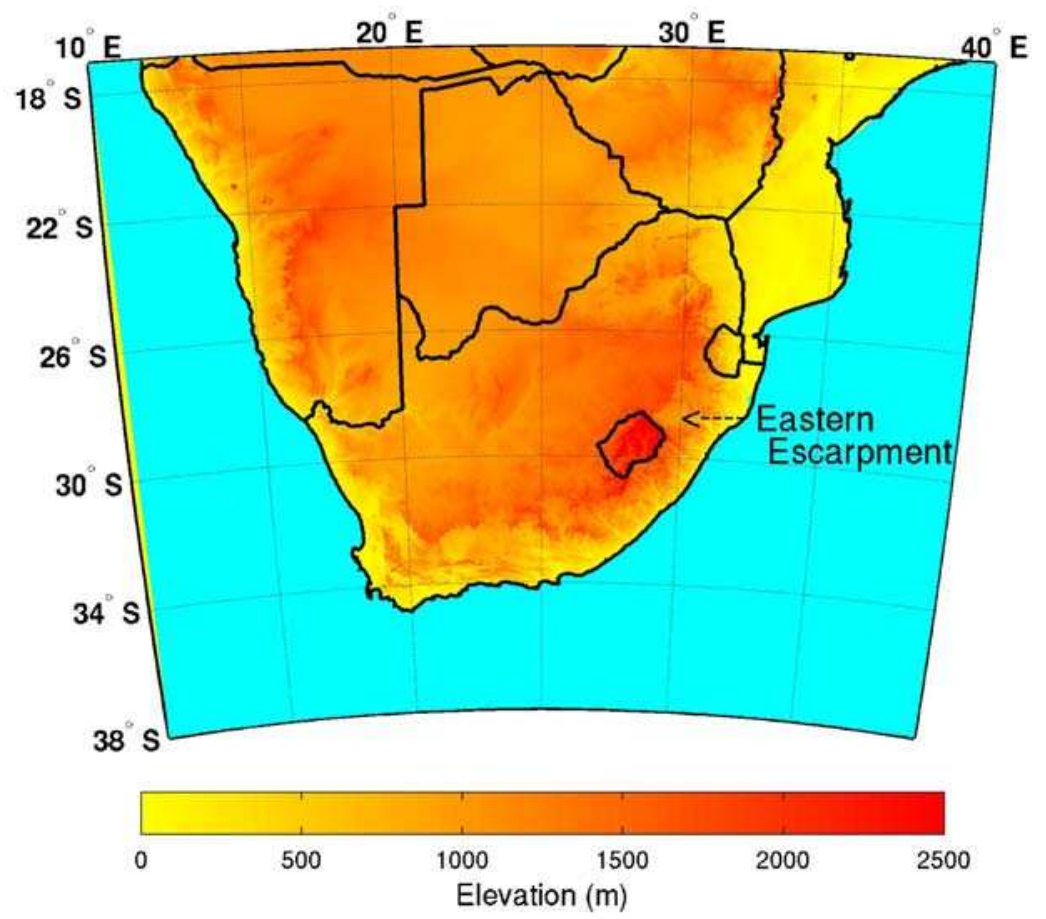

Figure 1.2: Topography of southern Africa (shaded, $500 \mathrm{~m}$ intervals). The eastern escarpment is highlighted in the figure. 


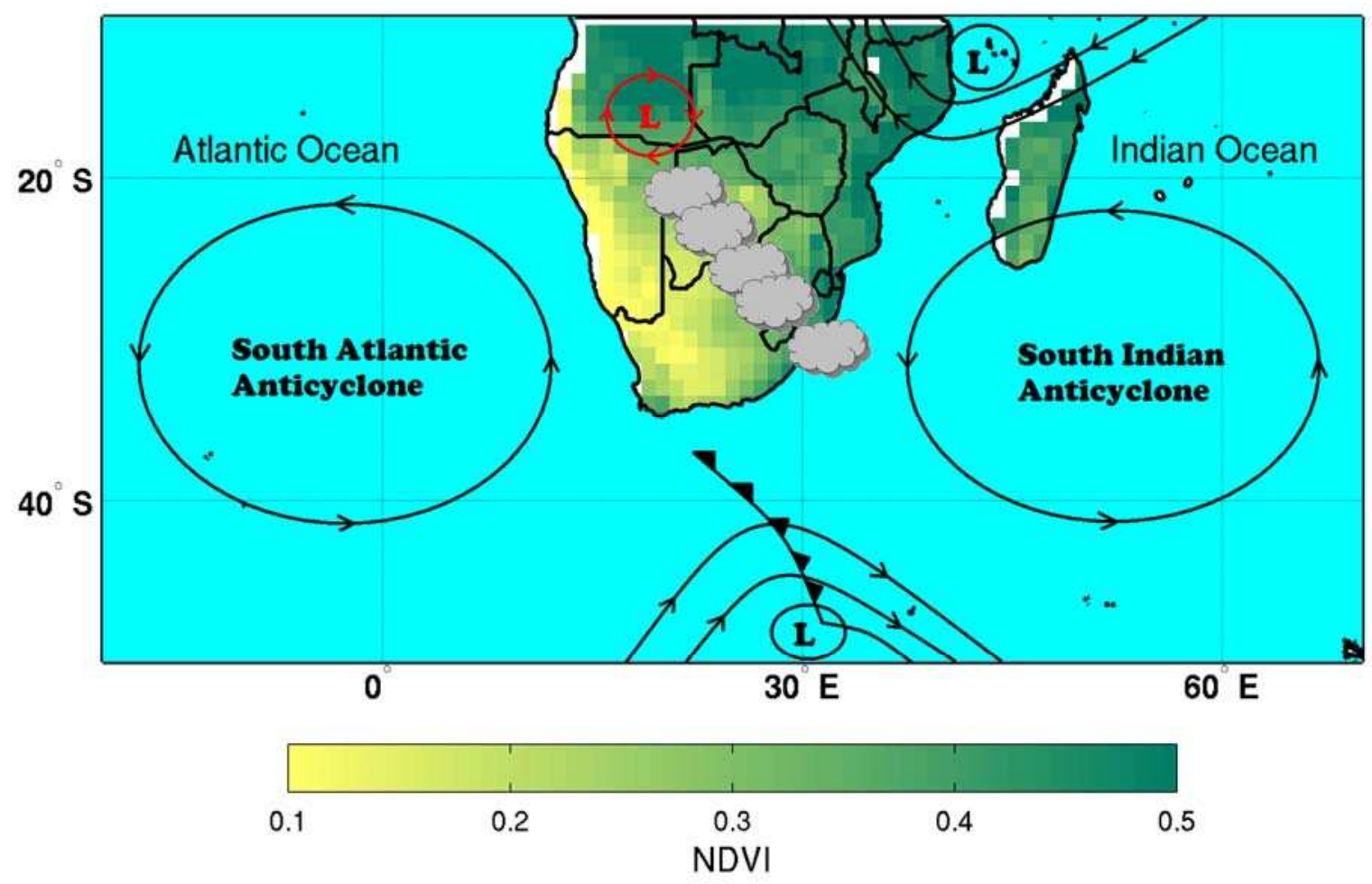

Figure 1.3: Schematic showing the common surface synoptic features that influence the weather and climate of southern Africa. These include: the subtropical anticyclones positioned over the oceans, westerly wave and low to the south, easterly wave and low to the north and the Angola low (red circle). Also shown is the common position of tropicaltemperate troughs (grey clouds) over the continent during summer months. Surface shading over land is the average normalised difference vegetation index (NDVI; $1^{\circ}$ resolution) for the region for the 1982-2001 period. 


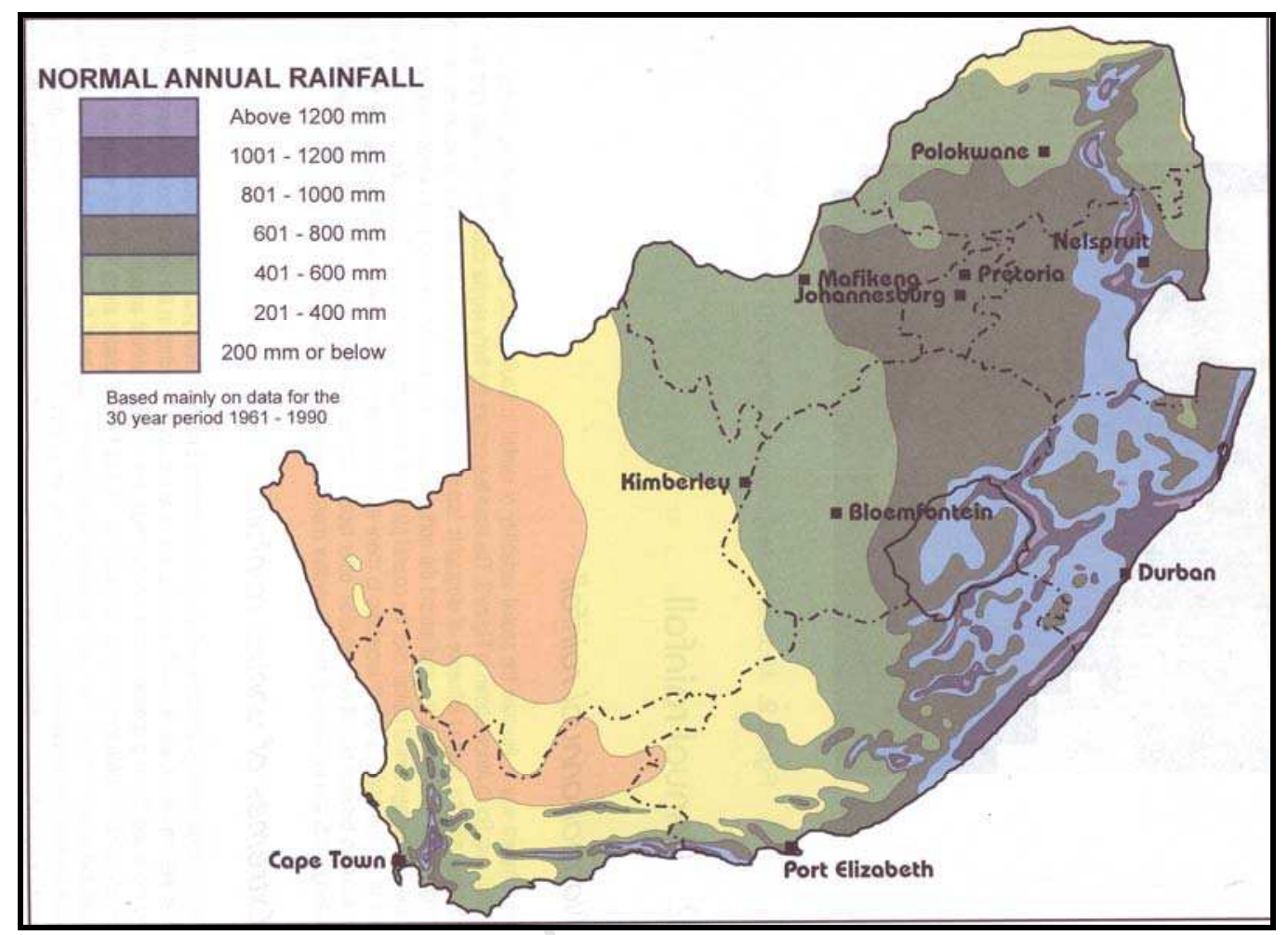

Figure 1.4: Average annual rainfall, in millimetres, over South Africa for the period 1961-1990 (from Kruger 2007). 
Chapter Two

Literature Review 


\subsection{The Mesoscale Convective Complex}

The term mesoscale convective system (MCS) is used to describe an ensemble of convective storms that satisfy certain spatial and temporal criteria. Zipser (1982) defines a MCS as cloud and precipitating system, together with their associated circulation systems, which include a group of cumulonimbus clouds during most of the lifetime of the system. Not only must this cumulonimbus cloud group associated with this weather feature exist for several lifetimes of its constituent clouds, but it must also contribute at some time to a common upper tropospheric shield of outflow air. Its convective-scale downdrafts must also merge at some time to form a continuous zone of cool air in the low troposphere. As noted by Fritch and Forbes (2001), this broad definition includes a wide variety of mesoscale phenomena, which range from a collection of a few short-lived thunderstorms to long-lived tropical storms and even hurricanes. Some of the other early definitions of MCSs usually categorized them as having a length exceeding $250 \mathrm{~km}$ and persisting at least 3 hours (e.g., Bartels et al. 1984). Thus, due to the variety of MCSs, a very broad definition could be accepted that they are a long-lived ( $\geq 3$ hours) cumulonimbus cloud system that contains a nearby precipitation area of roughly $100 \mathrm{~km}$ or more in at least one direction (Houze 2004). The different types or modes of MCSs are not only based on size, but also on the geometry of the system, as well as the relative arrangement of the convective and stratiform rainfall regions.

The mesoscale convective complex (MCC), defined by Maddox (1980), is among the largest of the MCSs. They are identified as convective cloud systems that are large, longlived and exhibit a quasi-circular cloud shield (Table 2.1). It is the eccentricity criterion that usually separates the quasi-circular MCC from other MCSs, such as the squall line. These large systems are of great interest because they are typically associated with intense rain rates over large contiguous rain areas, as well as being associated with a host of severe weather phenomena. Not only are MCCs important in terms of a local hydrological cycle, but on the larger scale, convective systems in general play important roles in the distribution of energy, momentum and mass in general circulation (Cotton and Anthes 1989). An important link between MCCs and global climate may exist through the global distribution of upper-tropospheric water vapour (UTWV). Water 
vapour in the troposphere is believed to play an important role in global climate as a greenhouse gas as well as through interactions with clouds, aerosols and tropospheric chemistry (Price 2000). UTWV originates from hydrometers (i.e., hail, ice crystals, droplets, etc) that are transported upwards through deep convective storms, which once evaporated/sublimated, are then distributed zonally and meridionally in the upper troposphere (Newell et al. 1996). Thus, MCCs are likely to be major contributors to UTWV due to their size and hence, have an influence on global climate.

Most of the work pertaining to MCCs has been conducted within the United States of America (U.S.). Not only are MCCs common there, but the U.S. has a very good weather observation network. However, over the past few decades, data on the populations of MCCs have been accumulated for nearly all regions of the world. From the global research it has become evident that some key patterns emerge about these systems, ranging from the regions over which they develop to the life cycles they display. Some of the key findings from the literature, including the previous findings on southern Africa systems, are discussed in this chapter.

\subsection{Distribution}

MCCs are more or less a global phenomenon, being distributed throughout the tropics and midlatitudes, over both land and ocean (Fig. 2.1). These systems have been documented in many regions of the world, including parts of the U.S. (Maddox 1980; Augustine and Howard 1991; Anderson and Arritt 1998; Ashley et al. 2003, among others), South America (Velasco and Fritsch 1987; Durkee and Mote 2009), Europe (Laing and Fritsch 1997; García-Herrera et al. 2005b), Asia (Laing and Fritsch 1993a; Miller and Fritsch 1991), Australia (James 1992) and Africa (Laing and Fritsch 1993b; Laing et al. 1999). There appears to be particular global locations where MCCs tend to cluster (Fig. 2.2), which include the gradient zones between outgoing long-wave radiation maxima and minima (especially along the periphery of considerable outgoing longwave radiation (OLR) minima) and in the lee (relative to prevailing mid-level flow) 
of elevated terrain (Laing and Fritsch 1997). Therefore, particular features may play a role in the development of such systems.

Although MCCs are predominantly a summer season phenomena, they also known to occur during the transition seasons of spring and autumn. Using 15 years worth of MCC data, Ashley et al. (2003) found that $86 \%$ of the MCCs in the U.S. occurred during the May to August period, with the maximum peak in MCC activity occurring in the month of June. Augustine and Howard (1991) noted that MCC numbers in the U.S. maximised in late spring and early summer. This period of maximum activity has also been identified in regions outside the U.S., such as the western Pacific region (Miller and Fritsch 1991) or South America (Durkee and Mote 2009). However, it should be noted that there are even periods during the warm season when MCC cease to form. Augustine and Howard (1991) found that during 1986-87, both years had a period of no MCCs activity during late spring and early summer, normally a period abundant in MCC production.

Laing and Fritsch (1997) suggest that the global population of MCCs is strongly influenced by the seasonal radiation cycle. This is evident in the seasonal distribution of MCCs in the U.S., where the peak activity in MCC development progresses northward from about $35^{\circ} \mathrm{N}$ in April to $40^{\circ}-45^{\circ} \mathrm{N}$ in July and then back to about $40^{\circ} \mathrm{N}$ in August and September (Augustine and Howard 1991). Velasco and Fritsch (1987) identify that a large number of the systems in South America developed much later in the annual cycle compared to U.S systems. This resulted in the MCC season in midlatitude South America being 8 months long compared to the 5 month MCC season in North America. They suggest that one possible reason for this is the greater lag of the seasons with the solar cycle in the ocean-dominated Southern Hemisphere. It could also be due to their midlatitude domain extending up to $20^{\circ} \mathrm{S}$, which could result in the data showing some tropical systems, and hence the longer season.

The frequency of MCCs is not completely known, but on average about 380 of these systems occur around the world per year (Laing and Fritsch 1997). The difficulty in determining the annual average of MCCs in some places is due to the considerable 
variability from month to month and from one year to the next (e.g., Velasco and Fritsch 1987). Some regions, such as the Americas, experience over 30 MCCs per warm season (Velasco and Fritsch 1987; Ashley et al. 2003; Durkee and Mote 2009), while other MCC regions experience considerably less ( $<15$ per season), such as Australia (Perrin and Reason 1997) or India (Laing and Fritsch 1993a). Previous work by Laing and Fritsch (1993b) found that midlatitude South Africa also experiences few systems per season ( 11) compared to the Americas.

\subsection{The MCC Life Cycle}

A common characteristic of MCCs is the clear diurnal cycle they exhibit, tending to favour night time (Maddox 1980; Velasco and Fritsch 1987; Miller and Fritsch 1991; Laing and Fritsch 1993a, 1993b). They appear to have a similar onset times for the different life cycle stages, with the four main stages being First storms, Initiation, Maximum extent and Termination (Laing and Fritsch 1997; Jirak et al. 2003). The first thunderstorms generally develop in mid-to-late afternoon, followed by the amalgamation of the cloud shield into a mesoscale structure around sunset. This is followed the system obtaining the MCC size criteria during the early night time, reaching maximum extent after midnight and then begins to dissipate around sunrise (Maddox 1980; Velasco and Fritsch 1987; Miller and Fritsch 1991; Laing and Fritsch 1993a, 1993b; Laing and Fritsch 1997; Anderson and Arritt 1998). However, some seasonal differences are evident in the initiation of the systems. An example of this is shown by Anderson and Arritt (1998) who found that a large percentage of MCCs in the U.S. during 1992 and 1993 initiated at different times during the summer and spring months.

The characteristic of these systems to occur predominately during the night time is believed to be related to the differential radiative heating between the convective cloud area and its environment (Gray and Jacobson 1977; Cotton 2000). As illustrated in Figure 2.3, during the night, radiation emitted by the earth is absorbed at the base of the stratiform cloud cover, where a fraction of it is re-emitted towards the earth and another fraction is emitted upwards (this continues at each layer). Due to clouds being relatively 
good absorbers of infrared radiation, this process results in less of the re-emitted radiation reaching the inner clouds. At the top of the cloud cover there is a net loss of radiation due to the air above it not being able to absorb a lot of the emitted radiation and hence none is re-emitted downwards to the top of the cloud. The end result is that there is a net warming at the base of the cloud and cooling at the top, which results in the cloud layer being unstable, resulting in convective overturning. Gray and Jacobson (1977) suggest that this differential radiative heating would lead to an enhancement in the environmental subsidence on the periphery of the cloud shield and thereby increase low-level convergence into the system. Obviously this pattern will differ in the day time hours, since shortwave radiation from the sun is reflected at the cloud tops or absorbed into the atmosphere. Another feature resulting in an unstable cloud layer is latent heating (Cotton 2000). Latent heating, which results from condensation on cloud droplets, freezing and vapour deposition growth of ice crystals, causes a warming of the mid-levels and hence a rising motion. Below the mid-levels, there is a cooling due to melting precipitation particles.

However, Fritsch and Forbes (2001) argue that because free-troposphere longwave cooling is typically small $\left(<0.1^{\circ} \mathrm{C} \mathrm{h}^{-1}\right.$; Dopplick 1972; Machado and Rossow 1993) compared to convective heating rates observed in MCSs $\left(\approx 5^{\circ} \mathrm{C} \mathrm{h}^{-1}\right.$; Ogura and Chen 1977 ) it is unlikely that free troposphere radiatively driven circulations can create convective available potential energy (CAPE) fast enough to offset the rates at which it is consumed in MCS overturning. This may especially apply to the larger MCCs, which exhibit intense and massive convective overturning for many hours. Thus, other factors likely play a role in the nocturnal nature of these systems. One such factor is possibly the presence of a nocturnal low level jet (LLJ) advecting high equivalent potential temperature (high- $\theta_{\mathrm{e}}$ ) air into the MCC region (e.g., Maddox 1983; Velasco and Fritsch 1987; Miller and Fritsch 1991). The influence of the LLJ on MCC evolution is discussed in more detail in the next section of this chapter. 


\subsection{Factors limiting duration and size}

As mentioned previously, MCCs are the largest of the convective storms and can obtain a dimension exceeding a 500,000 $\mathrm{km}^{2}$ and last longer than 24 hours (Velasco and Fritsch 1987). However, on average, these systems generally produce a cold cloud shield of approximately $354,000 \mathrm{~km}^{2}$ and persist for about 10 hours (Laing and Fritsch 1997). It is due to the size and duration of such systems that they are known to interact and modify the large-scale environment, which then may affect other meteorological features elsewhere (e.g., Stensrud 1996b). In terms of duration of MCCs, it is recognised that there is a nearly linear relationship between the average convective system radius and its life cycle (Machado et al. 1998). This supports the findings of Laing and Fritsch (1997) who noted that MCCs with large cloud shields usually last longer than those with small shields.

The factors that result in these systems attaining these large dimensions are not fully understood, but it is believed that a combination of dynamic and thermodynamic properties are responsible for limiting the size and duration of the system (Cotton 2000; Houze 2004). The effect that these two limiting factors may have on an individual system varies according to the geographic location in which the system develops. Laing and Fritsch (1997) found that, on average, MCCs in the Southern Hemisphere are slightly larger than the Northern Hemisphere counterparts, but have a shorter duration. They also noted that oceanic systems are slightly larger and last longer than those forming over land. In addition, differences in size and duration of midlatitude versus tropical systems are also apparent (e.g., Velasco and Fritsch 1987). In order to understand why this may occur, one need took look at the influence that the two limiting factors may have.

\subsubsection{Dynamic Factor}

It is due to the size and duration of an MCC that Coriolis force becomes an important factor. As discussed by Cotton (2000), the vertical structure of large quasi-circular MCS 
is composed into regions of organised high or low pressure, which are developed through various processes such as evaporation, melting of precipitation, condensation, etc. These pressure zones are sustained for many hours, resulting in air being drawn in from greater distances. This circulation eventually becomes large enough for the airstream being drawn in to respond to the Earth's rotation. Over time this wind field slowly adjusts to the pressure field and the rotation of the Earth so that the flow then approaches geostrophic balance. However, another apparent force has to be taken into consideration when flow occurs around curved isobars, which is the centrifugal force. When Coriolis, the pressure gradient force and the centrifugal force are in balance then the system is referred to being gradient balance. Cotton et al. (1989) identified from observations and modelling studies that deep convection becomes less intense as the system reaches maturity and the flow becomes increasingly geostrophically balanced and non-divergent. Cotton (2000) suggests that although the systems hardly ever reach true balance, it is the adjustment toward a balanced state, which separates MCCs from ordinary convective storms. Due to the variation of the Coriolis force with latitude, systems in the higher latitudes do not have to be as large as those in the tropics to experience the same rotation.

As rotation of the system develops, it also develops inertial stability. This means that if the system moves into a region of increased static stability (i.e., more stable environment) it can continue to survive as an organized system, whereas a non-rotating system will rapidly decay (Cotton, 2000). The scale at which a MCS is sufficiently influenced by rotation to be dominated by inertial stability is known as the Rossby radius of deformation $\left(\lambda_{\mathrm{R}}\right)$, an important dynamic factor. In other words, the $\lambda_{\mathrm{R}}$ could be described as the length scale at which the rotational effects become as important as buoyancy effects in the development of the flow about the MCS. This value varies with latitude and static stability, being larger at lower latitudes, so that tropical systems will have to be larger than their mid-latitude counterparts in order to be inertially stable (Cotton 2000). Cotton et al. (1989) found that for midlatitude MCC environments, $\lambda_{R}$ is about $300 \mathrm{~km}$, while Fritsch and Forbes (2001) add that for midlatitude systems of this scale it typically takes about 3 to 6 hours for Coriolis influences to become substantial. 
Ultimately, the result is that distinctive circulation patterns being to develop at different levels within the MCC during the later stages of the life cycle. The lower and mid-levels are dominated by cyclonic circulation, while a meso-high in the upper levels is associated with anticyclonic flow. This circulation is sometimes evident in the mid-level clouds, by the presence of spiral bands, after the main convection and stratiform rainfall has dissipated. This circulation feature is more commonly known as a mesoscale convective vortex $(\mathrm{MCV})$. They have been found to generate within the stratiform precipitation region of the mesoscale system, during the mature and later stages of the life cycle (e.g., Leary and Rapport 1987; Zhang and Fritsch 1988; Menard and Fritsch 1989). Through the use of a numerical model, Chen and Frank (1993) propose that the development of such a vortex in the stratiform region of the MCS is due to the reduced vertical stability caused by the saturated atmosphere. This in turn results in the reduction of the local Rossby radius of deformation to a scale smaller that that of the stratiform region. These authors suggest that this, in combination with the widespread latent heat release, results in the spin-up of the vortex.

Nearly all cases documenting MCVs that have evolved from MCSs have occurred in the U.S. (e.g., Menard and Fritsch 1989; Bartels and Maddox 1991; Trier et al. 2000a; 2000b). The diameters of these systems can range from tens to hundreds of kilometres and have temporal scales ranging from hours to days (Bartels and Maddox 1991; Bartels et al. 1997; Weisman and Davis 1998). Most MCV cases documented have been linked to the quasi-circular MCC in the midlatitudes, where they appear to develop in the same regions as MCCs and even show similar migration patterns as MCCs (Bartels and Maddox 1991). However, MCVs are not only restricted to MCCs since research has revealed that vortices may develop at the ends of the quasi-linear systems (Weisman 1993; Skamarock et al. 1994). These vortices are known to have an influence on the symmetry of the quasi-linear MCSs in the midlatitudes, where Coriolis enhances MCV development (Houze et al. 1989; Houze et al. 1990; Houze 2004). Although the formation of a MCV may occur in the tropics (e.g., Gamache and Houze, 1982), these features are not as strong and prominent as those in the midlatitudes. This could be attributed to the variation of Coriolis force with latitude, with it being smaller in the 
equatorial regions compared to the higher latitudes. It has also been documented that some MCVs are associated with subsequent convective activity, where occasionally this subsequent convective activity is know to produce severe weather (Bartels and Maddox, 1991; Menard and Fritsch 1989; de Coning et al. 1998; Trier at al. 2000a). Essentially, it appears that an MCV may not only contribute to the longevity of MCCs, but also influence convective activity elsewhere. It is also possible that a tropical cyclone may even develop from an MCV (e.g., Simpson et al. 1997).

\subsubsection{Thermodynamic Factor}

The second factor that possibly limits the size and thus, the duration of an MCC, is the thermodynamic factor. This refers to the thermodynamic structure of the boundary layer, which plays a crucial role in sustaining a system. Houze (2004) noted that deep broad MCSs often developed in a region that contained a boundary layer that was warm and moist throughout its depth. This could account for the larger systems over the tropical oceans, where a moist warm boundary layer exists over a broad region and it is not heavily influenced by any diurnal cycle. The opposite tends to occur over land in the tropics, which may inhibit these systems from obtaining a similar size to those occurring over the ocean. However, as discussed previously, MCCs frequently occur over land during the night, which suggests that other features must play a role.

One possible factor that helps sustain the boundary layer over land during the night time hours is that of the low level jet (LLJ). MCCs in the U.S. usually thrive on moist air masses brought in by the nocturnal LLJ, which comes from the warm waters of the Gulf of Mexico, while the air mass that feeds the South American systems usually comes from the tropical rainforest regions of the Amazon and Parana River basins (Maddox 1983; Velasco and Fritsch 1987; Vera et al. 2005). Miller and Fritsch (1991) also note that most of the MCC population centres in the Western Pacific Region occur downstream of a long fetch of low level flow over very warm water. Nocturnal LLJs are not only responsible for the inflow of high- $\theta_{\mathrm{e}}$ air, but have been shown to promote a favourable environment for long-lived nocturnal convection to take place through enhanced low 
level convergence, increased frontogenesis and stronger vertical wind shear (Augustine and Caracena 1994; Fritsch and Forbes 2001; Trier et al. 2006). It is arguably for these reasons that the global population of MCCs often coincide with regions that contain regular LLJ activity (Fig. 2.4). Strensrud (1996a) suggests that due to the similar life cycle pattern (i.e., the similar diurnal component) between the global MCC and the LLJ population, the LLJ may be a key feature in MCC development and evolution. Augustine and Howard (1991) even noted that there are sometimes periods during the late spring and early summer where MCCs fail to develop in the U.S. These authors found that during these periods it was evident that there was reduced $850 \mathrm{mb}$ warm advection and moisture flux in the Great Plains.

The termination of an MCC is identified as when the system no longer meets the requirements of being classified as a MCC. This usually occurs when the system moves into an environment that is more stable and convectively less favourable (Maddox et al. 1986). Maddox (1983) found that in the U.S. this process occurs at a stage when the LLJ no longer feeds moisture into the system and that cool air advection replaces the warm advection in the lower troposphere. These unfavourable conditions are usually as a result of the changing synoptic patterns.

\subsection{Favourable Synoptic and Mesoscale Environments}

Research by Laing and Fritsch (2000) suggest that the MCC-producing synoptic $(\geq 500$ $\mathrm{km}$ ) and mesoscale environments around the world are all very similar, and that they exhibit many of the same dynamic and thermodynamic structures that were found in early composite studies by Maddox (1983) and Cotton et al. (1989). Maddox (1983) provided the first evidence of the large-scale meteorological conditions seen before, during and after the mature stage of an MCC. It is found that the typical MCC develops within a large-scale environment that contains considerable horizontal temperature, moisture and stability gradients, along with considerable variations in both horizontal and vertical wind shear. Essentially, the environment in which an MCC may develop in is required to be unstable, whereby the low levels contain warm and moist air, while the upper levels 
contain relatively cold air aloft. Maddox et al. (1986) note that midlatitude systems often occur in a region favouring upward vertical motion ahead of a mid-level shortwave trough, in an environment that is conditionally unstable. Additionally, other features during the development of such systems includes low level warm advection, low levels winds that increase in speed and veer during the night, as well as the atmosphere becoming more moist with time.

The previously mentioned low level jet (LLJ) is another prominent feature in most MCC environments, both before and during. Not only is it responsible for advecting high equivalent potential temperature (high $\theta_{\mathrm{e}}$ ) air into the MCC region, thus destabilizing the environment and sustaining the system during the night, but it is also associated with strong low level convergence and ascending motion. It is likely for these reasons that Walters and Wilkins (2001) noted that in 95\% of LLJ events they studied over the Great Plains, cloud-to-ground lightning activity occurred. The convective activity associated with the low level wind maximum appears to occur in preferred locations, either at the end of the jet or along the west flank (Beebe and Bates 1955; Augustine and Caracena 1994; Walters and Wilkins 2001). However, as illustrated by Walters and Wilkins (2001), low level wind maxima configurations are considerably complex and favourable convective locations vary according to the spatial pattern of the jet.

An additional mechanism that may result in the release of instability is that of upper-level disturbances, which are associated with dynamic lifting. MCCs have also been found to occur on the anticyclonic side (right exit zone in the Northern Hemisphere) of a broad, weak upper-level westerly jet stream (Maddox 1983; Cotton et al. 1989). This has also been noted by Velasco and Fritsch (1987) who show that as the midlatitude jet stream migrates latitudinally over North America, the centre of MCC activity migrates with it, whereas in South America, the westerly jet remains pretty much stationary during the warm season and so does the centre of activity of midlatitude MCCs. In comparison, Miller and Fritsch (1991) found that in the western Pacific region, the Northern Hemisphere midlatitude MCCs tend to shift poleward from spring to summer as the climatological westerly jet migrates northward. Thus, there seems to be some pattern 
where the centre of MCC activity migrates or remains stationary depending on the meridional movement of the jet.

It appears that the interaction of a low level and upper level jet could possibly play a crucial role in the development and evolution of MCCs. Early studies (e.g., Beebe and Bates 1955) suggested that there are specific regions in which severe thunderstorm development is favoured when these two features are coupled. In MCC environments, Cotton et al. (1989) noted that the coupling of low level convergence and upper level divergence is perceived to maintain the inflow and outflow of mass, which is necessary to sustain the long periods of deep convection. However, as identified by Maddox and Doswell (1982), the positions of the upper and lower jet streams, which are linked to severe thunderstorms, show considerable variability. Walters and Wilkins (2001) also found considerable variability within LLJ configurations and hence, convergence patterns.

The influence of topography on the evolution of MCSs, particularly MCCs, should not be ignored. Topography appears to play a role in the formation of MCCs, with the majority of the systems globally being found to form downwind of elevated terrain (Laing and Fritsch 1997). Maddox (1980) found that half the systems studied in the U.S. seemed to have initially developed along the eastern slopes of the Rocky Mountains, while the rest developed from storms that developed over the plains. Approximately $30 \%$ of the systems in South America also appeared to have developed on the eastern slopes of the Andes (Velasco and Fritsch 1987). Similar topographic influences on MCC development have been identified other regions, such as Australia (Perrin and Reason 1997) and South Africa (Laing and Fritsch 1993b). It is interesting to note that regions that have relatively flatter topography, compared to that in the Americas, generally have fewer systems (e.g., Australia, South Africa). This highlights the importance of topography for initiating the individual storms that merge into an MCC. Topography is also known to have an influence on features associated with MCCs, such as the LLJ (Uccellini 1980; Pan et al. 2004). 
There have been several attempts to categorise the different environments in which MCC develop. For example, Kane et al. (1987) document the different surface synoptic patterns that lead to the formation of MCCs in the United States by classifying them as either synoptic, frontal, mesohigh or extreme right moving events. These synoptic patterns were first documented by Maddox et al. (1979) when they were researching flash flooding events in the U.S. From the results, Kane et al. (1987) identified that the different categories were very much dependent on the time of year. Synoptic events tended to occur more frequently in late spring - early summer, while mesohigh events occurred more often in the mid- to late summer, thus reflecting the influence of the large-scale dynamics on these systems, particularly during the early warm season. Systems later in the warm season may also be more dependent upon latent heat release as well as the processes that take place within the convective system.

Fritsch and Forbes (2001) categorized MCCs into two types, depending upon the dynamical mechanism whereby the convection and the large cold cloud shields are produced. Their Type-1 event occurs when mesoscale region of low level potentially unstable air is forced to ascend in a frontal zone or other baroclinic region (e.g., warm or stationary frontal overrunning situation). However, some MCC events occur in the warm sector and do not occur in conjunction with frontal lifting. Fritsch and Forbes (2001) classify these events that develop in a more barotropic environments as Type-2 events. These events are more dependent on the production of the surface cold pool and its interaction with the ambient vertical wind shear to produce mesoscale ascent and the associated large stratiform cloud shield characteristic of MCCs. Essentially the two different scenarios are based on the environment in which the systems develop. Type-1 systems develop largely as a consequence of externally imposed forcing, whereas Type-2 systems are primarily dependent on features and processes imposed by the convection itself.

However, as noted by Tucker and Zentmire (1999), it should be kept in mind that the conditions which favour the formation of convective weather systems do not necessarily differentiate between days where large clusters of thunderstorms, such as MCCs form, 
and those for which there are scattered thunderstorms. According to Hane (1986), the synoptic-scale conditions that are favourable for the development of squall lines are very similar to the already mentioned MCC-favourable environment and even to that of strong thunderstorms in general. In a study of South American MCCs, Velasco and Fritsch (1987) found that areas which exhibit frequent and widespread deep convection (such as the Amazon river Basin) did not necessarily result in the formation of MCCs. In general, there are some essential ingredients required for the development of a thunderstorm or at least deep, moist convection. These include the presence of low level convergence, upward motion, potential instability and high levels of moisture in the atmospheric boundary layer (McNulty 1995; Doswell et al. 1996). It could be argued that synopticscale processes are required to provide the right conditions for convection to take place, while mesoscale features/processes are required to focus these conditions into a specific region or to initiate convection (Doswell 1987). Romero et al. (2000) suggest that synoptic and mesoscale conditions must remain favourable for the development of an MCS over a specific region and last for several hours. This situation is needed so that convection can be continuously generated in the specific region, which then allows the system to become long-lived and quasi-stationary. This theory is supported by Cotton (2000) who suggests that the genesis of MCSs usually requires sustained forcing from the large-scale environment in order to initiate formation. However, in the absence of strongly forced environments, mesoscale features become important for the development and evolution of the convective event (Stensrud and Fritsch 1993, 1994).

\subsection{The propagation of MCCs}

For forecasting purposes, it is essential to identify some key propagation characteristics of these systems. Most methods of determining MCC tracks involve studying their cold cloud shields using satellite imagery. There appears to be some skill in forecasting the movement of these systems based on the large-scale flow. For example, in the U.S., MCCs are found to move with the mean eastward flow in the 700-500 mb layer (Maddox 1980; Maddox et al. 1986). However, the systems movement appears to be influenced by the seasons, where systems in the U.S. and midlatitude South America curve equatorward 
during mid-summer compared to the usual west to east track found in late spring (Velasco and Fritsch 1987).

Apart from the mid-level flow, another key feature could be the direction in which the system is fed from in the low levels. Miller and Fritsch (1991) found that systems in the western Pacific Region tend to depart from the prevailing mid-level flow and head towards the inflow of low-level high- $\theta_{\mathrm{e}}$ air. It has also been identified that systems forming near the eastern escarpment in South Africa tend to move east or northeastward towards the high- $\theta_{\mathrm{e}}$ associated with warm waters (Agulhas Current) along the southeastern African coast (Fig. 2.5) (Laing and Fritsch 1993b). Miller and Fritsch (1991) suggested that this pattern where systems tend to propagate to the right (left) of the prevailing mid-level flow in the Northern Hemisphere (Southern Hemisphere) could be due to the inflow of low-level high- $\theta_{\mathrm{e}}$ air, which is always to the right (left) of these systems. However, this may not always be the case because some MCS events may be fed by an inflow of high- $\theta_{\mathrm{e}}$ air from behind the system (Parker and Johnson 2000; Pettet and Johnson 2003).

Corfidi et al. (1996) attempted to predict the movement of MCC, by looking at the movement of the meso- $\beta$-scale convective elements (MBEs). They constructed a very simple conceptual kinematic model, which shows the MBE movement as the vector sum of the mean flow in the cloud layer and the propagation component. The authors found that this technique seemed to provide a good estimate of the rate of movement and also revealed that there is an overwhelming tendency for MBEs to propagate towards or "into" the LLJ. However, Corfidi (2003) noted that the LLJ appears to play a role in the vector motion of MCSs, but other features appear to have a bigger influence in the motion.

There are numerous processes, some not completely understood, that are thought to govern the movement of MCSs, which range from cold pool dynamics to waves generated externally of the system. Cold pool dynamics are possibly the most common concept with regards to the propagation of convective systems. The cold pool is the area beneath the system that is formed due to cooling of the air by evaporation and melting of 
precipitation. Simply put, the cold pool then pushes outwards as a gravity current and results in lifting the conditionally unstable air at its border, generating new convection at its leading edge. However, Houze (2004) does not regard this process as being able to explain all the aspects of MCS propagation due to the organisation of these systems being rather complex.

In some cases, it is evident that convective cells form way in front of the gust front and are not initiated by the cold pool itself (Crook and Moncrieff 1998). These authors found that when air entering the convective system was near saturation, due to large-scale lifting, any random perturbation could initiate convection ahead of the cold pool. This formation, known as discrete propagation, could possibly be linked to waves generated by the MCS itself (Houze 2004). Convective cells heat the atmosphere during precipitation through the release of latent heat, resulting in disturbance travelling at gravity wave speed that propagate horizontally and vertically out of the system (e.g., Schmidt and Cotton 1990; Mapes 1993). These waves then propagate out of the system and may initiate new convective cells. It should also be noted that waves generated outside of the system may also contribute to the propagation of the system, such as Kelvin waves interacting with convection in the Intertropical Convergence Zone (ITCZ) over West Africa (e.g., Mounier et al. 2007) or gravity waves driven by diurnal heating in the Andes, South America (Mapes et al. 2003).

\subsection{Precipitation Characteristics}

A large fraction of the warm season precipitation in the U.S. is often attributed to MCCs. Fritsch et al. (1986) suggest that a series of MCSs, including MCCs, are very likely to be the most prolific precipitation produces in the U.S., rivalling or even sometimes exceeding that of a hurricane. Early investigations of MCC rainfall in the US found that these systems accounted for $20 \%-40 \%$ of the recorded hourly rain rates during May through August (Tollerud and Collander 1993). Ashley et al. (2003) established that some locations within the central U.S. may receive up to $40 \%$ of the total warm season 
precipitation from MCCs. However, these authors found that the percentage of total rainfall contributed by MCCs in the U.S. varies year to year and month to month. Outside of the U.S., Laurent et al. (1998) found that even though MCCs over the Sahelian region Africa are not numerous (about 20 per year), they possibly accounted for about $75 \%$ of the rainfall over their study region during 1990 - 1993. They also found that the average rain yield associated to each MCC was about $17 \mathrm{~mm}$ and that it varied little. In comparison, Laing et al. (1999) found that the estimated volumetric rainfall amount from the average West African system was larger than that of the average U.S. system and that MCCs accounted for 22\% of the Sahel rainfall for the July-September 1987 period. Durkee et al. (2009) document that MCCs in subtropical South America accounted for $15 \%-21 \%$ of the total rainfall in some regions during $1998-2007$. They also note that the percentage contribution can increase when one looks at individual months (e.g., 30\%$50 \%$ in December) or warm seasons (e.g., up to 50\% in some areas).

Kane et al. (1987) compared the precipitation from 32 MCSs with that of 74 MCCs and found that apart from the size of the rainfall area, there were no considerable differences between MCC and MCS rainfall characteristics. These authors found that that the average MCC rainfall area was nearly $80 \%$ greater than that of the MCSs, but the average maximum and the average rainfall per unit area were about the same. In terms of rainfall volume, the authors found that the "typical" MCC in the U.S. generates an average rain depth of $16.1 \mathrm{~mm}$ over $510000 \mathrm{~km}^{2}$, with the most frequently occurring size of the MCC precipitation area tending to be about 250-350 x $10^{3} \mathrm{~km}^{2}$. Results from McAnelly and Cotton (1989) differ slightly since they find that the systems have a smaller rainfall average $(10.8 \mathrm{~mm})$, smaller rainfall volume $\left(3.46 \mathrm{~km}^{2}\right)$ and over a smaller area $(320000$ $\mathrm{km}^{2}$ ). They suggest that this could be due to several factors, with probably the main difference being that of the sample period since they only use summer month events compared to Kane et al. (1987) who also use springtime events.

It has been documented that springtime MCCs are heavier-raining systems than those found in June and August (Kane et al. 1987). This difference may be attributed to the size of the systems during this period, which Ashley et al. (2003) found were larger and lasted 
longer. As discussed previously, this could be related to the influence of the large-scale dynamics on these systems with synoptic features having more of an influence during late spring compared to late summer (Kane et al. 1987). Studies have shown that there appears to be a link between the size of systems and the precipitation pattern, where larger systems are more prolific rain producing systems compared to the smaller systems (McAnelly and Cotton 1986, 1989; Jirak et al. 2003). Not only does size play a role on the precipitation efficiency, but larger systems appear to produce more severe weather reports per system, which is possibly also due to the longer duration (Jirak et al. 2003). Anderson and Arritt (1998) also suggest that concentrated occurrences and storm precipitation efficiency of MCCs are more important factors contributing to regional flooding than frequency. This is supported by Ashley et al. (2003), who illustrated that during 1985 there was a record amount of MCCs in the U.S., but no regional flooding occurred because the storms were dispersed across a large region.

As found in the life cycle of MCCs, the systems in the U.S. display a distinctive precipitation pattern, where the heaviest precipitation occurs within the first half of the storm's life cycle (Kane et al. 1987; Jirak et al. 2003). McAnelly and Cotton (1986) found that the maximum hourly rain rate in MCCs occurs early in the intense growth rate, followed by a steady decrease, while the resultant rain volume reaches a maximum 1-2 hours prior to the maximum infrared area. Similar results were obtained by Collander (1993) who found that the maximum frequency of observations of heavy rainfall $(\geq 25$ $\mathrm{mm} \mathrm{h}^{-1}$ ) in MCCs in the United States most commonly occurred during the period 2-6 hours after initiation. The system is then transformed into a larger precipitating system of increasingly lighter and more stratiform anvil rainfall, which gradually decreases in size as it decays.

There also appears to be preferential regions within MCCs which are more likely to receive heavy rainfall. Kane et al. (1987) divided the systems into different quadrants to reveal that the right-rear quadrant (southwest side), followed by the right-front quadrant (southeast side), are the regions where the precipitation patterns are most frequented by heavy rainfall. These quadrants mentioned above (both on the equatorward side of the 
system) represent the flank of the system which is most directly exposed to the low level warm, moist inflow in the United States. As shown by Cotton et al. (1989), during the early stages of the MCC lifecycle the southern flank of the system is exposed to the LLJ, while during the mature stage the strongest moisture advection takes place along the southwestern flank. Kane et al. (1987) also find that the heaviest rainfall occurs slightly to the right of the path of the centroid of the MCC. Similar results were obtained by McAnelly and Cotton (1989) who found that the heaviest rainfall normally occurs around 50-100 km equatorward of the anvil-cloud-shield track.

In convective storms, precipitation is generally classified as either being stratiform or convective, with one form usually dominating at a given stage of the storms life cycle. All MCSs are comprised of both convective and stratiform precipitation regions, with the former accounting for about $60 \%$ of the total MCS precipitation and the latter contributing about 40\% (Cotton 2000). McAnelly and Cotton (1986) suggest that most of the precipitation produced in MCCs appear to be largely confined to the meso- $\beta$ convective features within the system. The convective regions are made up of intense vertical cores of updrafts and downdrafts coinciding with heavy precipitation, whereas the stratiform region, which is larger, contains the lighter precipitation (Houze 2004). The stratiform region is believed to be a product of the dissipation of older convective cells and partly by broader-sloping mesoscale ascent (Houze et al. 1990; Houze 1997; Parker and Johnson 2000). A common pattern found in various studies is that the location of the stratiform region in relation to the convective region may be very important in predicting the flooding potential of systems (Doswell et al. 1996; Pettet and Johnson 2003; Gallus et al. 2008). Factors that appear to have an influence on the distribution of precipitation and determining stratiform region shapes include the flow during the formation of the system as well as the storm relative winds (Cotton 2000; Parker and Johnson 2000). Thus, in terms of forecasting such events, the speed and direction of the environmental mid- and upper-level winds relative to the storm's motion need to be taken into consideration.

Apart from the precipitation produced, it is likely that a fair amount of research on these systems is due to the potential damage they may cause through extreme weather 
phenomena, such as flash floods, hail, lightning and even tornadoes. Maddox (1980) documents that one in every five MCCs produces injuries or death. It is no coincidence that the global distribution of MCCs occur in the same regions that are dominated by strong convective storms and lightning (Laing and Fritsch 1997; Toracinta and Zipser 2001; Zipser et al. 2006). Looking at the association between severe weather events and the morphology of convective systems, Gallus et al. (2008) noted that $71 \%$ of the convective systems studied in 2002 were associated with at least one report of flooding or severe weather report. These authors found that severe weather events occurred with all morphologies/modes of convective storms, but it was evident that different morphologies/modes were found to favour the production of specific severe phenomena. This is possibly due to the different systems being dominated by different dynamics.

Earlier work suggested that the organization of the convective system may play a role in the development of severe events. Tollerud and Bartels (1988) found that twice as many severe events occur in linearly organized systems compared to the more circular MCCs. Fritsch and Forbes (2001) suggest that this could be linked to the moist downdrafts having difficulty reaching the surface due the underlying cold layer found in MCCs events that have evolved in a frontal zone or other baroclinic region (i.e., their Type-1 events). Thus, severe events that are linked to the moist downdrafts, such as microburst winds or tornado-bearing mesocyclones, may be minimal due to this cold layer. They apply a similar reasoning to MCC events that have developed in a more barotropic environment (i.e., Type-2 events), but only under conditions when the cold pool has become well developed in the latter stages in the MCC life cycle.

In general, most flash-flooding events in the U.S. appear to be associated with MCSs, which includes MCCs (Doswell et al. 1996). This finding is supported by more recent research by Schumacher and Johnson (2005) who found that $65 \%$ of 116 extreme rainfall events in the U.S. were linked to MCSs. The early growth period of these systems appears to be the most crucial time for the development of severe weather (e.g., hail, tornadoes, lightning, etc), particularly in MCCs (Maddox et al. 1986; Tollerud and Collander 1993). However, flooding becomes more likely as the system matures, 
particularly if the system moves slowly (Maddox et al. 1986). It is also evident that certain type of systems may produce different severe weather phenomena depending on the environment they evolve in. For example, Maddox et al. (1986) noted that in some MCC case studies, damaging winds and heavy rainfall events were produced under different vertical wind shear strengths. This just highlights the potential threat that all modes of MCS possess, as well as the complexity associated with issuing severe weather warnings.

\subsection{Chapter Summary}

This chapter has covered some of the more important features of MCCs that make these systems unique. Ultimately, it has created a platform in which results from this study can be compared with that of the literature. To date, limited research has focused on MCCs over southern Africa and thus, resulting in the large paucity in knowledge of these systems compared to other regions of the world. This could possibly be attributed to the poor spatial coverage of weather networks within the country, as well as the limited observations available. However, one must bear in mind that most of the results from other studies presented here are based on systems within the U.S. Comparisons can be made between the systems in the U.S. with those found in southern Africa, but this is limited because there are differences in the factors that play a role in the development and location of these systems.

One key difference is that of the geographic settings of these two regions. South Africa is a much narrower land mass and bordered by the surrounding oceans along its western, eastern and southern borders. The South African landmass terminates near $34^{\circ} \mathrm{S}$, whereas North America extends into high latitudes. Another key difference is that the U.S. contains large areas of flat plains with considerable mountain ranges near each coast, whereas South Africa has much smaller areas of flat terrain. The major moisture source for MCSs in the U.S. is the Gulf of Mexico (e.g., Maddox 1983; Velasco and Fritsch 1987; Laing and Fritsch 2000), whereas moisture sources for the South African summer rainfall region include the neighbouring tropical oceans (D'Abreton and Lindesay 1995; 
Cook et al. 2004), tropical Africa (D’Abreton and Lindesay 1993; Cook et al. 2004) and the Agulhas Current region (Jury et al. 1993; Rouault et al. 2002; Singleton and Reason 2006, 2007). Thus, different features to the U.S. may play a role in the development and life cycle of MCSs in South Africa. However, the little research that has been done in South Africa has found that the systems themselves do not differ that much from the global population (e.g., Laing and Fritsch 1993b, 1997).

Even though there has been a fair amount of global research on these systems over the last few decades there are many features/characteristics about these systems that remain unknown. The locations of where these systems develop appear to have an influence on the systems characteristics and life cycle, which is likely due to the varying local environment settings. There are notable differences in the appearance and life cycle of systems that develop over land compared to ocean or that form in the northern hemisphere compared to the southern hemisphere or tropical versus mid-latitude MCCs. There also remains a fair amount of uncertainty in the processes which result in MCC development. As highlighted by Zeigler (2000), the processes whereby MCSs organise into either a squall line or an MCC are not well understood, nor is it known why the convective regions of other MCSs remain disorganised. Even the understanding of the synoptic and mesoscale conditions that possibly result in the development of these large convective systems remains poor. 


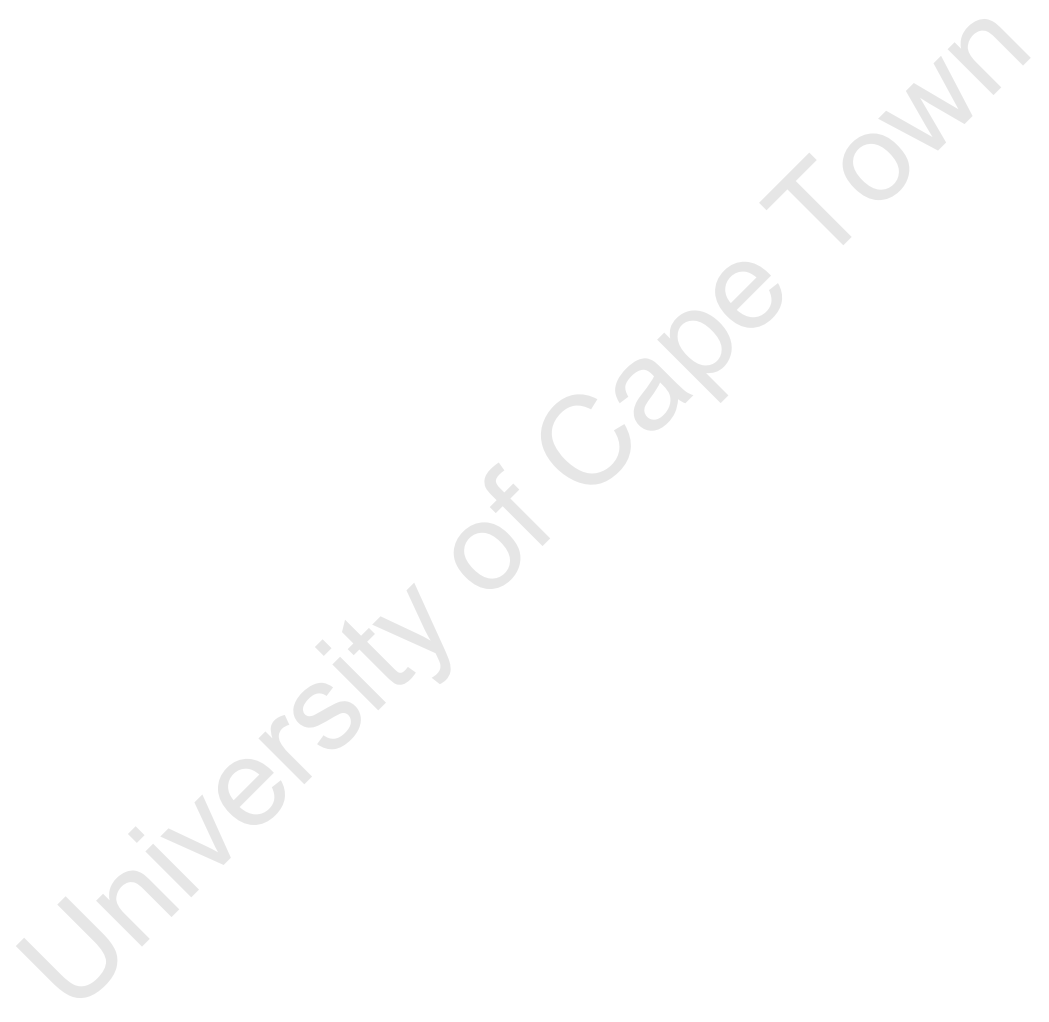




\begin{tabular}{|c|c|}
\hline & MCC Criteria \\
\hline Size $^{*}$ & $\mathrm{~A}-\geq 100000 \mathrm{~km}^{2}$ \\
& $\mathrm{~B}-\geq 50000 \mathrm{~km}^{2}$ \\
\hline Cloud Shield Temperature* & $\mathrm{A}-\leq 32^{\circ} \mathrm{C}$ \\
& $\mathrm{B}-\leq 52^{\circ} \mathrm{C}$ \\
\hline Shape / Eccentricity & $\begin{array}{c}\geq 0.7 \text { at max. extent (i.e. round or oval) } \\
\end{array}$ \\
\hline Initiation & $\begin{array}{c}\text { When Size and Temperature thresholds are } \\
\text { first met }\end{array}$ \\
\hline Duration & $\begin{array}{c}\text { Size and Temperature definition must be } \\
\text { met for a period } \geq 6 \text { hours }\end{array}$ \\
\hline \hline Termination & $\begin{array}{c}\text { Size definitions A and B are no longer } \\
\text { satisfied }\end{array}$ \\
\hline
\end{tabular}

Table 2.1: The original MCC criteria defined by Maddox (1980). Note there are two size and two cloud shield temperature thresholds in this definition. 


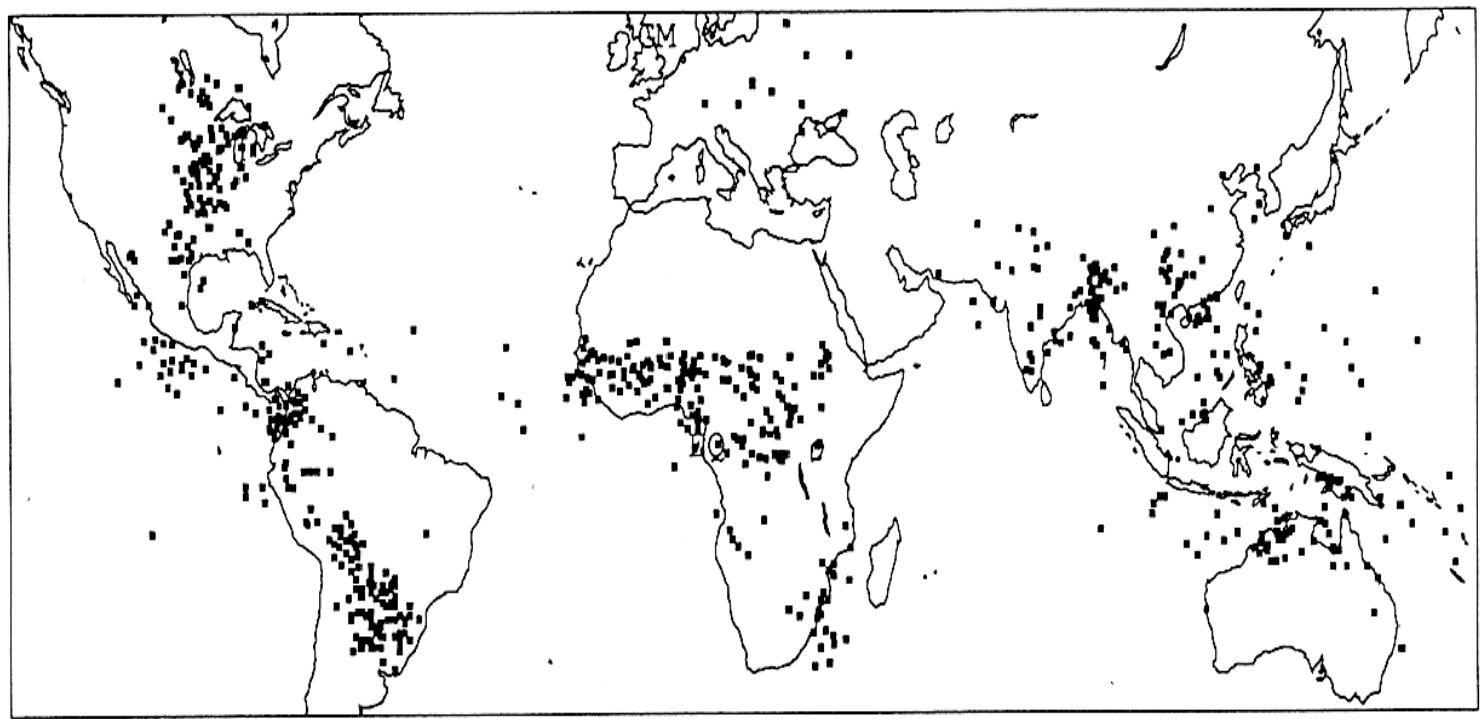

Figure 2.1: The global distribution of MCCs, based on satellite imagery. Small squares indicate location of MCC at time of maximum extent (from Laing and Fritsch 1997).

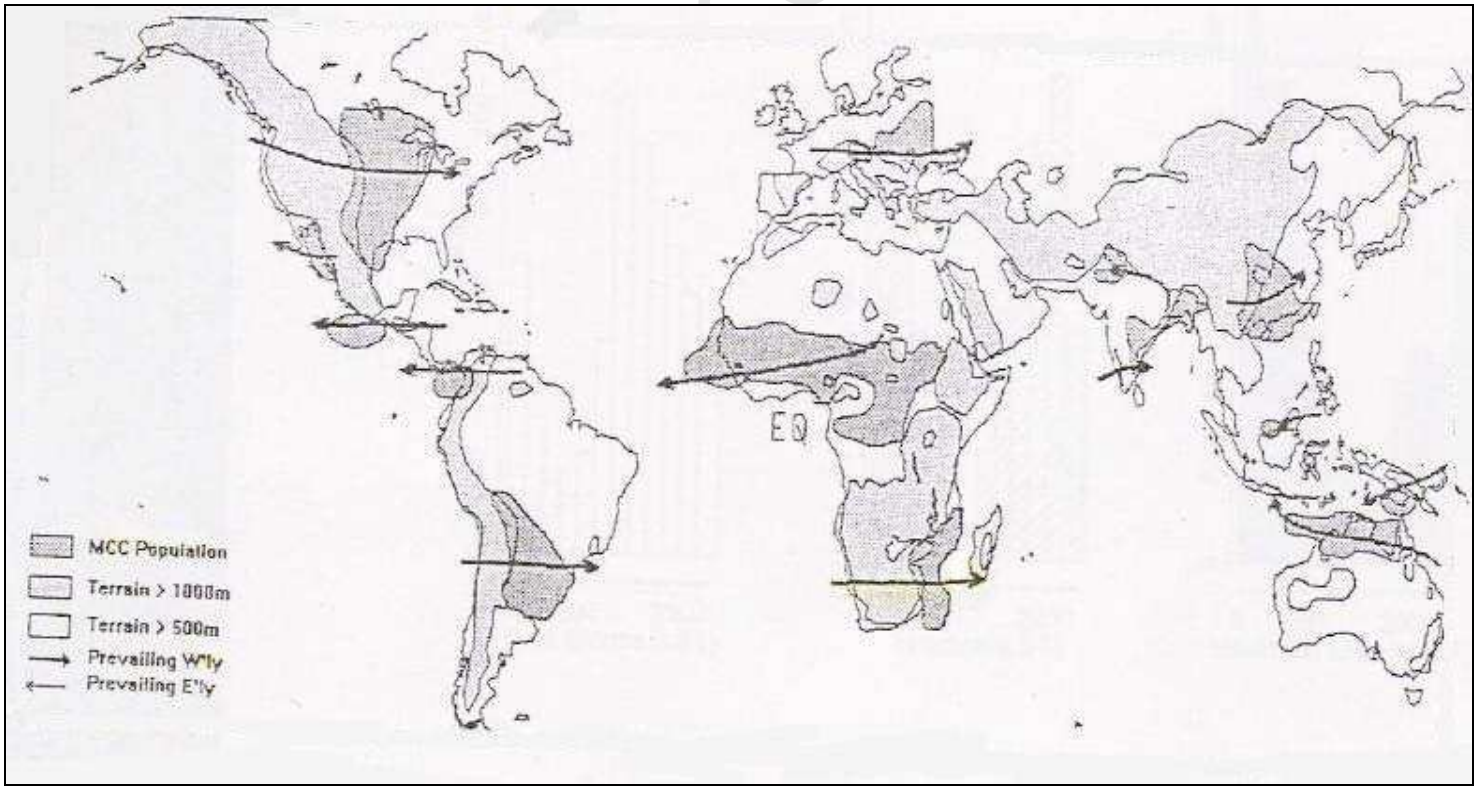

Figure 2.2: The distribution of MCC populations, elevated terrain and the prevailing mid-level flow (from Laing and Fritch 1997). 


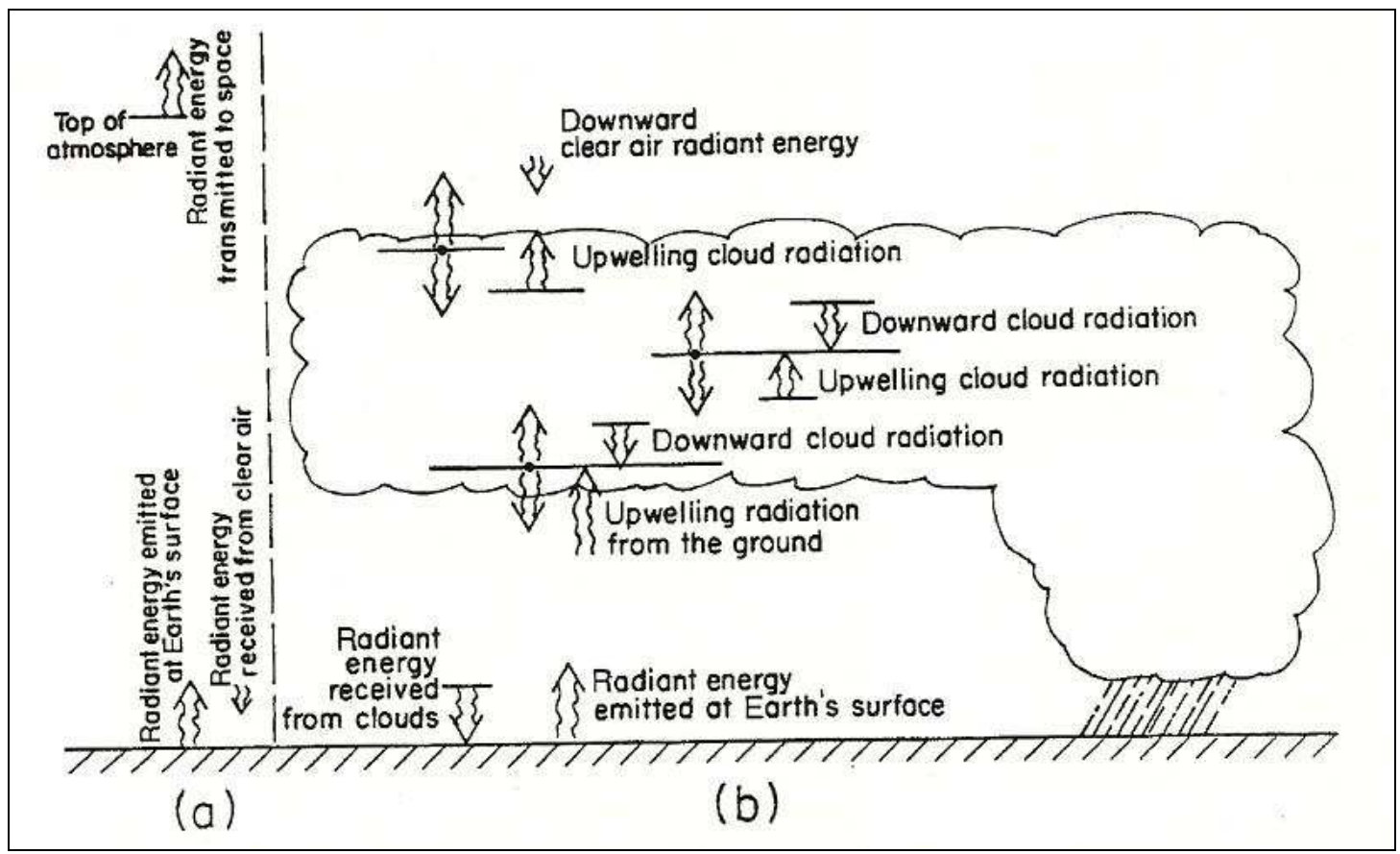

Figure 2.3: Illustration of infrared radiant energy absorbed and received at different levels in the atmosphere (From Cotton 2000). Left panel (a) illustrates a cloud-free atmosphere, while the right panel (b) illustrates a stratiform-anvil cloud layer. Length of arrows is proportional to the amount of radiant energy per unit area.

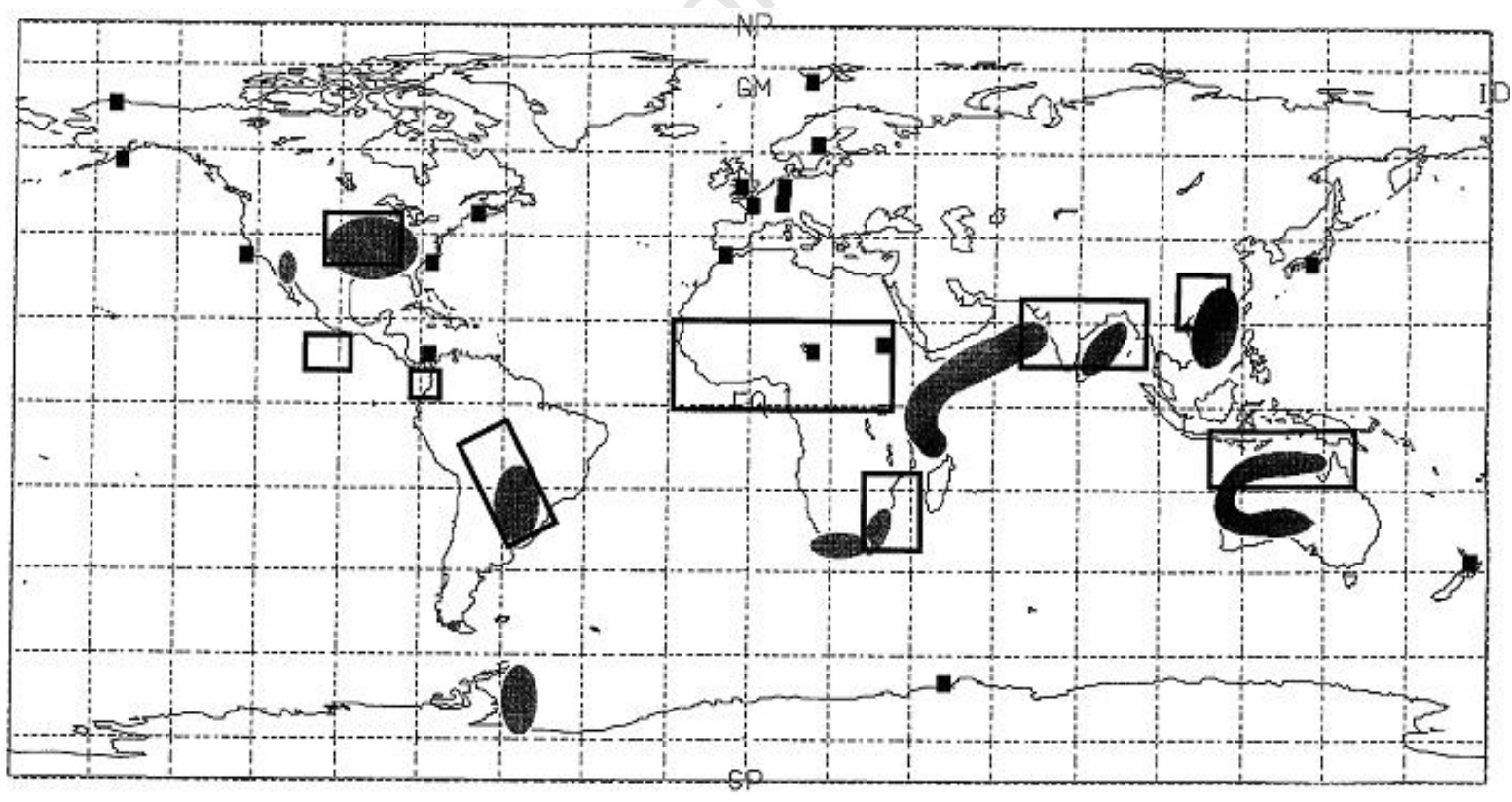

Figure 2.4: Regions where LLJ are known or suspected to regularly occur (dark shading) and the global location of frequent warm season MCC activity (square boxes). This figure is taken from Stensrud (1996a). 


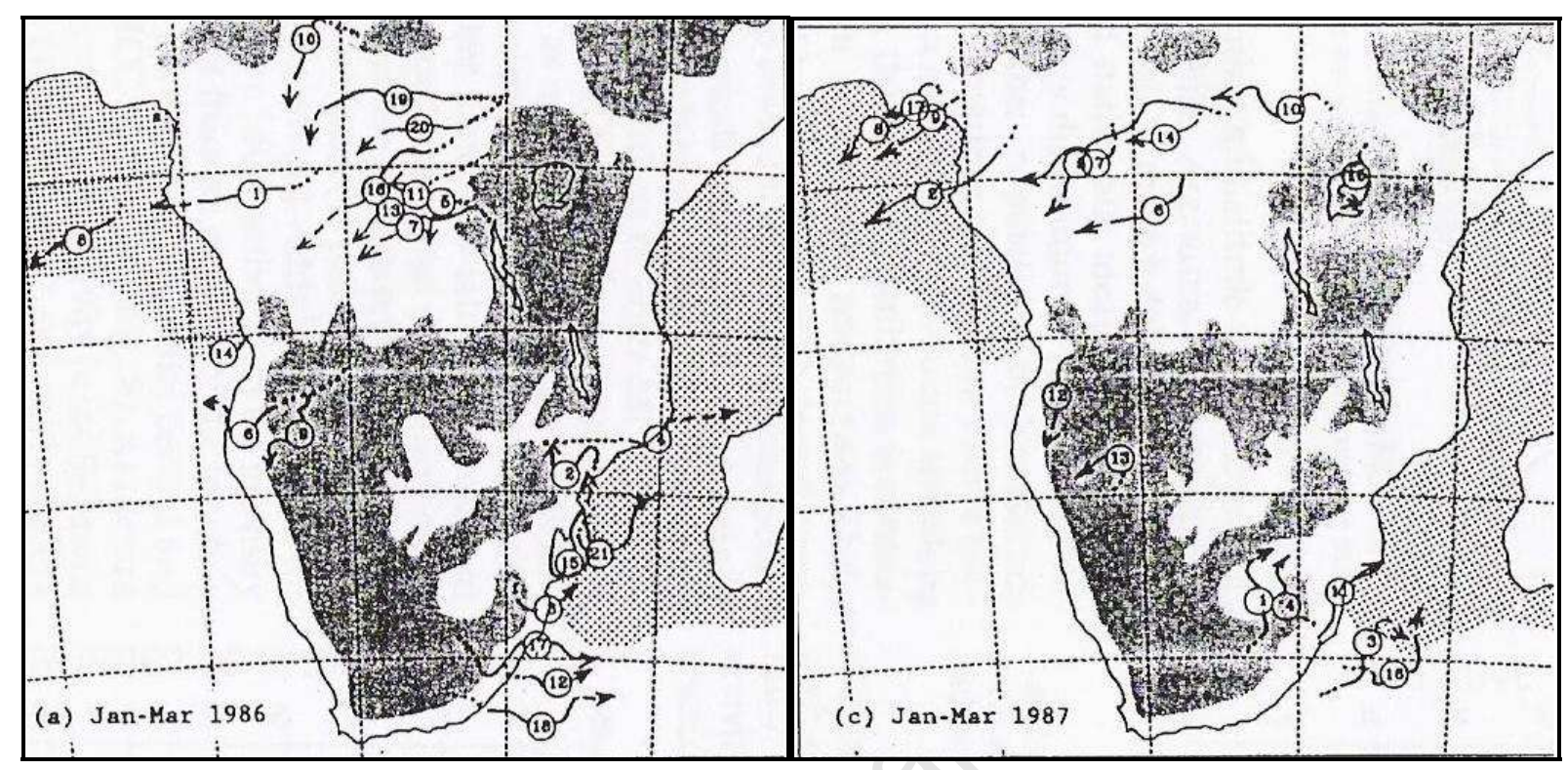

Figure 2.5: Tracks of MCCs during January-March 1986 (left) and January-March 1987 (right) over Africa (from Laing and Fritsch 1993b). 


\section{Chapter Three}

Satellite Tracking Methods and MASCOTTE 


\subsection{Introduction}

The development in satellite technology has resulted in unequalled observations of weather features around the world, which is due to these instruments being able to cover a very large range of space and timescales. This is particularly useful for regions that have sparse observations or that are difficult to access. Not only have satellites been useful in detecting MCCs, but they have also provided another way in which to monitor the evolution of such large systems. This observation technology also plays a key role in complimenting other observation systems, such as surface radar and atmospheric profilers (Machado et al. 1998). As alluded to earlier, nearly all MCC climatologies have been constructed based on data provided by various satellites, which highlights the importance of such observation technology. From these studies, statistics based on the geographic, seasonal and diurnal frequencies of occurrence and size distributions of MCC have been developed for various regions.

All satellite research of MCCs is based on infrared (IR) and/or visible radiance images produced from geostationary satellites (e.g., Velasco and Fritsch 1987; Miller and Fritsch 1991, Laing and Fritsch 1993a, 1993b, Durkee and Mote 2009 and others). This is due to the IR and visible radiance being mostly influenced by clouds and the surface rather than being influenced by the atmosphere. Additionally, MCCs are often associated with very cold cloud top temperatures, due to these systems being associated with strong convection. The large difference between these cold cloud tops and the warmer surrounding make these systems easily identifiable in IR satellite images, particularly in the tropics (Mapes and Houze, 1993). Raw radiance or brightness temperature $\left(\mathrm{T}_{B}\right)$ has often been used to identify and determine properties of convective systems, but additional sensors, such as those that gather passive microwave data, have become useful. Machado et al. (1998) suggest that using microwave retrievals of cloud and precipitation properties allow for a more physical interpretation of such systems. However, for the purpose of building large MCC climatologies, it appears that simple and efficient methods based on $\mathrm{T}_{B}$ are sufficient. 
One of the initial steps in detecting MCCs using satellite imagery is selecting a suit of criteria which classifies the storm as being an MCC. As alluded to in the previous chapter, these criteria are usually based on cloud top temperature, size, duration and shape (see Table 2.1). With regards to MCC identification, a contentious issue is whether to use both temperature thresholds as defined by Maddox (1980). The single colder threshold (i.e., the $-52^{\circ} \mathrm{C}$ cloud top temperature) is believed to sufficiently define the life cycle of a MCC, while the warmer threshold $\left(-32^{\circ} \mathrm{C}\right)$ has been found to be largely redundant and seems to introduce more complications and uncertainty (Augustine and Howard 1988; McAnelly and Cotton 1989). It is for this reason that some papers have omitted the warmer threshold of the system and instead concentrated on the colder cloud temperature (e.g., Augustine and Howard 1988, 1991; Cotton et al. 1989; Anderson and Arritt 1998, 2001).

In comparison, the majority of the $\mathrm{T}_{B}$ values for general MCS detection used in the literature range from $208 \mathrm{~K}\left(-65^{\circ} \mathrm{C}\right)$ to $245 \mathrm{~K}\left(-28^{\circ} \mathrm{C}\right)$, with this large range being attributed to various reasons discussed below (Williams and Houze 1987; Miller and Fritsch 1991; Arnaud et al. 1992; Mapes and Houze 1993; Laing and Fritsch 1993a, 1993b; Machado et al. 1998; García-Herrera et al. 2005b). The "warmer" end of this range is more commonly used as an indicator for the presence of an MCS in the satellite image, while some studies also incorporate lower "colder" temperature thresholds to make sure that some stage during the systems life cycle contains active deep convection (e.g., Machado et al. 1998) or that active convective clouds are present at all times (e.g., Maddox 1980). Lower thresholds are also used so that the threshold value identifies cloud areas that correspond closely with radar-detected precipitation (e.g., Williams and Houze 1987; Mapes and Houze 1993). However, using a lower threshold may eliminate some of the stages within the life cycle (e.g., Maddox 1980) or even exclude some of the other cloud features, such as the light precipitating clouds (e.g., Williams and Houze 1987). Nevertheless, it should also be kept in mind that there needs to be some consistency when selecting a temperature threshold so that valid comparisons with MCCs statistics elsewhere can be made. Once the cloud top temperature minimum is established, one can 
calculate other key criteria, such as areal extent (from pixel counts) and duration (from consecutive images).

Developing an MCC climatology may be done by either visually inspecting satellite imagery and then subjectively identifying systems (e.g., Velasco and Fritsch 1987; Miller and Fritsch 1991; García-Herrera et al. 2005a) or by applying an automated method that is objectively able to classify the systems within the images (e.g., Woodley et al. 1980, Williams and Houze 1987; Laing and Fritsch 1993a, 1993b; Chen et al. 1996; Machado et al. 1998). The former method is believed to be time consuming and may lead to inconsistencies in identification, whereas the latter method is perceived to be more efficient and allows for larger, more complete climatology to be developed (Machado et al. 1998; Carvalho and Jones 2001). Machado et al. (1998) found that their automated method tracked more convective systems (particularly smaller systems) compared to the number tracked subjectively with the same data. A similar result was obtained by GarcíaHerrera et al. (2005b) who found that the automated method utilized in their research identified more systems compared to those obtained from a subjective method (GarcíaHerrera et al. 2005a). Essentially, a tracking method works by identifying a similarity between two convective systems in sequential satellite images. However, depending on what method is used or what criteria are set may affect the total number of systems identified as well as the lifetime of the systems (Machado et al. 1998). These authors also found that the number of systems identified may be influenced by the spatial resolution of the image, with higher resolutions resulting in more systems being detected.

Within automated methods, there are two common techniques that are used to track convective systems. The first technique defines the cloud system as a connected set of pixels (or cells) which satisfy a certain temperature and area threshold. The same thresholds are applied to successive images to test if they are satisfied and if so the system is then classified (e.g., Woodley et al. 1980, Williams and Houze 1987; Arnaud et al. 1992; Chen et al. 1996). The other technique involves using pattern correlation, whereby a target is identified in the satellite image and then searched for until the best correlation match is found in consecutive images (e.g., Schmetz and Nuret 1987). 
However, it has been documented that the evolution of MCSs or MCCs identified in automated methods can be misleading, particularly in cases of splitting and merging systems (Machado et al. 1998, Durkee and Mote 2009). Thus, hybrid automated/manual approaches have also been developed, whereby systems are first identified via an automated routine and then the system evolution is manually observed (e.g., Durkee and Mote 2009). In this study, a hybrid approach is adopted, with systems first identified using an automated method and then followed by a visual inspection to verify the system evolution. The automated method used here to develop the climatology of MCCs over southern Africa is the maximum spatial correlation technique (MASCOTTE), which was developed by Carvalho and Jones (2001).

\subsection{Maximum Spatial Correlation Technique (MASCOTTE)}

Carvalho and Jones (2001) developed a new alternative to existing techniques, which is a fully automated method that determines simultaneously both the structural properties and evolution (tracking) of cloud shields of convective systems. These authors noted that even though some satellite methods relied on the same kind of data (i.e., IR, visible, microwave, etc) to describe the structural properties of convective systems, considerable differences existed in the methodology that tracked the evolution of the system. Thus, they developed a simple and efficient method that was not only able to track convective systems, but could also characterise the structural properties of the system. This method is based on the maximum spatial correlation technique (MASCOTTE) and has been successfully applied in South America (Carvalho and Jones 2001) and Spain (GarcíaHerrera et al. 2005b). The versatility of MASCOTTE allows application to any extensive satellite imagery database and any geographic region (Carvalho and Jones 2001). These authors suggest that an accurate and automated method to identify convective system properties allows objective rather than subjective analysis of case studies. This particular method has also been shown to have higher detection ability than visually inspecting satellite images (García-Herrera et al. 2005b). 
The method was originally based on $\mathrm{T}_{B}$ from Geostationary Operational Environmental Satellite (GOES-8) images as input, but has now been adapted to other satellite $\mathrm{T}_{B}$ input. From the $\mathrm{T}_{B}$ input, MASCOTTE identifies and isolates convective systems satisfying certain size and temperature criteria and then spatially correlates these systems with all possible convective systems in the subsequent image. However, further processing using computer programs such as IDL, Matlab, etc, is required if additional criteria are a prerequisite for a system, such as duration or shape in MCC classification. Nevertheless, MASCOTTE has the versatility of being used in case study related MCS/MCC research and for developing a large climatology of these systems over a specific region. To describe this process in more detail, the following steps are performed in MASCOTTE (as described by the original developers, Carvalho and Jones 2001):

1. Identify cloud systems that satisfy the T-R criteria - Consider $N$ satellite images containing $\mathrm{T}_{B}$ values at a certain time interval $\Delta \mathrm{t}$ (in this case, a 30 minute time interval is used). For each satellite image at $t_{i}, 0 \leq i \leq N$, regions of MCS are identified according to the Temperature-Radius (T-R) criteria. Regions that do not meet the threshold criteria are set to null value, which allows a large difference between clouds and background mask, which highlights the overlapping systems. Thus, at time $\mathrm{t}_{\mathrm{i}}$, there are $m$ MCS identified.

2. Correlate the MCS with the next satellite image - At time $\mathrm{t}_{\mathrm{i}}$, the $k$ th MCS (1 $\leq \mathrm{k} \leq \mathrm{m}$ ) is first isolated in the image (i.e., the remainder of the image is set to the background mask value), which has a size $\mathrm{I}_{C x L}$, where ' $\mathrm{C}$ ' and ' $\mathrm{L}$ ' are the number of pixels in the east-west and north-south directions, respectively. The next satellite image $\left(t_{i+1}\right)$ is then searched and all the possible systems within it are identified. The MCS at $t_{i+1}$ that has maximum spatial correlation $(r>0.30)$ with the $k$ th MCS at $t_{i}$ is considered the new spatial position of the MCS. The value of $\mathrm{r}(>0.30)$ was determined by Carvalho and Jones (2001) from numerous tests while developing the algorithm. The process is then repeated for all MCS at time $t_{i}$ and starts again for the next satellite image. These authors noted that when the time interval $(\Delta \mathrm{t})$ was increased to 2 and 3 hour intervals 
(instead of the original 1 hour), the criterion of maximum spatial correlation still holds, but the magnitudes of $r$ decreases.

3. Compute structural properties - For each time $t_{i}$, and each MCS, numerous structural properties are then computed. These include horizontal area $(A)$, perimeter $(P)$, mean and variance of $\mathrm{T}_{B}$, minimum $\mathrm{T}_{B}$ and fractional convective area $\mathrm{Fc}=100\left(A_{\mathrm{TC}} / A\right)$, where $A_{\mathrm{TC}}$ is area within the MCS such that $\mathrm{T}_{B}$ is less than $210 \mathrm{~K}\left(-63^{\circ} \mathrm{C}\right)$. In addition, the spatial coordinates of the centre of gravity $\left(\mathrm{X}_{\mathrm{CG}}, \mathrm{Y}_{\mathrm{CG}}\right)$ are also calculated, which are defined as the $\mathrm{T}_{B}$-weighted average. This involves the summation of all the MCS pixel coordinates (see equation 1 in Carvalho and Jones 2001). It should be noted that one can calculate the distance travelled, the direction of displacement and velocity from the calculated centre of gravity. However, caution must be taken in these calculations because the centre of gravity may rapidly change location due to merging or splitting of MCSs and therefore produce misleading results. Thus, when merging or splitting is evident in cases, it is optimal that no velocity is computed (Carvalho and Jones 2001; García-Herrera et al. 2005b).

4. Calculate orientation and eccentricity - The orientation of the MCS cloud shield is then determined via two processes. First a straight line is fitted to the $\left(\mathrm{X}_{\mathrm{i}}, \mathrm{Y}_{\mathrm{i}}, \mathrm{i}=1, \mathrm{~N}_{p}\right)$ pixel coordinates by a least squares criterion and the counter clockwise angle between the east-west direction and the straight line determined. Carvalho and Jones (2001) noted that this method could sometimes produce misleading results. Thus, the authors propose another method, which uses an empirical orthogonal function (EOF) analysis. The same array of pixels coordinates are given by $\left(\mathrm{X}_{\mathrm{i}}, \mathrm{Y}_{\mathrm{i}}, \mathrm{i}=1, \mathrm{~N}_{p}\right)$. The average $\mathrm{X}$ and $\mathrm{Y}$ are first subtracted from the vectors $\mathrm{X}_{\mathrm{i}}$ and $\mathrm{Y}_{\mathrm{i}}$ and an EOF analysis is computed on the covariance matrix determined by $X^{\prime}$ and $Y^{\prime}$ perturbations. This produces a pair of eigenvalues and eigenvectors that explains the total variance of the geographical coordinates of the given MCS. A second orientation is then computed as the counterclockwise angle between the east-west direction and the 
direction of the first eigenvector. The result is that the first eigenvector maximises the spatial variance of the MCS cloud shield. It also allows for the calculation of the eccentricity (interval $=0<\operatorname{Ecc} \leq 1$ ) of the MCS, which is defined by the ratio of the norms $\|\mathrm{EOF} 2\| /$ / EOF $1 \|$, where EOF2 and EOF 1 are the second and first eigenvectors, respectively. High values are associated with MCS shapes that are circular, while low values are associated with more linear MCS shapes.

5. Take splitting and merging into account - The splitting of MCSs may take place when changes in the precipitation pattern and three-dimensional cloud structure occur. In MASCOTTE, splitting of a MCS at $t_{i}$ is identified when more than one system with positive and high spatial correlation is observed at $\mathrm{t}_{\mathrm{i}+1}$ (at this time the horizontal area of the system decreases). The MCS with the highest spatial correlation is then tracked for the remainder of the satellite images. MASCOTTE also allows for the merging of systems, where the anvils of two cloud systems connect. This is evident when the spatial correlation decreases (around 10\%), but the horizontal area increases between two consecutive images. It also results in the shape of the system drastically changing because of the modification that takes place at the merge. Carvalho and Jones (2001) showed that the tracking method must be able to determine splits and merges during MCS life cycle due to a fairly high percentage that occurred ( $8 \%$ and $30 \%$ of the total, respectively). This percentage increases when they took into consideration the number of MCSs that did not satisfy the T-R criteria once split or merged. If merges are taken into consideration, these authors found that it resulted in some systems having durations longer than 48 hours, whereas if they do not take merging MCSs into account then the longest duration was 23 hours. In other studies, similar results have been obtained. Machado et al. (1998) found that 20\% (of the total number of cases) were involved in merges, while 10\% were involved in splits. García-Herrera et al. (2005b) found that $17 \%$ of the systems were involved in merges and in $8.6 \%$ of the systems splits occurred. It should be noted that in the García-Herrera et al. 
(2005b) modified MASCOTTE, the life cycle of a system is ended when merging between different MCSs or splitting of a developed MCS takes place.

In summary, MASCOTTE requires satellite images containing brightness temperature, from which it can identify convective systems reaching a certain size and that contain a specified cloud top temperature. Once a system satisfying the predefined criteria is identified it is then spatially correlated to possible systems in the next image. After the process has been run for the duration of study it produces a report than contains all the structural properties of the identified systems. Further processing on these reports can then be performed to identify specific types of convective systems, such as MCCs.

\subsection{South African Adaptation of MASCOTTE}

As discussed previously, MASCOTTE was originally designed using GOES-8 imagery (Carvalho and Jones 2001), but has recently been adapted so that it can use Meteosat IR imagery as input (García-Herrera et al. 2005b). The Meteosat data, which has an approximate $5 \mathrm{~km}$ spatial resolution over South Africa (Stefan Scherzer, EUMETSAT Technician, personal communication) and 30 minute temporal resolution, is taken from the Meteosat-7 satellite. In this case, the Meteosat-7 data is available for the period of September 1998 through to April 2006. One limitation is that nearly 21\% of the IR data between 0130 and 0230 local time (UTC $+2 \mathrm{~h}$ ) were not available. Thus, a visual inspection was performed to check MCC life cycles that occurred on days with missing images. This limitation further supports the notion of using a hybrid approach when using automated tracking programs.

For the purpose of this study, only systems developing during the summer months, as well as the transitional seasons (spring and early autumn) are considered (OctoberMarch). This choice is due to the study predominantly focusing on the influence these systems have on the summer rainfall. It should be noted that some studies have restricted their study period to only the core summer months (i.e., DJF in this case) in ordered to minimize the influences of strong baroclinicity compared to the more barotropic summer 
season (e.g., Cotton et al. 1989). There is also a possibility that considerable year to year variability in MCC activity over South Africa may occur and thus, one has to take into consideration that a particular study period may not be representative for the average conditions over the region. It is for these reasons that 8 warm seasons (October $1998-$ March 2006) are selected, instead of a smaller sample period. A combination of Meteosat-7 with that of the more recent Meteosat-8 (more commonly known as Meteosat Second Generation (MSG)) data would have been ideal to develop a longer climatology, but access to the latter dataset is limited. However, it does provide an opportunity to extend the climatology with the higher resolution Meteosat-8 (spatial resolution of $\sim 3$ $\mathrm{km}$, and temporal resolution 15 minutes) at a later stage.

The geographical window over which MASCOTTE is applied extends from $18^{\circ} \mathrm{S}$ to $36^{\circ} \mathrm{S}$ and $17^{\circ} \mathrm{E}$ to $36^{\circ} \mathrm{E}$, which entirely envelops subtropical southern Africa and the neighbouring oceans (Fig. 3.1). Thus, the domain extends over the Agulhas Current region, positioned off the east and south coast of South Africa, which is known to be a convective hot spot (e.g., Zipser et al. 2006). The domain does not extend north of $18^{\circ} \mathrm{S}$ so as to exclude mainly tropical systems. It must be noted that the Meteosat-7 resolution varies as one extends farther from the centre location $\left(0^{\circ} \mathrm{E}, 0^{\circ} \mathrm{S}\right)$. Thus, changes in the pixel resolution of the satellite image would have to be taken into consideration when adjusting the geographical window. Additionally, having a very large study domain would result in the inaccurate calculations of the size of systems due to the pixel size varying considerably over the domain.

In order to detect MCCs, an adapted version of Maddox (1980) criteria is used here, which identifies MCCs as systems that contains a cloud top temperature less than $-52{ }^{\circ} \mathrm{C}$, an areal extent greater than $50000 \mathrm{~km}^{2}$, lasting longer than 6 hours and must have an eccentricity $\geq 0.7$ at maximum extent (see Table 2.1). As alluded to earlier in the chapter, there is some subjectivity in selecting a temperature threshold for MCC identification and in particular, whether using both thresholds determined by Maddox (1980) is still valid. Based on the literature presented earlier and results from the testing phase of this study, there appears to be some advantage in using just the colder $\mathrm{T}_{B}$ threshold since it tracks the 
centre of the storm better and there is a better representation of two systems that are in close proximity of each other (i.e., cloud tops might overlap). Also, it avoids those systems that are outside the region of interest, but whose cloud shield extends across the boundary. In addition, by using the $-52^{\circ} \mathrm{C}$ threshold, we can then make direct comparisons with previous MCC studies using the same threshold, such as Durkee and Mote (2009). Thus, for the purposes of this study, we have omitted the warmer $\left(-32^{\circ} \mathrm{C}\right)$ cloud top threshold, but we have kept the remaining Maddox (1980) criteria the same (see Table 2.1). The life cycle of an MCC is considered to start when all the criteria are first met and ended one the one of the criteria are no longer fulfilled. Life cycles are also ended if merging between two different MCCs occur or an MCC splits into several convective systems.

The original MASCOTTE algorithm uses a maximum spatial correlation value (r) greater than 0.3 when identifying a system in subsequent satellite images (Carvalho and Jones 2001). Garcia-Herrera et al. (2005b) also found that a correlation threshold of 0.3 accurately captures the systems evolution in the $30 \mathrm{~min}$ interval Meteosat-7 satellite images. Due to similar geographical positions (in terms of latitude) and a similar satellite dataset being used, this threshold value is kept constant for this study. The result of using this particular correlation threshold is that it allows tracking of a system to a maximum limit of 1.5 hour interval between images, which is less that the original 3 hour of missed images for the original tracking algorithm (García-Herrera et al. 2005b). These authors suggest that this decrease in time interval between missing images is caused by the smaller convective systems usually found in the midlatitudes compared with those in the tropics, as discussed in the previous chapter. It may also be due to the more restrictive criteria used by García-Herrera et al. (2005b) compared to that adopted by Carvalho and Jones (2001).

Once each system has been identified through MASCOTTE, a set of structural properties are computed for each system. These properties include areal extent, centre of gravity, distance travelled, direction of displacement and velocity. From these results, other sets of statistics can then be developed on the population of MCSs, such as the general 
initiation time, duration, locations and the tracks. It should be remembered that caution should be taken when analysing results of variables obtained using the centre of gravity, such as distance travelled, the direction of displacement and velocity. This is due the possibility that the centre of gravity may rapidly change location due to merging or splitting of MCSs and CCs (Carvalho and Jones 2001; García-Herrera et al. 2005b).

\subsection{Chapter Summary}

This chapter has introduced the use of cloud tracking programs in studies relating to convective systems and MCCs in particular. However, it should be kept in mind that focus in this thesis is not only placed on the development of the MCC climatology, but also on the influence these systems have on the subtropical southern African summer rainfall. Additionally, analysis on the favourable synoptic environments for the regional development of these systems is also presented. It is for this reason that the reader is reminded that the data and methodology used to analyse favourable MCC synoptic environments and MCC rainfall are reserved for Chapters Five and Six, respectively.

Nearly all the methods used to identify MCCs are based on the size, cloud top temperature and duration of these events, which can be obtained from IR satellite images. From these tracking methods, which can be applied to large satellite datasets, one is able to build statistics relating to the evolution and distribution of such systems in a particular region. The maximum spatial correlation tracking technique (MASCOTTE) is one such efficient and automated method that has been developed to determine the structural properties, as well as the evolution characteristics of MCCs. This method is based on the spatial correlation of convective systems within subsequent satellite images. An MCC is identified within an image by a set of predefined criteria, which is calculated based on the values and number of pixels within the convective system, as well as the number of subsequent images the system is identified in.

The set of criteria used to define an MCC is highly subjective, particularly the choice of temperature thresholds. As stated previously, the use of different temperature thresholds 
used in general MCSs studies is based on factors ranging from the study region (i.e., convection in the tropics vs. midlatitudes) to the desire to ensure that active deep convection is taking place (i.e., cold cloud top temperatures). Some criteria are unique, such as the original definition of an MCC by Maddox (1980), which has two temperature thresholds applied to it. However, some prefer to omit the warmer threshold because it is seen as being "largely redundant and introduces more complications and ambiguity" (Cotton et al. 1989: pg 766). Ultimately, this suggests that further work is still required on MCC temperature thresholds in order to establish a common set of criteria on which MCC statistics can be developed. However, for consistency the $-52^{\circ} \mathrm{C}$ threshold has been adopted for MCC identification in this study. Furthermore, results by Kane et al. (1987) showed that the $-52^{\circ} \mathrm{C}$ cold cloud shield is more accurate in depicting the precipitation region of MCCs compared to the $-32^{\circ} \mathrm{C}$ shield. This provides additional support for using the $-52^{\circ} \mathrm{C}$ for $\mathrm{MCC}$ tracking, considering that this study also looks at the precipitation produced by the systems.

Both the previous studies using MASCOTTE have only used relatively small satellite datasets, with Carvalho and Jones (2001) applying MASCOTTE to seven days and García-Herrera et al. (2005) used three years of data. Nevertheless, their results indicate that there is a lot of potential to apply this method over much larger datasets. The versatility of this particular method is also evident, whereby it has been applied to two dissimilar geographic regions, one within the tropics and the other in the midlatitudes. Brightness temperature from various satellites can also be used as input for MASCOTTE, with GOES-8 and Meteosat-7 data so far being successfully tested. It should be noted that the spatial and temporal resolution of these two satellites is fairly similar and thus, likely contributes to the success of adapting MASCOTTE with both satellites. The results from the two previous MASCOTTE studies indicate that this method may be successfully applied to the southern African region. 


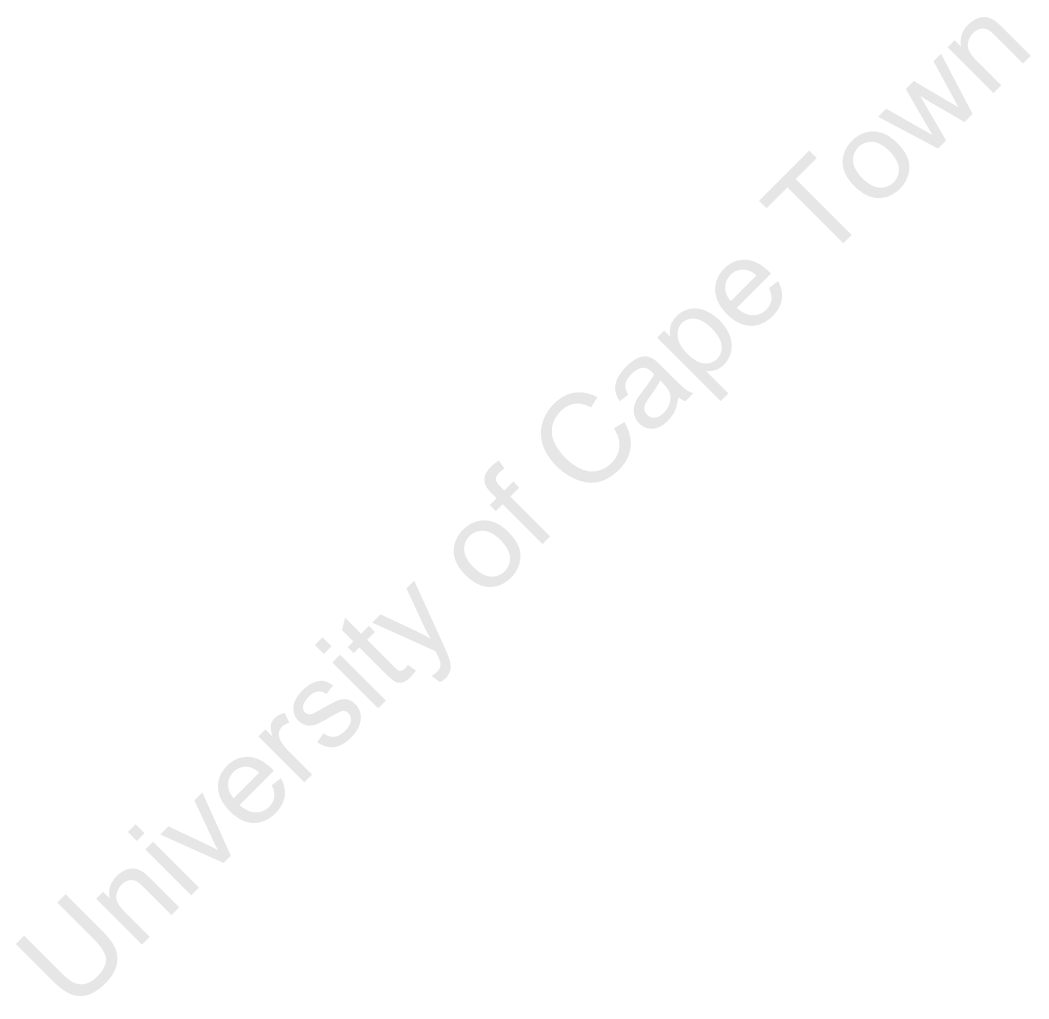




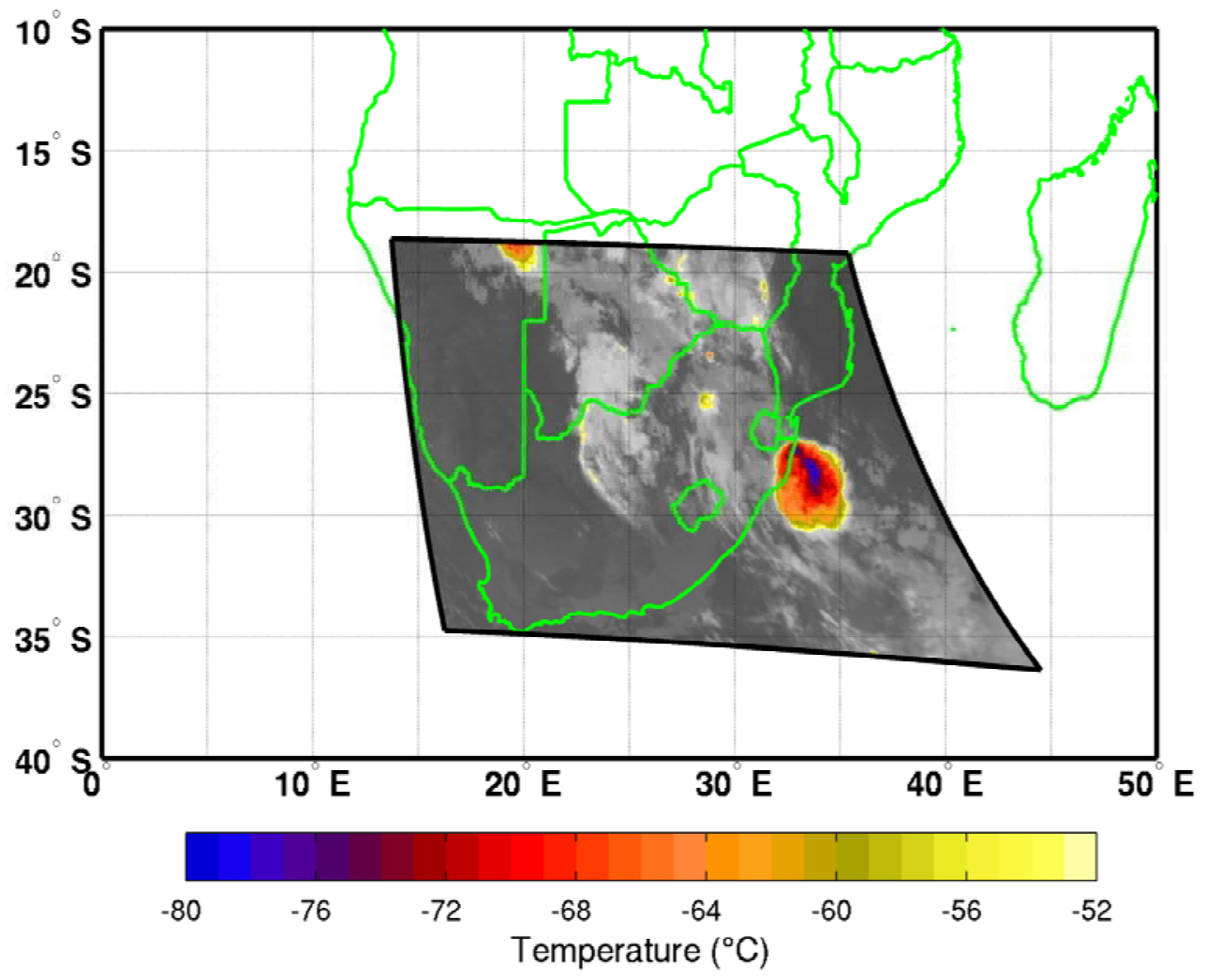

Figure 3.1: The domain of MASCOTTE over southern Africa is represented here by the area covered by the IR satellite data (brightness temperature overlaid; ${ }^{\circ} \mathrm{C}$ ). Included in this figure is an example of an MCC positioned off the east coast of South Africa on the 26 November 1999 at 0100 LST. 


\section{Chapter Four}

\section{Mesoscale Convective Complexes over southern African}




\subsection{Spatial Distribution}

A total of 70 MCCs were identified and tracked during the eight warm seasons for the 1998-2006 period (Fig. 4.1). This result is less than the number of systems observed in subtropical South America (e.g., Durkee and Mote 2009) or the central plains of the U.S (e.g., Ashley et al. 2003), but greater than that found in southeast Australia (e.g., Perrin and Reason, 1997). The reasons for this lower number compared to the Americas are not obvious, but it is likely a combination of the geographic setting of southern Africa, as well as prevailing summer synoptic conditions in the region. For example, subtropical South America and the U.S. both have nearby large sources of tropical moisture (Amazon River Basin and the Gulf of Mexico, respectively) whereas the corresponding land mass equatorward of subtropical southern Africa is relatively dry. Although the Mozambique Channel is a moisture source for subtropical southern Africa, it is much smaller than the Gulf of Mexico / Caribbean or the tropical Atlantic / Amazon.

Figure 4.2 spatially displays the origin points of the MCCs found in Figure 4.1. It is evident from these two figures that most systems are located along the eastern region of southern Africa, with a large portion initiating along the eastern escarpment (see Fig. 1.2 for location). The interaction between the topography of the northeastern escarpment with that of westerly waves propagating across the southern tip of Africa has been shown to assist in the development of convective storms in the region (Garstang et al. 1987). In addition, the eastern escarpment has previously been linked (as an initiating mechanism) to the development of MCSs (Laing and Fritsch 1993b; Blamey and Reason 2009). Elsewhere, MCCs are often found near large mountain ranges, such as the Andes in South America (e.g., Durkee and Mote 2009) or the Rockies in the U.S. (e.g., Ashley et al. 2003). In addition to developing in the lee (relative to prevailing mid-level flow) of elevated terrain, the global population of MCCs have been documented to have a strong tendency to occur in the gradient zones between outgoing longwave radiation (OLR) maxima and minima (Laing and Fritsch 1997). Consistent with other MCC regions, systems over southern Africa appear to occur within or along the border of zones containing regional OLR minima (Fig. 4.3). 
The clustering of MCCs along the eastern border and over the adjacent ocean is also apparent in Fig. 4.4. Here the domain is divided into one degree resolution gridboxes and calculated the number of times a system is tracked through each box. The tendency for the systems to track eastwards towards the high equivalent potential temperature (high $-\theta_{\mathrm{e}}$ ) air associated with warm waters (Agulhas Current) along the southeastern African coast is not uncommon (Laing and Fritsch 1993b; Blamey and Reason 2009). This pattern of the systems propagating downstream from where they originated, has been documented in numerous MCC regions and linked to the large-scale mid-level flow (700-500 $\mathrm{hPa}$ ) in combination with a low-level jet (LLJ) (Maddox et al. 1986; Velasco and Fritsch 1987; Miller and Fritsch 1991; Corfidi et al. 1996). Over South Africa, strong mid-level westerly flow often exists, consistent with the general tracks of the systems (Fig. 4.1). The mean summer low level flow along the east coast is predominantly onshore due to ridging anticyclones (not shown), which is opposite in direction to the general MCC tracks. Systems in the northeastern corner of the domain tend to move less than their counterparts farther south due to the absence of a westerly mid-level flow in the lower latitudes of the domain.

Although not numerous in number over the eight warm seasons, Fig. 4.1 shows that a few systems may develop over Namibia or Botswana, likely as a result from tropicalextratropical interactions taking place over southern Africa during the austral summer. These tropical-extratropical interactions result in the development of cloudbands or tropical temperate troughs (TTTs), which extend from southern Angola to the midlatitudes southeast of South Africa (Harrison 1984). A common circulation feature that assists in the development of these cloudbands, through sustained moisture transport into southern Africa, is the Angola low (Todd and Washington 1999; Hart et al. 2010). The Angola low is defined as heat low existing only during the summer months and is typically located over southern Angola / northern Namibia (Reason et al. 2006). The circulation around the Angola low and the interaction with the local topography is also thought to also create favourable conditions for precipitation in the region (Cook et al. 2004; Monaghan et al. 2010). 
Furthermore, in southern Africa, common summer LLJ activity regions have been identified over Botswana, Namibia-Angola (Rife et al. 2010) and South Africa (Stensrud 1996a). Nocturnal LLJs are not only responsible for the inflow of high- $\theta_{\mathrm{e}}$ air, but have been shown to promote a favourable environment for long-lived nocturnal convection to take place through enhanced low level convergence, increased frontogensis and stronger vertical wind shear (Augustine and Caracena 1994; Fritsch and Forbes 2001; Trier et al. 2006). It is arguably for these reasons that the global population of MCCs often coincides with regions that contain regular LLJ activity (Strensrud 1996a). Extreme precipitation events associated with the Namibia-Angola and Botswana LLJs, as identified by Monaghan et al. (2010), correspond to the same location where most MCC activity in the region occurs. Thus, these results suggest that MCC activity in these two regions is likely influenced by the moisture transported into the region via the LLJ.

\subsection{Evolution Characteristics}

The key stages to the MCC life cycle, which are first storms, initiation, maximum size and termination, are illustrated in Fig. 4.5. In this case, the stages have been divided into three-hourly bins and are in local standard time (LST $=\mathrm{UTC}+2 \mathrm{~h})$. The first storms tend to initiate in the early afternoon, which are followed by MCC initiation in the late afternoon / early evening. The maximum extent of the systems is found to occur during the night, predominantly between 0000 and 0300 LST, which is followed by the decay of the system during the morning hours. The diurnal frequency of MCCs is more clearly seen in Fig. 4.6, where the first storms and the number of images containing an MCC are plotted in half-hourly Meteosat-7 bins. This predominant nocturnal life cycle pattern in southern Africa MCCs is consistent with the earlier findings of Laing and Fritsch (1993b), as well as that of global population of these systems, as discussed in Chapter Two.

The tendency of these systems to occur predominately at night is believed to be related to the differential radiative heating between the convective cloud area and its environment, as well as latent heating (Gray and Jacobson 1977; Cotton 2000). However, Fritsch and 
Forbes (2001) argue that because free-troposphere longwave cooling is typically small compared to convective heating rates observed in MCSs, it is unlikely that radiatively driven circulations above the planetary boundary layer can create convective available potential energy (CAPE) fast enough to offset the rates at which it is consumed in MCS overturning. This behaviour may especially apply to the larger MCCs, which exhibit intense and massive convective overturning for many hours. Thus, other factors likely play a role in the nocturnal nature of these systems. One such factor is possibly the presence of the previously mentioned nocturnal LLJ.

The average duration of the 70 systems over southern Africa ( 9.5 hours; Fig. 4.7) is slightly shorter than the global average ( 10 hours; Laing and Fritsch 1997) and much less than those found in subtropical South America (14 hours; Durkee and Mote 2009). Following the general practice in the literature, 3 hour bins have been used to analyse the duration in Figure 4.7. Over 75\% of the southern African systems last between 6 and 12 hours. The southern African systems also tend to be smaller than their global counterparts. Figure 4.8 illustrates that fewer than $25 \%$ of the systems exceed 150,000 $\mathrm{km}^{2}$, with most systems obtaining a maximum size of roughly $75,000-125,000 \mathrm{~km}^{2}$. The average size of the systems is just over $121,100 \mathrm{~km}^{2}(95 \%$ confidence limits $\pm 10,700$ $\mathrm{km}^{2}$ ), which is almost $50 \%$ of the average size of midlatitude South African systems documented by Laing and Fritsch (1993b). Using a Behrens-Fischer test (Zar 2010), it is found that the two populations differ significantly in size at a 0.05 level $\left(t_{0.05(2), 22.6}=\right.$ $5.54, \mathrm{p}<0.05)$.

A factor that may contribute to this large difference in size with previous findings of Laing and Fritsch (1993b) is the length of the study period, with eight warm seasons (1998-2006) being used here versus only two years (1986-1987) in the Laing and Fritsch study. Thus, the characteristics of 70 systems are evaluated in this study, compared to 21 in Laing and Fritsch (1993b). Furthermore, satellite data with a much lower spatial and temporal resolution $(\sim 30 \mathrm{~km}$ and 3 hours, respectively) was used in their research. However, it is also found that the average size of the systems here is approximately $47 \%$ of the average size of systems in subtropical South America (Durkee and Mote 2009). 
Using a Welch $t$ test (Welch 1947), the difference in the average population size of systems in southern Africa (mean=121,000 km², $\mathrm{SD}=45,800 \mathrm{~km}^{2} ; \mathrm{n}=70$ ) appear significantly smaller (at a 0.05 level) than those in South American (mean=256,500 km²; $\left.\mathrm{SD}=186,937 \mathrm{~km}^{2} ; \mathrm{n}=330\right), \mathrm{t}_{0.05(2), 391.91}=-11.62, \mathrm{p}<0.05$.

\subsection{Seasonal Cycle}

Over the eight warm seasons, it is found that peak MCC occurrence over southern Africa is during the months of November and December, followed closely by February (Fig. 4.9). January, one of the core summer months, receives slightly fewer systems than February. The November/December peak in activity has also been documented in South America (Velasco and Fritsch 1987; Durkee and Mote 2009), whereas the peak in activity in southeast Australia occurs in January (Perrin and Reason 1997). This peak in activity during the early summer months is likely linked to the synoptic-scale environment, which is more baroclinic in nature compared to the late summer months (Tyson and PrestonWhyte 2000). As noted by Maddox (1983), the typical MCC develops within a largescale environment that contains considerable horizontal temperature, moisture and stability gradients, along with considerable variations in both horizontal and vertical wind shear. In addition, Velasco and Fritsch (1987) suggest that MCCs require baroclinic environments to help sustain the inflow of high- $\theta_{\mathrm{e}}$ air.

Outside of the core summer months, MCCs are relatively infrequent, with no systems found in the month of October and only a few found in March. The five-month MCC season in southern Africa is shorter than the eight-month season found in South America, but similar in extent to that of the U.S. This difference could be due to systems in South America thriving off the moisture brought in from the Amazon by the South American LLJ. However, it may also be due to some tropical systems been incorporated in the South American data, and hence the longer season. Velasco and Fritsch (1987) suggest that the longer MCC season in South America compared to the U.S. may be due to the influence of the oceans on the relatively smaller land mass. 
MCCs in southern Africa also appear to display seasonal migration with systems occurring farther poleward in the earlier part of the season (November and December) and then shifting back equatorward during the later stages (Fig. 4.9 and Fig. 4.10). A seasonal migration pattern, with systems shifting farther poleward in the later summer months, is not uncommon in the global population and has been explained by the seasonal radiation cycle (Laing and Fritsch 1997). However, there are likely other mitigating factors in southern Africa, because the southernmost extent of the intertropical convergence zone (ITCZ) over land occurs in February. It is possible that the seasonal distribution in MCCs may be at least partially explained by the same processes that result in the eastward displacement of TTTs during the late summer months. For example, the influence of the midlatitude circulation on water vapour transport and moisture convergence zones over the region is more prominent during the early summer months compared to the late summer months, when tropical processes become more important (D'Abreton and Tyson 1995; Todd et al. 2004). The result is that TTTs tend to develop more over the southwest Indian Ocean in the late summer instead of extending over the continent through South Africa (Todd et al. 2004).

There is also considerable inter-annual variability in MCC occurrences in the region, with the average (median) being about 9 (8) events per season and ranging from a minimum of 4 to a maximum of 18 events per season (Fig. 4.11). In some seasons, more than double the average amount of events occur (e.g., 1999/2000), while in others less than half the average amount develop (e.g., 2002/2003). Similar large inter-annual variability in warm season MCC frequency has been documented in North and South America and elsewhere (e.g., Velasco and Fritsch 1987; Augustine and Howard 1991). Atmosphere circulation and rainfall patterns over southern Africa during the austral summer months are often influenced by numerous factors, such as El Niño-Southern Oscillation (ENSO) (e.g., Lindsay 1988; Mason and Jury 1997; Reason et al. 2000; Reason and Jagadeesha 2005) or sea surface temperatures of the neighbouring ocean (e.g., Landman and Mason, 1999; Reason and Mulenga 1999; Behera and Yamagata 2001). For this reason, a section in the next chapter is used to provide some analysis on the possibly causes for such inter-annual variability in MCCs over the region. 


\subsection{Continental versus Oceanic Systems}

In order to gain a better understanding of the role the local environment plays in organised convection, we have categorised MCC data into continental or oceanic systems. As alluded to previously, the warm Agulhas Current, flowing polewards along the east coast of southern Africa, is known to be a noteworthy feature in the South African climate. The close proximity of the core of the Agulhas Current to the east coast has been shown to not only result in high latent heat fluxes of several hundred watts per square meter, thereby transferring more moisture to the atmosphere than the surrounding waters (Rouault et al. 2003b), but also to lead to local storm intensification (e.g., Rouault et al. 2002; Singleton and Reason 2006, 2007).

In this study, an oceanic (continental) MCC is defined as a system that reaches maximum extent while positioned over the ocean (land). Globally, oceanic systems have been found to be slightly larger and last longer than their land based counterparts (Laing and Fritsch 1997). However, this may not apply to all regions, as Durkee and Mote (2009) note that oceanic systems in subtropical South America show no difference in duration and are only slightly larger at the time of maximum extent compared to continental systems.

Out of the 70 MCCs over southern Africa, 19 systems are categorised as oceanic and the rest as continental (see Fig. 4.12 for location). This distribution is comparable with the global population of MCCs, which are predominantly concentrated over land (Laing and Fritsch 1997). Of the oceanic systems, a few systems (7) initiate over the ocean, while just less than double (12) are initiated over coastal land areas and then propagate out over the adjacent ocean. The results suggest the oceanic systems are slightly smaller ( $117,000 \mathrm{~km}^{2}$ ) than the entire southern Africa population and also have a longer duration ( $\sim 14 \mathrm{hrs}$ ). In general, there appears to be no preferential region in the domain where systems obtain a larger cloud shield than elsewhere (Fig. 4.12). However, significant conclusions are not possible based on this small sample size. Most of the oceanic systems follow the life cycle described previously, with the systems initiating during the 
afternoon, reaching maximum size during the late night / early morning hours and then terminating later that morning (not shown).

\subsection{Chapter Summary}

Using a hybrid automated/manual tracking method, 70 MCCs that occurred over southern Africa during 1998-2006 are identified. Most MCCs over southern Africa generally last for 6-9 hours (about a quarter last for 9-12 hours) and obtain an average cold cloud shield of approximately $121,100 \mathrm{~km}^{2}$. They are found to occur predominantly during the night time hours, initiating during the late afternoon / evening ( 1500-2000 LST) and reaching maximum extent after midnight ( 0000-0300 LST). Apart from the average size of systems being relatively small, these findings compare favourably with the global population.

The systems over southern Africa are predominately an austral summer (NovemberFebruary) phenomenon with peak MCC activity taking place during November and December, followed closely by the months of February, January, with far fewer systems in March. The peak in MCC activity during the early summer is common among MCC populations elsewhere (e.g., Ashley et al. 2003, Durkee and Mote 2009). Although no MCCs were found during October, systems that reached the size and shape criteria, but fell just short of the duration threshold were identified during this month. This finding again highlights that there are certain synoptic settings and mesoscale processes that favour the development of such systems in the region. An uncharacteristic finding is that MCCs in the region were more likely to occur farther poleward in the early summer, rather than later in summer as found elsewhere. It is likely that seasonal changes in the synoptic-scale circulation over southern Africa are responsible for this behaviour. In particular, the transition from a more midlatitude dominated circulation to a more tropical circulation during the late summer months (e.g., Todd et al. 2004) is key.

The systems tend to cluster in preferred locations, particularly along the eastern coastline. It is found that most systems initiate along the eastern escarpment and then propagate 
downstream across the warm waters of the Agulhas Current / Mozambique Channel. This eastward propagation pattern is not unique and has been documented in the global MCC population, as well as in southern Africa (Laing and Fritsch 1997). One potential mechanism for this distribution or propagation of systems in the region is through gravity waves driven by diurnal heating over the elevated terrain, as documented in South America (Mapes et al. 2003). These findings also provide additional support for the major role the Agulhas Current plays in the region. Historically, this warm current has been recognised as an influential feature in South African weather patterns, particularly on austral summer rainfall and severe weather events in the region (e.g., Jury et al. 1993; Crimp and Mason 1999; Reason 2001b; Rouault et al. 2002; Blamey and Reason 2009). Despite this influence of the Agulhas Current region, it is likely that the neighbouring tropical South Indian Ocean, tropical southeast Atlantic Ocean (D'Abreton and Lindesay 1995; Cook et al. 2004) and tropical Africa (D’Abreton and Lindesay 1993; Cook et al. 2004; Jury 2010) also may act as moisture sources for MCC development.

Over the eight warm seasons, there are a few systems that develop over Botswana and Namibia. The development of MCCs in these two regions could possibly be related to the formation of cloudbands, resulting from tropical-extratropical interactions. The circulation associated with the Angola low is a key facilitator of moisture flow into these cloudbands and may also play a role in enhancing local convection. Furthermore, SST patterns off the Namibian / Angolan coastline are thought to have an influence on rainfall events along the west coast (Rouault et al. 2003a; Muller et al. 2008; Jury 2010). Additional research on this possible link between the Angola low, SSTs along the west coast and MCCs in Namibia and Botswana is required. de Coning et al. (1998) also describe how a large MCS embedded in the northern extent of one of these cloudbands had an influence on South African rainfall through the development of an mesoscale convective vortex (MCV; Bartels and Maddox 1991). Essentially, it is possible that MCCs may be embedded within the cloudbands and thus, the frequency of such systems may be modulated by large-scale perturbations (e.g., Hart et al. 2010). 
On average, roughly 9 systems occur per season (median value of 8), which, apart from Australia, is considerably less than in the Americas. This average is biased by the 1999/2000 warm season, which contained 18 systems. The reason for this relatively low frequency in summer is not obvious, but is likely due to the geographic setting of the study region and is discussed in more detail in the final chapter. The results also show that there is variability in MCC frequency on monthly and seasonal timescales, as might be expected given that the climate variability of the region is complex and often influenced by numerous forcing factors. Some of this variability is related to remote forcing such as the El Niño-Southern Oscillation (ENSO) (Lindesay 1988; Mason and Jury 1997; Reason et al. 2000) and some is linked to changes within the neighbouring Atlantic and Indian Oceans (e.g., Reason 1998; Reason and Mulenga 1999; Behera and Yamagata 2001; Rouault et al. 2003a; Reason et al. 2006). Thus, the forcing factors behind local MCC variability are not yet well understood, presenting a need for further work.

However, it should be emphasized that the results presented here are based on a limited sample size and thus, should be viewed with caution. To gain confidence in the statistics acquired for the southern African MCC population would require a much longer study period. Nevertheless, the results will not only benefit local understanding and forecasting of these systems, but will hopefully also contribute to the global knowledge of MCCs. Additionally, they also provide a platform to ascertain how important such systems are for southern Africa rainfall. 


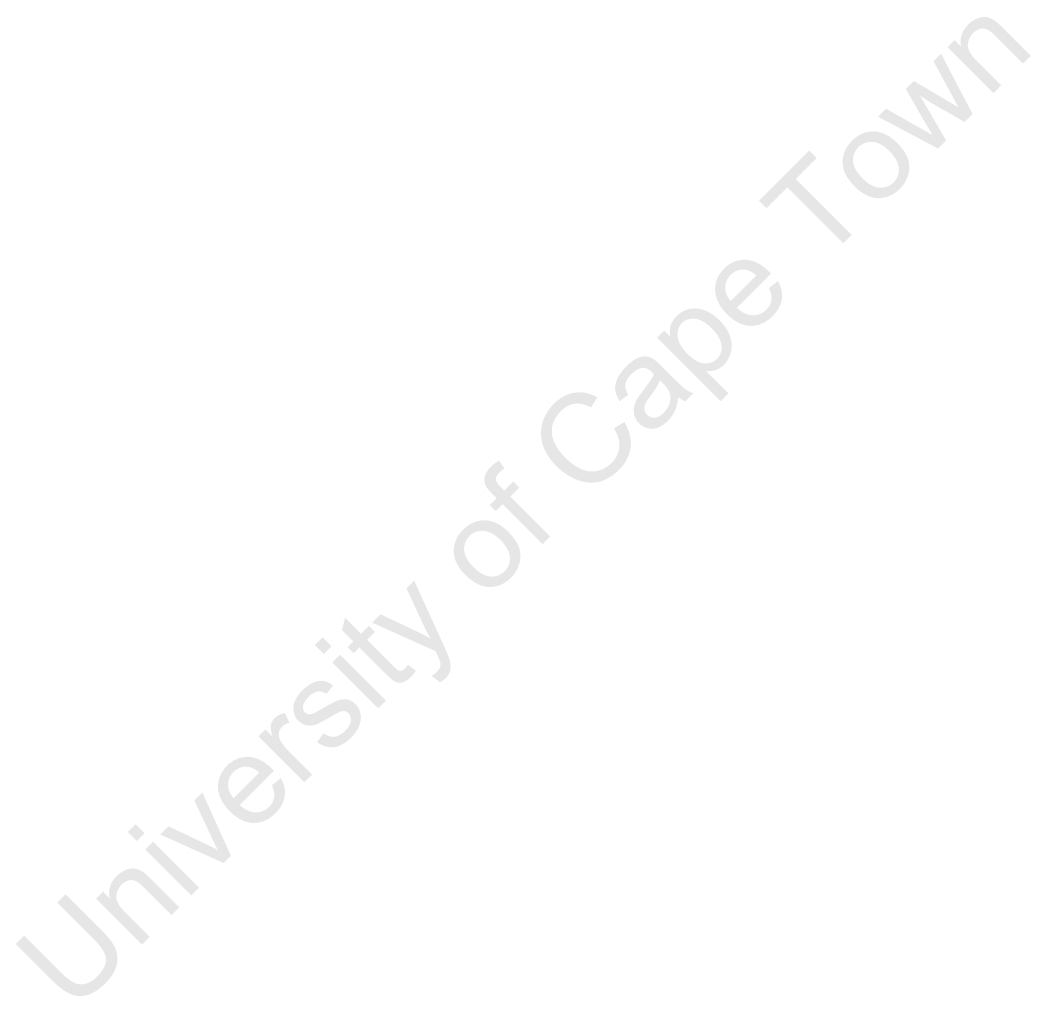




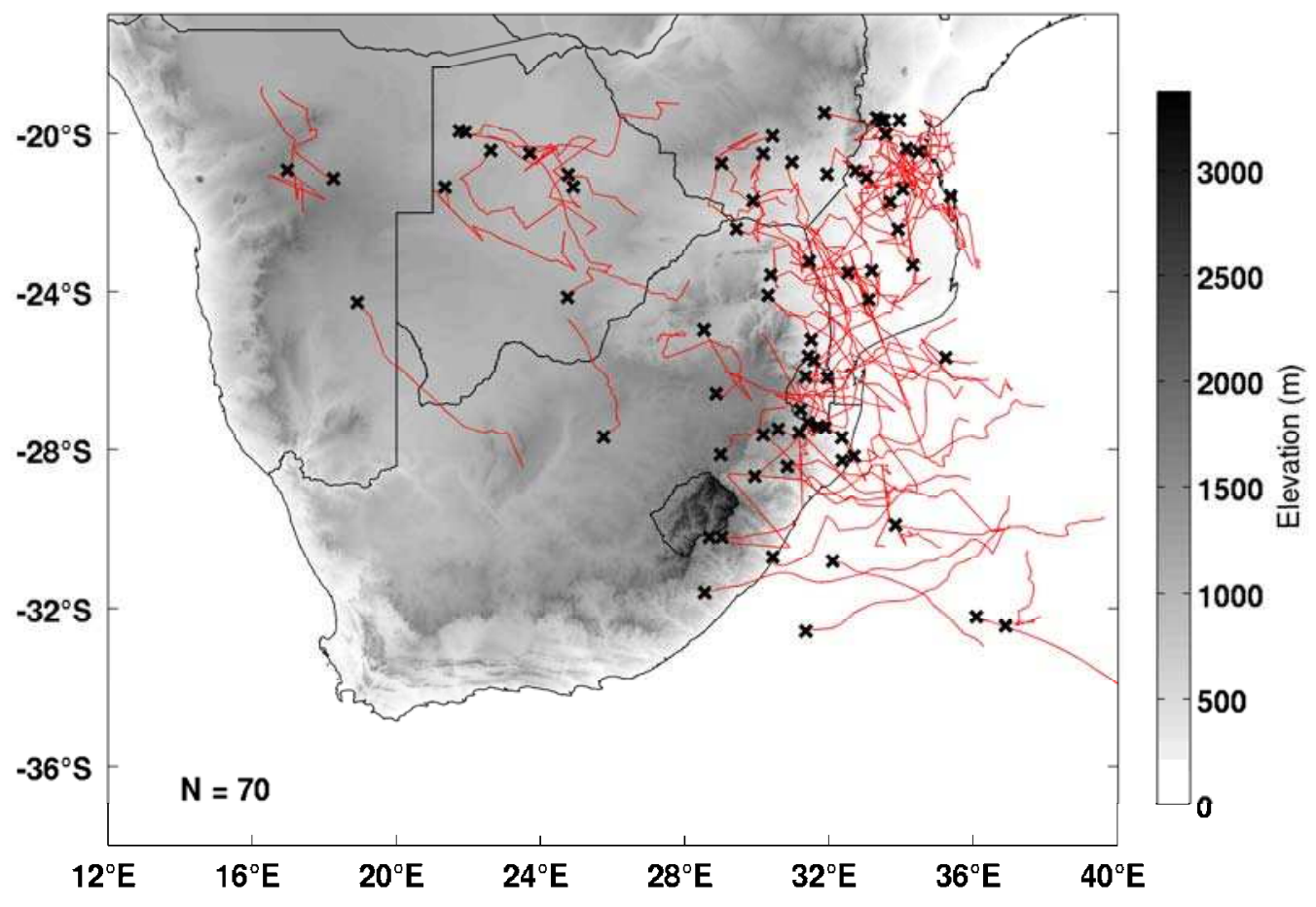

Figure 4.1: MCC tracks (red lines) and origin points (x) for the October-March period, 1998-2006. Also shown is the topography of the region (shaded, 500m intervals). "N" is equal to the number of systems during this period (bottom left corner).

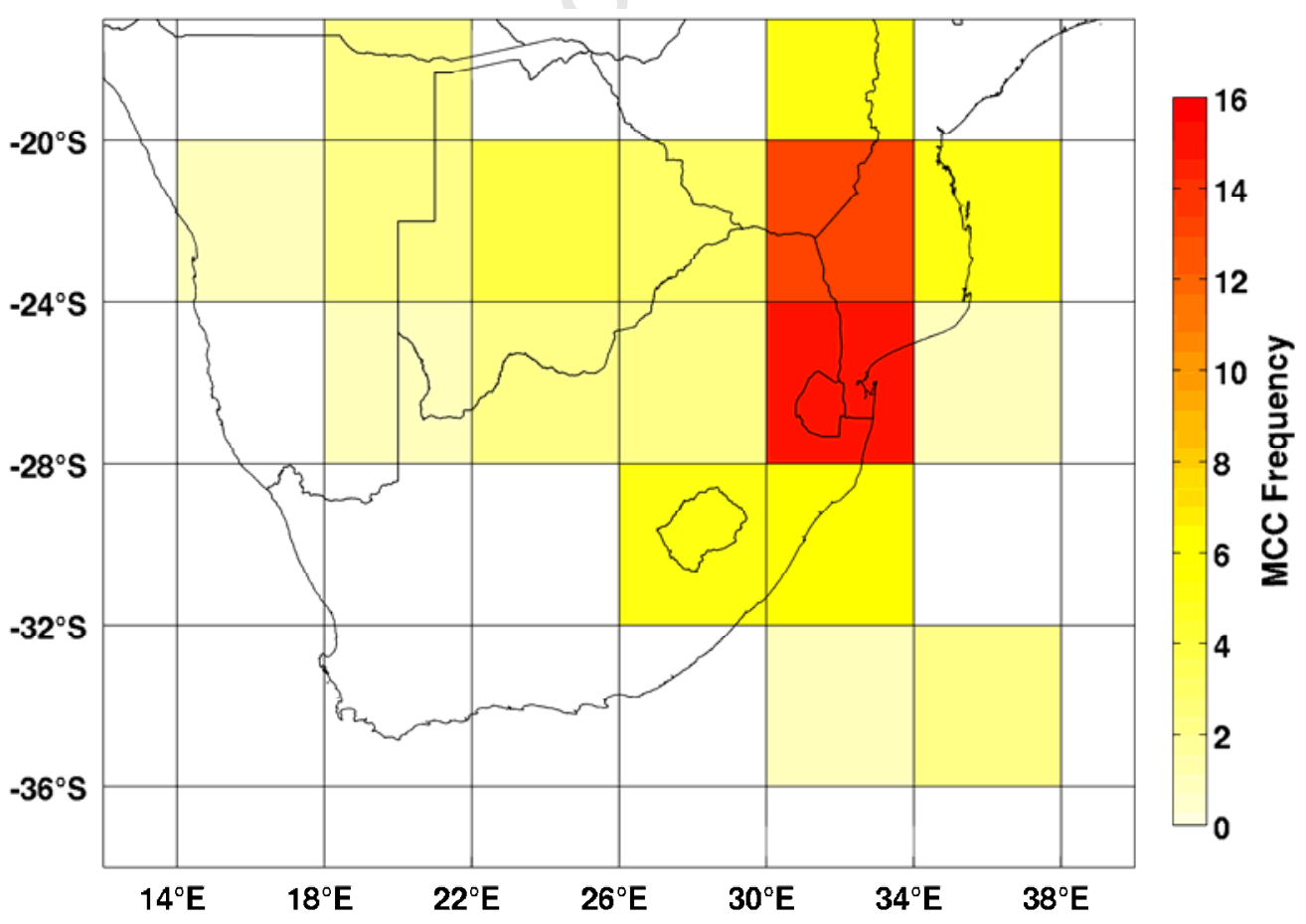

Figure 4.2: The origin or trigger locations of MCCs in southern Africa. The figure is created by clustering the MCC origins found in Fig. 4.1 into $4^{\circ}$ blocks. 


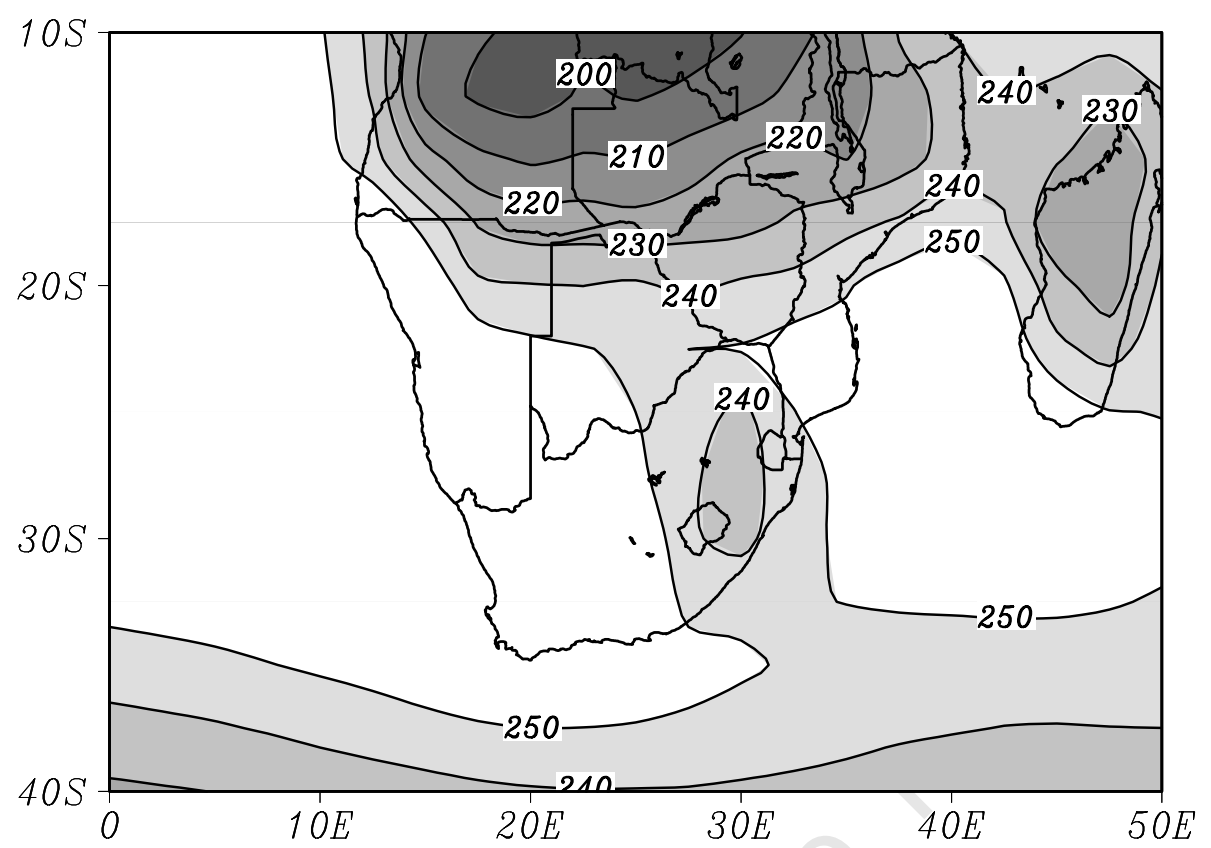

Figure 4.3: Monthly mean outgoing longwave radiation (OLR, W. $\left.\mathrm{m}^{-2}\right)$ over southern Africa. Monthly means created using the dataset described in Liebmann and Smith (1996).

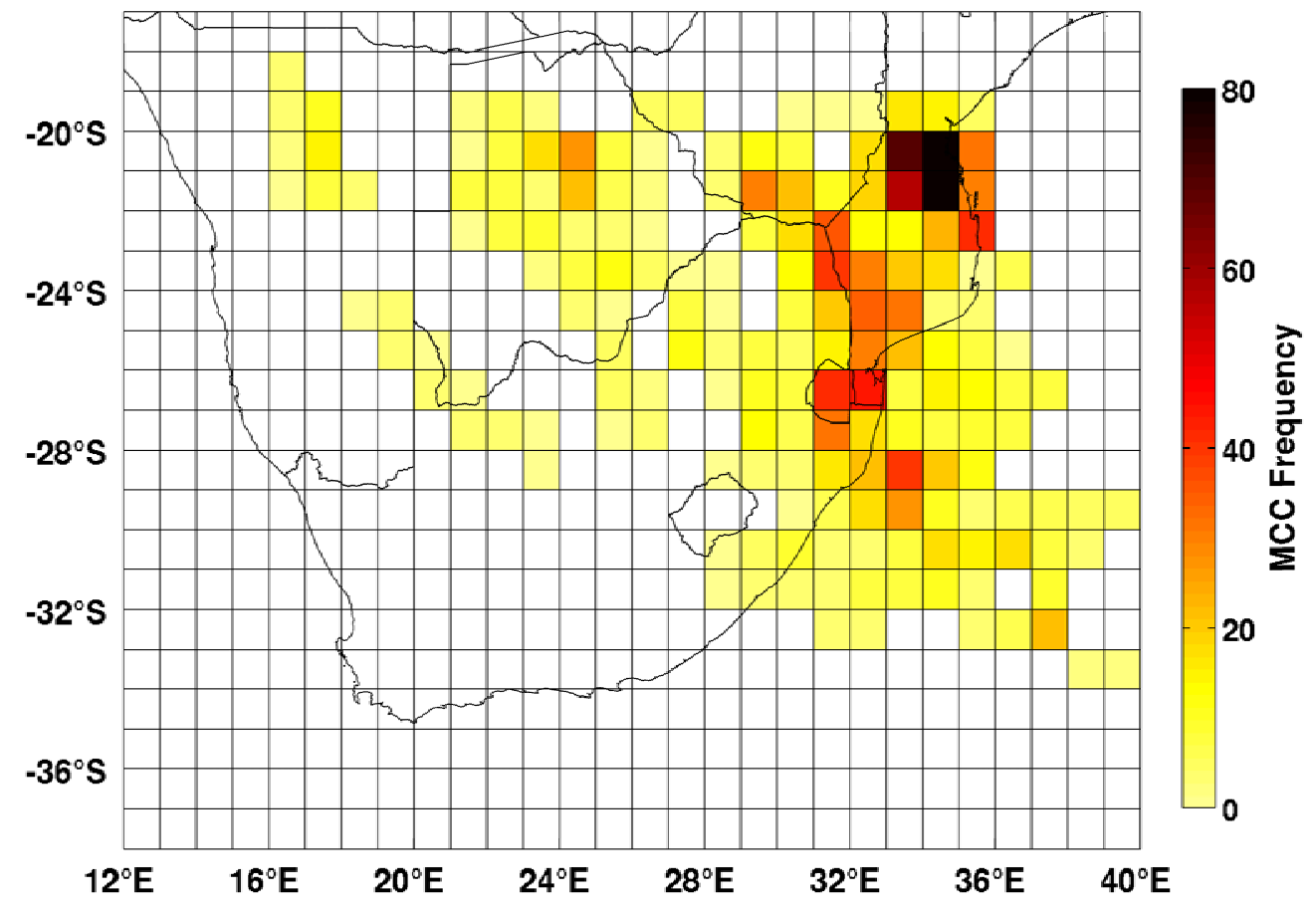

Figure 4.4: Same as Fig. 4.2, but now for all stages of the MCC evolution. The grid spacing is at $1^{\circ}$ resolution. 


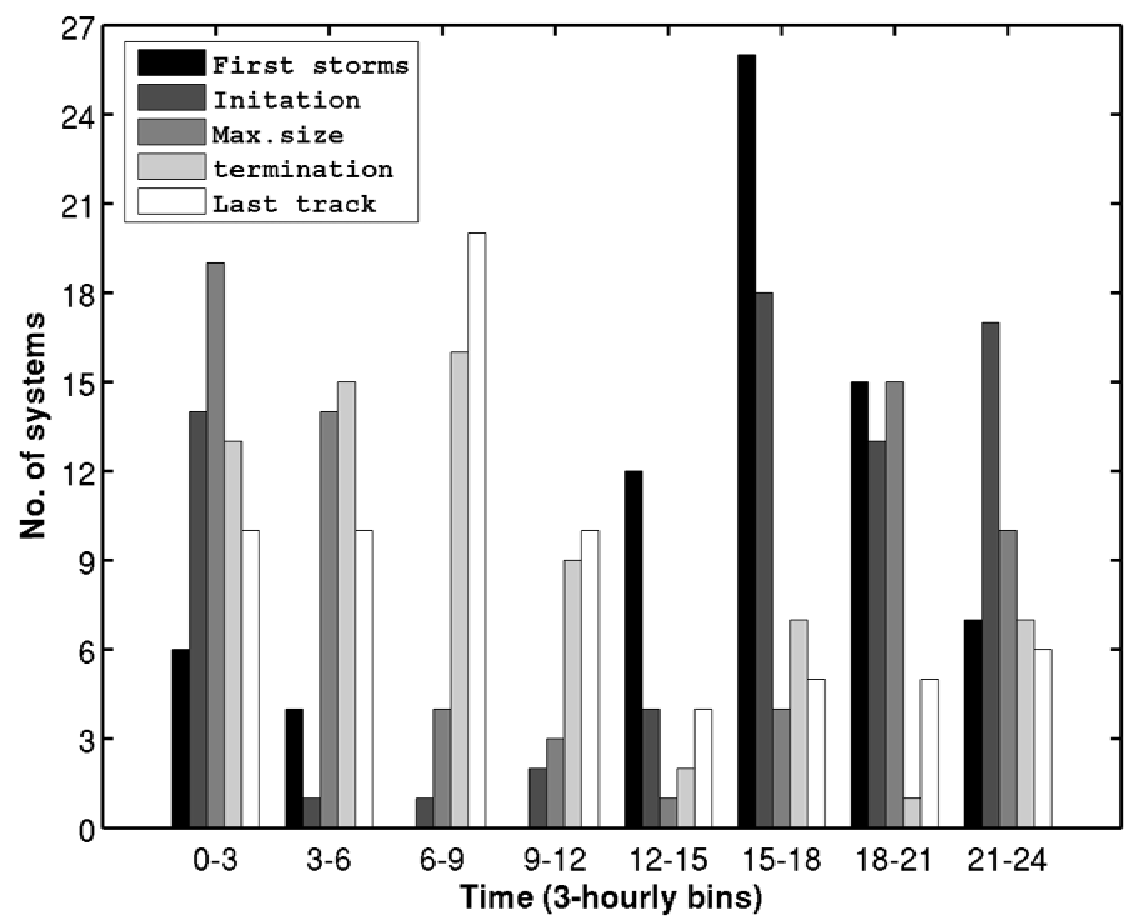

Figure 4.5: The key stages of the MCC lifecycle as described in the text, as well as an addition of "last track", which refers to the last time the evidence of the system is tracked in the program. The times have been binned into three-hourly time slots for ease of reading and are in local standard time.

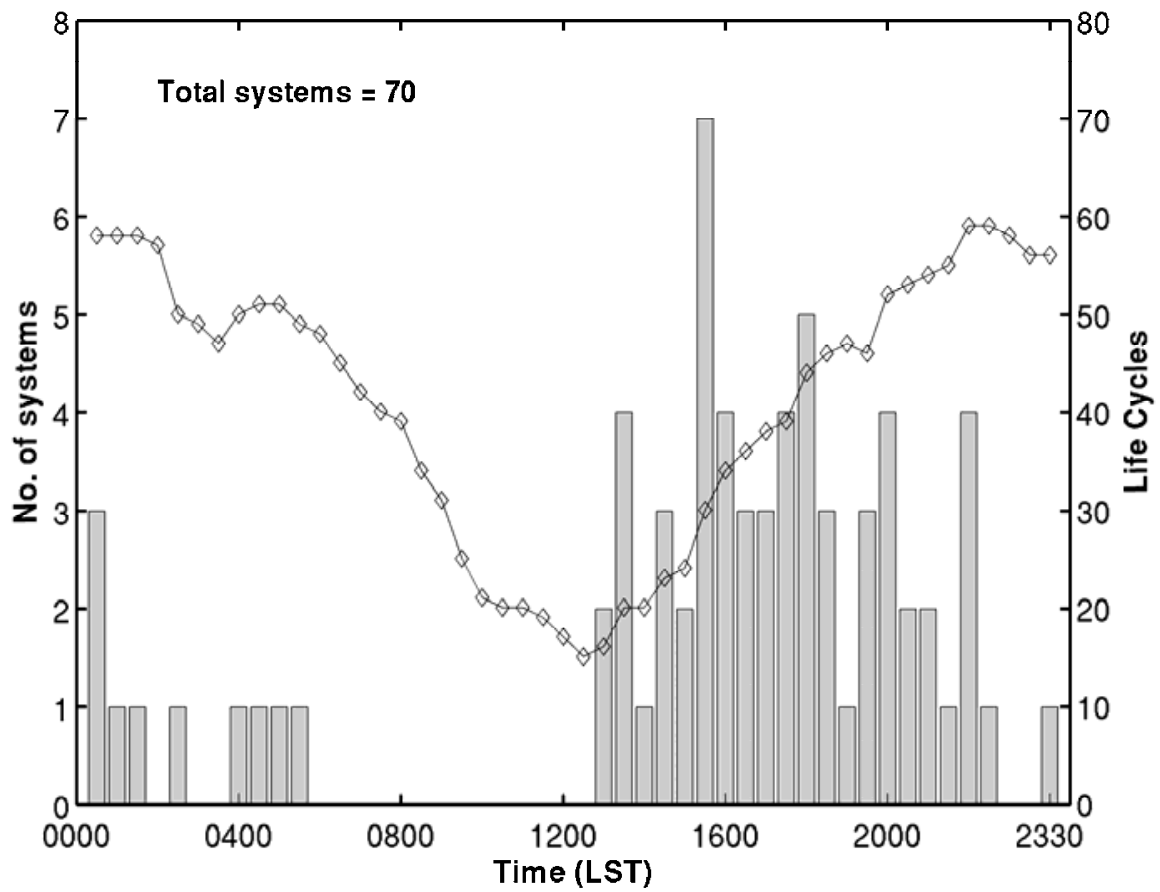

Figure 4.6: The initiating times of the first storms of MCCs (shaded bars, left y-axis) and the number of images containing an MCC (line graph, right y-axis) in the half-hourly Meteosat-7 images. 


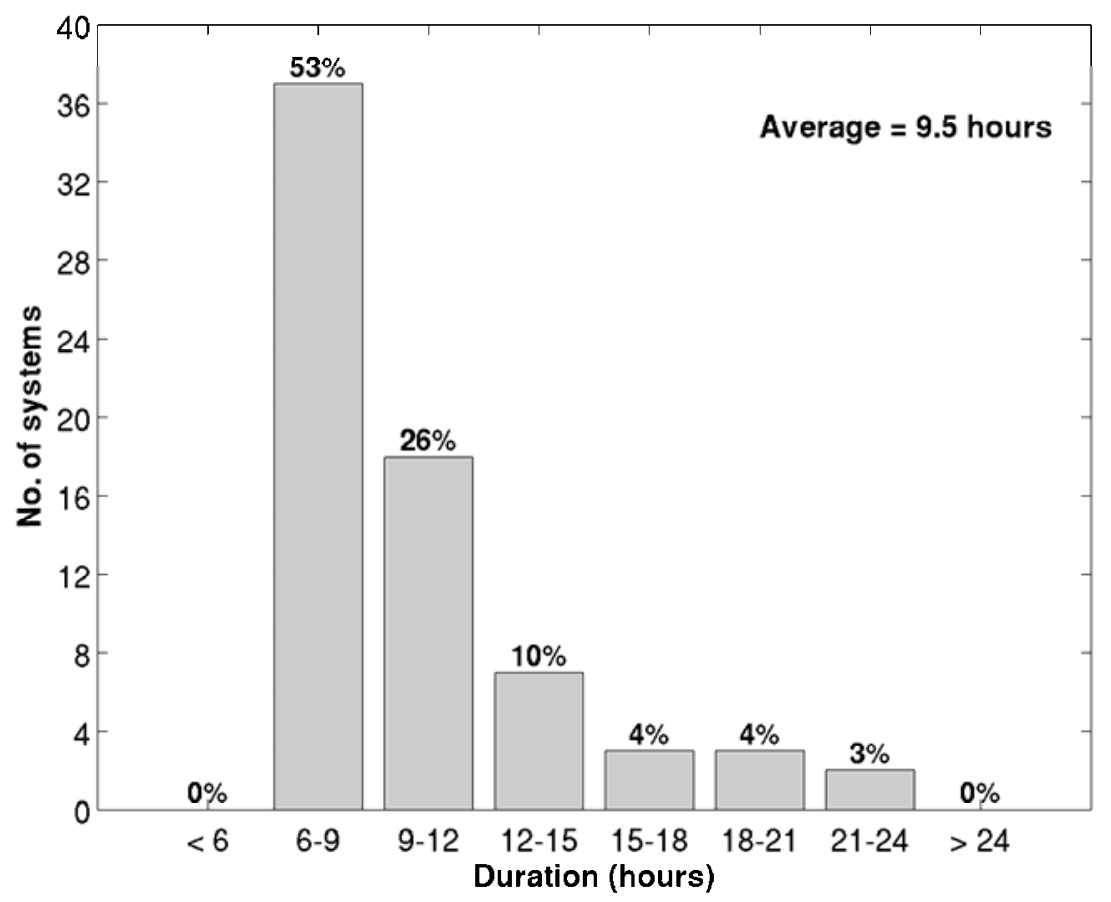

Figure 4.7: Bar graph of warm season MCC duration. The percentage contribution of each category is shown at the top of each bar. The average duration is included in the top right hand corner.

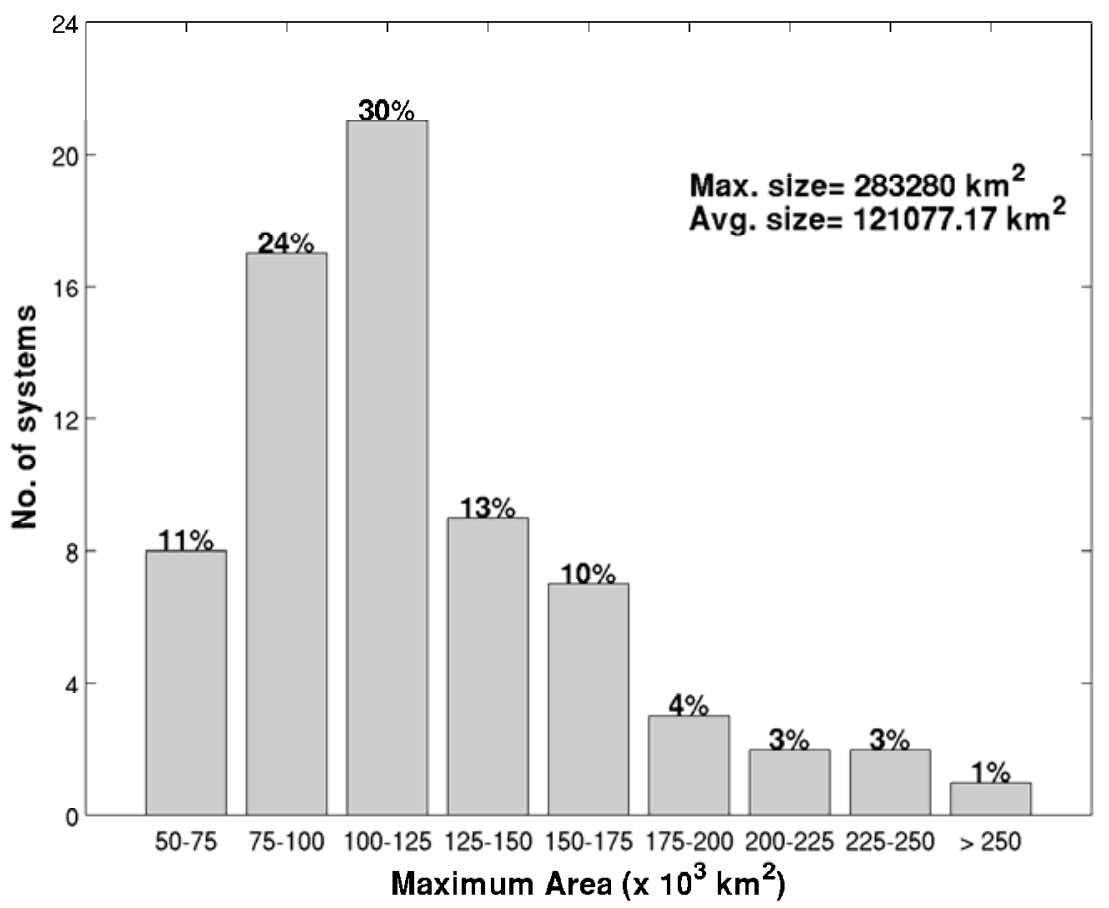

Figure 4.8: Same as Fig. 4.7, but for maximum size. Note that the size here refers to the maximum extent of the $-52^{\circ} \mathrm{C}$ cloud shield. 


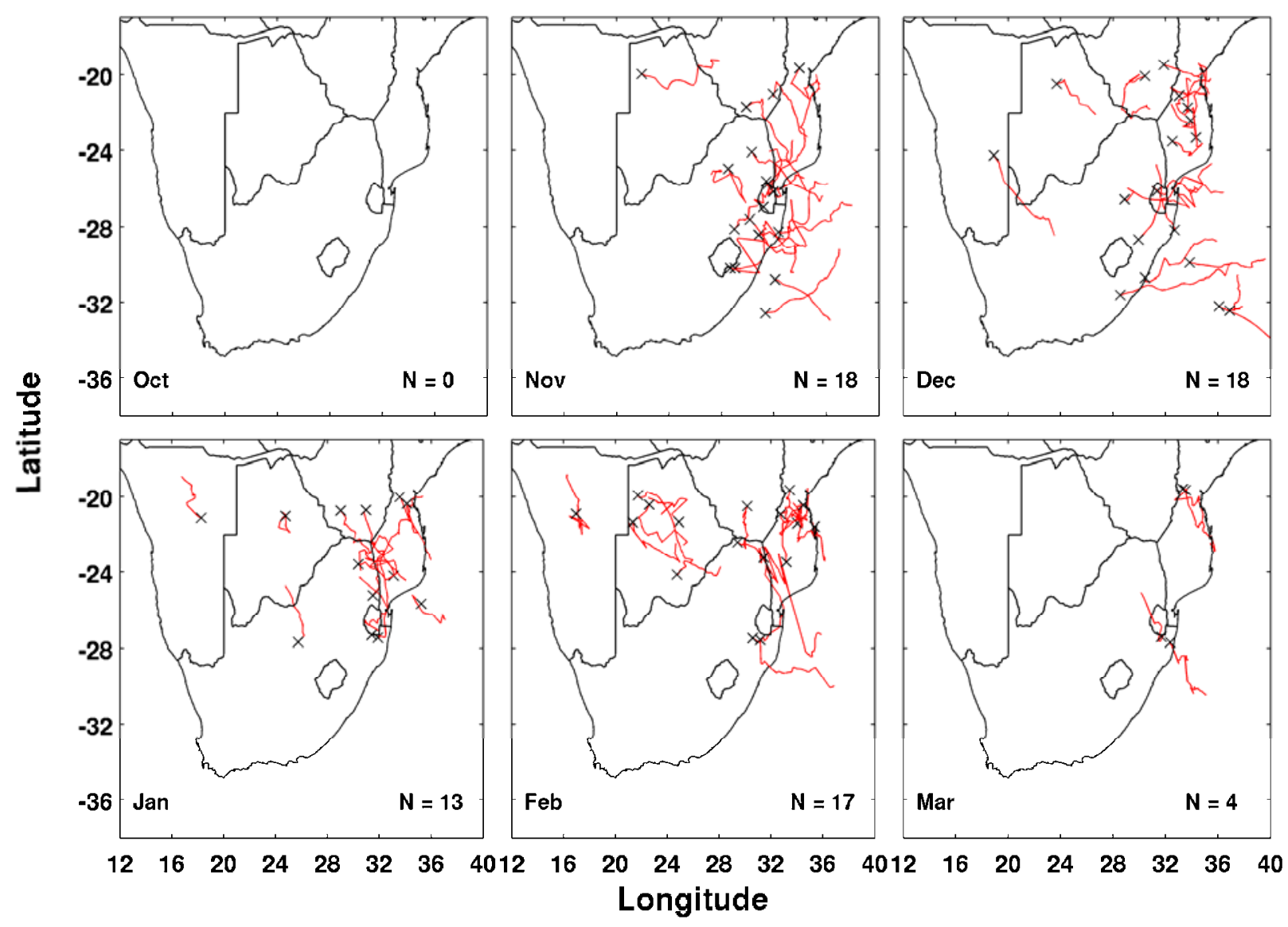

Figure 4.9: The 70 MCCs divided up into the months in which they occurred (' $x$ ' denotes origin and red line denotes the track). The month is given in the bottom left corner of each panel, while the number of systems for that month is in the bottom right. 


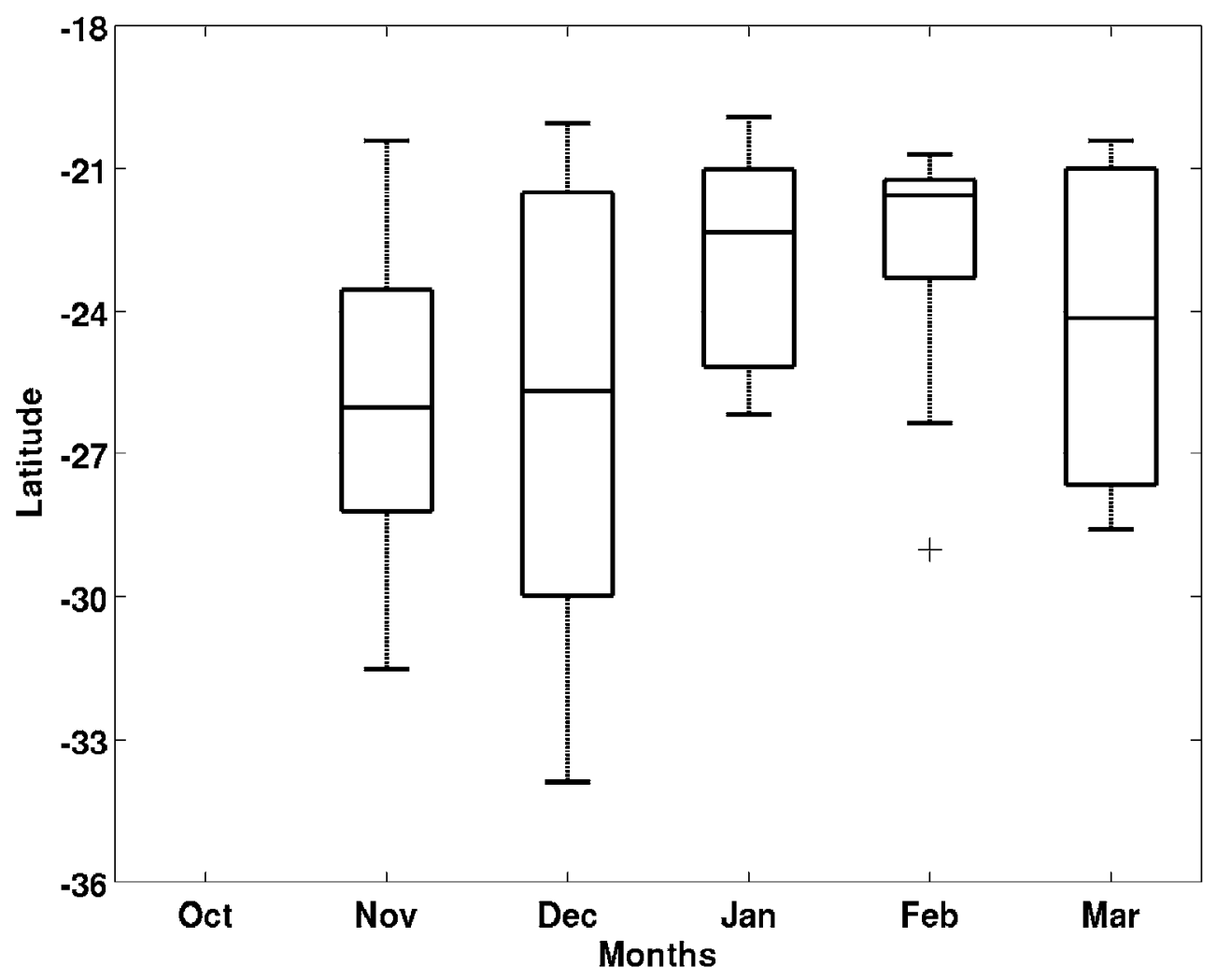

Figure 4.10: Box plots of the latitudinal distribution of MCCs during each month. Each box is drawn between the $25^{\text {th }}$ and $75^{\text {th }}$ percentiles of the data in Fig. 4.9, while the line in the middle is the median. Whiskers extend to extreme data points, while outliers are denoted by a black star. 

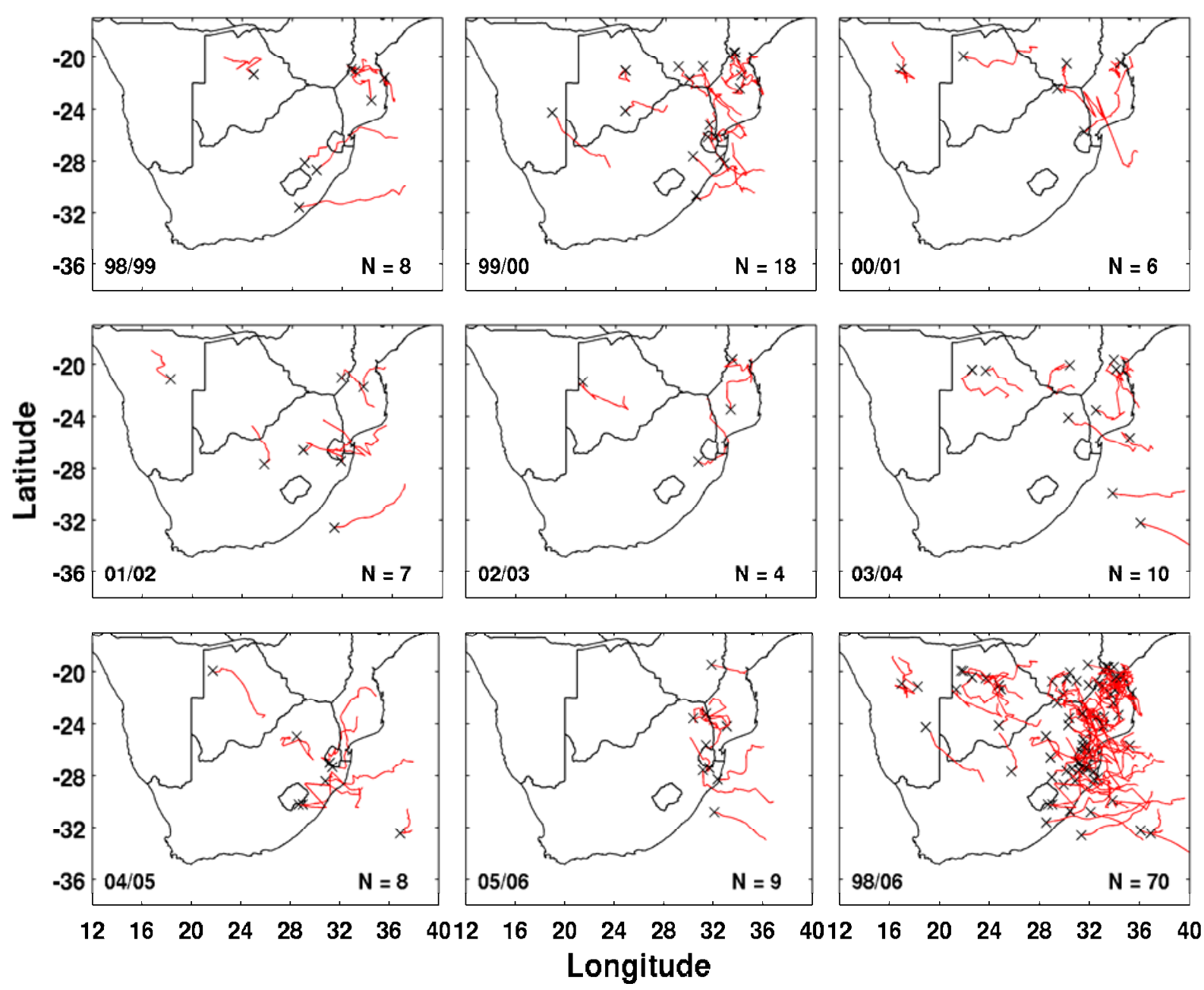

Figure 4.11: Same as Fig. 4.9, but for the eight warm seasons and the entire period (bottom right). The season is given in the bottom left corner of each panel, while the number of systems in the season is in the bottom right. 


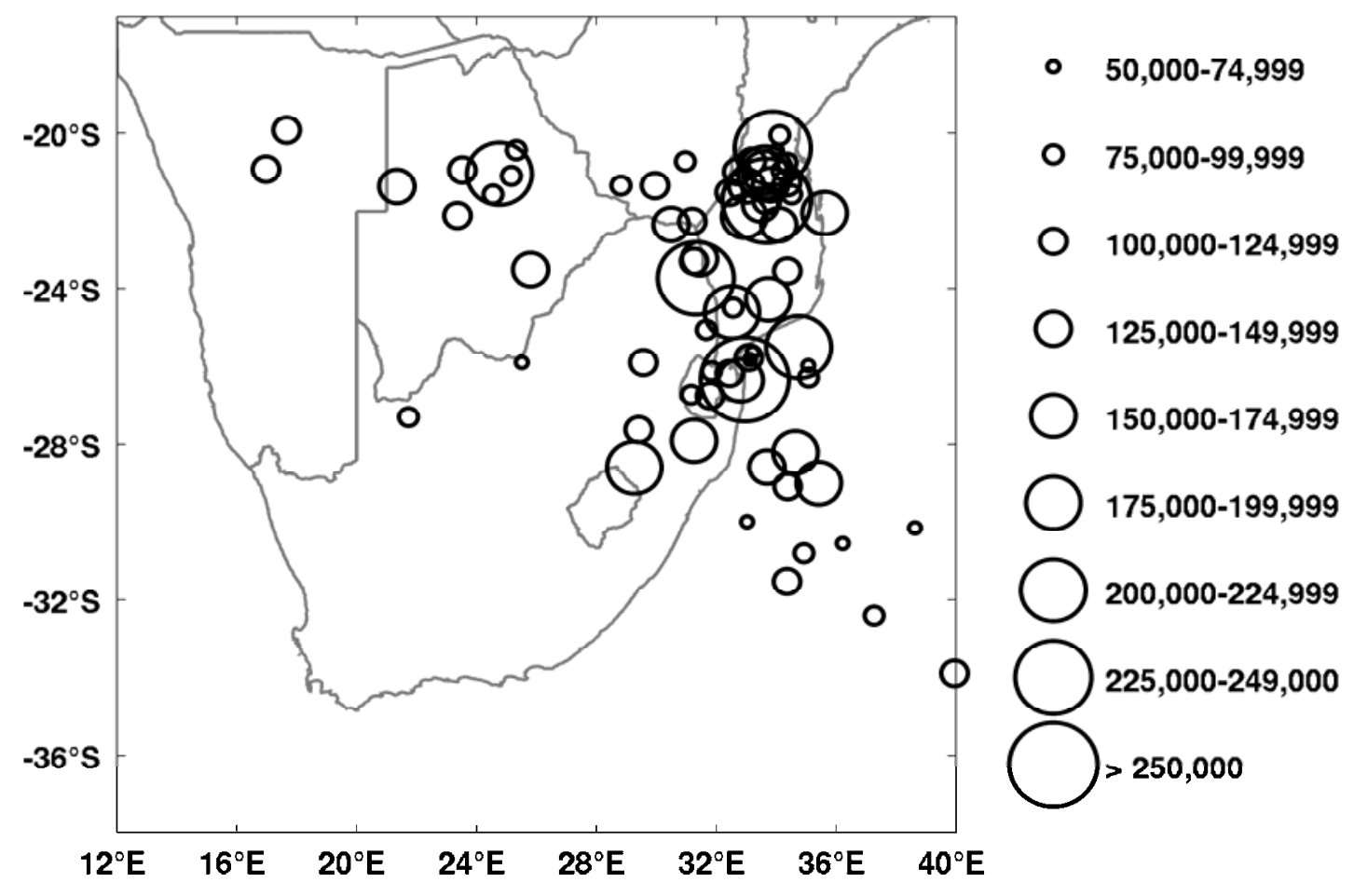

Figure 4.12: The distribution of MCCs at maximum extent (centre of circle), with the circles representing the cloud shield size $\left(\mathrm{km}^{2}\right)$. 


\title{
Chapter Five
}

\author{
Monthly mean large-scale \\ environments over southern Africa
}




\subsection{Introduction}

Environments that favour convective system development often tend to include a few crucial ingredients; namely, low level convergence, lift, potential instability and high levels of moisture in the atmospheric boundary layer (McNulty 1995; Doswell et al. 1996). However, as suggested by Tucker and Zentmire (1999), the combination of these elements does not necessarily distinguish days in which scattered, isolated thunderstorms develop or days that contain more organised, long-lived MCSs. Furthermore, deep convection is known to occur in many regions around the world, which includes areas where MCCs are not frequent, such as over the Amazon (e.g., Velasco and Fritsch 1987). This situation suggests that certain conditions, both thermodynamic and dynamic, play a key role in the development and organisation of MCCs.

Climatological work by Laing and Fritsch (2000) has shown that MCCs are frequently occurring systems, but only in specific regions around the world. Furthermore, these authors note that the MCC-producing synoptic and mesoscale environments around the world are all very similar. Analogous to earlier studies of MCCs within the United States (e.g., Maddox 1983, Cotton et al. 1989, Augustine and Howard 1991), their results indicate that the large-scale environments of the systems, on a global scale, are typically associated with considerable horizontal temperature, moisture and stability gradients, along with considerable variations in both horizontal and vertical wind shear. Therefore, the large-scale environment may be crucial for the development of the long-lived convective systems, such as MCCs.

To date, no extensive work has been conducted on the environments that favour southern African MCCs. From the preceding chapter, it is evident that MCC frequency over southern Africa varies considerably on monthly and seasonal timescales. Furthermore, the spatial distribution of these systems suggests that changes in atmospheric conditions may be responsible for the seasonal migration patterns. As alluded to previously, due to the geographic location of southern Africa, it is likely that numerous features influence the development and evolution of MCCs in the region. For these reasons, this chapter's focus is placed on the large-scale environments within which these systems develop. The 
key objective of the chapter is to identify any common synoptic-scale patterns, on monthly and seasonal timescales, that may influence the formation and spatial distribution of MCCs over the region. Although the timescale of an individual MCC is considerably shorter than a month, the analysis may provide possible insight to conditions that favour or inhibit MCC development during a particular summer month or period.

In addition, an analysis is performed on the potential influence of El Niño-Southern Oscillation (ENSO) and local sea surface temperatures (SSTs) on MCC frequency over the region. Considering that ENSO is primarily a tropical Indo-Pacific phenomenon, the influence it has on southern Africa is perceived to be through modulation of the local Walker Circulation and SSTs in the neighbouring Indian and Atlantic Oceans (e.g., Lindesay 1988; Rocha and Simmonds 1997; Reason et al. 2000; Tyson and PrestonWhyte 2000; Cook 2001; Fauchereau et al. 2009). However, the study here is limited by the number of summer seasons containing MCCs and ENSO events during this period. Therefore, it must be emphasised that this analysis regarding the influence of ENSO should be regarded as preliminary.

Finally, due to the relatively coarse resolution of the reanalysis data, which is discussed in detail in the subsequent section, three case studies are presented in the final chapter using a much high resolution reanalysis dataset. These two chapters have been kept separate to limit the amount of content in each chapter, which hopefully allows for ease of reading. Essentially, these two chapters in conjunction are used to highlight the varying conditions under which these systems develop in southern Africa.

\subsection{Data and Methods}

In the early 1990s, the National Centers for Environmental Prediction-National Center for Atmospheric Research (NCEP-NCAR) reanalysis (Kalnay et al. 1996) was developed (NCEP R1). This global data, which contains a horizontal resolution of $2.5^{\circ}$ and temporal resolution of six hours, is available at all standard pressure levels from 1000 to $10 \mathrm{hPa}$ for the period 1948 until present. Although there has been extensive use of this dataset, there 
has been concern for possible errors found in the data in the Southern Hemisphere prior to 1979 (Kalnay et al. 1996; Kanamitsu et al. 2002; Tennant 2004). Biases within the data are not restricted to the Southern Hemisphere, with errors in some parameters, such as tropical divergent circulations and rainfall, also being identified (e.g., Poccard et al. 2000; Kinter et al. 2004). Other concerns regarding the NCEP-NCAR data relate to the poor representation of some variables around steep topography (Trenberth and Guillemot 1995).

In order to address some of these problems, the NCEP-Department of Energy (DOE) Second Atmospheric Model Intercomparison Project (AMIP-II) reanalysis for the period 1979 to present was developed (Kanamitsu et al. 2002). This new dataset (NCEP R2), which contains the same horizontal and temporal resolution as NCEP R1, but only covers the satellite era, uses an improved data assimilation system and forecast model that featured upgraded physics and soil moisture forcing. It must be kept in mind that the Southern Hemisphere is dominated by oceans, which makes validating the reanalysis data over this region difficult. The introduction of satellites the late 1970's have provided another means to not only validate the data, but also provide more observations in the data assimilation. The result is a potentially more accurate representation of the global atmosphere conditions.

In this study, the NCEP R2 data are used to portray the atmosphere conditions on monthly and seasonal timescales during which MCCs develop. By doing so, common features that result in favourable conditions for MCC development may be identified. However, it must be recognised that the results and conclusions based on the NCEPNCAR data must be treated with caution due to the coarse resolution of the data and the limited observations over the Southern Hemisphere. The data are also used to identify possible causes to the increase or decease in the number of systems during the different years (e.g., 1999/2000 or 2003/2004). Variables that are incorporated in the study include air temperature, $\mathrm{u}$ and $\mathrm{v}$ winds, mean sea level pressure, geopotential height and vertical velocities (omega). Horizontal moisture fluxes and moisture divergence were also computed from the NCEP R2 data. Specific humidity, used to calculate the moisture flux, 
is determined using temperature and relative humidity data by means of the Goff-Gratch (1946) equation, which derives saturated vapour pressure. Anomaly plots were created using a 31-year (1979-2010) monthly climatology from the NCEP R2 data. Other variables, such as outgoing longwave radiation (OLR) (Liebmann and Smith 1996) and Optimally Interpolate Sea Surface Temperature V2 (OISST) (Reynolds et al. 2002) are used to assist in understanding seasonal synoptic changes that may influence MCC development.

Atmospheric static stability is often evaluated by means of numerous indices, which have been developed in an attempt to better understand the potential for the development of rain-producing systems. Not only do these indices assist in determining where conditions are favourable for thunderstorm development, but can also aid in distinguishing severe versus non-severe thunderstorm environments (e.g., Brooks et al. 2003). Some of the common indices used include, the $K$-Index (KI), Severe Weather Threat Index (SWEAT) and Convective Available Potential Energy (CAPE). The computation of these indices can be found in Appendix B. However, due to the lack of quality controlled and lack of sufficient upper air soundings over southern Africa, the reanalysis data are used to evaluate the mean monthly stability of environments which favour MCC development.

\subsection{Large-scale Environments}

\subsubsection{Monthly Analysis}

To recap the findings of Chapter Four, MCCs over southern Africa are predominantly found to occur during the austral summer months. The peak in frequency is found to take place during the months of November and December, followed closely by February. January contains slightly fewer systems than that documented in the other summer months. The transitional months of October and March contain considerably fewer systems, with none being identified in October. Although no MCCs were found during October, systems that reached the size and shape criteria, but fell just short of the duration threshold were identified during this month. As alluded to previously, this finding 
suggests that there are certain synoptic settings and mesoscale processes that favour the development of such systems in the region.

\subsubsection{Moisture Transport}

A notable feature found in MCC environments worldwide is the availability of abundant moisture in the atmosphere. Systems in the U.S. generally thrive on moisture transported from the warm waters of the Gulf of Mexico via a nocturnal low level jet, while midlatitude South American systems feed off moisture from the tropical rainforest regions of the Amazon and Parana River basins (Maddox 1983; Velasco and Fritsch 1987; Vera et al. 2005). Over southern Africa, moisture is typically advected in from the neighbouring tropical South Indian Ocean, tropical southeast Atlantic Ocean (D'Abreton and Lindesay 1995; Cook et al. 2004) and tropical Africa (D’Abreton and Lindesay 1993; Cook et al. 2004; Jury 2010). In the preceding chapter it was found that the Americas experienced nearly three times as many MCCs per warm season than that of southern Africa. This difference could be related to the availability of moisture, with a larger quantity being available to systems in the Americas than that found southern Africa.

Figures 5.1 and 5.2 illustrate the mean monthly $850 \mathrm{hPa}$ moisture flux over southern Africa and South America, respectively. The $850 \mathrm{hPa}$ level is used to minimize the influence of surface topography on results. The red box in the figures denotes the location of the major MCC activity for the two subtropical regions. It is evident that during the early summer months the major moisture transport is from the tropical ocean, positioned to the east of the continent, into the equatorial region and then transported polewards. However, the transport over Africa is not as apparent as that found in South America. This difference is likely due to the strength and persistence of the South America Low Level Jet (SALLJ) that runs parallel to the Andes Mountains (Vera et al. 2005). The Andes are not only much farther inland from the moisture source than the South African eastern escarpment, but are also much higher. Results by Insel et al. (2010) suggest that Andes have a considerable influence of moisture transport into the region, by channelling the SALLJ as well as blocking cold and dry westerly flow from the Pacific Ocean. Not 
only is more moisture transported polewards over South America, but the atmosphere above equatorial Africa has been found to relatively dry compared to other tropical regions, including South America (McCollum et al. 2000). This result is supported by Fig. 5.3 and Fig. 5.4, which show equatorial Africa containing less precipitable water (30-40 $\left.\mathrm{kg} \mathrm{m}^{-2}\right)$ than its South American counterpart (45-50 $\mathrm{kg} \mathrm{m}^{-2}$ ) during the summer months.

In contrast, eastern/southeastern Australia experiences fewer systems than both midlatitude South America and southern Africa (e.g., Perrin and Reason 1997). Even though the region to the north of Australia contains a higher moisture content $(45-50 \mathrm{~kg}$ $\mathrm{m}^{-2}$ ) than that found in tropical Africa (Fig. 5.5), no persistent mechanism to advect the moisture polewards is apparent (Fig. 5.6). However, heavy rainfall events over southeastern Australia have often been found to be associated with moisture transported from the tropics (McIntosh et al. 2007). This poleward transport is due to the eastward propagation of extra-tropical cyclones to the south of the continent or cut-off lows, positioned over the southeast, drawing moisture from the tropics. It is also possible that during an active Australian monsoon season, additional moisture may be transported farther polewards over mainland Australia via stronger low level northwesterlies (Tapper and Hurry 1993). Another factor that has to be taken into consideration is the topography of southeast Australia, which is both lower in altitude and narrower in width than the eastern escarpment of South Africa. The weaker influence of smaller topography on the development and propagation of long-lived convective systems, compared to more pronounced mountain ranges, has previously been recognized in Australia (e.g., Keenan and Carbone 2008). Figure 5.6 also indicates that one of the major moisture sources for eastern Australia appears to be the neighbouring ocean, which includes the Tasman and Coral Seas. Relatively considerable moisture transport, associated with the southeast trade winds blowing over these waters into eastern Australia, begins around January and continues through the rest of the late summer months. The start of this westward moisture flux into the region coincides with a maximum in circular MCS activity over southeast Australia (see red box in Fig. 5.5) during the month of January (Perrin and Reason 1997). 
In an investigation of potential sources for South African summer rainfall D'Abreton and Tyson $(1995,1996)$ suggested that moisture transport in the early summer months is influenced more by midlatitude circulation, while the later summer months are dominated by tropical circulation. Changes in synoptic weather patterns are seen to be the driver behind this seasonal moisture transport pattern. During late summer (JFM), the ITCZ is usually positioned farther south (i.e., over Mozambique and northern Zimbabwe) and the South Indian anticyclone moves southeastwards (Tyson and Preston-Whyte 2000). A similar finding is shown in Fig. 5.1, which depicts the strengthening of tropical features during the later summer months. The cyclonic flow in the Mozambique Channel is thought to originate from easterly flow south of the ITCZ adjusting to the local topography and forming a pronounced trough in the southern Mozambique Channel (Cook et al. 2004). This results in a distinct increase in moisture transport from the southwest Indian Ocean into southern Africa (Fig. 5.1) and potentially results in more moisture being available along the east coast of the domain, as evident in Fig. 5.3. In addition, the cyclonic flow around Angola Low intensifies during the late summer months, resulting in the increase in moisture flux from the tropical Atlantic. This intensification could lead to more moisture being transported farther south over the continent through the development of tropical-extratropical interactions and associated cloudbands.

Cross-sections depicting monthly zonal moisture flux along $25^{\circ} \mathrm{E}, 30^{\circ} \mathrm{E}$ and $35^{\circ} \mathrm{E}$ confirm the increased onshore transport of moisture along the northeast coastline during the later summer months (Fig. 5.7, Fig. A5.1 ${ }^{\ddagger}$ and Fig. A5.2, respectively). In addition, they reveal the presence of a low level jet (LLJ) positioned over Zimbabwe/Botswana around $20^{\circ} \mathrm{S}$ between $900-800 \mathrm{hPa}$ (Fig. 5.7). Common LLJ activity during the summer has been identified in this region and has previously been linked to extreme precipitation events (Rife et al. 2010; Monaghan et al. 2010). The core of the jet appears to be well defined during the later summer months, particularly during February (Fig. 5.7e), which coincides with maximum frequency of MCCs over this region.

\footnotetext{
\$ "A" denotes figure can be found in Appendix C
} 
Figure 5.8 shows the $850 \mathrm{hPa}$ moisture convergence pattern over southern Africa during the different summer months. The early summer months are characterised by moisture divergence taking place over northeast South Africa, Mozambique and eastern Zimbabwe, while a northwest-southeast orientated band of convergence is located from southern Angola running diagonally across central South Africa. It is evident that this convergence pattern is made up of three predominant convergence centres. The most northern one is located to the east of the Congo Basin (around $30^{\circ} \mathrm{E}$ ), another over southern Angola, representing the previously discussed Angola Low, and the most southern centre to the south of Botswana corresponding with a sub-tropical heat low (Tyson and Preston-Whyte 2000). These convergence/divergence patterns are fairly consistent throughout the summer months, but have considerably weakened by March.

\subsubsection{Thermodynamic and Kinematic Aspects}

At the surface, a strong northwest-southeast temperature gradient is located over the east coast during the early summer months (Fig. 5.9). During the latter summer months, this gradient considerably weakens, particularly over the Mozambique coastal region. Pronounced temperature gradients have been identified in the genesis regions of MCCs (Maddox 1983; Cotton et al. 1989; Laing and Fritsch 2000). Along the east coast, weak onshore winds are present during the early summer months, which strengthen during the late summer months as the South Indian anticyclone moves farther southeast and the ITCZ moves polewards. As alluded to previously, this circulation pattern plays a key role in the transport of moisture into the region. At the $850 \mathrm{hPa}$ level, a tongue of moist air containing a relatively high mixing ratio $\left(\geq 10 \mathrm{~g} \cdot \mathrm{kg}^{-1}\right)$ extends from Zimbabwe polewards along the eastern interior, essentially positioned along the eastern escarpment, during the core summer months (Fig. 5.10). The position of this tongue coincides with the general location of MCCs.

Apart from playing a major role in moisture advection, regional circulations patterns, including winds, divergence and vertical motions, arguably provide a mean basic state that may favour or inhibit the development of widespread convection. Another factor is 
the atmospheric stability, discussed in the next sub-section. Given favourable conditions in the lower levels, the intensification and deepening of convection may be enhanced through mid-level convergence and upper level divergence. At mid-levels, strong divergence is evident extending across the land from northern Namibia to southeast South Africa throughout the summer months (Fig. A5.3). Over eastern southern Africa, weak mid-level convergence is replaced by weak divergence during the late summer months. MCCs tend to occur along the boundaries of mid-level zones of weak convergence / divergence.

In the upper levels (Fig. 5.11), a dipole type divergence pattern exists during the early summer months, with divergence occurring over the western region of southern Africa and convergence over the eastern region. Most notably, strong upper level convergence occurs over eastern South Africa, Zimbabwe and Mozambique during October. By November, upper level convergence remains over most of Zimbabwe and Mozambique, while the eastern regions of South Africa are replaced with weaker convergence or weak divergence. As the ICTZ moves polewards during the later summer months, upper level divergence exists over the entire northern region of the domain, while convergence is now predominantly restricted to the southeast of the region. Again, MCC locations coincide between zones of upper level convergence and divergence.

A very similar spatial pattern to the $200 \mathrm{hPa}$ divergence is found in the mean monthly $500 \mathrm{hPa}$ omega (Fig. 5.12). During the early summer months, relative subsidence is found over most of the eastern region of the domain, while strong uplift is present in a band running from northern Namibia to southeast South Africa. Strong uplift is found to dominate the northern regions of the domain during December through to February as the ITCZ moves polewards. At the same stage, the upward motion over central South Africa weakens, while a core of subsiding motion persists over the ocean to the east of South Africa. Similar to the divergence patterns, MCC development appears to occur on the boundary between zones of upward and downward vertical motions. 
Low level vertical shear has often been viewed as an indicator to the possible development of certain types of convective storms or the potential development of severe weather phenomenon (Wiseman and Klemp 1982, 1986). In terms of MCC development, systems in the U.S. typically develop slightly upshear from a zone of maximum shear (1000-700 hPa layer) and then move towards the higher shear, whereas systems in South America tend to develop further upshear from the maximum shear (Laing and Fritsch 2000). However, severe weather produced by MCCs, such as damaging wind and heavy rainfall, is known to be produced under different vertical wind shear strengths (Maddox et al. 1986). Figure 5.13 indicates that systems over southern Africa possibly develop under varying shear strengths in the 1000-700 hPa layer. Systems along the east coast of South Africa potentially develop in a stronger shear environment $\left(6-8 \mathrm{~m} . \mathrm{s}^{-1}\right)$ compared to those developing farther north over Mozambique (2-4 m.s ${ }^{-1}$ ). Additionally, systems along the South African coastline develop slightly equatorward of the zone of maximum shear. However, these values are monthly means and a clearer indication of the shear environments under which MCC develop may be obtained in the case studies.

\subsubsection{Atmospheric Stability Indices}

Thunderstorm or convective activity has often been related to the potential instability of the atmosphere. An air parcel is considered to be potentially unstable if the mid-levels of the atmosphere are fairly dry, while near saturated conditions are found in the low levels (Tyson and Preston-Whyte 2000). Therefore, factors that may contribute to high levels of potential instability include warm air advection and moisture accumulation in the low levels, with drier, cooler air above. Additionally, a lifting mechanism, such as orography or low level convergence, is also required as part of the process to assist in lifting the moisture laden air from the low levels. Strong solar heating of the earth's surface also plays a key role. The mean monthly spatial distribution of potential instability over the region is evaluated by subtracting the equivalent potential temperature at $500 \mathrm{hPa}$ from the equivalent potential temperature at $925 \mathrm{hPa}$ and then dividing it by the difference in height between the two levels (van Delden 2001). The degree of potential instability over southern Africa appears to be related to changes in the seasonal insolation cycle (A5.4). 
The atmosphere over the eastern coastline and neighbouring ocean is mostly stable during October. By November, the stability of the region starts declining, with potentially unstable conditions starting to dominate. The main summer months of December through to February all contain similar spatial patterns and values of potential instability. Most notably, during this period the entire eastern region of the domain contains potential unstable conditions, with greatest potential instability occurring during January. The region starts to become more stable by March, evident by the decrease in potential instability.

Maximum mean monthly CAPE values are found along the eastern border of the domain over the Mozambique Channel and extending down over the Agulhas Current (Fig. 5.14). During the month of October, the mean CAPE rarely exceeds $100 \mathrm{~J} \mathrm{Kg}^{-1}$ over land, with the highest values located along the north eastern coastline. By the core summer months (DJF), the mean CAPE has risen to approximately $500 \mathrm{~J} \mathrm{Kg}^{-1}$ along the coastal regions between KwaZulu-Natal and central Mozambique, while over northern Mozambique values are almost double that with a mean CAPE near $1000 \mathrm{~J} \mathrm{Kg}^{-1}$. Higher values are still located over the adjacent ocean, with maximum CAPE located off the coast of northern Mozambique. By March, the mean CAPE starts decreasing over most of the land, but still remains relatively high over the adjacent ocean.

Laing and Fritsch (2000) found that MCCs around the world generally develop in environments that contain a CAPE value in excess of $1500 \mathrm{~J} \mathrm{Kg}^{-1}$ near the genesis region, with an average of $1820 \mathrm{~J} \mathrm{Kg}^{-1}$. If one looks at the mean number of days per month which exceed $1500 \mathrm{~J}_{\mathrm{Kg}}{ }^{-1}$ over southern Africa, it is evident that apart from northern Mozambique, "favourable" MCC days do not exceed 6 per month during the core summer months (Fig. 5.15). However, as illustrated in Chapter Four, most systems initiate over land and then track towards the ocean, which in this case is where the highest number of days ( $>15$ days per month) containing a CAPE value exceeding $1500 \mathrm{~J} . \mathrm{Kg}^{-1}$. The fewest favourable days per month are found during October, which is when no MCCs are identified. 
If the CAPE value is decreased to days exceeding $1000{\mathrm{~J} . \mathrm{Kg}^{-1}}$ per month (Fig. A5.5), a very similar spatial pattern is found as in Fig. 5.15, but the number of favourable days during November through to February are almost double along the eastern coastline. October still contains the fewest number of days, with a mean of 1 day per month satisfying this CAPE threshold over land. It is interesting to note that March contains a very similar CAPE spatial pattern to February and contains only slightly less favourable MCC days, but has much fewer systems. This result arguably suggests that a combination of favourable parameters are required for MCC development.

Another parameter used to assess the convective potential of a region is the $K$-Index (KI) (George 1960). This particular stability index is useful as an indicator for heavy rainfall and possibly flash flooding. In general, the higher the ambient or KI inflow value, the greater the potential for heavy rain. MCCs in the U.S. and South America are found to originate and feed on air emanating in regions containing the highest KI values (Laing and Fritsch 2000). Steep zonal gradients in KI values are evident throughout the summer months over South Africa, with a peak in KI being located over the eastern escarpment and the adjacent interior and lowest values occurring farther offshore (Fig 5.16). It appears that KI values (28-32) are similar along the entire eastern coastline of southern Africa, with the highest values (32-34) occurring during the core summer months (December-February). Thus, MCCs over southern Africa tend to initiate and evolve in regions of relatively high KI values ( $\geq 30$; Fig 5.16). However, unlike the Americas, the low level wind (Fig. 5.1) flowing into the MCC region possibly does not always feed in air from highest KI areas. This situation would particularly be the case for systems developing along the South African east coast, where the onshore flow traverses areas with KI values of 22-24 located farther offshore. The major monthly changes in KI tend to occur over the neighbouring ocean, with higher KI values occurring farther polewards during the later some months compared to the early summer months. 


\subsubsection{The Influence of ENSO, SSTs and Atmospheric Circulation}

\subsubsection{Uncharacteristic MCC Seasons}

Over the eight warm seasons, two summers stood out from the rest by containing considerably more/fewer systems than that usually found over the region. The warm season of 1999/2000 contained almost double the amount of systems, while during 2002/2003 the fewest number of systems were identified. Coincidently, the season containing more than average systems took place under La Niña conditions in the Pacific Ocean, while the season with fewest systems occurred during El Niño conditions. However, to suggest any correlation here between MCC frequency and ENSO would be premature due to the limited sampling period. It is of interest to contrast this very active 1999/2000 season (La Niña) with the inactive 2002/2003 season (El Niño). Although they are of opposing ENSO polarity, one cannot assume they are representative of ENSO in general. Nevertheless, it does provide some insight to factors that may influence weather patterns in the region and hence, MCC development.

As alluded to at the beginning of the chapter, even though ENSO is primarily a tropical Indo-Pacific phenomenon, it is thought to influence southern Africa weather patterns through modulation of the local Walker Circulation and SSTs in the neighbouring Indian and Atlantic Oceans (e.g., Lindesay 1988; Rocha and Simmonds 1997; Reason et al. 2000; Tyson and Preston-Whyte 2000; Cook 2001; Fauchereau et al. 2009). Of particular interest is the displacement of the South Indian convergence zone (SICZ) under ENSO conditions. The SICZ could be viewed as the aggregated expression of cloud bands evolving from tropical-extratropical interactions, regionally known as tropical temperate troughs (TTTs). TTTs have previously been recognised as the main synoptic rainfall producing systems over southern Africa (Harrison 1984; Todd and Washington 1999). During La Niña years, the SICZ tends to be located over the continent and as a result, wet conditions take place (Fauchereau et al. 2009). Conversely, during El Niño, the SICZ shifts northeastwards and is now positioned over the Indian Ocean, resulting in dry conditions prevailing over southern Africa (Cook 2001). Effectively, during El Niño, unfavourable precipitation conditions occur over the continent through a reduction in 
moisture convergence, uplift and instability. The importance of this situation is based on the notion that several major MCC locations (Laing and Fritsch 1997) often coincide with the three Southern Hemisphere convergence zones, the other two being the South Pacific convergence zone and South Atlantic convergence zone (SPCZ and SACZ, respectively). This result suggests that processes favouring TTT development over southern Africa may also facilitate MCC production or that MCCs may be embedded within the cloudbands.

\subsubsection{Anomalous SST patterns}

Warm (cold) SST anomalies in the southwest Indian Ocean (SWIO) have often been linked to southern Africa experiencing above (below) average summer rainfall (e.g., Walker and Lindsay 1989; Jury 1992; Reason and Mulenga 1999; Behera and Yamagata, 2001; Reason 2001, Reason 2002; Washington and Preston 2006). The subtropical Indian Ocean dipole (SIOD; Behera and Yamagata 2001; Reason 2001a) is one such SST pattern, with a positive (negative) phase in the SIOD being characterized by warm (cool) SST anomalies in the southwest Indian Ocean, cool (warm) SSTs in the southeast and above (below) average rainfall over parts of southern Africa. There is some suggestion that years of low MCC frequency (e.g., 2001/2002, 2002/2003) coincide with a negative SIOD, while some years of relatively high frequency (e.g., 2003/2004, 2005/2006) coincide with a positive phase (not shown). However, due to the small sample size, this possible relationship between the SIOD and MCC frequency cannot be confirmed.

During 1999/2000, under La Niña conditions, a 'dipole' type SST pattern is found in the SWIO, with a warm SST anomaly in the southwest and a cooler SST anomaly to northeast of it (Fig 5.17a). In contrast to the SIOD, the dipole here is confined to the SWIO, whereas the SIOD extends over most of the subtropical Indian Ocean (Behera and Yamagata 2001; Reason 2001). In addition, the waters offshore from the west coast of Australia are the same anomalous sign to that found poleward of Madagascar. Similar meridional dipole structures, with warming (cooling) in the southwest (northeast) SWIO, have also been found to correspond with favourable rainfall conditions over southern Africa (e.g., Fauchereau et al. 2003; Washington and Preston 2006; Manhique et al. 
2011). However, the cores of the warm and cold anomaly here are located slightly farther poleward in comparison to these meridional dipole patterns. The position of the warm anomaly found here, being centred closer to southern Africa, may still have an impact of regional circulation patterns (Reason 2002) and rainfall (e.g., Walker 1990; Mason 1995). The SST pattern may also coincide with main location of TTTs being predominantly positioned over southern Africa, as documented by Manhique et al. (2011). There is some evidence to support a possible increase in TTT frequency over land during 1999/2000 (Fig. 5.18a), but in essence there is a general increase in cloudiness (negative OLR anomaly) over most of the land and there is no consistent cloudband type pattern.

Interestingly, a warm SST anomaly is also located in the tropical southeast Atlantic Ocean, along the Namibian and Angola coastline during the 1999/2000 period (Fig 5.17a). As already indicated, this region has been found to be a possible moisture source for the region (e.g., Rouault et al. 2003b; Reason et al. 2006; Vigaud et al. 2009) and also be influential on heavy rainfall events along the west coast (Muller et al. 2008; Jury 2010). Given favourable conditions in the large-scale circulation, this warm anomaly could also be associated with rainfall farther inland (e.g., Rouault et al. 2003b). Considering the close proximity of these warm SST anomalies to the Angola low, it is possible that additional moisture is advected into the region and transported polewards, favouring the development of convective systems along the southeastern region of southern Africa.

During 2002/2003, the summer of few MCCs, anomalously warm SSTs are present over much of the tropical Indian Ocean and extend into the subtropics (Fig. 5.17b). At the same time, cooler SSTs are found in most of the midlatitude regions. This SST pattern has been previously been associated with dry conditions over southern Africa (e.g., Jury et al. 1996; Reason 2001a, 2002). Furthermore, Manhique et al. (2011) have found that such a SST pattern coincides with the main TTT location being position offshore instead of over the land. Figure 5.18b supports this argument, with negative OLR anomalies (i.e., increase in cloudiness) extended from northern Madagascar southeastwards into the South Indian Ocean. Unsurprisingly, this pattern is reminiscent of El Niño associated 
anomalies in which warm SST anomalies are present over large parts of the tropical and subtropical Indian Ocean (Mo 2000; Reason et al. 2000).

\subsubsection{Circulation Changes associated with SST Anomalies}

The relationship between anomalous SSTs in the neighbouring oceans and the atmospheric circulation is seen as possibly one of the main drivers behind variability in rainfall patterns over southern Africa. However, it is not obvious if the SST anomalies found here in the Indian Ocean act independently from ENSO or if it is a combination of the two that influence regional circulation patterns. Some research suggests that conditions over southern Africa are primarily influenced by SST in the neighbouring Oceans and that through ENSO forcing, anomalies in these oceans impact southern Africa (e.g., Mason 1995; Nicholson and Kim 1997; Goddard and Graham 1999). Results by Cook (2001), using idealized GCM simulations, imply that the basic forcing of precipitation over southern Africa during ENSO events may come through the atmosphere alone and not from SST anomalies in the neighbouring oceans. Changes in atmospheric convection over the Pacific Ocean is thought to alter atmospheric circulation remotely in both the tropics and extra-tropics via atmospheric planetary wave adjustments often referred to as an "atmospheric bridge" (Liu and Alexander 2007). However, some SST anomaly configurations in the SWIO have been found to be independent of ENSO and have played a key role in generating above average rainfall over southern Africa (e.g., Reason 1999; Washington and Preston 2006).

Cold SST anomalies in the Indian Ocean have at times been considered to be produced by strong wind anomalies over the ocean, resulting in an increase in the latent heat flux (Reason 2002; Fauchereau et al. 2003; Hermes and Reason 2005; Manhique et al 2011). Similarly, the cold SST anomaly in the northeast section of SWIO during 1999/2000 occurs beneath strong south-easterly wind anomalies and coincides with a region of increased latent heat flux (Fig. 5.19). Conversely, positive latent heat flux anomalies are also found in regions to the south and west of southern Africa and off the west coast of Australia, all of which contained warm SST anomalies. Thus, these results suggest that 
other mechanisms are responsible for the warm SST anomalies in these regions during this period. Strong positive anomalies of latent heat fluxes are also present over most of southern Africa, which could be linked to the additional moisture found in the region.

A common feature associated with the negative SST anomaly in the northeast SWIO is the development of anomalous anticyclonic circulation above the SST anomaly (e.g., Washington and Preston 2006). This circulation has been shown to result in an increase in low level easterly moisture being advected into eastern southern Africa, between $10^{\circ}$ $20^{\circ} \mathrm{S}$, leading to atmospheric conditions that favour an increase in regional rainfall (e.g., Todd and Washington 1999; Washington and Preston 2006; Manhique et al. 2011). Using an atmospheric general circulation model and forced SST anomalies in the SWIO, Reason (2002) illustrated that a low (high) pressure anomaly that decays with height was generated near the warm (cold) SST anomaly, which is consistent with quasi-geostrophic theory (e.g., Gill 1982). In agreement with this, during 1999/2000 a greater inflow of low level moisture took place polewards of $20^{\circ} \mathrm{S}$ (Fig. 5.20a). This inflow pattern observed here is likely associated with the anomalous anticyclonic circulation present over the negative SST anomaly in the SWIO (Fig. A5.6a). It should be kept in mind that the negative SST anomaly in this case was located farther poleward compared to that found in Washington and Preston (2006) or Manhique et al. (2011).

The anticyclonic circulation is a result of the positive anomaly in the mean sea level pressure (Fig. A5.7) and $500 \mathrm{hPa}$ geopotential height (Fig. 5.21a) over the South Indian Ocean during this period. Figure 5.21a indicates that during this period a wavenumber 3 or 4 pattern, with positive anomalies in geopotential height over the three ocean basins, was present. A similar wave configuration has been identified during conditions when TTTs were more likely to be position over land instead of over the neighbouring ocean (Manhique et al. 2011).

Another key feature here is the enhanced moisture flux from the tropical Atlantic and tropical Africa region (Fig. 5.20a). This suggests a deepening of the Angola low, which is also evident in $700 \mathrm{hPa}$ winds (Fig. 5.22a) and $500 \mathrm{hPa}$ geopotential height (Fig. 
5.21a). A stronger Angola low has previously been associated with La Niña conditions and an increase in rainfall in the region (e.g., Reason and Jagadheesha 2005; Manhique et al. 2011). Essentially, these changes resulted in additional moisture being available over southern Africa, which was evident by a positive anomaly in precipitable water over the region (Fig. A5.8a). Enhanced low level moisture convergence (Fig. 5.20a) and upper level divergence (Fig. 5.23a) was present over the Angola region, as well as the northern domain of southern Africa, consistent with a stronger Angola low. Over the east coast of South Africa, reduced moisture convergence at low levels is evident, with enhanced divergence at upper levels. Further evidence for favourable conditions for convective development is provided by negative anomalies in omega (i.e., enhanced upward motion) being present over the eastern coastal regions and adjacent ocean at both the $700 \mathrm{hPa}$ (Fig. 5.22a) and $500 \mathrm{hPa}$ level (Fig. A5.9a). In combination, these factors lead to favourable conditions for deep convection to persist over east southern Africa during 1999/2000.

In contrast, the summer of 2002/2003 was dominated by unfavourable conditions for convective system and rainfall development over the eastern regions of southern Africa. The low level moisture transport during this period is characterised by reduced onshore (i.e., easterly flux) flow into the eastern regions of southern Africa (Fig. 5.20b). This pattern is consistent with a negative anomaly in surface precipitable water, indicating reduced moisture, over most of the eastern regions of southern Africa (Fig. A5.8b). The reduced easterly flux may have also resulted in a reduction in the moisture into the central regions, such as Botswana (Fig. A5.8b). Another noticeable difference is the lack of moisture from the tropical regions to the north of the domain. Anomalous anticyclonic (cyclonic) circulation over the northwest (northeast) coast and adjacent ocean appear to play a role in reducing the moisture from the tropics. In addition, positive values in mean sea level pressure south of the country (Fig. A5.7b) suggest that midlatitude low pressure systems, which are integral for the formation of TTTs and hence, the transport of moisture and energy polewards, were possibly weaker or located farther polewards. This situation implies that moisture transported from the Angola region across southern Africa towards the east coast was likely reduced. 
Although there is some evident to suggest possible enhanced moisture transport along the Mozambique coastline during the period (Fig. 5.20b), adverse conditions in the mid- to upper levels likely suppressed convection over land. In the mid-levels, positive anomalies in $500 \mathrm{hPa}$ geopotential height were located across the Indian Ocean and southern Africa during 2002/2003 (Fig. 5.21b). Such height anomalies during El Niño are consistent with earlier findings (e.g., Kiladis and Mo 1998; Reason et al. 2000) and are thought to reduce favourable conditions for convective system development, resulting in dry conditions over southern Africa (e.g., Mulenga et al. 2003). Similarly, weakened mid- and upperlevel divergence was present during this period (Fig. 5.23b). Furthermore, most of southern Africa was dominated by descending air (Fig. 5.22b). These patterns are consistent with the anticyclonic circulation over the region and reduced OLR (Fig. 5.18b). In combination, these conditions likely played a role in the reduced frequency of MCCs over southern Africa during this warm season.

However, during the same period, conditions over northern Madagascar and to the southeast, display a favourable environment for the development of cloudbands and rainfall. Enhanced low level moisture convergence and upper level divergence, coupled with strong upward vertical motion in the lower to mid-levels is apparent over this region. The cyclonic circulation over Madagascar also results in an increase moisture flux from the surrounding anomalously warmer ocean into the region. This pattern is consistent with the Walker Circulation and associated convection shifting farther eastward instead of being based over the land during El Niño, as previously indicated in the literature (e.g., Cook 2001; Manhique et al. 2011).

\subsection{Chapter Summary}

Over the years, advances in reanalysis datasets have resulted in more comprehensive studies of synoptic and mesoscale environments of weather phenomena around the world. Additionally, these reanalyses have provided a means to distinguish atmospheric or SST patterns that result in changes in the mean climate. In this chapter, focus was placed on 
the synoptic environments in which MCC develop over southern Africa through the use of NCEP reanalysis data. Particular attention was focused on monthly atmosphere changes that may result in seasonal shift in MCC distribution, where systems were found to occur more equatorward during the late summer months.

It appears that moisture advection into the region and potential moisture sources play a key role in the frequency of systems. The number of MCCs occurring over subtropical South America vastly exceeds that of southern Africa and southeast Australia. The reasons for this are not obvious, but results here show that southern Africa likely contains less ambient moisture than that of midlatitude South America during the summer months. This difference is primarily due to the continuous moisture being fed into midlatitude South America from a larger moisture source via the South American low level jet. Thus, once initiated in South America, there is sufficient moisture to sustain the system for long periods, increasing the chances of it evolving into an MCC. In contrast, the lack of moisture being fed into southeast Australia, in combination with a smaller topography, likely leads to less MCCs developing in the region.

The importance of moisture transport is also evident in the seasonal migration of systems over southern Africa. The equatorward migration of MCCs during the late summer months is possibly related to an increase of moisture being advected from the southwest Indian Ocean (SWIO) into the northeastern parts of the domain during this period. This migration is as a result of the ITCZ shifting polewards, resulting in an increase in easterly winds over the SWIO. Furthermore, an increase in the frequency of systems over Botswana during the late summer months is consistent with the development of a low level jet, flowing from Mozambique westwards.

The lack of MCCs during October could be attributed to the atmosphere being relatively drier and more stable compared to the other summer months. Most regional atmospheric changes favouring convective development, such as moisture availability and unstable atmosphere, first appear during November. These conditions persist and strengthen throughout the core summer months, before starting to weaken during March. However, 
these findings merely highlight conditions that likely favour convection and do not necessarily result in MCC development. Furthermore, it must be emphasised that the work here pertains to a very small sampling period and for this reason the results should be viewed with caution. Nevertheless, it does provide some idea of processes that take place over southern Africa that arguably favour the development of MCCs in the region.

Results here also reinforce the idea that ENSO can play a key role in southern Africa precipitation patterns. Analogous to previous studies, during El Niño years unfavourable conditions for deep convection take place over land, whereas as favourable conditions are found over the adjacent ocean to the east. Results show that during 2002/2003, a positive pressure anomaly over southern Africa played a key role in suppressing convection, while a weaker Angola low coincided with reduced poleward transport of moisture from the tropics. Instead, during this period the SICZ shifted eastward, with conditions favouring cloudband formation and rainfall now positioned over Madagascar and the SWIO. This shift in turn results in unfavourable conditions for MCC development over southern Africa and hence, fewer systems are found during El Niño. However, again it must be emphasised that due to the limited period of study here, this relationship between ENSO and MCCs cannot be confirmed.

Consistent with previous regional studies, favourable conditions for an increase in $\mathrm{MCC}$ frequency or enhanced convection in general can exist over southern Africa during La Niña periods. Prominent changes during this period include a stronger tropical low over Angola, enhanced easterly moisture flux over the SWIO and coupled low level convergence and upper level divergence. The enhanced moisture advection from the SWIO is consistent with regional modelling results by Hansingo and Reason (2006), which show that anomalous warm SSTs during the summer months over the SWIO were resulting in enhanced easterly moisture inflow over southern Africa. However, further analysis is required in order to establish whether SST anomalies in the SWIO are directly a result of ENSO or act independent of them

\section{$+\dagger+\dagger+\dagger+\dagger \dagger \dagger+\dagger$}



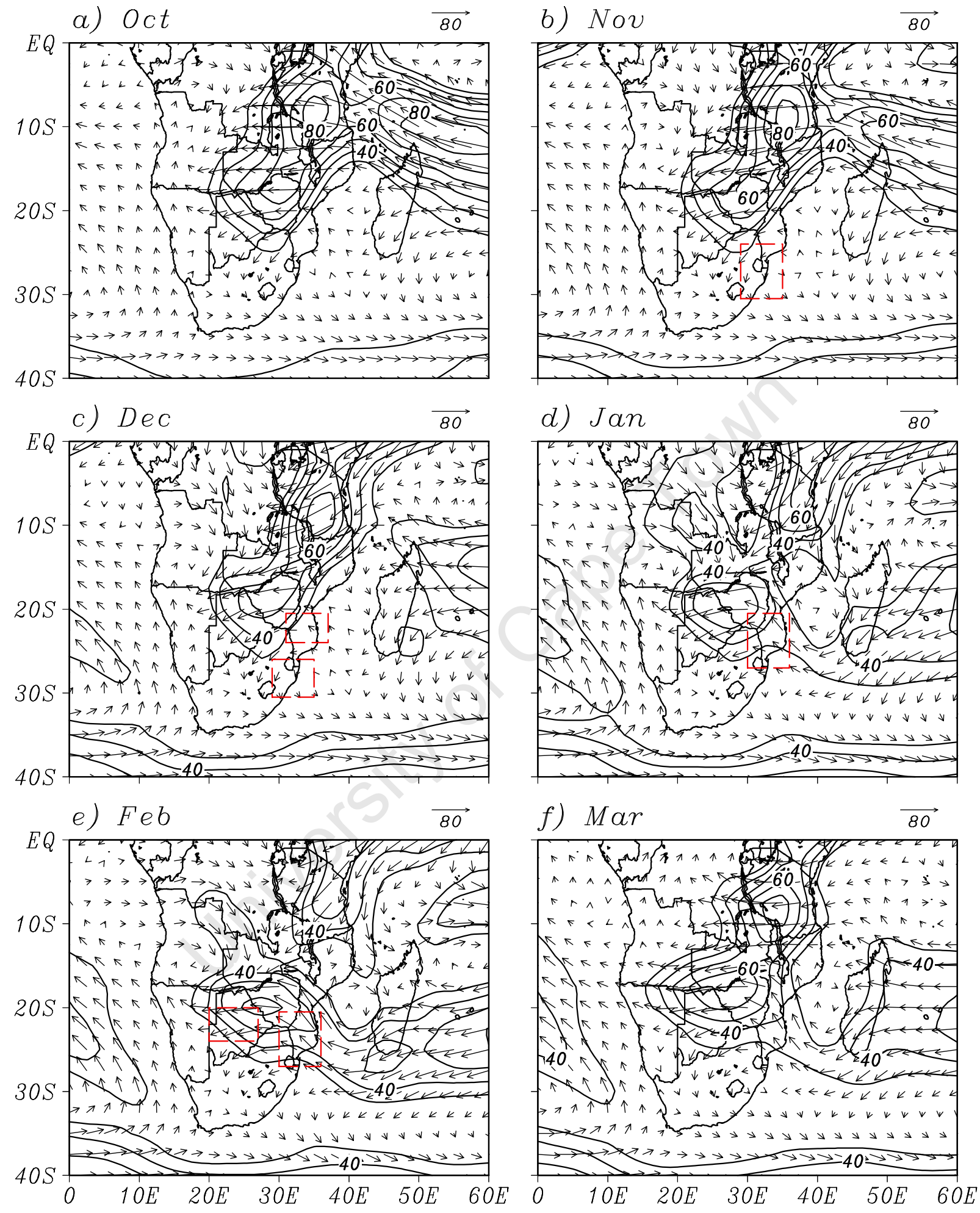

Figure 5.1: Monthly mean $850 \mathrm{mb}$ moisture flux $\left(\mathrm{g} \cdot \mathrm{kg}^{-1} \mathrm{~m} \cdot \mathrm{s}^{-1}\right)$ over Africa, south of the equator. Months are given at the top left corner of each panel and the red boxes in some of the panels depict the region where the most MCC activity took place for that month. 

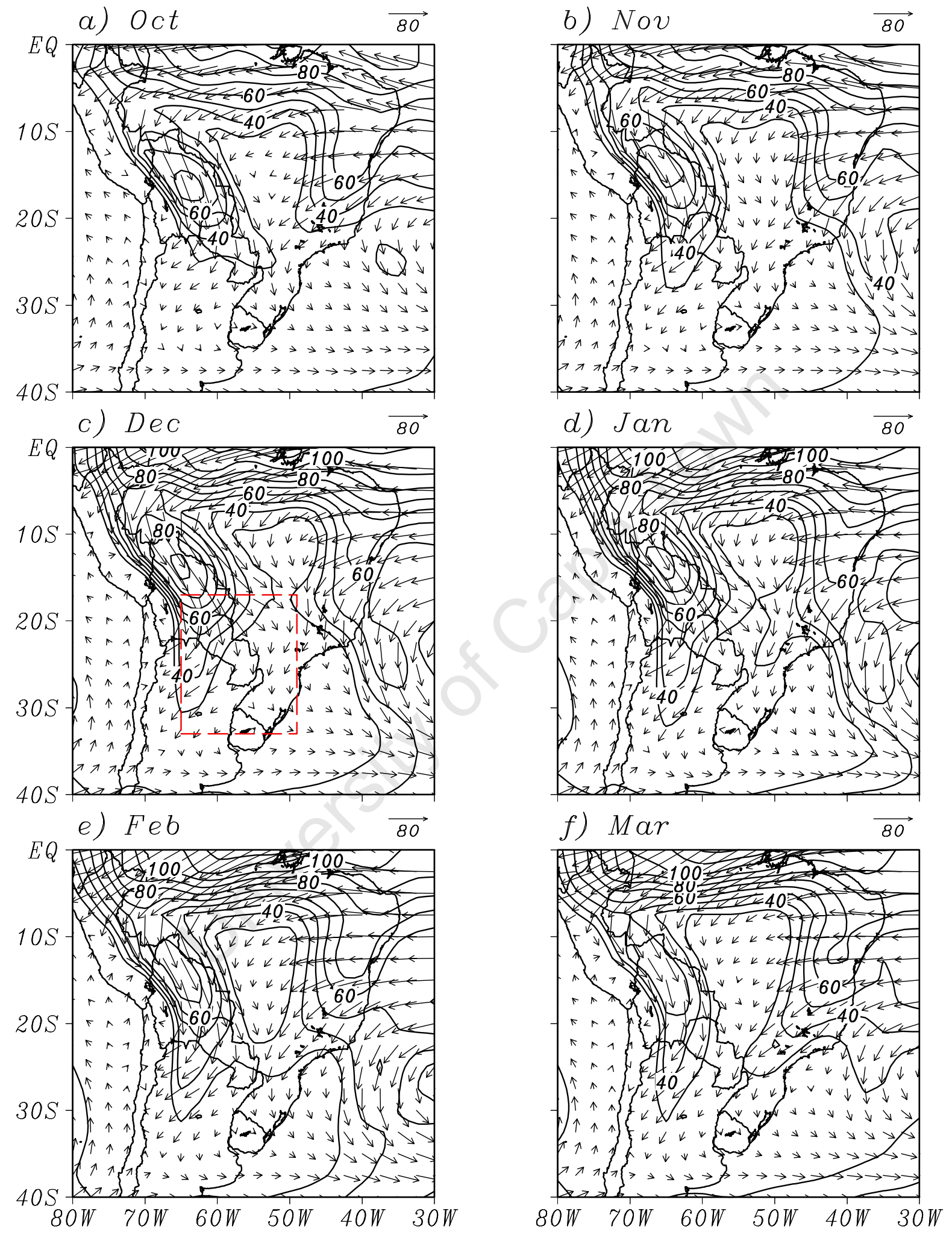

Figure 5.2: Same as Fig. 5.1, except for South America and only December has a red box depicting the main region of MCC activity (determined from Durkee and Mote 2009). 
a) Oct

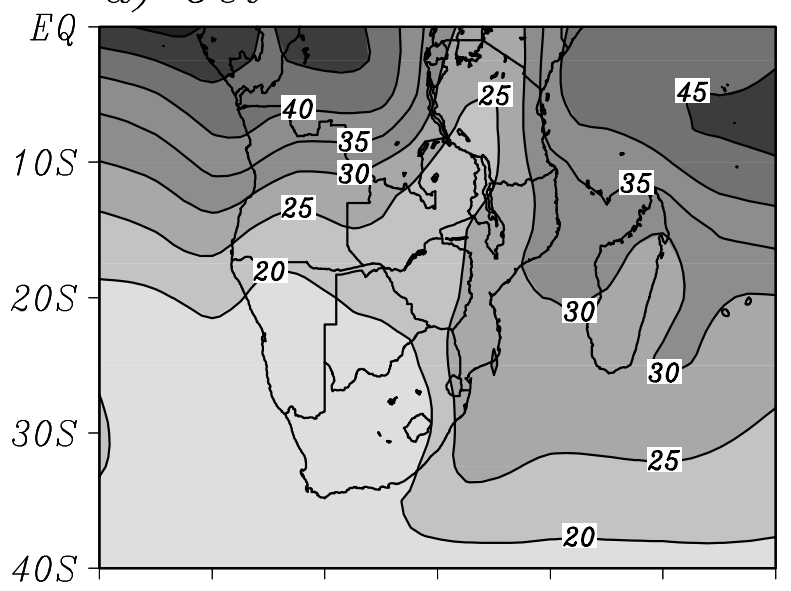

c) $\mathrm{Dec}$

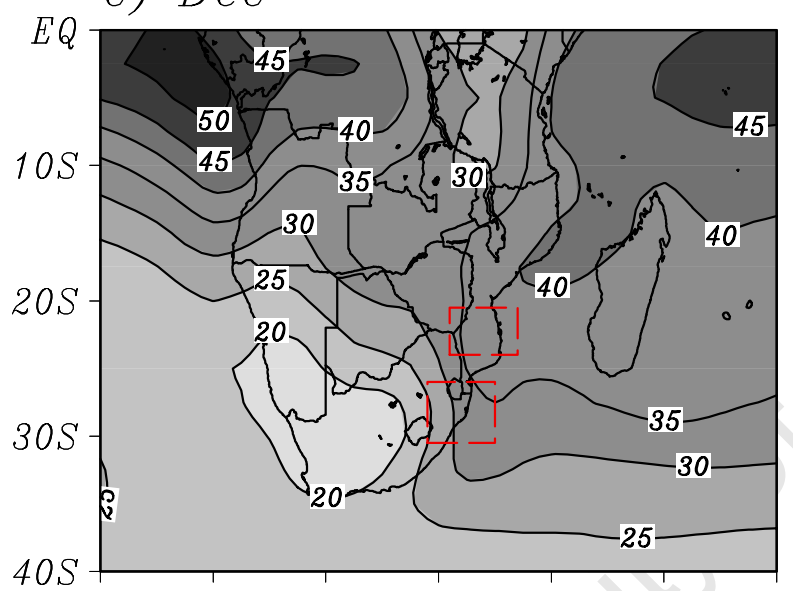

e) $\mathrm{Feb}$

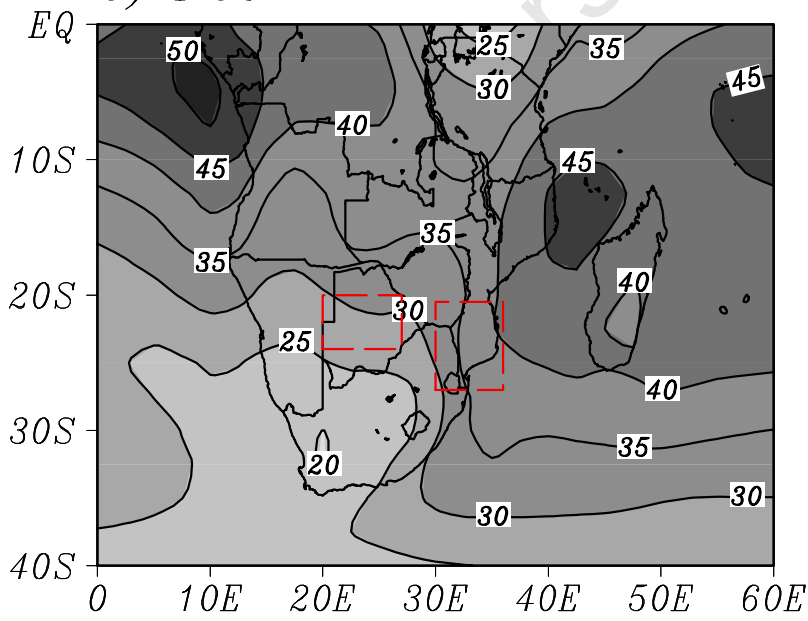

b) Nov

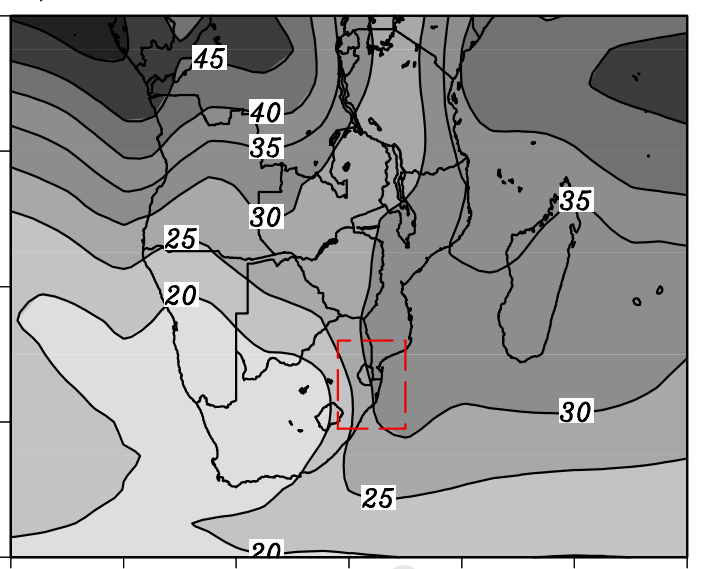

d) $\operatorname{Jan}$

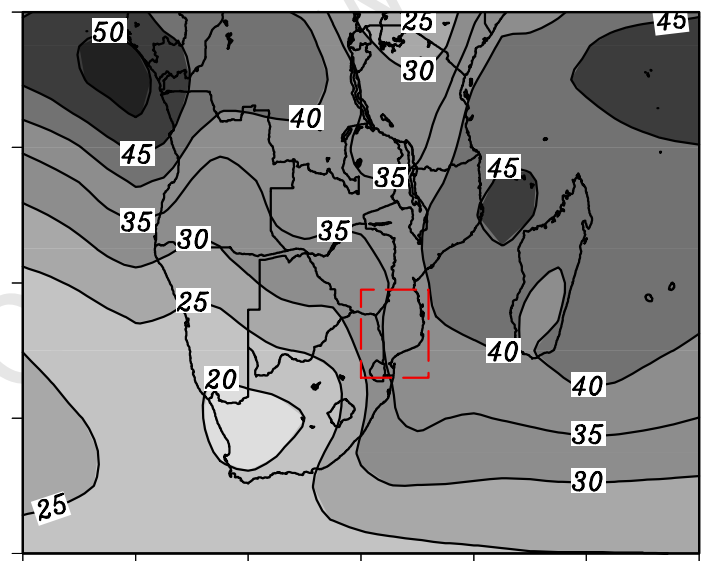

f) $M a r$

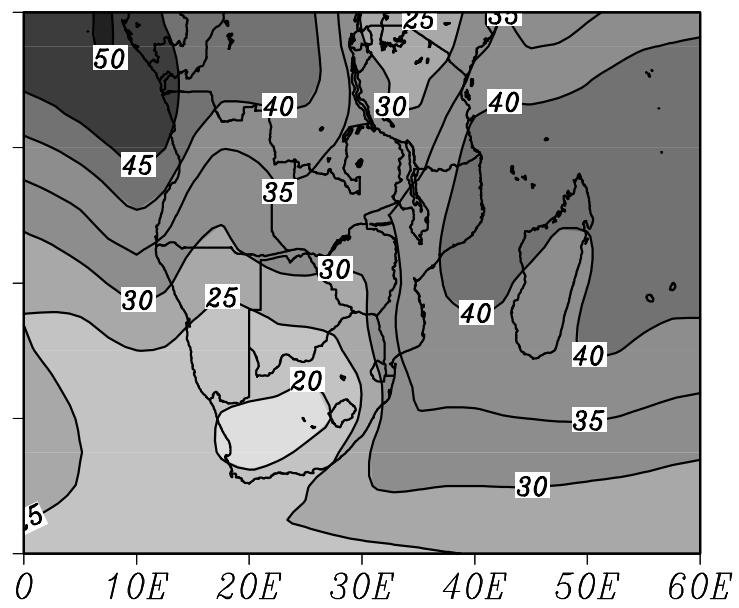

Figure 5.3: Same as Fig. 5.1, except now illustrating precipitable water $\left(\mathrm{kg} \mathrm{m}^{-2}\right)$ 
a) Oct

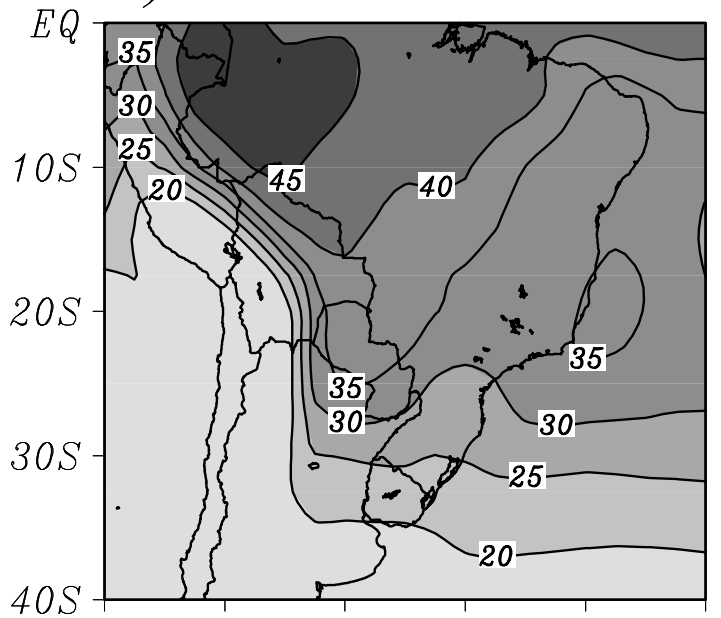

c) $\mathrm{Dec}$

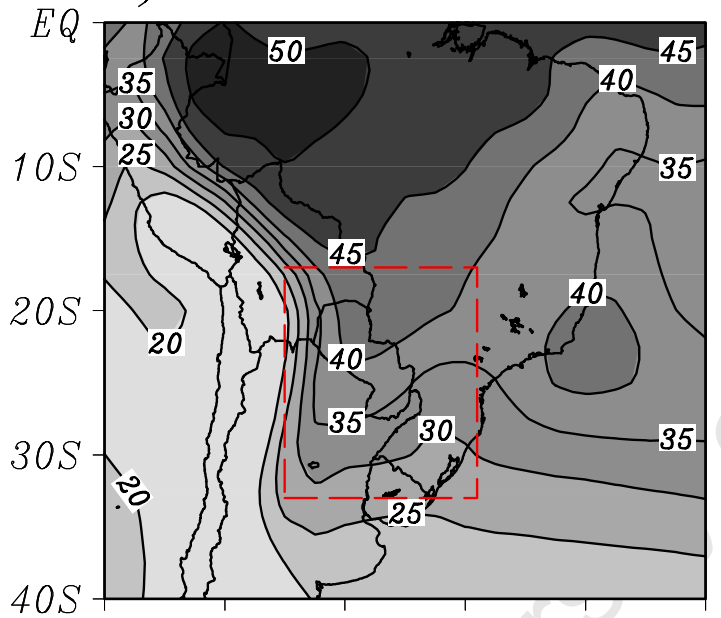

e) $\mathrm{Feb}$

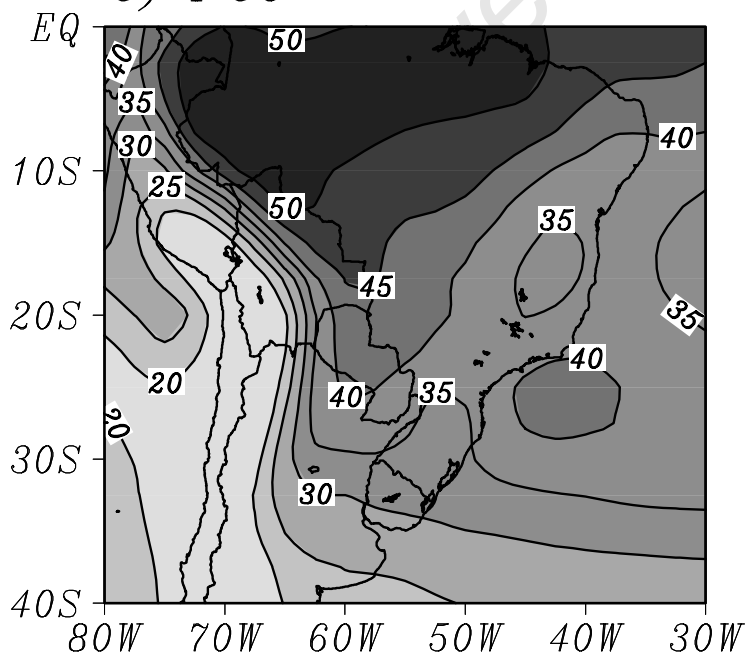

b) $\mathrm{Nov}$

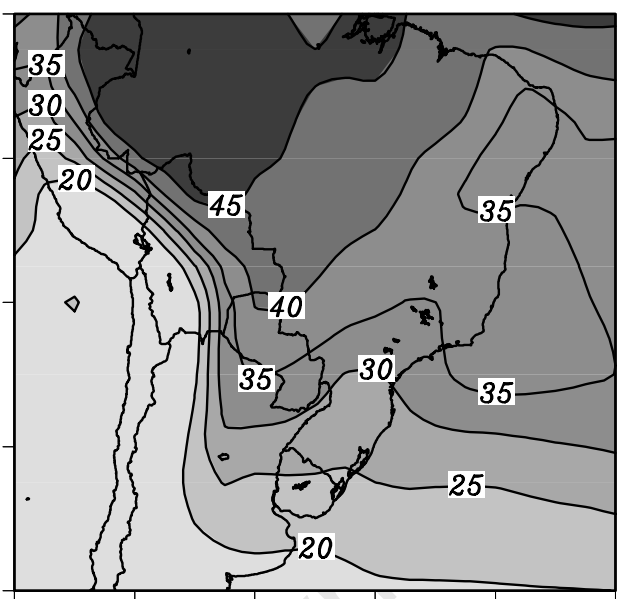

d) Jan

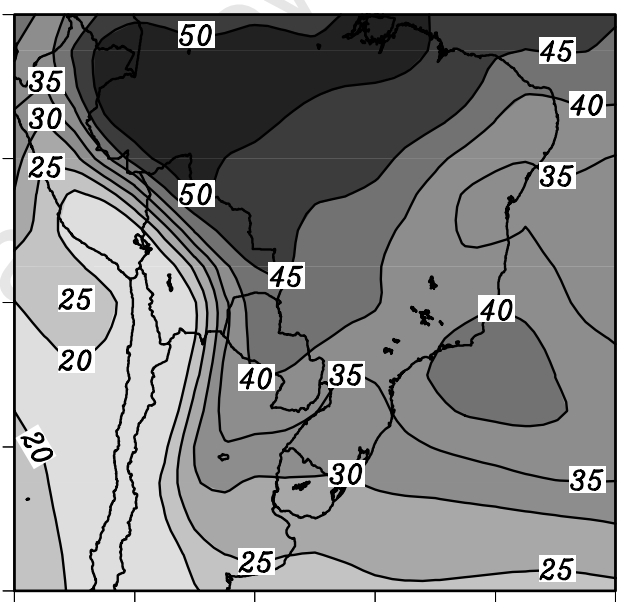

f) $M a r$

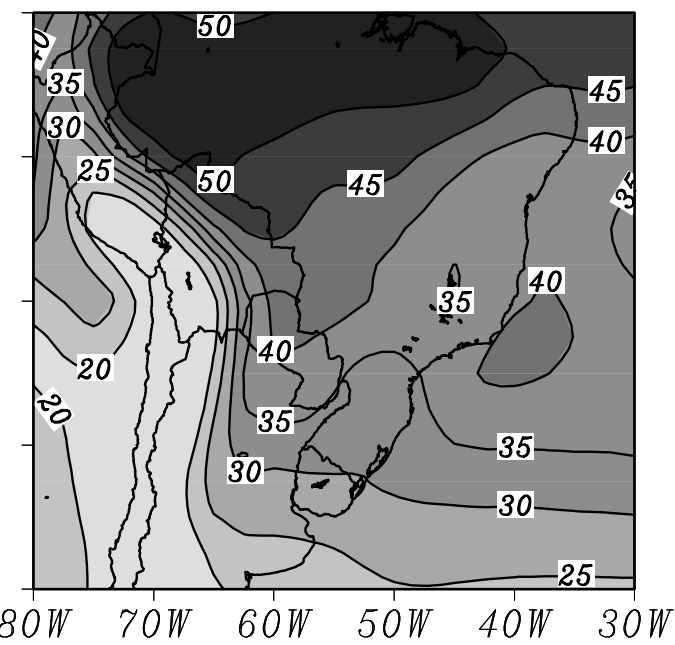

Figure 5.4: Same as Fig 5.2, except now illustrating precipitable water $\left(\mathrm{kg} \mathrm{m}^{-2}\right)$. 
a) $O c t$

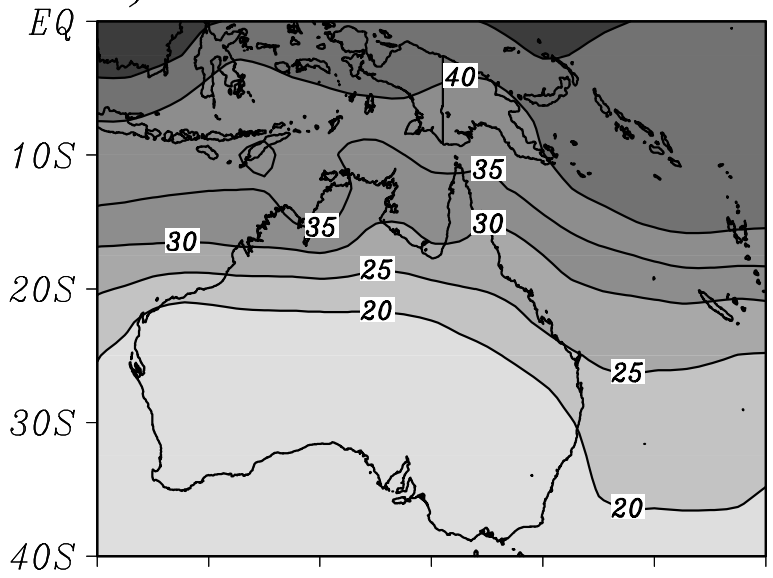

c) $\mathrm{Dec}$

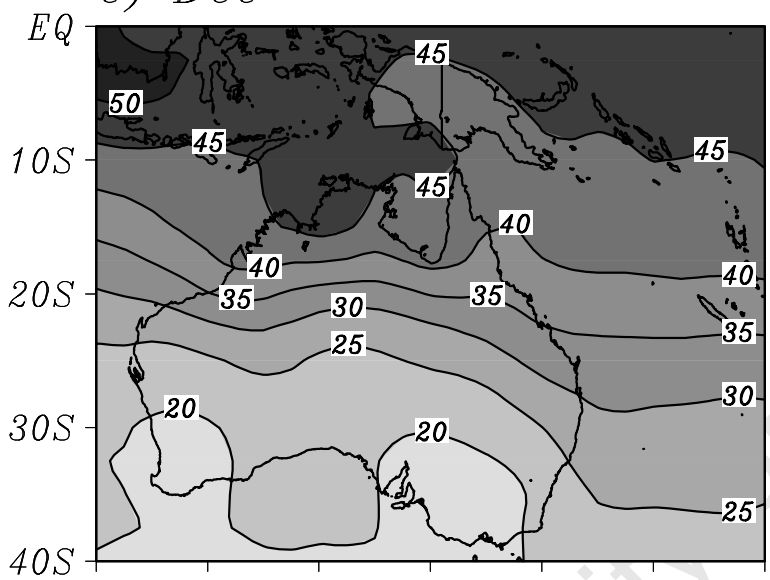

e) $F e b$

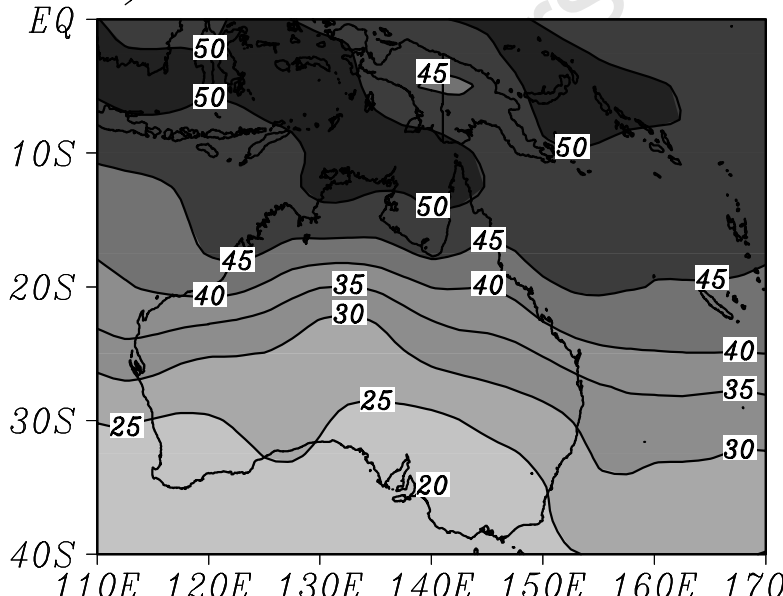

b) Nov

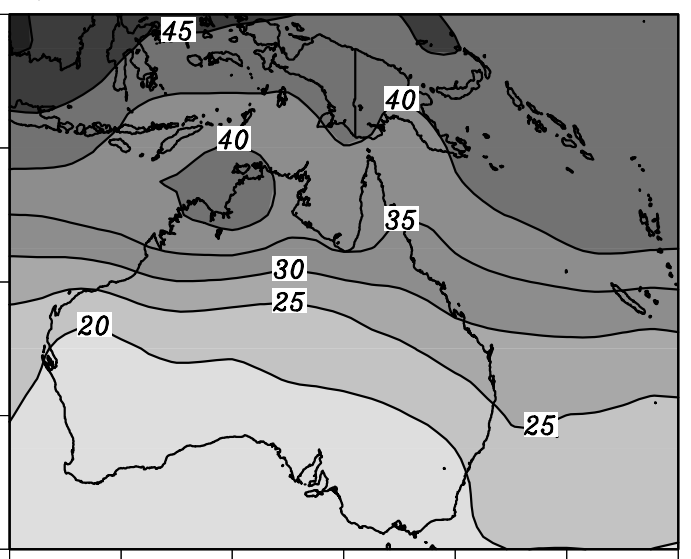

d) Jan

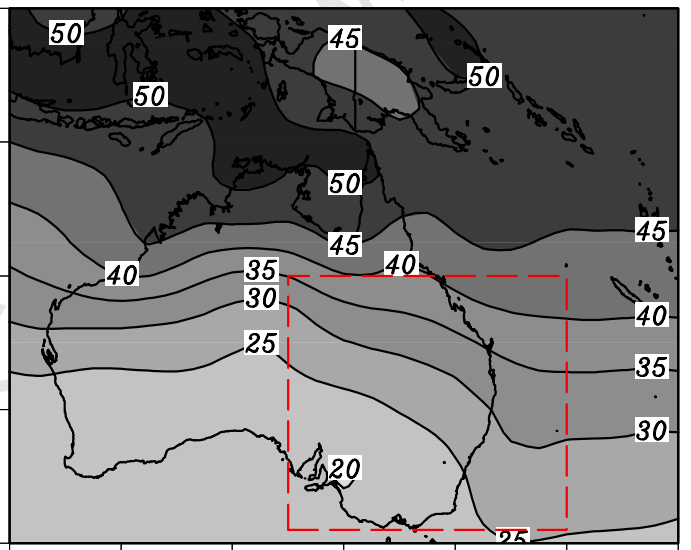

f) $M a r$

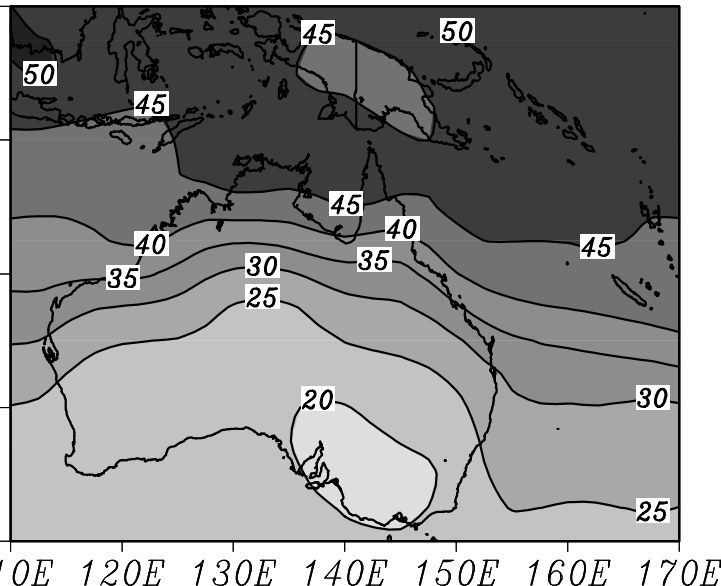

Figure 5.5: Monthly mean precipitable water $\left(\mathrm{kg} \mathrm{m}^{-2}\right)$ over Australia. Months are given at the top left corner of each panel. The red box in (d) refers to the study domain used by Perrin and Reason (1997), which extended to $45^{\circ} \mathrm{S}$. 

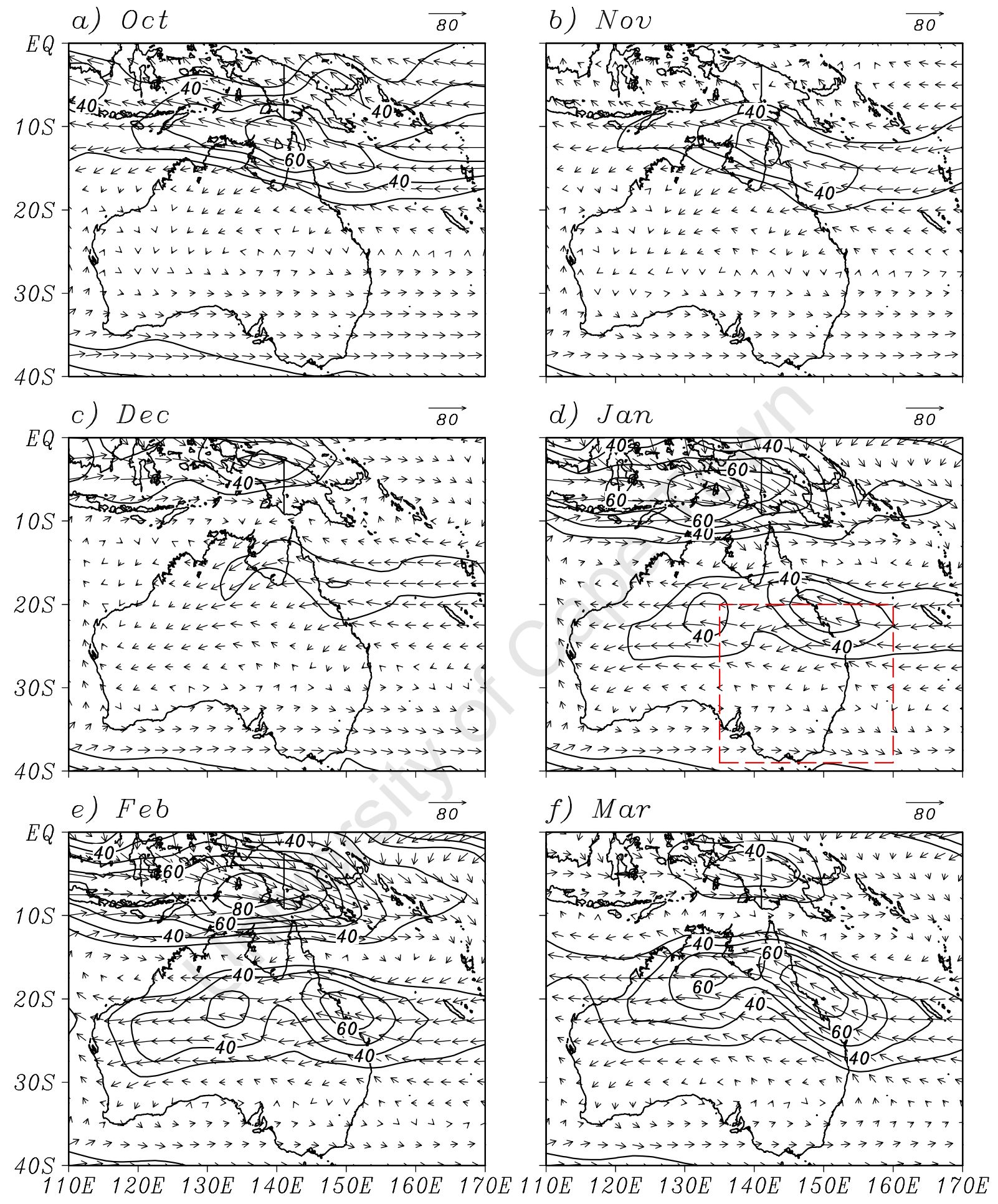

Figure 5.6: Same as Fig. 5.5, but for monthly mean $850 \mathrm{mb}$ moisture flux $\left(\mathrm{g} \cdot \mathrm{kg}^{-1} \mathrm{~m} . \mathrm{s}^{-1}\right)$. 

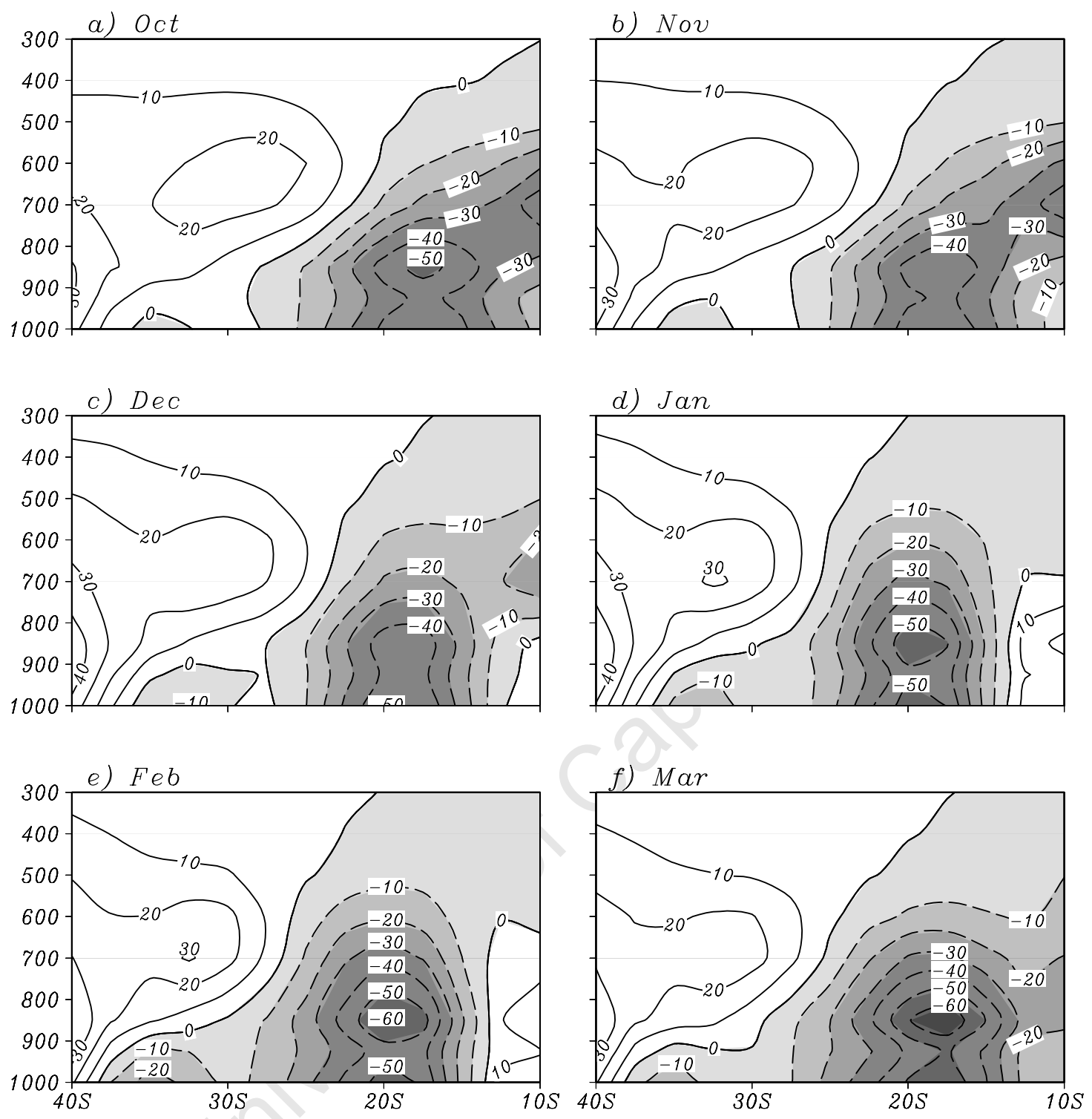

Figure 5.7: Vertical cross-section taken along $25^{\circ} \mathrm{E}$ showing the zonal moisture flux (g. $\left.\mathrm{kg}^{-1} \mathrm{~m} \cdot \mathrm{s}^{-1}\right)$. Easterly flux is shaded with a dash contour, while westerly flux contains just solid contours. 

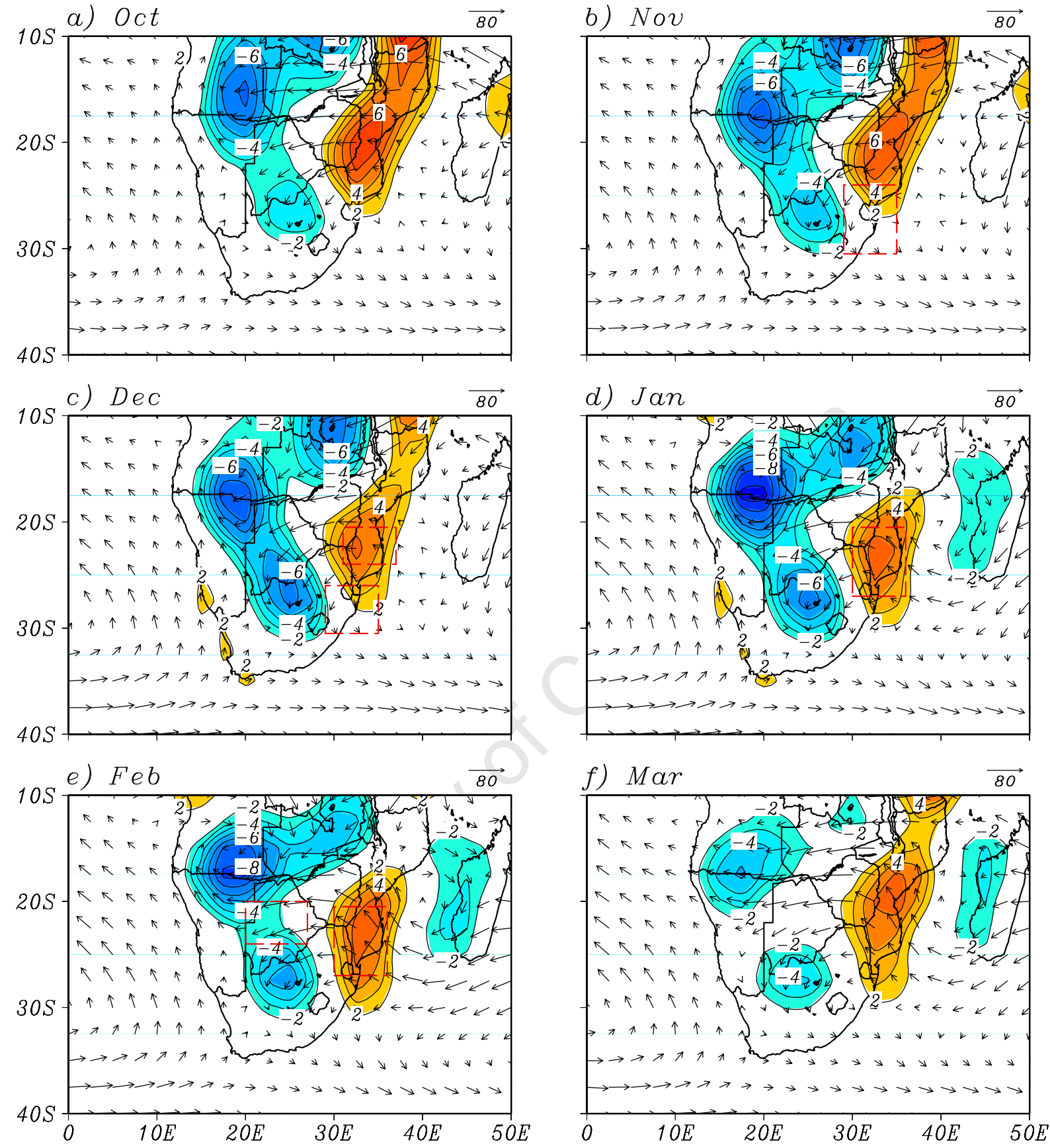

Figure 5.8: Monthly mean moisture convergence (shaded; $x 10^{-5}$ g.kg.s ${ }^{-1}$ ) and moisture flux (vector, $\mathrm{g} . \mathrm{kg}^{-1} \mathrm{~m} . \mathrm{s}^{-1}$ ) at the $850 \mathrm{hPa}$ level. Moisture convergence is negative, while divergence is positive. Scale of moisture flux is given above the top right hand corner of each panel. 

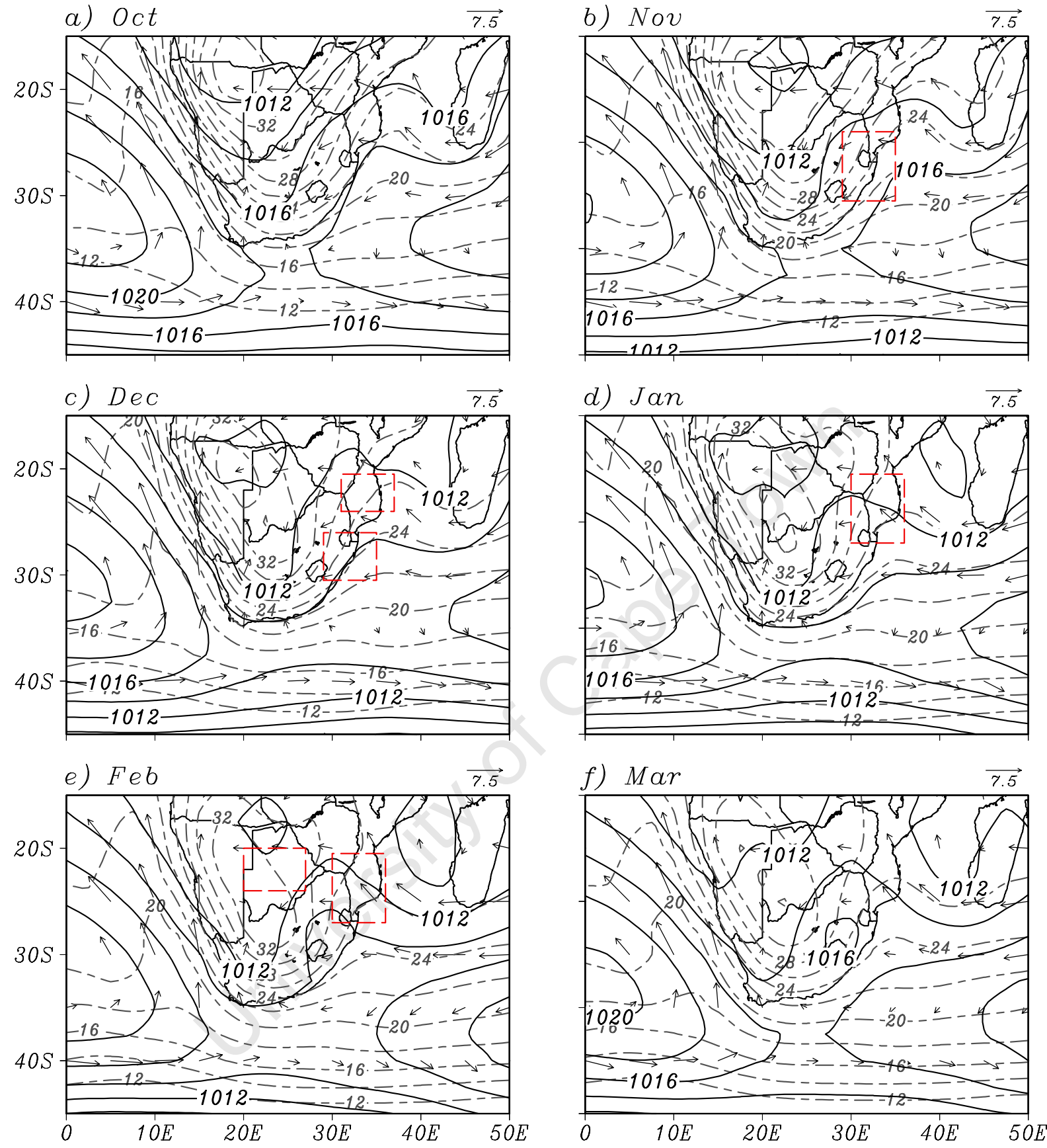

Figure 5.9: Monthly mean sea level pressure (hPa), temperature $\left({ }^{\circ} \mathrm{C}\right)$ and wind $\left(\mathrm{m} . \mathrm{s}^{-1}\right)$ at $1000 \mathrm{hPa}$. Scale of vector wind is given above the top right hand corner of each panel. 

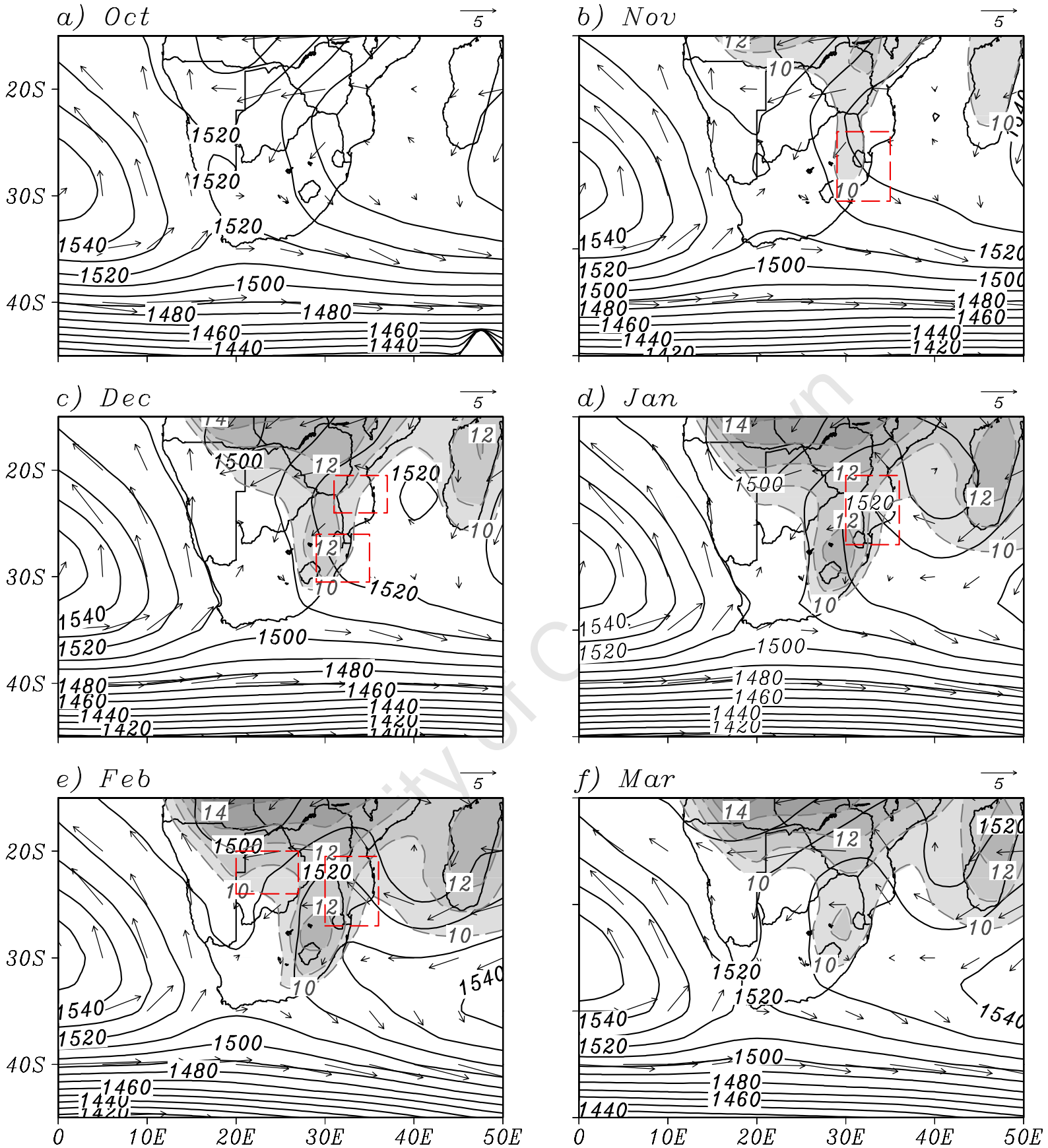

Figure 5.10: Monthly mean geopotential height (solid contours, $m$ ), wind vectors (vectors, $\mathrm{m} . \mathrm{s}^{-1}$ ) and mixing ratio (shaded, only values greater than $10 \mathrm{~g} \cdot \mathrm{kg}^{-1}$ are shown) at $850 \mathrm{hPa}$. 

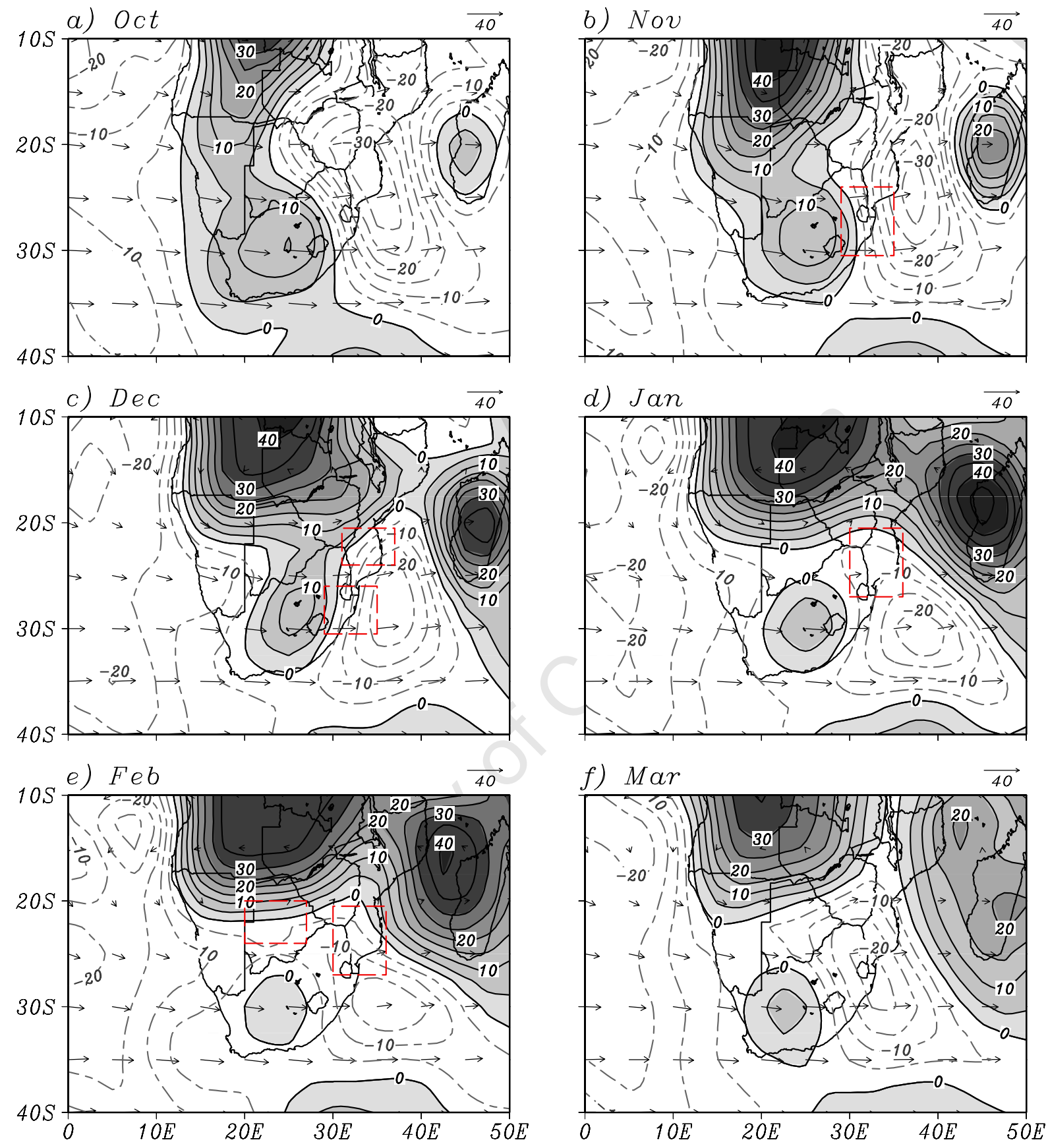

Figure 5.11: Mean $200 \mathrm{mb}$ divergence $\left(\times 10^{-7} \mathrm{~s}^{-1}\right)$ and vector winds $\left(\mathrm{m} . \mathrm{s}^{-1}\right)$. Divergence (positive values) is shaded with solid contours (interval $5 \times 10^{-7} \mathrm{~s}^{-1}$ ), while convergence (negative values) is depicted by grey dashed contours. 
a) Oct

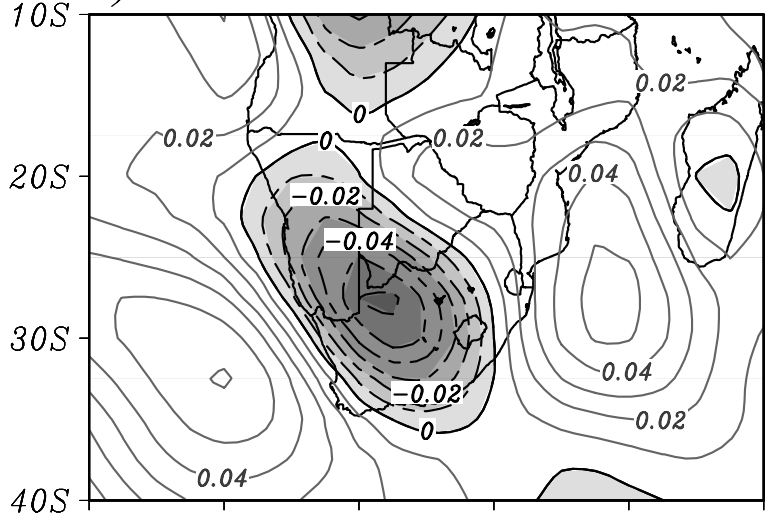

c) $\mathrm{Dec}$

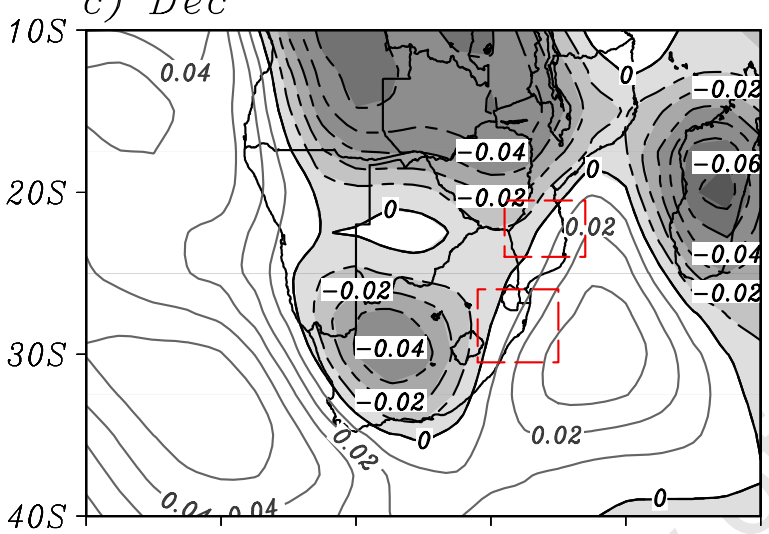

e) $\mathrm{Feb}$

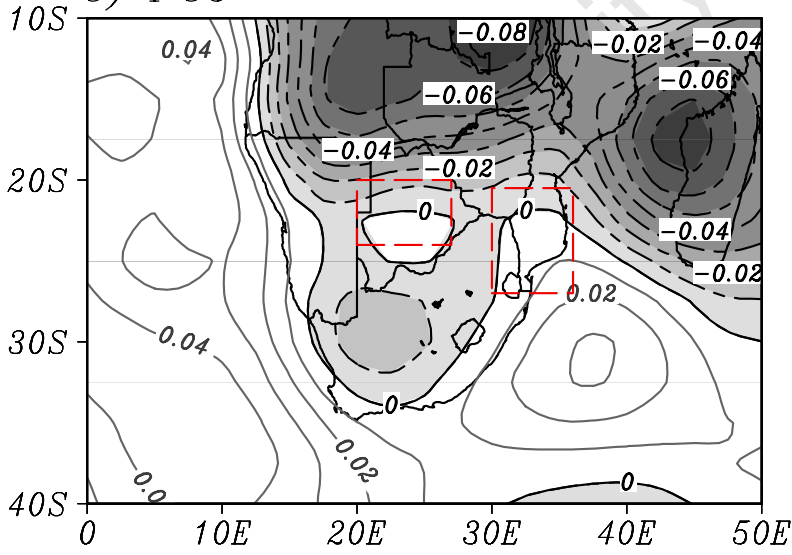

b) Nov

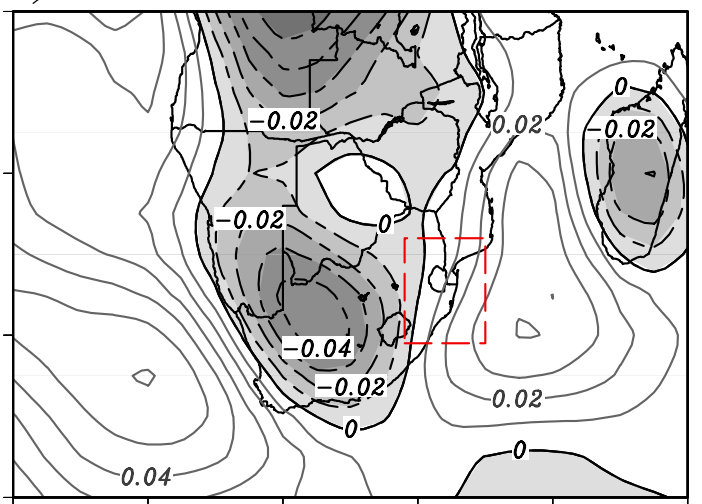

d) Jan

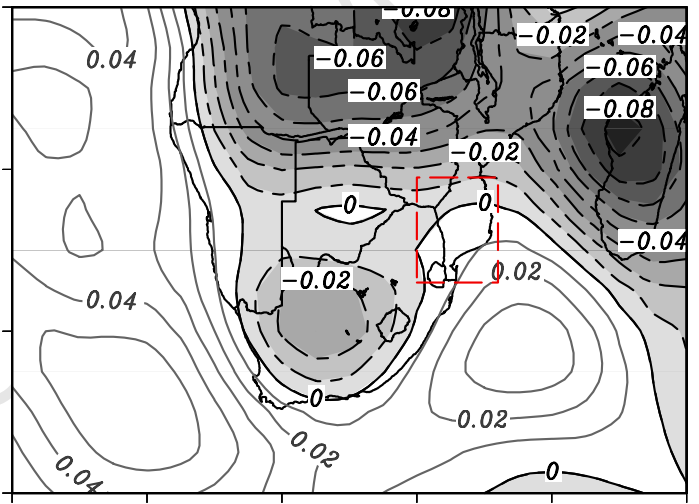

f) $M a r$

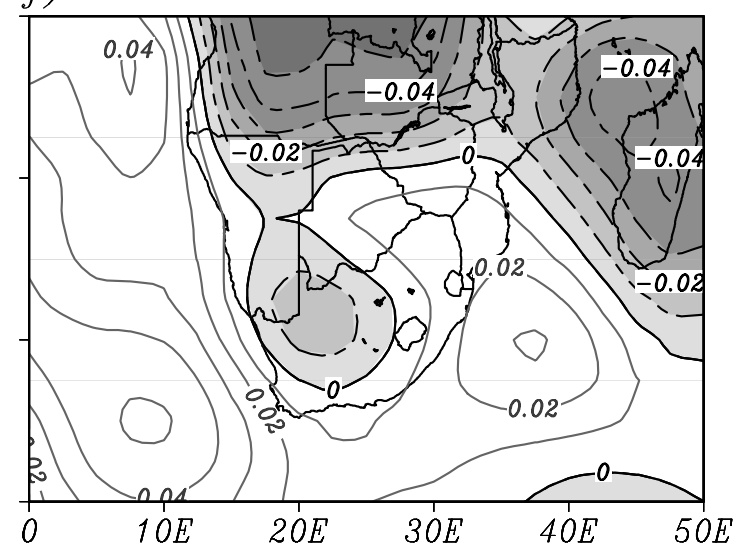

Figure 5.12: Mean vertical motion (omega, $\mathrm{Pa}_{\mathrm{s}} \mathrm{s}^{-1}$ ). Upward vertical motion is shaded and dashed contours (interval 0.01 $\mathrm{Pa}_{\mathrm{s}} \mathrm{s}^{-1}$ ), while downward motion is depicted by grey solid contours. 

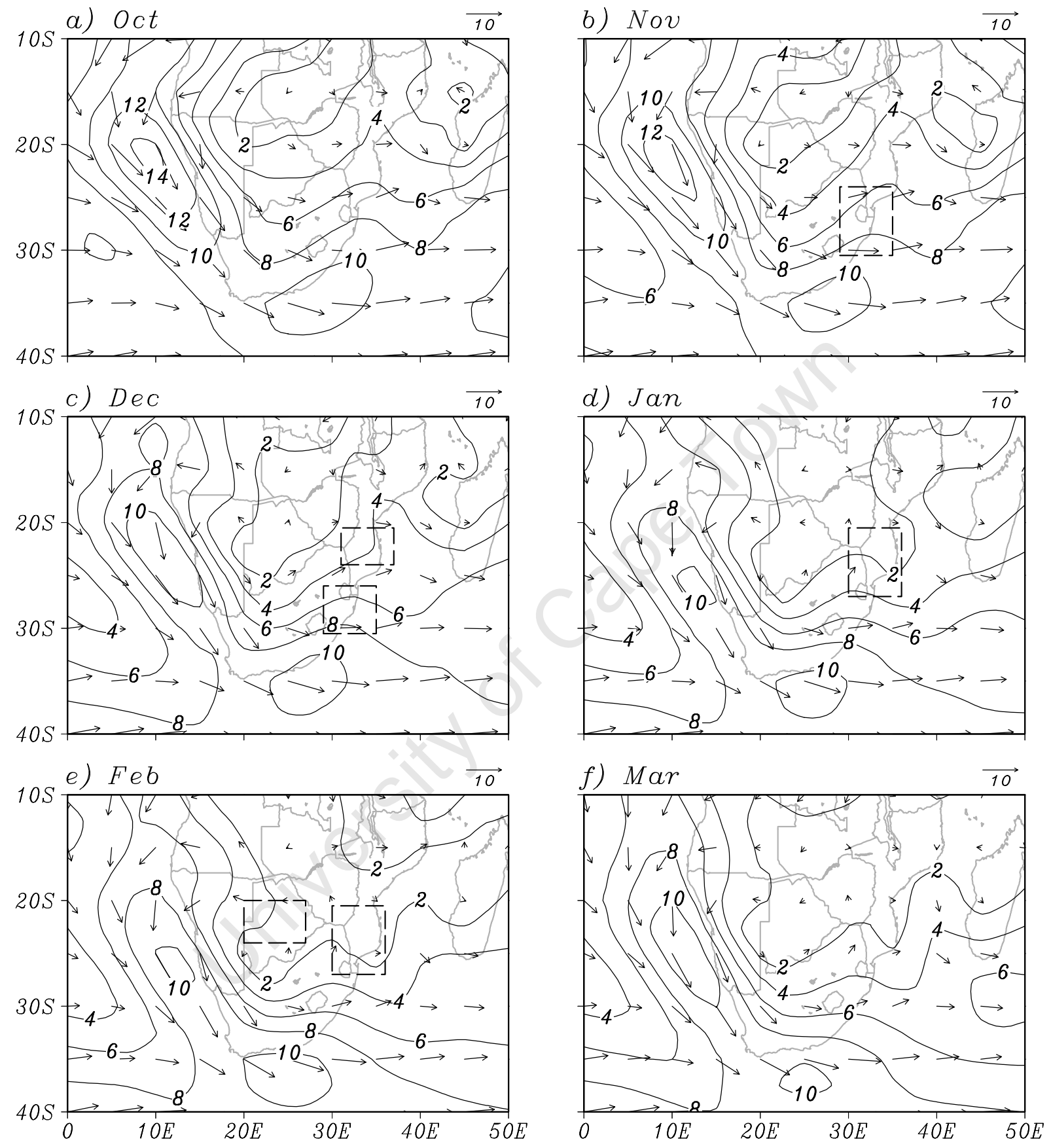

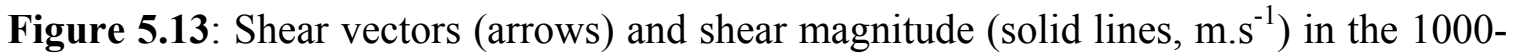
$700 \mathrm{mb}$ layer. 

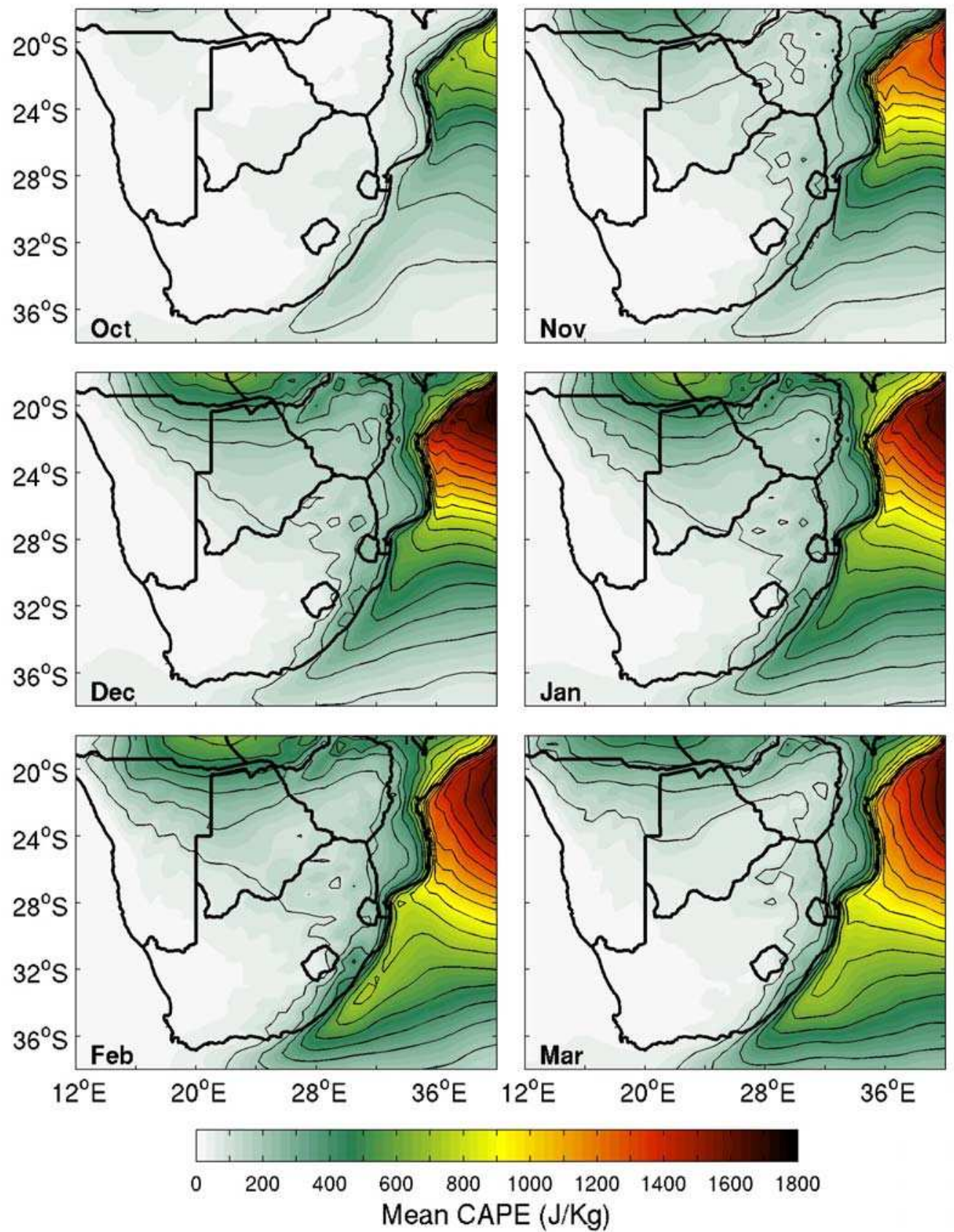

Figure 5.14: Mean monthly surface CAPE ( shaded with solid contours, J.kg-1). 

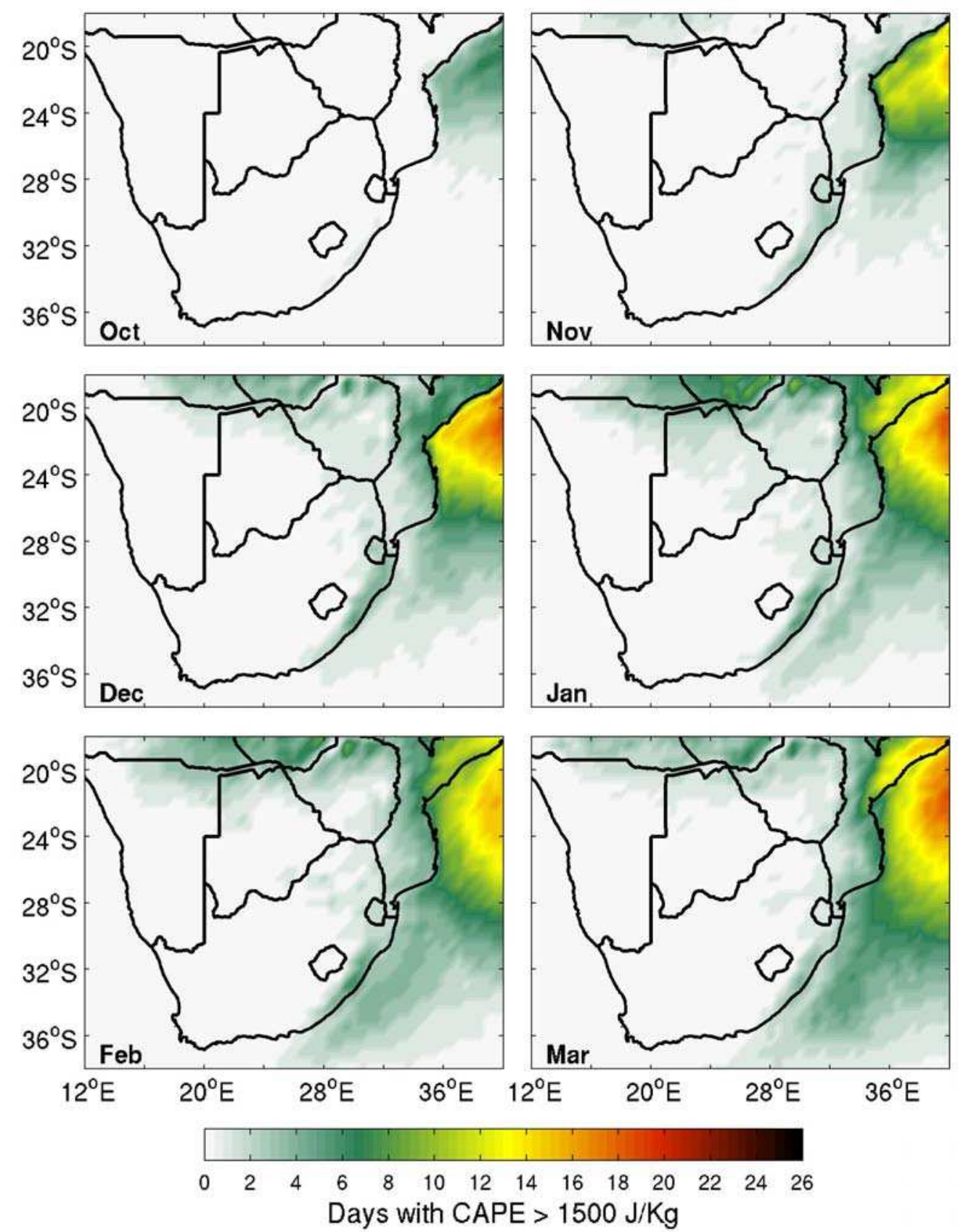

Figure 5.15: The number of days per month at $12 \mathrm{~h} 00$ UTC that contain CAPE $>1500$ J.kg ${ }^{-1}$. 


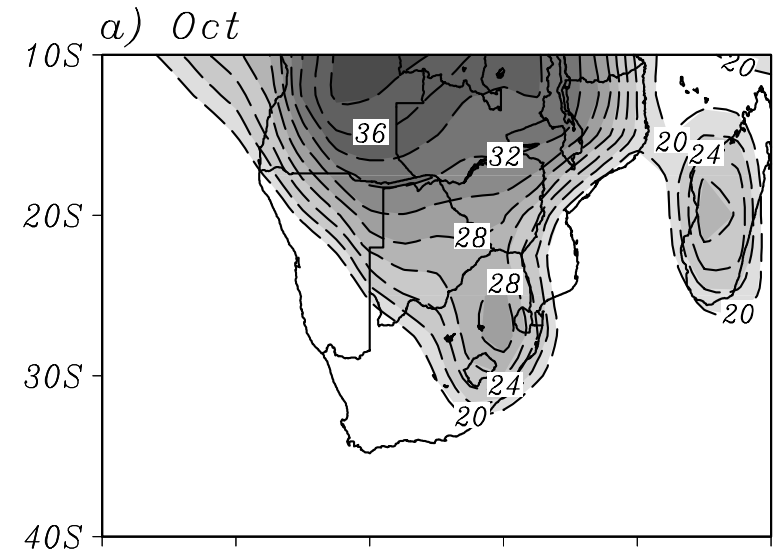

b) Nov

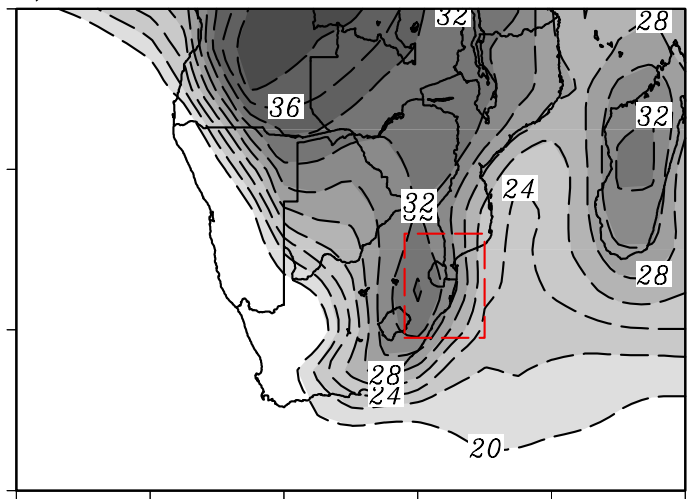

c) $\mathrm{Dec}$

d) $\operatorname{Jan}$
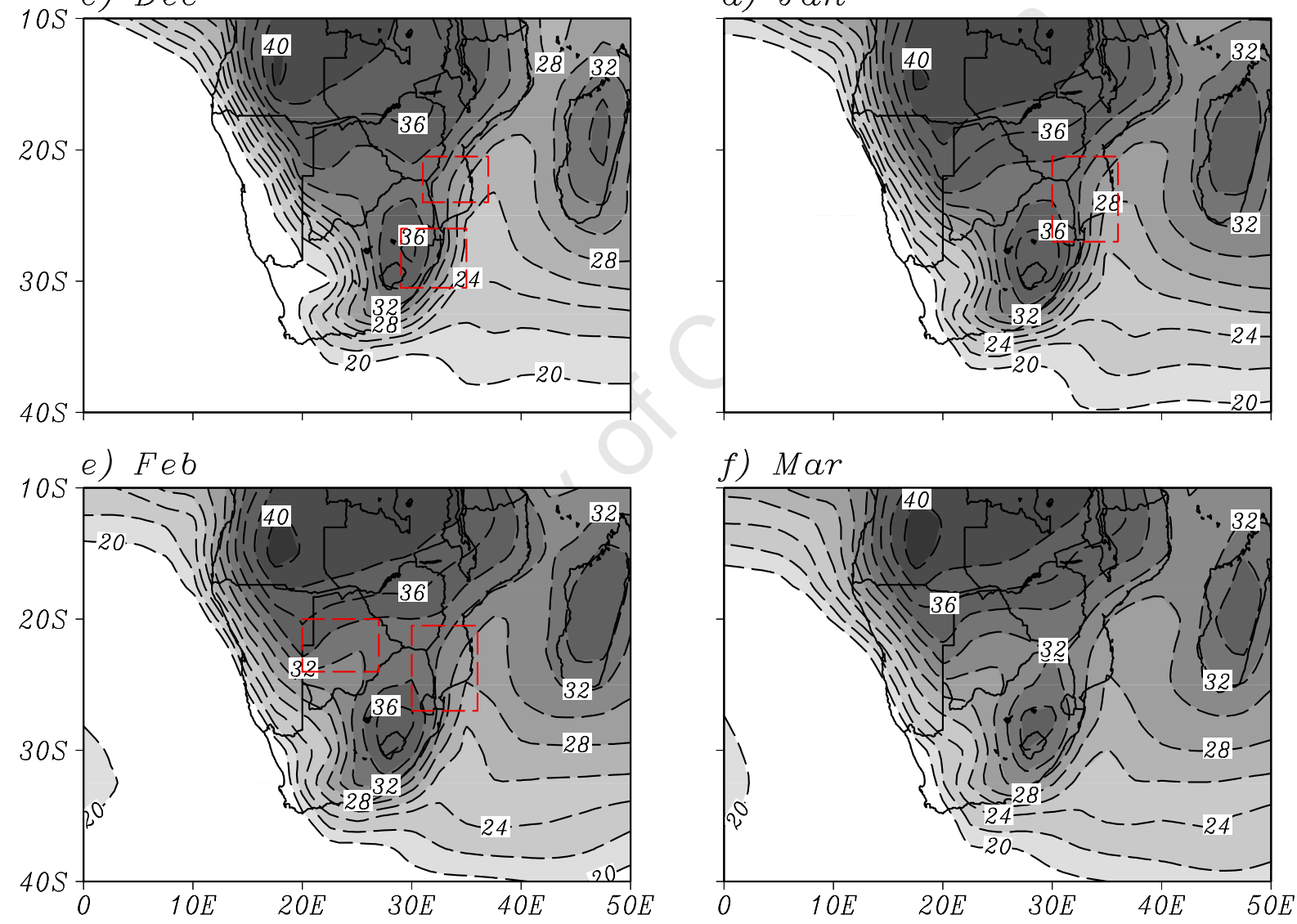

Figure 5.16: Mean monthly $K$-Index (shaded with dashed contours). 

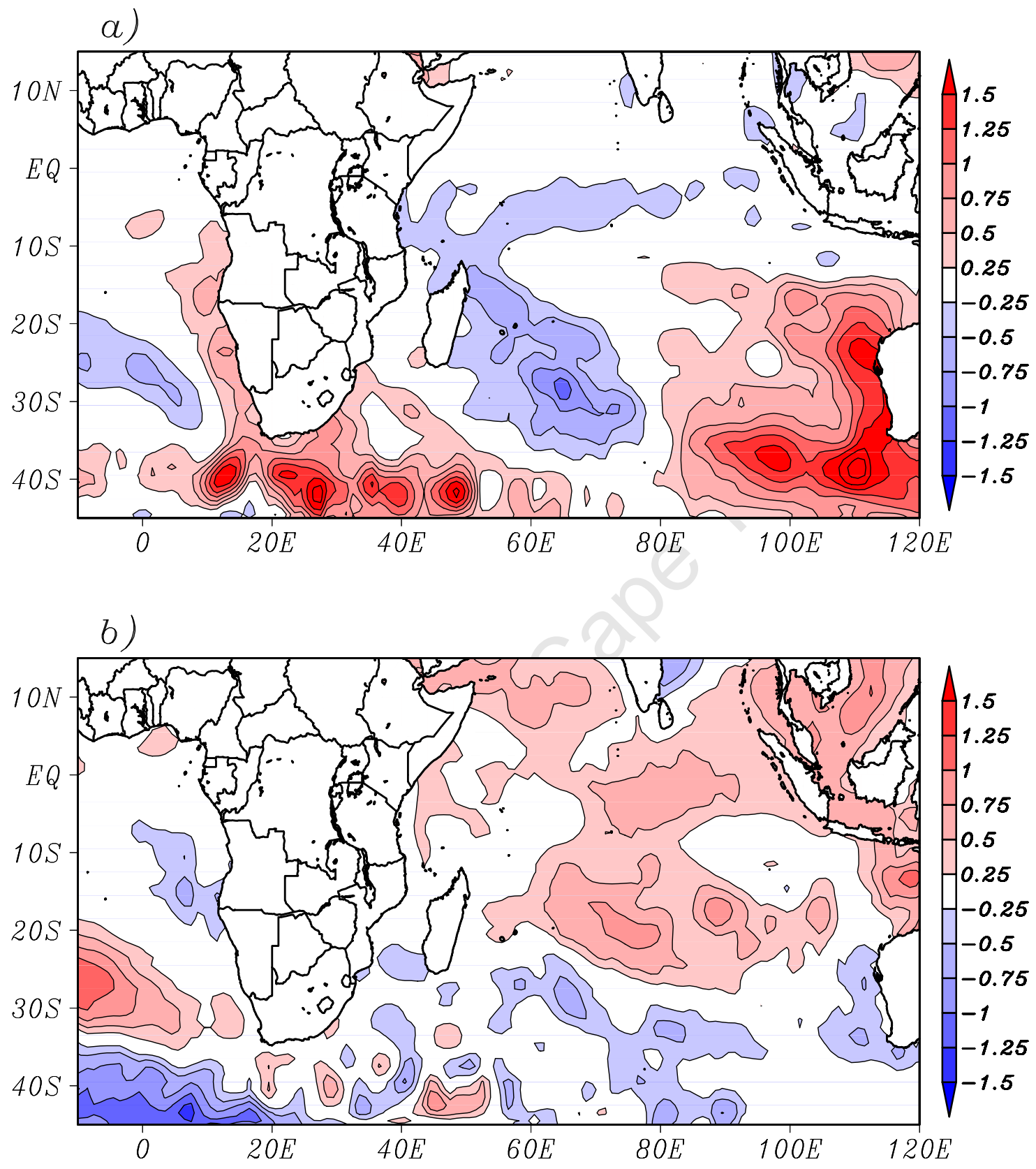

Figure 5.17: NDJF sea surface temperature (SST) anomalies $\left({ }^{\circ} \mathrm{C}\right)$ during a) 1999/2000 and b) $2002 / 2003$. 

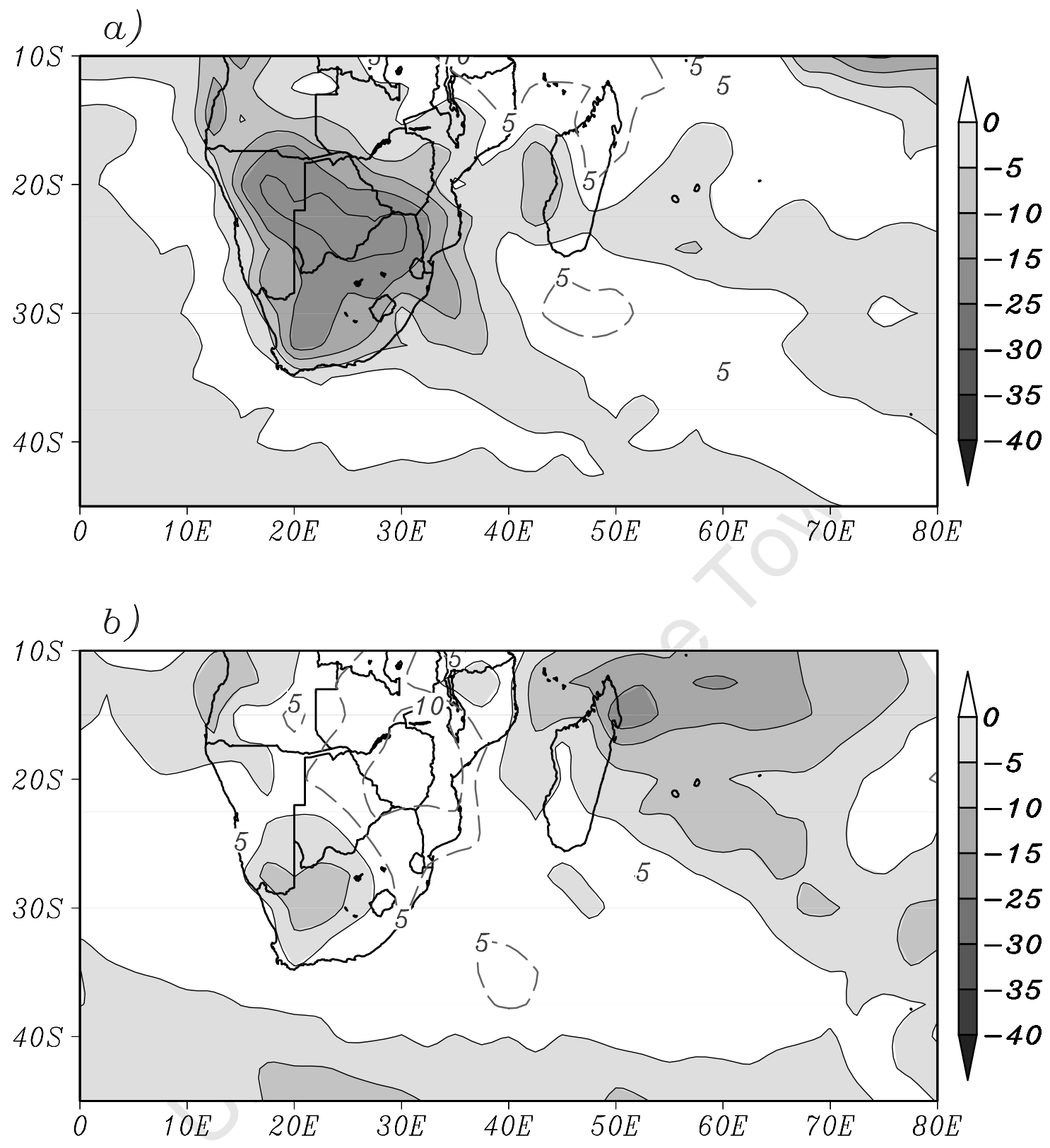

Figure 5.18: Same as Fig. 5.17, but for outgoing longwave radiation (OLR, W.m ${ }^{-2}$ ) 


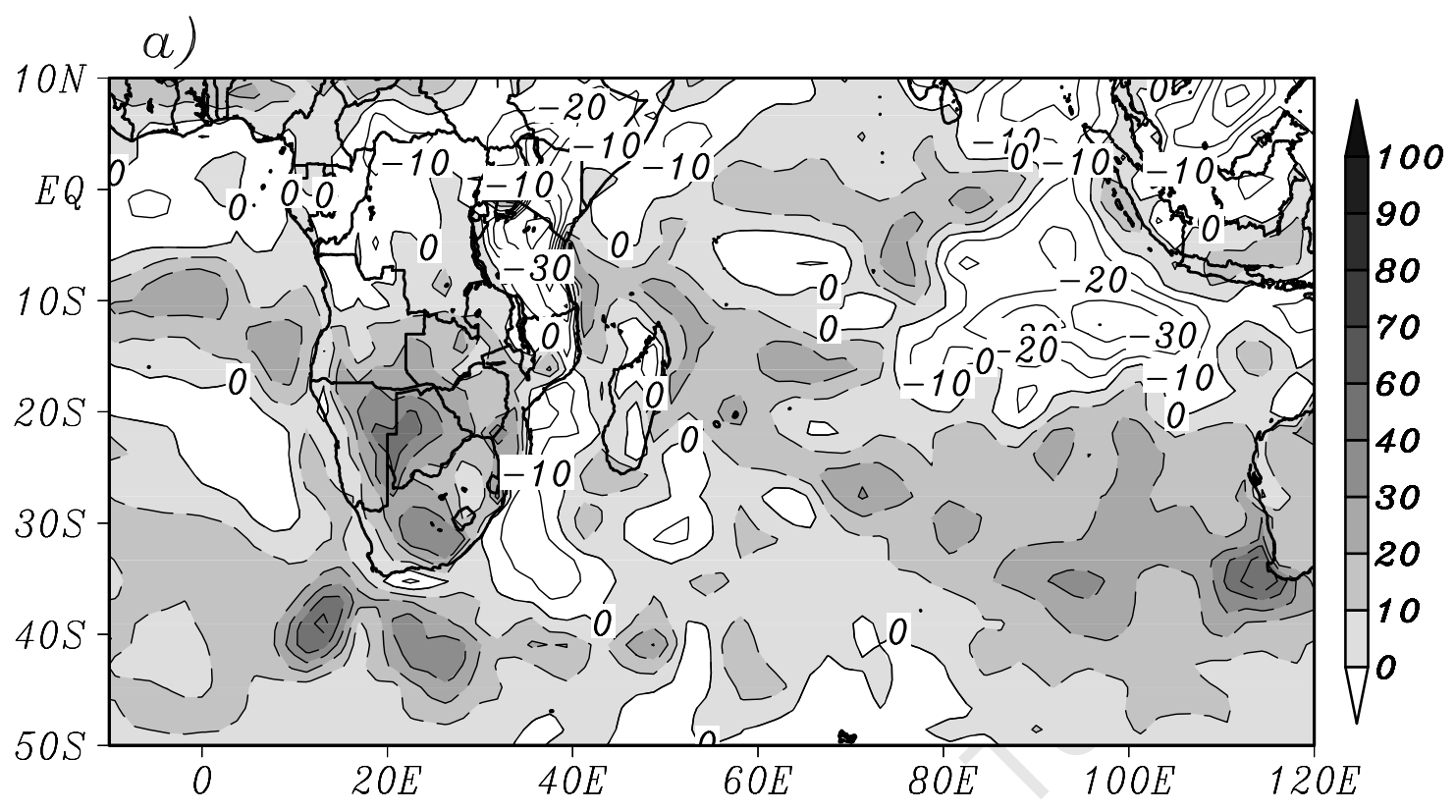

b)

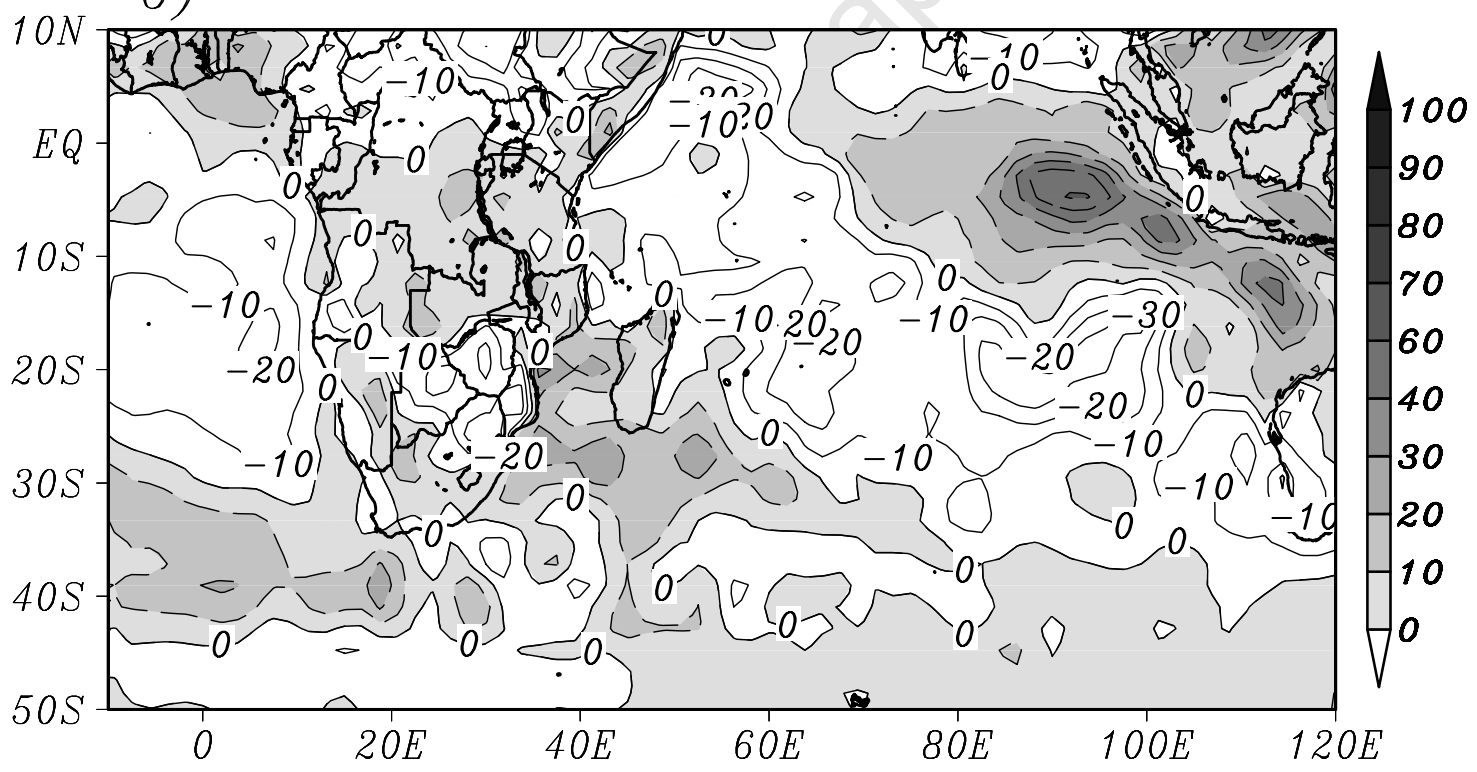

Figure 5.19: Same as Fig. 5.17, but for surface latent heat flux (W.m²) 


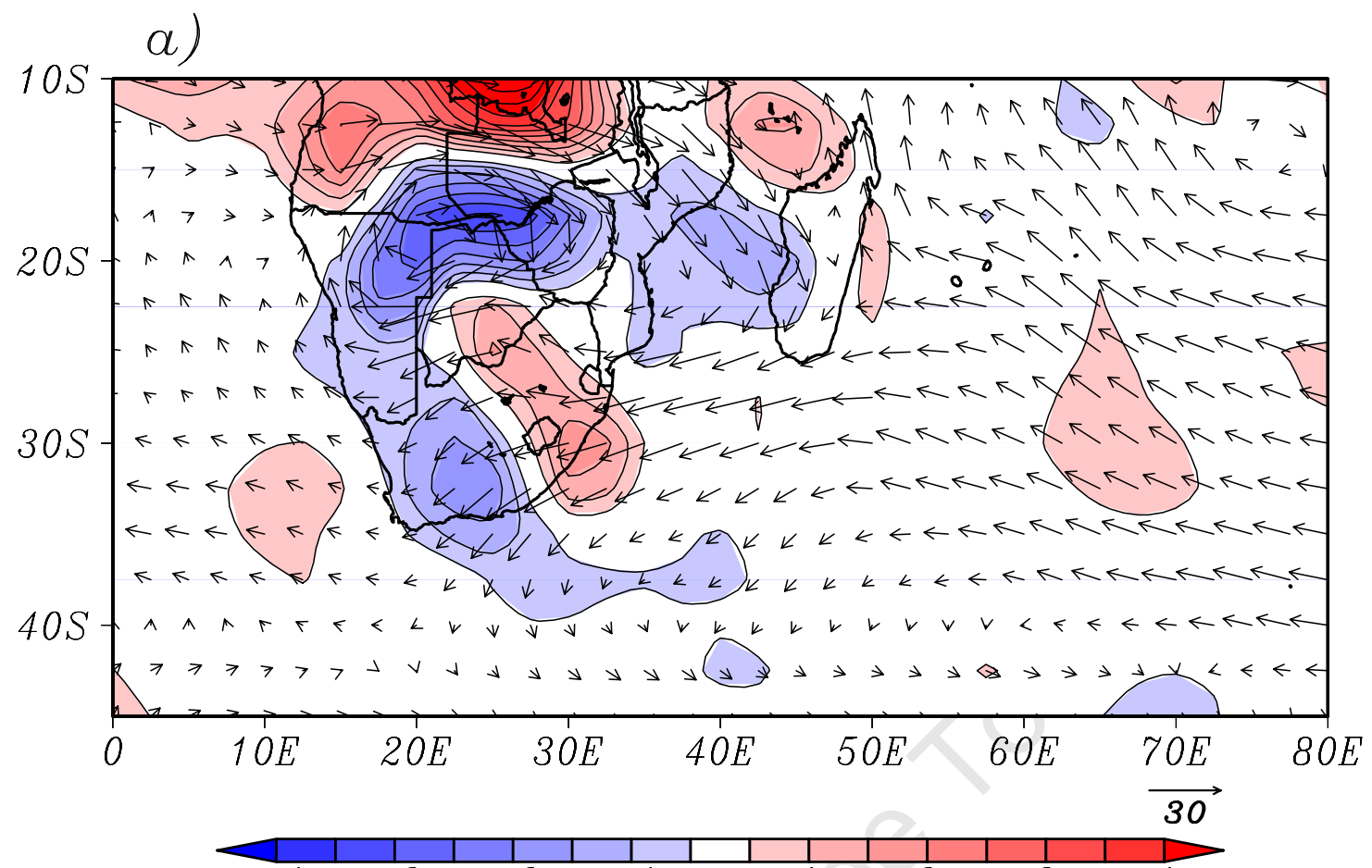

b)

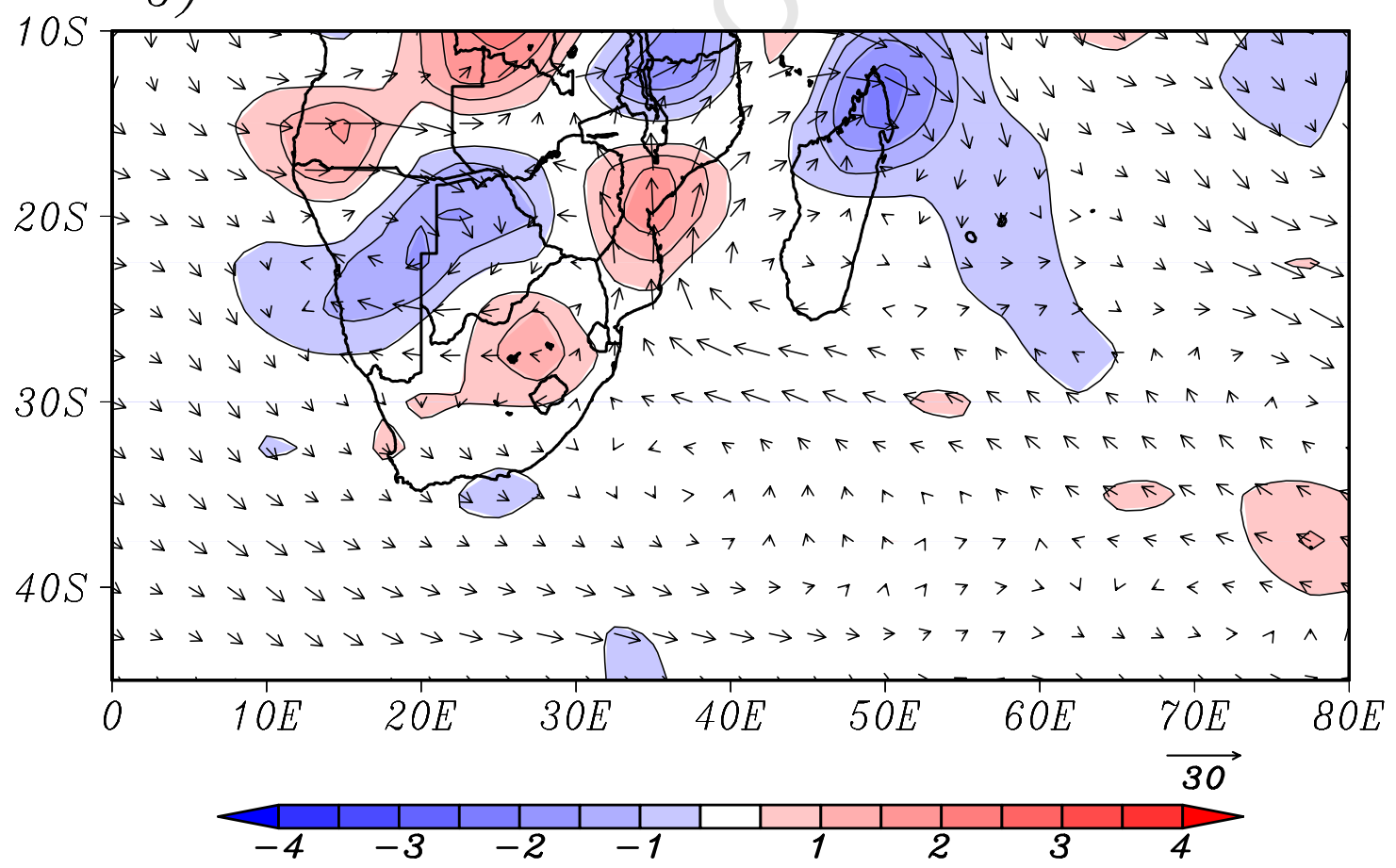

Figure 5.20: Same as Fig. 5.17, but for moisture flux (vectors, $\mathrm{g} . \mathrm{kg}^{-1} \mathrm{~m} . \mathrm{s}^{-1}$ ) and moisture convergence (shaded; $x 10^{-5} \mathrm{~g} \cdot \mathrm{kg}^{-1} \mathrm{~s}^{-1}$ ) at $850 \mathrm{hPa}$. 
a)

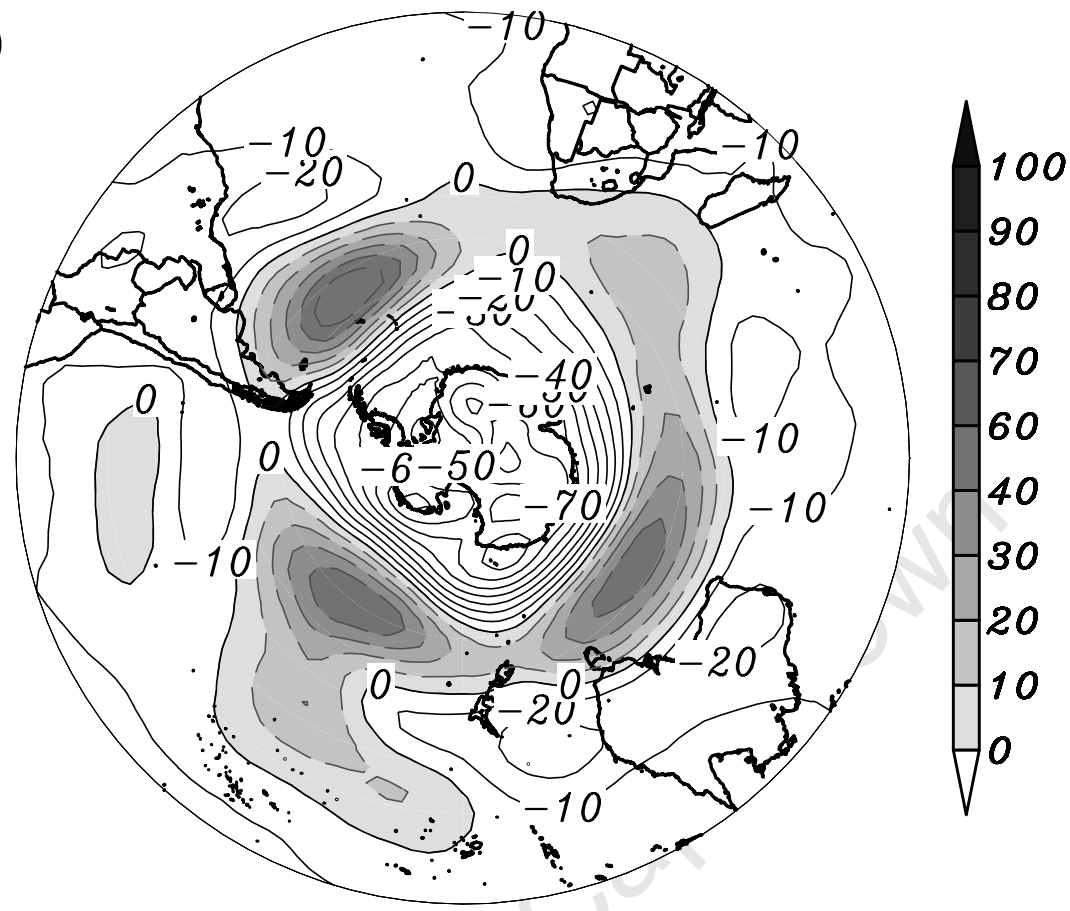

b)

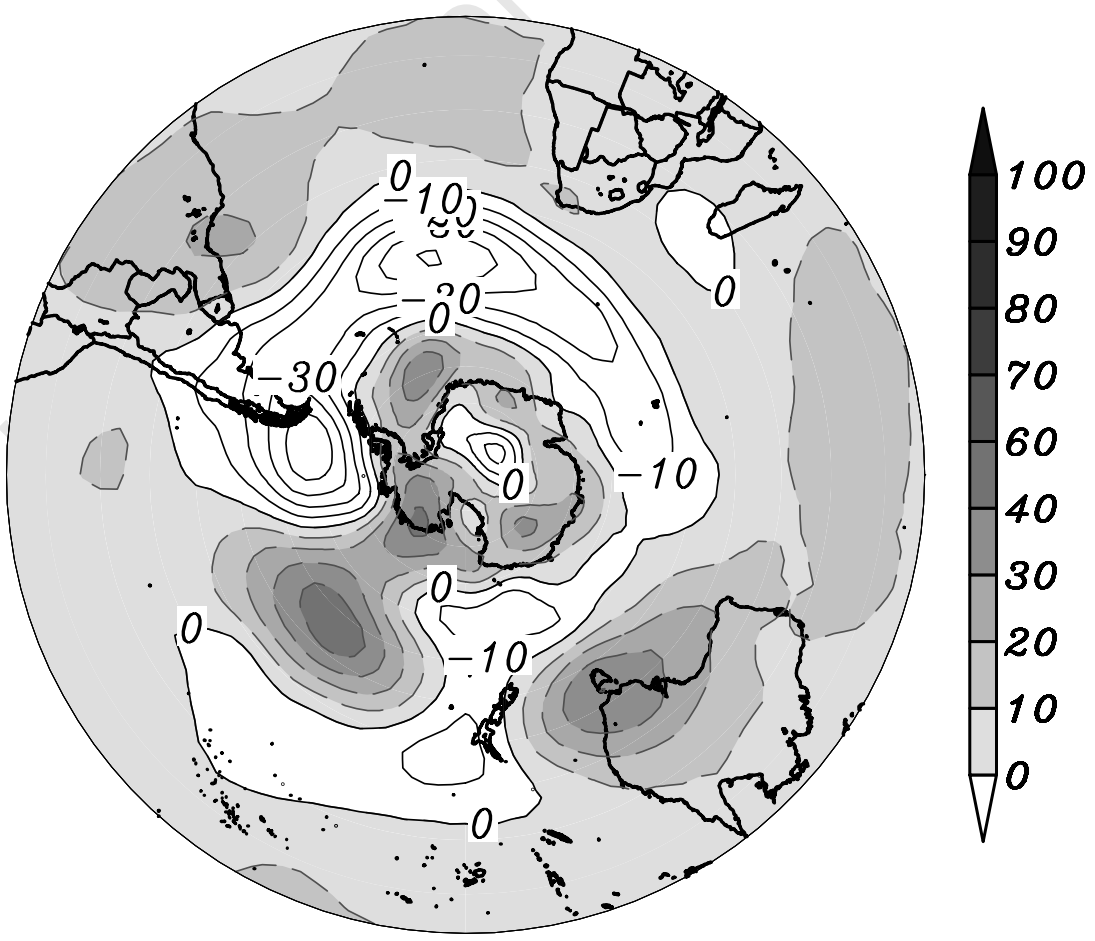

Figure 5.21: Same as Fig. 5.17, but for geopotential height at $500 \mathrm{hPa}$ (shaded; m). 


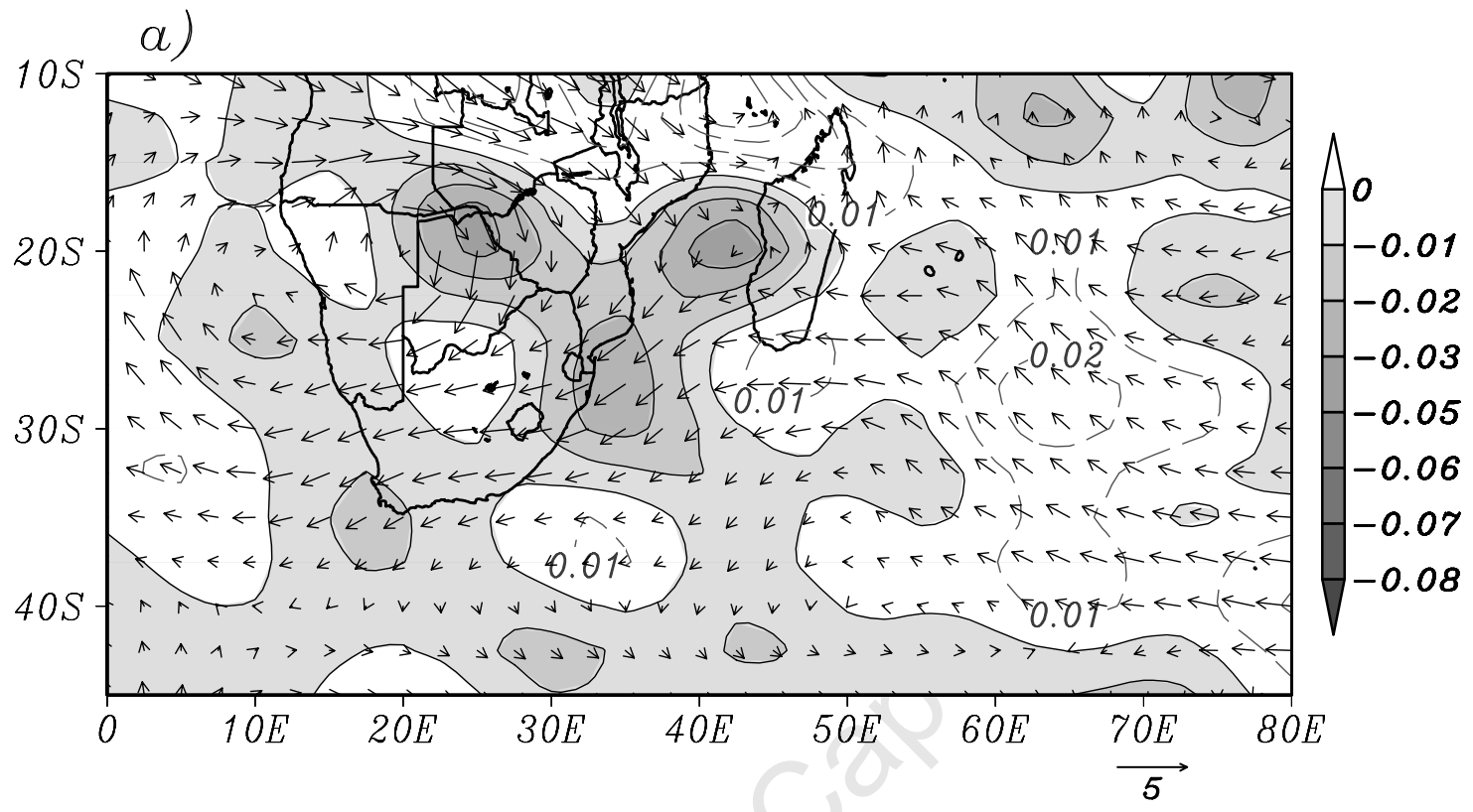

b)

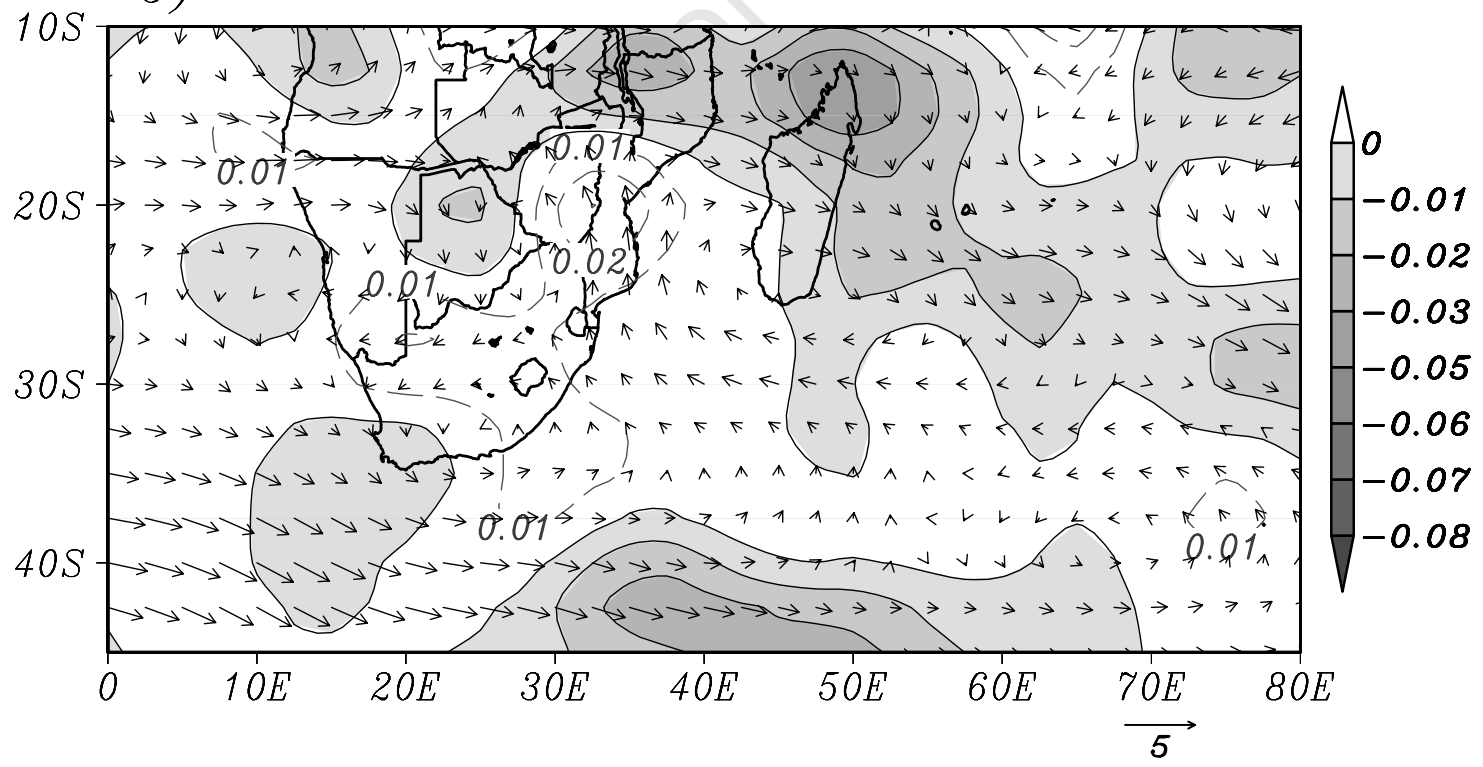

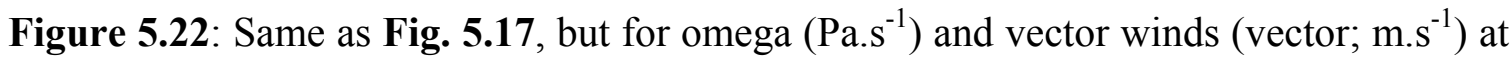
$700 \mathrm{hPa}$. 

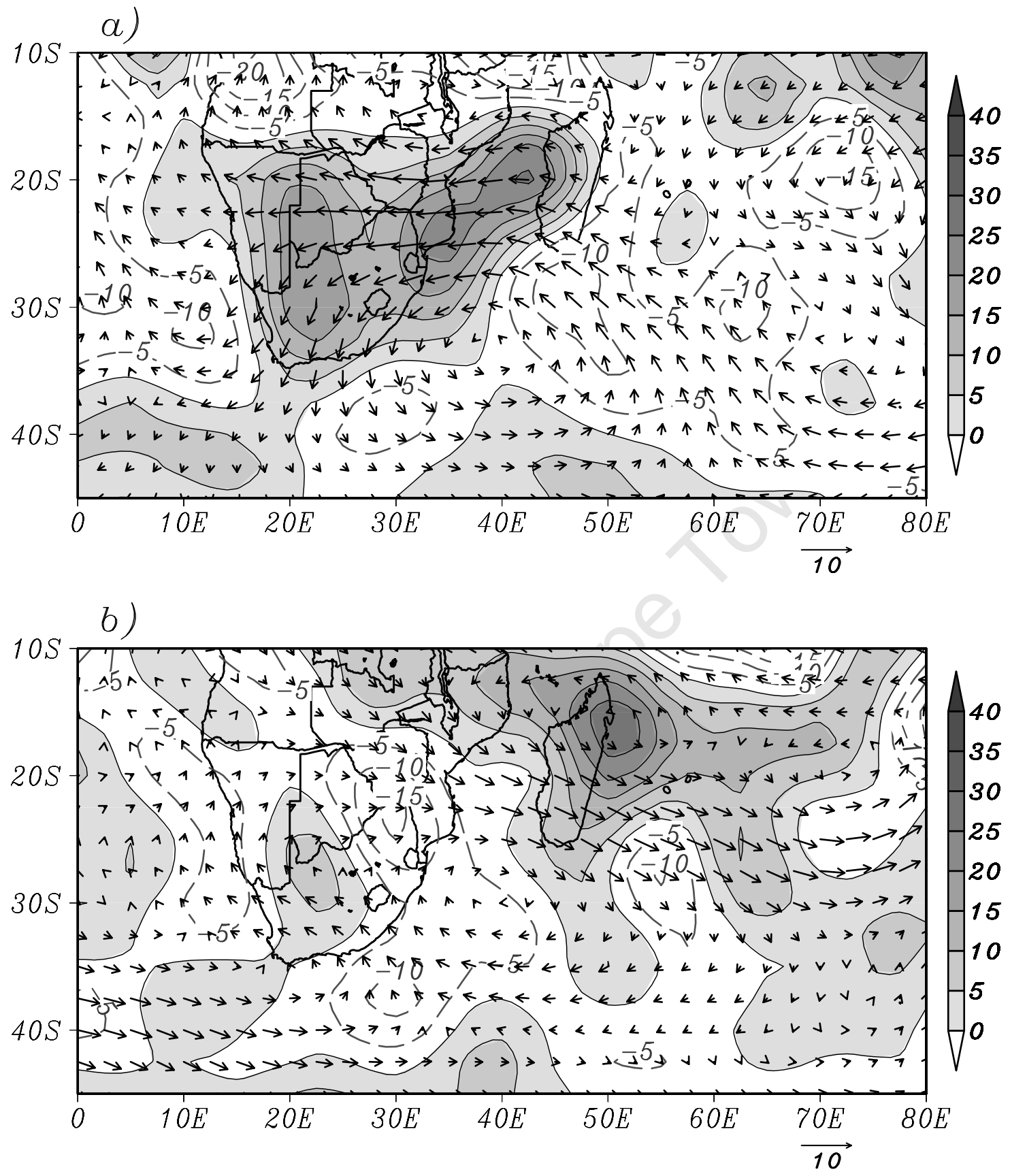

Figure 5.23: Same as Fig. 5.17, but for divergence $\left(\times 10^{-7} \mathrm{~s}^{-1}\right)$ and vector winds (vector

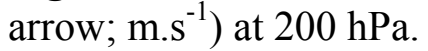




\section{Chapter Six}

MCCs and southern Africa Summer Rainfall 


\subsection{Introduction to Satellite-Derived Rainfall}

In terms of surface-based weather observation platforms (i.e. rain-gauges, radar, etc), southern Africa is mainly a data sparse region, which generates a problem for monitoring mesoscale weather systems and their precipitation characteristics. Not only are there issues with spatial and temporal availability of data, but the data is further limited due to the lack of quality control. However, these issues are not confined to the region, but are problematic worldwide. Thus, the emergence of numerous sensors aboard various satellites in recent years has played a vital role in attempts to fill the data void.

Early methods used to infer satellite-based precipitation estimates were based on the reflectivity of clouds and from cloud top temperature, which is provided by the visible and infrared (IR) data from satellites (e.g., Arkin and Meiser 1987) Although this approach provided data at relatively greater spatial and temporal resolution than rain gauge data, these approximations proved to be ineffective due to the link between cloud properties and precipitation being weak (Ebert et al. 2007). Essentially, it was the development of passive microwave sensors aboard polar orbiting satellites that appears to have helped improve the accuracy, coverage and resolution in precipitation estimates. One such example is that of the Tropical Rainfall Measuring Mission (TRMM) satellite, which was launched in November 1997. The primary objective of the TRMM satellite is to study the variability of rainfall in the tropics and midlatitudes using a cluster of instruments that are designed to provide both radar vertical structure information and high resolution passive microwave measurements (Simpson et al. 1988; Kummerow et al. 1998). This particular satellite has assisted in our understanding of precipitation characteristics or regimes on various spatial and temporal scales (e.g., Nesbitt and Zipser 2003; Hirose and Nakamura 2005; Nesbitt et al. 2006 and others). However, it is the combination of these types of sensors on multiple satellites and the advance in precipitation estimate algorithms that are now being used to produce merged precipitation products. These merged precipitation products are believed to produce better results than singular instruments, such as IR-based data (Kidd et al. 2003). 
Initial merged products, such as the Global Precipitation Climatology Project (GPCP; Huffman et al. 1997; Adler et al. 2003), were relatively low in resolution on both temporal and spatial scales (monthly and $2.5^{\circ} \times 2.5^{\circ}$ latitude-longitude grid) and thus, were inadequate for monitoring finer-scale precipitation features. Since then, precipitation products have been produced at a higher spatial and temporal resolution and have given researchers the ability to monitor precipitation events in near real time. An example of this would be the TRMM Multi-satellite Precipitation Analysis 3B42 version 6 dataset (TMPA). The TMPA product is derived from a combination of the amalgamation of passive microwave estimates from a host of low earth orbiting satellites and calibrated IR estimates from geostationary platforms (the reader is referred to Huffman et al. (2007) and Huffman et al. (2010) for further details on the TMPA algorithm and 3B42 processing). The advantage of using these data is that it provides quasi-global $\left(50^{\circ} \mathrm{S}-\right.$ $50^{\circ} \mathrm{N}$ ) precipitation rate estimates over a $0.25^{\circ} \times 0.25^{\circ}$ spatial resolution and contains a temporal resolution of 3 hours (centred on synoptic times - 0000, 0300, 0600, etc). The TMPA has been computed for the entire TRMM period and is available in both near real time (2002-present) and post-processed format or research product (1998-present), with the latter used in this study. As noted by Huffman et al. (2007), one of the key differences between these two products is that the research product uses the TRMM Combined Instrument (TCI) as the precipitation calibrator, while the real time data uses the TRMM Microwave imager (TMI). In addition, the research product re-scales the monthly sums of the 3-hourly fields to a monthly rain-gauge analysis, which is not available for the real time. The advantage of incorporating rain-gauge data in TMPA is that it is considered to reduce bias in storm rainfall volume and average rainfall rate (Tian et al. 2007; Demaria et al. 2011).

The full utilization of satellite-based precipitation datasets is hindered by the uncertainty and reliability associated with the precipitation estimates. Thus, numerous satellitederived precipitation validation studies (i.e. "ground truthing") have been conducted over the past few years (e.g., Adler et al. 2001; Wolff et al. 2005; Huffman et al. 2007; Ebert et al. 2007; Dinku et al. 2008; Sapiano and Arkin 2009; Demaria et al. 2011 and others). Results by AghaKouchak et al. (2011) indicate that none of the current satellite-derived 
precipitation products are ideal for detecting extreme precipitation and that there is considerable seasonal variability of precipitation algorithms' skill in detecting extreme precipitation rates. One of the primary concerns regarding the reliability of the TMPA data is that it has been shown to contain too many high precipitation rate values and it may underestimate the occurrences of low precipitation rates (Wolff and Fisher 2008; Villarini and Krajewski 2007). This is supported by Jiang et al. (2008), who report that the fraction of precipitation produced by tropical cyclones is as much as $10-30 \%$ higher in the TMPA real-time product than in comparable radar and rain-gauge data. Thus, regions that contain a concentration of high precipitation rates will likely have an excess in the TMPA product (Huffman et al. 2010). Similar results were produced by Habib et al. (2009), where they found that both estimation and underestimation occurred in their analysis of the TMPA product and tropical-related heavy rainfall events. In addition, results from Villarini and Krajewski (2007) suggest that TMPA contains a lack of sensitivity to lower values of rainfall causing atmosphere conditions. This bias might be a concern for regions that are dominated by frequent, but not very intense precipitation regimes.

The problem may lie in the passive microwave rainfall algorithm used over land. High frequency channels (i.e. $85 \mathrm{GHz}$ ) are used to associate the concentration of ice particles with precipitation. Nesbitt et al. (2004) note that the microwave based algorithm has a high bias over land due to the inappropriateness of the empirically derived $85 \mathrm{GHz}$ ice scattering - rain relationship in storm types found during the warm season. These authors found that the TMI, aboard the TRMM satellite, generally overestimated rainfall in the tropics and in the midlatitudes during the warm season. In addition, the underlying terrain (i.e. land/coast vs. ocean) appears to influence the performance or skill of some of the microwave sensors used to create the TMPA data (Wolff and Fisher 2009). Thus, these authors suggest that caution should be applied when incorporating the various satellites into a global rainfall product and, instead of the precipitation estimates just being averaged in the TMPA data, they should rather be weighted by quality. 
Another concern is that of spatial and temporal resolution of satellite derived rainfall products. Negri et al. (2002) suggest that applying a 4-hour running mean on data produced by the instruments aboard the TRMM satellite (hourly output) can reduce spatial variability in the sampling. In terms of the TMPA product, Hossain and Huffman (2008) suggesting that when more time/space averaging is applied there is an improvement in the uncertainty. Scheel et al. (2010) showed that, over the central Andes region, South America, temporal aggregation (daily to monthly) of the TMPA data produces better results compared to rain-gauge data, but they found no significant improvements when spatial aggregation $\left(0.25^{\circ} \times 0.25^{\circ}\right.$ to $1^{\circ} \times 1^{\circ}$ grid $)$ was applied. Similarly, Su et al. (2008) evaluated the TMPA product as a source of forcing data for hydrological models in the La Plata Basin, South America. These authors found that the TMPA data agrees well with gridded rain-gauge data on monthly scales, but was less successful on daily time scales. Nevertheless, they concluded that the TMPA product has the potential for hydrological forecasting on data sparse regions.

From the validation studies there is evidence that the TMPA data seems to have skill in precipitation estimates over land regions that contain convective regimes, particularly during the warm season. In a comparative analysis between precipitation estimates for satellite observations, including the TMPA data, and numerical models, Ebert et al. (2007) found that the accuracy of satellite-derived rainfall totals was greatest in the warm season, particularly in regions dominated by a convective precipitation regime. These derived rainfall totals were compared against relatively dense rain-gauge networks across the United States, Australia and northwest Europe. It should be kept in mind that all of these domains are comprised of various precipitation regimes (e.g., convective, frontal, orographic, etc). Sapiano and Arkin (2009) also note that TMPA data exhibited little bias in warm season convective precipitation estimates over the Great Plains in the United States, when compared to rain-gauge estimates. On a smaller scale analysis, Villarini and Krajewski (2007) also found that the TMPA product produced the best results during the warm season. In addition, operational IR-based precipitation algorithms have been shown to perform reasonably well during the summer months, when convective precipitation regimes are dominant (e.g., Feidas et al. 2008; de Coning and Poolman 2011). The same 
data has also already successfully been used in MCC rainfall variability studies in South America (Durkee et al. 2009) and global tropical cyclones precipitation patterns (Jiang and Zipser 2010). Furthermore, in terms of MCS rainfall rate and rainfall volume, Demaria et al. (2011) found that the TMPA product correlated extremely well with ground observations in South America, but the maximum rainfall produced by the MCS was often overestimated. Thus, using the TMPA research product to look at MCC rainfall variability over southern Africa appears to be a feasible solution considering the limitations of the sparse rain-gauge network. It should be noted that the TRMM precipitation product has previously been utilised in South Africa to document extreme rainfall events in the region (e.g., Rouault et al. 2003b; Blamey and Reason 2009; Hart et al. 2010), but has not been used for climatology studies.

\subsection{Methods and Validation}

The construction of various regional MCC precipitation studies around the world have been based on a mixture of precipitation measuring / detection techniques, as well different approaches in the methodology. Some studies have used only rain gauge data (e.g., Kane et al. 1987; McAnelly and Cotton 1989; Laurent et al. 1999) or a combination of both rain gauge data with that of radar or satellite data or both (e.g., Fritsch et al. 1986; Ashley et al. 2003) or just satellite derived rainfall data (Laing et al. 1999). Different methods are also used to delineate MCC precipitation, with some studies (e.g., Fritsch et al. 1986; Kane et al. 1987) including the precipitation produced by the "first storms", whereas others often exclude this phase of the MCC life cycle (e.g., McAnelly and Fritsch 1989; Ashley et al. 2003). Furthermore, some make the use of concentric circles of specific areas during the four key MCC stages (see Chapter Two) to demarcate the systems rainfall and then extract the precipitation within the circles (e.g., Ashley et al. 2003). Other studies have made use of a convex hull placed around the systems cloud shield at each stage of the life cycle (e.g., Durkee et al. 2009). Ultimately, this difference in methods does produce some difficulty in comparing the results from the various MCC regions. 
For the purpose of this thesis, MCC precipitation is assumed to have fallen within the aerial swath of the storm track. To determine the rainfall produced by each system, a polygon is created for the spatial distribution of the system (based on the $-52^{\circ} \mathrm{C}$ cloud cover) during each stage of its life cycle. Each "life cycle" polygon is then combined to form a single convex hull (Barber et al. 1996), which is then overlaid onto the 3B42 rainfall grid to extract the precipitation. Only precipitation occurring during the time of the event is extracted from the domain. An example of the process is given in Fig. 6.1 and Fig. 6.2, which depicts the MCC that took place along the east coast of southern Africa during the night of 26-27 November 1999. The estimation task is then performed for each of the 70 systems and the output is then aggregated into monthly and summer season totals. The contribution of MCC rainfall is then expressed as the ratio of MCC rainfall to the total rainfall at each grid point.

As alluded to earlier, in this study the 3-hourly TMPA rain data are used, which are at 0.25 degree spatial resolution and are based on measurements from both IR and passive microwave satellite data, as well as rain-gauge data. A key issue with respect to using TMPA data over southern Africa is validation. In a comparison between a 10-year period of South African Weather Service (SAWS) rainfall data and TMPA data for a South African Summer rainfall region, Rouault et al. (2010) note that the TRMM product is able to accurately capture the diurnal cycle, as well as match the daily rainfall patterns reasonably well. However, it was also shown to overestimate rainfall, particularly during the late evening / early night time hours. It should be noted that this analysis was performed using only one rainfall station, due to the lack of stations containing hourly data.

The annual and core summer (DJF) precipitation derived from the TMPA data for the 1998-2007 period is shown in Fig 6.3. It is evident that the TMPA data accurately captures the spatial distribution of subtropical southern Africa rainfall reasonable well, with the highest precipitation totals near topography and over Mozambique, and the marked decrease in rainfall in the far west and southwest. In comparison with the analysis of Kruger (2007), the TMPA data tends to underestimate the precipitation amount in the 
South African summer rainfall regions, particularly along the eastern escarpment. However, it must be kept in mind that the Kruger (2007) analysis is for the period 19611990 and was created using SAWS station data.

Figure 6.4 illustrates that the TMPA data also compares reasonably well with SAWS monthly station data with regards to the annual cycle. These few stations are distributed across the South African summer rainfall region (see Fig. 6.3 for locations), while the TMPA data is extracted using a $1^{\circ} \times 1^{\circ}$ box surrounding the location of each station. It is evident that the TMPA data accurately captures the annual precipitation cycle, with most of the rainfall for these stations coming during the summer months (November to February). It is interesting to note that the annual cycle (in terms of rainfall totals) is more accurately captured in the TMPA data for the inland stations (e.g., Mbombela, Ermelo, Johannesburg), while less so for the coastal stations (e.g., Durban and Richards Bay). As noted by Wolff and Fisher (2009), the underlying terrain or surface is known to have an influence on the retrieval of information by microwave sensors, which could be the case here (i.e. land vs. ocean). Furthermore, it should be recognised that the TMPA data used here is from a $1^{\circ} \times 1^{\circ}$ grid, compared to the single point of the weather station. Thus, it is likely that the TMPA data will not capture features that are specific to that weather station location, such as the surrounding terrain. Figure 6.5 illustrates the spatial distribution of rainfall over subtropical southern Africa during the summer months according to the TMPA data. Caution must be advised regarding the TMPA results outside the borders of South Africa, due to the lack of station data to validate the data. This is particularly a concern for the Mozambique region, which contains frequent MCC activity.

In terms of core summer (DJF) rainfall totals, the TMPA data tends to underestimate the seasonal totals at most stations (Fig 6.6). It is evident that the TMPA data derives rainfall moderately better over the inland stations compared with that of the coastal stations. The spatial distribution of the DJF rainfall for the whole region is shown in Fig. 6.7. Using the mean TMPA data from January 1998 - December 2007 as a baseline, anomaly maps were created for subtropical southern Africa to spatially illustrate the wet and seasons 
(Fig. 6.8). Although TMPA underestimates the summer totals in most cases, it appears to capture most of the wet and dry seasons reasonably well.

\subsection{Rainfall over Southern Africa}

\subsubsection{Entire Climatology}

The 70 MCCs presented in Chapter Four are used here to investigate the role MCCs play in summer rainfall over subtropical southern African. The spatial distribution of MCC cloud cover, created using the polygons discussed in the methodology, is shown in Fig. 6.9. As found in Chapter Four, it is clear that most systems are concentrated over the eastern border of the study region, which includes eastern Southern Africa, eastern Zimbabwe, Mozambique, and the adjacent ocean. This spatial pattern of the systems is clearly evident in the precipitation produced by these systems. A summed total of all the precipitation produced by these 70 systems is presented in Fig. 6.10a. Most of the rainfall associated with MCCs is found to occur over central Mozambique and extending southwards to the east of the eastern escarpment in KZN. High precipitation totals associated with these systems also occur over the neighbouring ocean, particularly off the northeast coast of South Africa. The precipitation produced by MCCs over Botswana and Namibia are considerably less by comparison. However, this is due to the infrequent occurrence of systems in these regions.

The average MCC in subtropical southern Africa is found to produce $17.6 \mathrm{~mm}$ of rainfall over an area of approximately $195,000 \mathrm{~km}^{2}$, with a volume of $3.4 \mathrm{~km}^{3}$. On average, the systems tend to produce a rainfall maximum in excess of $130 \mathrm{~mm}$ (median of $106 \mathrm{~mm}$ ). It is clear that in terms of MCC precipitation, southern Africa systems are similar to those of South America and possibly the U.S., but this precipitation is produced over a much smaller area (see Table 6.1). As discussed in Chapter Four, systems identified in southern Africa appear to be considerable smaller than their global counterpart. However, caution should be applied with direct comparisons because the differences in precipitation characteristics between the regions may be due to several factors. For example, the 
biggest producers of precipitation are those systems found in Sahelian Africa, but this was based on systems occurring during a single warm season. In the U.S., differences between Kane et al. (1987) and McAnelly and Cotton (1989) may be attributed to the different sampling period, with the former including springtime events, while the latter only focused on summer months. Not only are spring events larger and of longer duration than those in summer, but they have also been documented to be heavier-raining systems compared to those in the summer months (Kane et al. 1987; Ashley et al. 2003). However, not only does the average size of systems have to be taken into consideration for this precipitation analysis, but also the type of data and methods used to construct the MCC precipitation contribution. In this case, Laing et al. (1999) used an Special Sensor Microwave Image (SSM/I) derived precipitation product and IR data, while McAnelly and Cotton (1989) used a network of hourly surface rain gauges. As alluded to previously, the TMPA data is made from a combination of datasets and these two datasets here are incorporated in this precipitation dataset, which is used in this study and by Durkee et al. (2009). Furthermore, the results may be influenced by the size criteria threshold used to identify MCCs (i.e. $-32^{\circ} \mathrm{C}$ vs. $-52^{\circ} \mathrm{C}$ ), with the $-32^{\circ} \mathrm{C}$ producing a much larger cloud shield and thus, possibly resulting in a greater rainfall area and total.

The spatial distribution of the mean contribution of MCC to southern Africa summer rainfall (Fig. 6.10b) is very similar to that of the spatial distribution of systems as shown in Fig. 6.9. MCCs are found to contribute up $20 \%$ of the total summer rainfall (November - March) in parts of the eastern region of the domain. In general, the MCC summer rainfall contribution for most of the eastern region is approximately between $8 \%-16 \%$. If the month of March is excluded from the analysis, then the contribution of MCCs to summer rainfall increases, with these systems contributing up to $24 \%$ in some places over Mozambique (Fig 6.10c). The few systems that occur over Botswana contribute up to $6 \%$ $(8 \%)$ of the total summer (excluding March) rainfall for the region, while over Namibia, the contribution is less than $2 \%$.

This summer rainfall contribution to the various regions of subtropical southern Africa is similar, if not slightly less, to that documented by Durkee et al. (2009) for MCCs in 
subtropical South America, which contributed between 11\% - 20\%. Similarly, results of Ashley et al. (2003) show that systems in the U.S. contribute between $8 \%-18 \%$ during the warm season. However, it must be noted that the MCC criteria used by Ashley et al. (2003) included the $-32^{\circ} \mathrm{C}$ cloud top temperature. Elsewhere in Africa, Laing et al. (1999) suggest that MCCs in the West Africa region contribute up to $22 \%$ of the Sahelian rainfall. However, all these studies note that the MCC contribution varies considerably on monthly and seasonal scales.

\subsubsection{Monthly Analysis}

MCCs are found to contribute throughout the summer months from November through to February, but less so during the transitional months of October and March (Fig 6.11). However, the spatial distribution of this contribution varies from month to month. During November, the major MCC contributions (up to 28\%) are located off the east coast of South Africa, over the Agulhas Current. In general, most of eastern South Africa and southern Mozambique are influenced by rainfall produced by MCCs during the month of November. This pattern shifts slightly during December, whereby the maximum contribution, up to $30 \%$, is now positioned over central southern Mozambique, as well as over the ocean off the east coast. At the same time, the influence of MCCs on the rainfall over the interior of South Africa is reduced. By January, the contribution by MCCs is confined to northeast South Africa and southern Mozambique, with contributions up to $28 \%$. The contribution of MCCs to regional rainfall begins to reduce during February, with a maximum of $26 \%$ over central southern Mozambique. Furthermore, Botswana tends to receive its maximum contribution of MCCs to rainfall during the month of February. By March the contribution of the systems as considerably weakened, with the maximum contribution being $12 \%$ along the northeast coast of South Africa. This result is expected due to the considerable reduction of systems during this month.

These monthly contributions are similar in extent to that identified by Ashley et al. (2003) for the U.S. These authors found that MCCs contributed $10 \%-20 \%$ of the monthly rainfall across the central U.S., with a maximum of $28 \%$. However, southern African systems 
contribute less compared to their South American counterpart, with the latter containing monthly contributions of up to $50 \%$ in some places (Durkee et al. 2009). It is interesting to note that the equatorward shift of systems over southern Africa during the late summer months, discussed in Chapter Four, is reflected in the MCC rainfall contribution. This feature is evident by the reduced influence or contribution these systems have to regional rainfall farther polewards during the months of January and February compared to that of November and December. This behaviour is in contrast to what happens in the U.S., where there is a poleward shift in the larger contribution percentages during the later summer months (Ashley et al. 2003). This spatial distribution is also evident when the warm season is divided into 3 month intervals, in an attempt to identify any pattern during the early (OND), core (DJF) and late (JFM) summer (Fig. 6.12). The contribution by MCCs is more widely distributed off the east coast of South Africa and contains a higher percentage contribution during the early summer months compared to the late summer.

\subsubsection{Seasonal Analysis}

The impact that MCCs may have on southern African summer rainfall is more apparent in their contribution to individual warm season total rainfall (Fig. 6.13). It is evident that there is considerable interannual variability associated with the contribution these systems make to the total rainfall. In some years, they may contribute up to $42 \%$ (e.g., 1999/2000) of the total rainfall, while in others the maximum contribution does not exceed 18\% (e.g., 2001/2002). Similarly, systems in the U.S. and South America are also found to occasionally contribute in excess of $40 \%$ of the total warm season precipitation (Ashley et al. 2003; Durkee et al. 2009). In addition, there is considerable spatial variability associated with the warm season contribution by MCCs over southern Africa. Although most of the rainfall contribution is restricted to the eastern portion of the domain, there does not appear to be any consistent pattern throughout the years. There is some indication that when more systems occur per season, the greater the contribution by MCCs to the total warm season total (e.g., 1999/2000, 2003/2004, 2005/2006). However, 
if the spatial distribution is not concentrated, the contribution is not as great (e.g., 2001/2002).

It is difficult to evaluate whether the development of MCCs or lack there of may influence the region having an above or a below average rainfall for the season. Other systems, such as cloudbands and tropical depressions, make a considerable contribution to rainfall over southern Africa (e.g., Harrison 1984). Using the mean TMPA data for the January 1998 - December 2007 period as a baseline, rainfall anomalies (in percentage) were created for each warm season (Fig. 6.14). Of the eight warm seasons, the summer of 1999/2000 experienced well above average rainfall, as well as containing the most MCC activity, while the driest summer, that of 2002/2003, experienced the lowest MCC frequency. However, the warm seasons of 1998/1999, 2003/2004, 2004/2005 and 2005/2006 all contained similar amount of MCCs, yet yielded diverse anomalous precipitation patterns over eastern southern Africa and the adjacent ocean.

Even though no obvious relationship was found between MCC activity and ENSO in Chapter Four, the influence ENSO has on southern African summer rainfall has to be taken into consideration. It must be emphasised that this study only focuses on eight warm seasons and is thus not suitable for any robust statistical analysis. The summer seasons of 1998/1999, 1999/2000 and 2005/2006, which correspond to La Niña years, all received above average rainfall over the eastern southern Africa (Fig. 6.14). MCCs were found to be fairly consistent contributors during these periods, particularly for the latter two warm seasons (Fig. 6.13). Conversely, the dry summer years of 2002/2003 and 2004/2005 correspond to El Niño years. During both these seasons, MCCs were found to contribute slightly less towards the warm season rainfall. In the subsequent chapter, an MCC that developed during the 2002/2003 El Niño is shown to produce less rainfall than the other case studies. It was also evident in Chapter Five that the large-scale conditions were not conducive to long-lived convection and heavy rainfall during 2002/2003. Thus, it is suggested that the low contribution to seasonal rainfall during El Niño years could be due to the large-scale conditions not favouring long-lived, organised systems such as 
MCCs, but rather most of the rainfall could be produced by short-lived convective systems.

\subsection{Chapter Summary}

This chapter has focused on the precipitation characteristics of 70 MCCs that occurred during the summer months for the period of 1998-2006. The results suggest that over southern Africa, on average, MCCs tend to produce approximately $17.6 \mathrm{~mm}$ of rainfall over an area of $195,000 \mathrm{~km}^{2}$ per event. Apart from the spatial distribution of the rainfall, which is much smaller, these precipitation patterns are consistent with that found in other MCC regions. However, as alluded to previously, caution is advised when comparing the different MCC rainfall studies due to the various methods and datasets used. To gain more confidence in the results here would require a longer period of study, as well as using alternative precipitation datasets (e.g., a higher resolution rain gauge network). Nevertheless, the results do provide a good indication of the impact these systems can have on the regional rainfall patterns.

In terms of rainfall over subtropical southern Africa, it is evident that MCC are more prolific rainfall producers over the eastern regions of southern Africa (i.e. Mozambique and eastern South Africa), compared to either Botswana / Namibia or the interior of South Africa. On average, places in eastern South Africa and southern Mozambique receive approximately $8 \%-16 \%$ of the total warm season rainfall from MCCs. Southern Mozambique appears to be the biggest beneficiary from MCC rainfall during the warm season, particularly during the core summer months of December through to February. The reasons for this are not obvious, but it could due to the systems in Mozambique not propagating as much as systems found farther south, over eastern South Africa. The result is that more rainfall is produced over a smaller area when systems propagate less. The case study in the previous chapter demonstrated the high volume of rainfall produced by a system over Mozambique with limited propagation. Elsewhere, MCCs are a major contributor to the summer rainfall over northeastern South Africa, along the border of South Africa and Mozambique, as well as along the South African east coast. 
The results also show that there is considerable variability in the contribution these systems make towards monthly and warm season rainfall totals. More of the rainfall can be attributed to MCCs if one looks at individual months or even more so when analysing individual warm seasons. In some years, MCCs accounted for up to $40 \%$ of the warm season rainfall. However, there is considerable spatial variability associated with the warm season contribution by MCCs, and there does not appear to be any consistent pattern throughout the years. This result poses challenges for weather forecasting and seasonal prediction. The fact that these systems can be crucial for rainfall patterns, particularly when a few systems occur over a concentrated region, argues the necessity for a high resolution observational network over areas such as southern Mozambique and eastern South Africa, to facilitate improved disaster warning and mitigation. 


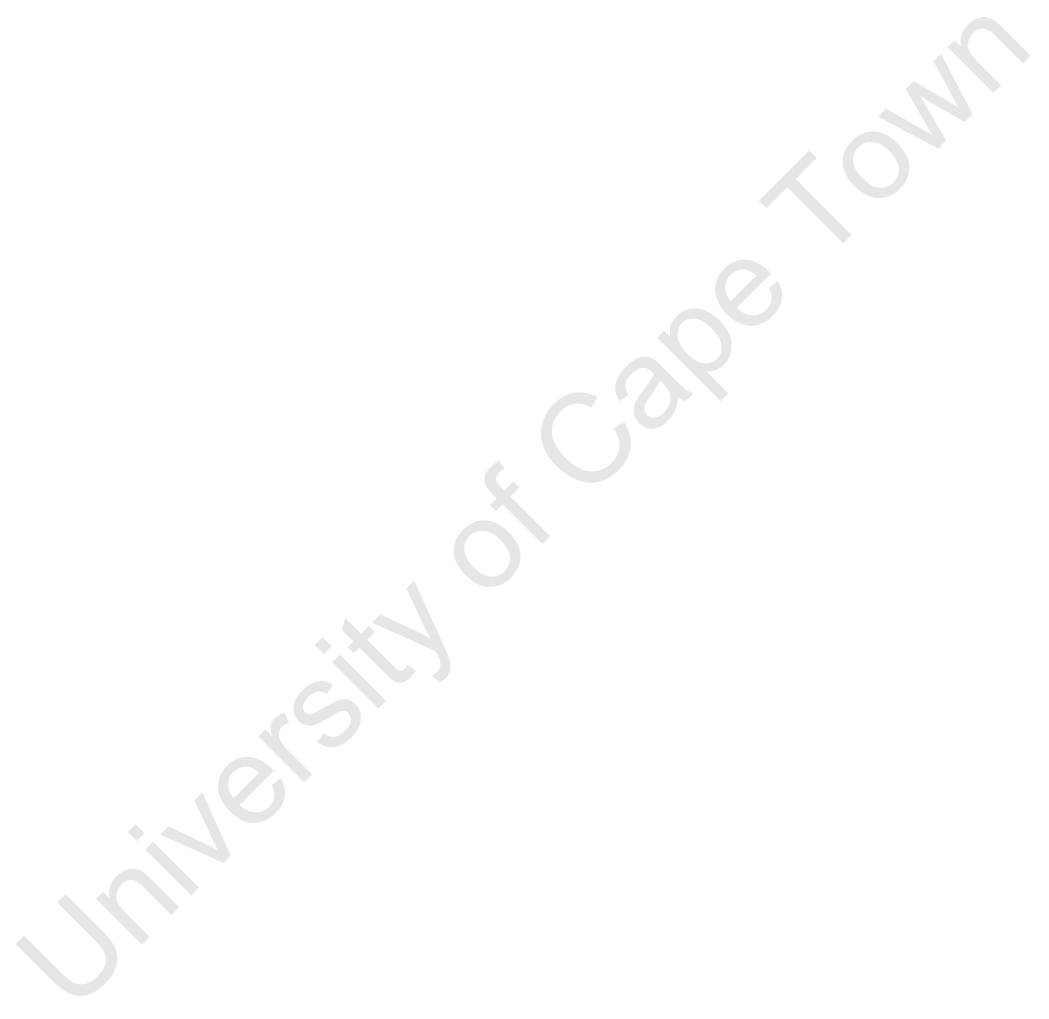

- 139 - 

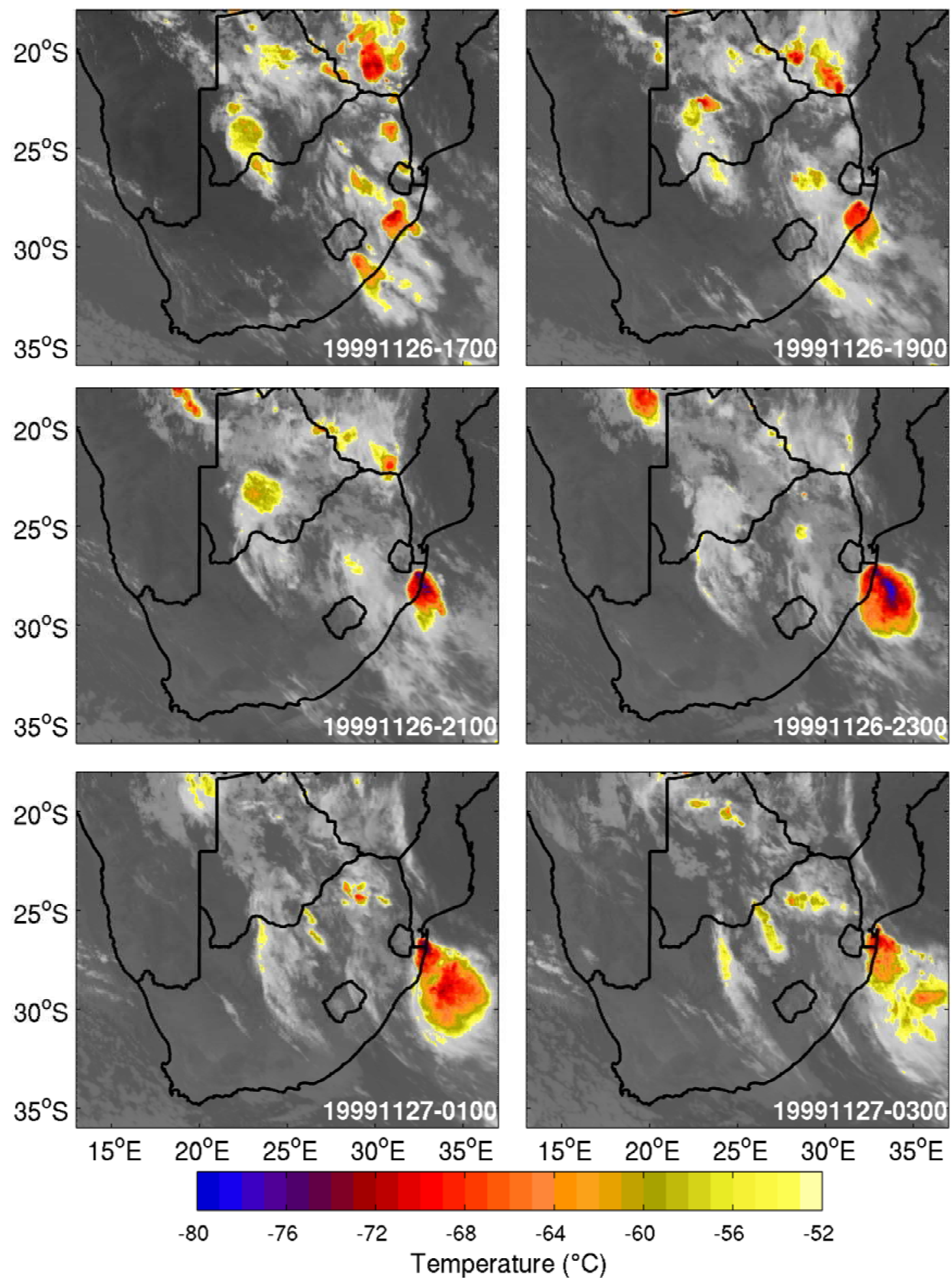

Figure 6.1: Satellite images (cloud top temperature shaded from $-52^{\circ} \mathrm{C}$ to $-80^{\circ} \mathrm{C}$ ) at 2 hour intervals (time, in UTC, and date in bottom right-hand corner) for the MCC that took place along the east coast of South Africa during 26-27 November 1999. 

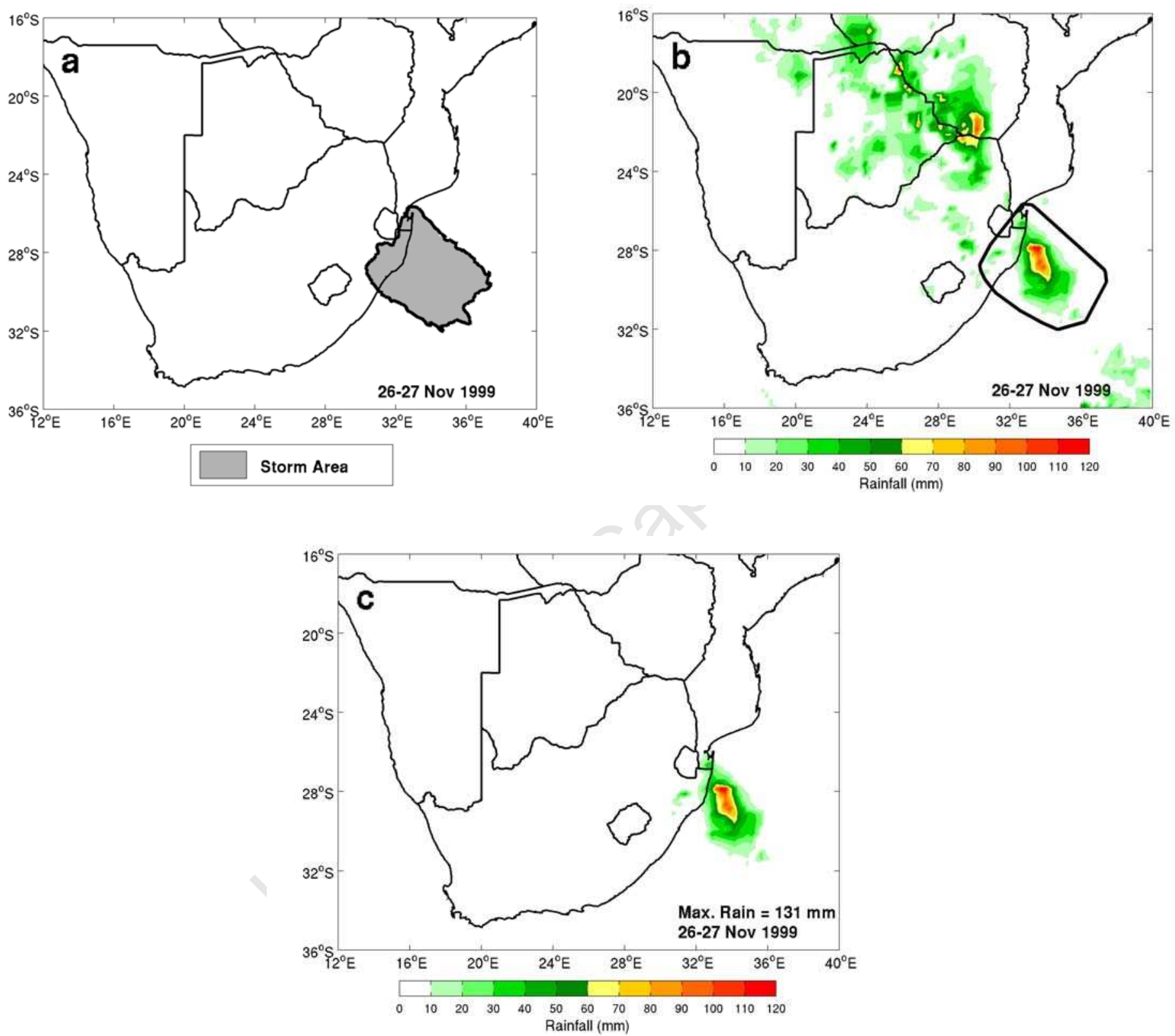

Figure 6.2: The process used to identify the rainfall produced by each system. This particular figure is for the MCC that occurred during the 26-27 November 1999 (see Fig. 6.1). The process is a) first identify the spatial extent of the cloud shield and produce polygon, b) convert polygon into a convex hull and overlay on the TMPA 3 hourly rainfall and c) extract only the rainfall occurring within the cloud shield. 


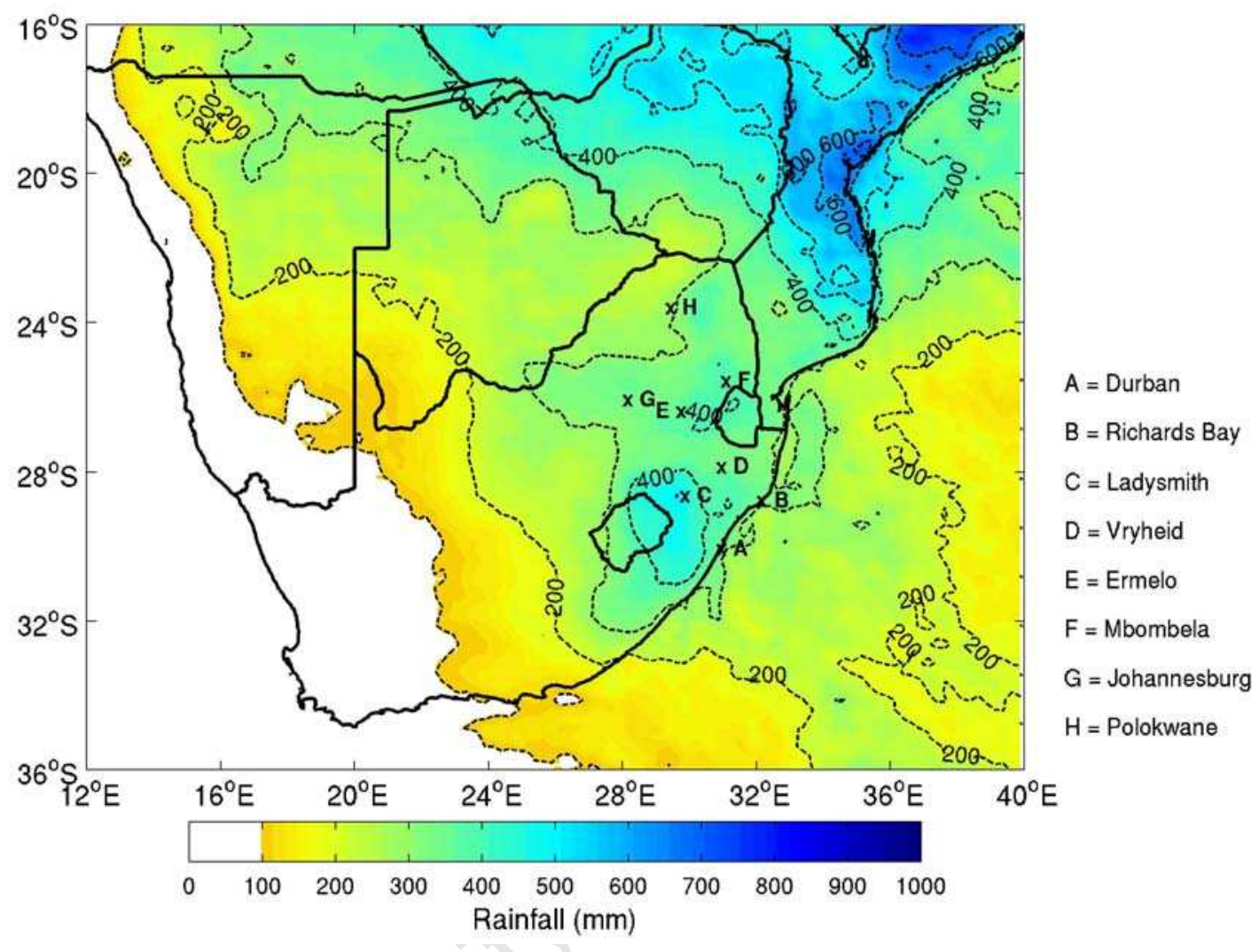

Figure 6.3: Mean DJF rainfall over southern Africa using TMPA data for the period January 1998 - December 2007. SAWS station locations are marked with an "X". 


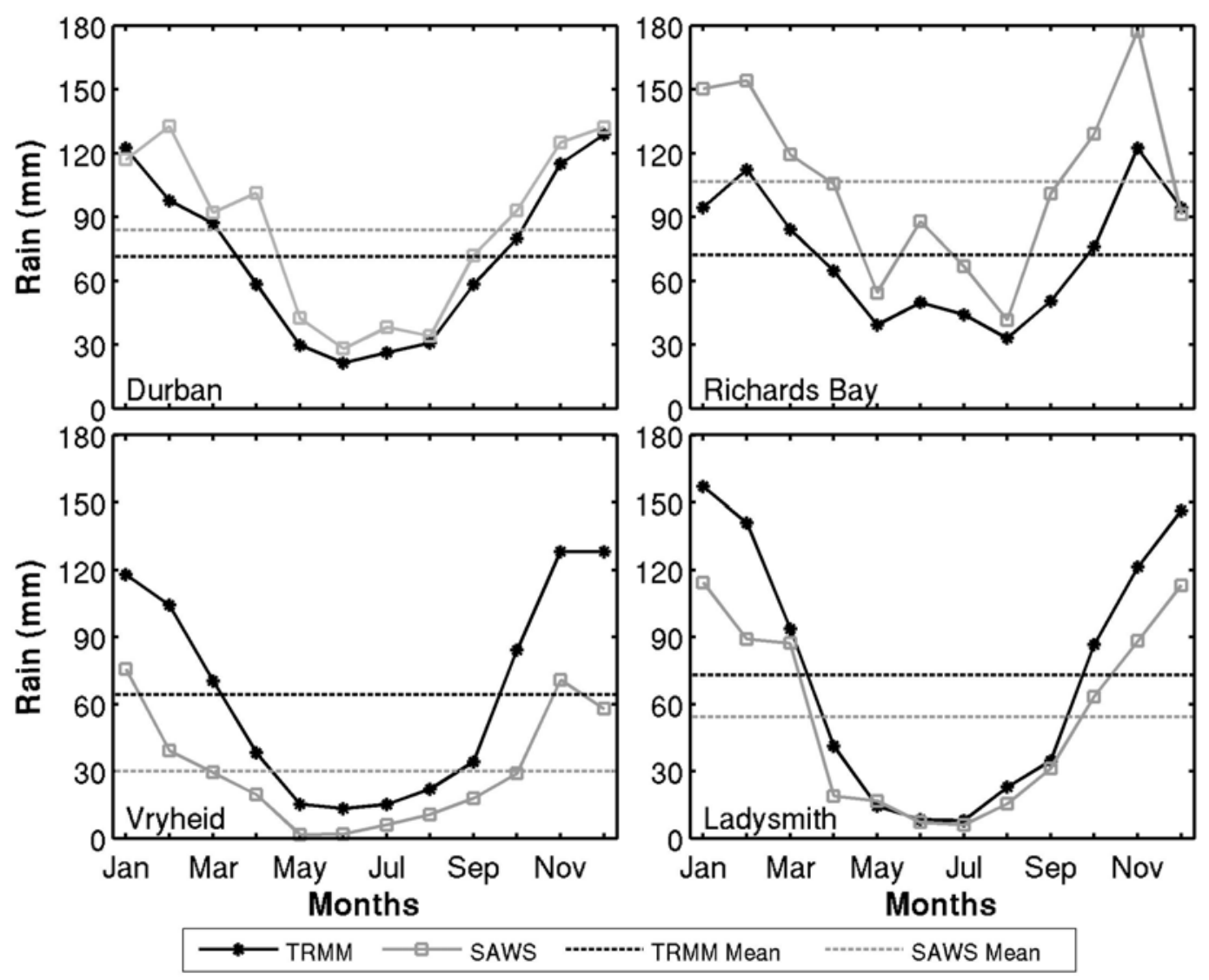

Figure 6.4: Mean monthly rainfall totals for a few SAWS weather stations (see Fig. 6.3 for locations) and the TMPA data (averaged over a $1^{\circ} \times 1^{\circ}$ ). 

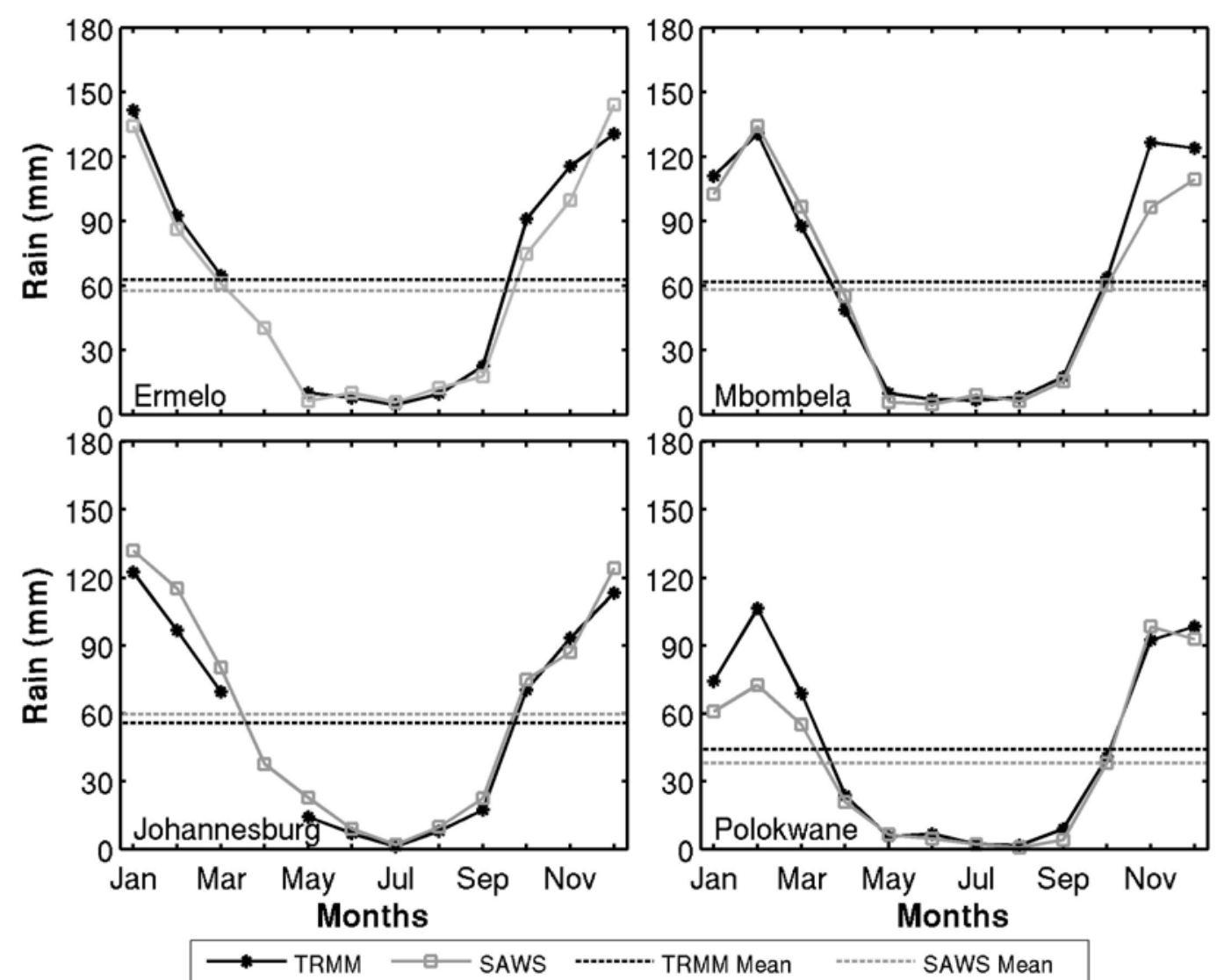

Figure 6.4 (cont): Mean monthly rainfall totals for SAWS weather stations (see Fig. 6.3 for locations) and the TMPA data (averaged over a $1^{\circ} \mathrm{x} 1^{\circ}$ grid). 

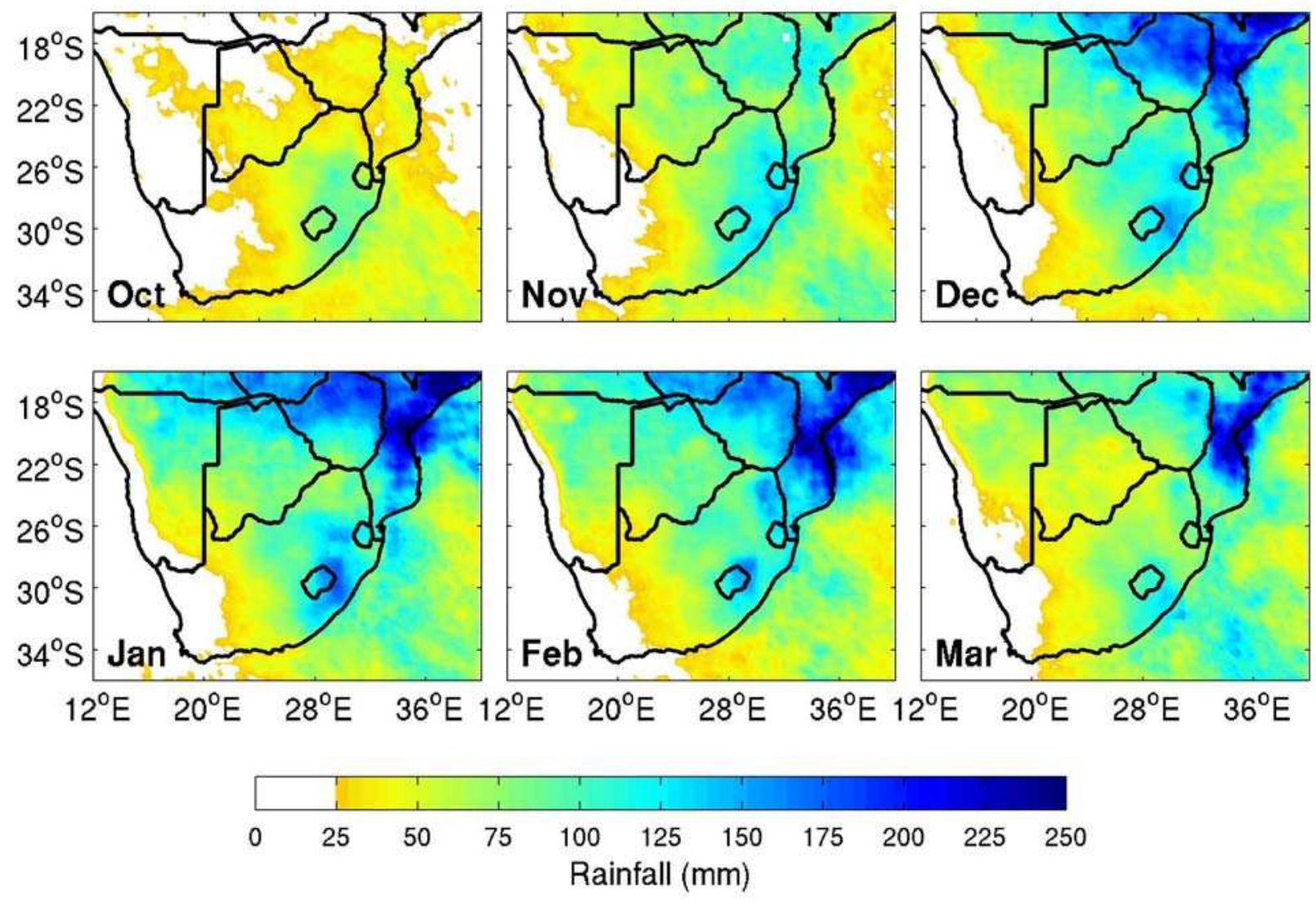

Figure 6.5: Mean spatial distribution of TMPA monthly rainfall (months in bottom left hand corner) for the period 1998-2007. 

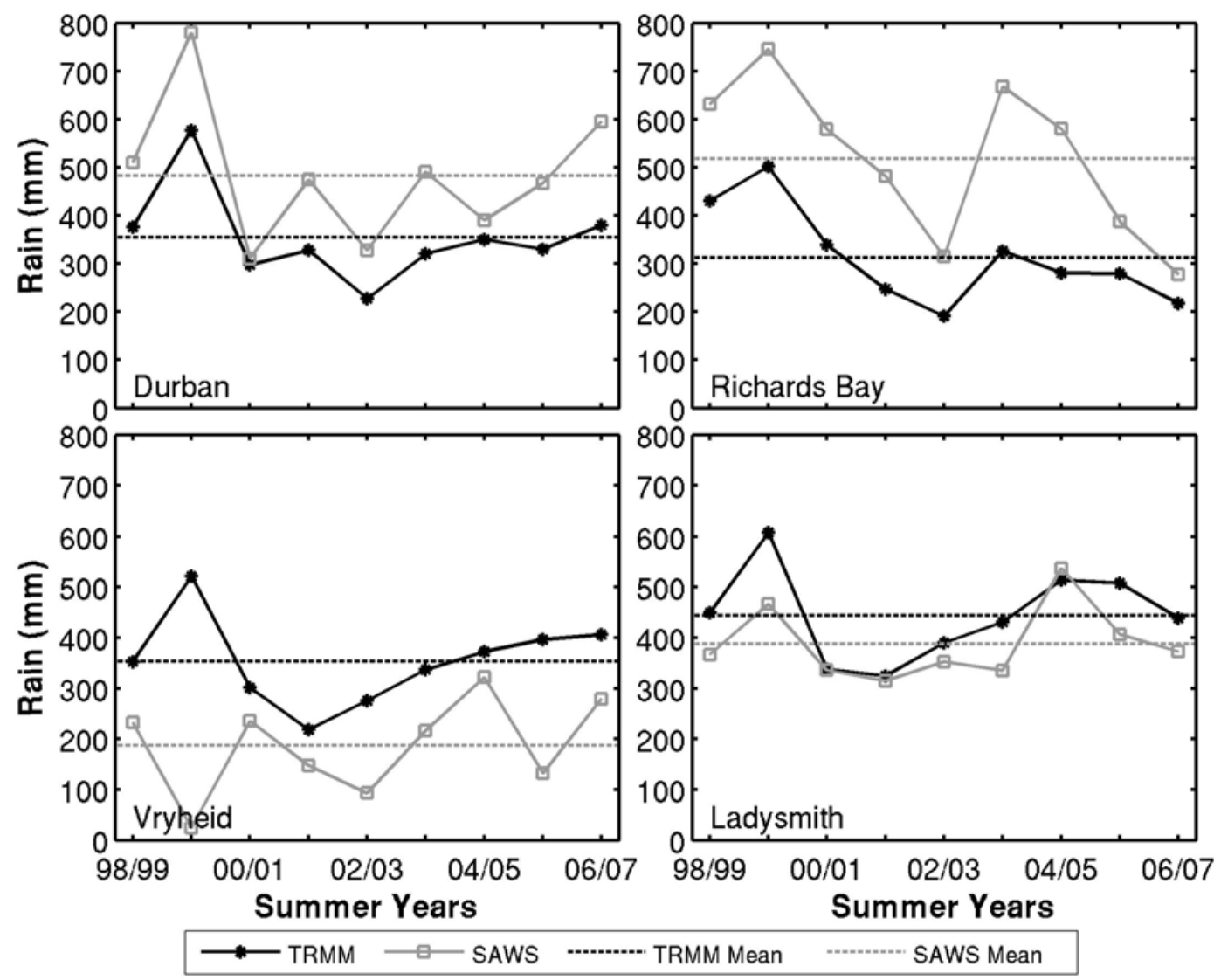

Figure 6.6: Core summer (DJF) rainfall totals for the SAWS weather stations used in Fig. 6.3 and the TMPA data (averaged over a $1^{\circ} \times 1^{\circ}$ ) for the period 1998-2007. 

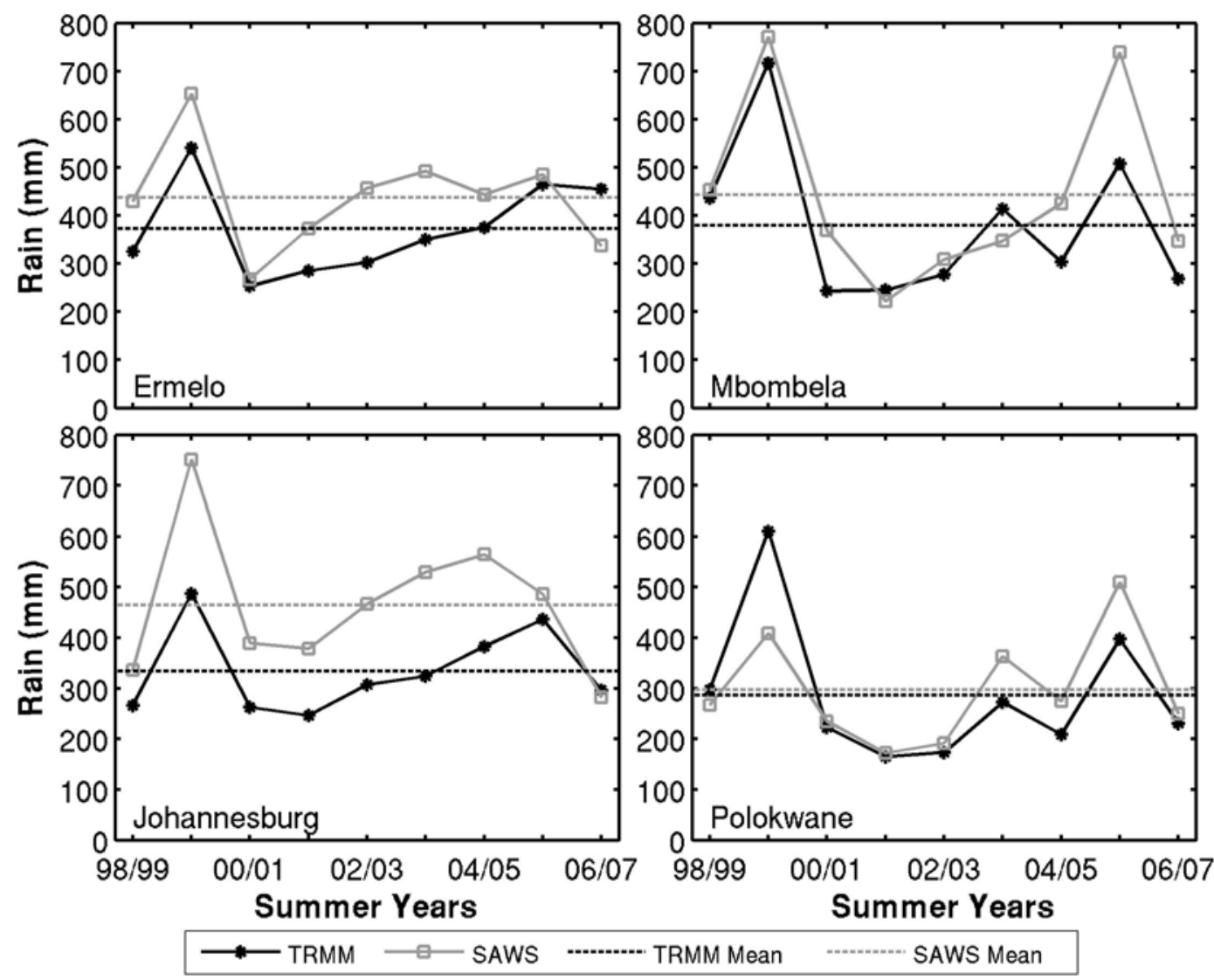

Figure 6.6 (cont): Core summer (DJF) rainfall totals for the SAWS weather stations used in Fig. 6.3 and the TMPA data (averaged over a $1^{\circ} \times 1^{\circ}$ ) for the period 1998-2007. 

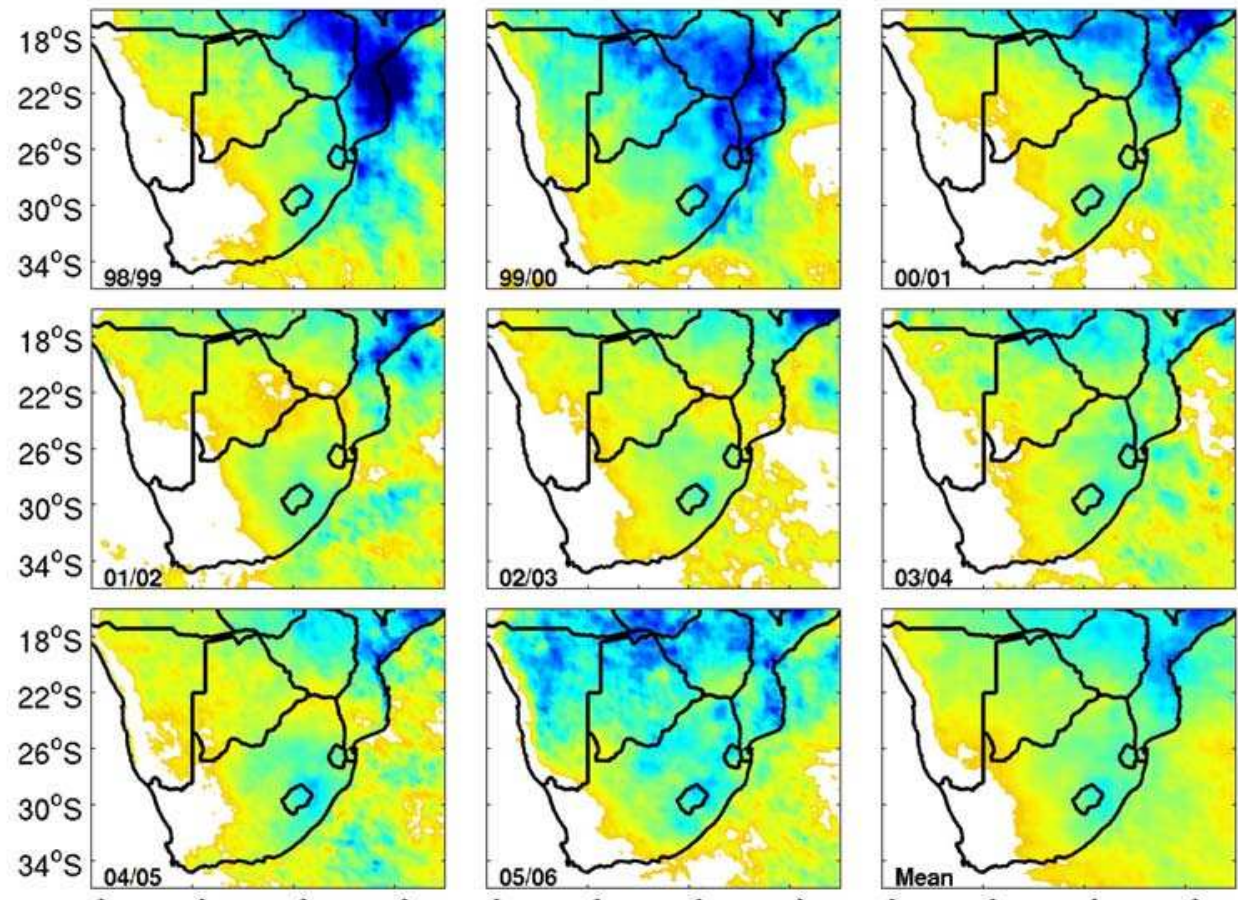

$12^{\circ} \mathrm{E} \quad 20^{\circ} \mathrm{E} \quad 28^{\circ} \mathrm{E} \quad 36^{\circ} \mathrm{E} \quad 12^{\circ} \mathrm{E} \quad 20^{\circ} \mathrm{E} \quad 28^{\circ} \mathrm{E} \quad 36^{\circ} \mathrm{E} \quad 12^{\circ} \mathrm{E} \quad 20^{\circ} \mathrm{E} \quad 28^{\circ} \mathrm{E} \quad 36^{\circ} \mathrm{E}$

Figure 6.7: DJF rain totals determined from the TMPA data.
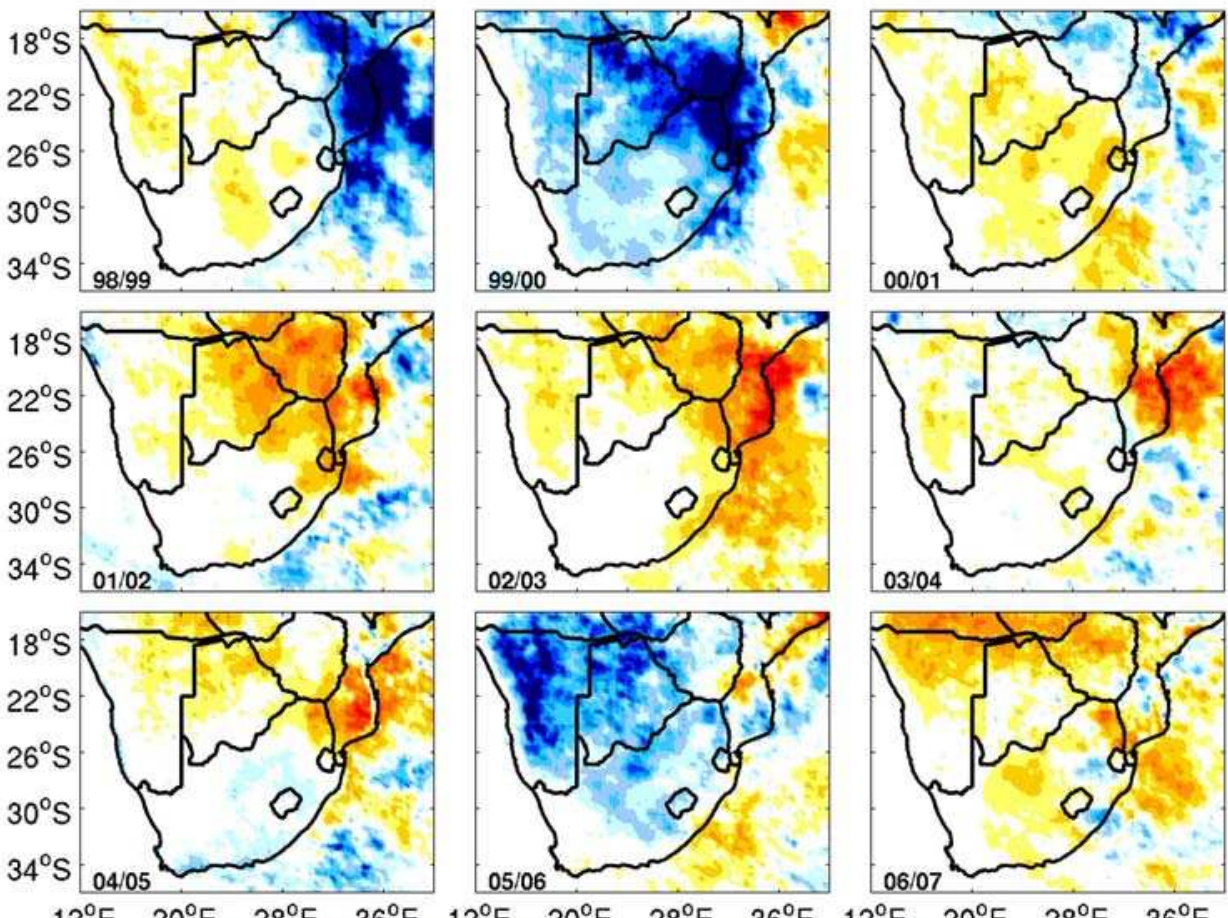

$12^{\circ} \mathrm{E} \quad 20^{\circ} \mathrm{E} \quad 28^{\circ} \mathrm{E} \quad 36^{\circ} \mathrm{E} \quad 12^{\circ} \mathrm{E} \quad 20^{\circ} \mathrm{E} \quad 28^{\circ} \mathrm{E} \quad 36^{\circ} \mathrm{E} \quad 12^{\circ} \mathrm{E} \quad 20^{\circ} \mathrm{E} \quad 28^{\circ} \mathrm{E} \quad 36^{\circ} \mathrm{E}$

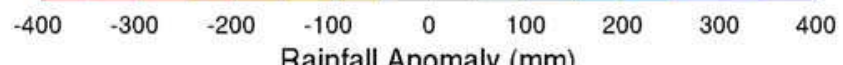

Figure 6.8: DJF Anomalies using the mean of the TMPA data for the period 1998-2007. 


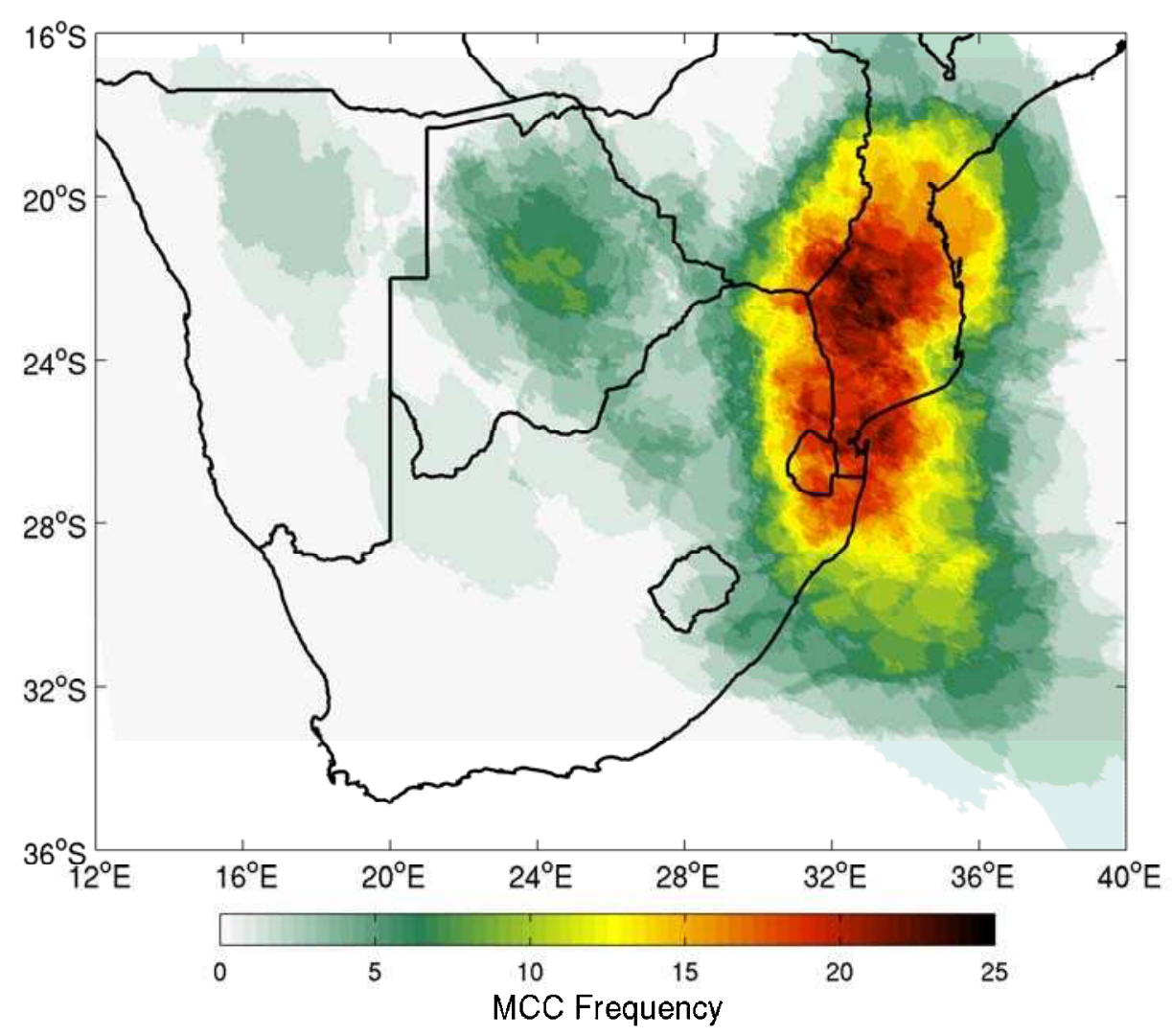

Figure 6.9: Spatial distribution of MCCs during October - March for the period 19982006. The frequency is determined by the adding the cloud shield polygons discussed in the methods and validation section. 

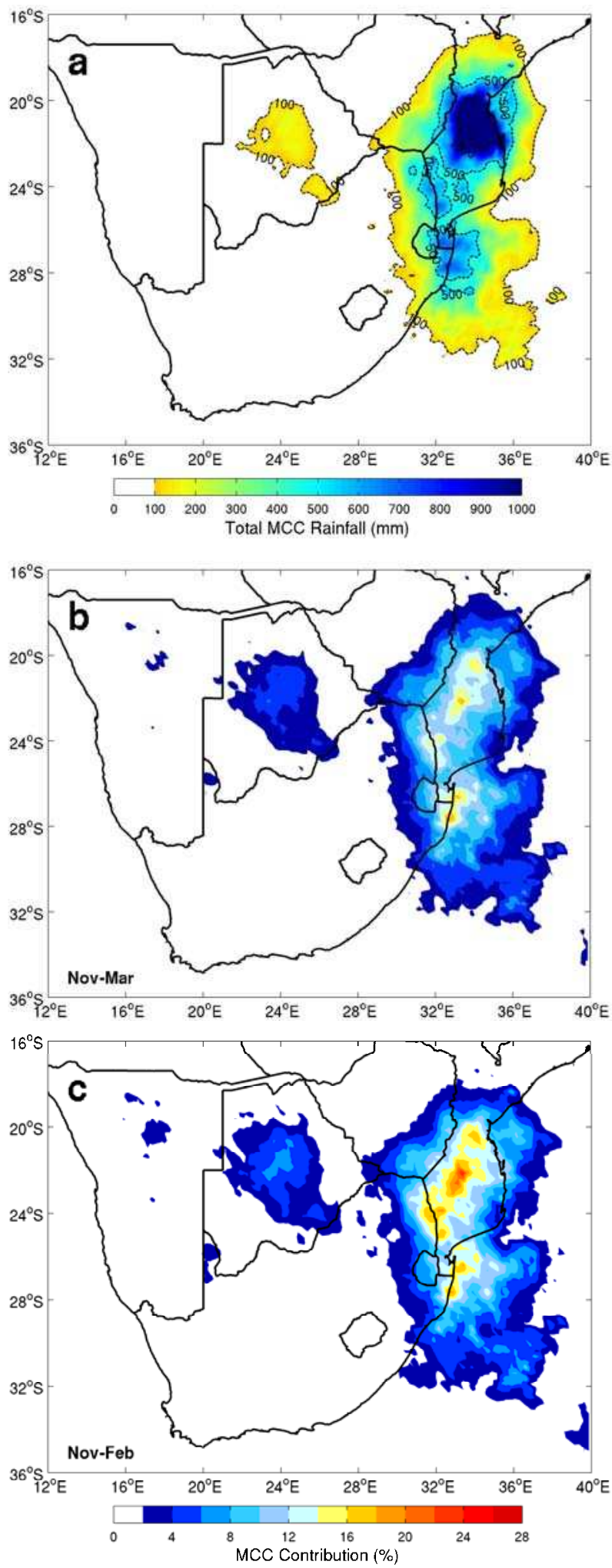

Figure 6.10: a) Total MCC rainfall for the 1998-2006 period and b) Spatial distribution of the mean MCC contribution (shaded, $2 \%$ interval) to the total summer (November March) rainfall over the region and c) same as Fig. 6.10b, but for November - February. 

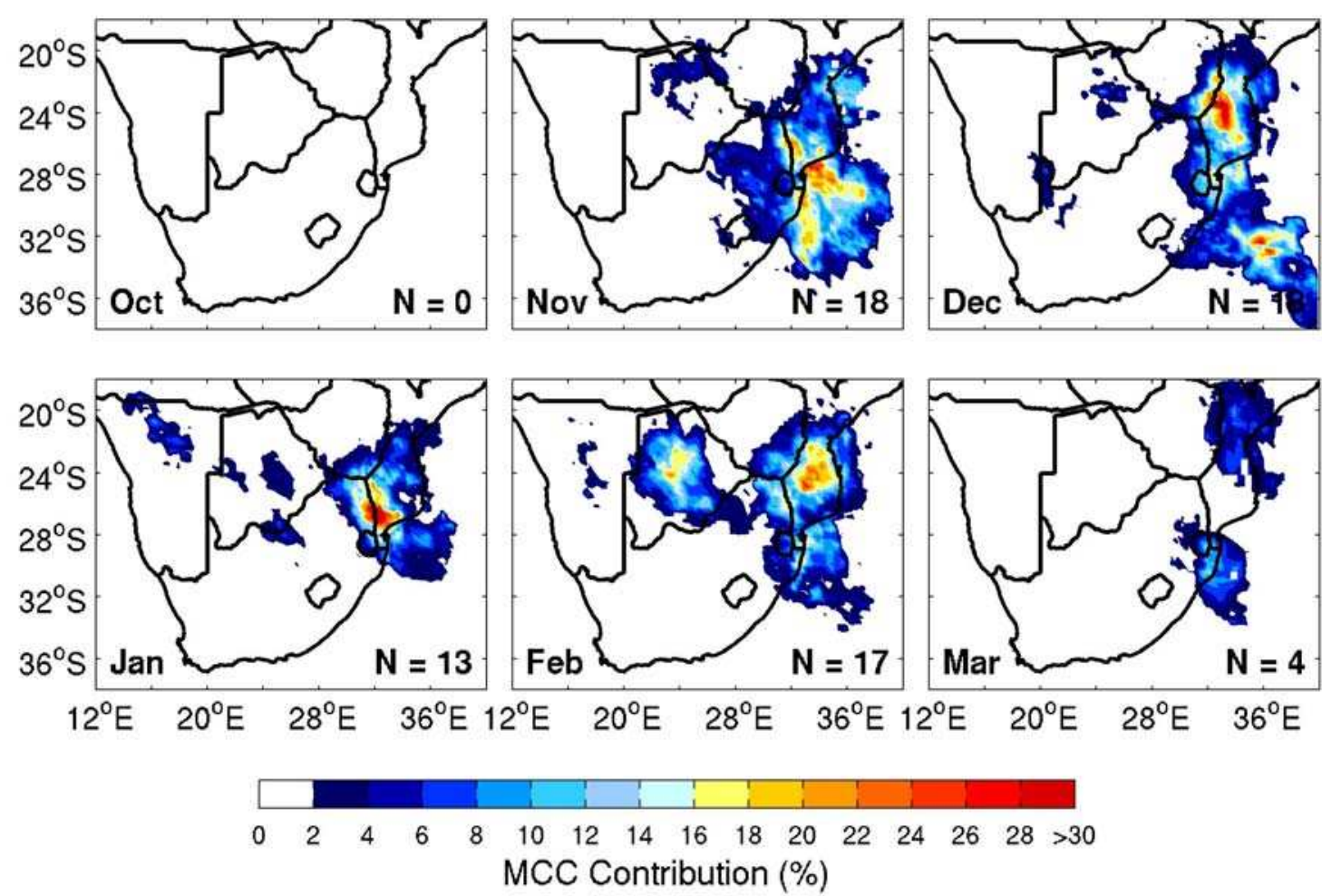

Figure 6.11: Spatial distribution of the mean MCC contribution to monthly rainfall. The month is indicated in bottom left hand corner and number of systems (" $N$ ") in bottom right. 


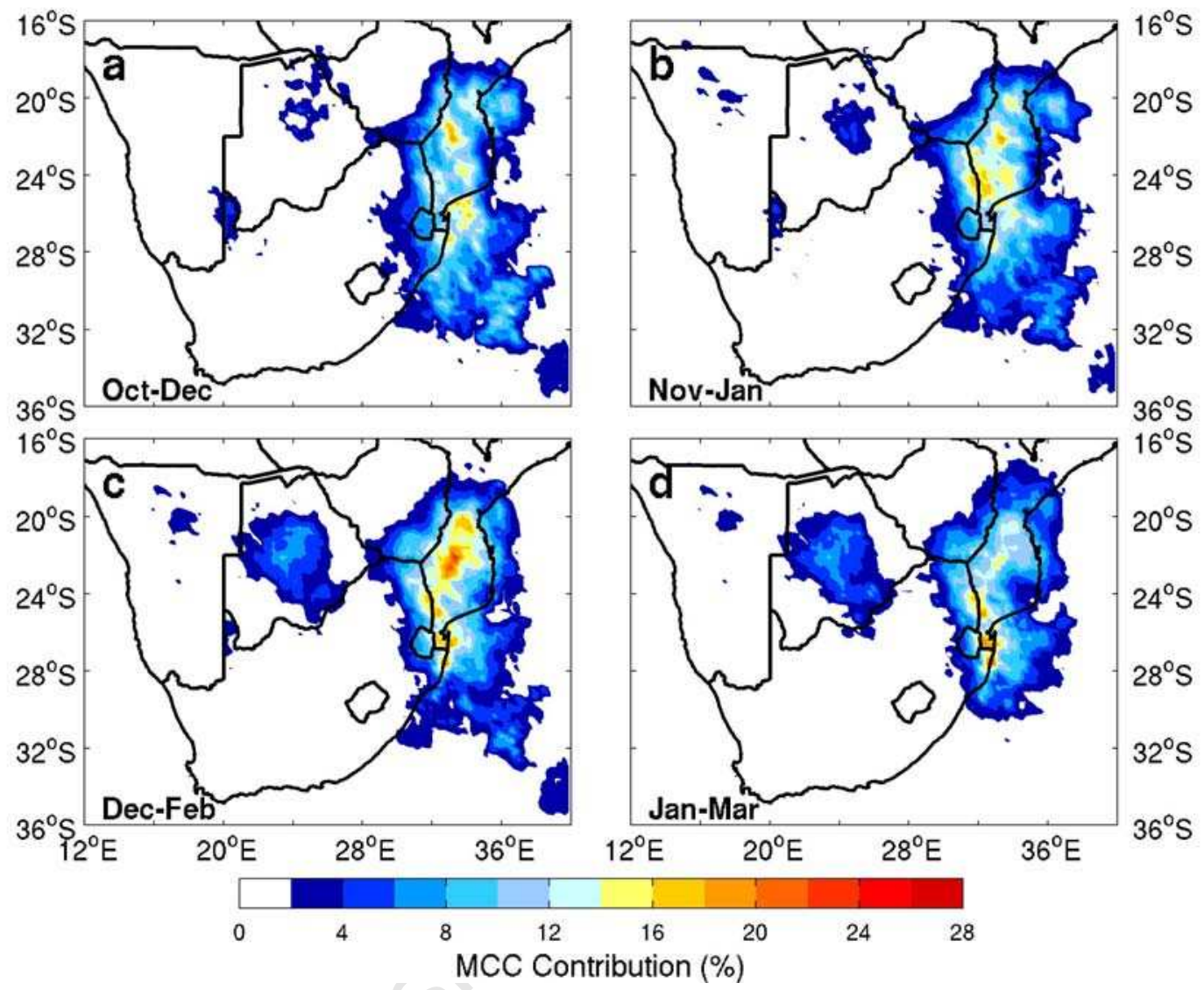

Figure 6.12: Mean contribution of MCCs to rainfall over three month periods, which are a) October - December, b) November - January, c) December - February and d) January - March. 

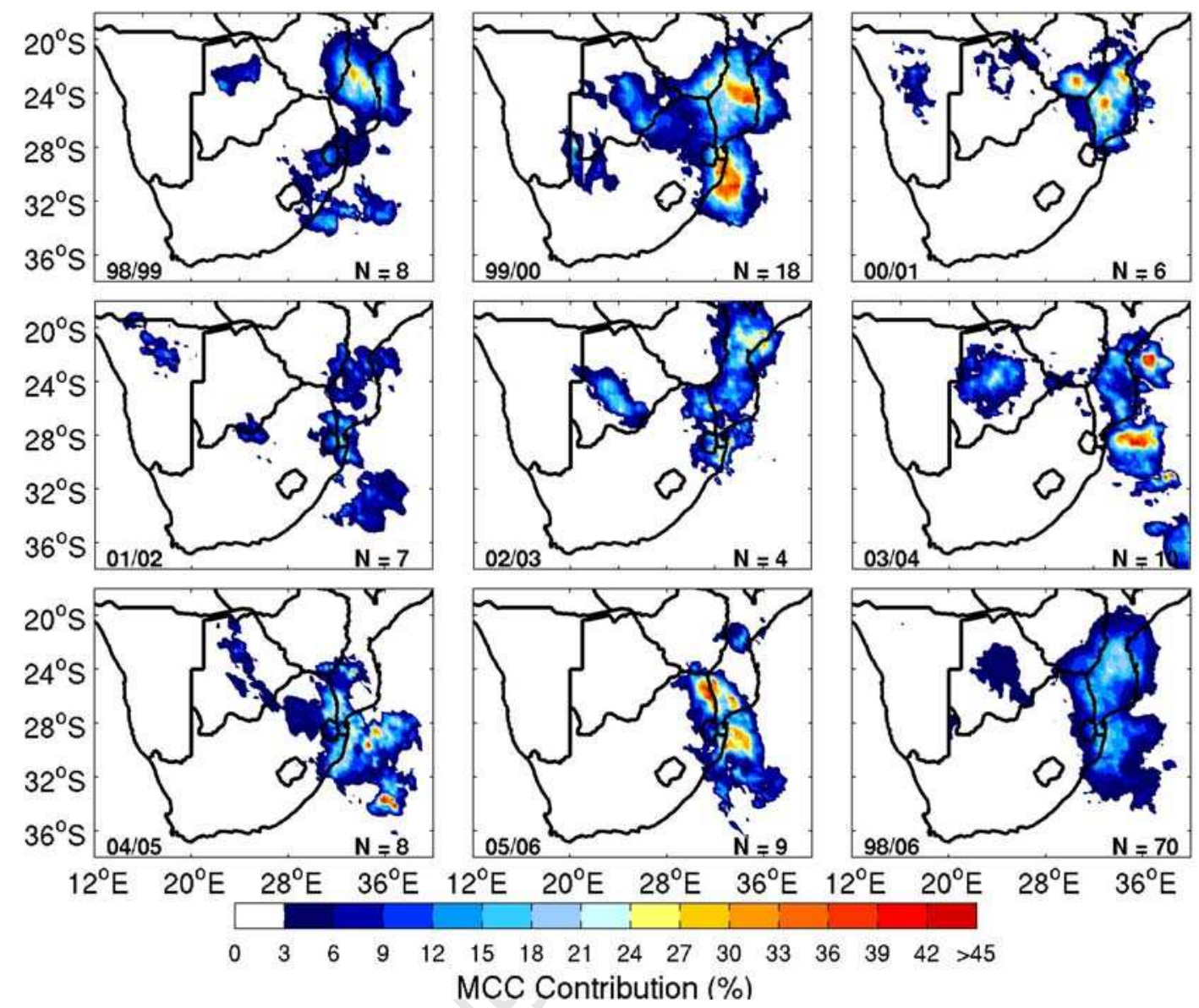

Figure 6.13: MCC contribution to the individual warm season (November - March) precipitation. 

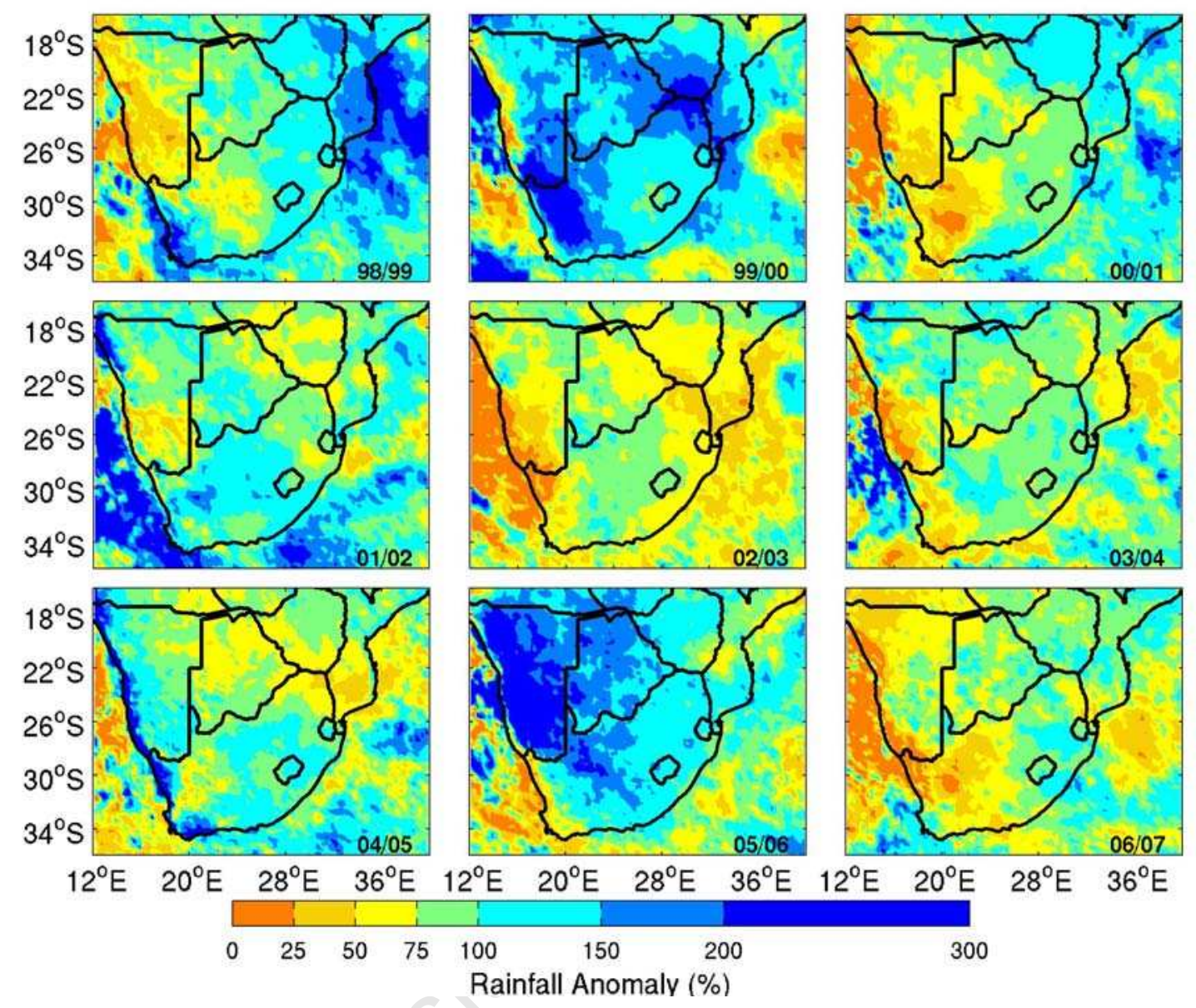

Figure 6.14: NDJF rain anomalies (\%) 


\begin{tabular}{|c|c|c|c|c|c|}
\hline \multicolumn{6}{|c|}{ Mean Precipitation Characteristics } \\
\hline & $\begin{array}{c}\text { Period } \\
\text { (months) }\end{array}$ & $\begin{array}{c}\text { Number of } \\
\text { MCCs }\end{array}$ & $\begin{array}{c}\text { Amount } \\
(\mathrm{mm})\end{array}$ & $\begin{array}{l}\text { Area } \\
\left(\mathrm{km}^{2}\right)\end{array}$ & $\begin{array}{c}\text { Volume } \\
\left(\mathrm{km}^{3}\right)\end{array}$ \\
\hline Southern Africa & $\begin{array}{c}1998-2006 \\
\text { (Oct-Mar) } \\
1987\end{array}$ & 70 & 17.6 & 195,000 & 3.4 \\
\hline Sahelian Africa & $\begin{array}{c}\text { (Jul-Sep) } \\
1998-2007\end{array}$ & 41 & 34 & 285,000 & 11.9 \\
\hline South America & $\begin{array}{c}\text { (Oct - May) } \\
1982-1983\end{array}$ & 330 & 15.7 & 381,000 & 7 \\
\hline United States ${ }^{1}$ & $\begin{array}{l}\text { (Mar-Sep) } \\
1977-1983\end{array}$ & 74 & 16.1 & 510,000 & $\sim$ \\
\hline United States $^{2}$ & (Jun - Aug) & 122 & 10.8 & 320,000 & 3.5 \\
\hline
\end{tabular}

Table 6.1: MCC precipitation characteristics for four different regions, which include systems from this study, Sahelian Africa (Laing et al. 1999), subtropical South America (Durkee et al. 2009) and the United States ( ${ }^{1}$ Kane et al. $1987 ;{ }^{2}$ McAnelly and Cotton, 1989). 


\title{
Chapter Seven
}

\author{
Case Studies of \\ MCCs over southern Africa
}




\subsection{Introduction}

Features associated with the initiation and evolution of MCCs often occur on scales smaller than that contained in NCEP R2 data, which was used in Chapter Five. Recently, the NCEP has developed a new generation of reanalysis products, which is known as the Climate Forecast System Reanalysis (CFSR) (Saha et al. 2010). This reanalysis dataset forms part of the Climate Forecast System Reanalysis and Reforecast (CFSRR) project (Saha et al. 2010). The major differences between CFSR with that of NCEP R1 and R2 is that the CFSR contains a higher horizontal and vertical resolution ( $\sim 38 \mathrm{~km}$ and 64 sigmapressure hybrid levels, respectively), the guess forecast is generated from a coupled atmosphere-ocean-sea ice-land system and historical satellite radiance measurements are assimilated. The CFSR atmospheric, oceanic and land surface output products are at a $0.5^{\circ}$ horizontal resolution and available at 6-hour intervals over a 31-year period of 1979 to 2009.

Initial comparisons between CFSR with that of NCEP R1 and R2 have found that there has been a notable improvement (in terms of precipitation statistics over the U.S. and South America) in the reanalysis products (e.g., Higgins et al. 2010; Silva et al. 2011). However, both these studies note that there are still biases present within the CFSR product. These biases could be related to the model physics parameterizations, assimilation of observations in the model and the model not capturing local circulation features (especially over Africa, which has fewer observations than most other areas). Another advantage of using the higher resolution CFSR data is that it has been shown to produce better results compared to NCEP R1 and R2 in regions of high terrain (e.g., Silva et al. 2011). Due to storage and computation limitations, the CFSR data are primarily used here for case study analysis. Other data which are used for the case studies include South Africa Weather Service (SAWS) synoptic charts and 3-hourly TRMM rainfall data. It should be noted that the latter dataset was discussed thoroughly in the previous chapter.

Using this higher resolution reanalysis dataset, three MCC case studies are presented in this chapter. Each case study presented covers the evolution of the MCC, the precipitation produced by the system and the large-scale environment in which it developed. The 
objective is to highlight conditions that favour MCC development over southern Africa, as well as identify any similarities in the synoptic environment as documented elsewhere. In order to be consistent and to emphasize the contrasting environments in which these systems may occur, all three events chosen took place during the month of February (presented in chronological order). They were selected based on unique features in the evolution, the location of the system or SST conditions in the Pacific Ocean.

This first case study developed under La Niña condition prevailing in the Pacific Ocean in February 2001 and thus, could potentially be viewed as a La Niña case study. Furthermore, the system was associated with a copious amount of precipitation, warranting for further investigation. The second case study highlights the splitting of an MCC over eastern South Africa / southern Mozambique in February 2003. The splitting of MCSs is somewhat rare and in most cases occurs in about $10 \%$ of the population (e.g., Machado et al. 1998; Carvalho and Jones 2001; García-Herrera et al. 2005b). The final case study documents the life cycle of an MCC positioned over the Agulhas Current during February 2006. As indicated in previous chapters, this warm current is an influential local feature, which has often been linked to the intensification of severe weather systems along the coastal regions due to the core of the current being near the east coast (e.g., Rouault et al. 2002; Singleton and Reason 2006, 2007; Blamey and Reason 2009). Over this core, high latent heat fluxes of several hundred watts per square meter occur, leading to the transfer of more moisture to the atmosphere than from the surrounding waters (Rouault et al. 2003a).

\subsection{Case Study I: 04 - 05 February 2001}

\subsubsection{Overview of Storm and Precipitation}

The first case study relates to a system positioned in the northeast corner of the domain, over central Mozambique during 04-05 February 2001 (Fig. 7.1). As alluded to previously, this system developed under La Niña condition prevailing in the Pacific Ocean. The evolution of this particular system was very similar to that documented in the 
global population of MCCs. First storms appeared during the early afternoon (local time) in the form of a linear convective line running from central Mozambique southeastwards to the Mozambique Channel. By the early evening hours, the individual storms began to merge and form under one cold cloud shield. Soon after, the system reached MCC status and continued to grow until the early morning hours. After reaching maximum extent at about 00h00 UTC, convection began to weaken considerably and the system began to decay. Evidence of the system being over Mozambique was still apparent in the satellite imagery up until the early afternoon on 05 February.

Due to the lack of quality controlled station data in the region, rainfall derived from the Tropical Rainfall Measuring Satellite (TRMM) is used as a replacement. An estimate of the rainfall that took place during the event is shown in Figure 7.2. It is evident that a core of high rainfall values associated with the MCC was located over central Mozambique. It is estimated that the system produced a maximum value of $324 \mathrm{~mm}$. The 3-hourly TRMM data also reveals that most of the rainfall associated with the system took place during the night time hours (not shown). Unfortunately, no station data for Mozambique was available to validate this high amount of rainfall. An interesting finding with this particular MCC is the lack of movement during its evolution, which likely resulted in the spatial distribution of high rainfall being very concentrated.

\subsubsection{Synoptic Setting and Moisture Transport}

South African Weather Service synoptic charts (Fig. 7.3) and the CFSR reanalysis (Fig. 7.4) reveal that certain low level synoptic features played a key role in the development of the system as well as sustaining it through the night. On 03 February, the day prior to the event, a weak cold front passed to the south of South Africa (not shown). Behind the frontal system, the South Atlantic anticyclone began to ridge around, bringing light rain along the southern coastal regions (not shown). A ridging anticyclone is a common occurrence during the summer rainfall season and is known to produce widespread rainfall over the eastern parts of southern Africa (Tyson and Preston-Whyte 2000). During the same period, an inland trough was present over much of central southern 
Africa with another surface low pressure positioned over the Mozambique Channel. By $12 \mathrm{~h} 00 \mathrm{UTC}$ on 04 February, the frontal system was now located to the southeast of the region and the ridging high pressure had migrated all the way around to the south of the continent. The anticyclonic (cyclonic) circulation associated with the ridging high pressure (cold front) resulted in strong southerly onshore flow into the south of Mozambique (Fig. 7.4). Additionally, the cyclonic flow around the surface low, position over the coastal regions of Mozambique resulted in easterly onshore flow into the region.

At the mid-levels, a westerly wave was located over the southern/southeastern parts of the continent between $00 \mathrm{~h} 00$ and 12h00 UTC 04 February (Fig. 7.5). The interaction between the eastern escarpment and westerly waves propagating along the southern tip of the continent has previously been identified as a mechanism resulting in the development of convective systems (Garstang et al. 1987). This is unlikely to be the case here due to the location of the MCC. Mid-level winds are not only often linked to the propagation of MCCs, in terms of speed and direction, but also to the spatial distribution of rainfall. As highlighted by Trier and Parsons (1993), the strength of the mid-level flow could possibly have an affect on the significance and location of flooding, because it is likely to determine the speed at which the MCC passes through an area. The weak mid-level winds over Mozambique during this period possibly resulted in the system here being quasistationary and thus, the rainfall was concentrated over a smaller area. However, other factors have to be taken into consideration, such as the low level flow (e.g., Corfidi et al. 1996).

As previously indicated, the neighbouring oceans play a key role in supplying moisture into the region. In particular, the SWIO has been known to fuel heavy rainfall events along the eastern coastal regions (e.g., Crimp and Mason 1999; Rouault et al. 2002; Singleton and Reason 2006; Blamey and Reason 2009). The circulation associated with the ridging high pressure and cold front resulted in low levels winds transporting a large quantity of moisture into the region from the SWIO, including from the lower Agulhas Current (Figs. 7.6). The easterly flow associated with the surface low positioned just off the Mozambique coastline resulted in moisture being transported from the Mozambique 
Channel into Mozambique (Fig. 7.7). High levels of moisture transport $(\geq 150$ g.kg-1 m.s

${ }^{1}$ ) began in the early morning hours of 04 February and increased throughout the day. By the late afternoon (between $12 \mathrm{~h} 00$ and $18 \mathrm{~h} 00 \mathrm{UTC}$ ), values exceeding $250 \mathrm{~g} \cdot \mathrm{kg}^{-1} \mathrm{~m} . \mathrm{s}^{-1}$ were being advected into the region. Although the quantity of moisture being fed into the region decreased during the night and early morning hours of 05 February (between 00h00 and 06h00 UTC) compared to earlier, it was still relatively high, with values around $150 \mathrm{~g} \cdot \mathrm{kg}^{-1} \mathrm{~m} \cdot \mathrm{s}^{-1}$. These circulation patterns also resulted in low level advection of cold air from behind the frontal system into southern Mozambique (Fig 7.8). At the same time, warm air advection occurred to the northeast and east of the storms genesis region.

The availability of a large quantity of moisture, often transported via a LLJ, is frequently identified in MCC environments (e.g., Maddox 1983; Velasco and Fritsch 1987; Cotton et al. 1989). Similarly, persistent onshore flow, in the form of a LLJ, resulted in sustained moisture transport into the region for over 24 hours. For the purpose of this study, a LLJ is arbitrarily defined as a core of maximum winds exceeding $15 \mathrm{~m} . \mathrm{s}^{-1}$ and is confined to the lowest $200 \mathrm{mb}$ of the atmosphere. It appears that a strong pressure gradient between the ridging high pressure and the surface low over Mozambique played a key role in the formation of the LLJ (Fig. 7.8). Vertical cross-sections taken to the south of the MCC position highlight the evolution of the LLJ, with a maximum in wind speed occurring during the night (Fig. 7.9). As noted in Chapter Four, the LLJ is not only responsible for the transport of moisture into the region, but often also associated with low level convergence, increased frontogenesis and stronger vertical wind shear (Augustine and Caracena 1994; Fritsch and Forbes 2001; Trier et al. 2006). In addition to the LLJ, strong inflow of high equivalent potential temperature (high- $\theta_{\mathrm{e}}$ ) from the Mozambique Channel was also apparent during this period (Fig. 7.8).

\subsubsection{Favourable Convective Environment}

Apart from abundant moisture in the low levels, favourable environments for convective system development often requires other ingredients, such as low level convergence, upward motion and potential instability (McNulty 1995; Doswell et al. 1996). In addition 
to the sustained moisture inflow found during 04-05 February, low level moisture convergence was present over the region from early afternoon and continued through most of the night (Fig. 7.7). The position and orientation of the low level moisture convergence zone over Mozambique is similar to that of the line of convective storms from which the MCC emerged. Coupled with the low level moisture convergence, prolonged periods of upper level divergence were present during the event (Fig. 7.10), which likely assisted in enhancing convection. Upper level jet streams have often been linked to surface weather patterns over the region through the development of upper level convergence or divergence zones (Tyson and Preston-Whyte 2000). It is possible that favourable conditions for upper level divergence on 04 February were due to the position of the upper level jet, with a trough in the jet stream located over central South Africa between $06 \mathrm{~h} 00$ and 12h00 UTC 04 February (not shown).

In addition to the low level convergence and upper level divergence, strong upward vertical motion was also present during this period (Fig. 7.11). The uplift of moist air brought in extends from the boundary layer up to 300 or $200 \mathrm{hPa}$, particularly during the night on 04 February (Fig. 7.12). This persistent pattern of strong low level moisture convergence along the Mozambique coastline, coupled with upper level divergence and strong vertical motion likely resulted in the intensification of the storm. Not only did this lead to the system being long-lived, but is also consistent with the high amount of rainfall experienced in this region during the event.

Similar to the environments found in the global population of MCC (e.g., Laing and Fritsch 2000), low level winds feeding into the MCC genesis region originated from areas containing highest values of both KI (Fig. 7.13) and CAPE (Fig. 7.14). This pattern suggests that the air feeding into the system was unstable and likely assisted in also favouring long-lived convection. The early afternoon environment over central Mozambique contained very high CAPE (exceeding $2500 \mathrm{~J} . \mathrm{kg}^{-1}$ ), which decreased considerably during the late afternoon / early evening. In contrast, values over the neighbouring Mozambique Channel stayed consistent throughout the night, with large parts exceeding $2000 \mathrm{~J} . \mathrm{kg}^{-1}$. The KI contained values of over 35 during most stages of 04- 
05 February, which suggests favourable conditions for heavy rainfall were present throughout this period.

As discussed previously, low level shear has in the past has also been used to distinguish the type of convective storm that may develop (e.g., Wiseman and Klemp 1982, 1986). The location of the genesis region for MCCs is often characterised by the system developing upshear from a zone of maximum shear (1000-700 hPa layer) and then moving over towards the higher shear (Laing and Fritsch 2000). In this particular case study, the system develops only slightly upshear from the zone of maximum shear (Fig. 7.15) and does propagate slightly towards it. However, in comparison between the satellite images (Fig. 7.1) and Fig. 7.15, the system appears to stay along the northeast border of the local maximum shear. Essentially, the system develops and evolves in an environment that contains moderate shear, approximately between $6-10 \mathrm{~m} \cdot \mathrm{s}^{-1}$.

The termination of an MCC in the U.S. is often associated with a weakening of the LLJ, signifying reduced moisture being fed into the region (Maddox 1983). Similarly, the decay of the system over Mozambique during the morning hours of 05 February (between 00h00 and 0600 UTC) is simultaneous with the weakening of the nocturnal LLJ (Fig. 7.9) and reduced moisture flux (Fig. 7.6). During this period, the ridging high pressure had migrated farther eastward and was being absorbed into the South Indian Anticyclone. The surface low over Mozambique had also weakened by this stage, resulting in a weaker pressure gradient existing over the region. Essentially, the conditions on the synoptic scale were no longer sustainable for strong convection.

\subsection{Case Study II: 05 - 06 February 2003}

\subsubsection{Overview of Storm and Precipitation}

During the late afternoon on 05 February 2003, isolated thunderstorms located over eastern southern Africa begun to merge into a single system (Fig. 7.16). The system reached MCC status by the early evening and continued to strengthen into the night. After 
reaching its maximum extent around $21 \mathrm{~h} 00 \mathrm{UTC}$, the system began to lose structure, with the cloud shield becoming disorganised. It then appeared to split into two portions around 01h00 UTC, with the equatorward section being slightly more developed than its poleward counterpart. This behaviour is indicated by the colder cloud top temperatures and longer duration associated with the equatorward cloud system.

The splitting of the system is clearly evident in the rainfall pattern, with two regions standing out (Fig. 7.17). Most of the rainfall associated with the system fell over southern Mozambique, the northeast coast of South Africa and neighbouring Swaziland. Rainfall that fell once the system had split is mainly restricted to northeastern South Africa and adjacent Mozambique. Unlike the previous case study, the rainfall associated with this particular MCC is considerably less, with a maximum estimation of only $100 \mathrm{~mm}$. The reasons for this could be twofold, with the first relating to the duration and movement of the system and the second, to the amount of moisture being advected into the region. Results by McAnelly and Cotton (1989) suggest that less organised systems produce less rainfall than the more organised systems. Consistent with this, the MCC here appeared to be less organised, which was evident by the shorter duration and the splitting of the system. It should also be noted that this system developed during the 2002/2003 El Niño, which was analysed in the previous chapter. Not only was there less moisture available during this period, but mean synoptic environments during the summer months revealed that conditions for deep convection over southern Africa were highly unfavourable (e.g., Fig. 5.22 and Fig 5.23).

\subsubsection{Synoptic Setting and Moisture Transport}

On 05 February 2003, a surface trough was present over most of southern Africa, extending from southern Angola all the way to southeast South Africa (Fig. 7.18 and Fig. 7.19). Low level convergence often occurs to the east of this surface trough, while divergence usually takes place to the west of it (Tyson and Preston-Whyte 2000). In this case, low level moisture convergence was present along the eastern coastal regions during 
throughout the 05-06 February (Fig. 7.20). However, this low level convergence was confined to the surface levels and was considerably weaker by the $850 \mathrm{hPa}$ level.

In conjunction with the surface trough, the potential for strong uplift over the eastern regions can occur if the flow in the mid-levels or above is divergent. On the 05 February, strong anticyclonic flow was evident over southern Africa at the $500 \mathrm{hPa}$ level (Fig. 7.21). Associated with this circulation was a region of mid-level divergence, favouring conditions for strong convection (Fig. A7.1). Additionally, the propagation of the system is consistent with the changing winds in the mid-levels. The early stages of the life cycle of the system is dominated by northeastward propagation due to the southwesterly winds during the afternoon (12h00 UTC) and evening (18h00 UTC) on 05 February. During the night (00h00 UTC 06 February), the winds contained a more southerly component, resulting in the system tracking northwards. Upper level divergence at $200 \mathrm{hPa}$ was also present over the coastal region of eastern South Africa at 12h00 UTC (Fig. A7.2). By $18 \mathrm{~h} 00 \mathrm{UTC}$, the zone of upper level divergence had spread in a northeastward direction towards southern Mozambique and the adjacent ocean, following the exit zone of the upper level jet. Later that night, upper level divergence was now confined to northeast South Africa and southern Mozambique. The movement of the system is consistent with the location of the zones of upper level divergence.

Upward vertical motion was present over most of the eastern region of southern Africa during the afternoon on 05 February (Fig. 7.22), which was likely enhanced by the low level convergence and upper level divergence pattern. In this case, the strongest vertical motion at $700 \mathrm{hPa}$ took place at $12 \mathrm{~h} 00 \mathrm{UTC}$ on 05 February (Fig. 7.23), which is consistent with the early stages of the convective systems development. However, the strong vertical motion is not incessant and was considerably weaker by $18 \mathrm{~h} 00$ UTC that night. By 00h00 UTC there is some evidence in the upward vertical motion of the split in the system, but this is likely just a reflection of the breaking up of the MCC.

Other low level synoptic features on 05 February 2003 include the South Indian anticyclone positioned just off the east coast of South Africa and a surface low located to 
the north of the anticyclone, over southern Madagascar. The anticyclonic (cyclonic) flow associated with the South Indian anticyclone (surface low over Madagascar) resulted in strong onshore flow along the east coast of South Africa from early afternoon on 05 February through to about 06h00 UTC the next morning (Fig. 7.20). This resulted in moisture being collected off the warm adjacent ocean and transported into the coastal regions (Fig. 7.24). The strongest influx of high $-\theta_{\mathrm{e}}$ into the storm region was also associated with this onshore flow (Fig. A7.3).

In contrast to the previous case study, moisture flux into the region was considerably less and confined to the lower atmosphere, weakening considerably above $850 \mathrm{hPa}$ (Fig. 7.20). In this case, moisture flux values rarely exceeded $100 \mathrm{~g} \cdot \mathrm{kg}^{-1} \mathrm{~m} . \mathrm{s}^{-1}$ along the east coast during 05-06 February. Although, this easterly flux did originated over the waters to the south of Madagascar, where flux values in excess of $200 \mathrm{~g} \cdot \mathrm{kg}^{-1} \mathrm{~m} . \mathrm{s}^{-1}$ were present. Additionally, this low level easterly moisture flux (of about $100 \mathrm{~g} \cdot \mathrm{kg}^{-1} \mathrm{~m} . \mathrm{s}^{-1}$ ) was consistent throughout the late afternoon and night (Fig. 7.24), with a peak in moisture flux along southern Mozambique at $850 \mathrm{hPa}$ occurring around the same time (around 18h00 UTC 05 February) the MCC moved into the region. It only began to weaken around 00h00 UTC 06 February, the same stage at which the MCC began to become disorganised.

\subsubsection{Favourable Convective Environment}

The genesis region of the MCC coincided with an area containing high values of CAPE, particularly at $12 \mathrm{~h} 00 \mathrm{UTC}$ on 05 February (Fig. 7.25). Additionally, the easterly winds feeding into the system originated from the high CAPE located over the adjacent ocean. The highest mixing ratio values $\left(\geq 14\right.$ g. $\left.\mathrm{kg}^{-1}\right)$ at $850 \mathrm{hPa}$ over the coastal regions of eastern South Africa also coincide with the genesis location of the MCC (Fig. 7.26). Once initiated, the system continued to evolve in the region containing highest mixing ratio in comparison to its surrounding. Conditions over northeast South Africa and neighbouring southern Mozambique (i.e., the region to which the system propagated to) 
remained potentially unstable throughout this period (Fig. A7.4). This pattern likely played a role in sustaining the equatorward portion of the system once it split.

The KI over eastern South Africa during storm initiation was fairly high, exceeding 35 (Fig. 7.27). The system also continued to evolve in a region containing a KI value which was higher than the surrounding area. At 00h00 UTC 06 February, the location of the system is consistent with the highest KI values over northeastern South Africa and neighbouring Mozambique. These indices suggest that the MCC developed in an environment which was unstable and that the air feeding into the region continued to destabilise it. Very high surface temperatures were also apparent over most of the region during this period, with temperatures just less than $40^{\circ} \mathrm{C}$ being recorded in northeast South Africa (Fig. 7.18) and the central interior of southern Africa (Fig. 7.19). Thus, differential heating could have played a role in initiating the event.

Similar to the previous case study, the system here develops slightly upshear of a zone of maximum low level shear, where shear values are between 6-10 m.s ${ }^{-1}$ (Fig. 7.28). As the system evolves it propagates towards the zone of maximum shear, which at 18h00 UTC, is located to the east of Swaziland and runs to the north along the South Africa and Mozambique border. By 00h00 UTC on 06 February, the zone of maximum shear is positioned over southern Zimbabwe, northern South Africa and Mozambique. Again, even once the system has split, the dominant remaining part of the system is still found on the boundary of the zone of maximum shear.

A notable absence in the environment of the storm, unlike the previous case, is that of a prominent LLJ. As highlighted in the previous case study, a LLJ can play a key role in transporting moisture into the region for prolonged periods. Results here suggests that even in the absence of a LLJ, strong onshore flow from the Agulhas Current region is still sufficient to sustain deep convection over the east coast of southern Africa. Additionally, similar to the role of a LLJ, the weakening of the onshore flow and reduced moisture transport by 00 h00 UTC 06 February coincided with the disorganisation and termination of the system. 


\subsection{Case Study III: 09-10 February 2006}

\subsubsection{Overview of Storm and Precipitation}

The final MCC case study pertains to a system that developed over the Agulhas Current during 09-10 February 2006. In this case study, the system initiated over the coastline of eastern South Africa and the adjacent ocean during the mid-afternoon on 09 February 2006 (Fig. 7.29). By late evening, the system had obtained MCC status and contained strong convection, which is evident by the very cold cloud top temperatures during this stage. By this point, the system had tracked eastwards and was now positioned over the Agulhas Current. The system continued to expand throughout the night, before reaching maximum extent during the early morning hours of 10 February. The system then began to lose shape and its organisation, and by $05 \mathrm{~h} 00$ UTC, the system had become fragmented and no longer satisfied the MCC criteria. However, new convection continued to take place along the equatorward flank of the fragmented system up until 09h00 UTC. The renewed convection resulted in another smaller MCS being developed (Fig. A7.5).

Most of the rainfall associated with the MCC was confined to the Agulhas region, with only a small fraction being estimated to have fallen over the coastal regions of eastern South Africa and southern Mozambique (Fig. 7.30). Although the spatial distribution of rainfall over land was limited, large totals were still recorded at some coastal stations. SAWS station data indicate that a maximum of $143 \mathrm{~mm}$ was recorded at Mbazwana Airfield during the event (see Fig. $\mathbf{7 . 3 0}$ for location). The spatial distribution of the TRMM data is captured reasonably well, with stations such as Charters Creek and Richards Bay recording similar rainfall values $(55.0 \mathrm{~mm}$ and $16.8 \mathrm{~mm}$, respectively). A maximum value of $154 \mathrm{~mm}$, according to TRMM data, was estimated to have occurred during this period. Consistent with the previous case studies, most of the heavy rainfall was found to occur during the early stages of the systems development. 


\subsubsection{Synoptic Setting and Moisture Transport}

The influence of the midlatitudes seems more apparent in the development of the MCC in this case study than in the other two. During 09 February 2006, the passage of a frontal system to the south of the Africa was associated with southwesterly winds flowing up along the South Africa coastline (Fig. 7.31 and Fig. 7.32). To the east of southern Africa, anticyclonic flow around the South Indian anticyclone resulted in northerly/northeasterly winds over much of the eastern regions of the domain. The opposing flow resulted in low level wind convergence off the east coast of South Africa, starting at 06h00 UTC 09 February (Fig. A7.6). As the frontal system continued to propagate into the South Indian Ocean on 10 February, the southwesterly flow was maintained by the ridging South Atlantic anticyclone.

At $500 \mathrm{hPa}$, strong northwesterly winds were located diagonally across the central and eastern regions of southern Africa on 09 February (Fig. 7.33). This circulation pattern is due to the combination of the mid-level westerly wave located to the south of the continent with the anticyclonic flow to the east, over the southwest Indian Ocean. As the mid-level westerly wave propagates to the east, the core of strong northwesterlies begins to weaken. By 06h00 UTC 10 February, the mid-level circulation over South Africa has returned to the mean zonal flow. In the upper levels, divergence associated with a jet stream, running diagonally from Namibia to southeast South Africa, is present over much of the eastern region of southern Africa (Fig. A7.7). Strong convection in central southern Africa (Fig. 7.34) likely assisted in the formation of the strong upper level anticyclonic circulation experienced over southern Africa at $200 \mathrm{hPa}$ during the event (Fig. 7.35). The position of this jet remains semi-stationary throughout most of 09-10 February.

An interesting observation in the synoptic settings of this case study is that most of these circulation patterns have been identified in the formation of tropical-extratropical cloudbands over the region (e.g., Hart et al. 2010). Furthermore, a cloudband type pattern is identified in the outgoing longwave radiation (OLR) data, which is used here as a proxy for cloud cover, during 09-10 February 2006 (Fig. 7.34). Not only does this imply 
that dynamics responsible for the development of MCCs over southern Africa can be similar to that of cloudband formation, but it also suggests that using OLR data interpolated to daily means will in some cases not capture MCC events. Essentially, heavy rainfall events caused by MCCs may be misinterpreted as cloudbands.

Low level moisture transport into the storms genesis region is comprised of two main circulations. To the north of the genesis region, northerly and northeasterly winds associated with the South Indian anticyclone transport moisture from the Mozambique Channel polewards, while to the south, southwesterly winds associated with the frontal system transport moisture up along the Agulhas Current (Fig. 7.36). Strong moisture transport ( $\left.\geq 150 \mathrm{~g} . \mathrm{kg}^{-1} \mathrm{~m} . \mathrm{s}^{-1}\right)$ is evident from 06h00 UTC 09 February until 00h00 UTC 10 February. High moisture transport is still apparent during the morning hours of 10 February, but this transport is very localised. A similar moisture circulation pattern is evident at $850 \mathrm{hPa}$, but at this level the main moisture transport occurs between $06 \mathrm{~h} 00$ 18h00 on 09 February (Fig. A7.8). Furthermore, moisture convergence associated with the southwesterly flow with that of northeasterly flow off the east coast is apparent throughout most of 09 and 10 February (Fig. 7.37). Ultimately, results here suggest that the influx of abundant moisture was sustained throughout the night, while low level moisture convergence was also present during this period.

\subsubsection{Favourable Convective Environment}

In addition to the coupled strong low level convergence and upper level divergence, strong upward velocities were evident throughout 09-10 February along the east coast and over the adjacent ocean (Fig. 7.38). The northeastward propagation of the system is captured in the vertical velocity cross-sections (Fig. 7.39). Initially, strongest vertical velocities were located over the coast of South Africa during the late afternoon on 09 February, by 00h00 UTC 10 February the core of strong upward movement had propagated over the ocean. During the morning hours of 10 February, the dominant upward motion began to weaken and likely indicates the decay of the system. 
A closer inspection of vector winds and geopotential height at $850 \mathrm{hPa}$ indicate that strong pressure gradients resulted in the development of a LLJ (Fig. 7.40). A similar forcing mechanism was found in the first case study, but in contrast, the LLJ runs in a polewards direction here. Another key difference is that the LLJ here appears to only influence the early stages of storm development. By $18 \mathrm{~h} 00$ UTC, the flow over the east coast of South Africa has become slightly weaker and disorganised, while at the same time, convergence of the southwest flow associated with the frontal system with that of the northeasterly flow of the anticyclone becomes more apparent. Inflow of high $\theta_{\mathrm{e}}$ air into the storm region from the north was apparent throughout 09-10 February (Fig. 7.40). This circulation here also played a key role in warm air advection from the north and cold air advection from the south in to the storm region (Fig. A7.9). The horizontal gradient found in the temperature advection over the east coast (Fig. A7.10) could possibly assist in forcing the air to rise through frontogenesis. The presence of this dipole-type structure in the horizontal temperature advection suggests that the atmosphere may attempt to reach thermal wind balance by creating vertical motions (Holton 1992).

Similar to the previous case studies analysed here, air flowing into the genesis region originated from areas containing high mixing ratio (Fig. 7.41), high CAPE (Fig. 7.42) and high KI values (Fig. A7.11). As implied previously, this illustrates that air flowing into the system continued to destabilise the environment for a sustained period of time. The highest mixing ratio $\left(\geq 15 \mathrm{~g} \cdot \mathrm{kg}^{-1}\right)$ and $\mathrm{KI}$ values $(\geq 35)$ were found over the eastern regions of southern Africa, whereas highest CAPE $\left(\geq 2000 \mathrm{~J}^{\mathrm{kg}} \mathrm{kg}^{-1}\right)$ was located over the surrounding ocean. High values of CAPE $\left(\geq 1500{\mathrm{~J} . \mathrm{kg}^{-1}}^{-1}\right)$ were present over the region where the storm developed, but it is likely the high CAPE over the ocean played a major role. Furthermore, consistent with the other two case studies, the system developed in an environment containing a strong horizontal gradient in low level vertical shear (Fig. 7.43). Initially the system evolves upshear of a zone of strong low level shear shear. Later in the life cycle, the system moves towards a zone of higher shear.

Another interesting feature present in the high resolution CFSR data is the low level cyclonic flow around a low pressure system, positioned off the east coast at both $00 \mathrm{~h} 00$ 
and 06h00 UTC on 10 February (e.g., Fig. 7.41). This circulation could possibly indicate the existence of a mesoscale convective vortex (MCV). To date, nearly all cases documenting MCVs have been linked to the quasi-circular MCSs in the midlatitudes in the U.S. (e.g., Menard and Fritsch 1989; Bartels and Maddox 1991; Trier et al. 2000a; 2000b). Over southern Africa, the information regarding such features is very limited, with only one study by de Coning et al. (1998) documenting a MCV. Consistent with the literature, the low- to mid-levels in this case study are dominated by cyclonic circulation, while the upper levels contain anticyclonic circulation during the decaying stages of the system (Fig. A7.12). Animation of the satellite data also indicates the spiralling of the clouds during the early morning hours on 10 February. However, without observation data, such as upper air soundings, this feature cannot be confirmed. MCVs have been found to be associated with further convection after the MCC has been terminated (e.g., Bartels and Maddox, 1991; de Coning et al. 1998). Thus, this feature could have played a role in the development of the smaller MCS during the mid-morning hours on 10 February.

By 12 h00 UTC on 10 February, conditions favouring deep convection had been considerably reduced. The frontal system had propagated farther eastwards and the anticyclonic flow to the northeast of the system had weakened. In combination, this behaviour resulted in the reduction the amount of moisture travelling into the region. Additionally, the mid-level flow over South Africa was now dominated by weak zonal flow. Changes in the jet position in the upper levels resulted in convergence replacing the region of divergence. This lead to the reduction in strong upward vertical motion. With reduced moisture and a more stable environment, the lifecycle of the system ended.

\subsection{Chapter Summary}

In this chapter, three MCC case studies were presented, each forming under different large-scale environments. Apart from the synoptic environments, attention was also placed on the precipitation and related variables (e.g., moisture flux, convergence, vertical velocities) of the systems. Unfortunately, the study is limited by the observation 
data available. For example, radiosonde data are not actively collected in many parts of southern Africa and are only routinely available for a few South African stations. During these events, no radiosonde data was available for the closest stations, these being Durban in South Africa and Maputo in Mozambique. For this reason, no direct comparisons of stability indices could be made with other MCC populations. The CFSR data was chosen over other reanalysis datasets for the case studies due to it containing a much higher spatial resolution. However, apart from using SAWS synoptic charts, no thorough validation could be made of the CFSR data.

As implied by Romero et al. (2000), in order for an MCS to develop, the synoptic and mesoscale conditions must remain favourable over a specific region and last for several hours. The key patterns identified here suggest that MCCs over southern Africa evolve in an environment that contains considerable moisture transport and is convectively unstable for long periods of time. A noticeable feature in all three case studies presented was that large values of CAPE were either in the storm genesis region or in close proximity, which is consistent with the global population (Laing and Fritsch 2000). It is believed that both CAPE and the relative humidity of the low to mid-levels are important in determining cold pool strength and depth of convective systems (Rotunno et al. 1988). Results by Weisman (1992) suggest that the generation of a deep cold pool is significant in sustaining a MCS. However, observation data is required to confirm the existence of high CAPE in southern Africa MCC environments.

In two of the cases presented, the presence of a LLJ is evident, which is often the case with systems in midlatitude North and South America. The LLJ was defined as a narrow core of maximum winds, exceeding $15 \mathrm{~m} \cdot \mathrm{s}^{-1}$, in the lower part of the atmosphere. However, a slight contrast to these regions is that in the cases analysed here, the systems tend to develop near the entrance region of the LLJ. Strong low level flow, transporting moisture and high- $\theta_{\mathrm{e}}$ from the neighbouring ocean, was found to converge in this entrance region and thus, likely assisted in developing a zone of prolonged convergence. In the case excluding a LLJ, strong moisture transport over the land was still present through the onshore flow of moisture from the adjacent warm ocean. However, it was 
noticeable that the system not containing a LLJ was shorter lived and produced less precipitation. The demise of the systems often coincided with a reduction of moisture transported into the storm region. At this stage, it was found that the environment was more stable and convectively less favourable.

The systems in these case studies show very similar propagation patterns to that of the global population of MCCs (e.g., Laing and Fritsch 1997). In all three cases, the system moved in the general direction of the mean mid-level flow. However, the systems also deviated slightly from the mid-level flow and moved towards the inflow of high equivalent potential temperature (high- $\theta_{\mathrm{e}}$ ) air. It is likely that the stronger mid-level flow for the systems developing over South Africa, compared to Mozambique, resulted in these systems travelling farther.

The results also clearly demonstrate the influence that both the tropics and midlatitudes have on the development and evolution of systems over southern Africa. Disturbances in the form of easterly waves in the northern part of the domain provide favourable conditions for deep convection through low level convergence and assist in moisture advection. At the same time, divergence associated with midlatitude westerly waves in the mid-levels and configurations in the upper level jet stream result in favourable conditions for enhanced convection. It is not surprising that the results here also imply that large-scale circulation patterns that are found to result in the development of tropicalextratropical cloudbands over southern Africa also favour the development of MCCs. This provides further evidence between the link between El Nino-Southern Oscillation and MCC frequency, as discussed in the Chapter Five. Another conspicuous characteristic associated with these case studies is that MCCs over southern Africa can produce a large quantity of precipitation. This again highlights the importance of these systems to summer rainfall patterns over southern Africa. 


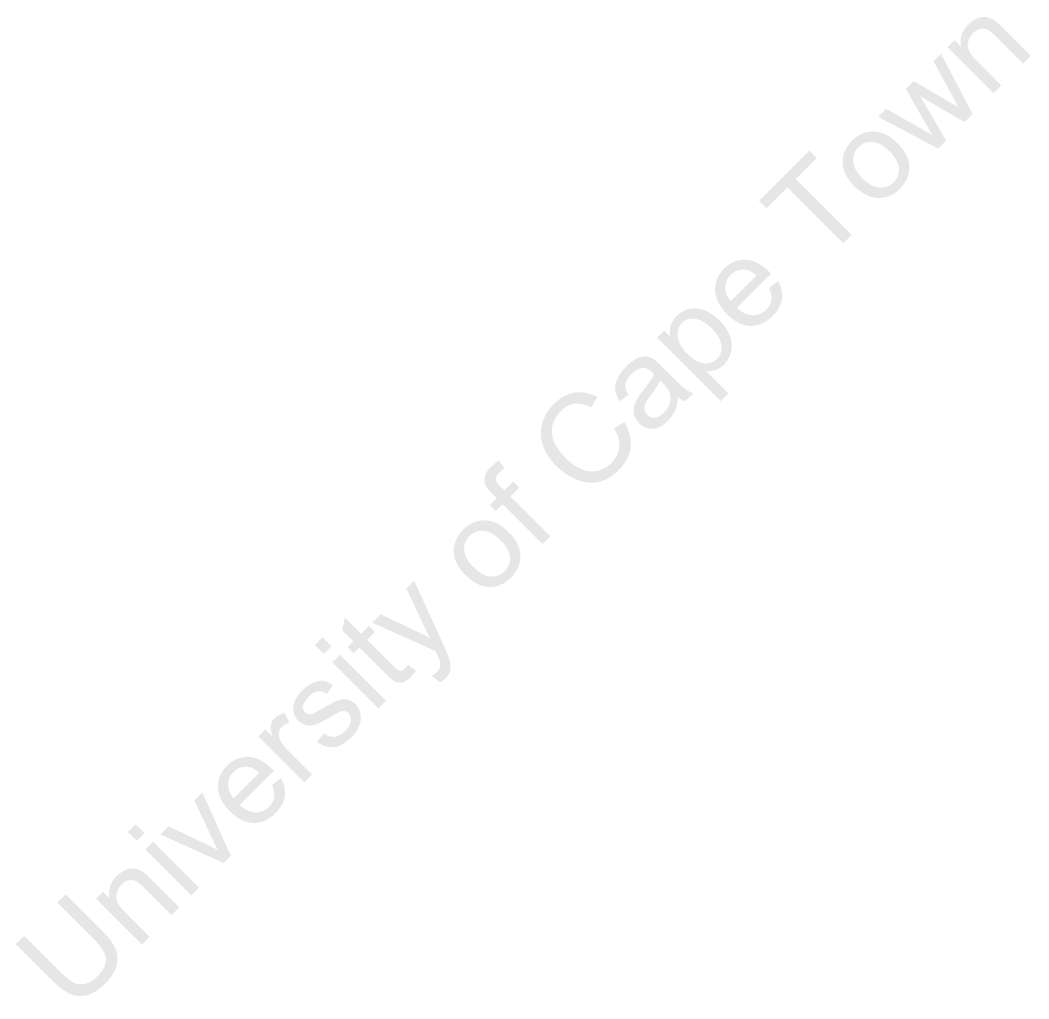

- 175 - 

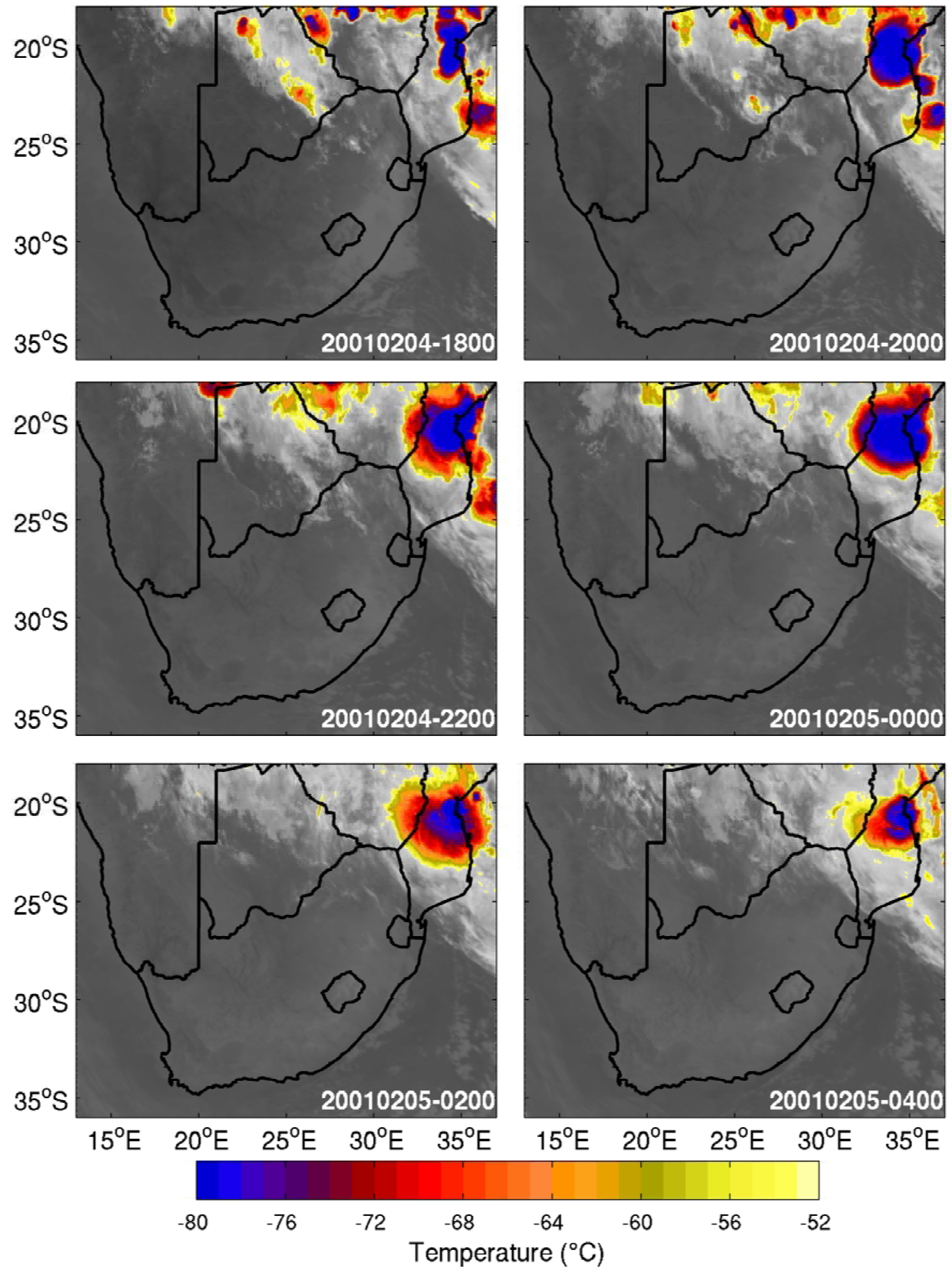

Figure 7.1: Meteosat-7 IR images showing cloud top temperature $\left({ }^{\circ} \mathrm{C}\right)$ of the MCC that took place during 04-05 February 2001. Times shown are in UTC (LST - 2). 


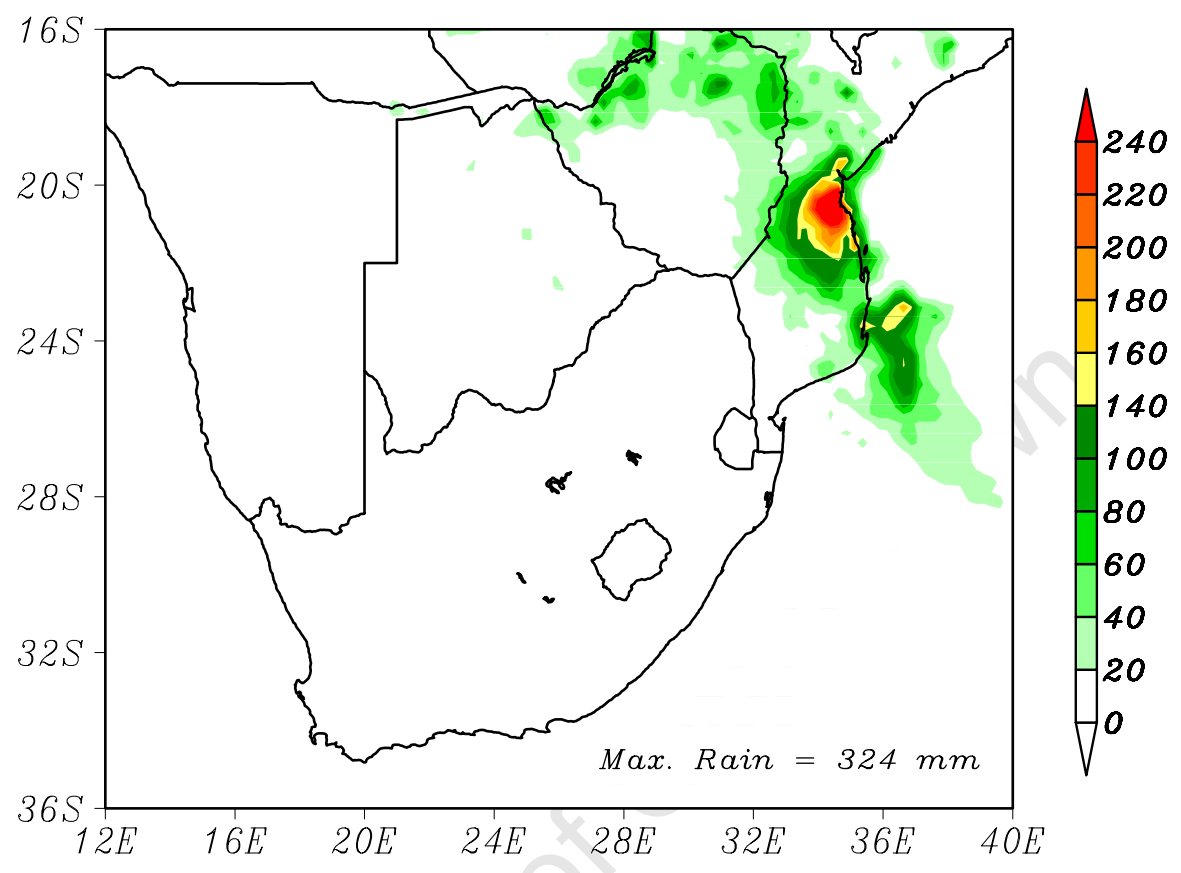

Figure 7.2: Rainfall (mm) derived by the 3 hourly TMPA data from $12 \mathrm{~h} 00$ UTC 04 February through to 06 h00 UTC 05 February. 

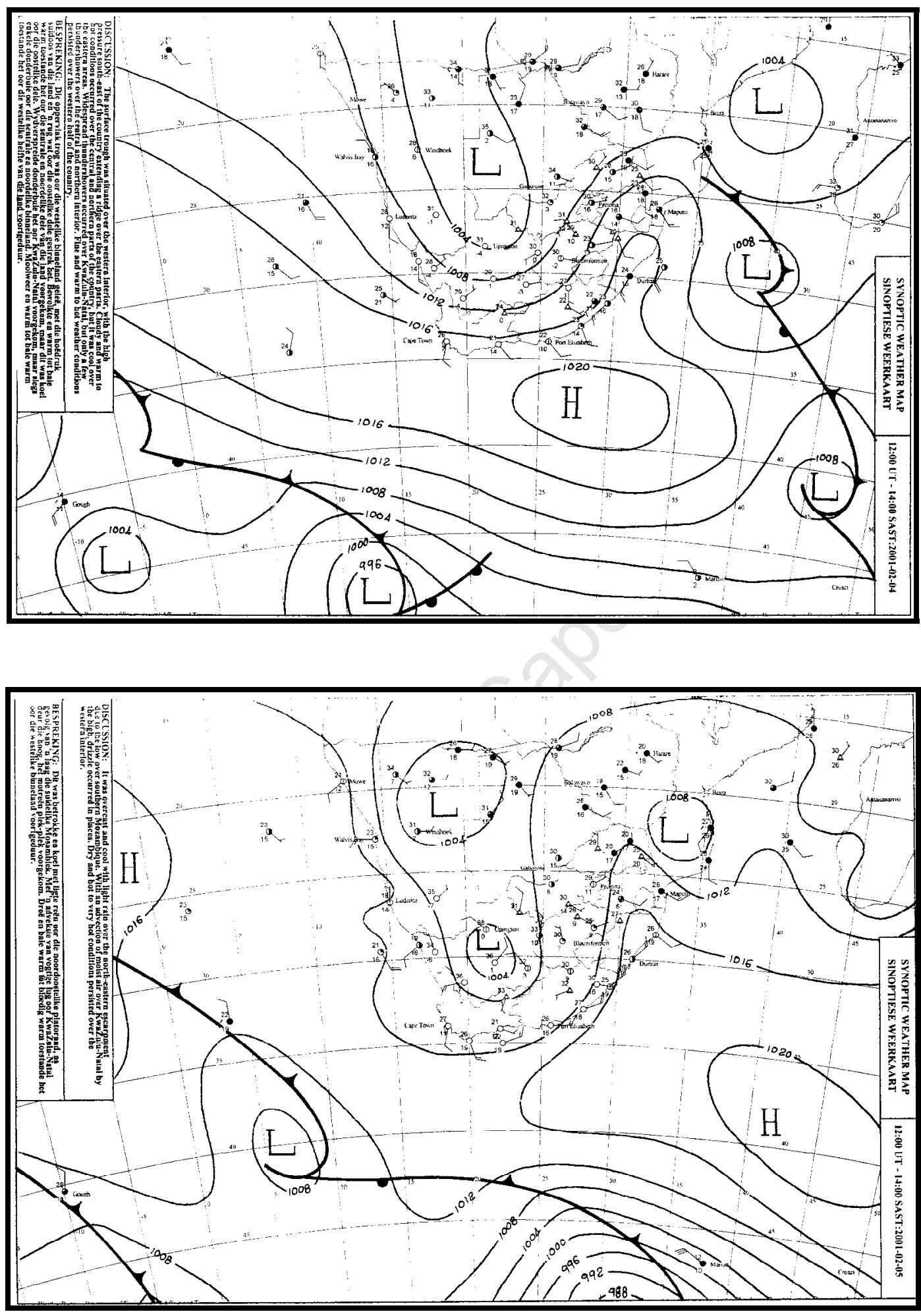

Figure 7.3: South African Weather Service (SAWS) synoptic charts for the 04 February 2001 (top) and 05 February 2001 (bottom). 

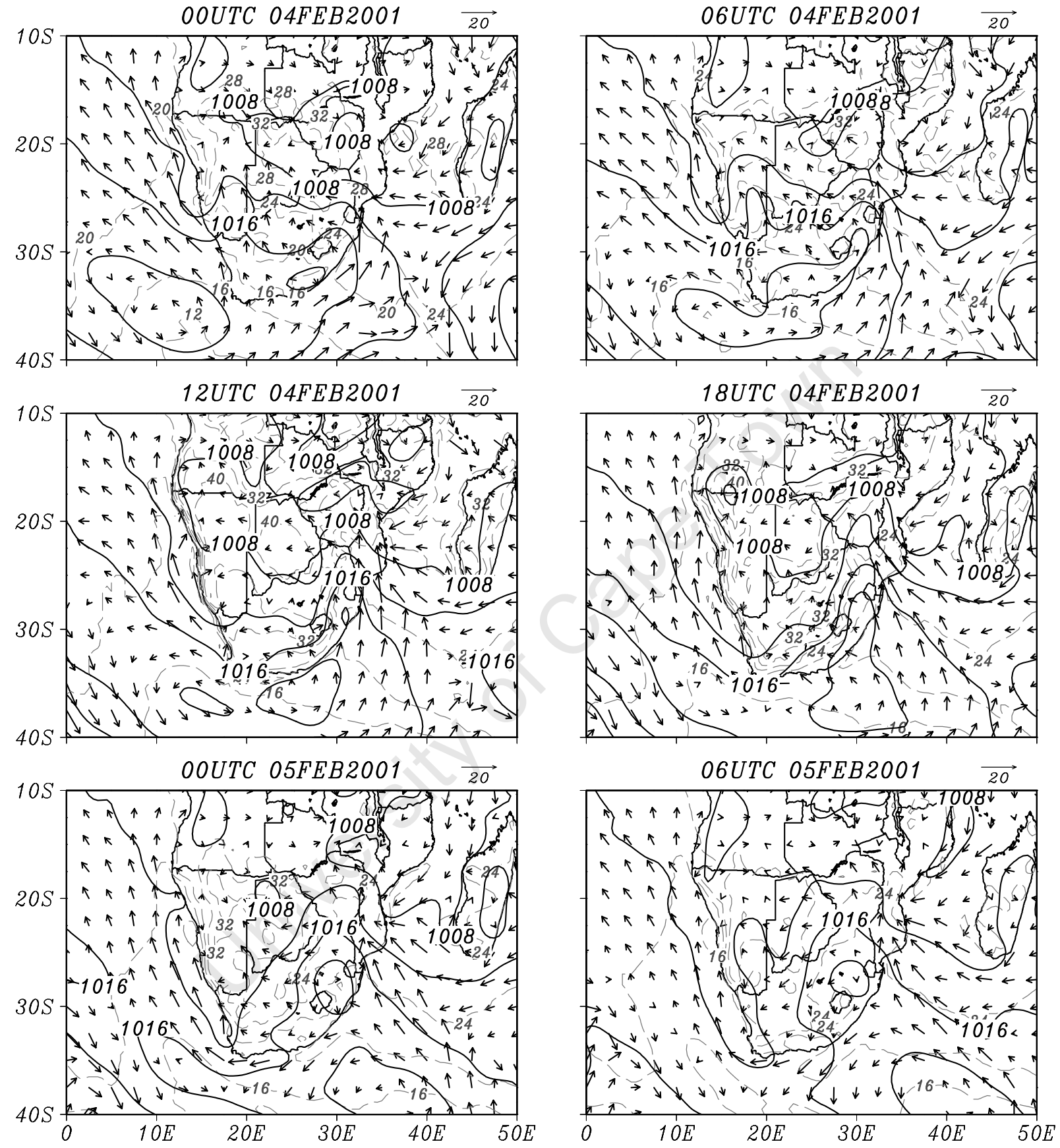

Figure 7.4: Mean sea level pressure (solid contours; $4 \mathrm{hPa}$ interval), temperature (grey dashed contours, $2^{\circ} \mathrm{C}$ interval) and vector winds $\left(\mathrm{m} . \mathrm{s}^{-1}\right.$, proportion of wind speed to arrow length given above top right corner) at the $1000 \mathrm{hPa}$ level. Times indicate here are UTC. 

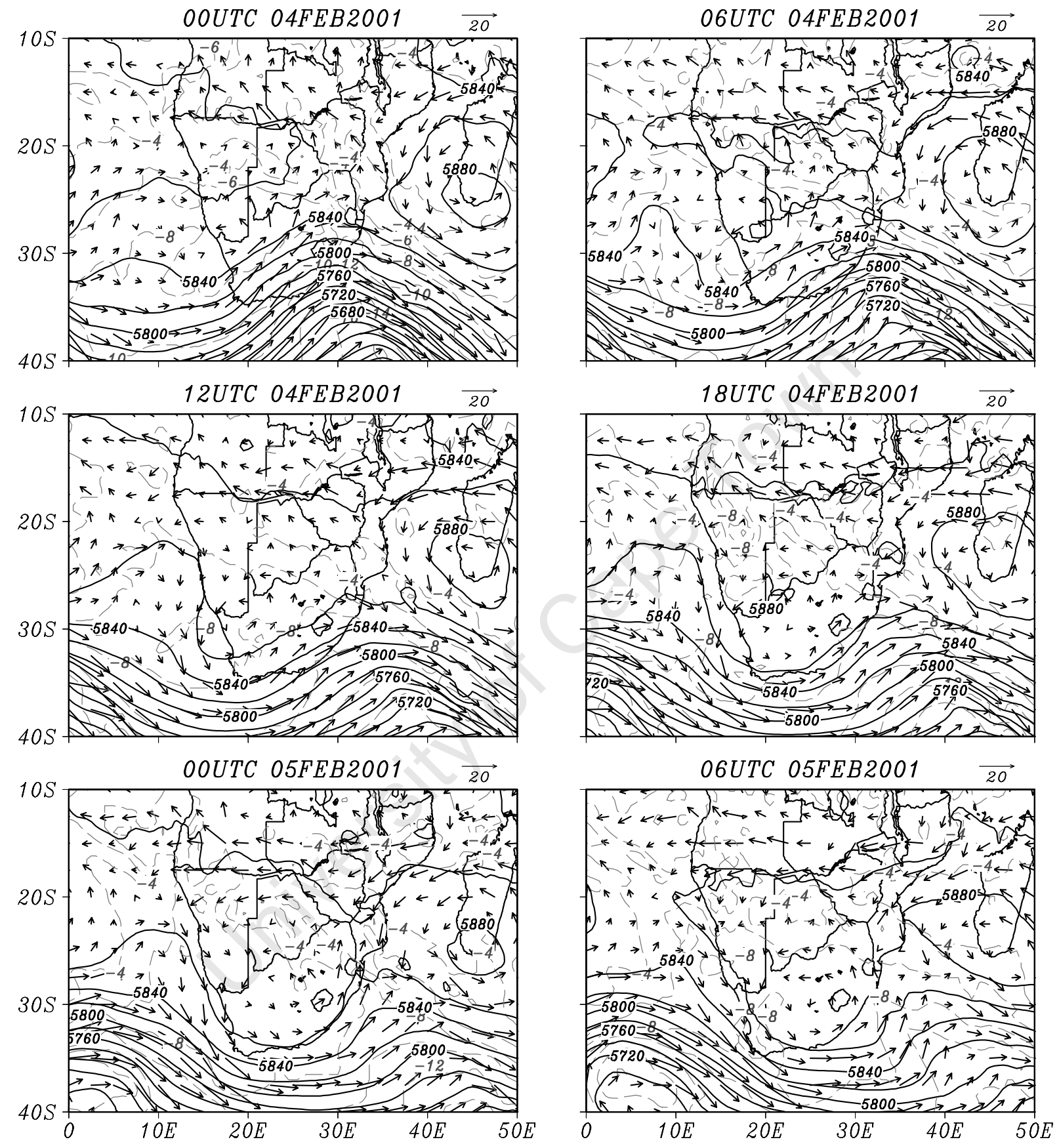

Figure 7.5: Geopotential height (solid contours; $20 \mathrm{~m}$ interval), vector winds $\left(\mathrm{m} . \mathrm{s}^{-1}\right.$, proportion of wind speed to arrow length given above top right corner) and temperature (dashed contour; units in ${ }^{\circ} \mathrm{C}$ ) for the $500 \mathrm{hPa}$ level. 

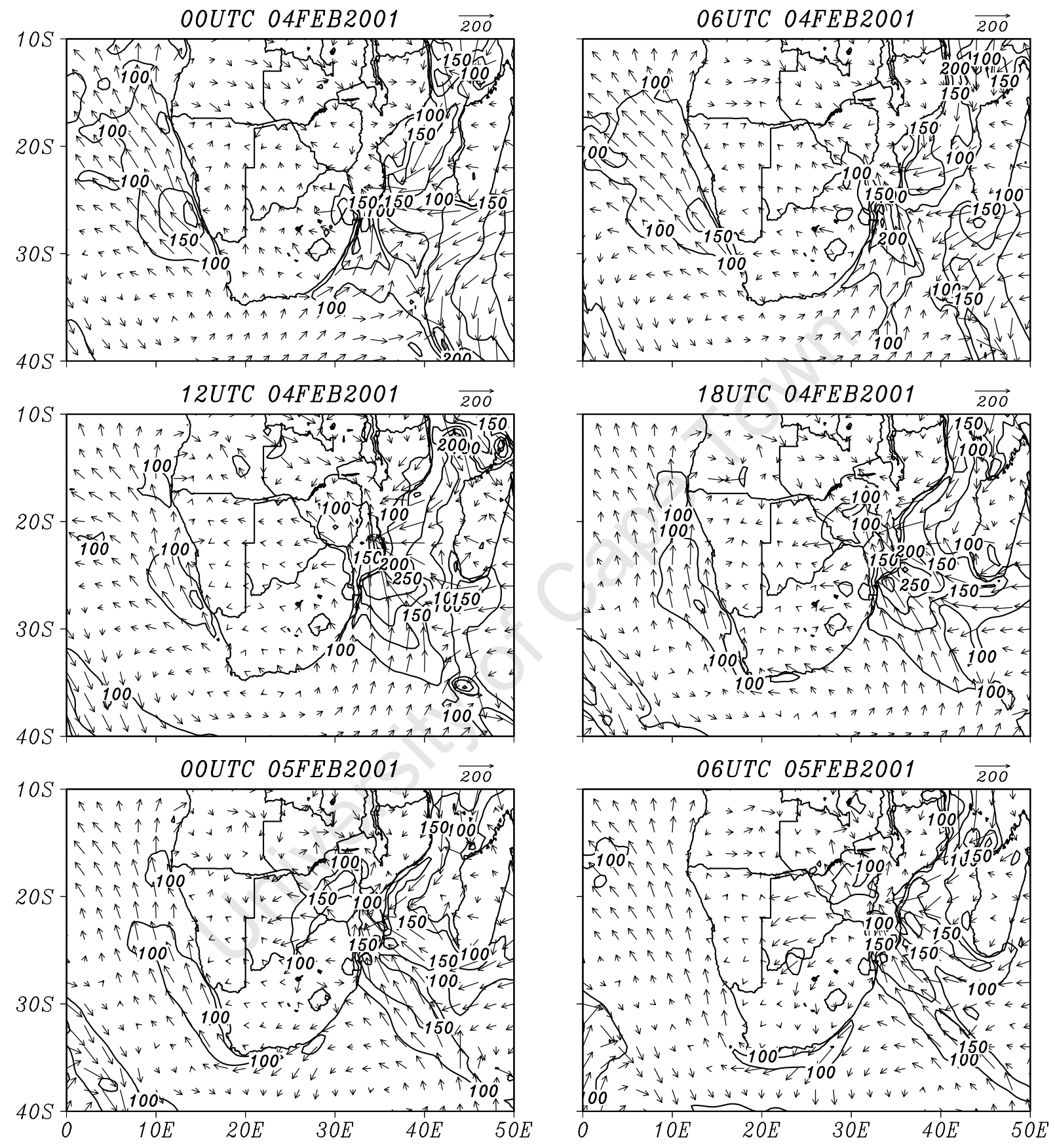

Figure 7.6: Moisture flux (g. $\mathrm{kg}^{-1} \mathrm{~m} . \mathrm{s}^{-1}$, both arrow and contours) at the $1000 \mathrm{hPa}$ level. 


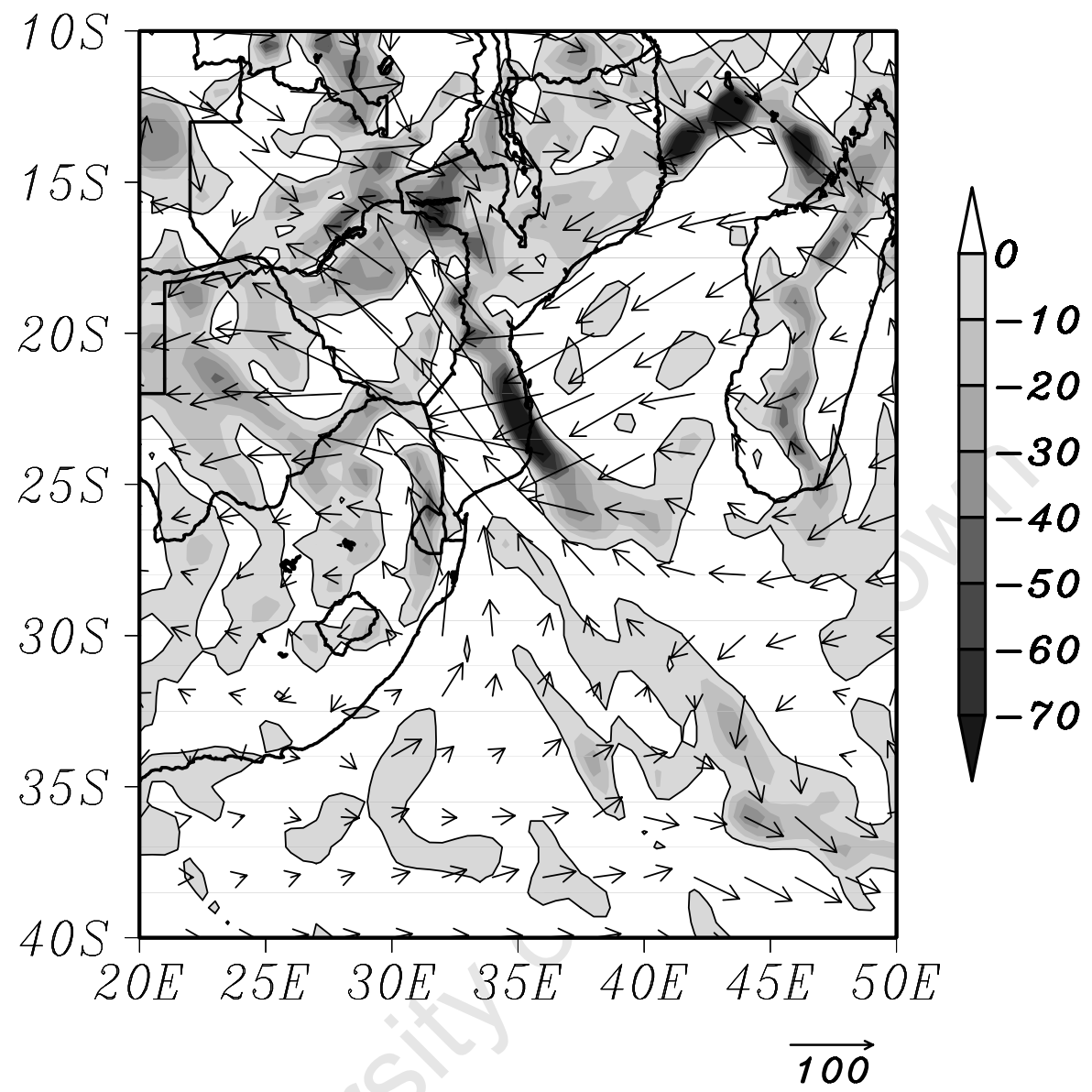

Figure 7.7: The average 6 hourly moisture flux (vector, $\mathrm{g} . \mathrm{kg}^{-1} \mathrm{~m} . \mathrm{s}^{-1}$ ) and moisture convergence (shaded, $\mathrm{x} 10^{-5} \mathrm{~g} \cdot \mathrm{kg}^{-1} \mathrm{~s}^{-1}$ ) at $850 \mathrm{hPa}$ from $12 \mathrm{~h} 00$ on 04 February through to $06 \mathrm{~h} 00$ on 05 February. Note that for clarity, moisture divergence is not shown. 

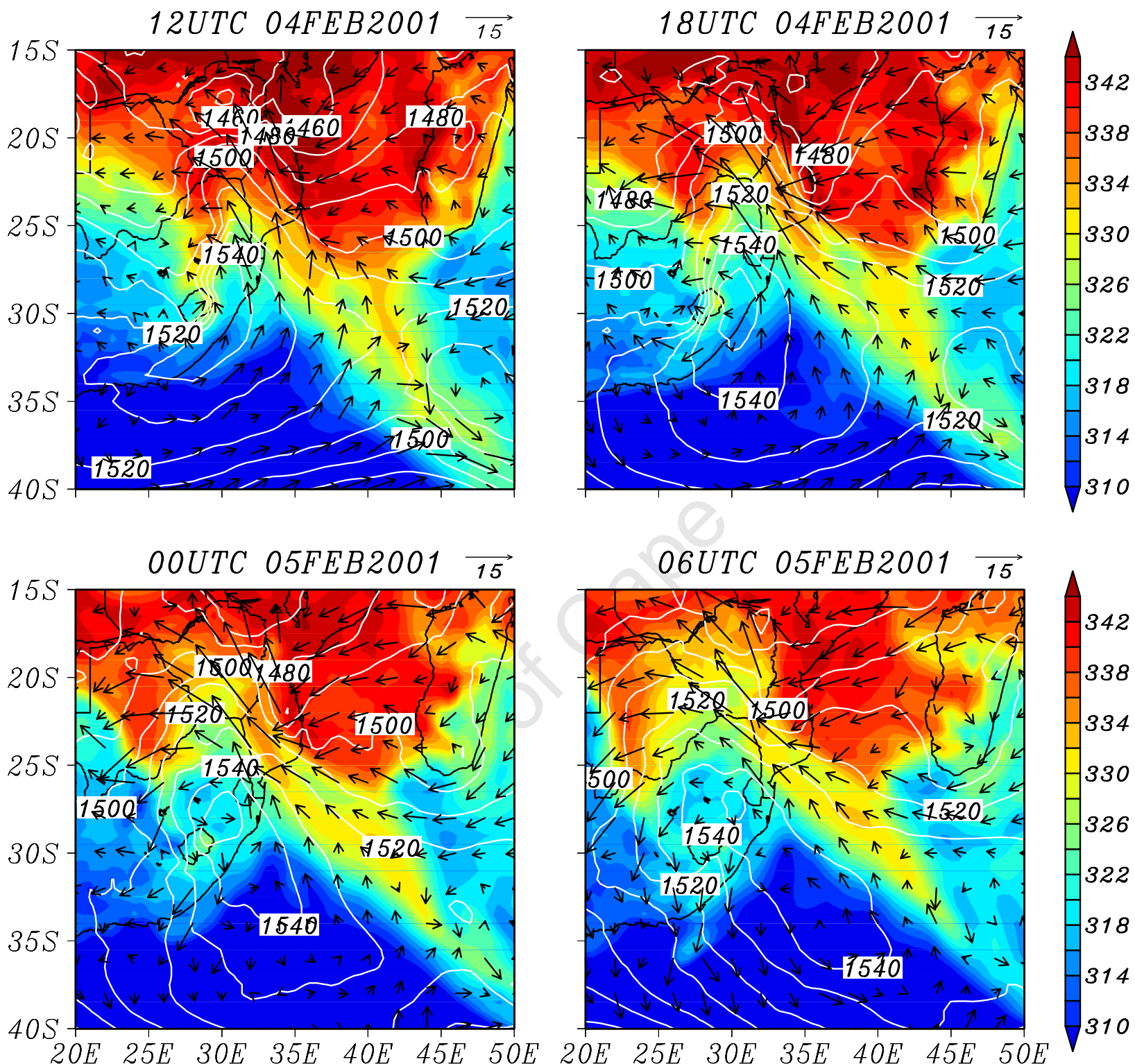

Figure 7.8: Equivalent potential temperature (shaded; units are ${ }^{\circ} \mathrm{K}$ ), geopotential height

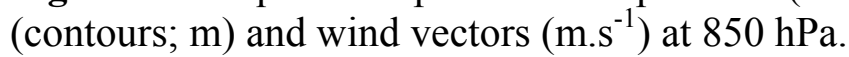



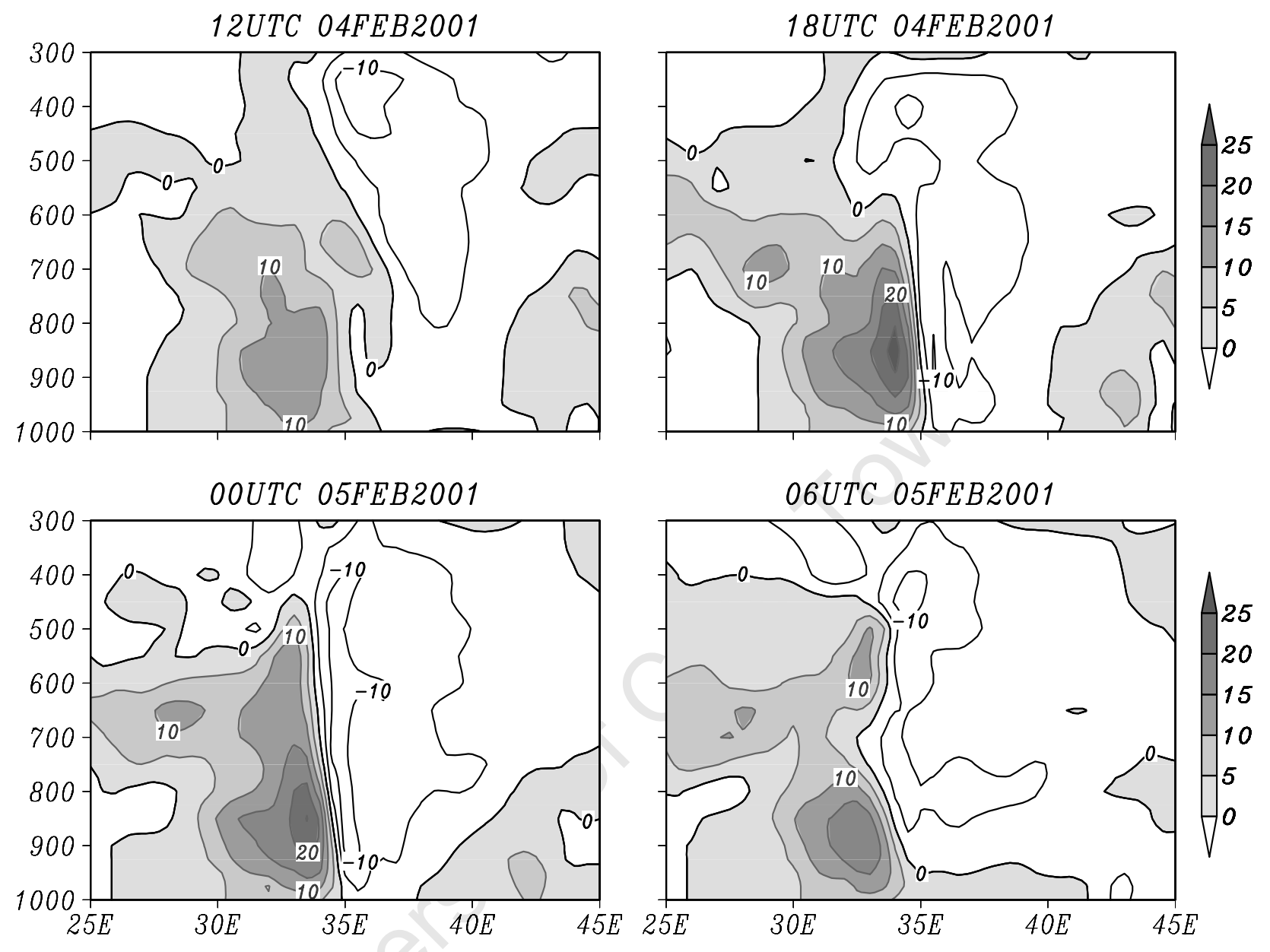

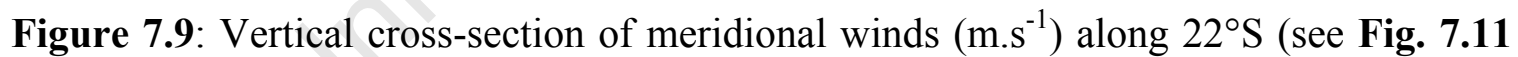
for location). Southerly winds are shaded, while northerly winds are depicted with contours. 

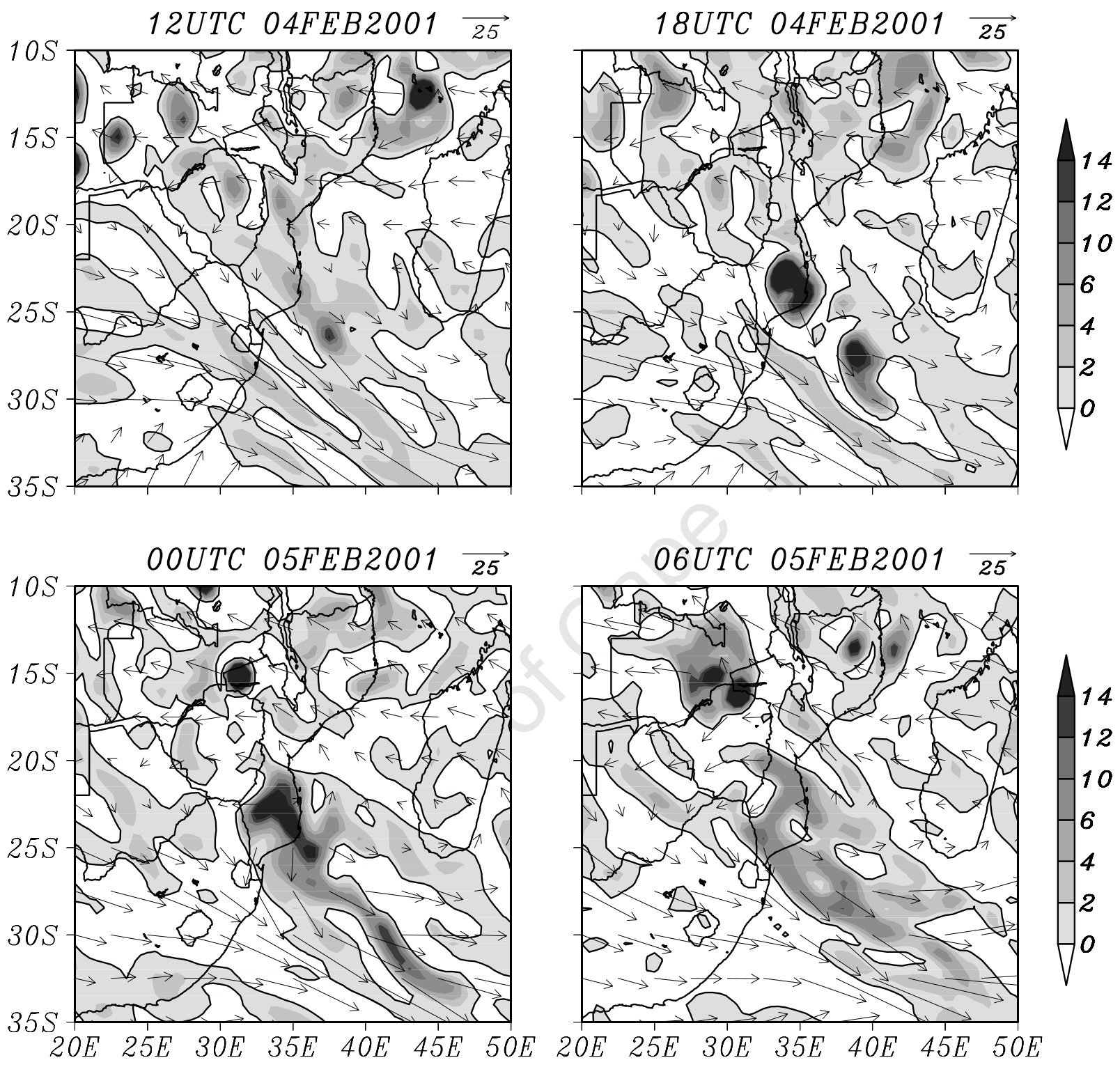

Figure 7.10: Divergence (shaded, $\left.\times 10^{-5} \mathrm{~s}^{-1}\right)$ and vector winds $\left(\mathrm{m} \cdot \mathrm{s}^{-1}\right)$ at $200 \mathrm{hPa}$. 

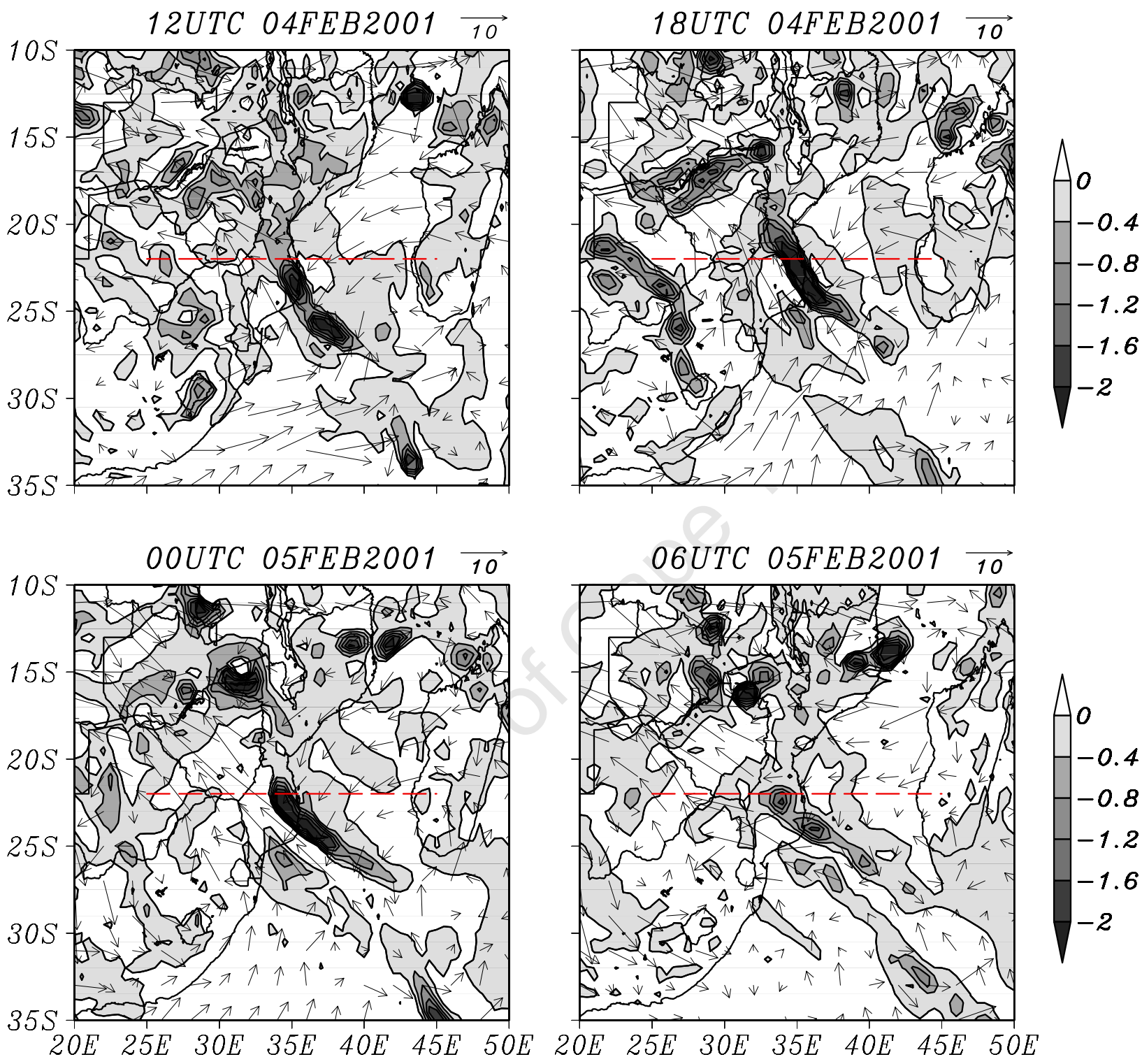

Figure 7.11: Omega (shaded with contours, Pa.s ${ }^{-1}$ ) and vector winds $\left(\mathrm{m} . \mathrm{s}^{-1}\right)$ at $700 \mathrm{hPa}$. Note that only upward motion is plotted. Red line denotes latitude of which the crosssection Fig. 7.12 is based. 

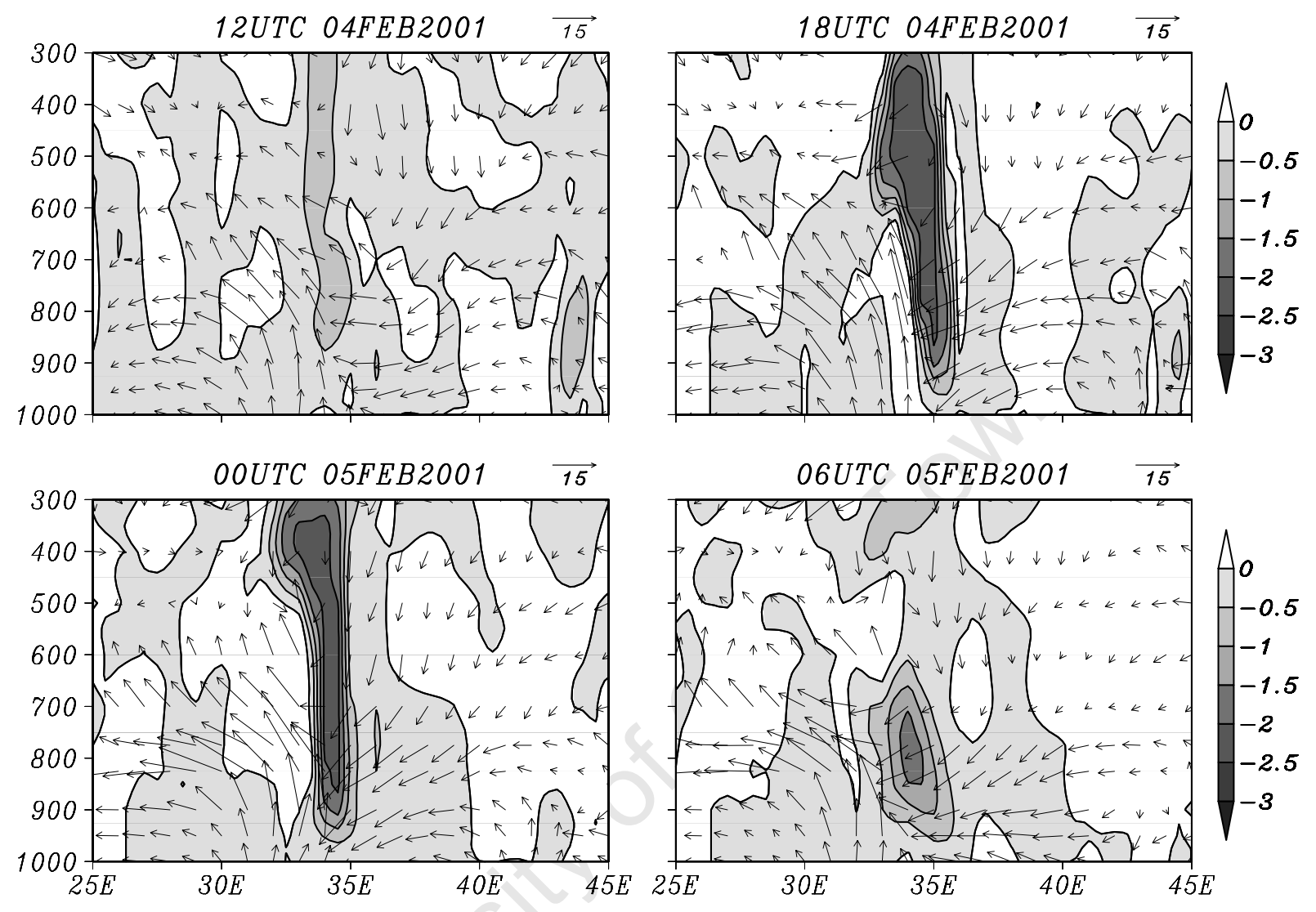

Figure 7.12: Cross section of omega (shaded with contours, Pa. $\mathrm{s}^{-1}$ ) along $22^{\circ} \mathrm{S}$ (see Fig. 7.11 for location). Also shown are vector winds $\left(\mathrm{m}^{-1} \mathrm{~s}^{-1}\right)$. 

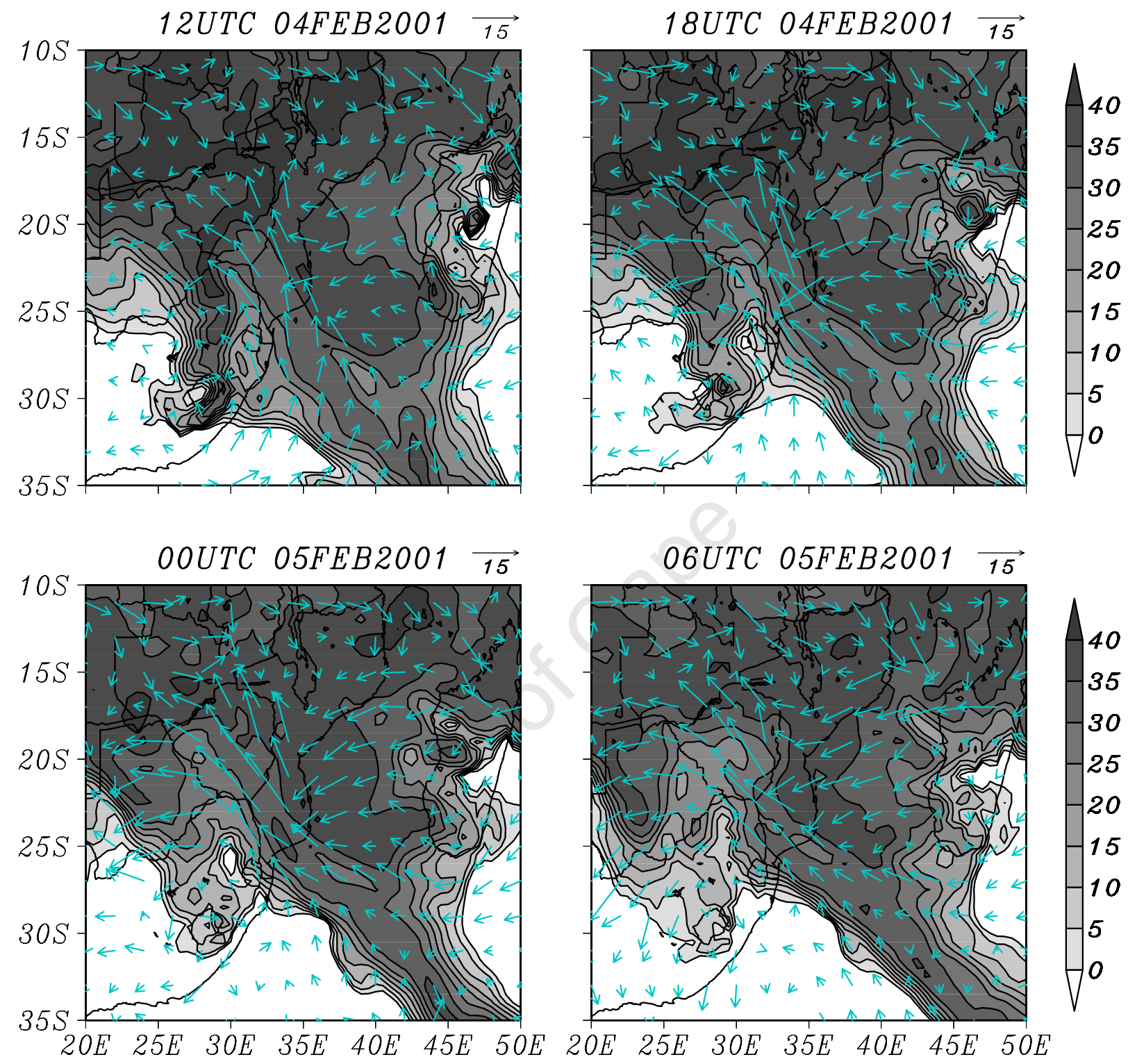

Figure 7.13: The $K$-Index (shaded) and vector winds $\left(\mathrm{m} . \mathrm{s}^{-1}\right)$ at $850 \mathrm{hPa}$. 

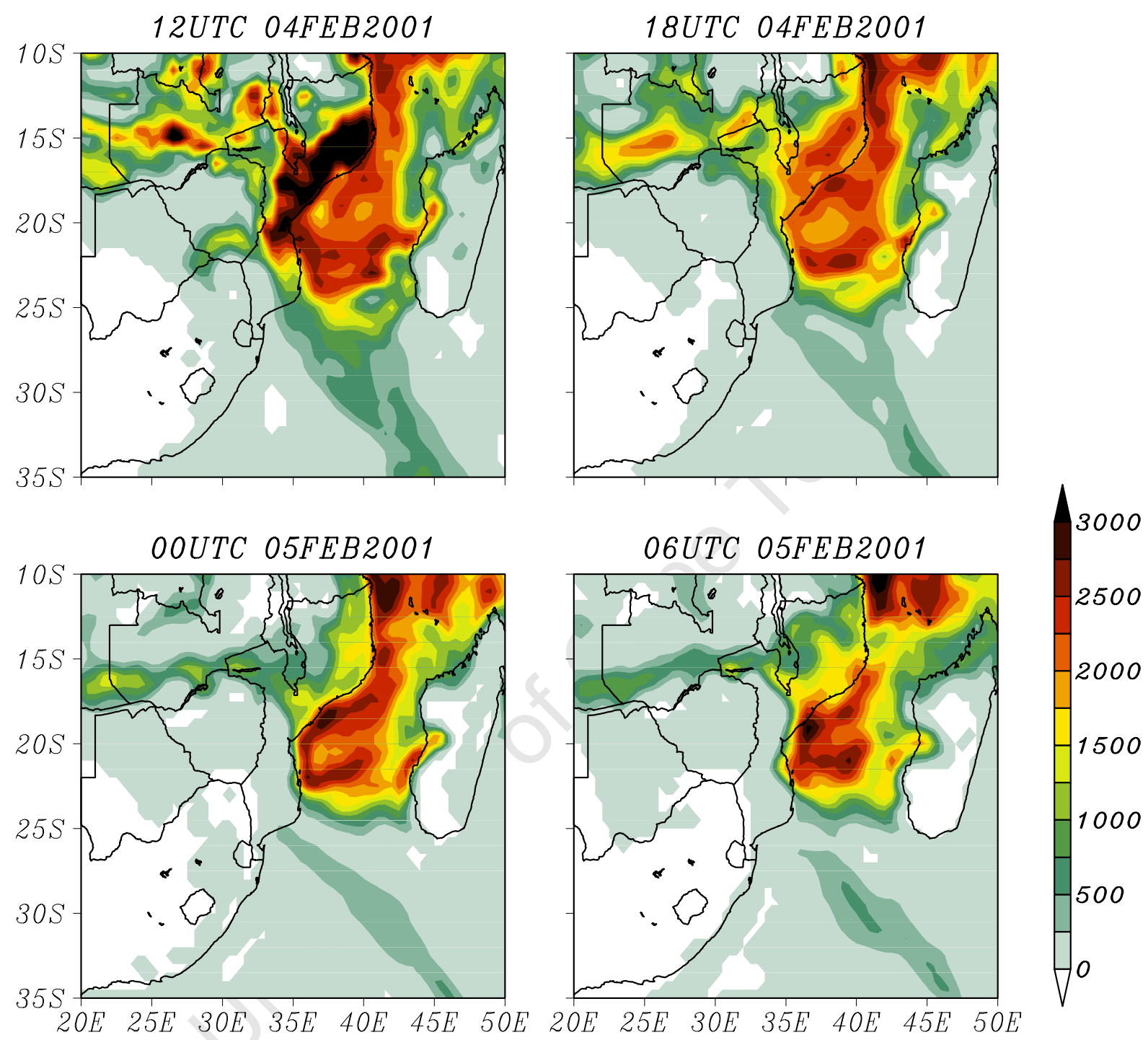

Figure 7.14: Surface convective available potential energy (shaded, J. $\mathrm{kg}^{-1}$ ). 

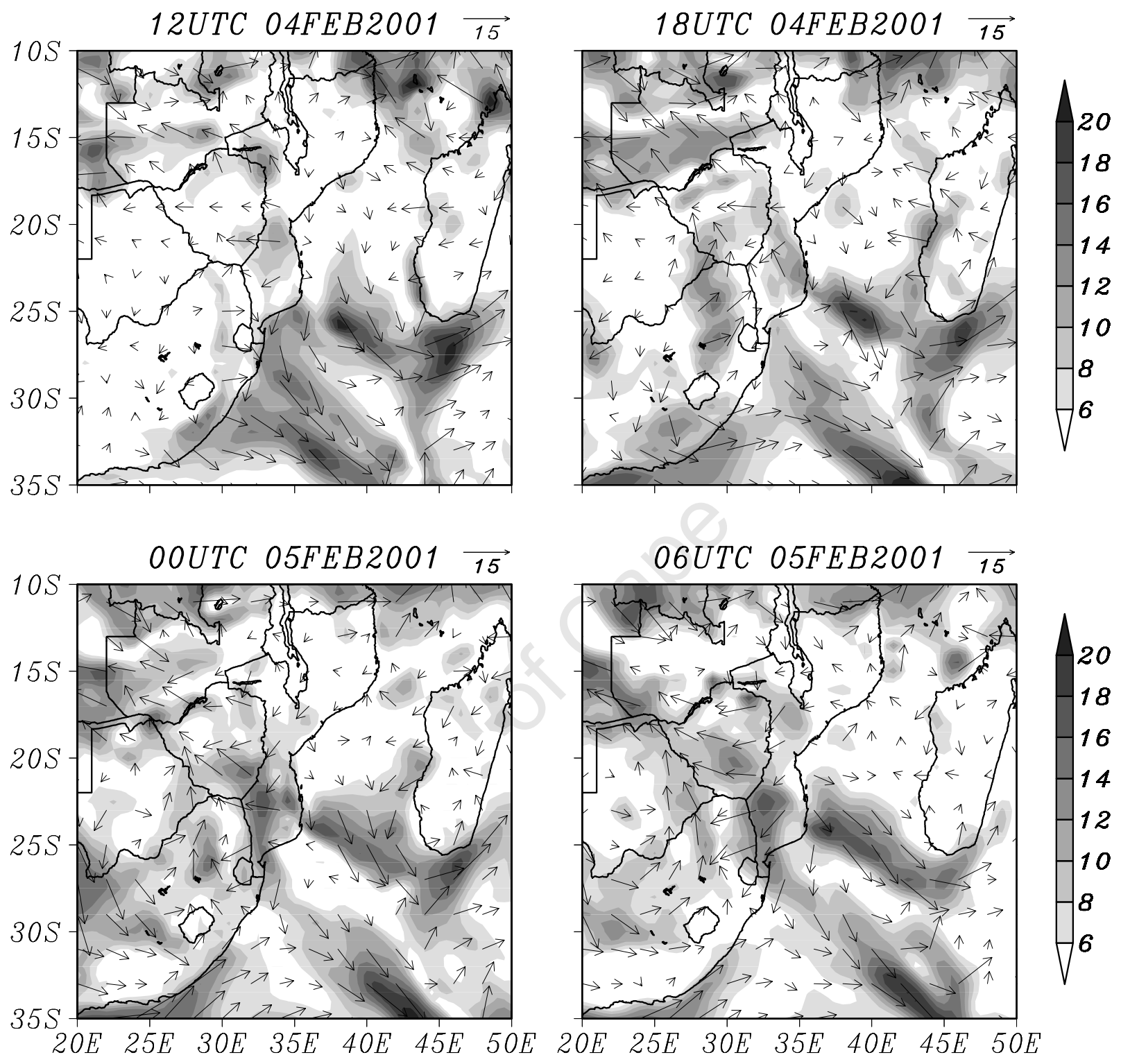

Figure 7.15: Low level shear (1000-700 hPa) in $\mathrm{m} . \mathrm{s}^{-1}$. 

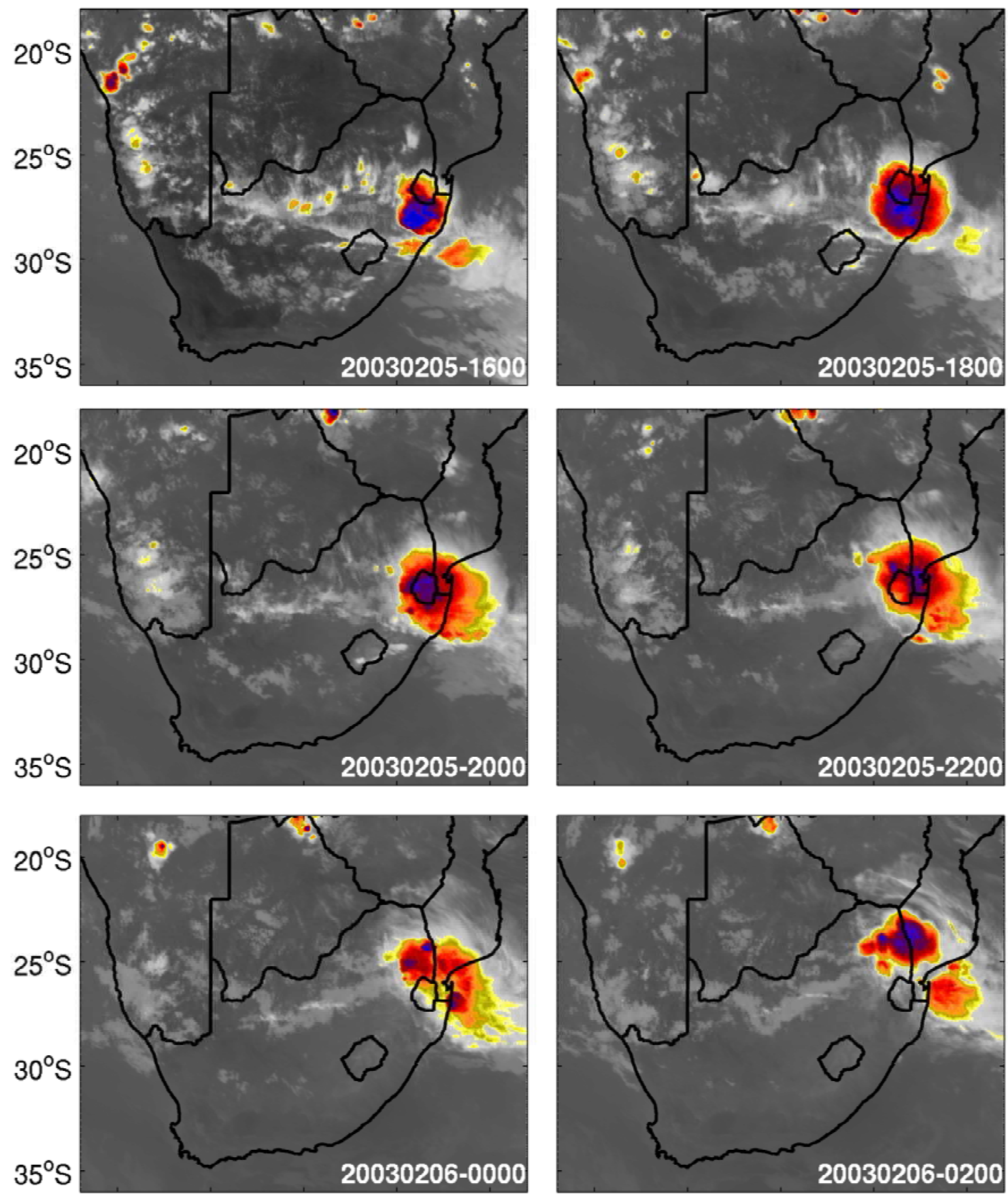

$15^{\circ} \mathrm{E} \quad 20^{\circ} \mathrm{E} \quad 25^{\circ} \mathrm{E} \quad 30^{\circ} \mathrm{E} \quad 35^{\circ} \mathrm{E}$

$15^{\circ} \mathrm{E} \quad 20^{\circ} \mathrm{E} \quad 25^{\circ} \mathrm{E} \quad 30^{\circ} \mathrm{E} \quad 35^{\circ} \mathrm{E}$

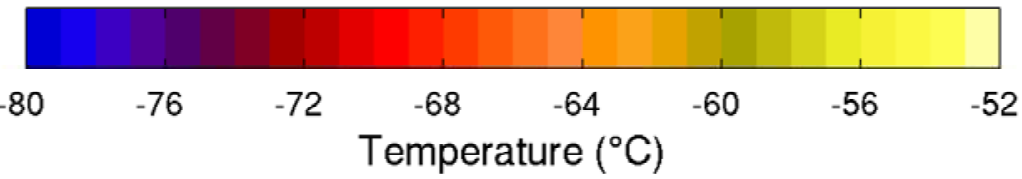

Figure 7.16: Meteosat-7 IR images showing cloud top temperature $\left({ }^{\circ} \mathrm{C}\right)$ of the $\mathrm{MCC}$ that took place during 05-06 February 2003. Times shown are in UTC (LST - 2). 


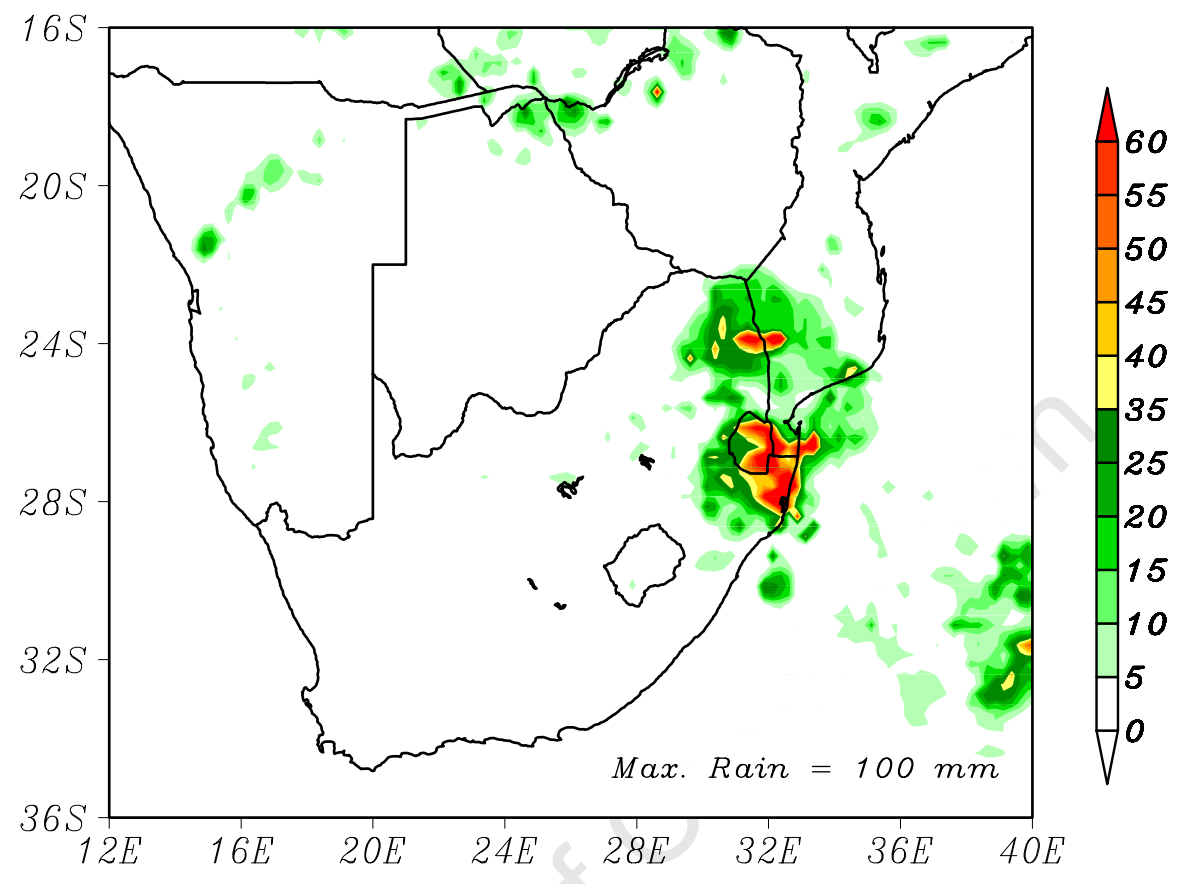

Figure 7.17: Rainfall (mm) derived by the 3 hourly TMPA during the duration of the event. 

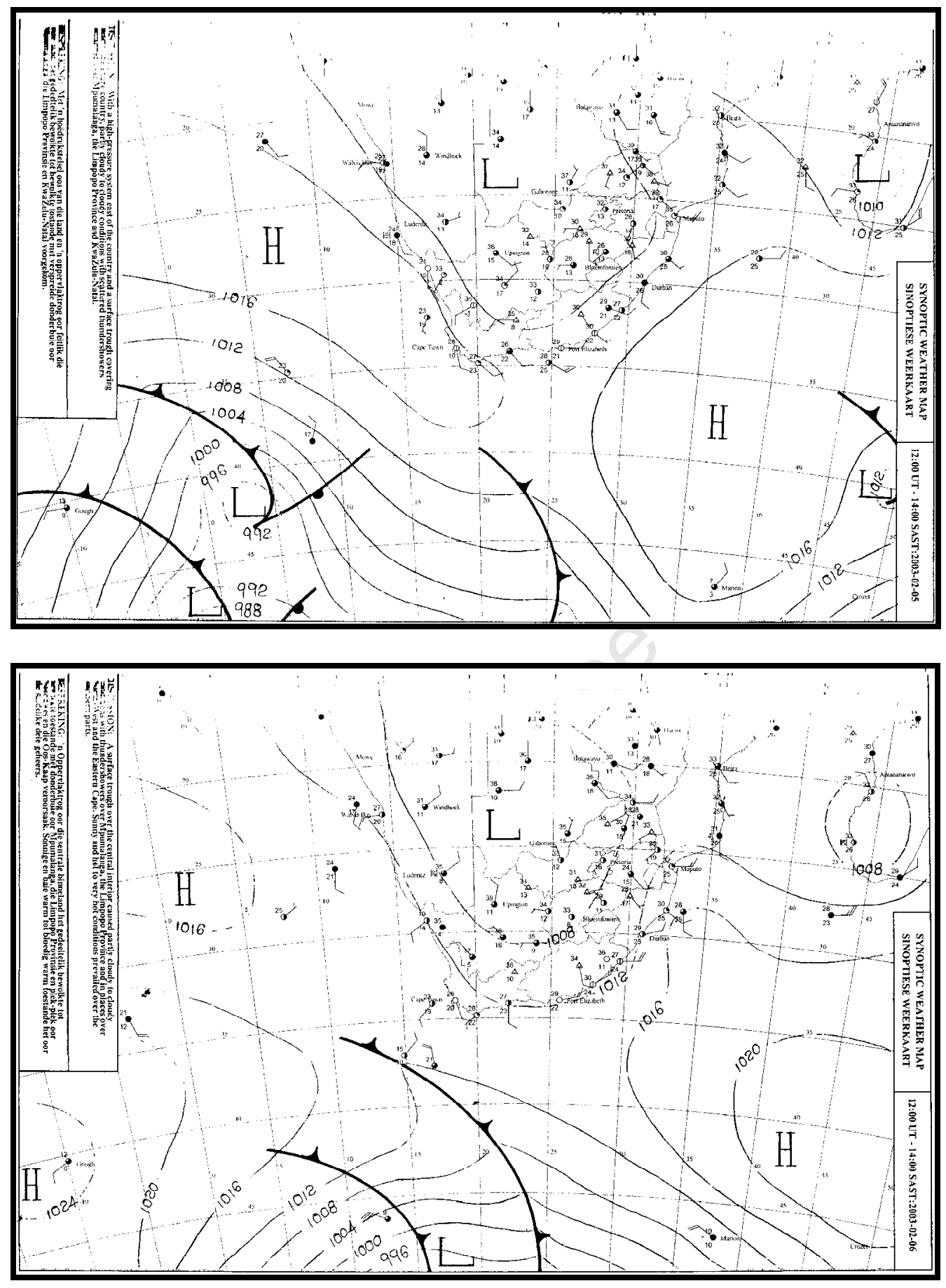

Figure 7.18: South African Weather Service synoptic charts for the 05 February 2003 (top) and 06 February 2003 (bottom). 

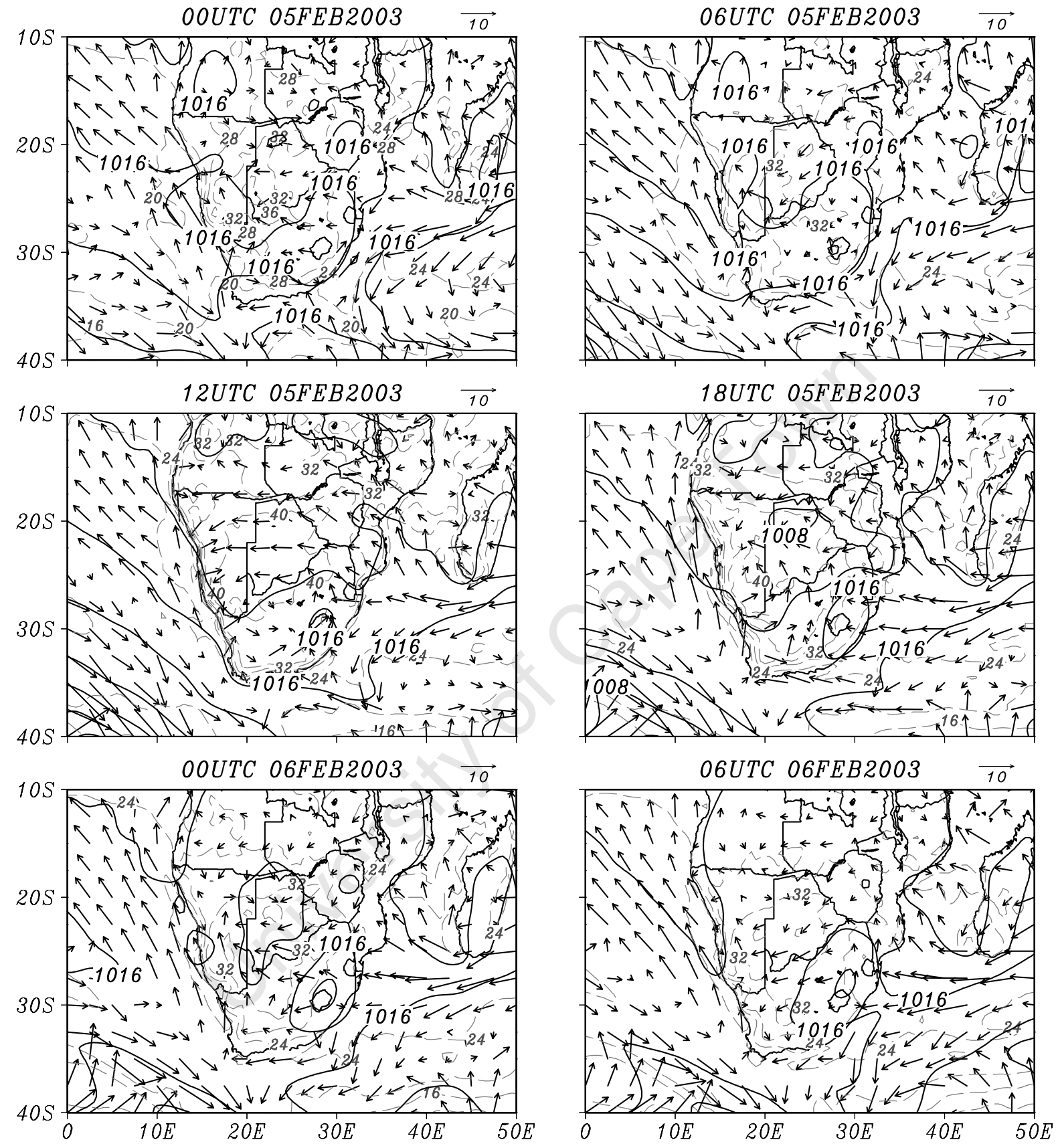

Figure 7.19: Mean sea level pressure (solid contours; $4 \mathrm{hPa}$ interval), temperature (grey dashed contours, $2^{\circ} \mathrm{C}$ interval) and vector winds $\left(\mathrm{m}_{\mathrm{s}} \mathrm{s}^{-1}\right.$, proportion of wind speed to arrow length given above top right corner) at the $1000 \mathrm{hPa}$ level. Times indicate here are UTC. 


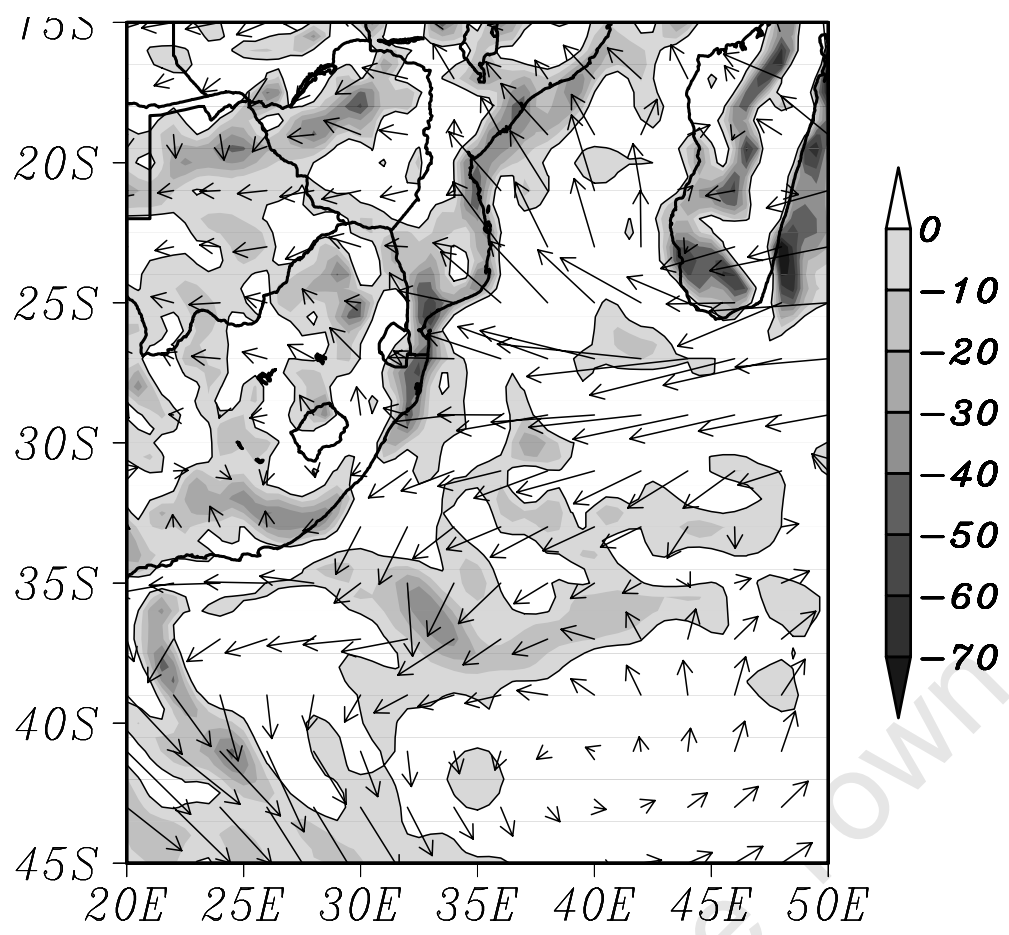

$\overrightarrow{100}$

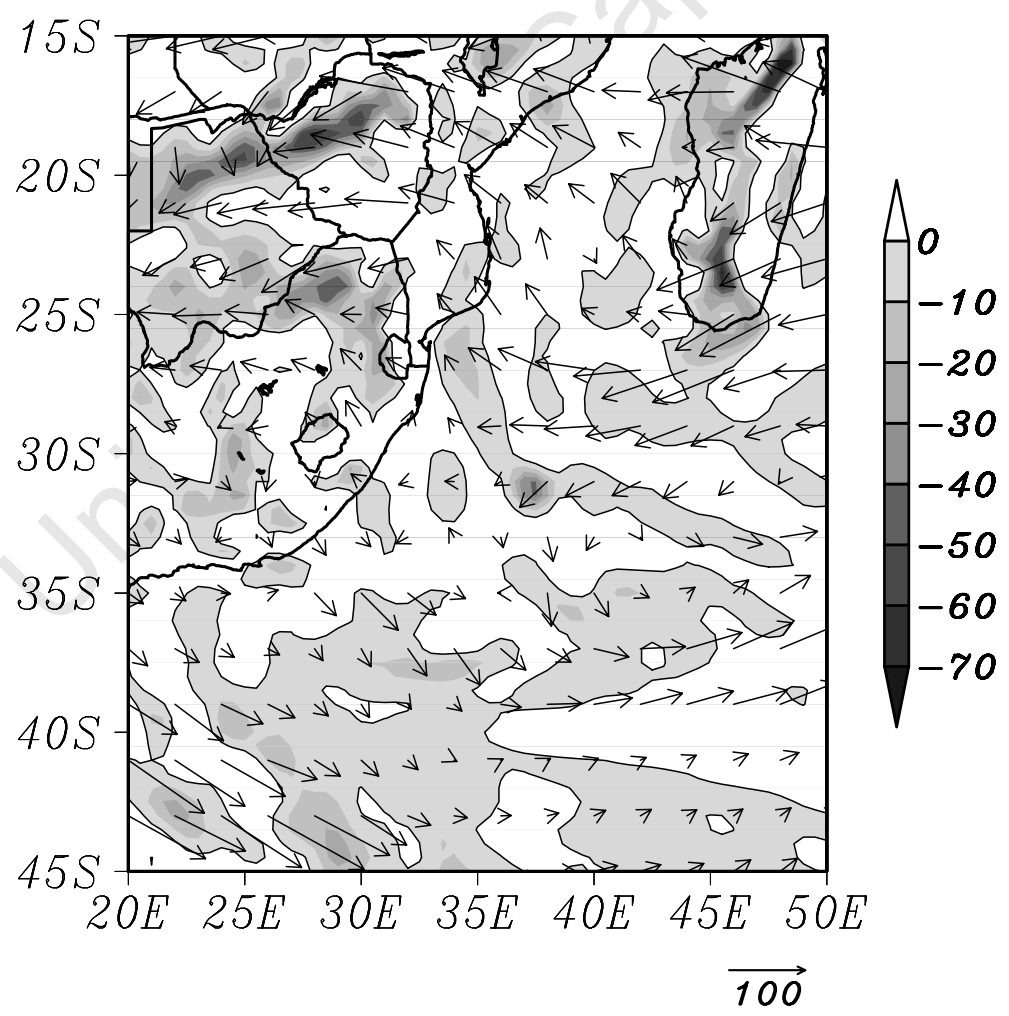

Figure 7.20: Average moisture convergence (shaded; $x 10^{-5} \mathrm{~g}_{\mathrm{kg}} \mathrm{kg}^{-1} \mathrm{~s}^{-1}$ ) and moisture flux (vector arrow; g. $\mathrm{kg}^{-1} \mathrm{~m} \cdot \mathrm{s}^{-1}$ ) at $1000 \mathrm{hPa}$ (top) and $850 \mathrm{hPa}$ (bottom) from $12 \mathrm{~h} 00$ UTC on 05 February through to 06 h00 UTC on 06 February 2003. Only moisture convergence is shown. 

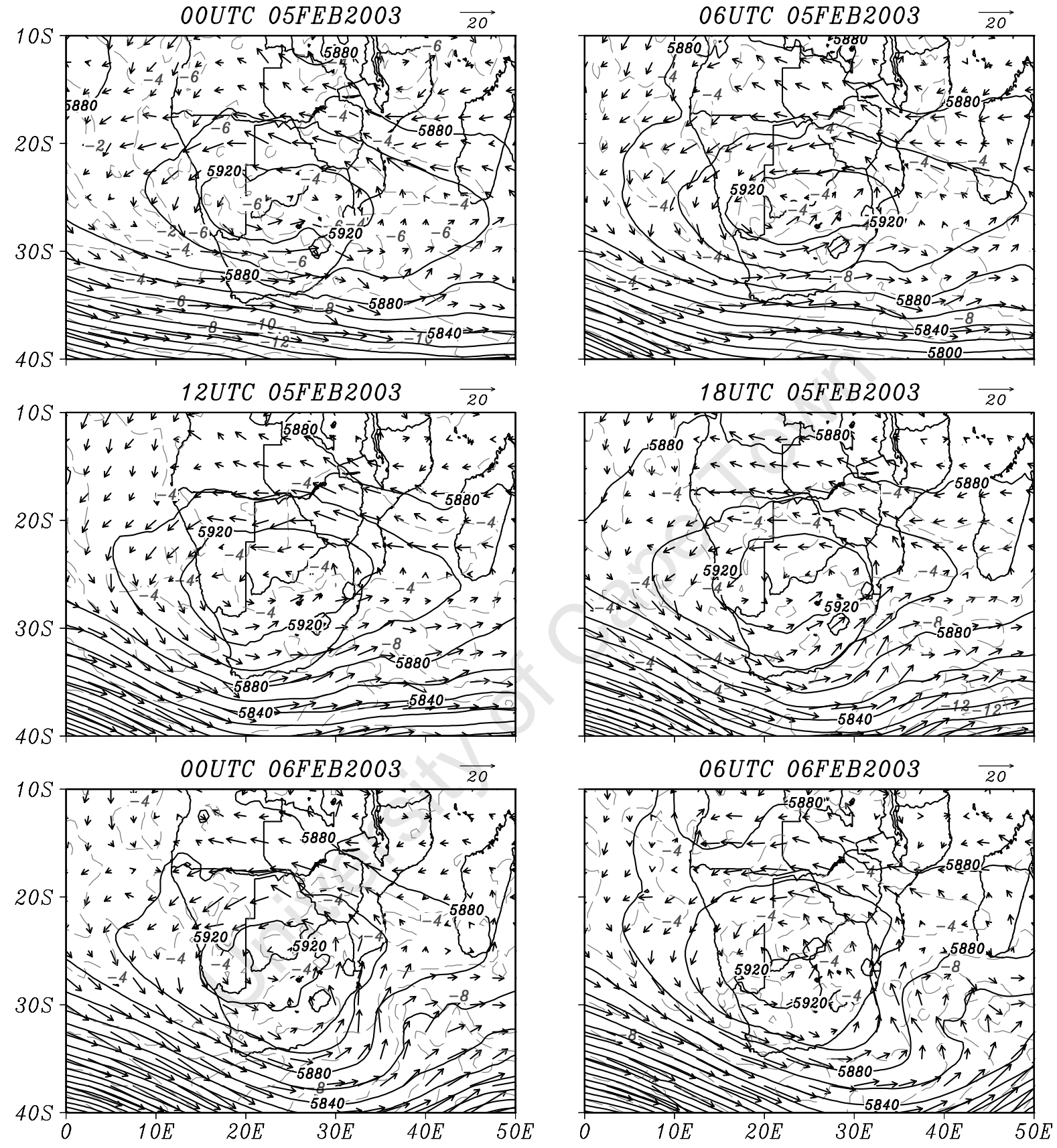

Figure 7.21: Geopotential height (solid contours; $20 \mathrm{~m}$ interval), vector winds $\left(\mathrm{m} . \mathrm{s}^{-1}\right.$, proportion of wind speed to arrow length given above top right corner) and temperature (dashed contour; units in ${ }^{\circ} \mathrm{C}$ ) for the $500 \mathrm{hPa}$ level. 

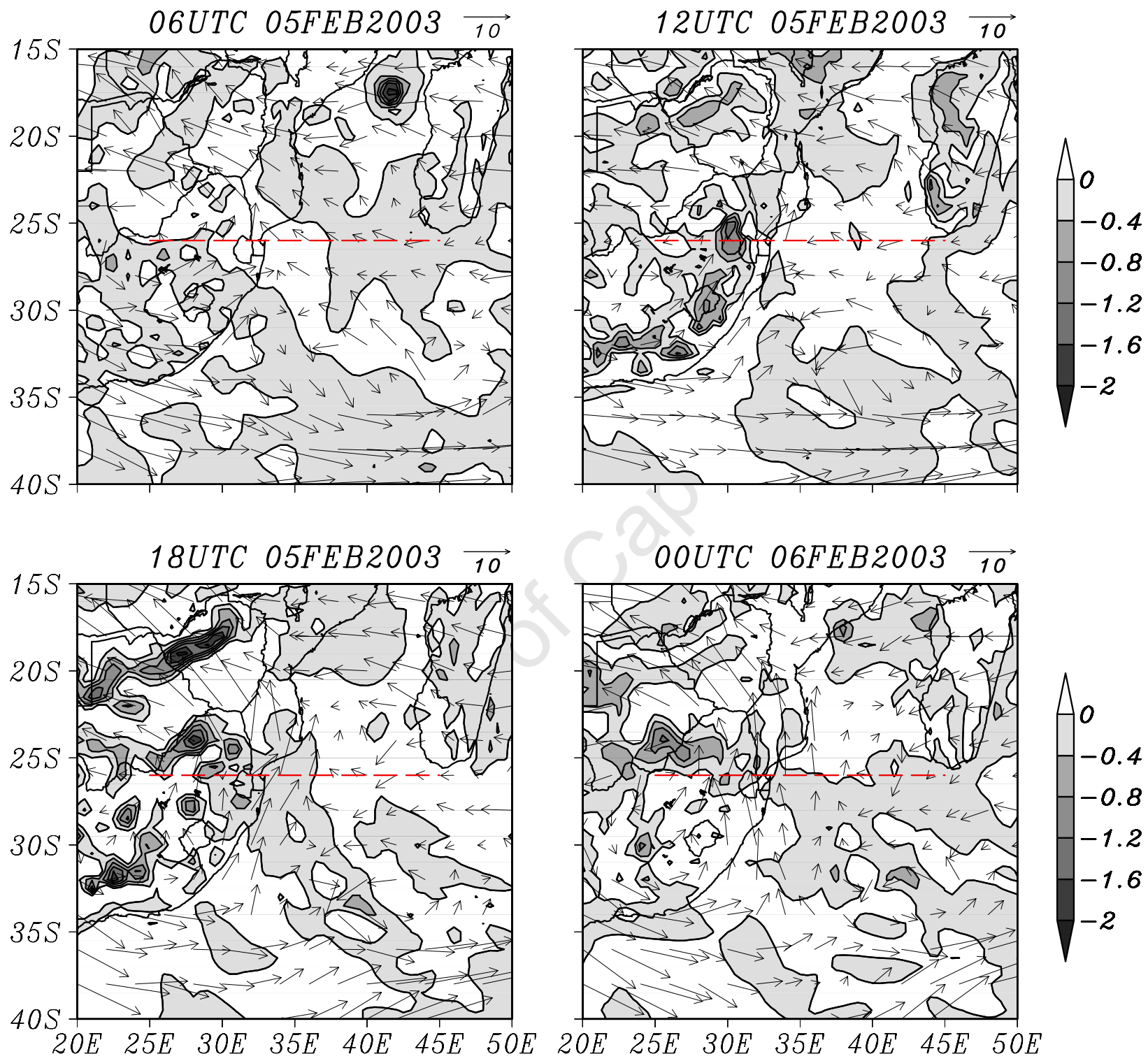

Figure 7.22: Omega (shaded with contours, Pa.s ${ }^{-1}$ ) and vector winds $\left(\mathrm{m}_{\mathrm{s}} \mathrm{s}^{-1}\right)$ at $700 \mathrm{hPa}$. Note that only upward motion is plotted. Red line denotes latitude of which the crosssection Fig. 7.23 is based. 

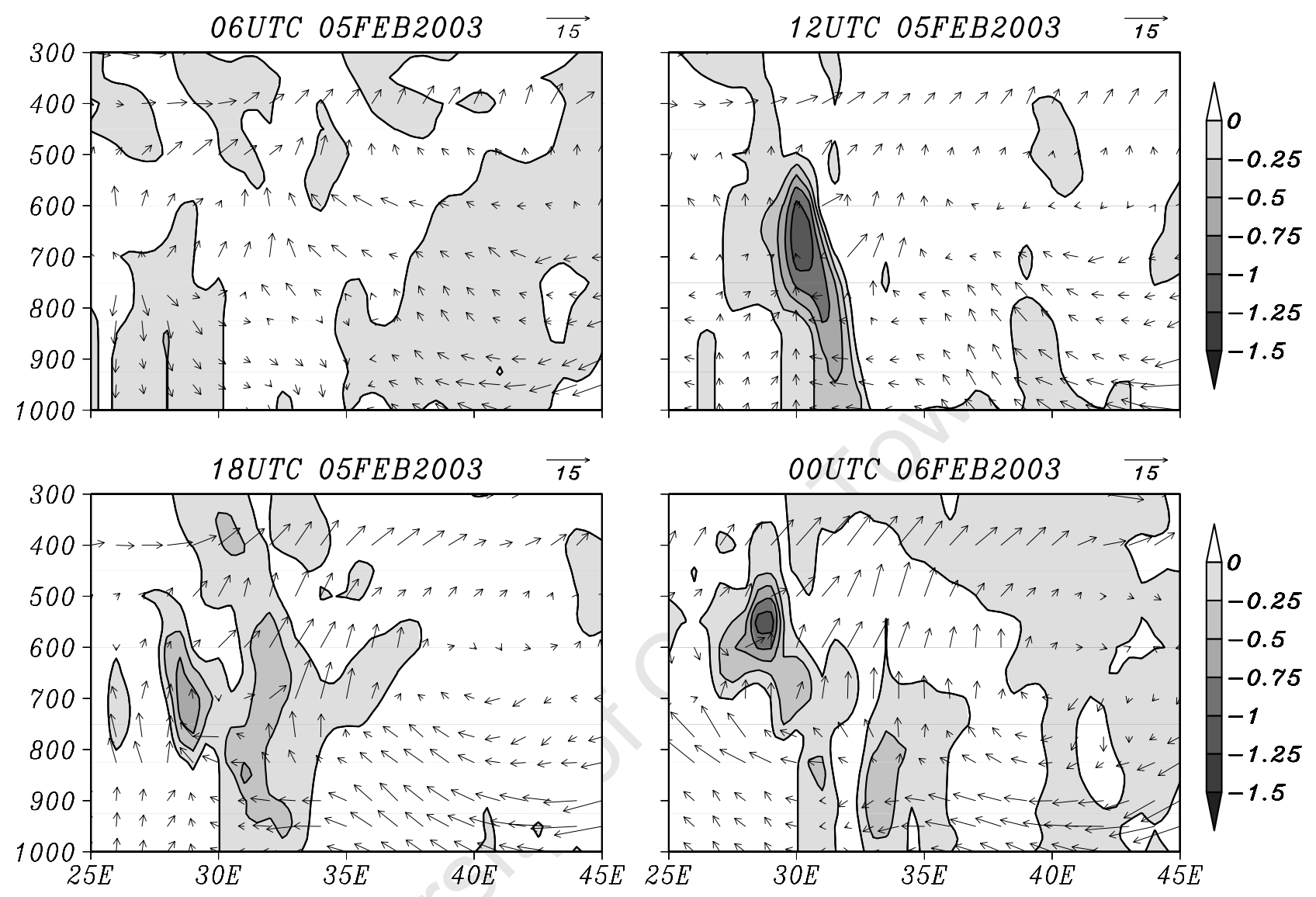

Figure 7.23: Cross section of omega (shaded with contours, Pa. $\mathrm{s}^{-1}$ ) along $26^{\circ} \mathrm{S}$ (see Fig. 7.22 for location). Also shown are vector winds $\left(\mathrm{m} \cdot \mathrm{s}^{-1}\right)$. 

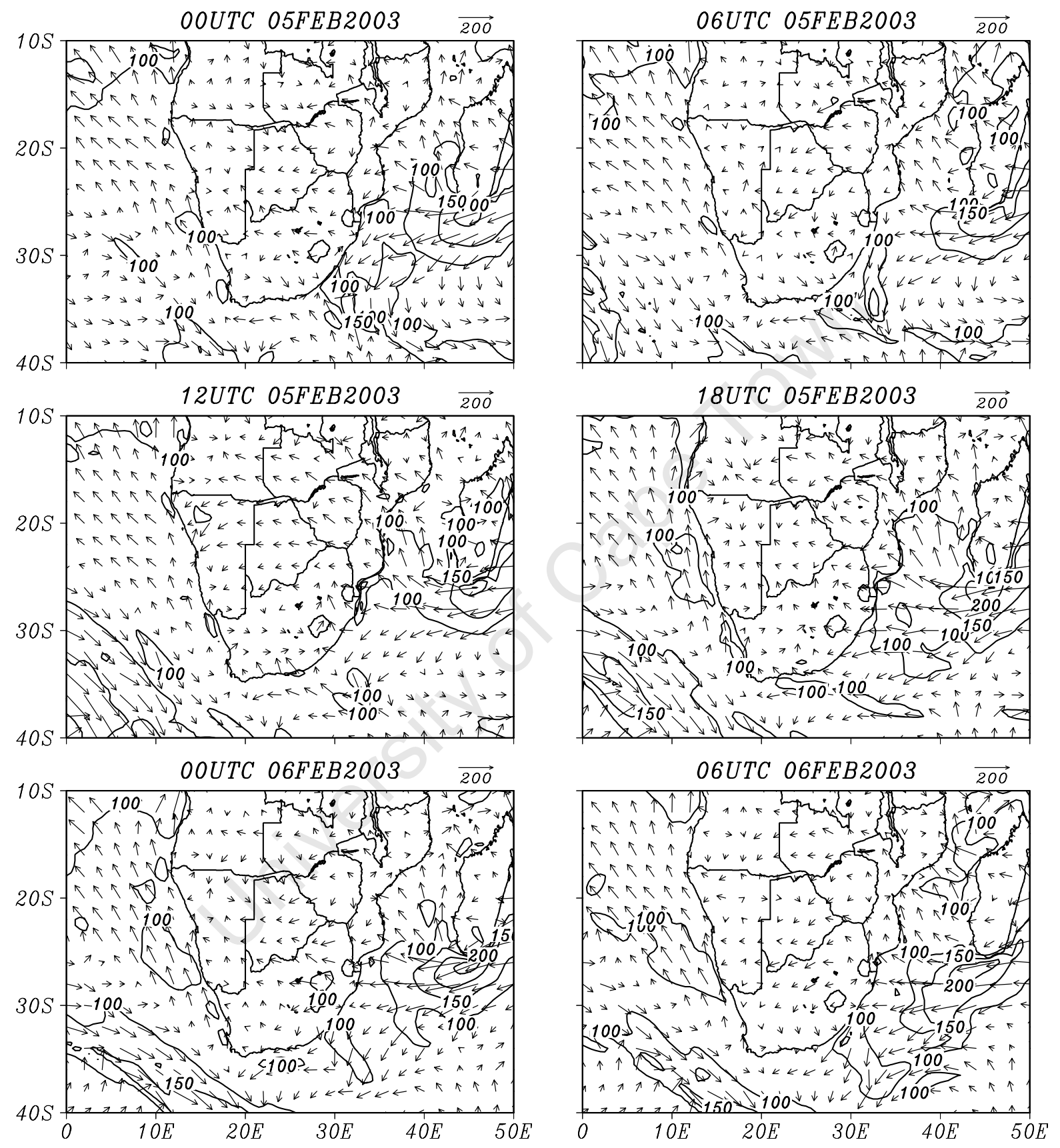

Figure 7.24: Moisture flux (g. $\mathrm{kg}^{-1} \mathrm{~m} \cdot \mathrm{s}^{-1}$, both arrow and contours) at the $1000 \mathrm{hPa}$ level. 

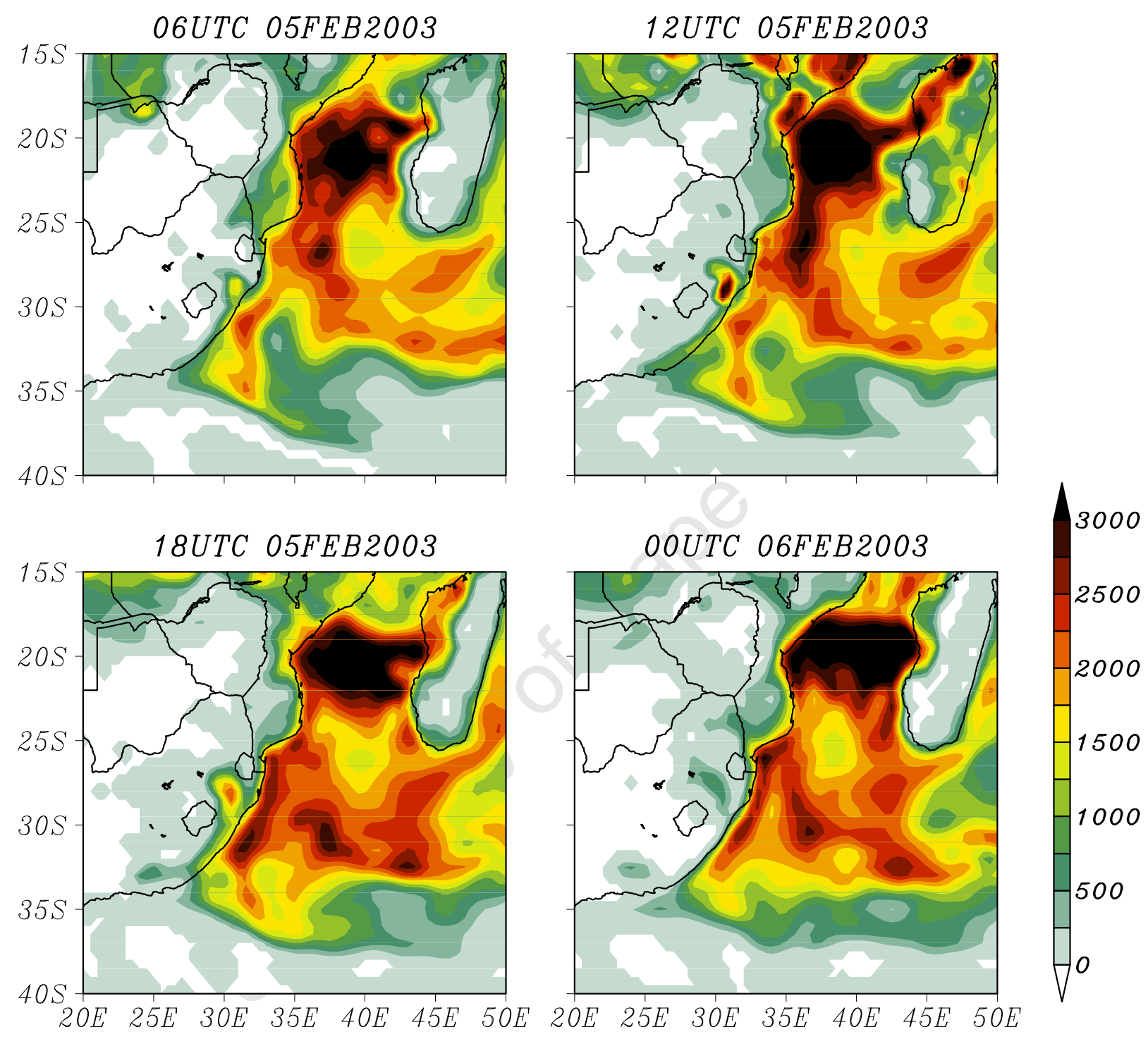

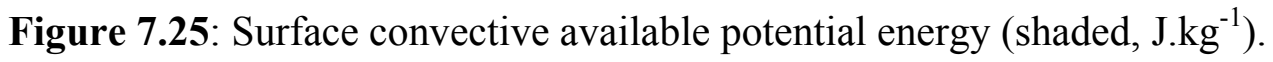



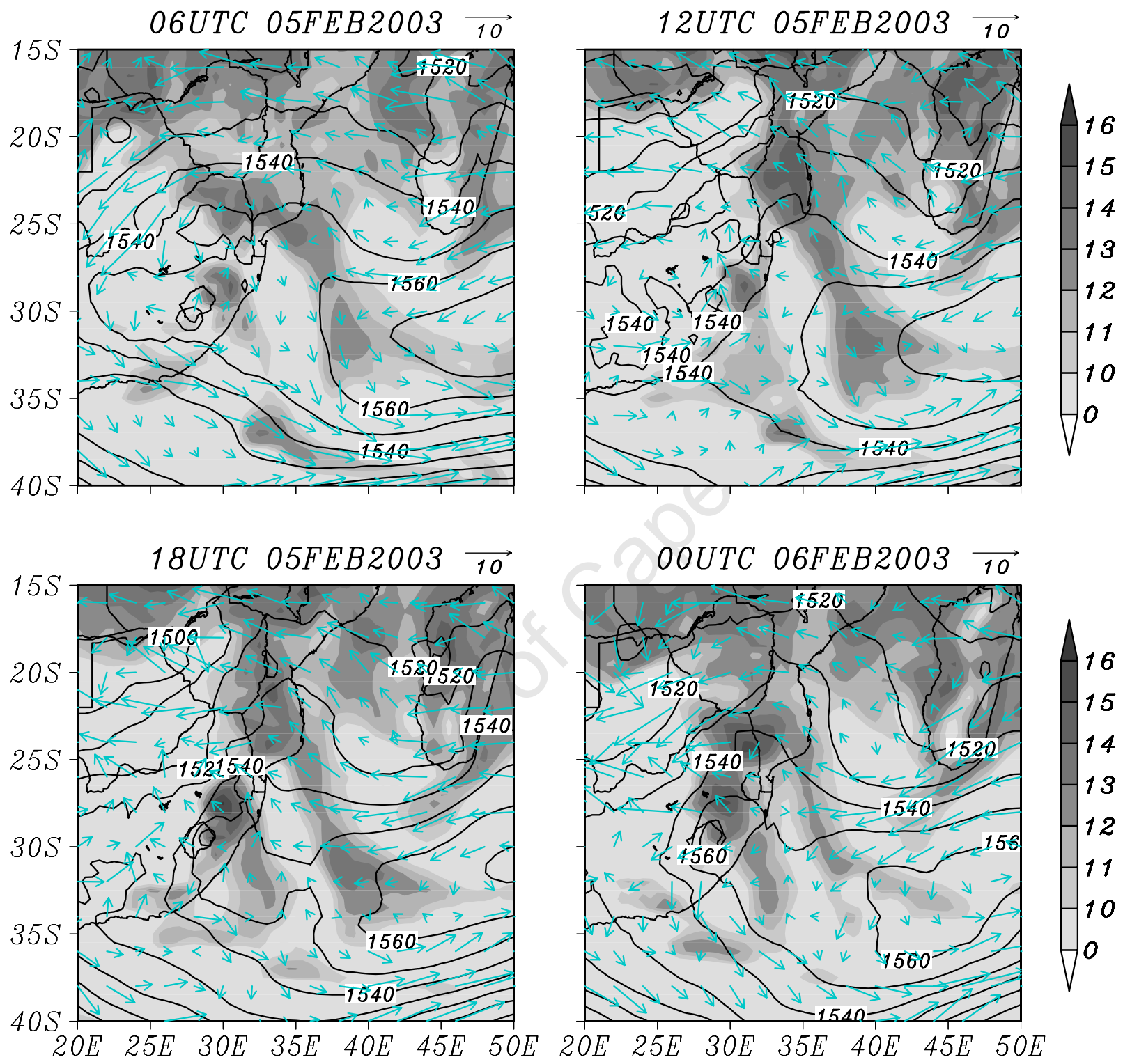

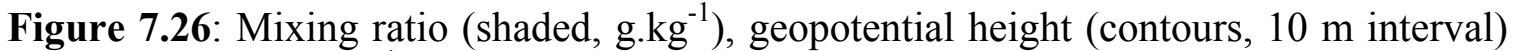
and vector winds $\left(\mathrm{m} . \mathrm{s}^{-1}\right)$ at $850 \mathrm{hPa}$. 

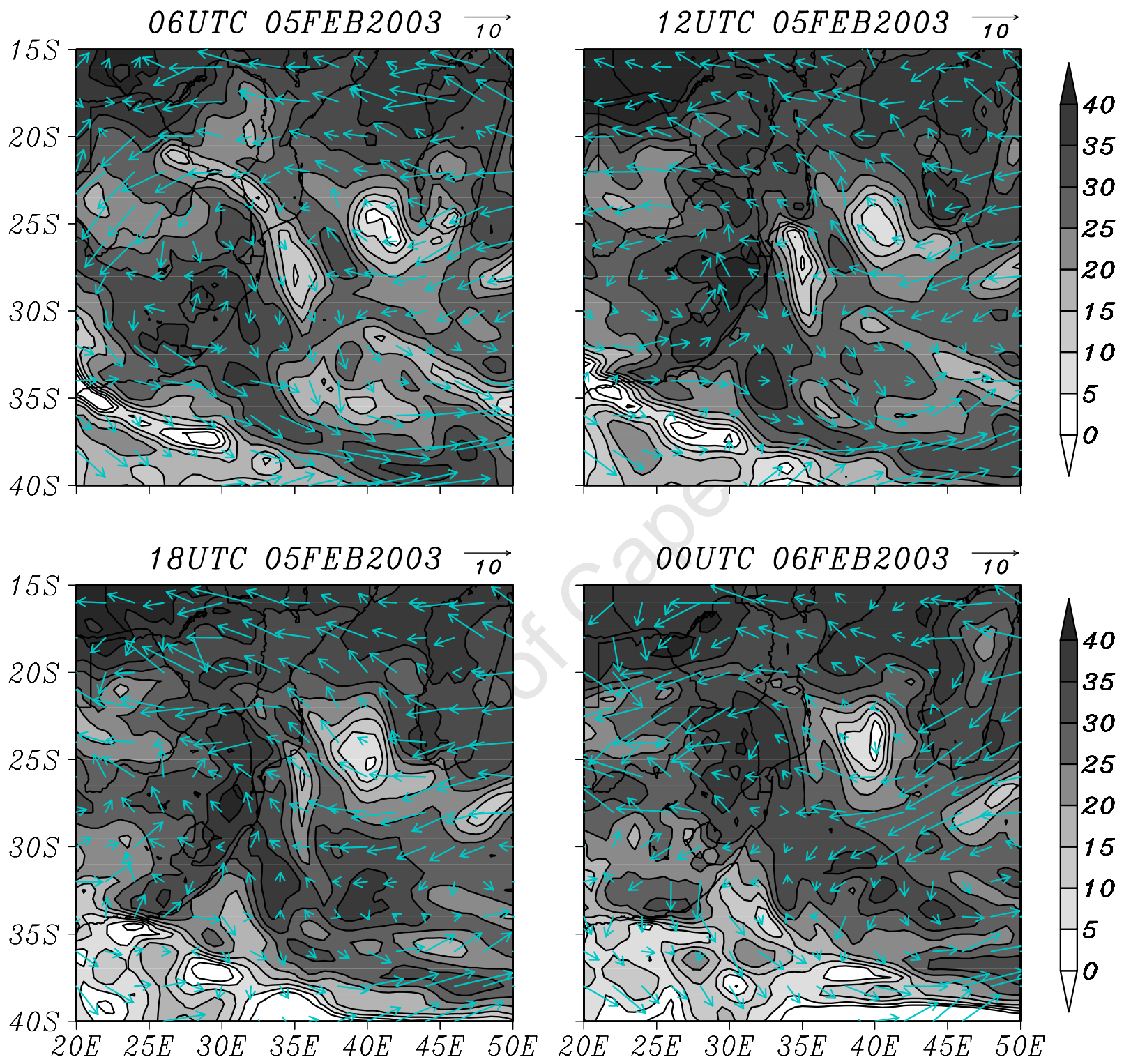

Figure 7.27: The $K$-Index (shaded) and vector winds $\left(\mathrm{m} . \mathrm{s}^{-1}\right)$ at $850 \mathrm{hPa}$. 

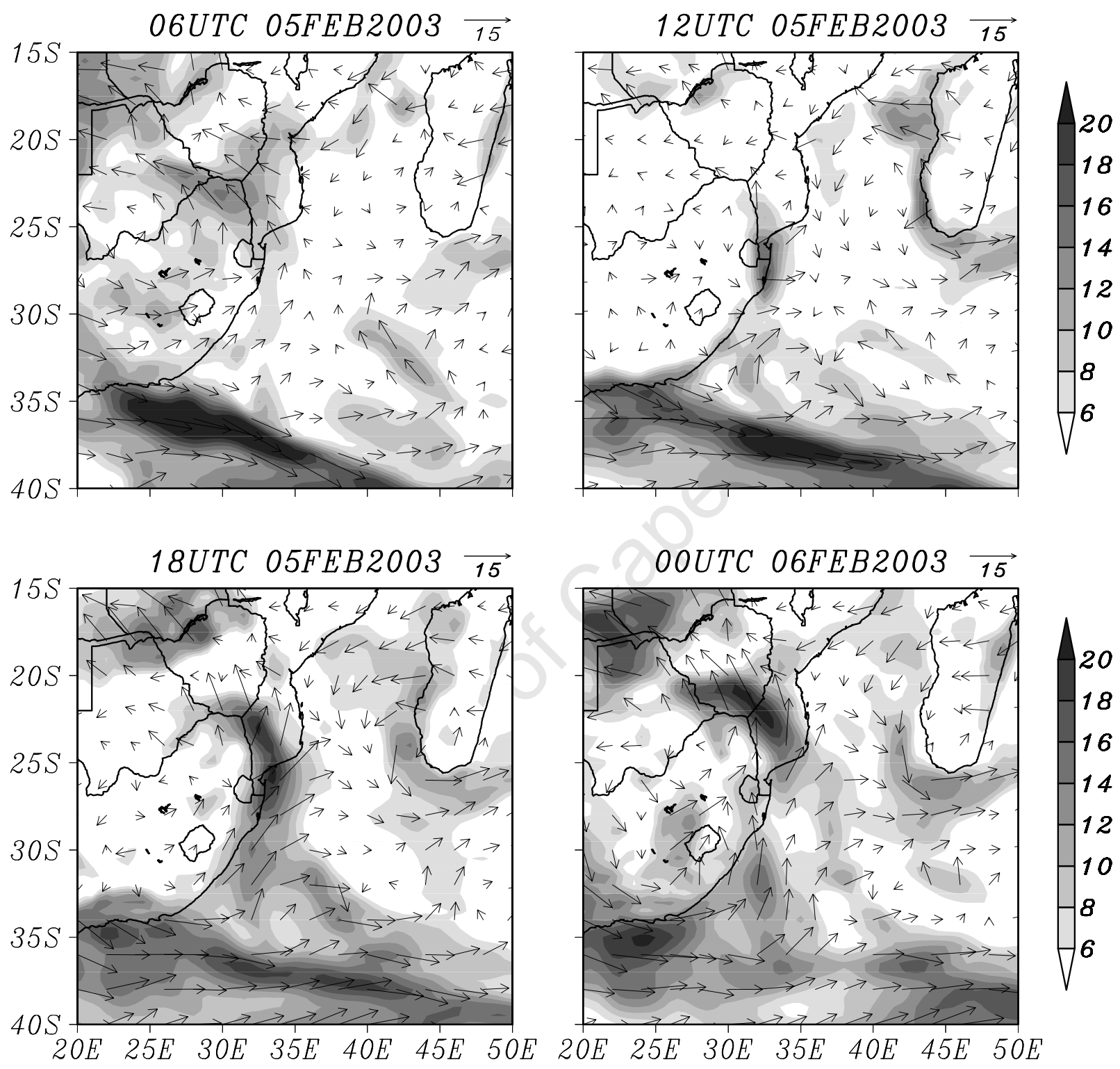

Figure 7.28: Low level shear $\left(\mathrm{m} . \mathrm{s}^{-1}\right)$ between the 1000-700 hPa layer. 

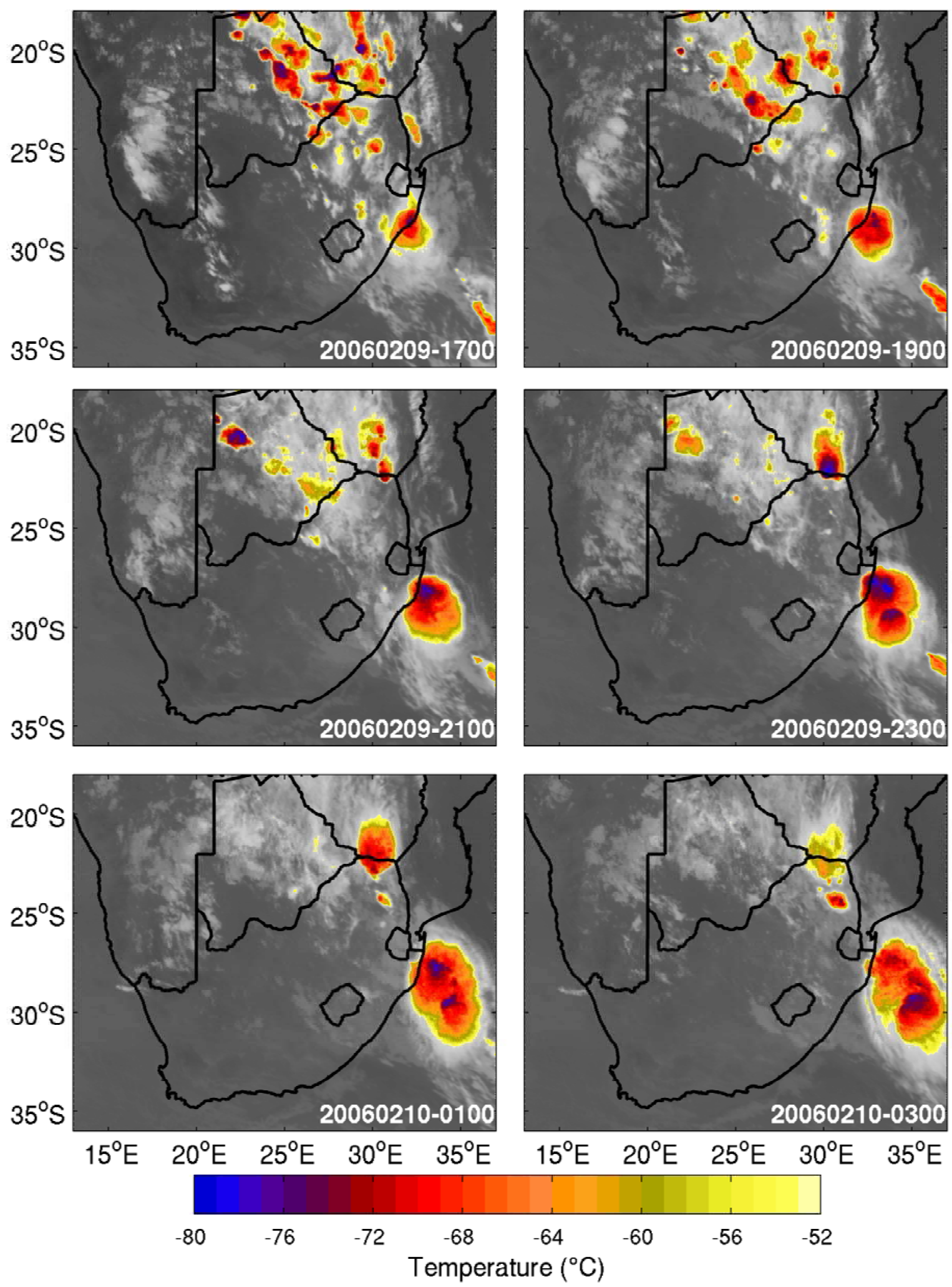

Figure 7.29: Meteosat-7 IR images showing cloud top temperature $\left({ }^{\circ} \mathrm{C}\right)$ of the $\mathrm{MCC}$ that took place during 09-10 February 2006. Times shown are in UTC (LST - 2). 


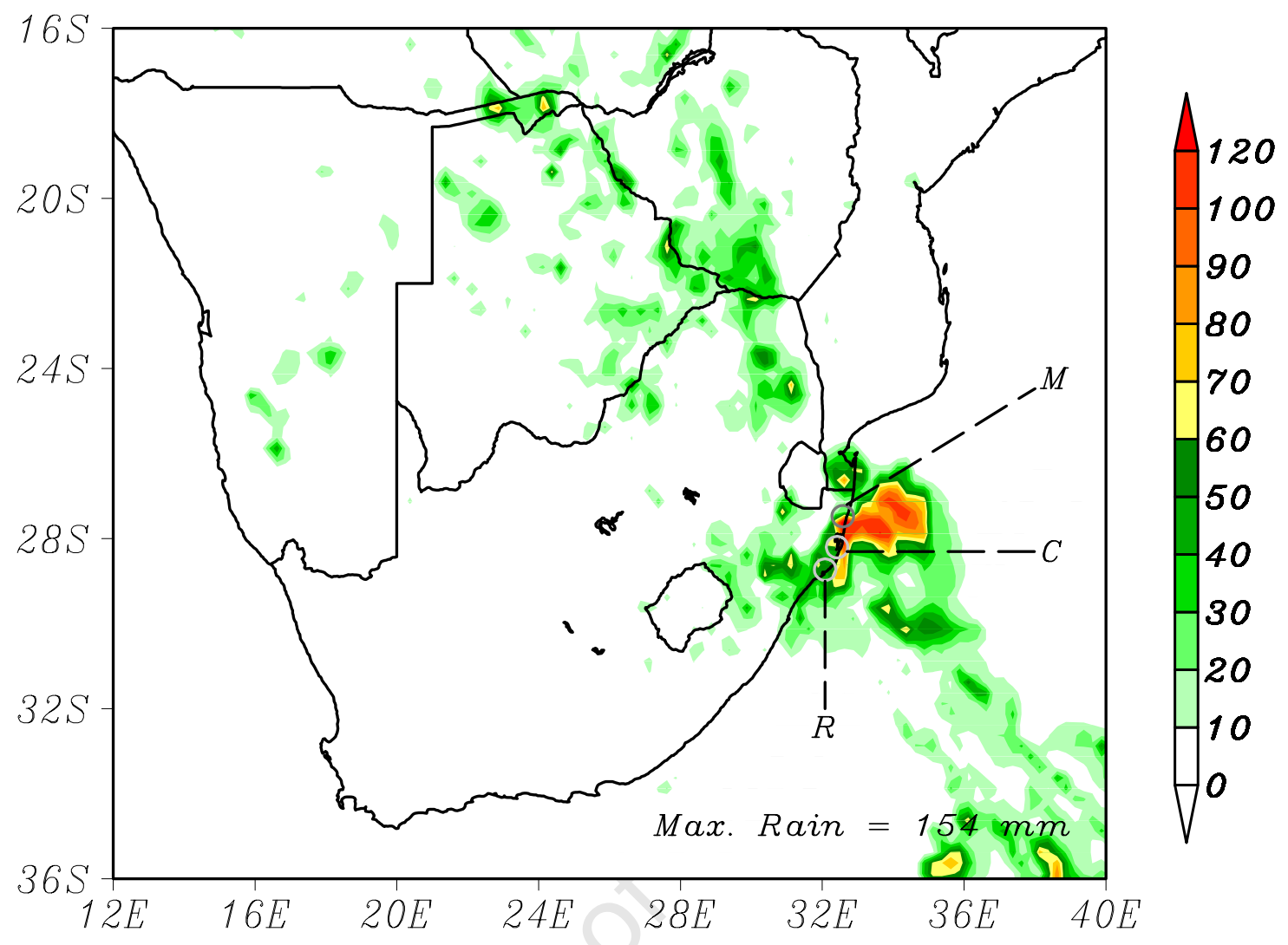

Figure 7.30: Rainfall $(\mathrm{mm})$ derived by the 3 hourly TMPA during the duration of the event. The stations of Charters Creek, Mbazwana Airfield and Richards bay are denoted by ' $C$ ', ' $M$ ' and ' $R$ ', respectively. Open grey circles identify the station location. 

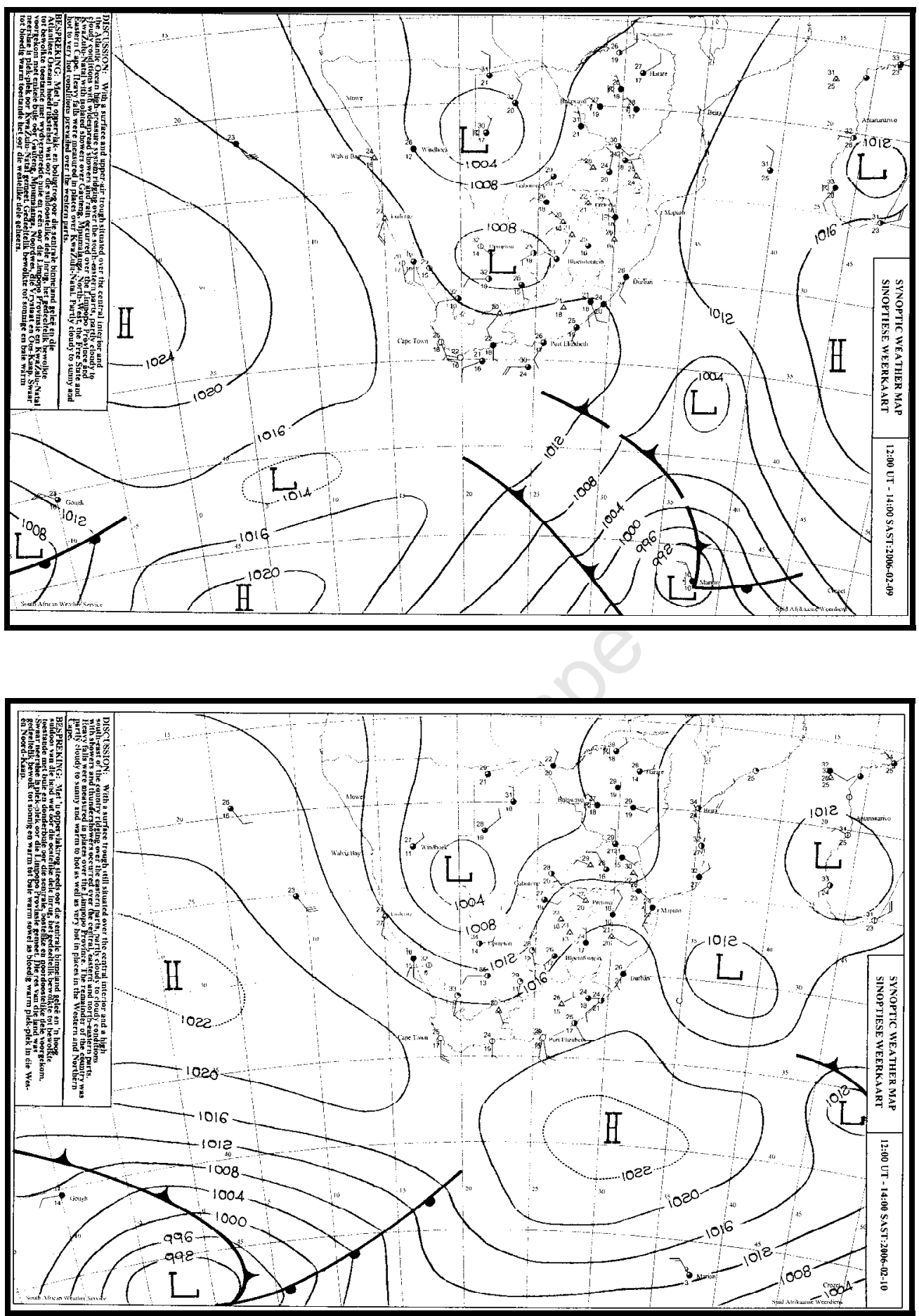

Figure 7.31: South African Weather Service synoptic charts for the 09 February 2006 (top) and 10 February 2006 (bottom). 

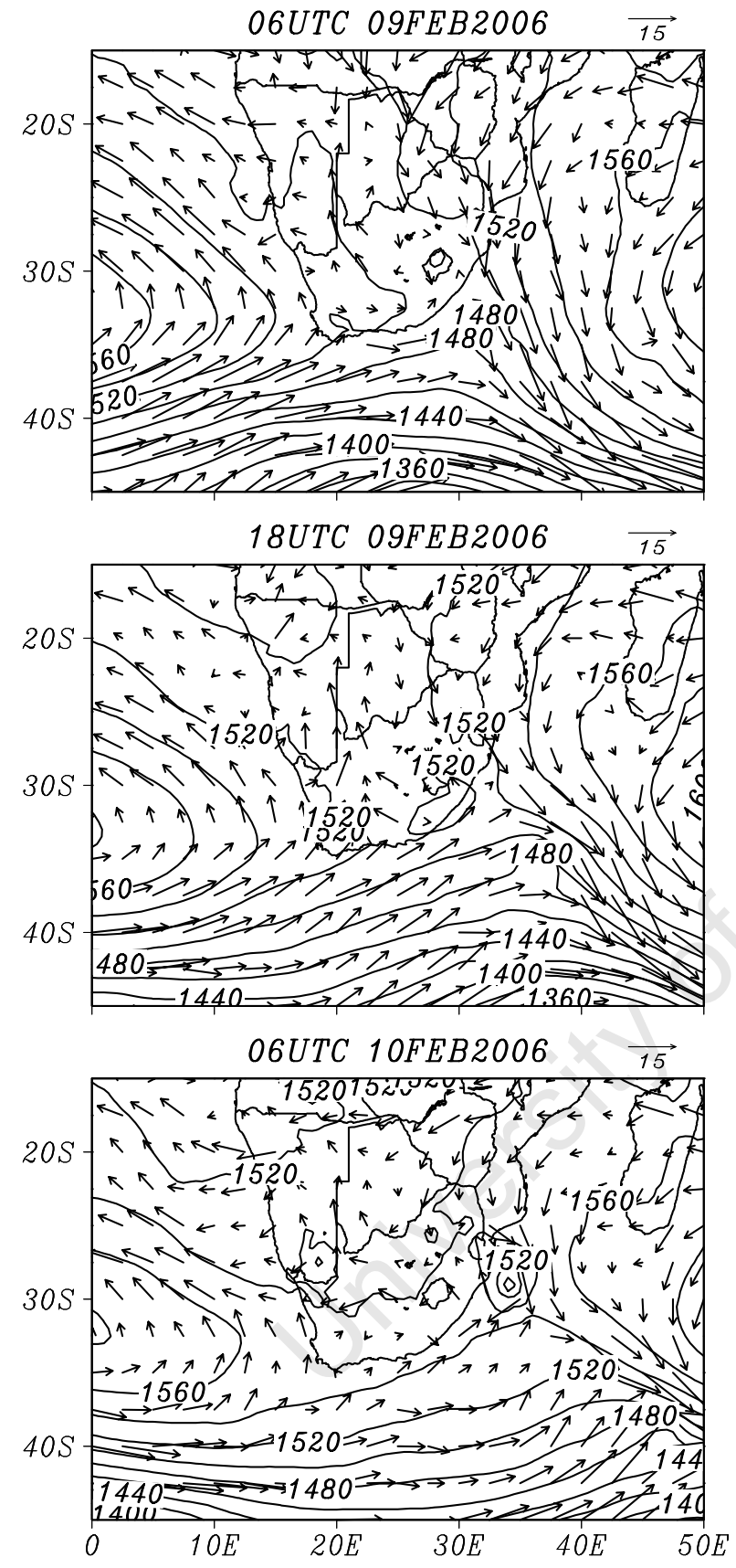
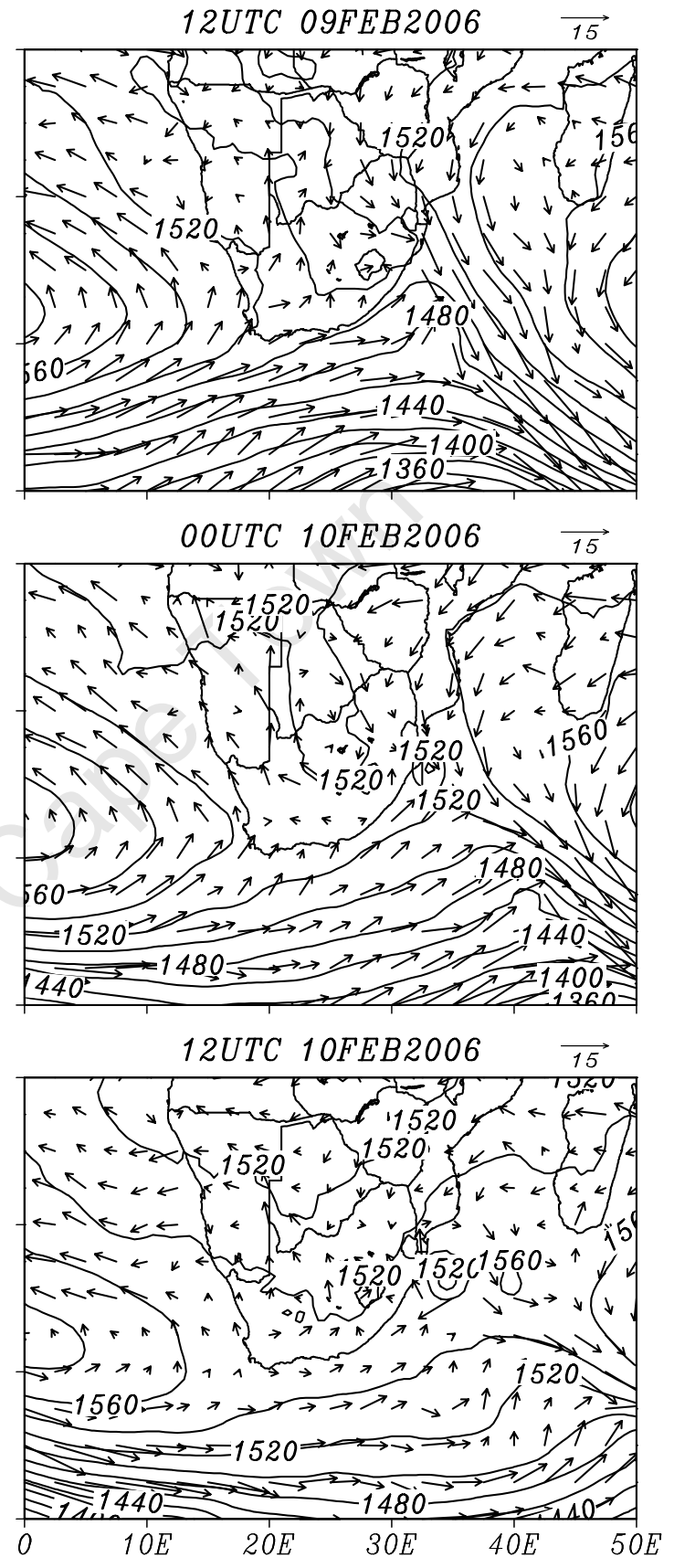

Figure 7.32: Mean sea level pressure (solid contours; $4 \mathrm{hPa}$ interval) and vector winds $\left(\mathrm{m} . \mathrm{s}^{-1}\right.$, proportion of wind speed to arrow length given above top right corner) at the 850 $\mathrm{hPa}$ level. Times indicate here are UTC. 

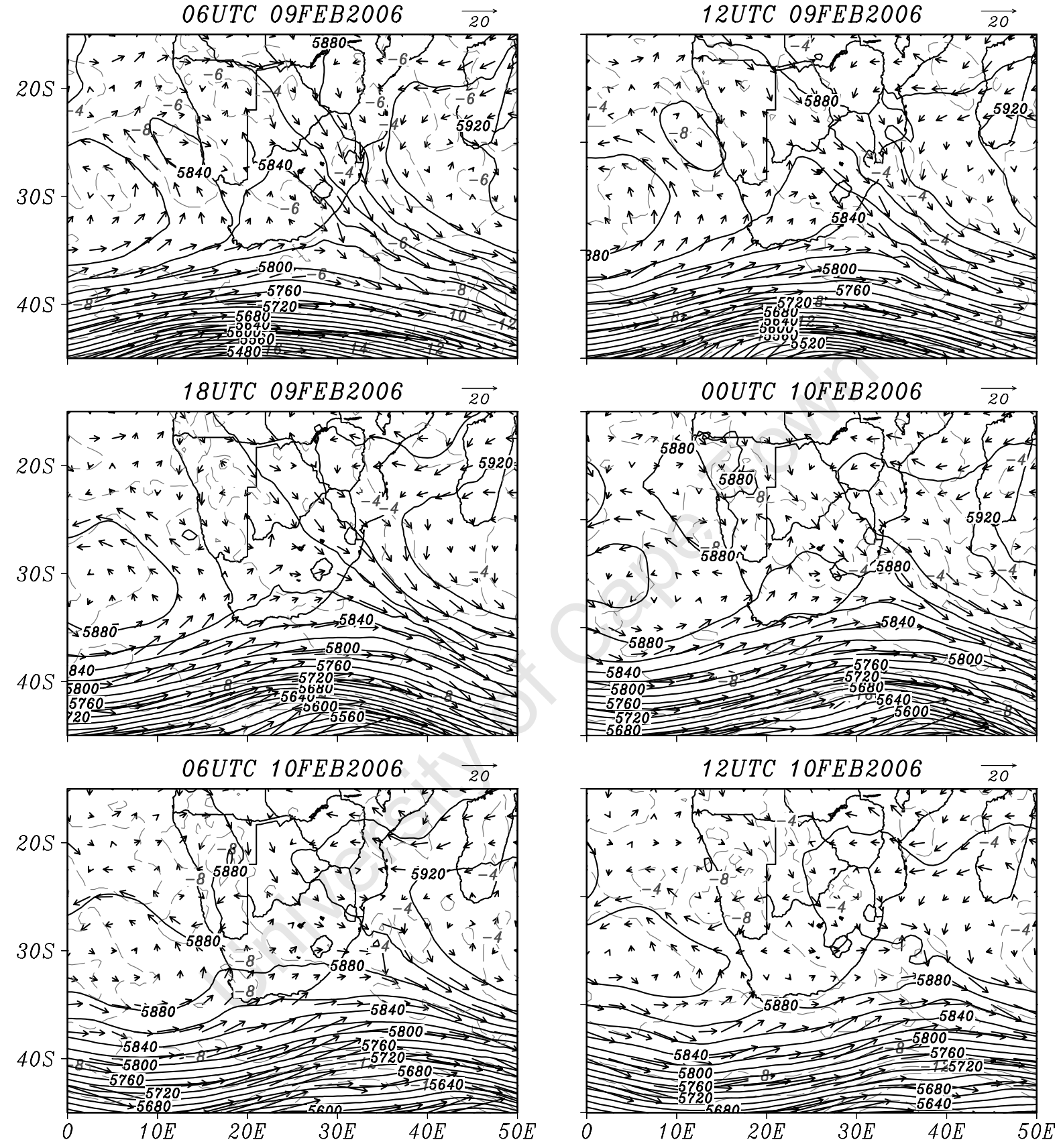

Figure 7.33: Geopotential height (solid contours; $20 \mathrm{~m}$ interval), vector winds $\left(\mathrm{m} . \mathrm{s}^{-1}\right.$, proportion of wind speed to arrow length given above top right corner) and temperature (dashed contour; units in ${ }^{\circ} \mathrm{C}$ ) for the $500 \mathrm{hPa}$ level. 


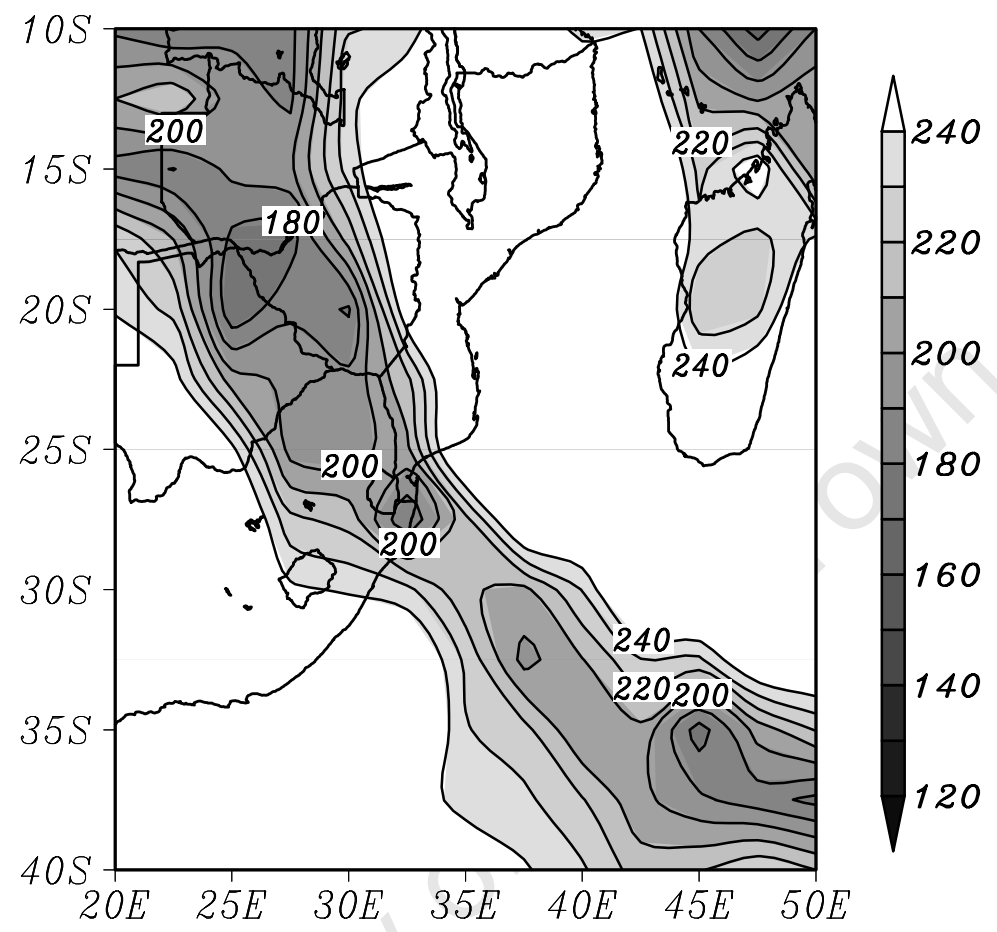

Figure 7.34: Daily outgoing longwave radiation (shaded with contours, units are W. $\mathrm{m}^{-2}$ ) for 09 - 10 February 2006. Dataset described in Liebmann and Smith (1996). 

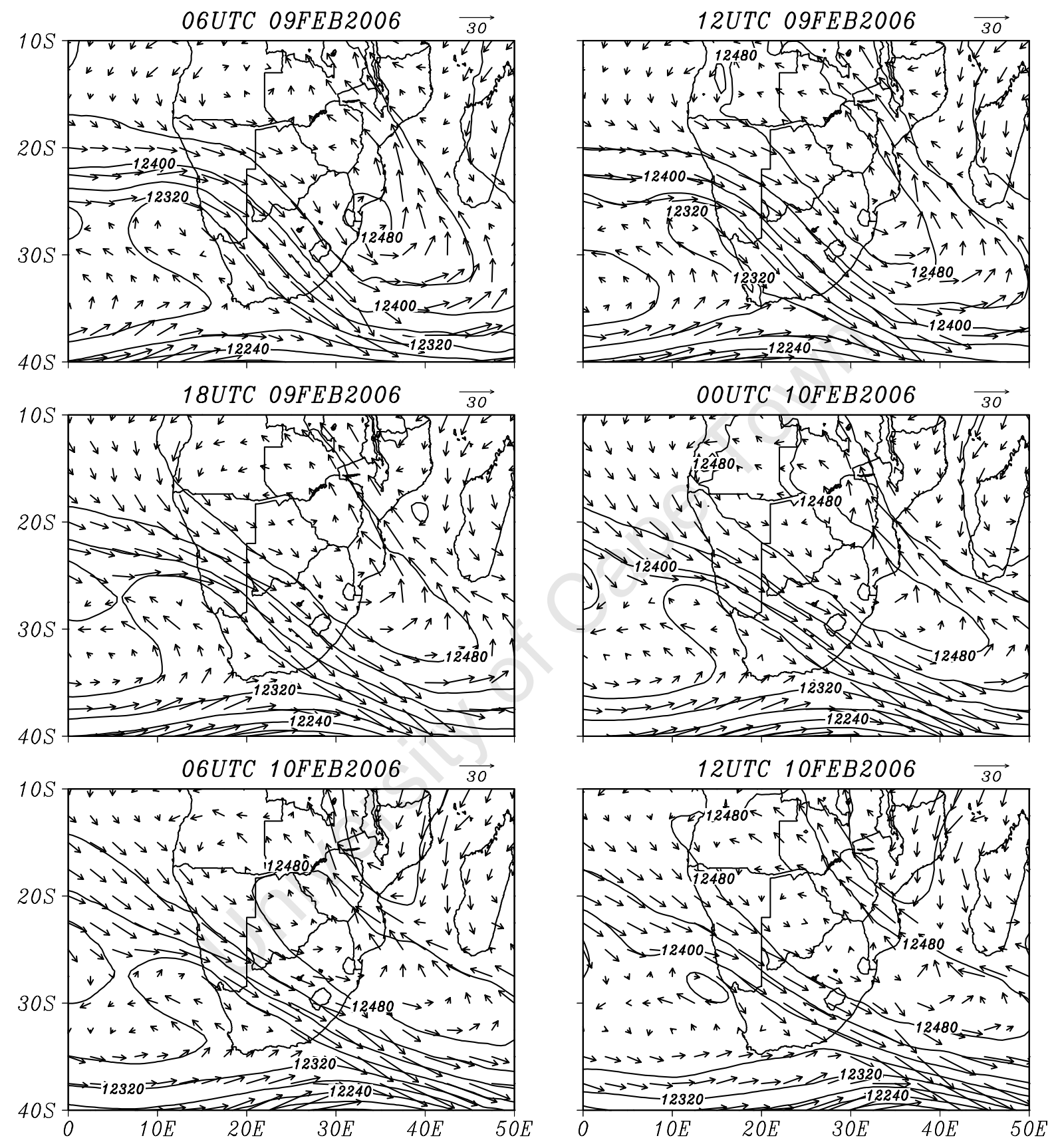

Figure 7.35: Same as Fig. 7.33, except for $200 \mathrm{hPa}$ and temperature is not shown. 

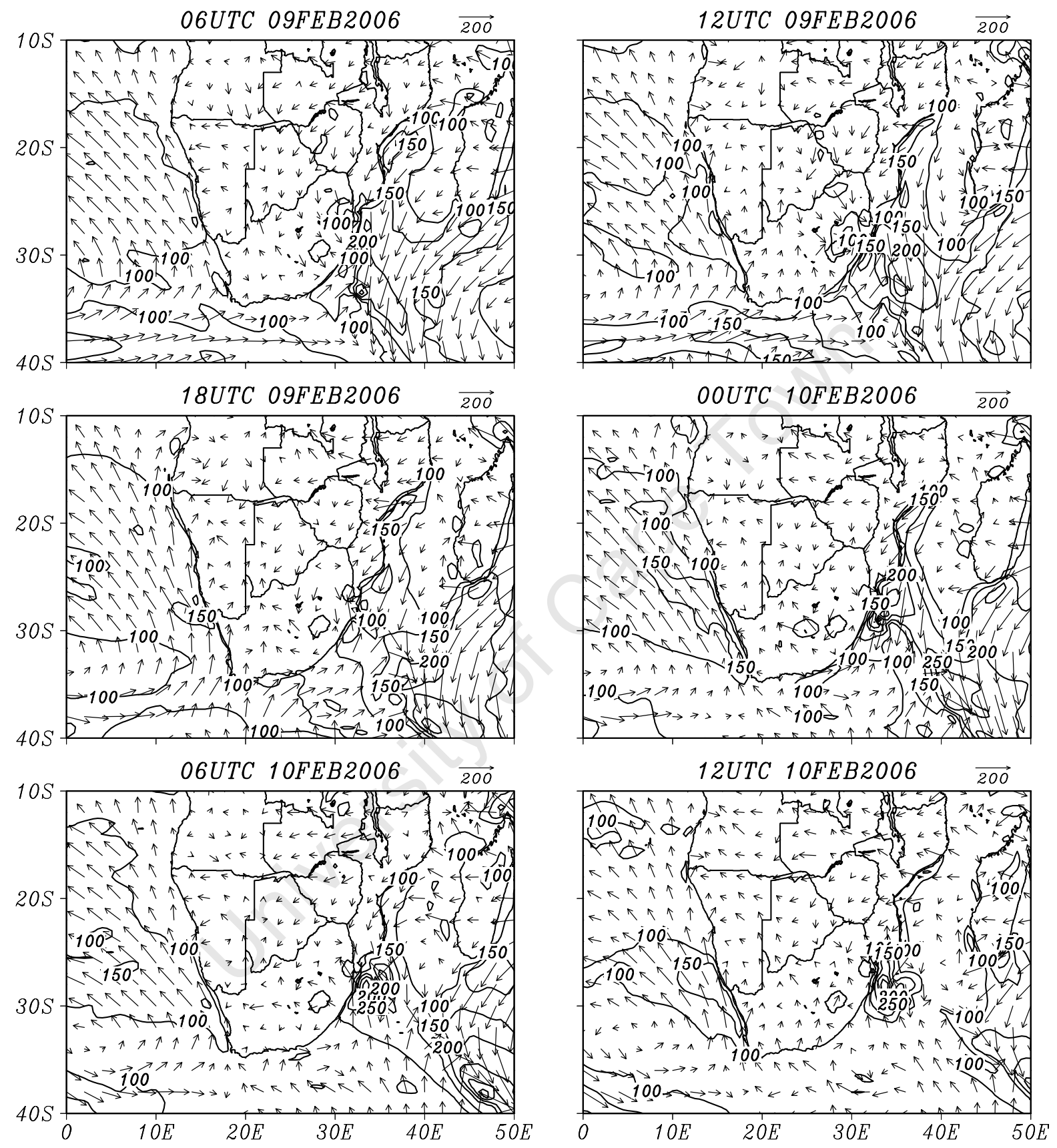

Figure 7.36: Moisture flux (g. $\mathrm{kg}^{-1} \mathrm{~m} \cdot \mathrm{s}^{-1}$, both arrow and contours) at the $1000 \mathrm{hPa}$ level. 


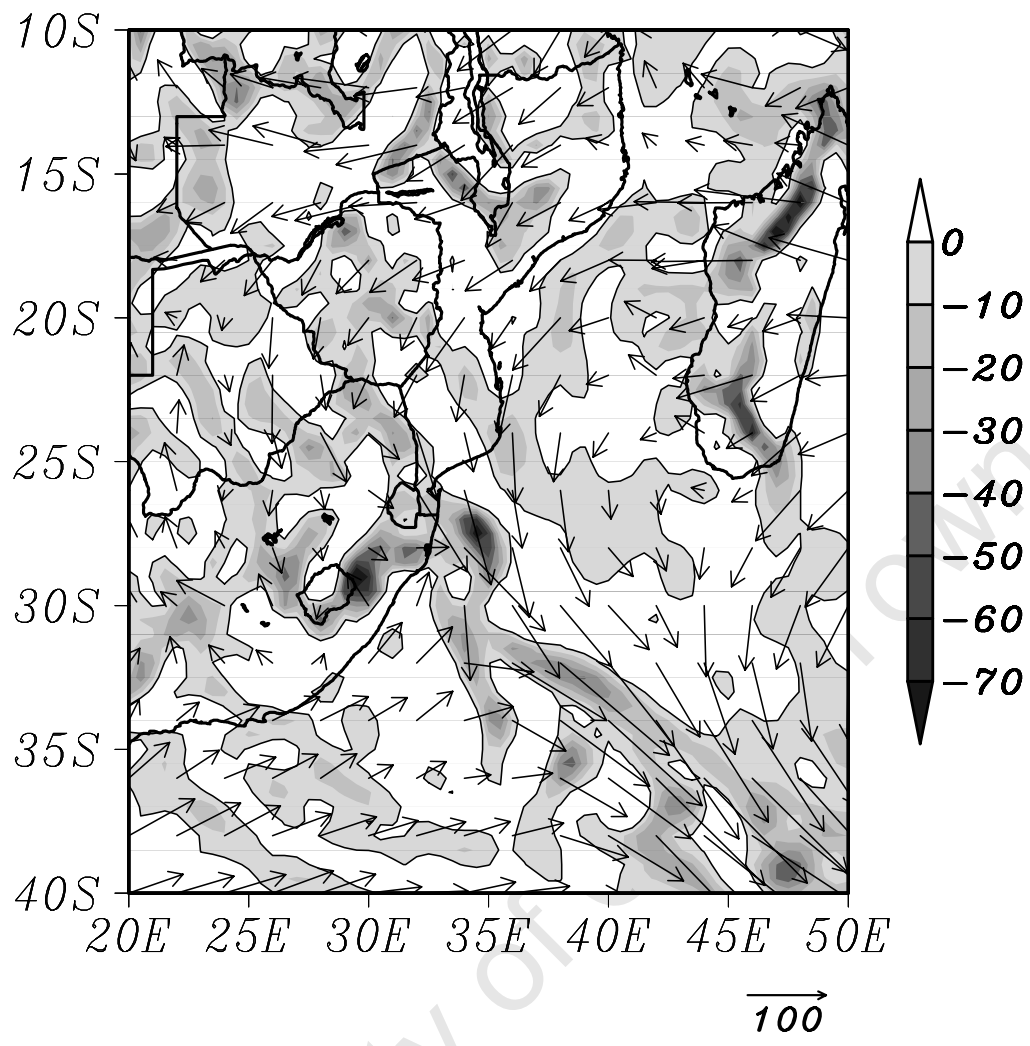

Figure 7.37: Average moisture flux (vector, g. $\mathrm{kg}^{-1} \mathrm{~m} \cdot \mathrm{s}^{-1}$ ) and convergence (shaded, $\mathrm{x} 10^{-5}$ g. $\mathrm{kg}^{-1} \cdot \mathrm{s}^{-1}$ ) at $850 \mathrm{hPa}$ between $12 \mathrm{~h} 00$ UTC on 09 February and $06 \mathrm{~h} 00 \mathrm{UTC}$ on 10 February 2006. Note that for clarity, moisture divergence is not shown. 

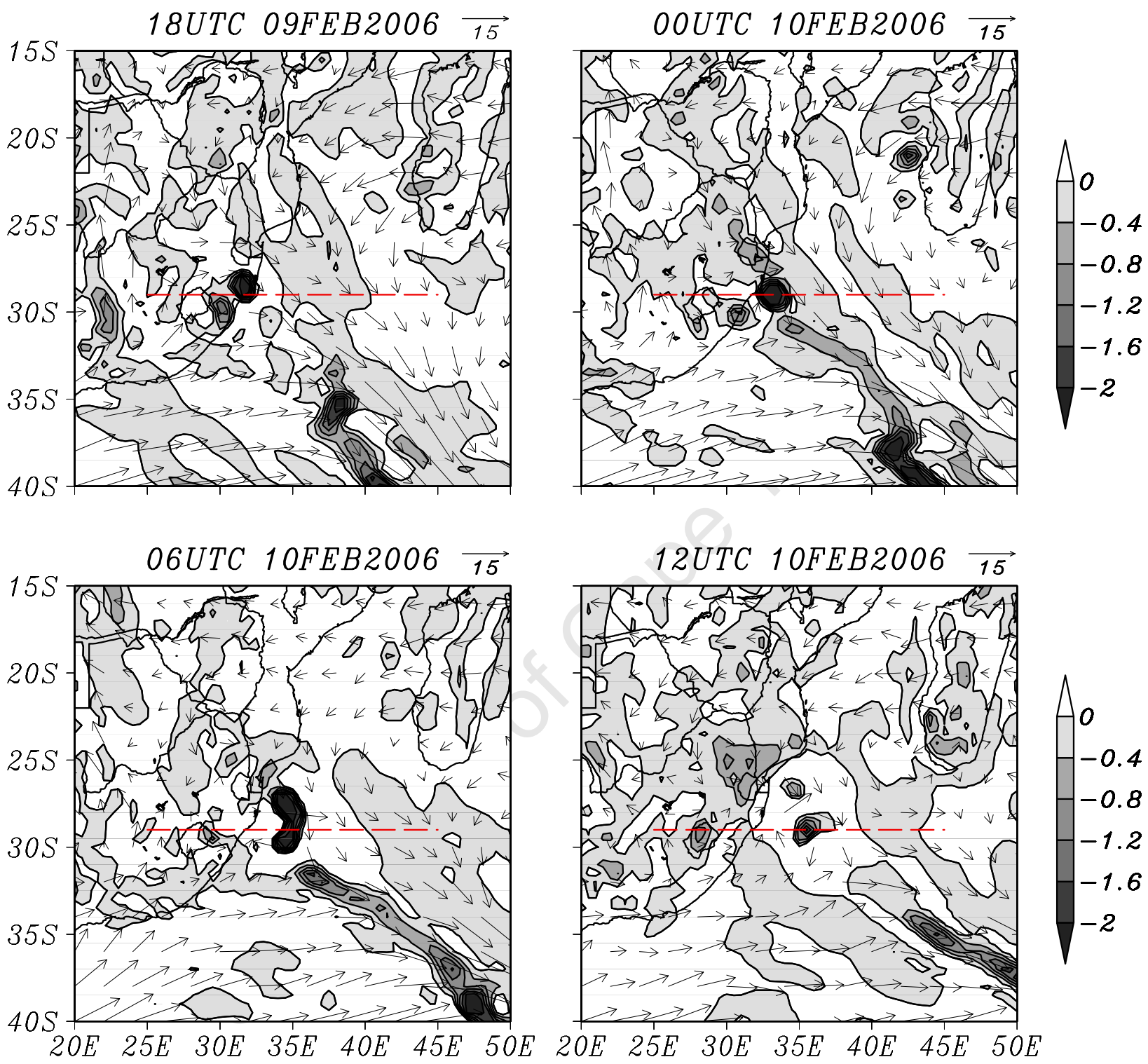

Figure 7.38: Omega (shaded with contours, Pa.s ${ }^{-1}$ ) and vector winds $\left(\mathrm{m} . \mathrm{s}^{-1}\right)$ at $700 \mathrm{hPa}$. Note that only upward motion is plotted. Red line denotes latitude of which the crosssection Fig. 7.39 is based. 

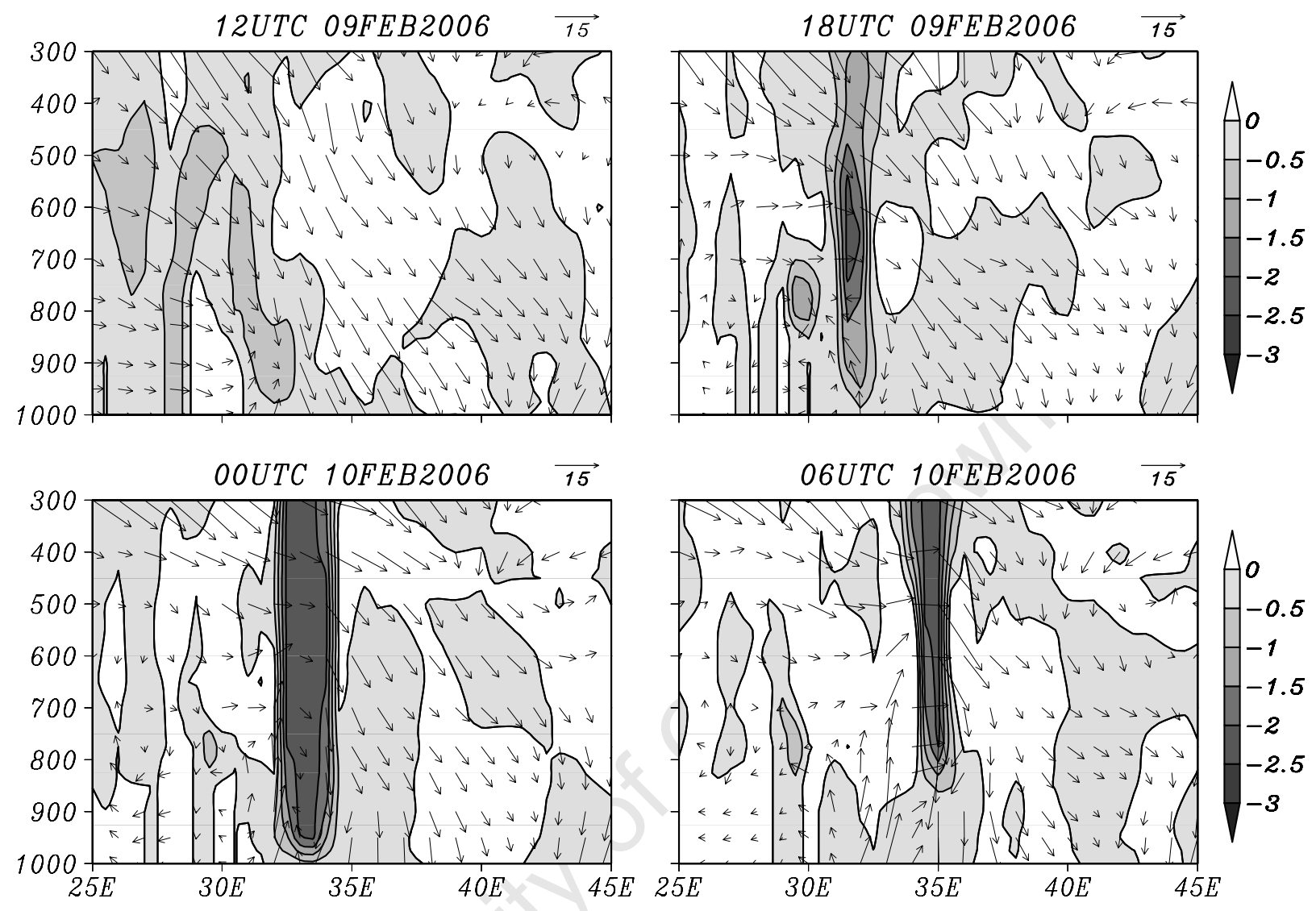

Figure 7.39: Cross-section of omega (shaded with contours, Pa.s ${ }^{-1}$ ) along $29^{\circ} \mathrm{S}$ (see Fig. 7.38 for location). Also shown are vector winds $\left(\mathrm{m} \cdot \mathrm{s}^{-1}\right)$. 

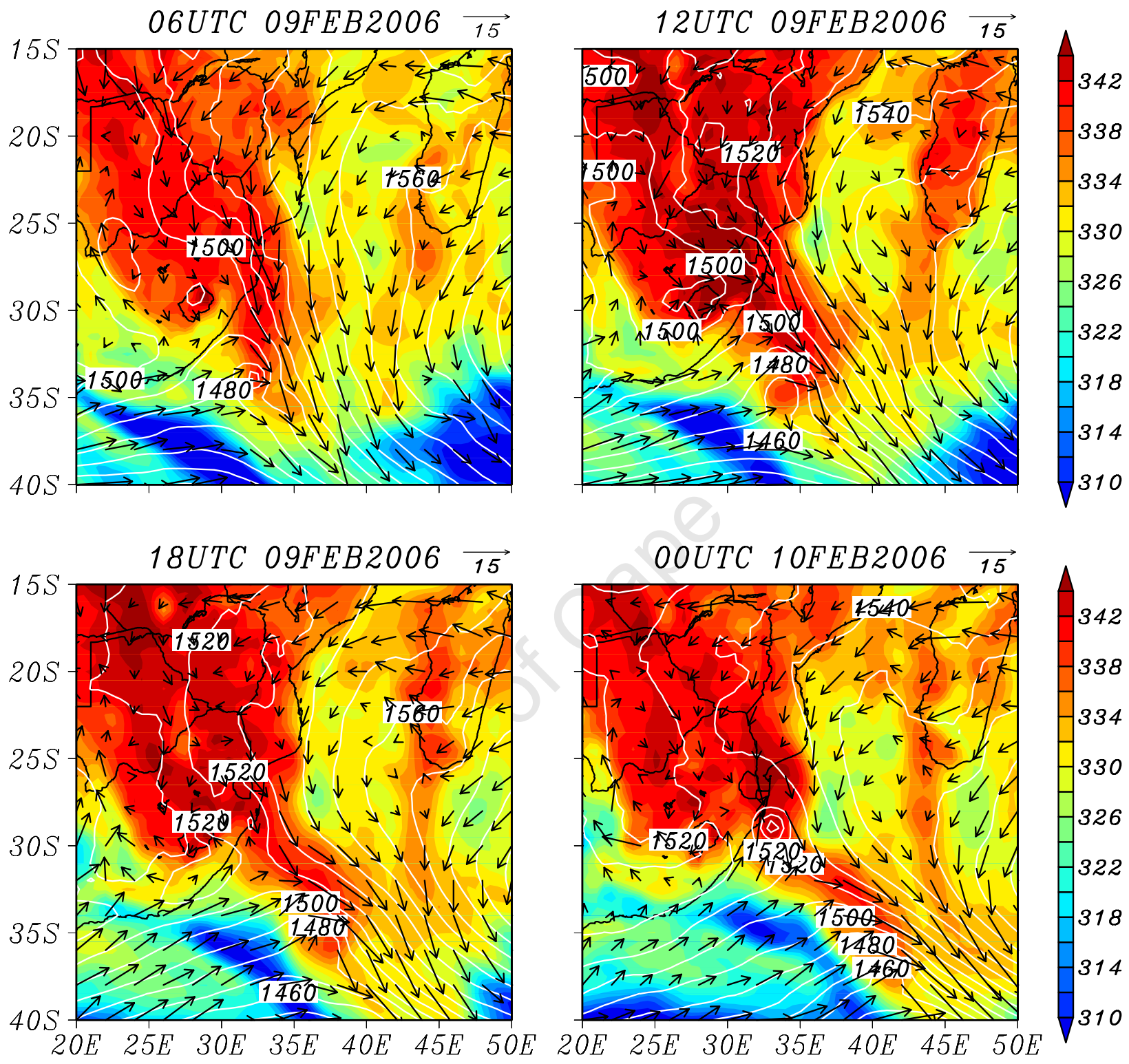

Figure 7.40: Equivalent potential temperature (shaded; units are ${ }^{\circ} \mathrm{K}$ ), geopotential height (contours; $\mathrm{m}$ ) and wind vectors $\left(\mathrm{m} . \mathrm{s}^{-1}\right)$ at $850 \mathrm{hPa}$. 

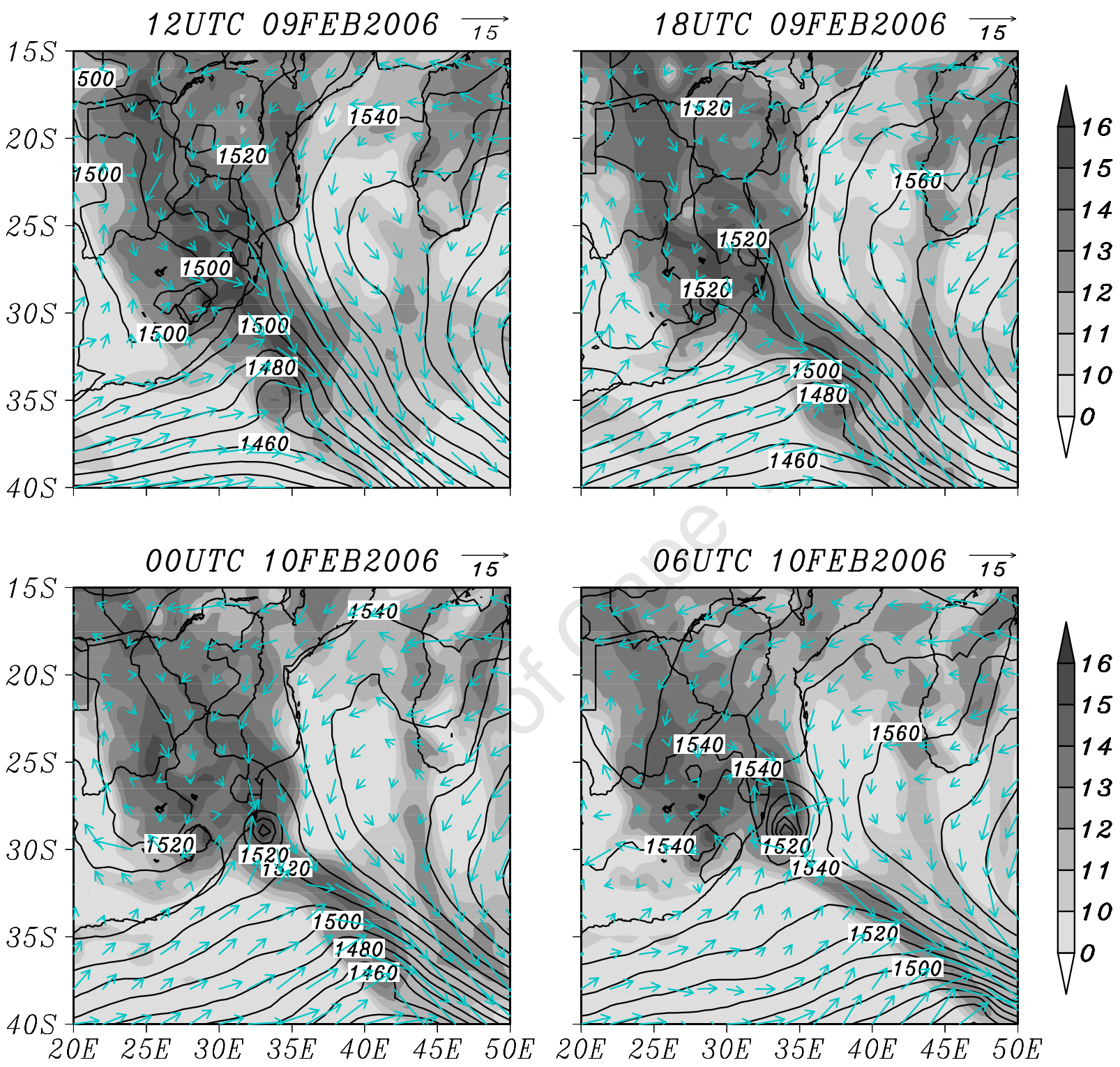

Figure 7.41: Mixing ratio (shaded, g.kg ${ }^{-1}$ ), geopotential height (contours, $10 \mathrm{~m}$ interval) and vector winds $\left(\mathrm{m} . \mathrm{s}^{-1}\right)$ at $850 \mathrm{hPa}$. 

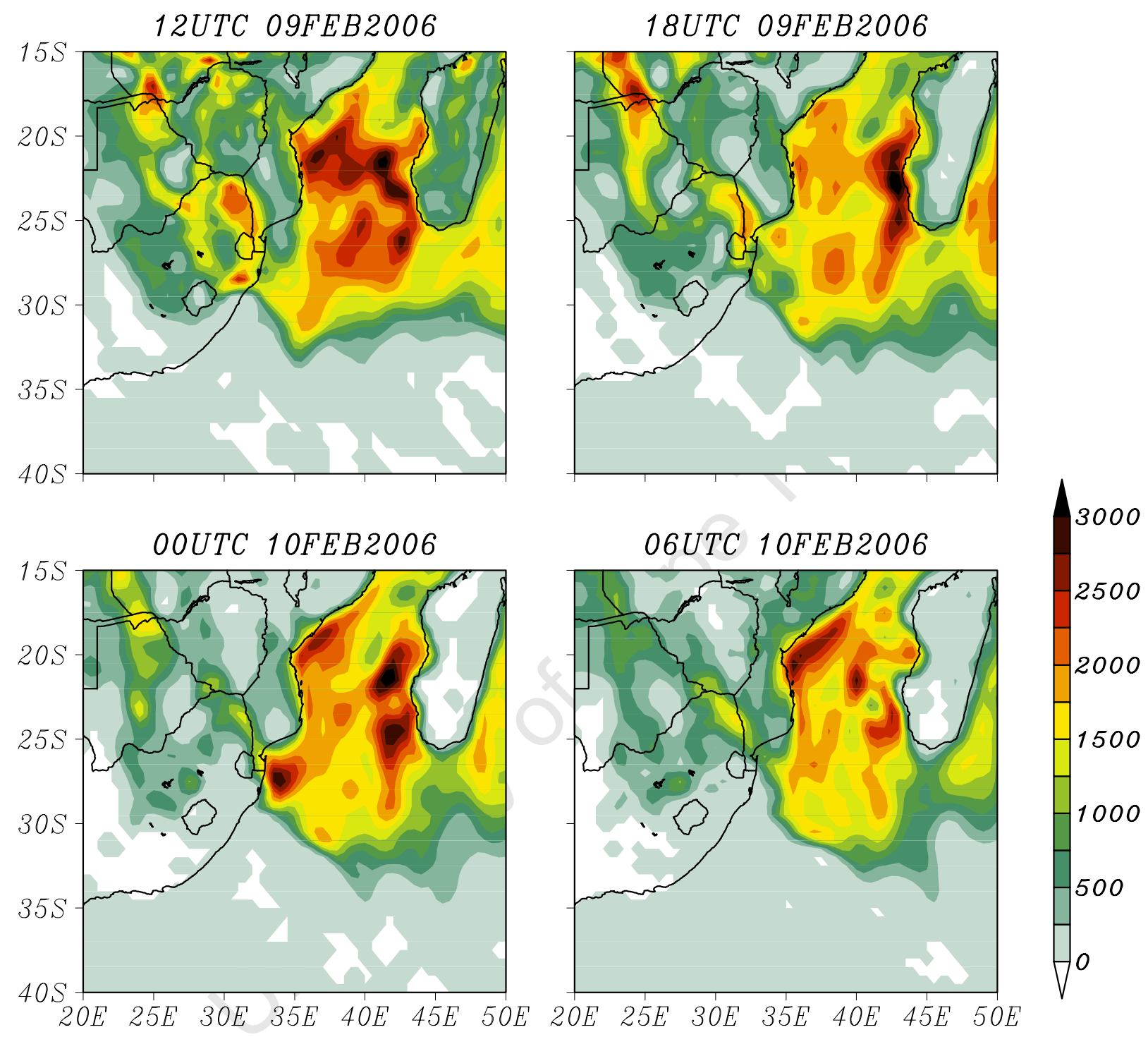

Figure 7.42: Surface convective available potential energy (shaded, J.kg ${ }^{-1}$ ). 

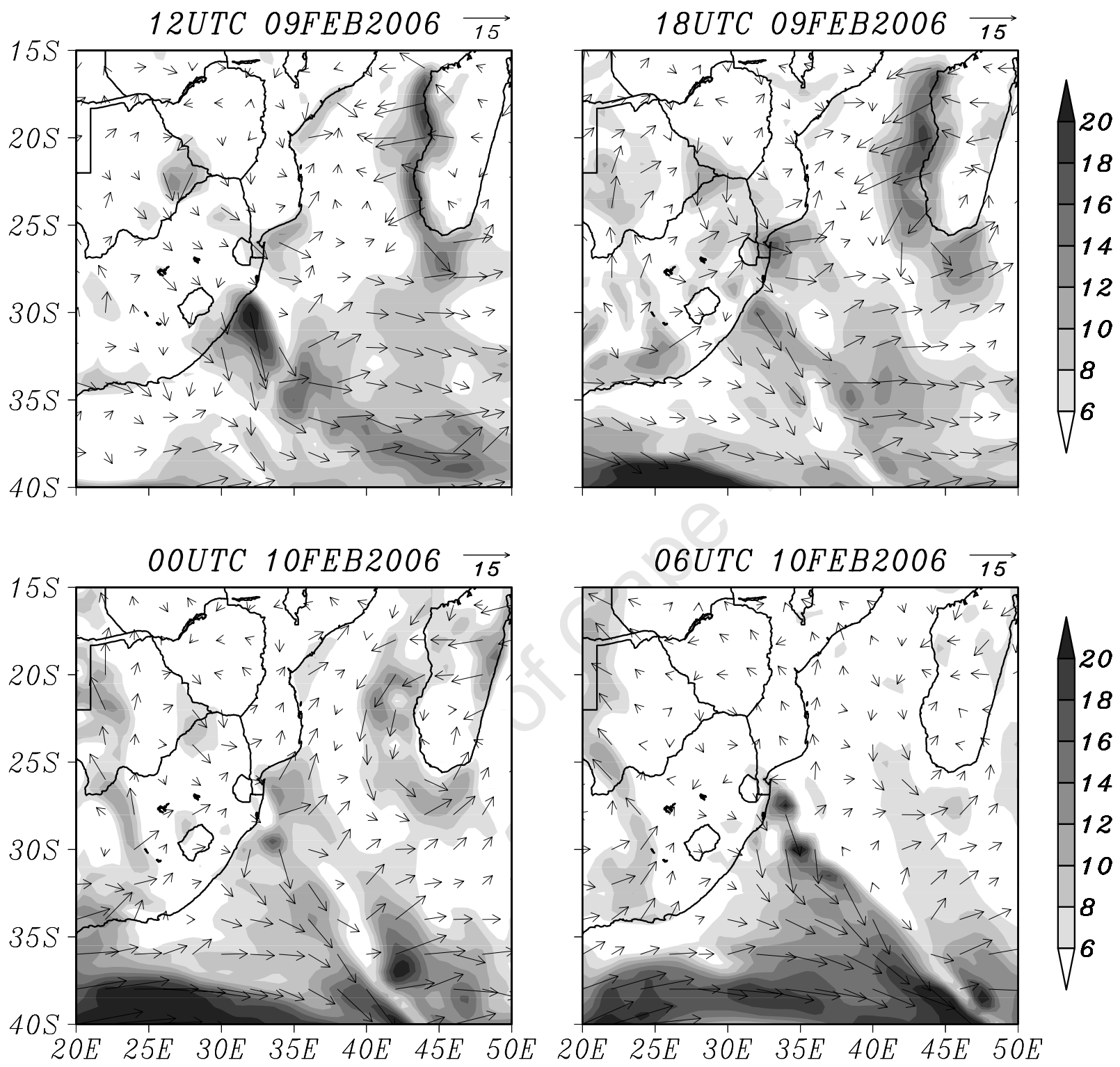

Figure 7.43: Low level shear $(1000-700 \mathrm{hPa})$ in $\mathrm{m} \cdot \mathrm{s}^{-1}$. 


\section{Chapter Eight}

\section{Discussion and Conclusions}




\subsection{Introduction}

Over the past few decades, detailed climatology studies on large organised convective systems have become more frequent, which is predominantly due to advances in technology. In particular, the increase in available satellite imagery has allowed researchers to observe convective systems over vast regions at regular time intervals. One such system that has received some attention is the mesoscale convective complex (MCC). As introduced earlier, the MCC is a large, long-lived, quasi-circular convective system and is often associated with a host of severe weather phenomenon (Maddox 1980). Not only have these particular systems been associated with many severe weather phenomena, they have also been shown to be large contributors to warm season rainfall (e.g., Ashley et al. 2003; Durkee et al. 2009).

Initial regional studies looking at the frequency and spatial distribution of these systems were restricted to a few warm seasons (e.g., Maddox 1980; Augustine and Howard 1991; Velasco and Fritsch 1987; Laing and Fritsch 1993b), but more recent studies now cover a much longer period (e.g., Ashley et al. 2003; Durkee and Mote 2009). To date, the study of MCCs over southern Africa has been very limited compared to elsewhere, likely due to the relatively low frequency of such events there and poorer observational network. Similar to other regional studies, this study has attempted to contribute towards the knowledge of the global population of MCCs by developing a longer climatology for southern Africa than what currently exists. Focus was not only placed on MCCs and the large-scale environment which favour their development, but also on the role these systems play in southern African rainfall patterns.

This final chapter is provided to discuss some of the concerns and limitations in developing this MCC climatology and how it may have influenced the results. It is also used to examine the process undertaken to determine the contribution these systems make to the regional rainfall. A brief synthesis of favourable large-scale environments resulting in MCC development is also presented. The chapter is then concluded with the key findings of this study and the implications they have for southern Africa. 


\subsection{The southern Africa MCC Climatology}

\subsubsection{MASCOTTE Results}

The development of a MCC climatology is primarily based on either visual inspection of satellite images or by applying an algorithm that automatically identifies systems within the image. For the purposes of this study, a quasi-hybrid approach was utilised, with an automated identification algorithm primarily used to detect and track the systems and then visual inspection was carried out on the results. The automated method chosen for this study is based on the maximum spatial correlation technique developed by Carvalho and Jones (2001). This particular identification and tracking algorithm, known as MASCOTTE, had previously been successfully applied to cases in South America (Carvalho and Jones 2001) and Spain (García-Herrera et al. 2005b) and was adapted here for southern Africa. However, unlike the two previous studies, which focused on MCSs in general, it is only used to develop a climatology of MCCs over southern Africa in this study.

Through the use of MASCOTTE, 70 MCCs were identified over southern Africa during the austral summer for 1998-2006. The systems are predominately found to occur during the core summer months (November - February), with peak MCC activity taking place during November and December, followed closely by the months of February, January, with far fewer systems in March. Unfortunately, the study is limited by the data available and for this reason the sample size here may be too small to identify any robust monthly or seasonal patterns. Even though the study period of 8 warm seasons is generally longer than earlier MCC climatology studies (e.g., Velasco and Fritsch 1987; Miller and Fritsch 1991; Laing and Fritsch 1993a, 1993b), the study is restricted by the number of MCC events per season.

On average, 8 to 9 systems occur per season, but this is biased by the large number of systems (18) that occurred during 1999/2000. This average warm season frequency is considerably less than that found in the major MCC regions, such as the U.S. or South America, which experience in excess of 30 systems per season (Ashley et al. 2003; 
Durkee and Mote 2009). However, the geographic settings of these two regions differ considerably from that of southern Africa. Most midlatitude MCC locations are found downstream of pronounced elevated terrain, which southern Africa does not have to the same extent as North or South America. Although containing an elevation of up to 3200 meters, the eastern escarpment in South Africa is somewhat lower in average elevation and smaller in meridional extent than both the Andes and the Rockies. A similar argument could be made for the moderately low MCC occurrence along the east coast of Australia, which contains the Great Dividing Range, considerably lower in altitude and narrower in width than the Drakensberg of South Africa. Furthermore, considering that most global MCC populations are positioned over land, the fact that southern Africa is a narrow landmass with little land existing downstream of the escarpment may also be a limiting factor in MCC development in the region. Not only is southern Africa a much narrower landmass compared to that of the central U.S. or subtropical South America, but as demonstrated in Chapter Five, the regional moisture sources are not as large as either the Amazon or Parana River Basins or the Gulf of Mexico.

As documented elsewhere, MCCs over southern Africa are found to have a dominant nocturnal life cycle. They are found to occur predominantly during the night time hours, initiating during the late afternoon / evening ( 1500-2000 LST) and reaching maximum extent just after midnight ( 0000-0300 LST). Most systems $(\sim 80 \%)$ over southern Africa generally last for between 6 and 12 hours, with an average of 9.5 hours. A key difference between systems over southern Africa when compared to their global counterparts is that they are considerably smaller. As noted by Laing and Fritsch (1997), systems with a larger cloud shield generally last longer, which could account for the somewhat shorter average duration of southern African systems. Again, the reasons for the smaller systems found in this study are not obvious. Differences in moisture availability between the various MCC regions could account for the contrast in size. The fact that the results here are sensitive to the resolution of the Meteosat-7 satellite data can also not be excluded. The resolution used in this study is set at $4.5 \mathrm{~km}$ over the entire domain, but it is known to be approximately $5 \mathrm{~km}$ over parts of South Africa (Stefan Scherzer 2007, EUMETSAT, personal communication). Simply put, the horizontal 
resolution of the satellite data decreases farther away from the sub-satellite point, which in this case is $0^{\circ} \mathrm{E} ; 0^{\circ} \mathrm{S}$. The result is that a possible underestimation of the spatial extent of systems can occur. At a $4.5 \mathrm{~km}$ resolution, the average size of MCCs over southern Africa is $121,100 \mathrm{~km}$, while if the resolution is set at $5 \mathrm{~km}$ the average size increases to $149,000 \mathrm{~km}$. Nevertheless, this size is still smaller than the global population. The impact that this size may have on MCC identification is discussed in the next subsection.

To gain confidence in the statistics acquired for the southern African MCC population, a much longer study period would be needed. However, even though the climatology results presented in this thesis are based on a limited sample size, they do provide a good initial indicator of MCCs over southern Africa. They also clearly highlight the monthly/seasonal variability of these systems in the region. Thus, they can be used for comparison to other studies or as a platform from which local studies using more recent data, such as that from the Meteosat- 8 and Meteosat-9 satellites, could be built upon.

\subsubsection{Subjectivity in MCC Identification}

The foundation in developing the climatology from satellite imagery is selecting a suite of criteria that define the convective system as being an MCC. The original definition, proposed by Maddox (1980), identifies an MCC as a near circular system that contains two cloud top temperature thresholds that both satisfy a certain size criteria (see Table 2.1 in Chapter Two ). It is debatable whether the warmer cloud threshold $\left(-32^{\circ} \mathrm{C}\right)$ is still required as a prerequisite for MCC identification; some studies find it to be largely redundant (Augustine and Howard, 1988; McAnelly and Cotton, 1989). The reasoning is that the warmer cloud shield is often found to be bordering other MCSs or it may be part of a large-scale cloud pattern within which the MCC is embedded. Thus, difficulty in demarcating the systems boundary may result, impacting on determining the systems areal extent. It is for this reason that some studies have omitted the warmer threshold of the system and instead concentrated on the colder cloud temperature (e.g., Augustine and Howard 1988, 1991; Anderson and Arritt 1998, 2001; Cotton et al. 1989). Conversely, there is a possibility that by using only the colder threshold $\left(-52^{\circ} \mathrm{C}\right)$ may result in the 
omission of the identification of some stages within the MCC life cycle (Maddox, 1980) or excluding some of the light precipitating clouds (Williams and Houze 1987). It has to be kept in mind that the cloud structures of MCCs are complex with various cloud types involved at the different stages of the life cycle (e.g., convective and stratiform precipitation producing clouds). Thus, the identification of MCCs using tracking programs can be seen as being somewhat arbitrary and subjective.

A few temperature thresholds were tested in this study and each threshold was found to contain some limitations, similar as discussed above. For example, using a "warmer" threshold such as $-32^{\circ} \mathrm{C}$ or $-48^{\circ} \mathrm{C}$ often resulted in the shape being slightly distorted due to other cloud systems in close proximity to the MCC under consideration. Due to this distortion, the system did not meet the criterion of having an eccentricity greater than 0.7 and would then not have been included in the climatology. Using colder thresholds, such as $-64^{\circ} \mathrm{C}$, meant that some systems were then too small and would then have to be eliminated. Thus, only the $-52^{\circ} \mathrm{C}$ temperature threshold was used. The benefit of using just this particular threshold is twofold. Firstly, consistency with the literature (e.g., Augustine and Howard 1988; Anderson and Arritt 1998; Durkee and Mote 2009) is maintained, thereby allowing for direct comparisons with other MCC populations. Secondly, it enabled an analysis of the precipitation produced by the systems. As alluded to previously, most precipitation produced by MCCs is confined to areas beneath the colder cloud shield (McAnelly and Cotton 1986, 1989).

Although the process of system identification and tracking was primarily performed using an automated program, visual inspection of the output was still required. The MASCOTTE approach relies on the assumption that cloud top temperature distribution and the area of deep convection do not change strongly over time. In the case of smaller deep convective systems, such an approach may be problematic due to the possible explosive growth of such systems (Machado et al. 1998). The result of the rapid changes in the position and areal extent between successive images would lead to difficulties in tracking the system. Further tracking complications arise in the case of the merger and splitting of systems. In this study, the life span of a particular system was considered to 
end if merging between the MCC and a MCS occurred or if the MCC split into several convective systems.

Thus, a rather conservative approach was adopted with regards to $\mathrm{MCC}$ identification in this study, which may possibly influence the results. Figure 8.1 illustrates the tracks of potential systems that were omitted from the MCC climatology due to various reasons, such as merges with other MCSs before reaching MCC status, or their cloud shield extending too far out of the study domain, particularly along the northeast and eastern border. If systems that extended too far out of the domain had been included, it would have resulted in an underestimation of the average MCC size. A large portion of the systems shown in Fig. 8.1 are systems that just fell short of being classified as being an MCC. In some cases, a system failed to reach MCC status by 30 minutes (i.e., satisfied the size, shape and cloud top temperatures criteria for only 5 hours and 30 minutes). Differences in the horizontal resolution of Meteosat-7 data, as previously discussed, may have resulted in these systems being included in the climatology. In combination, these factors could explain the fewer number of systems identified in this study compared to Laing and Fritsch (1993b). However, Laing and Fritsch (1993b) used lower resolution data (both spatially and temporally) and hence, may have overestimated the frequency of MCC occurrence.

Apart from the issues of splitting and merging of systems, in some cases the tracking program identified disorganised cloud clusters as MCCs. For the latter, the automatic identification could be made slightly less subjective by the use of additional criteria. An example would be to use the fragmentation of the system (Fluct), which is calculated in MASCOTTE, to exclude poorly organised convective systems as being identified as MCCs. This value refers to the "smoothness" of the cloud shield at the boundary of the system and is based on an approximate linear relationship between the logarithm of perimeter versus the logarithm of area of the systems as described by Lovejoy (1982). Systems that are well formed tend to have positive Fluct values, while cloud systems that are not well formed or are irregular have negative values of Fluct. Carvalho and Jones (2001) suggest this parameter can be applied to characterise the different stages of 
development and decaying of a system. The tracking program also identified tropical cyclones or tropical lows over Mozambique as MCCs. These systems often matched the size, duration and shape criteria required, but are clearly not MCCs. Subjectivity may also arise for systems on the border of the domain, which was often the case in the northeast and eastern parts of the region. Essentially, the use of automated programs do have notable benefits in terms of processing large amounts of images in a relatively short time frame, but the output will have to be continuously checked for errors. For this reason, a hybrid identification process is deemed necessary.

\subsection{Synthesis of Environments Conducive to MCC development}

\subsubsection{The Importance of Moisture Availability}

The large-scale environments in which midlatitude MCCs evolve have often been shown to contain considerable variability (Maddox et al. 1986). However, attempts to discriminate the synoptic and mesoscale environments in which these systems thrive (e.g., Laing and Fritsch 2000) reveal that, on a global scale, very comparable patterns emerge amongst the different regions. A typical MCC is often found to develop in an environment that contains considerable horizontal temperature, moisture and stability gradients, along with considerable variations in both horizontal and vertical wind shear (Maddox 1983; Cotton et al. 1989; Laing and Fritsch 2000). In addition, the environment is required to be unstable, with the low levels containing substantial moisture for sustained convection. These features are not necessarily a prerequisite because they do not ensure that the convection will become organised into an MCC. Thus, there still remains uncertainty as to what factors play a role in the upscale growth of the individual storms to form into a single cloud system.

Ideally, it would have been useful to create a similar composite analysis of MCC largescale environments such as that produced by Maddox (1983), Cotton et al. (1989) or Laing and Fritsch (2000). Not only is this a more objective method, but it is likely to sufficiently extract the repetitive features of the large-scale environment associated with 
MCCs. However, such an approach was thought to be impractical in this study due to the limited number of systems occurring over southern Africa. In addition, the climate of the region is complex and influenced by numerous aspects, which make weaken any results from a composite analysis. Thus, focus was shifted to monthly atmospheric changes over southern Africa that may result in seasonal shift in MCC distribution. Three detailed case studies were also presented to highlight the different environments in which MCCs may develop.

Consistent with MCC populations elsewhere, the systems over southern Africa are found to develop in a wide variety of large-scale environments. Each of the three MCC case studies evolved in a different large-scale weather pattern. It is very likely that these case studies do not account for all facets of the large-scale environment that influence the formation and location of MCCs over the region. Nevertheless, the key characteristics identified here suggest that MCCs over southern Africa evolve in an environment that contains considerable moisture transport and is convectively unstable for long periods of time. In all cases, the moisture appeared to originate from the neighbouring southwest Indian Ocean (SWIO). The significance of this ocean region for southern Africa summer rainfall is well documented in the literature (e.g., Mason 1995; Reason and Mulenga 1999; Reason 2002; Washington and Preston 2006).

The importance of moisture availability and a means through which it can be transported appears to play a fundamental role in the frequency of systems. In a comparison of the three subtropical MCC regions found in the Southern Hemisphere, it was noted that the high frequency of systems in South America is primarily due to the continuous moisture being fed into the region from a large moisture source (i.e., Amazon Basin) via the South American low level jet. In contrast, the fewer MCCs over subtropical Australia are likely due to a combination of the lack of moisture being fed into the region, as well as the lower topography. A nocturnal LLJ is a prominent feature in most MCC regions and is responsible for the advection of moisture into the storm (e.g., Maddox 1983; Velasco and Fritsch 1987) region. As highlighted in the case studies presented here, a LLJ is not a prerequisite for MCC development over southern Africa, but does appear to play a key 
role in increasing the longevity of the system and may also influence the quantity of precipitation produced.

The influence of large-scale circulation patterns on moisture transport is also evident in the seasonal distribution of MCCs over southern Africa. Systems in the region were shown to have a preference to occur during the core summer months of November through to February. The large-scale analysis revealed that moisture transport and instability of the atmosphere were more favourable during these months as compared to the transition seasons of October and March. Furthermore, the equatorward migration of MCCs during the late summer months is possibly related to an increase of moisture being advected from the tropical SWIO into the northeastern parts of the domain during this period. This migration is as a result of the ITCZ shifting polewards, resulting in an increase in easterly winds over the SWIO. During the early summer months, low level moisture transport into the region is more controlled by the midlatitudes, whereas the tropics play a larger role during the late summer.

\subsubsection{ENSO, the SICZ and MCCs}

The results also clearly demonstrate the influence that the combination of features in both the tropics and midlatitudes have on the development and evolution of systems over southern Africa. Disturbances in the form of easterly waves in the northern part of the domain provide favourable conditions for deep convection through low level convergence and assist in moisture advection. At the same time, divergence associated with midlatitude westerly waves in the mid-levels and in the upper level jet stream result in favourable conditions for enhanced convection. These favourable large-scale environments for MCC development over southern Africa show similar characteristics to the large-scale environments of tropical-extratropical cloudbands in the region (e.g., Hart et al. 2010). These cloudbands, which develop through these tropical-extratropical interactions, have been shown to be a considerable contributor to South Africa summer rainfall (Harrison 1984). Furthermore, the aggregated expression of these synoptic-scale cloudbands is thought to form the South Indian convergence zone (SICZ) (Cook 2000). 
Although no obvious link between the frequency of MCCs over southern Africa and ENSO was identified here, a longer climatology may produce different results. The limited findings in this study indicate that ENSO may influence MCCs over the region via similar processes that govern the main location of the tropical-extratropical cloudbands. Under El Niño conditions, changes in the Walker Circulation result in the SICZ shifting eastward, with conditions favouring cloudband formation and rainfall now positioned over Madagascar and the SWIO. This shift in turn results in unfavourable conditions for MCC development over southern Africa and hence, fewer MCCs are found during El Niño. During La Niña periods, a stronger tropical low over Angola, enhanced easterly moisture flux over the SWIO and coupled low level convergence and upper level divergence favour MCC development. The highest frequency of MCCs in the region occurred during 1999/2000, a period of protracted La Niña.

The moisture source region in the Indian Ocean may be influenced by the Indian Ocean Dipole (IOD). This mode has been found to impact rainfall patterns over tropical eastern Africa (Saji et al. 1999). Saji and Yamagata (2003) and Meyers et al. (2007) conclude that only approximately half of IOD events occur independently from ENSO, indicating that such a process can be initiated by ENSO or on some occasions, be self-generating. Closer to southern Africa, a dipole mode in the South Indian Ocean, known as the subtropical dipole (SIOD), is thought to have more of an influence of weather patterns over the region (Behera and Yamagata 2001; Reason 2001a). In this case, there was no conclusive evidence of the SIOD having an influence of MCC frequency over southern Africa.

\subsection{Satellite-Derived MCC Rainfall over southern Africa}

Due to the high spatial and temporal variability of precipitation in the region much of the literature is dedicated to aspects of southern African circulation and weather patterns. However, lack of quality controlled rain-gauge data over southern Africa meant that the rainfall associated with MCCs can only be assessed via satellite data. In this case, the 
TRMM Multi-satellite Precipitation Analysis (TMPA) 3B42 version 6 data was used to fill the void created by the lack of surface-weather based observation platforms in southern Africa. Using TMPA data, an analysis was performed on the precipitation produced by MCCs over eight warm seasons. The 3-hourly TMPA data is used here instead of daily data in an attempt to exclude precipitation not associated with the MCC, which occurred in the same region before or after the event. Only precipitation associated with the $-52^{\circ} \mathrm{C}$ cloud shield is used. However, in some cases, the derived MCC rainfall may be contaminated by non-MCC precipitation due to the close proximity of another convective system and thus, might have ended up as being viewed as part of the MCC. Additionally, non-MCC precipitation may be captured within the convex hull (used to demarcate the MCCs position) if another system moved into the region while the MCC was still active. Conversely, the difference in resolution between the Meteosat-7 data and TMPA data may have resulted in the rainfall being under-estimated along the borders of systems. These factors highlight the complexity of extracting rainfall data associated with MCCs.

Even though satellite-derived rainfall products contain a vastly greater spatial and temporal coverage than rain-gauge data, there are some limitations with using these datasets. The data used to develop the TMPA product may not capture heavy rainfall associated with convective processes that take place on a smaller scale that the $0.25^{\circ}$ resolution. Some studies have also found that the TRMM data contains too many high precipitation rate values and may underestimate precipitation that occurs at low rates (e.g., Villarini and Krajewski 2007; Wolff and Fisher 2008; Jiang et al. 2008; Demaria et al. 2011). Su et al. (2008) suggests that the TMPA data agrees well with monthly raingauge data, but less so on daily scales. Thus, the rain-gauge adjustment of TRMM is possibly more effective on longer time scales (i.e., monthly). Furthermore, the skill of TRMM rainfall estimates over high terrain is also problematic (Dinku et al. 2008). Ultimately, this may result in an overestimation of the maximum rainfall produced by MCCs over southern Africa, which in this case was calculated to be on average in excess $130 \mathrm{~mm}$. 
Despite these caveats, the impact MCCs have on southern Africa is clearly illustrated in the results. The process by which the contribution of MCCs to the summer rainfall is calculated is summed up in Fig. 8.2. It was found that these systems can contribute up to $24 \%$ of the total warm season rainfall in the eastern parts of southern Africa. It must be taken into consideration that the confined spatial extent of MCCs and the rainfall they produce could be an artefact of the domain selected in the study. Thus, one could expect in a larger domain there may be more systems identified to the northeast and east of the current study domain, which may modify the results in terms of the spatial distribution of MCC rainfall and their contribution.

The main regions that experienced considerable MCC rainfall include southern Mozambique, Swaziland and northeastern and eastern South Africa. Of these regions, southern Mozambique was the largest beneficiary of MCC rainfall. As indicated previously, the reasons for this are not apparent, but it is speculated that it may be due to the slightly higher frequency of systems found there. Additionally, the lack of strong midlevel flow over southern Mozambique implies that these systems may not propagate large distances and thus, most of the rainfall is confined to a smaller region. There is also a larger coastal plain downstream from the orography in southern Mozambique and a closer proximity to the SWIO moisture source. There is also considerable spatial variability associated with the warm season rainfall contribution by MCCs, and there does not appear to be any consistent pattern throughout the years. This spatial variability in the rainfall is linked to the high seasonal variability of MCCs over the region.

These results are fairly consistent with the global literature on MCC contributions to regional rainfall patterns. As highlighted in Chapter Six, differences in methods and data used in quantifying MCC rainfall contributions needs to be taken into account when comparing the literature to results in this study. Thus, without any standardized process to evaluate the contribution of MCCs to seasonal rainfall, comparisons between the literature should be viewed with caution. Nevertheless, the results from this thesis highlight the benefit of using of satellite-derived data for regions containing sparse observations. However, it needs to be kept in mind that even though rain-gauge data does 
not extend over the same range as satellite-derived rainfall products, they have the advantage of recording the rainfall that actually reaches the surface. Ultimately, TMPA data should not be seen as a replacement for rain-gauge data in southern Africa, but rather as an additional source of information for this type of research. Continued research using satellite-based rainfall estimates will likely see improvements in this field, with an important development for future work being the use of combining such products with model data (e.g., de Coning and Poolman 2011).

\subsection{Thesis Conclusions}

The regional climate of southern Africa is complex and is influenced by numerous features, varying from the large-scale (e.g., ENSO) down to the local-scale (e.g., local topography, such as the Drakensberg). The result is that the region experiences considerable spatial and temporal variability in rainfall and is prone to both frequent flooding and drought events. Furthermore, southern Africa has often been identified as a highly convective region, particularly over the eastern parts and neighbouring ocean. One such system contributing to this high degree of convectivity and rainfall variability, due to its large size and long duration, is the mesoscale convective complex (MCC). The study of MCCs over southern Africa has been very limited compared to elsewhere, which is likely due to the relatively low frequency of such events there and poorer infrastructure. On this basis, this thesis has attempted to build on the original climatology developed by Laing and Fritsch (1993b) for the period 1986-1987. In addition, it attempts to fill the void in knowledge relating to the large-scale environments of MCCs over southern African, as well as the impact these systems have summer rainfall.

Through the use of a hybrid automated/manual tracking method, a detailed climatology of 70 MCCs occurring over southern Africa during the austral summer months between the 1998-2006 period was presented. As found by Laing and Fritsch (1993b), a large percentage of the systems are found to develop along the eastern escarpment and then track towards the warm Agulhas Current. The influence of this warm current on regional 
circulation patterns and on other heavy precipitation systems over the region (such as cutoff lows) is well known.

Some of the key findings regarding MCCs over southern Africa include:

- The systems over southern Africa are not as frequent as that found in other MCC populations, such as the Americas, but they still pose a threat when they occur.

- Apart from the average size of systems being relatively small, the southern Africa MCCs compare favourably with the global population in terms of having a similar nocturnal life cycle.

- The system develops in an environment that is unstable and contains considerable low level moisture advection from the neighbouring ocean for long periods.

- Intraseasonal changes in low level moisture circulation play a key role in the spatial distribution of MCCs in southern Africa.

- MCCs are found to be important contributors to the summer rainfall over eastern southern Africa. However, there is considerable variability in the contribution these systems make towards monthly and warm season rainfall totals.

There still remains a lot of uncertainty regarding the large-scale processes that modulate the frequency of such systems over the region. In the case studies presented, the largescale environment often contained features that favour the development of tropicalextratropical cloudbands over southern Africa. It is unclear why on such occasions an MCC develops as opposed to a cloudband. However, it does indicate that ENSO may play a role in MCC frequency through similar mechanisms resulting in the eastwards (i.e., offshore) shift of tropical extra-tropical cloudbands off the southern African landmass. Additionally, changes in moisture transport and low level circulation patterns associated with anomalous SST conditions of the surrounding Indian and Atlantic Oceans may also play a vital role in MCC frequency in the region. 
Lastly, this study emanates from the reality that southern Africa is frequently affected by severe weather events, but the scarcity of observations restricts our understanding of these weather systems. The severe weather phenomena that are produced by these systems, such as flooding, lightning, tornadoes, hail, strong winds, not only often result in the loss of life, but also typically lead to damage to infrastructure and to crops resulting in detrimental impacts on the economy. That, combined with the fact that large portions of the southern African population live in the rural areas (with limited access to medical services) or below the poverty line, results in them being more vulnerable to such severe weather phenomena than in many other parts of the world. Another perspective is that the same severe weather producing systems often provide much of the all important rainfall for the region. A key question going forward into the uncertainties related to climate change is whether heavy precipitating events, such as MCC, will be more frequent or intense under the various future greenhouse gas scenarios. It is for these reasons that a more concerted effort is required towards understanding severe weather producing systems in the region. Until then, our knowledge and ability to mitigate potential weather related disasters under a changing climate will remain limited. 


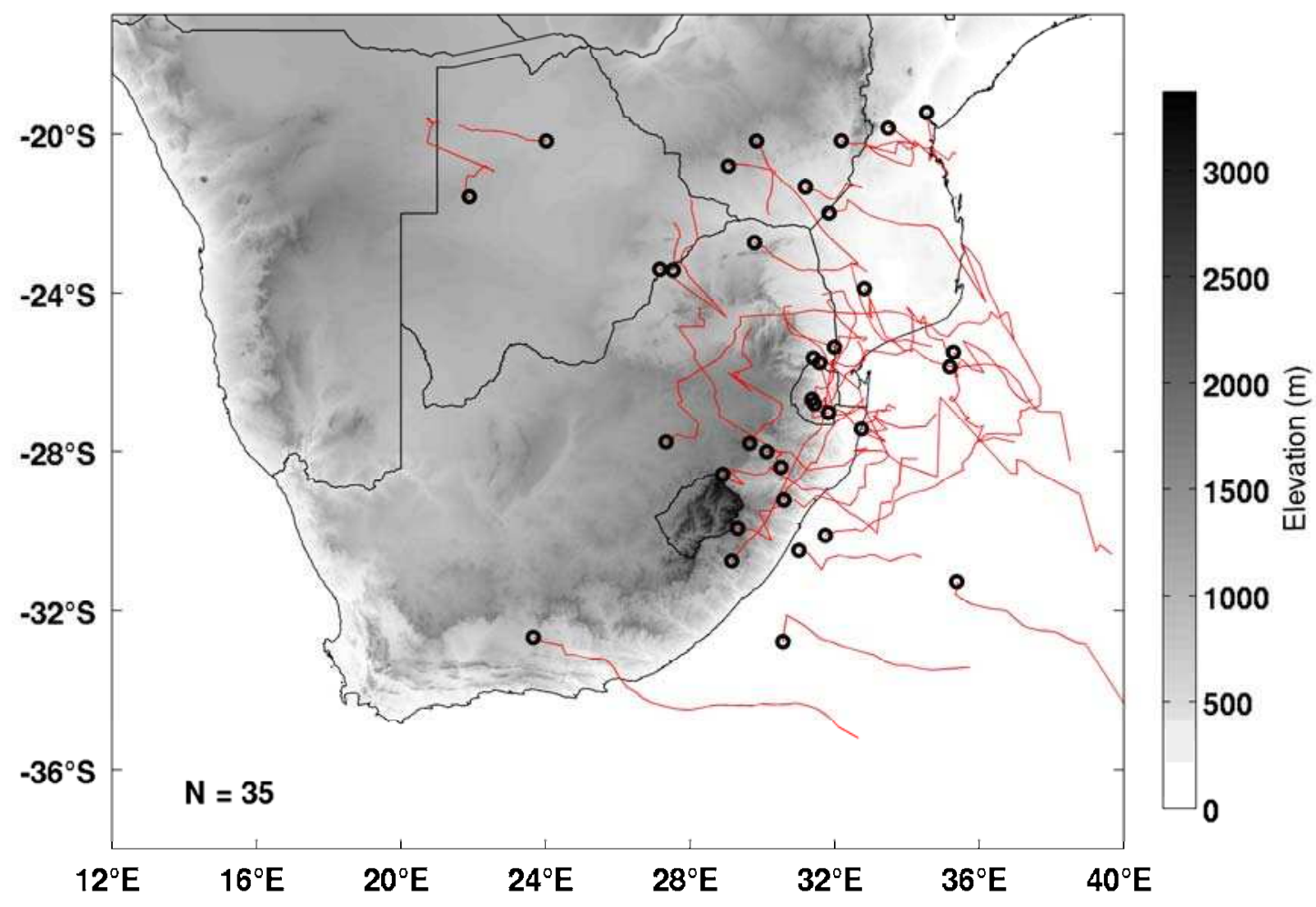

Figure 8.1: Tracks (red lines) and origin points (o) of systems that were not included in the climatology. Also shown is the topography of the region (shaded, $500 \mathrm{~m}$ intervals). $N$ is equal to the number of systems during this period. 


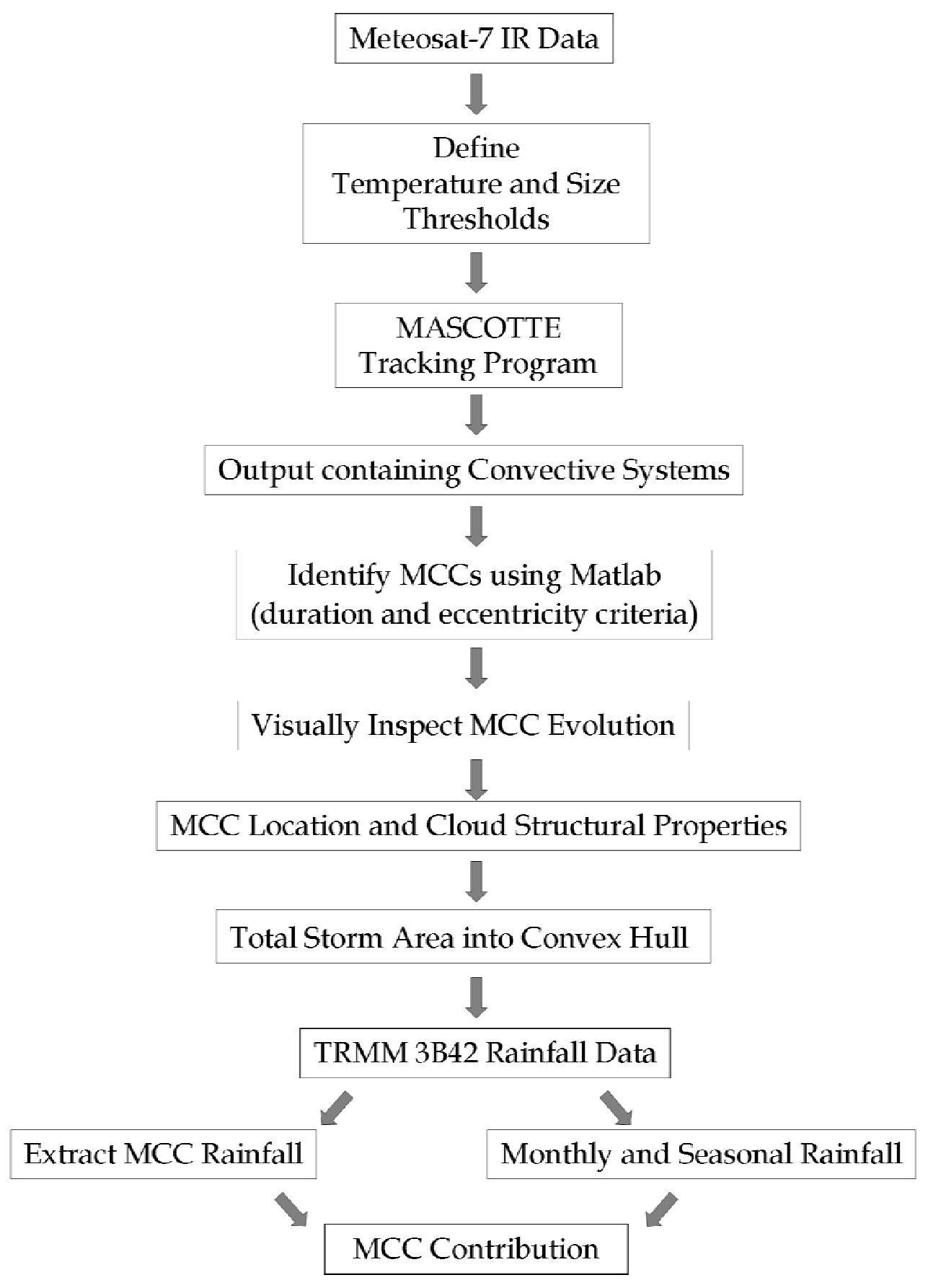

Figure 8.2: A flow diagram depicting the process used to determine the contribution by MCCs to southern Africa summer rainfall. 


\section{$\underline{\text { References }}$}


Adler, R. F., C. Kidd, G. Petty, M. Morissey, and H. M. Goodman, 2001: Intercomparison of global precipitation products: The Third Precipitation Intercomparison Project (PIP-3). Bulletin of the American Meteorology Society, 82, $1377-1396$.

Adler, R. F., G. J. Huffman, A. Chang, R. Ferraro, P.-P. Xie, J. Janowiak, B. Rudolf, U. Schneider, S. Curtis, D. Bolvin, A. Gruber, J. Susskind, P. Arkin, and E. Nelkin, 2003: The Version-2 Global Precipitation Climatology Project (GPCP) Monthly Precipitation Analysis (1979-Present). Journal of Hydrometeorology, 4, 1147-1167.

AghaKouchak, A., A. Behrangi, S. Sorooshian, K. Hsu, and E. Amitai, 2011: Evaluation of satellite-retrieved extreme precipitation rates across the central United States. Journal of Geophysical Research, 116, D02115, doi:10.1029/2010JD014741.

Anderson, C. J. and R. W. Arritt, 1998: Mesoscale Convective Complexes and Persistent Elongated Convective Systems over the United States during 1992 and 1993. Monthly Weather Review, 126, 578-599.

Anderson, C. J. and R. W. Arritt, 2001: Mesoscale convective systems over the United States during the 1997-98 El Niño. Monthly Weather Review, 129, 2443-2457.

Arkin, P. A., and B. N. Meisner, 1987: The relationship between large-scale convective rainfall and cold cloud over the Western Hemisphere during 1982-84. Monthly Weather Review, 115, 51-74.

Arnaud, Y., M. Debois and J. Maizi, 1992: Automatic tracking and characterization of African convective systems on Meteosat pictures. Journal of Applied Meteorology, 31, 443-453. 
Ashley, W. S., T. L. Mote, P Grady Dixon, S. L. Trotter, E. J. Powell, J. D. Durkee, and A. J. Grundstein. 2003: Distribution of Mesoscale Convective Complex Rainfall in the United States. Monthly Weather Review, 131, 3003-3017.

Augustine, J. A. and K. W. Howard, 1991: Mesoscale convective complexes over the United States during 1986 and 1987. Monthly Weather Review, 119, 1575-1589.

Augustine, J. A. and F. Caracena, 1994: Lower-tropospheric precursors to nocturnal MCS development over the central United States. Weather and Forecasting, 9, 116-135.

Barber, C. B., D. P. Dobkin and H. T. Huhdanpaa, 1996: The Quickhull algorithm for convex hulls, ACM Trans. on Mathematical Software, 22, 469-483.

Bartels, D. L. and R. A. Maddox, 1991: Midlevel Cyclonic Vortices Generated by Mesoscale Convective Systems. Monthly Weather Review, 119, 104-118.

Bartels, D. L., J. M. Skradski and R. D. Menard, 1984: Mesoscale convective systems: A satellite-data-based climatology. NOAA Tech. Memo. ERL ESG 8, Dept. of Commerce, Boulder, CO, 63 pp. [NTIS PB-85-187904].

Bartels, D. L., J. M. Brown, and E. I. Tollerud, 1997: Structure of a midtropospheric vortex induced by a mesoscale convective system. Monthly Weather Review, 125, 193211.

Beebe, R .G. and F. C. Bates., 1955: A mechanism for assisting in the release of convective instability. Monthly Weather Review, 83, 1-10.

Behera, S. K., and T. Yamagata, 2001: Subtropical SST dipole events in the southern Indian Ocean, Geophysical Research Letters, 28, 327-330. 
Behera, S. K., P. S. Salvekar, and T. Yamagata, 2000: Simulation of interannual SST variability in the tropical Indian Ocean, Journal of Climate, 13, 3487-3499.

Blamey, R. C. and C. J. C. Reason, 2009: Numerical simulation of a mesoscale convective system over the east coast of South Africa. Tellus, 61A, 17-34.

Brooks, H. E., J. W. Lee and J. P. Craven, 2003: The spatial distribution of severe thunderstorm and tornado environments from global reanalysis data. Atmospheric Research, 67-68, 73-94.

Carvalho, L. M. V. and C. Jones, 2001: A Satellite Method to Identify Structural Properties of Mesoscale Convective Systems Based on the Maximum Spatial Correlation Tracking Technique (MASCOTTE). Journal of Applied Meteorology, 40, 1683-1701.

Chen, S. S., and W. M. Frank, 1993: A numerical study of the genesis of extratropical convective mesovortices. Part I: Evolution and dynamics. Journal of. Atmospheric Science, 50, 2401-2426.

Chen, S. S., R. A. Houze, and B. E. Mapes, 1996: Multi-scale variability of deep convection in relation to large-scale circulation TOGA COARE. Journal of the Atmospheric Sciences, 53, 1380-1409.

Chen, C., W.-K Tao, P.-L. Lin, G. S. Lai., S.-F. Tseng and T.-C. C. Wang. 1998: The Intensification of the Low-Level Jet during the Development of Mesoscale Convective Systems on a Mei-Yu Front. Monthly Weather Review, 126, 349-371.

Collander, R. S., 1993: A ten year summary of severe weather in mesoscale convective complexes. Part 2: Heavy rainfall. Preprints, $17^{\text {th }}$ Conference on severe local storms, St. Louis, MO, American Meteorological Society. 533-537. 
Cook, K. H., 2000: The South Indian Convergence Zone and Interannual Rainfall Variability over Southern Africa. Journal of Climate, 13, 3789-3804.

Cook. K. H., 2001: A Southern Hemisphere Wave Response to ENSO with Implications for Southern Africa Precipitation. Journal of the Atmospheric Sciences, 58, 2146-2162.

Cook, C., C .J. C. Reason and B. C. Hewitson, 2004: Wet and dry spells within particularly wet and dry summers in the South African summer rainfall region. Climate Research, 26, 17-31.

Corfidi, S. F., 2003: Cold Pools and MCS Propagation: Forecasting the Motion of Downwind-Developing MCSs. Weather and Forecasting, 18, 997-1017.

Corfidi, S. F., J. H. Meritt, and J. M. Fritsch, 1996: Predicting the Movement of Mesoscale Convective Complexes. Weather and Forecasting, 11, 41-46.

Cotton, W. R., 2000: An overview of mesoscale convective systems. Chapter 31 in Storms vol. II. Pielke Jr., RA and RA Pielke Sr., Eds., Routledge, London, pp. 3-25.

Cotton, W. R. and R. A. Anthes, 1989: Storm and Cloud Dynamics. Academic Press, 880pp.

Cotton, W. R., M.-S. Lin, R. L. McAnelly, and C. J. Tremback, 1989: A composite model of mesoscale convective complexes. Monthly Weather Review, 117, 765-783.

Crimp, S. J. and S. J. Masson, 1999: The extreme precipitation event of 11-16 February 1996 over South Africa. Meteorology and Atmospheric Physics, 70, 29-42.

Crook, N. A. and M. W. Moncrieff, 1998: The effect of large-scale convergence on the generation and maintenance of deep moist convection. Journal of the Atmospheric Sciences, 45, 3606-3624. 
D’Abreton, P. C. and J. A. Lindesay. 1993: Water vapour transport over Southern Africa during wet and dry early and later summer months. International Journal of Climatology, 13, 151-170.

D’Abreton, P. C. and J. A. Lindesay. 1995: Divergent and non-divergent water vapour transport over southern Africa during wet and dry conditions. Meteorology and Atmospheric Physics, 55, 297-306.

de Coning, E. and E. Poolman, 2011: South African Weather Service operational satellite based precipitation estimation technique: applications and improvements. Hydrology and Earth System Sciences, 15, 1131-1145.

de Coning, E., G. S. Forbes and E. Poolman. 1998. Heavy precipitation and flooding on 12-14 February 1996 over the summer rainfall regions of South Africa: Synoptic and isentropic analyses. National Weather Digest, 22, 25-36.

Demaria, E. M. C., D. A. Rodriguez, E. E. Ebert, P. Salio, F. Su, and J. B. Valdes, 2011: Evaluation of mesoscale convective systems in South America using multiple satellite products and an object-based approach, Journal of Geophysical Research. 116, DO8103, doi:10.1029/2010JDO15157

Diab, R. D, R. A. Preston-Whyte, and R. Washington, 1991: Distribution of rainfall by synoptic type over Natal, South Africa. International Journal of Climatology, 11, 877888.

Dinku, T., S. Chidzambwa, P. Ceccato, S. Connor, and C. Ropelewski, 2008: Validation of high-resolution satellite rainfall products over complex terrain. International Journal of Remote Sensing, 29, 4097-4110. 
Dopplick, T. G., 1972: Radiative heating of the global atmosphere. Journal of Atmospheric Science, 29, 1278-1294.

Doswell, C.A. III, 1987: The distinction between large scale and mesoscale contribution to severe convection: A case study example. Weather and Forecasting, 2, 3-16.

Doswell, C. A., III, H. E. Brooks, and R. A. Maddox, 1996: Flash flood forecasting: An ingredients-based methodology. Weather and Forecasting, 11, 560-581.

Durkee, J. D., and T. L. Mote, 2009: A Climatology of warm-season Mesoscale Convective Complexes in subtropical South America. International Journal of Climatolology, 30, 418-431.

Durkee, J. D., T. L. Mote., and J. M. Sheppard., 2009: The Contribution of Mesoscale Convective Complexes to Rainfall across Subtropical South America, Journal of Climate, 22, $4590-4605$.

Dyson, L. L. and J. van Heerden, 2001: The heavy rainfall and floods over the northeastern interior of South Africa during February 2000. South African Journal of Science, 97, 80-86.

Ebert E. E., J. E. Janowiak, and C. Kidd, 2007: Comparison of near-real-time Precipitation estimates from Satellite observations and Numerical models, Bulletin of the American Meteorology Society, 88, 47-64.

Fauchereau, N., S. Traska, Y. Richard, P. Roucou, and P. Camberlin, 2003: Sea-surface temperature co-variability in the Southern Atlantic and Indian Oceans and its connections with the atmospheric circulation in the Southern Hemisphere. International Journal of Climatology, 23, 663-677. 
Fauchereau N, B. Pohl, C. J. C. Reason, M. Rouault, Y. Richard, 2009: Recurrent daily OLR patterns in the Southern Africa/Southwest Indian Ocean region, implications for South African rainfall and teleconnections. Climate Dynamics, 32, 575-591.

Feidas, H., G. Kokolatos, A. Negri, M. Manyin, N. Chrysoulakis, and Y. Kamarianakis, 2008: Validation of an infrared-based satellite algorithm to estimate accumulated rainfall over the Mediterranean basin. Theoretical and Applied Climatology, 95, 91-109.

Fritsch, J. M. and G. S. Forbes., 2001: Mesoscale Convective Systems. AMS Meteorological Monographs, Ed. C. A. Doswell III. American Meteorological Society. 28, 323-357.

Fritsch, J. M., R. J. Kane, and C. R. Chelius, 1986: The contribution of mesoscale convective weather systems to the warm season precipitation in the United States. Journal of Climate and Applied Meteorology, 25, 1333 - 1345.

Gallus, W. A., N. A. Snook and E. V. Johnson, 2008: Spring and summer severe weather reports over the Midwest as a function of convective mode: a preliminary study. Weather and Forecasting, 23, 101-113.

Galway, J. G., 1956: The lifted index as a predictor of latent instability. Bulletin of the American Meteorology Society, 37, 528-529.

García-Herrera, R., D. Barriopedro, E. Hernández, D. Paredes, J.F. Correoso and L. Prieto, 2005a: The 2001 Mesoscale Convective Systems over Iberia and the Balearic Islands. Meteorology and Atmospheric Physics, 90, 225-243.

García-Herrera, R., E. Hernández, D. Paredes, D. Barriopedro, J.F. Correoso and L. Prieto, 2005b: A MASCOTTE-based characterization of MCSs over Spain, 2000-2002. Atmospheric Research, 73, 261-282. 
Garstang, M. and P. Tyson, 2000: Mesoscale convective systems over South Africa. Chapter 38 in Storms vol. II. Pielke Jr., RA and RA Pielke Sr., Eds., Routledge, London, pp. 146-162.

Garstang, M., B. E. Kelbe, G. D. Emmit, and W. B. London, 1987: Generation of convective storms over the escarpment of NE South Africa. Monthly Weather Review, 115, 429-443.

George, J. J., 1960: Weather and Forecasting for Aeronautics. Academic Press, 673 pp.

Gill, A. E., 1977: Coastally trapped waves in the atmosphere. Quarterly Journal of the Royal Meteorological Society, 103, 431-440.

Gill, A. E., 1982: Atmosphere-Ocean Dynamics. Academic Press: New York; 662 pp.

Goddard, L. and N. E. Graham, 1999: Importance of the Indian Ocean for simulating rainfall anomalies over eastern and southern Africa. Journal of Geophysical Research, 104, 19,099-19,116

Goff, J. A., and S. Gratch, 1946: Low-pressure properties of water from -160 to $212^{\circ} \mathrm{F}$. Transactions of the American Society of Heating and Ventilating Engineers. 52nd annual meeting of the American Society of Heating and Ventilating Engineers, New York, 95122.

Gray, W. M. and R.W Jacobson, 1977: Diurnal variation of deep cumulus convection. Monthly Weather Review, 105, 1171-1188.

Habib, E., A. Henschke and R. F. Adler, 2009: Evaluation of TMPA satellite-based research and real-time rainfall estimates during six tropical-related heavy rainfall events over Louisiana, USA. Atmospheric Research, 94, 377-388. 
Hane, C. E., 1986: Extratropical squall lines and rainbands. Mesoscale Meteorology and Forecasting. P.S. Ray, Ed., American Meteorology Society, 359-389.

Hansingo, K. and C. J. C. Reason, 2006: Sensitivity of the atmospheric response to sea surface temperature forcing in the South West Indian Ocean: a regional climate modeling study, South African Journal of Science, 102, 137-143.

Harrison, M. S. J., 1984: A generalized classification of South African rain-bearing synoptic systems. International Journal of Climatology, 4, 547-560.

Hart, N. C. G., C. J. C. Reason and N. Fauchereau, 2010: Tropical-Extratropical Interactions over Southern Africa: Three Cases of Heavy Summer Season Rainfall, Monthly Weather Review, 138, 2608-2623.

Hermes, J. C., and C. J. C. Reason, 2005: Ocean model diagnosis of interannual coevolving SST variability in the South Indian and South Atlantic oceans, Journal of Climate, 18, 2864-2882.

Higgins, R. W., V. E. Kousky, V. B. S. Silva, E. Becker and P. Xie, 2010: Intercomparison of Daily Precipitation Statistics over the United States in Observations and in NCEP Reanalysis Products. Journal of Climate, 23, 4637-4650.

Hirose, M and K. Nakamura 2005: Spatial and diurnal variation of precipitation systems over Asia observed by the TRMM Precipitation Radar. Journal of Geophysical Research, 110, D05106, doi:10.1029/2004JD004815

Holton. J. R. 1992: An introduction to Dynamic Meteorology. $3^{\text {rd }}$ edition. Academic Press, New York, 507 pp.

Hossain, F. and G. J. Huffman, 2008: Investigating error metrics for satellite rainfall at hydrologically relevant scales. Journal of Hydrometeorology, 9, 563-575. 
Houze, R. A., Jr. 1997: Stratiform precipitation in regions of convection: A meteorological paradox. Bulletin of the American Meteorology Society, 78, 2179-2196.

Houze, R. A., Jr. 2004: Mesoscale Convective Systems. Reviews of Geophysics, 42. 10.1029/2004RG000150, 1-43.

Houze, R. A., S. A. Rutledge, M. I. Biggerstaff, and B. F. Smull, 1989: Interpretation of Doppler weather radar displays of midlatitude mesoscale convective systems. Bulletin of the American Meteorology Society, 70, 608-619.

Houze, R. A., Jr., B. F. Smull, and P. Dodge, 1990: Mesoscale organization of springtime rainstorms in Oklahoma. Monthly Weather Review, 118, 613-654.

Huffman, G. J., R. F. Adler, P. Arkin, A. Chang, R. Ferraro, A. Gruber, J. Janowiak, A. McNab, B. Rudolf and U. Schneider, 1997: The Global Precipitation Climatology Project (GPCP) combined precipitation datasets. Bulletin of the American Meteorology Society, 78, 5-20.

Huffman, G., R. Adler, D. Bolvin, G. Gu, E. Nelkin, K. Bowman, E. Stocker, and D. Wolff, 2007: The TRMM multi-satellite precipitation analysis: Quasi-global, multiyear, combined-sensor precipitation estimates at fine scale. Journal of Hydrometeorology, 8, $38-55$.

Huffman, G. J., R. F. Adler, D. T. Bolvin and E. J. Nelkin, 2010: The TRMM Multisatellite Precipitation Analysis (TMPA). Satellite Rainfall Applications for Surface Hydrology. M. Gebremichael and F. Hossain, Eds,. Springer, 327pp.

Insel, N., C. J. Poulsen and T. A. Ehlers, 2010: Influence of the Andes Mountains on South American moisture transport, convection and precipitation. Climate Dynamics, $\mathbf{3 5}$, 1477-1492. 
James J. 1992. A preliminary study of mesoscale convective complexes over the midlatitudes of eastern Australia. Technical Report 66, Bureau of Meteorology: Melbourne, 30 .

Jiang, H. and E. J. Zipser, 2010: Contribution of Tropical Cyclones to the Global Precipitation from Eight Seasons of TRMM Data: Regional, Seasonal, and Interannual Variations. Journal of Climate, 23, 1526-1543.

Jiang, H., J. B. Halverson and J. Simpson, 2008: On the Differences in Storm Rainfall from Hurricanes Isidore and Lili. Part I: Satellite Observations and Rain Potential. Weather and Forecasting, 23, 29-43.

Jirak, I. L., W. R. Cotton, and R. L. McAnelly, 2003: Satellite and Radar Survey of Mesoscale Convective System Development. Monthly Weather Review, 131, 2428-2449.

Jury, M. R. 1992: A climatic dipole governing the interannual variability of convection over the SW Indian Ocean and SE Africa region. Trends in Geophysical Research, 1, $165-172$.

Jury, M. R., 2010: Flood-producing cloud bands over the Kalahari Desert. Theoretical and Applied Climatology, 102, 367-378.

Jury, M. R., H. R. Valentine and J. R. E. Lutjeharms. 1993: Influence of the Agulhas Current on summer rainfall on the southeast coast of South Africa. Journal of Applied Meteorology, 32, 1282-1287.

Kalnay, E., M. Kanamitsu, R. Kistler, W. Collins, D. Deaven, L. Gandin, M. Iredell, S. Saha, G. White, J. Woollen, Y. Zhu, M. Chelliah, W. Ebisuzaki, W. Higgins, J. Janowiak, K. C. Mo, C. Ropelewski, J. Wang, A. Leetmaa, R. Reynolds, R. Jenne, and D. Joseph, 
1996: The NCEP/NCAR 40-year reanalysis project. Bulletin of the American Meteorology Society, 77, 437-471.

Kanamitsu, M., W. Ebisuzaki, J. Woollen, S. K. Yang, J. Hnilo, M. Fiorino, and G. L. Potter, 2002: NCEP-DOE AMIP II Re-Analysis (R-2). Bulletin of the American Meteorology Society, 83, 1631-1643.

Kane, R. J., C. R. Chelius, and J. M. Fritsch, 1987: Precipitation characteristics of mesoscale convective weather systems. Journal of Climate and Applied Meteorology, 26, $1345-1357$.

Keenan, T. D, and R. E. Carbone, 2008: Propagation and diurnal evolution of warm season cloudiness in the Australian and Maritime continent region. Monthly Weather Review, 136, 973-994.

Kidd, C. K., D. R. Kniveton, M. C. Todd, and T. J. Bellerby, 2003: Satellite rainfall estimation using combined passive microwave and infrared algorithms. Journal of Hydrometeorology, 4, 1088-1104.

Kiladis G. N., and K. C. Mo, 1998: Interannual and intraseasonal variability in the Southern Hemisphere. Meteorology of the Southern Hemisphere. Meteorological Monographs, No. 27, American Meteorological Society, 307-336

Kinter, J. L., III, M. J. Fennessy, V. Krishnamurthy, and L. Marx, 2004: An evaluation of the apparent interdecadal shift in the tropical divergent circulation in the NCEP-NCAR reanalysis. Journal of Climate, 17, 349-361.

Kruger, A. C., 2007: Climate of South Africa, Precipitation, Report No. WS47, South African Weather Service, Pretoria, South Africa, 41 pp. 
Kummerow, C., W. Barnes, T. Kozu, J. Shiue, and J. Simpson, 1998: The Tropical Rainfall Measuring Mission (TRMM) sensor package. Journal of Atmospheric and. Oceanic Technology, 15, 809-817.

Laing, A. G. and J. M. Fritsch, 1993a: Mesoscale convective complexes over the Indian Monsoon region. Journal of Climate, 6, 911-919.

Laing, A. G. and J. M. Fritsch, 1993b: Mesoscale convective complexes in Africa. Monthly Weather Review, 121, 2254-2263.

Laing, A. G. and J. M. Fritsch, 1997: The global population of mesoscale convective complexes. Quarterly Journal of the Royal Meteorology Society, 123, 389-405.

Laing, A. G. and J. M. Fritsch, 2000: The Large-Scale Environments of the Global Populations of Mesoscale Convective Complexes. Monthly Weather Review, 128, 27562776.

Laing, A. G., J. M. Fritsch, and A. J. Negri, 1999: Contribution of Mesoscale Convective Complexes to Rainfall in Sahelian Africa: Estimates from Geostationary Infrared and Passive Microwave Data. Journal of Applied Meteorology, 38, 957-964.

Landman, W. and S. Mason, 1999: Change in association between Indian Ocean seasurface temperatures and summer rainfall over South Africa and Namibia. International Journal of Climatology, 19, 1477-1492.

Laurent, H., N. D’Amato, and T. Lebel, 1998: How important is the contribution of mesoscale convective complexes to the Sahelian rainfall. Physics, Chemistry and Earth Sciences, 23, 629-633.

Leary, C. A. and E. N. Rapport, 1987: The life cycle and internal structure of a Mesoscale convective complex. Monthly Weather Review, 115, 1503-1527. 
Liebmann B. and C.A. Smith, 1996: Description of a Complete (Interpolated) Outgoing Longwave Radiation Dataset. Bulletin of the American Meteorological Society, 77, 12751277.

Lindesay, J. A., 1988: South African rainfall, the Southern Oscillation and a southern hemisphere semi-annual cycle. Journal of Climatology, 8, 17-30.

Liu, Z., and M. Alexander, M., 2007: Atmospheric bridge, oceanic tunnel, and global climatic teleconnections, Reviews of Geophysics, 45, RG2005, doi:10.1029/2005RG000172.

Lovejoy, S., 1982: The area-perimeter relationship for rain and cloud areas. Science, 216, 185-187.

Lyons, S. W., 1991: Origins of convective variability over equatorial Southern Africa during austral summer. Journal of Climate, 4, 23-39.

Machado, L. A. T. and W. B. Rossow, 1993: Structural characteristics and radiative properties of tropical cloud clusters. Monthly Weather Review, 121, 3234-3260.

Machado, L. A. T., W. B. Rossow, R. L. Guedes, and A. W. Walker, 1998: Life Cycle Variations of Mesoscale Convective Systems over the Americas. Monthly Weather Review, 126, 1630-1654.

Maddox, R. A. 1980: Mesoscale convective complexes. Bulletin of the American Meteorology Society, 61, 1374-1387.

Maddox, R. A. 1983: Large-scale meteorological conditions associated with mid-latitude, mesoscale convective complexes. Monthly Weather Review, 111, 1475-1493. 
Maddox, R. A. and C. A. Doswell, III, 1982: An examination of jet stream configurations, $500 \mathrm{mb}$ vorticity and low-level thermal advection patterns during extended periods of intense convection. Monthly Weather Review, 110, 184-197.

Maddox, R. A., C. F. Chappell, and L. R. Hoxit, 1979: Synoptic and meso- $\alpha$-scale aspects of flash flood events. Bulletin of the American Meteorology Society, 60, 115 - 123.

Maddox, R. A., K. W. Howard, D. L. Bartels, and D. M. Rogers, 1986: Mesoscale convective complexes in the middle latitudes. Mesoscale Meteorology and Forecasting. P.S. Ray, Ed., American Meteorology Society, 390-413.

Makarau, A. and M. R. Jury, 1997: Seasonal cycle of convective spells over southern Africa during austral summer. International Journal of Climatology, 17, 1317-1332.

Manhique, A. J., C. J. C. Reason, L. Rydberg and N. Fauchereau, 2011: ENSO and Indian Ocean sea surface temperatures and their relationships with tropical temperate troughs over Mozambique and the Southwest Indian Ocean. International Journal of Climatology, 31, 1-13.

Mapes, B. E., 1993: Gregarious tropical convection. Journal of the Atmospheric Sciences, 50, 2026-2037.

Mapes, B. E. and R. A. Houze Jr., 1993: Cloud clusters and superclusters over the oceanic warm pool. Monthly Weather Review, 121, 1398-1415.

Mapes, B. E., T. T. Warner, and M. Xu., 2003: Diurnal patterns of rainfall in northwestern South America, Part III: Diurnal gravity waves and nocturnal convection offshore. Monthly Weather Review, 131, 830 - 844.

Mason, S., 1995: Sea-surface temperature-South African rainfall associations, 1910-1989. International Journal of Climatology, 15, 119-135. 
Mason, S. J. and M. R. Jury, 1997: Climatic variability and change over southern Africa: A reflection on underlying processes. Progress in Physical Geography, 21, 23-50.

Mathon, V., H. Laurent and T. Lebel., 2002: Mesoscale Convective System Rainfall in the Sahel. Journal of Applied Meteorology, 41, 1081-1092.

McAnelly, R. L. and W. R. Cotton, 1986: Meso- $\beta$-scale aspects of an episode of meso- $\alpha-$ scale convective complexes. Monthly Weather Review, 114, 1740 - 1770.

McAnelly, R. L. and W. R. Cotton, 1989: The precipitation life cycle of mesoscale convective complexes over the central United States. Monthly Weather Review, 117, 784808.

McCollum, J. R., A. Gruber, and M. B. Ba, 2000: Discrepancy between gauges and satellite estimates of rainfall in equatorial Africa. Journal of Applied Meteorology, 39, $666-679$.

McIntosh, P.C., M. J. Pook, J. S. Risbey, S. N. Lisson and M. Rebbeck, 2007: Seasonal climate forecasts for agriculture: Towards better understanding and value. Field Crops Research, 104, 130-138

McNulty, R. P., 1995: Severe and convective weather. Weather and Forecasting, 10, 187-202.

Menard, R. D., and J. M. Fritsch, 1989: A mesoscale convective complex-generated inertially stable warm core vortex. Monthly Weather Review, 117, 1237-1261.

Meyers, G., P. McIntosh, L. Pigot, and M. Pook, 2007: The years of El Niño, La Niña, and interactions with the tropical Indian Ocean. Journal of Climate, 20, 2872-2880. 
Miller, R. C., 1972: Notes on analysis and severe-storm forecasting procedures of the Military Warning Center. Air Weather Service (MAC), Tech. Rep. 200, Scott Air Force Base, IL, 181pp.

Miller, D. and J. M. Fritsch, 1991: Mesoscale convective complexes in the western Pacific region. Monthly Weather Review, 119, 2978-2992.

Mo, K. C., 2000: Relationships between low-frequency variability in the southern hemisphere and sea surface temperature anomalies. Journal of Climate, 13, 3599-3610.

Monaghan, A.J., D. L. Rife, J. O. Pinto, C. A. Davis and J. R. Hannan, 2010: Global Precipitation Extremes Associated with Diurnally Varying Low-Level Jets. Journal of Climate, 23, 5065-5084.

Mounier, F., G. N. kiladis and S. Janicot, 2005: Analysis of the Dominant Mode of Convectively Coupled Kelvin Waves in the West African Monsoon. Journal of Climate, 20, $1487-1503$.

Mulenga, H. M., M. Rouault, C. J. C. Reason, 2003: Dry summers over northeastern South Africa and associated circulation anomalies, Climate Research, 25, 29-41.

Muller, A., C. J. C., Reason and N. Fauchereau, 2008: Extreme rainfall in the Namib Desert during late summer 2006 and influences of regional ocean variability. International Journal of Climatology, 28, 1061-1070.

Negri, A. J., T. L. Bell, and L. Xu, 2002: Sampling of the diurnal cycle of precipitation using TRMM. Journal of Atmospheric and Oceanic Technology, 19, 1333-1344.

Nesbitt, S. W., and E. J. Zipser, 2003: The diurnal cycle of rainfall and convective intensity according to three years of TRMM measurements. Journal of Climate, 16, $1456-1475$. 
Nesbitt, S. W., and E. J. Zipser, and C. D. Kummerow, 2004: An examination of version 5 rainfall estimates from the TRMM microwave imager, precipitation radar, and rain gauges on global, regional, and storm scales. Journal of Applied Meteorology, 43, 10161036.

Nesbitt, S. W., R. Cifelli, and S. A. Rutledge, 2006: Storm morphology and rainfall characteristics of TRMM precipitation features. Monthly Weather Review, 134, 27022721.

Newell, R. E., Y. Zhu, E. V. Browell, W. G. Read and J. W. Waters, 1996: Walker circulation and tropical upper tropospheric water vapor. Journal of Geophysical Research, 101, 1961-1974.

Nicholson, S. E., and Kim. J., 1997: The relationship of the El Niño-Southern Oscillation to African rainfall. International Journal of Climatology, 17, 117- 135.

Ogura, Y. and Y.-L Chen, 1977: A life history of an intense mesoscale convective storm in Oklahoma. Journal of the Atmospheric Sciences, 34, 1458-1476.

Pan, Z., M. Segal. and R. W. Arritt, 2004: The role of topography in forcing Low-level Jets in the Central United States during the 1993 Flood-Altered Terrain Simulations. Monthly Weather Review, 32, 396-403.

Parker, M. D. and R. H. Johnson, 2000: Organizational Modes of Midlatitude Mesoscale Convective Systems. Monthly Weather Review, 128, 3413-3436.

Perrin, G. M. and C. J. C. Reason, 1997: Southeast Australian mesoscale convective weather systems. Preprints, Fifth International Conf. on Southern Hemisphere Meteorology and Oceanography, Pretoria, South Africa, American Meteorological Society, 74-175. 
Pettet, C. R. and R. H. Johnson, 2003: Airflow and precipitation structure of two leading stratiform mesoscale convective systems determined from operational datasets. Weather and Forecasting, 18, 685-699.

Poccard, I., S. Janicot, and P. Camberlin, 2000: Comparison of rainfall structures between NCEP/NCAR reanalysis and observed data over tropical Africa. Climate Dynamics, 16, 897-915.

Price, C. 2000. Evidence for a link between global lightning activity and upper troposheric water vapour. Nature, 406, 290-293.

Reason, C. J. C., 1999: Interannual warm and cool events in the subtropical/mid-latitude South Indian Ocean region. Geophysical Research Letters, 26, 215-218.

Reason, C. J. C., 2001a: Subtropical Indian Ocean SST dipole events and southern African rainfall. Geophysical Research Letters, 28, 2225-2227.

Reason, C. J. C., 2001b: Evidence for the influence of the Agulhas Current on regional atmospheric circulation patterns. Journal of Climate, 14, 2769-2778.

Reason, C. J. C., 2002: Sensitivity of the Southern African circulation to dipole SeaSurface Temperature patterns in the South Indian Ocean. International Journal of Climatology, 22, 377-393.

Reason, C. J. C. 2006: A review of interannual climate variability over Southern Africa and its relationship with surface gradient forcing. South African Society Atmospheric Sciences (SASAS) Conference, Bloemfontein, South Africa. 
Reason, C. J. C. and M. R. Jury, 1990: On the generation and propagation of the southern Africa coastal low. Quarterly Journal of the Royal Meteorological Society, 116, 11331151.

Reason, C. J. C. and C. R. Godfred-Spenning, 1998: SST variability in the South Indian Ocean and associated circulation and rainfall patterns over southern Africa. Meteorology and Atmospheric Physics, 66, 243-258.

Reason, C. J. C. and H. M. Mulenga, 1999: Relationship between South African rainfall and SST anomalies in the southwest Indian Ocean. International Journal of Climatology, 19, 1652-1673.

Reason, C. J. C. and A. Keibel. 2004: Tropical Cyclone Eline and Its Unusual Penetration and Impacts over the Southern African Mainland. Weather and Forecasting, 19, 789-805.

Reason, C. J. C, and D. Jagadheesha, 2005: A model investigation of recent ENSO impacts over southern Africa. Meteorology and Atmospheric Physics, 89, 181-205.

Reason, C. J. C., W. Landman, W. Tennant, 2006: Seasonal to Decadal Prediction of Southern African Climate and its Links with Variability of the Atlantic Ocean, Bulletin of the American Meteorological Society, 87, 941-955.

Reason, C. J. C., R. J. Allan, J. A. Lindesay and T. J. Ansell, 2000: ENSO and climatic signals across the Indian Ocean Basin in the global context: part I, interannual composite patterns. International Journal of Climatology, 20, 1285-1327

Reynolds, R.W., N.A. Rayner, T.M. Smith, D.C. Stokes, and W. Wang, 2002: An improved in situ and satellite SST analysis for climate. Journal of Climate, 15, 16091625. 
Richard, Y., Trzaska, S., Roucou, P., Rouault, M., 2000: Modification of the southern African rainfall variability/ENSO relationship since the late 1960s. Climate Dynamics, $16,883-895$

Rife, D. L., J. O. Pinto, A. J. Monaghan, C. A. Davis, and J. R. Hannon, 2010: Global distribution and characteristics of diurnally varying low-level jets. Journal of Climate, 23, $5041-5064$.

Rocha, A. and I. Simmonds, 1997: Interannual variability of south-eastern African summer rainfall. Part 1: Relationships with air-sea interaction processes. International Journal of Climatology, 17, 235-265.

Romero, R., C. A. Doswell III and C. Ramis, 2000: Mesoscale numerical study of two cases of long-lived quasi-stationary convective systems over eastern Spain. Monthly Weather Review, 128, 3731-3751.

Rotunno, R., J.B. Klemp, and M.L. Weisman, 1988: A theory for strong, long-lived squall lines. Journal of the Atmospheric Sciences, 45, 463-485.

Rouault, M., S. A. White, C. J. C. Reason., J. R. E. Lutjeharms and I. Jobard., 2002: Ocean-Atmosphere interaction in the Agulhas Current region and a South African extreme weather event. Weather and Forecasting, 17, 655-669.

Rouault, M., P., Florenchie, N. Fauchereau, and C. J. C. Reason, 2003a: South east tropical Atlantic warm events and southern African rainfall. Geophysical Research Letters, 30, 8009-8013.

Rouault, M., C. J. C. Reason, J. R. E. Lutjeharms and A. C. M. Beljaars, 2003b: Underestimation of latent and sensible heat fluxes above the Agulhas Current in NCEP and ECMWF analyses. Journal of Climate, 16, 776-782. 
Rouault, M., N. Fauchereau, B. Pohl, P. Penven, Y Richard, C. J. C. Reason, G. G. S. Pegram, N. Phillippon, G. Siedler, A. Murgia, 2010: Multidisciplinary analysis of hydroclimatic variability at the catchment scale. Water Research Commission Report No.1747/1/10, 1-88

Saha, S., and Coauthors, 2010: The NCEP Climate Forecast System Reanalysis. Bulletin of the American Meteorology Society, 91, 1015-1057.

Saji, N. H., and T. Yamagata, 2003: Structure of SST and surface wind variability during Indian Ocean Dipole mode events: COADS observations, Journal of Climate, 16, 27352751.

Saji, N. H., B. N. Goswami, P. N. Vinayachandran, and T. Yamagata, 1999: A dipole in the tropical Indian Ocean, Nature, 401, 360-363.

Sall, A. M., H. Sauvagoet, A.T. Gaye, A. Viltard and P. Felice, 2005: A cyclogenesis index for tropical Atlantic off the African coast. Atmospheric Research, 79, 123-147.

Sapiano, M., and P. Arkin, 2009: An intercomparison and validation of high-resolution satellite precipitation estimates with 3-hourly gauge data. Journal of Hydrometeorology. 10, 149-166.

Scheel, M. L. M., M. Rohrer, C. Huggel, D. Santos Villar, E. Silvestre, and G. J. Huffman, 2010: Evaluation of TRMM Multi-satellite Precipitation Analysis (TMPA) performance in the Central Andes region and its dependency on spatial and temporal resolution. Hydrology and Earth System Sciences Discussions, 7, 8545-8586.

Schmetz, J. and M. Nuret, 1987: Automatic tracking of high level clouds in Meteosat infrared images with a radiance windowing technique. European Space Agency Journal, 11, 275-286. 
Schmidt, J. M. and W. R. Cotton, 1990: Interactions between upper and lower troposheric gravity waves on squall line structure and maintenance. Journal of the Atmospheric Sciences, 47, 1205-1222.

Schott, F. A., S.-P. Xie, and J. P. McCreary Jr., 2009: Indian Ocean circulation and climate variability, Review of Geophysics, 47, RG1002, doi:10.1029/2007RG000245.

Schumacher, R. S. and R. H. Johnson, 2005: Organization and Environmental Properties of Extreme-Rain-Producing Mesoscale Convective Systems. Monthly Weather Review, 133, 961-976.

Silva, V. B. S., V. E. Kousky and R. W. Higgins, 2011: Daily Precipitation Statistics for South America: An Intercomparison between NCEP Reanalyses and Observations. Journal of Hydrometeorology, 12, 101-117.

Simpson, J., R. F. Adler, and G. R. North, 1988: Proposed Tropical Rainfall Measuring Mission (TRMM) satellite. Bulletin of the American Meteorology Society, 69, 278-295.

Simpson, J., E. Ritchie, G. J. Holland, J. Halverson and S. Stewart, 1997: Mesoscale Interactions in Tropical Cyclone Genesis. Monthly Weather Review, 125, 2643-2661.

Singleton, A. T. and C. J. C. Reason, 2006: Numerical Simulations of a Severe Rainfall event over the Eastern Cape coast of South Africa: Sensitivity to sea surface temperature and topography. Tellus A, 58, 355-367.

Singleton, A. T. and C. J. C. Reason, 2007: A numerical model study of an intense cut-off low pressure system over South Africa. Monthly Weather Review, 135, 1128-1150.

Skamarock, W. C., M. L.Weisman, and J. B. Klemp 1994: Three-dimensional evolution of simulated long-lived squall lines, Journal of the Atmospheric Sciences, 51, 2563-2584. 
Stensrud, D. J., 1996a: Importance of low level jets to climate: A review. Journal of Climate, 9, 1698-1711.

Stensrud, D. J., 1996b: Effects of persistent, midlatitude mesoscale regions of convection on the large scale environment during the warm season. Journal of the Atmospheric Sciences, 53, 3503-3527.

Stensrud, D. J. and J. M. Fritsch, 1993: Mesoscale convective systems in weakly forced large-scale environments. Part I: Observations. Monthly Weather Review, 121, 33263344 .

Stensrud, D. J. and J. M. Fritsch, 1994: Mesoscale convective systems in weakly forced large-scale environments. Part II: Generation of a Mesoscale Initial Condition. Monthly Weather Review, 121, 2068-2083.

Su, F., Y. Hong, and D. P. Lettenmaier, 2008: Evaluation of TRMM Multisatellite Precipitation Analysis (TMPA) and its utility in Hydrologic Prediction in the La Plata Basin. Journal of Hydrometeorology, 9, 622-640.

Tapper, N. and L. Hurry, 1993: Australia's Weather Patterns: An Introductory Guide. Mount Waverley, Victoria, 130pp.

Tennant, W. 2004: Considerations when using pre-1979 NCEP/NCAR reanalyses in the southern hemisphere, Geophysical Research Letters. 31, L11112, doi:10.1029/2004GL019751.

Tennant, W. J. and B. C. Hewitson, 2002: Intra-seasonal rainfall characteristics and their importance to the seasonal prediction problem. International Journal of Climatology, 22, 1033-1084. 
Tian, Y., C. Peters-Lidard, B. J. Choudhury, and M. Garcia, 2007: Multitemporal analysis of TRMM-based satellite precipitation products for land data assimilation applications, Journal of Hydrometeorology. 8, 1165-1183.

Todd, M. C. and R. Washington, 1999: Circulation anomalies with tropical-temperate troughs in Southern Africa and the South West Indian Ocean. Climate Dynamics, 15, 937-951.

Todd, M. C., R. Washington, and P. I. Palmer, 2004: Water vapour transport associated with tropical-temperate trough systems over Southern Africa and the Southwest Indian Ocean. International Journal of Climatology, 24, 555-568.

Tollerud, E. I. and D. Bartels, 1988: A comparative study of the environment of severeweather-producing mesoscale convective systems: MCCs, meso-beta systems, and large convective lines. Preprints, 15th conference on Severe Local Storms, 18-22 Feb., Baltimore, MD, American Meteorological Society, 544-547.

Tollerud, E. I. and R. S. Collander, 1993: A ten year summary of severe weather in mesoscale convective complexes. Preprints, $17^{\text {th }}$ Conference on severe local storms, St. Louis, MO, American Meteorological Society. 533-537.

Tollerud, E. I., J. A. Augustine and B. D. Jamison, 1992: Cloud top characteristics of mesoscale convective systems in 1986. Preprints, Sixth conference on Satellite Meteorology and Oceanography, Atlanta, GA, American Meteorological Society. J3-J7.

Toracinta, E. R. and E. J. Zipser, 2001: Lightning and SSM/I-ice-scattering mesoscale convective systems in the global tropics. Journal of Applied Meteorology, 40, 983-1002.

Trenberth, K. E., and C. J. Guillemot, 1995: Evaluation of the global atmospheric moisture budget as seen from analyses. Journal of Climate, 8, 2255-2272. 
Trier, S. B., C. A. Davis, and J. D. Tuttle, 2000a: Long-Lived Mesoconvective Vortices and Their Environment. Part I: Observations from the Central United States during the 1998 Warm Season. Monthly Weather Review, 128, 3376-3395.

Trier, S. B., C. A. Davis, and W. C. Skamarock. 2000b: Long-Lived Mesoconvective Vortices and Their Environment. Part II: Induced Thermodynamic Destabilization in Idealized Simulations. Monthly Weather Review, 128, 3396-3411.

Trier, S. B., C. A. Davis, D. A. Ahijevych, M. L. Weisman, G. H. Bryan, 2006: Mechanisms Supporting Long-Lived Episodes of Propagating Nocturnal Convection within a 7-Day WRF Model Simulation. Journal of the Atmospheric Sciences, 63, 24372461.

Tucker, D. F. and K. S. Zentmire, 1999: On the Forecasting of Orogenic Mesoscale Convective Complexes. Weather and Forecasting, 14, 1017-1022.

Tyson, P. D. and R. A. Preston-Whyte, 2000: The atmosphere and weather of southern Africa. Oxford University press. Cape Town. 396pp.

Uccellini, L. W., 1980: On the role of upper tropospheric jet streaks and leeside genesis in the development of low-level jets in the Great Plains. Monthly Weather Review, 108, 1689-1696.

van Delden, A., 2001: The synoptic setting of thunderstorms in western Europe, Atmospheric Research, 56, 89-110.

Velasco, I. and J. M. Fritsch, 1987: Mesoscale convective complexes in the Americas. Journal of Geophysical Research, 92, 9591-9613.

Vera, C., J. Baez, M. Douglas, C. B. Emmanuel, J. Marengo, J. Meitin, M. Nicolini, J. Nogues-Paegle, J. Paegle, O. Penalba, P. Salio, C. Saulo, M. A. Silva Dias, P. Silva Dias, 
and E. Zipser, 2005: The South American low-level jet experiment (SALLJEX). Bulletin of the American Meteorology Society, 89, 63-77.

Vigaud, N., Y. Richard, M. Rouault, N. Fauchereau, 2009: Moisture transport between the South Atlantic Ocean and Southern Africa: relationships with summer rainfall and associated dynamics. Climate Dynamics, 32, 113-123.

Villarini, G. and W. Krajewski, 2007: Evaluation of the research version TMPA threehourly $0.25^{\circ}$ x $0.25^{\circ}$ rainfall estimates over Oklahoma. Geophysical Research Letters, 34: doi: 10.1029/2006GL029147.

Walker, N. D., 1990: Links between South African summer rainfall and temperature variability of the Agulhas and Benguela system. Journal of Geophysical Research, 95, $3297-3319$.

Walters, C. K. and J. A. Wilkins, 2001: Airflow Configurations of Warm Season Southerly Low-Level Wind Maxima in the Great Plains. Part I: Spatial and Temporal Characteristics and Relationship to Convection. Weather and Forecasting, 16, 513-530

Washington, R., and M. C. Todd, 1999: Tropical-temperature links in Southern African and Southwest Indian Ocean satellite-derived daily rainfall. International Journal of Climatology, 19, 1602-1616.

Washington, R. and A. Preston, 2006: Extreme wet years over Southern Africa: role of Indian Ocean Sea Surface Temperatures. Journal of Geophysical Research, 111, DOI:10.1029/2005JD00672415.

Weisman, M. L., 1992: The role of convectively generated rear-inflow jets in the evolution of long-lived mesoscale convective systems. Journal of the Atmospheric Sciences, 49, 1826 - 1847. 
Weisman, M. L., 1993: The genesis of severe, long-lived bow-echoes. Journal of the Atmospheric Sciences, 50, 645-670.

Weisman, M. L., and J. B. Klemp, 1982: The Dependence of Numerically Simulated Convective Storms on Vertical Wind Shear and Buoyancy. Monthly Weather Review, $110,504-520$.

Weisman, M. L., and J. B. Klemp, 1986: Characteristics of Convective Storms. Mesoscale Meteorology and Forecasting. P.S. Ray, Ed., American Meteorology Society, 331-358.

Weisman, M. L. and C. A. Davis, 1998: Mechanisms for the generation of mesoscale vortices within quasi-linear convective systems. Journal of the Atmospheric Sciences, 55, $2603-2622$.

Welch, B. L., 1947: The generalization of "Student's" problem when several different population variances are involved. Biometrika, 34, 28-35.

Williams, M. and R. A. Houze Jr., 1987: Satellite-observed characteristics of winter monsoon cloud clusters. Monthly Weather Review, 115, 505-519.

Wolff, D. B. and B. L. Fisher, 2008: Comparisons of Instantaneous TRMM Ground Validation and Satellite Rain-Rate Estimates at Different Spatial Scales. Journal of Applied Meteorology and Climatology, 47, 2215-2237

Wolff, D. B. and B. L. Fisher, 2009: Assessing the Relative Performance of MicrowaveBased Satellite Rain-Rate Retrievals Using TRMM Ground Validation Data. Journal of Applied Meteorology and Climatology, 48, 1069-1099. 
Wolff, D. B., D. Marks, E. Amitai, D. S. Silberman, A. Tokay, J. L. Pippitt, and J. Wang 2005: Ground validation for the Tropical Rainfall Measuring Mission (TRMM). Journal of Atmospheric and. Oceanic Technology, 22, 365-380

Woodley, W. L., C. G. Griffith, J. S. Griffin and S. C. Stromatt, 1980: The inference of GATE convective rainfall from SMS-1 imagery. Journal of Applied Meteorology, 19, 388-408.

Zar, J. H., 2010: Biostatistical Analysis. Fifth Edition. Pearson Prentice-Hall, Upper Saddle River, NJ, 944pp.

Zhang, D.-L. and J. M. Fritsch, 1988: A numerical simulation of a convectively generated inertially stable, warm core extratropical mesovortex over land. Monthly Weather Review, 116, 2660-2687.

Ziegler, C. L., 2000: Issues in forecasting mesoscale convective systems: An observational and modelling perspective. Storms vol. II. Pielke Jr., RA and RA Pielke Sr., Eds., Routledge, London, 26-42.

Zipser, E. J., 1982: Use of a conceptual model of the life-cycle of mesoscale convective systems to improve very-short-range forecasts. Nowcasting. K.A. Browning, Ed., Academic Press, London, 191-204.

Zipser, E. J., D. J. Cecil, C. Liu, S. W. Nesbitt and D. P. Yorty, 2006: Where are the most intense thunderstorms on Earth? Bulletin of the American Meteorology Society, 87, 10571071. 
Appendices 
Appendix A - MCCs over southern Africa

\begin{tabular}{|c|c|c|c|c|c|c|c|}
\hline \multirow[b]{2}{*}{ System No. } & (yyyymmdd) & \multicolumn{4}{|c|}{$\begin{array}{l}\text { Time } \\
\text { (UTC) }\end{array}$} & \multirow{2}{*}{$\begin{array}{c}\text { (hours) } \\
\text { Duration }\end{array}$} & \multirow{2}{*}{$\begin{array}{c}\left(\mathrm{km}^{2}\right) \\
\text { Max. Area }\end{array}$} \\
\hline & Date* $^{*}$ & First Storms & Initiation & Maximum & Termination & & \\
\hline 1 & 19981115 & 1200 & 1300 & 1530 & 1900 & 6 & 118356 \\
\hline 2 & 19981214 & 1330 & 1900 & 2330 & 100 & 6 & 70794 \\
\hline 3 & 19981227 & 1300 & 1500 & 1700 & 2200 & 7 & 141325 \\
\hline 4 & 19981229 & 1530 & 2300 & 300 & 630 & 7.5 & 91932 \\
\hline 5 & 19981231 & 1530 & 1530 & 2330 & 0 & 8.5 & 230538 \\
\hline 6 & 19990203 & 1800 & 1930 & 2330 & 430 & 9 & 120678 \\
\hline 7 & 19990204 & 1730 & 1800 & 2300 & 530 & 11.5 & 134237 \\
\hline 8 & 19990223 & 2200 & 230 & 730 & 930 & 7 & 173565 \\
\hline 9 & 19991117 & 1300 & 0 & 2000 & 1500 & 15 & 64283 \\
\hline 10 & 19991125 & 1100 & 1230 & 1630 & 0 & 11.5 & 120214 \\
\hline 11 & 19991127 & 1600 & 2200 & 200 & 400 & 6 & 117064 \\
\hline 12 & 19991205 & 1630 & 2030 & 2300 & 500 & 8.5 & 71398 \\
\hline 13 & 19991221 & 1830 & 1930 & 230 & 530 & 10 & 107902 \\
\hline 14 & 19991223 & 2000 & 30 & 300 & 630 & 6 & 99084 \\
\hline 15 & 19991227 & 1100 & 1300 & 1630 & 2000 & 7 & 106062 \\
\hline 16 & 19991231 & 1700 & 1800 & 2330 & 0 & 6 & 117863 \\
\hline 17 & 20000106 & 1700 & 1700 & 1730 & 100 & 8 & 81586 \\
\hline 18 & 20000109 & 0 & 0 & 0 & 630 & 6.5 & 215184 \\
\hline 19 & 20000117 & 1530 & 1530 & 0 & 330 & 12 & 139627 \\
\hline 20 & 20000127 & 1900 & 1900 & 1900 & 400 & 9 & 85303 \\
\hline 21 & 20000128 & 1730 & 1730 & 1900 & 100 & 7.5 & 116552 \\
\hline 22 & 20000204 & 1700 & 1930 & 100 & 1330 & 18 & 130941 \\
\hline 23 & 20000205 & 1430 & 1900 & 300 & 1300 & 18 & 117077 \\
\hline 24 & 20000208 & 1230 & 1230 & 1700 & 30 & 12 & 133344 \\
\hline 25 & 20000315 & 1830 & 2200 & 400 & 1330 & 15.5 & 97399 \\
\hline 26 & 20000318 & 1500 & 2100 & 330 & 900 & 12 & 139203 \\
\hline 27 & 20001102 & 1400 & 1700 & 2130 & 0 & 7 & 86783 \\
\hline 28 & 20001113 & 1300 & 1530 & 2030 & 200 & 10.5 & 113552 \\
\hline 29 & 20010205 & 1730 & 1900 & 130 & 1330 & 18 & 193568 \\
\hline 30 & 20010213 & 1600 & 1630 & 1600 & 230 & 10 & 113297 \\
\hline 31 & 20010219 & 1200 & 1500 & 1800 & 1430 & 23.5 & 176475 \\
\hline 32 & 20010221 & 1930 & 2000 & 100 & 500 & 9 & 102057 \\
\hline 33 & 20011120 & 1130 & 1230 & 1530 & 1900 & 6.5 & 109023 \\
\hline 34 & 20011124 & 200 & 930 & 1400 & 1530 & 6 & 57439 \\
\hline 35 & 20011202 & 1930 & 2100 & 1930 & 330 & 7 & 106355 \\
\hline 36 & 20011211 & 1600 & 1600 & 0 & 330 & 11.5 & 283280 \\
\hline 37 & 20020103 & 1500 & 1730 & 2100 & 2300 & 6 & 72770 \\
\hline 38 & 20020114 & 1800 & 1900 & 2300 & 130 & 7.5 & 101642 \\
\hline 39 & 20020130 & 1300 & 1530 & 2200 & 100 & 9.5 & 113060 \\
\hline 40 & 20030205 & 1430 & 1600 & 2300 & 600 & 14 & 153920 \\
\hline 41 & 20030219 & 1930 & 2130 & 1930 & 700 & 9.5 & 132608 \\
\hline 42 & 20030221 & 300 & 2200 & 800 & 1100 & 13 & 145132 \\
\hline 43 & 20030306 & 1200 & 1330 & 1830 & 2000 & 6.5 & 71094 \\
\hline 44 & 20031105 & 1100 & 1400 & 1800 & 2000 & 6 & 80132 \\
\hline
\end{tabular}




\begin{tabular}{|c|c|c|c|c|c|c|c|}
\hline \multirow[b]{2}{*}{ System No. } & \multirow{2}{*}{$\frac{\text { (yyyymmdd) }}{\text { Date* }^{*}}$} & \multicolumn{3}{|c|}{$\begin{array}{l}\text { Time } \\
\text { (UTC) }\end{array}$} & & \multirow{2}{*}{$\frac{\text { (hours) }}{\text { Duration }}$} & \multirow{2}{*}{$\frac{\left(\mathrm{km}^{2}\right)}{\text { Max. Area }}$} \\
\hline & & First Storms & Initiation & Maximum & Termination & & \\
\hline 45 & 20031129 & 1530 & 1700 & 2000 & 30 & 7.5 & 86947 \\
\hline 46 & 20031210 & 1030 & 1430 & 1730 & 2200 & 7.5 & 98265 \\
\hline 47 & 20031212 & 2300 & 700 & 1100 & 1330 & 6.5 & 60480 \\
\hline 48 & 20031214 & 1030 & 1230 & 1430 & 2000 & 6.5 & 116815 \\
\hline 49 & 20031221 & 1300 & 1430 & 1830 & 2330 & 9 & 172160 \\
\hline 50 & 20031225 & 2230 & 2230 & 330 & 500 & 6.5 & 75008 \\
\hline 51 & 20040122 & 2130 & 2300 & 230 & 800 & 9 & 83261 \\
\hline 52 & 20040124 & 130 & 2200 & 230 & 730 & 10 & 216512 \\
\hline 53 & 20040223 & 1930 & 2200 & 430 & 700 & 9 & 117288 \\
\hline 54 & 20041111 & 1430 & 1600 & 1900 & 330 & 11.5 & 112991 \\
\hline 55 & 20041114 & 1300 & 1500 & 1730 & 2200 & 7 & 91335 \\
\hline 56 & 20041121 & 1100 & 1330 & 2330 & 730 & 18 & 155685 \\
\hline 57 & 20041127 & 1300 & 1530 & 1800 & 2200 & 6.5 & 163092 \\
\hline 58 & 20041128 & 1330 & 1600 & 1700 & 2300 & 7 & 197600 \\
\hline 59 & 20041202 & 1530 & 1930 & 2230 & 530 & 10 & 86328 \\
\hline 60 & 20050123 & 1330 & 1500 & 2300 & 330 & 12.5 & 157375 \\
\hline 61 & 20050219 & 1400 & 1930 & 2300 & 300 & 7.5 & 78038 \\
\hline 62 & 20051122 & 2200 & 2330 & 200 & 600 & 6.5 & 118827 \\
\hline 63 & 20051122 & 1230 & 1400 & 1800 & 2000 & 6 & 88334 \\
\hline 64 & 20051127 & 1400 & 1900 & 30 & 130 & 6.5 & 58225 \\
\hline 65 & 20051218 & 230 & 430 & 730 & 1130 & 7 & 80962 \\
\hline 66 & 20060107 & 1730 & 2230 & 130 & 530 & 7 & 112725 \\
\hline 67 & 20060109 & 1500 & 1500 & 500 & 800 & 17 & 232609 \\
\hline 68 & 20060208 & 2200 & 2200 & 2200 & 500 & 7 & 130969 \\
\hline 69 & 20060210 & 1330 & 1930 & 530 & 700 & 11.5 & 151315 \\
\hline 70 & 20060316 & 1500 & 1700 & 2230 & 200 & 9 & 78558 \\
\hline
\end{tabular}

* Date refers to the date on which the system reached maximum extent. 


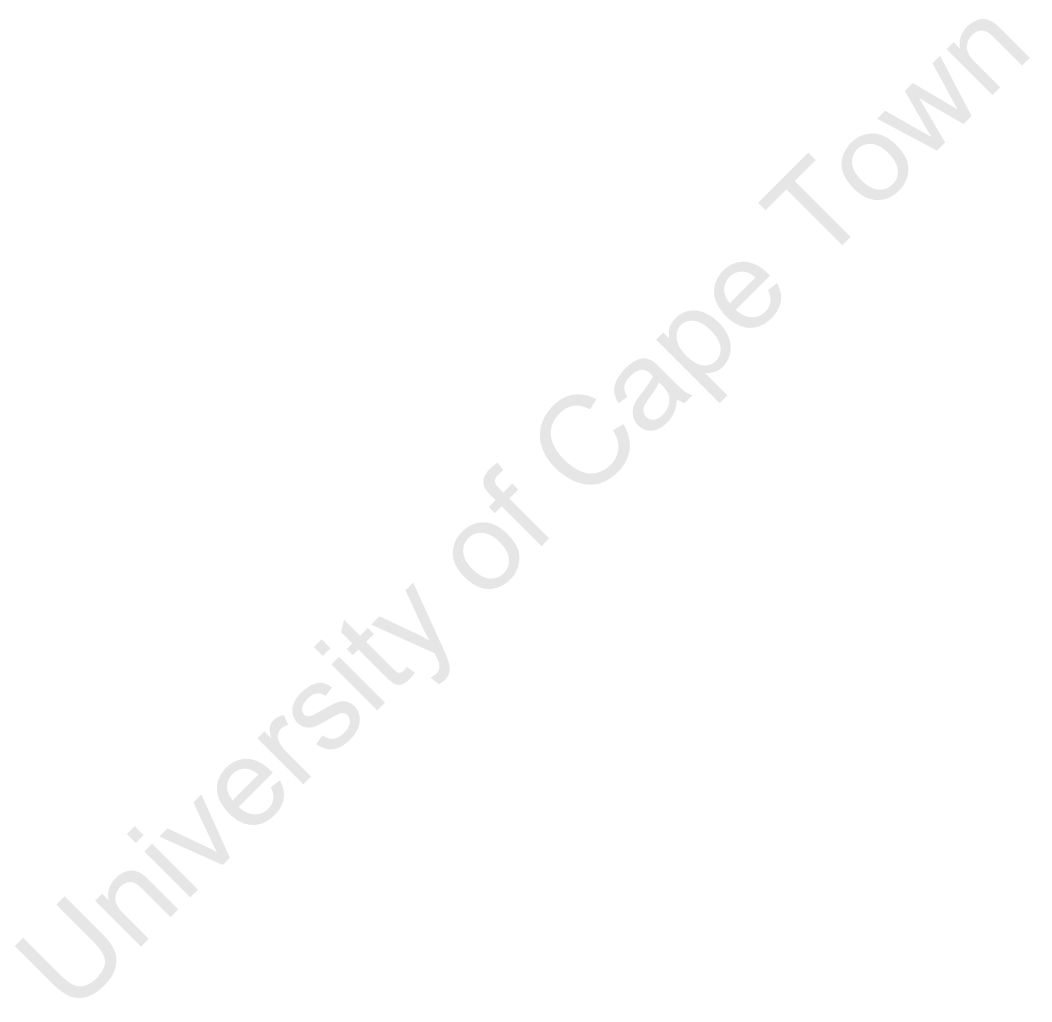




\section{Appendix B - Basic Severe Weather Parameters}

\section{Convective Available Potential Energy (CAPE)}

CAPE represents the amount of buoyant energy created in the process whereby a parcel of air passes its level of free convection and continues to rise due to it becoming warmer than its environment. This energy is then available to accelerate the parcel of air upwards. This parameter is determined from the positive area on a sounding between the parcel's ascent along a moist adiabat and the environmental temperature curve from the level of free convection (LFC) to the equilibrium level (EL).

\section{$E \boldsymbol{L}$$$
\mathrm{CAPE}=\mathrm{g}\{[(\text { Tparcel }- \text { Tenvir }) / \text { Tenvir }] \mathrm{dz}
$$$$
\text { LFC }
$$

Where:

$$
\mathbf{g}=\text { gravity }
$$

$\boldsymbol{E} \boldsymbol{L}=$ equilibrium level

$\boldsymbol{L F C}=$ level of free convection

" $\{$ " = vertical integration between the LFC and the EL

$\mathbf{d z}=$ incremental depth

Tparcel $=$ temperature of a parcel from the lowest $500 \mathrm{~m}$ of the atmosphere, raised dry adiabatically to the LCL and moist adiabatically thereafter

Tenvir $=$ temperature of the environment

\section{CAPE (J Kg $\left.{ }^{-1}\right)$}

\begin{tabular}{|l|l|}
\hline $0 \mathrm{~J} \mathrm{Kg}^{-1}$ & Stable \\
\hline $0-1000 \mathrm{~J} \mathrm{Kg}^{-1}$ & Marginally Unstable \\
\hline $1000-2500 \mathrm{~J} \mathrm{Kg}^{-1}$ & Moderately Unstable \\
\hline $2500-3500 \mathrm{~J} \mathrm{Kg}^{-1}$ & Very Unstable \\
\hline$>3500 \mathrm{~J} \mathrm{Kg}^{-1}$ & Extremely Unstable \\
\hline
\end{tabular}




\section{Lifted Index (LI)}

The LI (Galway 1956) is a measure of stability that expresses the temperature difference between a lifted parcel and the surrounding air at $500 \mathrm{mb}$. It is expressed in degrees Celcius.

\section{$\mathrm{LI}=T(500 \mathrm{mb}$ environment $)-T(500 \mathrm{mb}$ parcel $)$}

\section{LI $\left({ }^{\circ} \mathbf{C}\right)$}

\begin{tabular}{|l|l|}
\hline $0^{\circ}$ to $3^{\circ} \mathrm{C}$ & Stable \\
\hline $0^{\circ}$ to $-3^{\circ} \mathrm{C}$ & marginally unstable \\
\hline$-3^{\circ}$ to $-6^{\circ} \mathrm{C}$ & moderately unstable \\
\hline$-6^{\circ}$ to $-9^{\circ} \mathrm{C}$ & very unstable \\
\hline$<-9^{\circ} \mathrm{C}$ & extremely Unstable \\
\hline
\end{tabular}

\section{Total Totals Index (TT)}

This method uses the combination of two other parameters, which are Vertical Totals (VT) and the Cross Totals (CT). The former represents static stability (lapse rate) between 850 and $500 \mathrm{mb}$ while the latter includes the $850 \mathrm{mb}$ dewpoint. This then results in the TT being calculated as:

$$
\mathrm{TT}=\left(T d_{850}-T_{500}\right)+\left(T_{850}-T_{500}\right)
$$

Where:

$T_{850}$ - Temperature in Celsius at $850 \mathrm{mb}$

$T d_{850}$ - Dewpoint in Celsius at $850 \mathrm{mb}$

$T_{500}$ - Temperature in Celsius at $500 \mathrm{mb}$ 


\section{TT $\left({ }^{\circ} \mathrm{C}\right)$}

\begin{tabular}{|l|l|}
\hline 45 to 50 & Thunderstorms Possible \\
\hline 50 to 55 & $\begin{array}{l}\text { Thunderstorms likely, possibly } \\
\text { severe }\end{array}$ \\
\hline 55 to 60 & Severe thunderstorms most likely \\
\hline
\end{tabular}

\section{Severe Weather Threat Index (SWEAT)}

The SWEAT Index (Miller 1972) evaluates the potential for severe weather by combining several parameters into one index. The index includes variables for wind speed and vertical wind shear as well as thermodynamic variables, such as low level moisture.

$$
\text { SWEAT }=T d_{850}+20(T T-49)+2\left(V_{850}\right)+V_{500}+125(\text { Shear }+0.2)
$$

Where:

$T d_{850}-$ Dew point Temperature at $850 \mathrm{mb}$

$T T$ - Total Totals Index

$V_{850,500}=850 \mathrm{mb}$ and $500 \mathrm{mb}$ wind speed in knots, respectively,

Shear $=\sin (500 \mathrm{mb}-850 \mathrm{mb}$ wind direction in degrees $)$

\section{SWEAT}

\begin{tabular}{|l|l|}
\hline$>300$ & $\begin{array}{l}\text { Potential for Severe } \\
\text { Thunderstorms }\end{array}$ \\
\hline$>400$ & Potential for Tornadoes \\
\hline
\end{tabular}

\section{K-Index (KI)}

The K-Index (George 1960) is used as an indicator for heavy rainfall and possibly flash flooding. In general, the higher the ambient or inflow $\mathrm{K}$ index value, the greater the potential for heavy rain. Due to the index using $700 \mathrm{mb}$ dew point depression, during conditions when there is dry air at the $700 \mathrm{mb}$ level it will result in a low KI value. 
However, at the same time, there may be moisture below $700 \mathrm{mb}$, unstable air and a lifting mechanism which then can produce string thunderstorms and heavy rain.

$$
\mathrm{KI}=T d_{850}+\left(T_{850}-T_{500}\right)-D D_{700}
$$

Where:

$T d_{850}=$ Dew point temperature at $850 \mathrm{mb}$

$T_{850,500}=$ Temperature at $850 \mathrm{mb}$ and $500 \mathrm{mb}$, respectively

$D D_{700}=$ Dewpoint depression at $700 \mathrm{mb}$

\section{KI}

\begin{tabular}{|l|l|}
\hline & Probability of Thunderstorm (\%) \\
\hline$<15$ & 0 \\
\hline 15 to 20 & 20 \\
\hline 21 to 25 & 20 to 40 \\
\hline 26 to 30 & 40 to 60 \\
\hline 31 to 35 & 60 to 80 \\
\hline 36 to 40 & 80 to 90 \\
\hline$>40$ & Near 100 \\
\hline
\end{tabular}

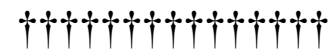




\section{Appendix C - Supplementary Figures}
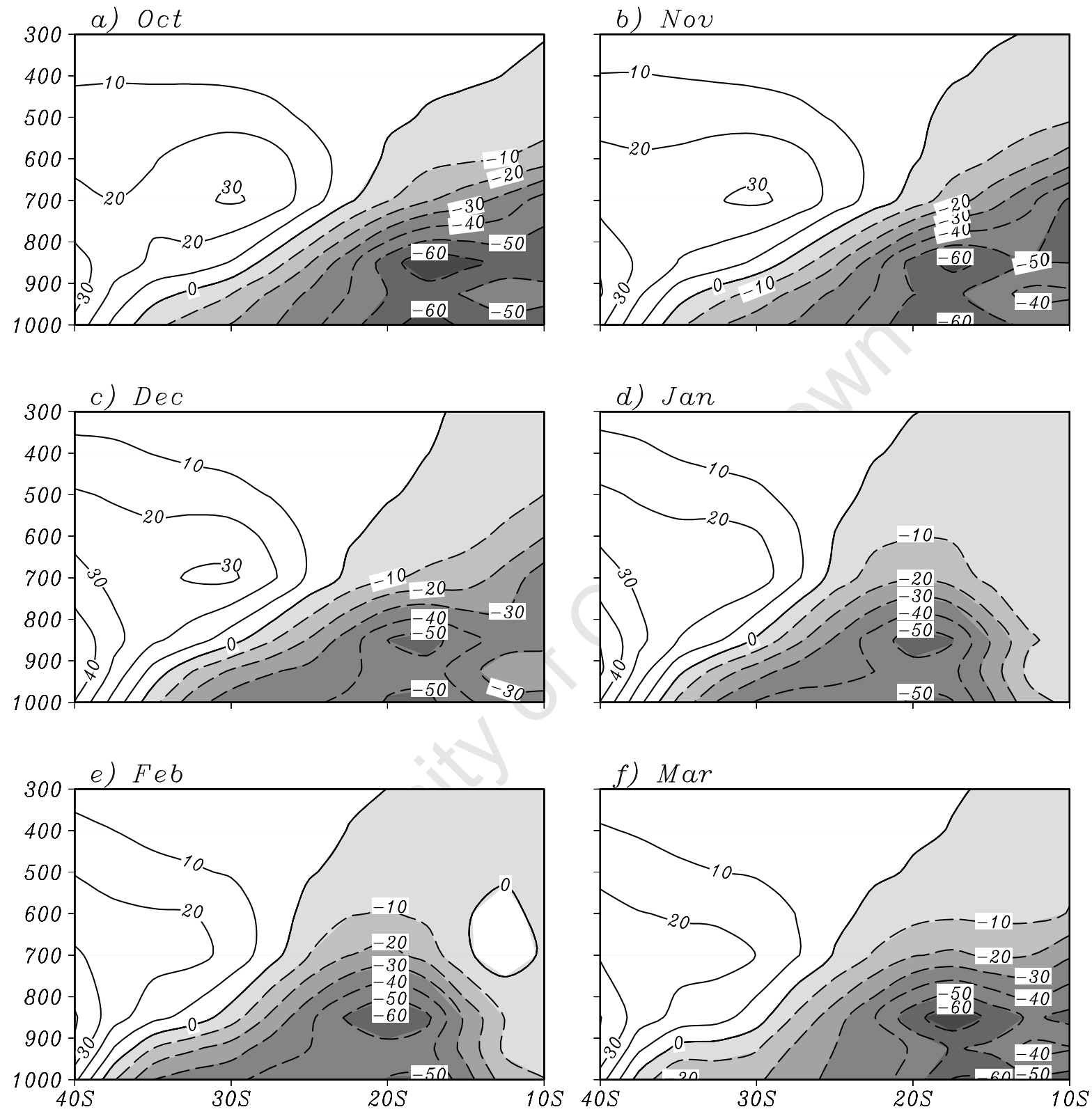

Figure A5.1: Vertical cross-section taken along $30^{\circ} \mathrm{E}$ showing the zonal moisture flux (g. $\left.\mathrm{kg}^{-1} \mathrm{~m} \cdot \mathrm{s}^{-1}\right)$. Easterly flux is shaded with a dash contour, while westerly flux contains just solid contours. 

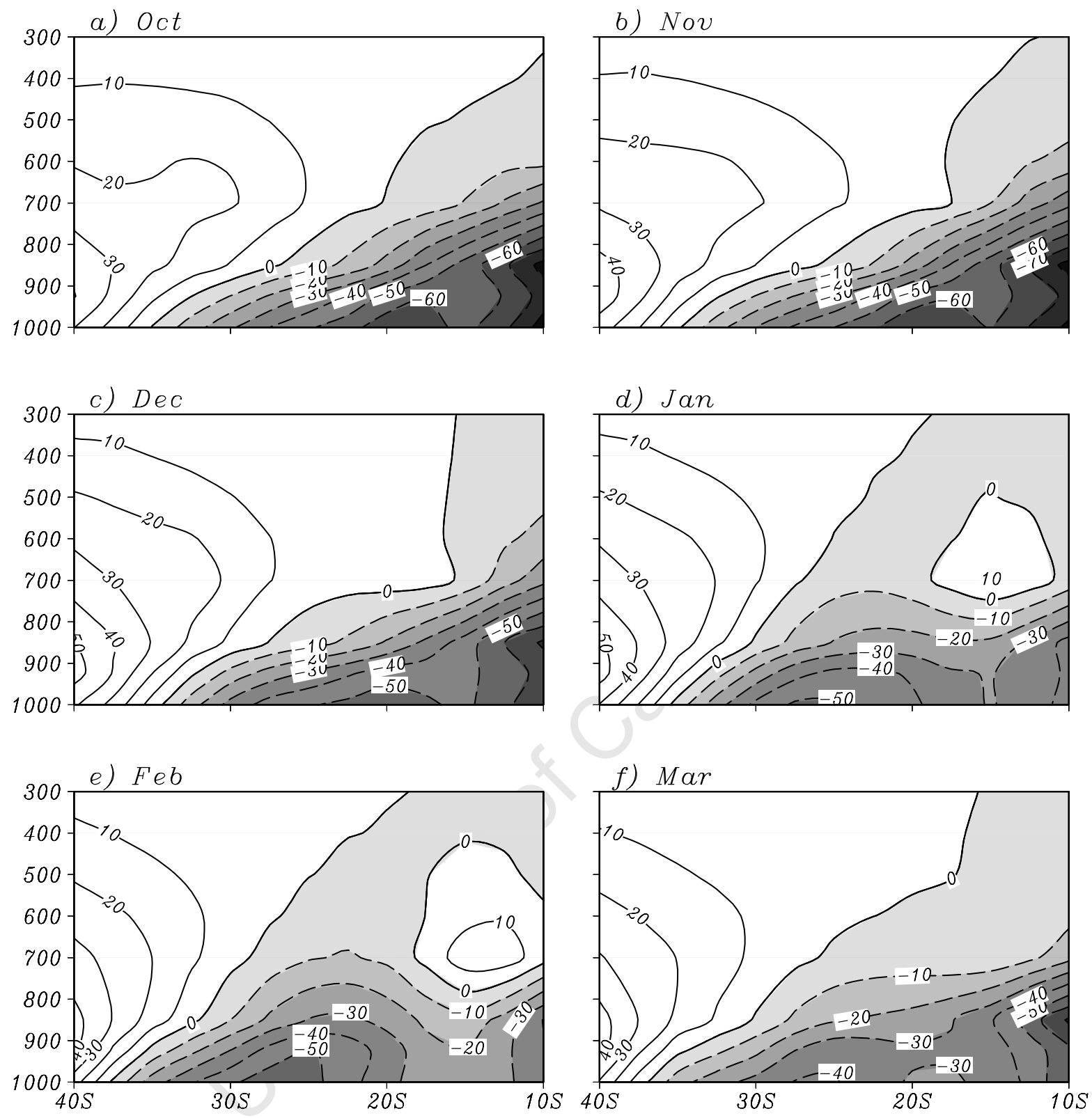

Figure A5.2: Same as Fig. A5.1, but now taken along $35^{\circ} \mathrm{E}$. 

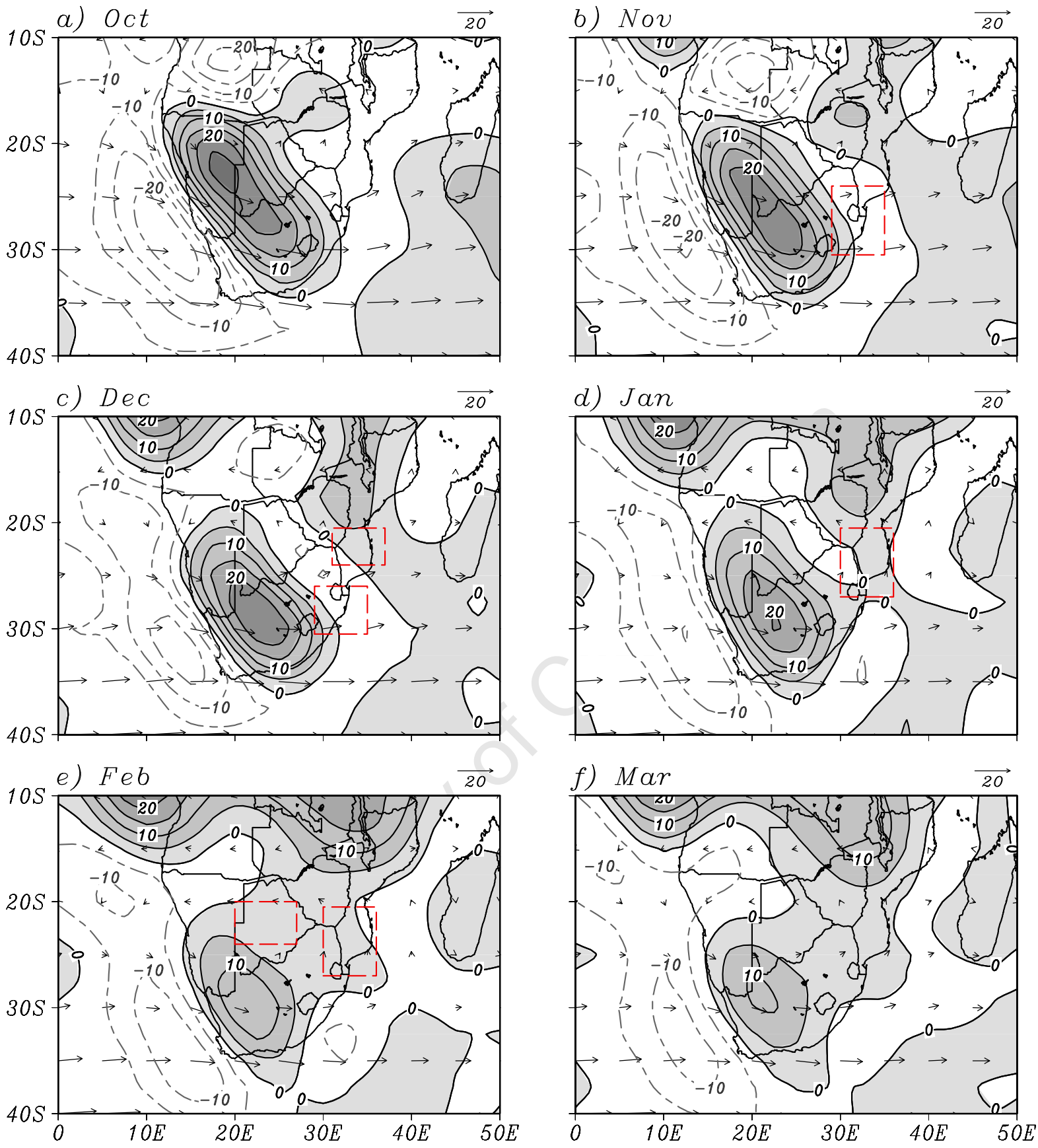

Figure A5.3: Mean $500 \mathrm{mb}$ divergence $\left(\mathrm{x}_{10} 10^{-7} \mathrm{~s}^{-1}\right)$ and vector winds. Divergence (positive values) is shaded with solid contours, while convergence (negative values) is depicted by grey dashed contours. 

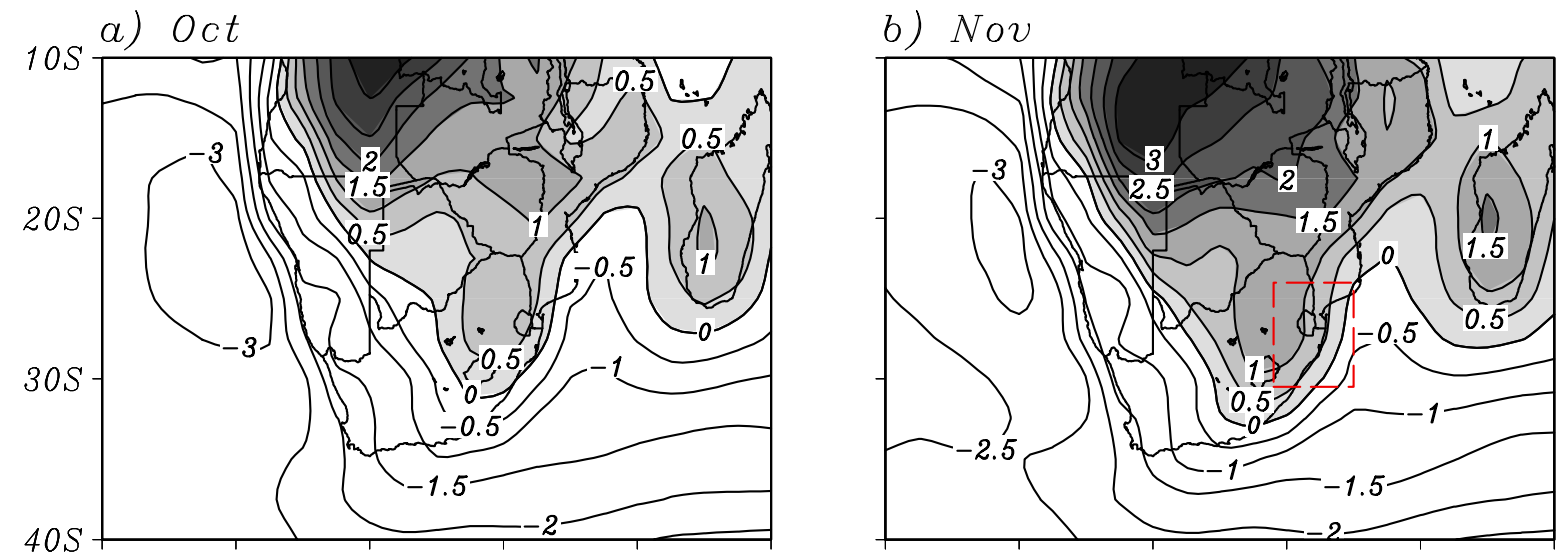

c) $\mathrm{Dec}$

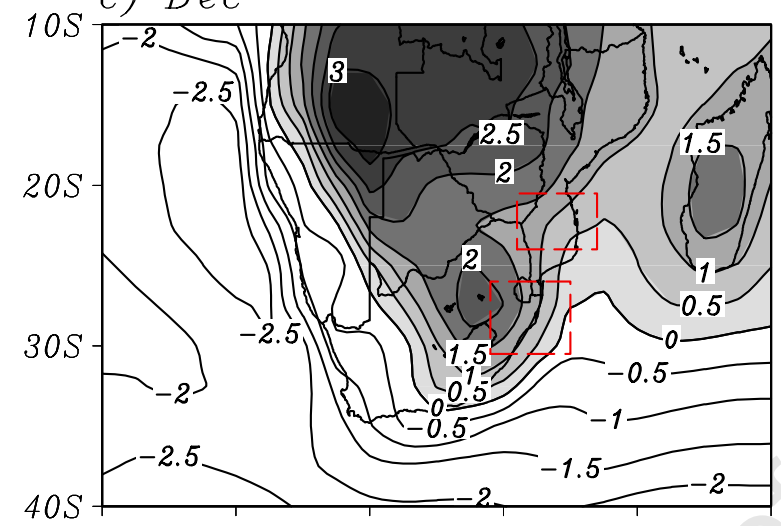

d) Jan

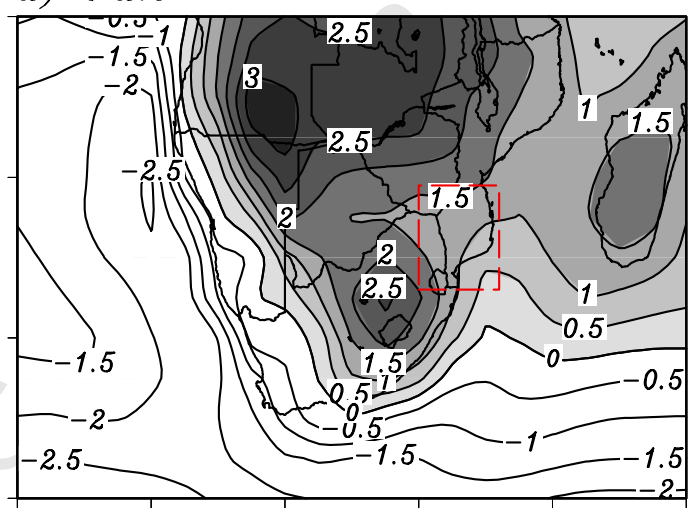

e) $\mathrm{Feb}$

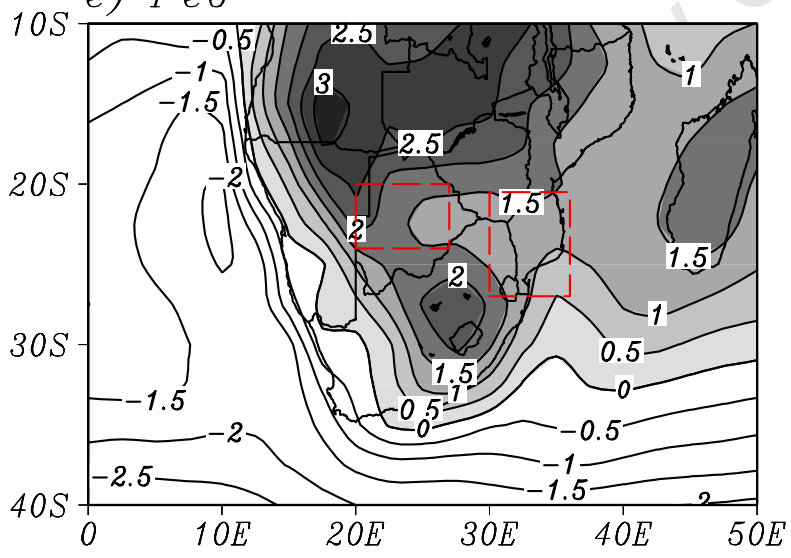

f) $M a r$

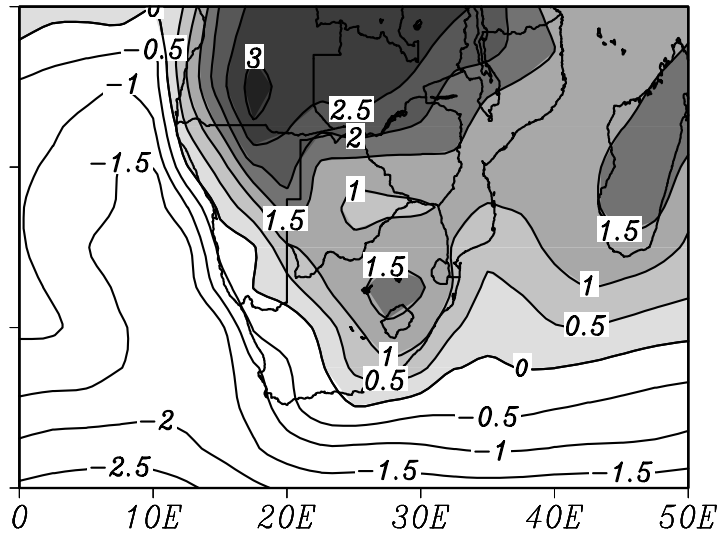

Figure A5.4: Mean monthly potential instability of the 925-500 hPa layer (only positive values are shaded with contours; units are $10^{-3} \mathrm{~K} \mathrm{~m}^{-1}$ ). Positive values indicate potentially unstable regions. 

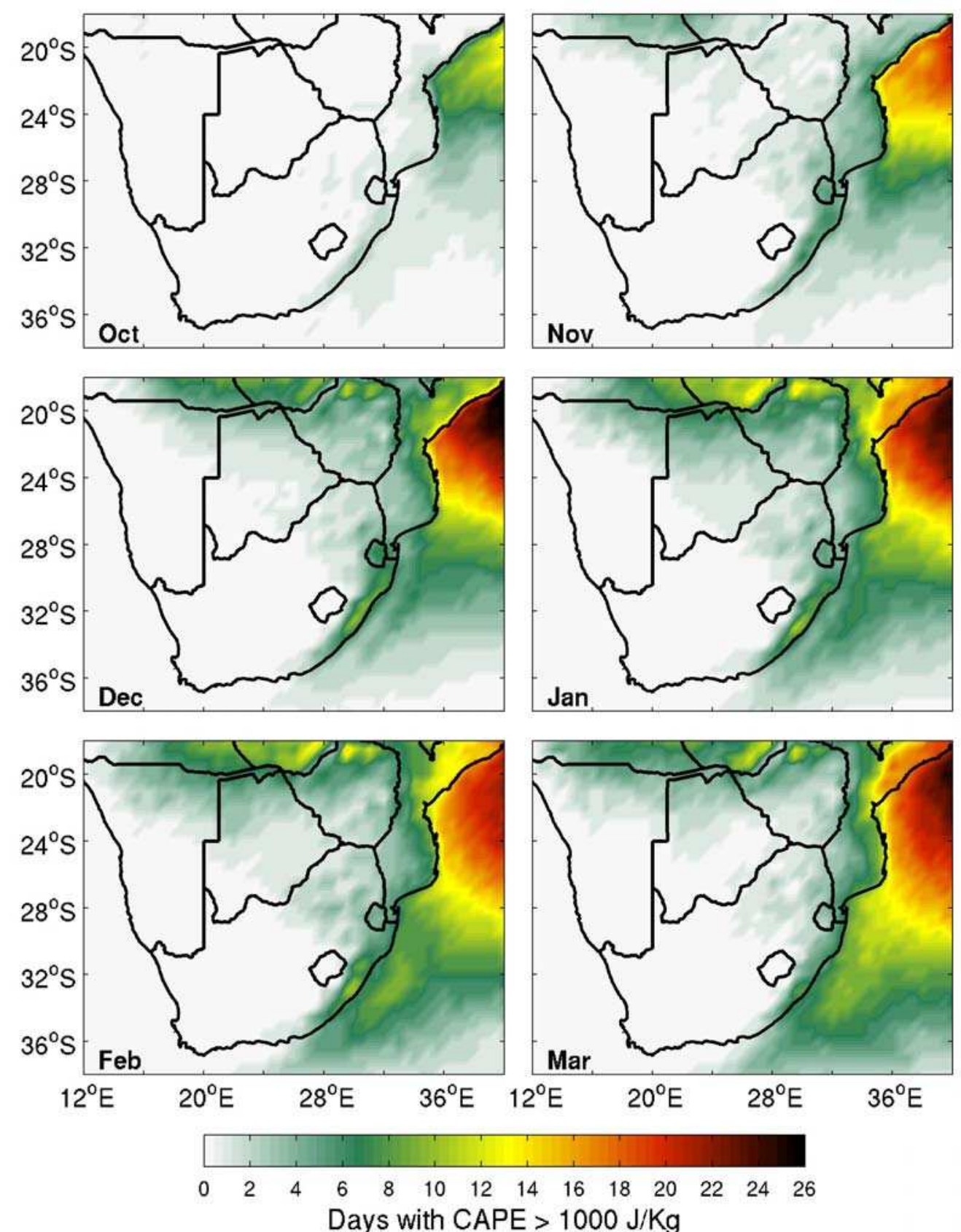

Figure A5.5: The number of days per month at $12 \mathrm{~h} 00$ UTC that contain CAPE $>1000$ J.Kg ${ }^{-1}$. 


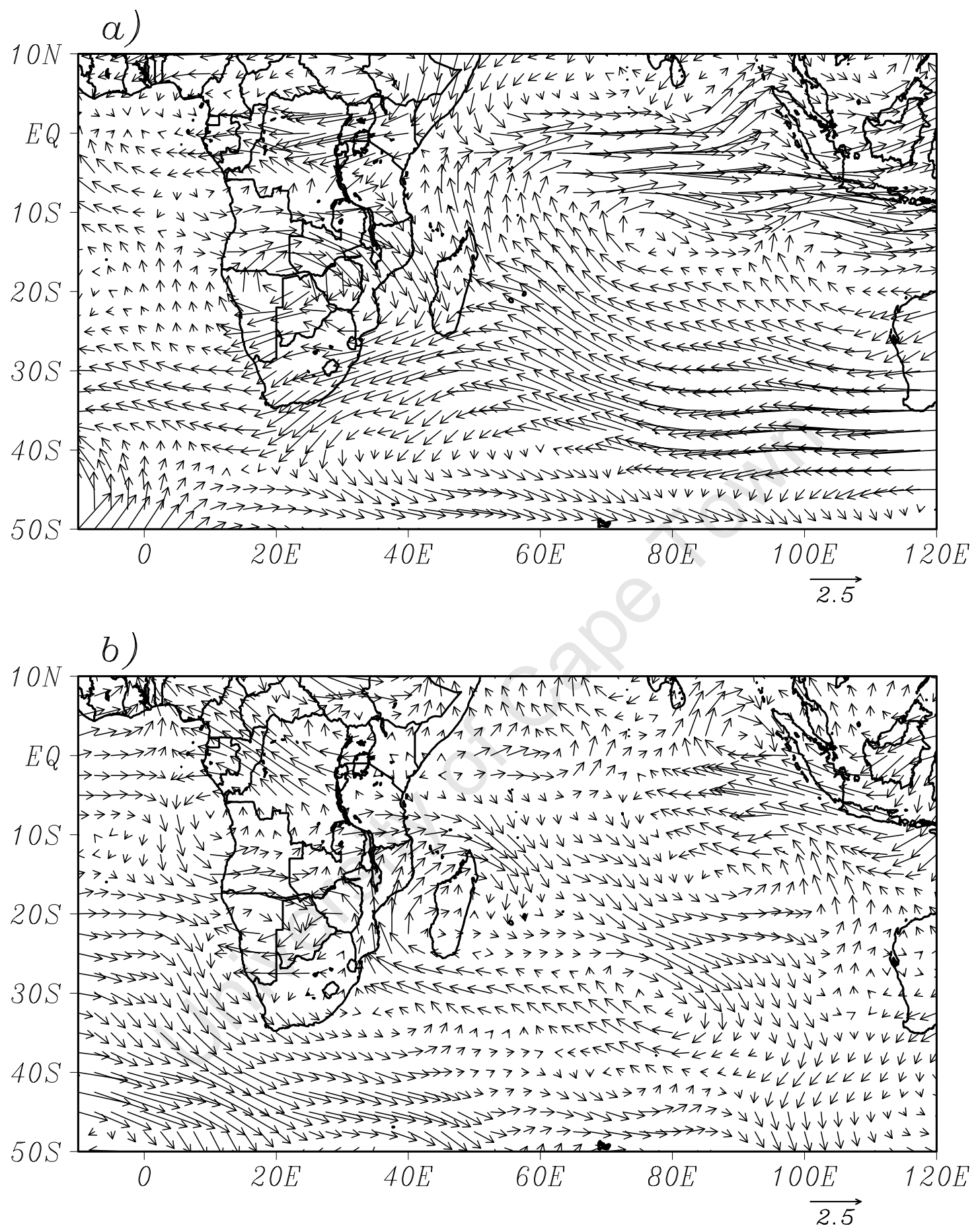

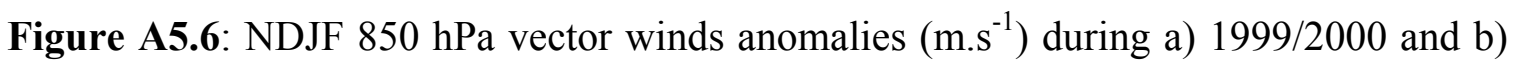
2002/2003. 
a)

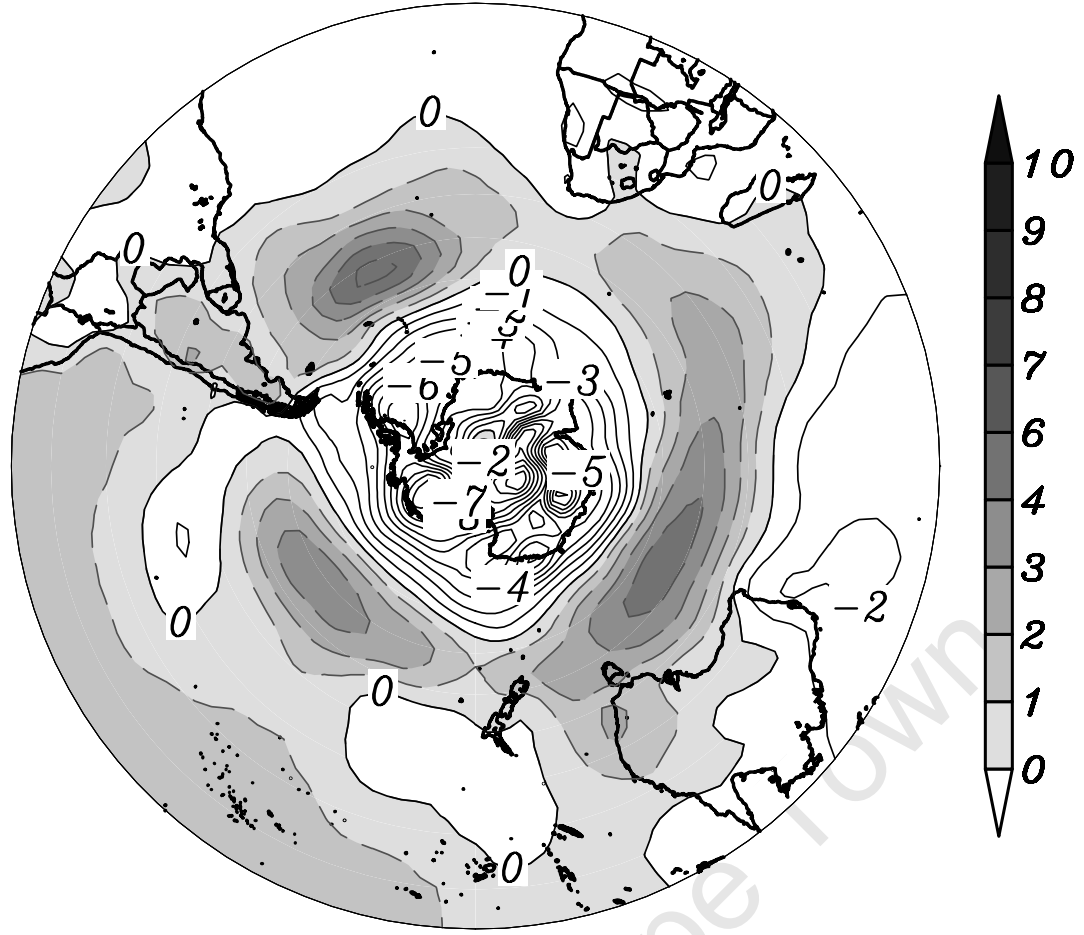

b)

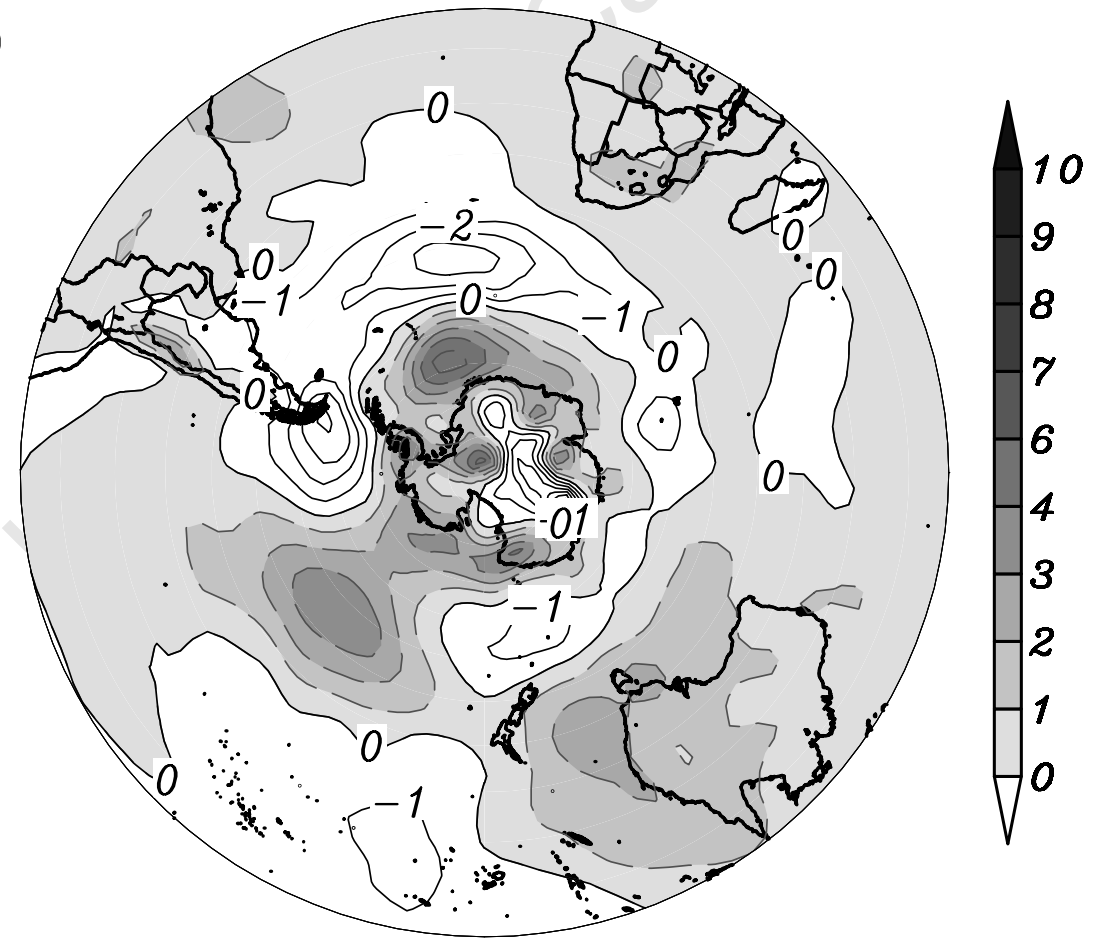

Figure A5.7: Same as Fig. A5.6, but for mean sea level pressure (hPa). 

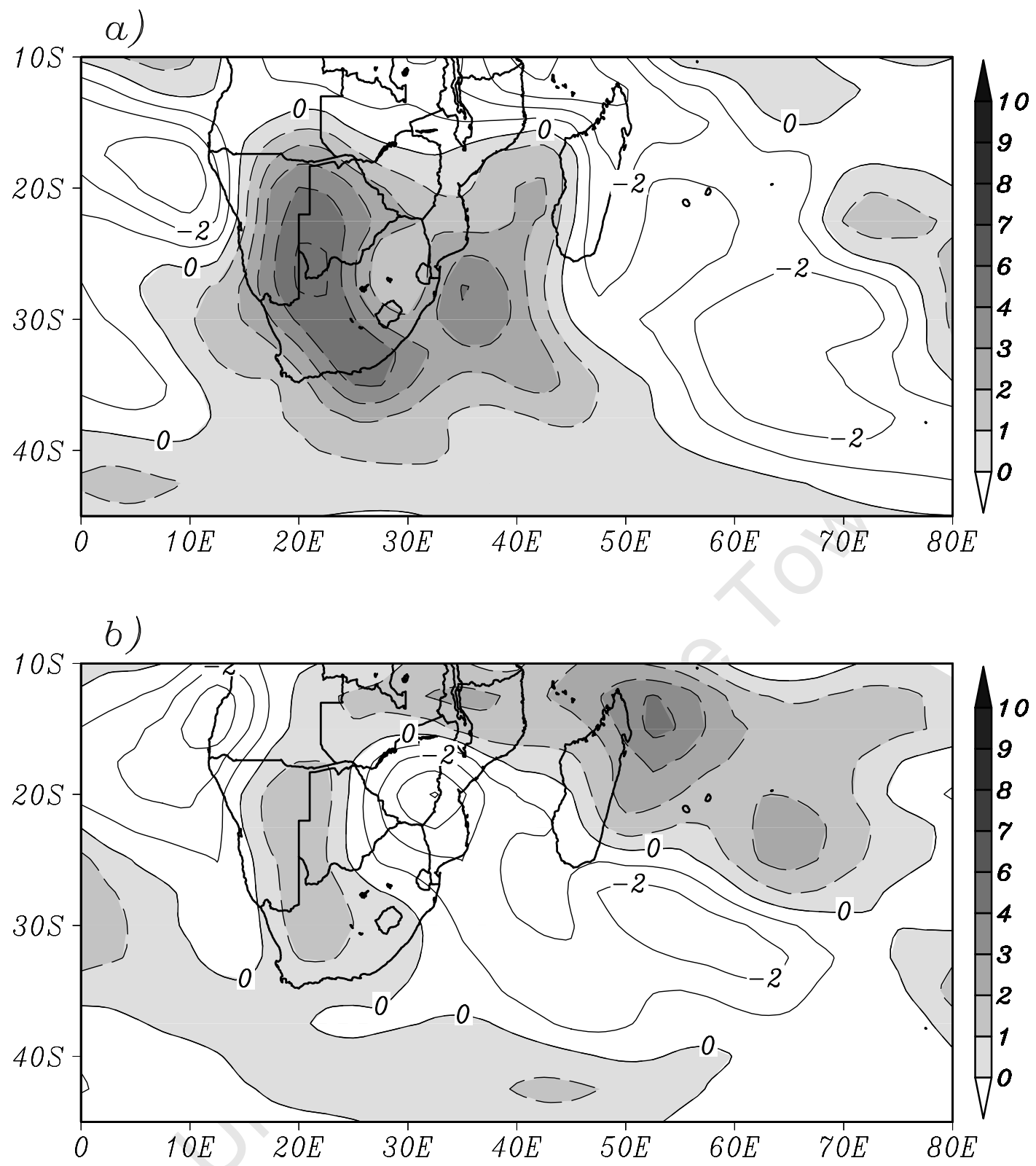

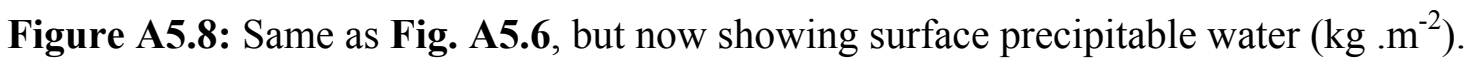



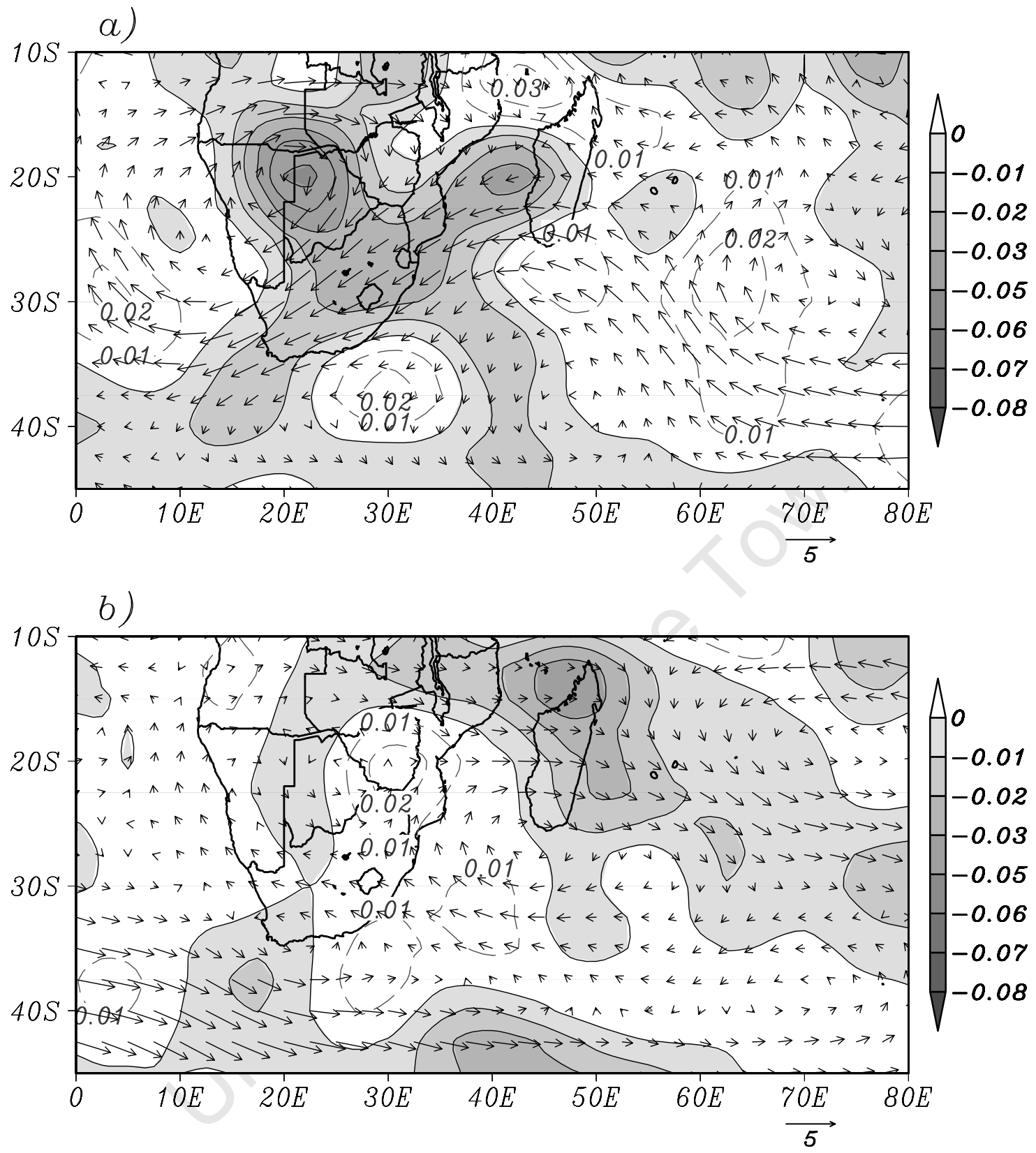

Figure A5.9: Same as Fig. A5.6, but for omega $\left(\mathrm{Pa}_{\mathrm{s}}{ }^{-1}\right)$ and vector winds (vector; $\mathrm{m} . \mathrm{s}^{-1}$ ) at $500 \mathrm{hPa}$. 

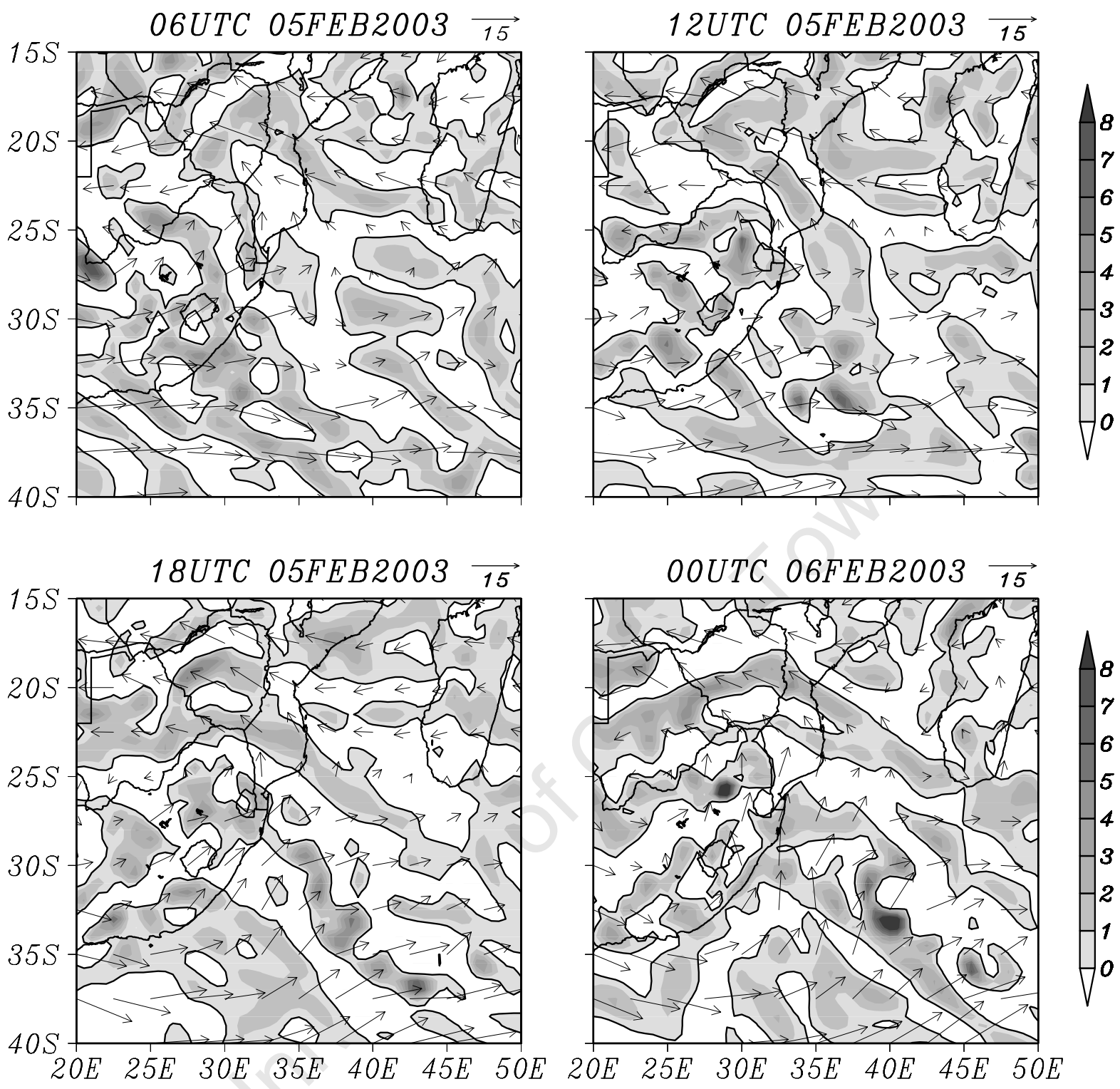

Figure A7.1: Divergence (shaded, x $\left.10^{-5} \mathrm{~s}^{-1}\right)$ and vector winds $\left(\mathrm{m} . \mathrm{s}^{-1}\right)$ at $500 \mathrm{hPa}$. 

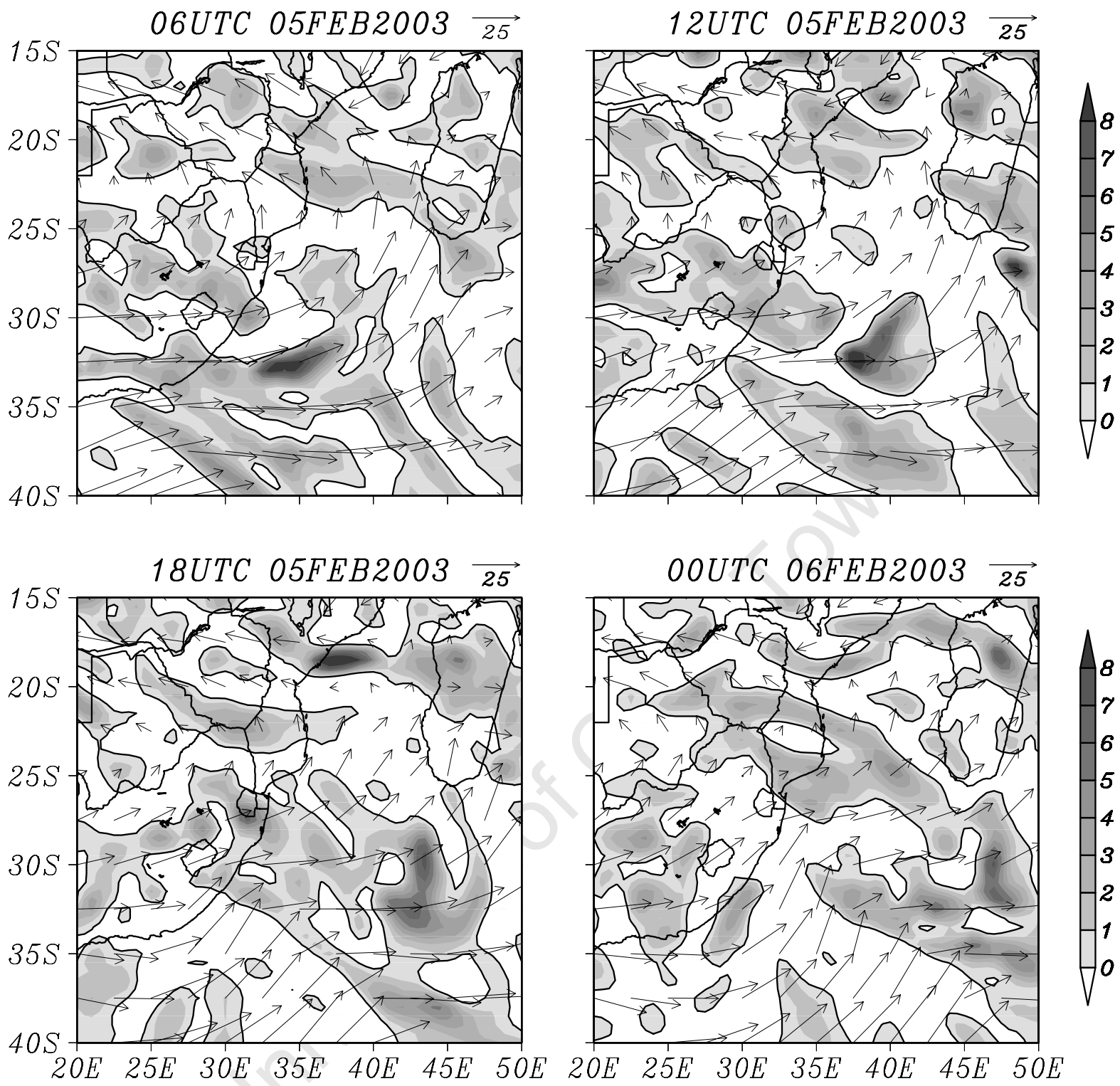

Figure A7.2: Divergence (shaded, x $10^{-5} \mathrm{~s}^{-1}$ ) and vector winds $\left(\mathrm{m}_{\mathrm{s}} \mathrm{s}^{-1}\right.$ ) at $200 \mathrm{hPa}$. 

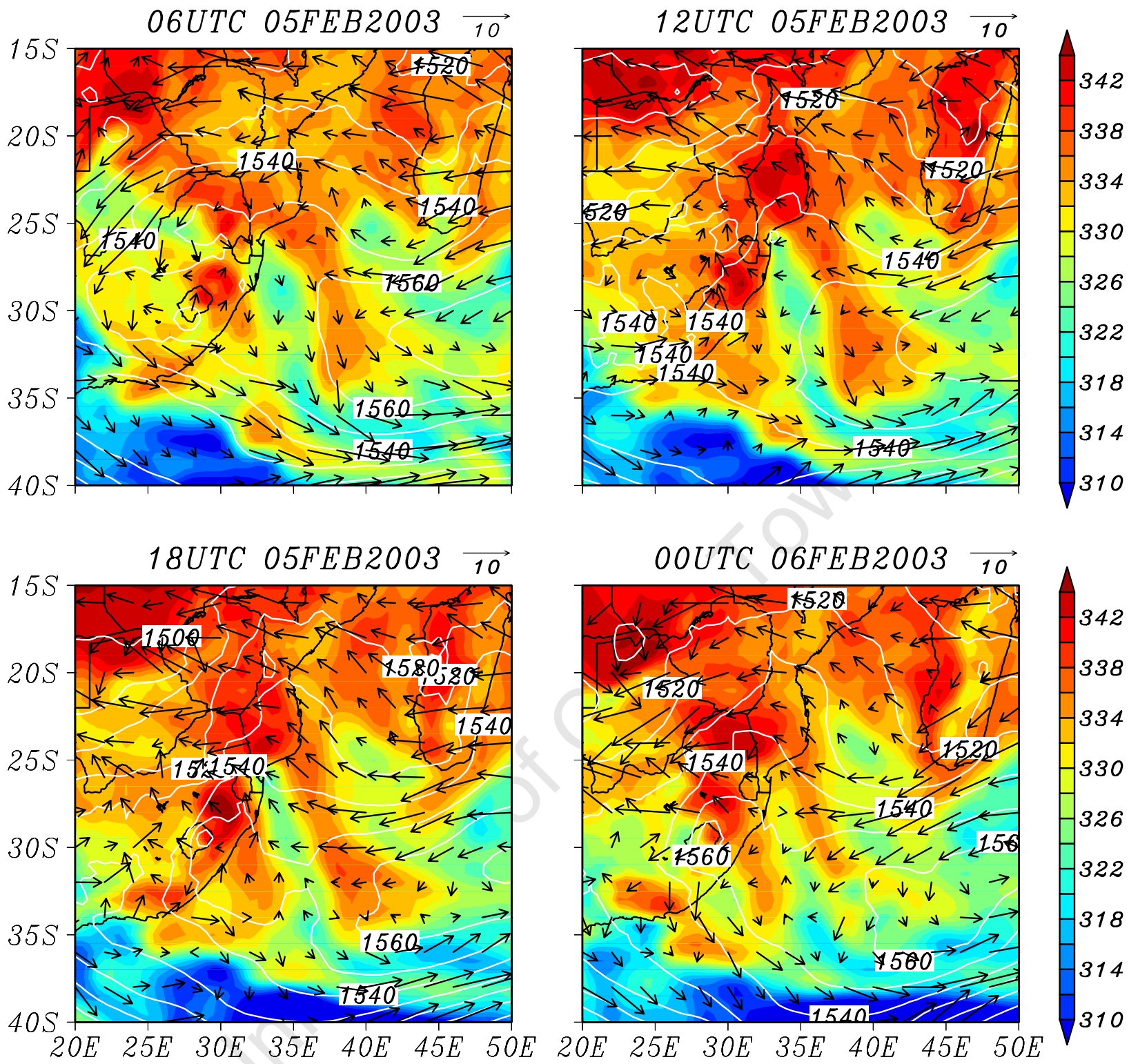

Figure A7.3: Equivalent potential temperature (shaded; units are ${ }^{\circ} \mathrm{K}$ ), geopotential height

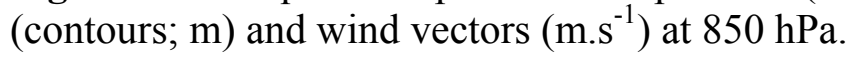



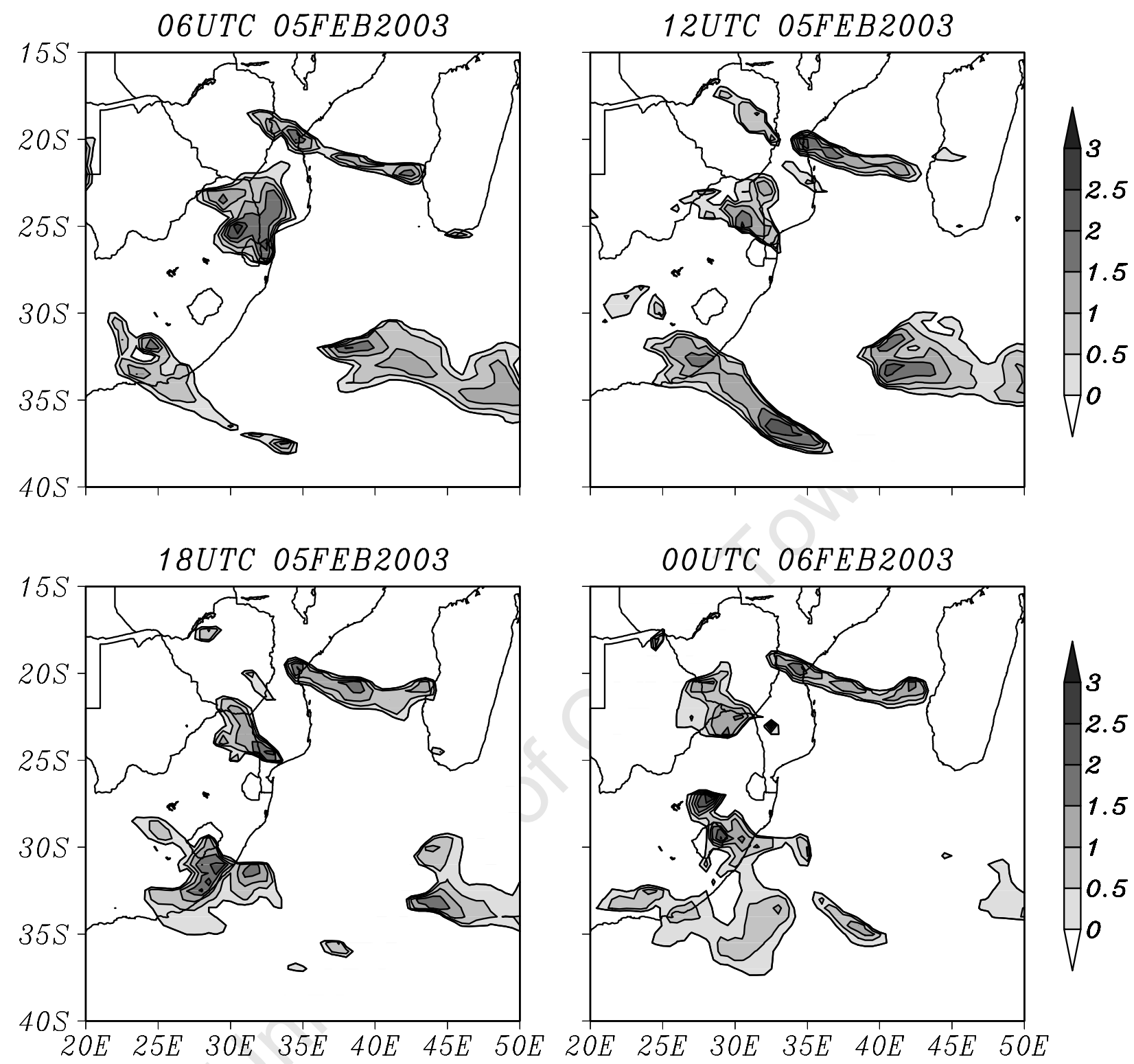

Figure A7.4: Potential instability (shaded, $\mathrm{K} \mathrm{m}^{-1}$ ) calculated between 925 and $500 \mathrm{hPa}$ using equivalent potential temperature and height between the two layers. 

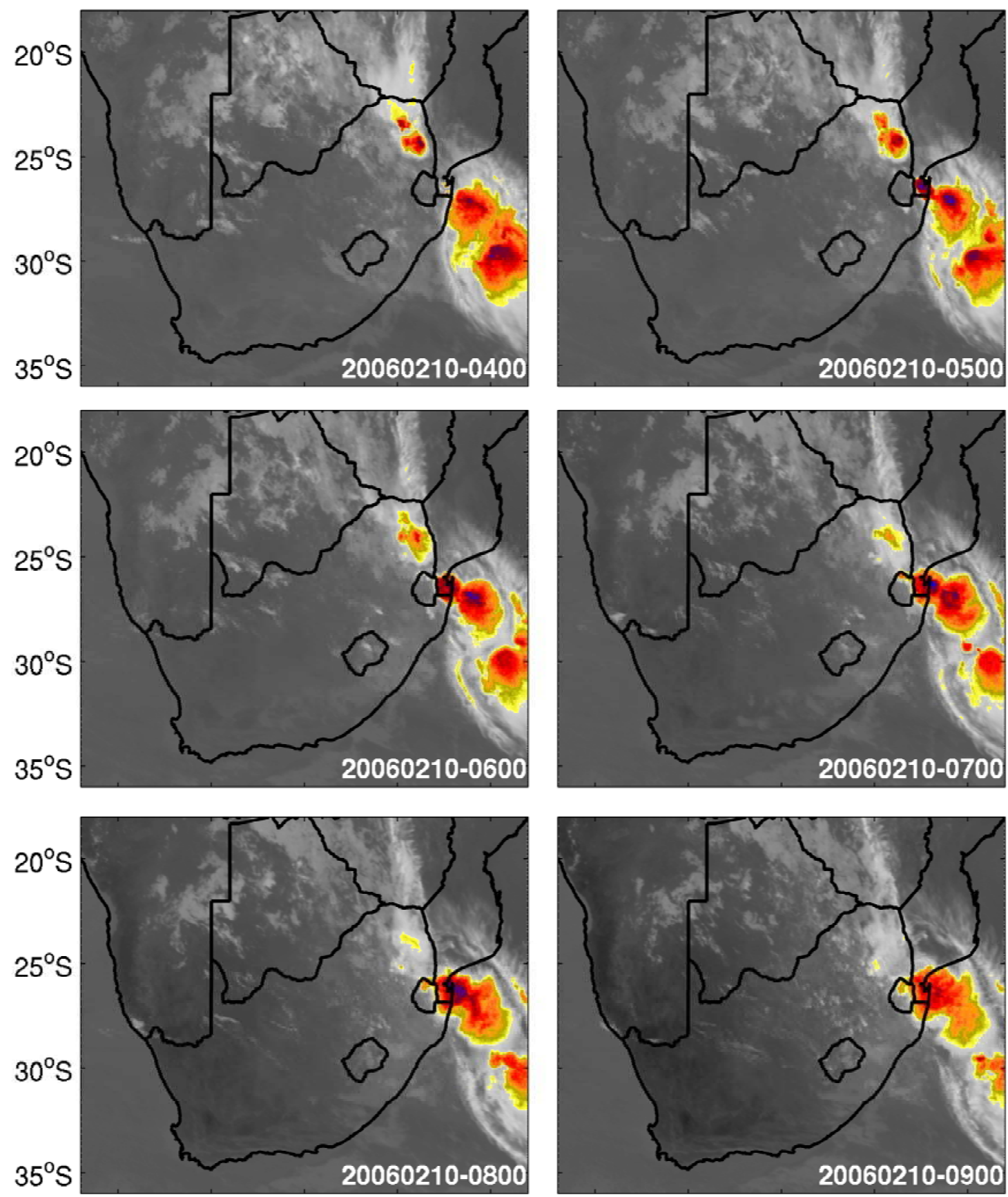

$15^{\circ} \mathrm{E} \quad 20^{\circ} \mathrm{E} \quad 25^{\circ} \mathrm{E} \quad 30^{\circ} \mathrm{E} \quad 35^{\circ} \mathrm{E}$
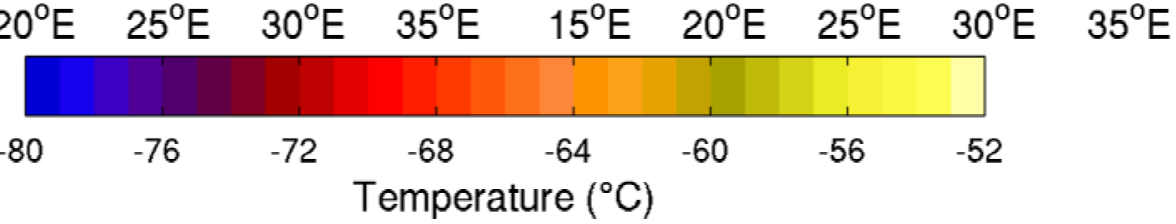

Figure A7.5: Meteosat-7 IR images showing cloud top temperature $\left({ }^{\circ} \mathrm{C}\right)$ of the MCS that took place on 10 February 2006. Times shown are in UTC (LST - 2). 

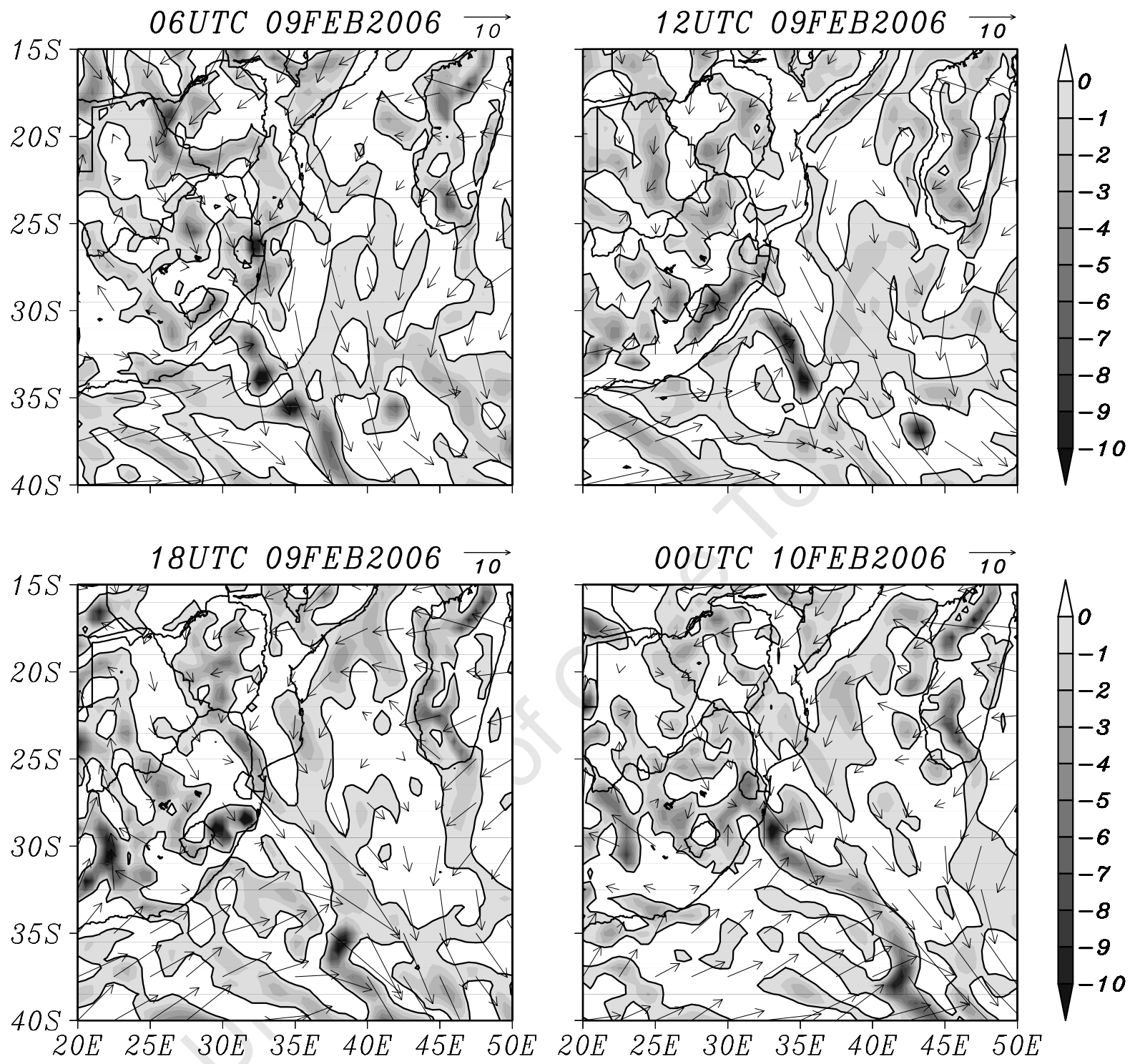

Figure A7.6: Horizontal convergence (shaded, $10^{-5} \mathrm{~s}^{-1}$ ) and vector winds $\left(\mathrm{m} . \mathrm{s}^{-1}\right)$ at 850 $\mathrm{hPa}$. Note that only convergence is shown. 

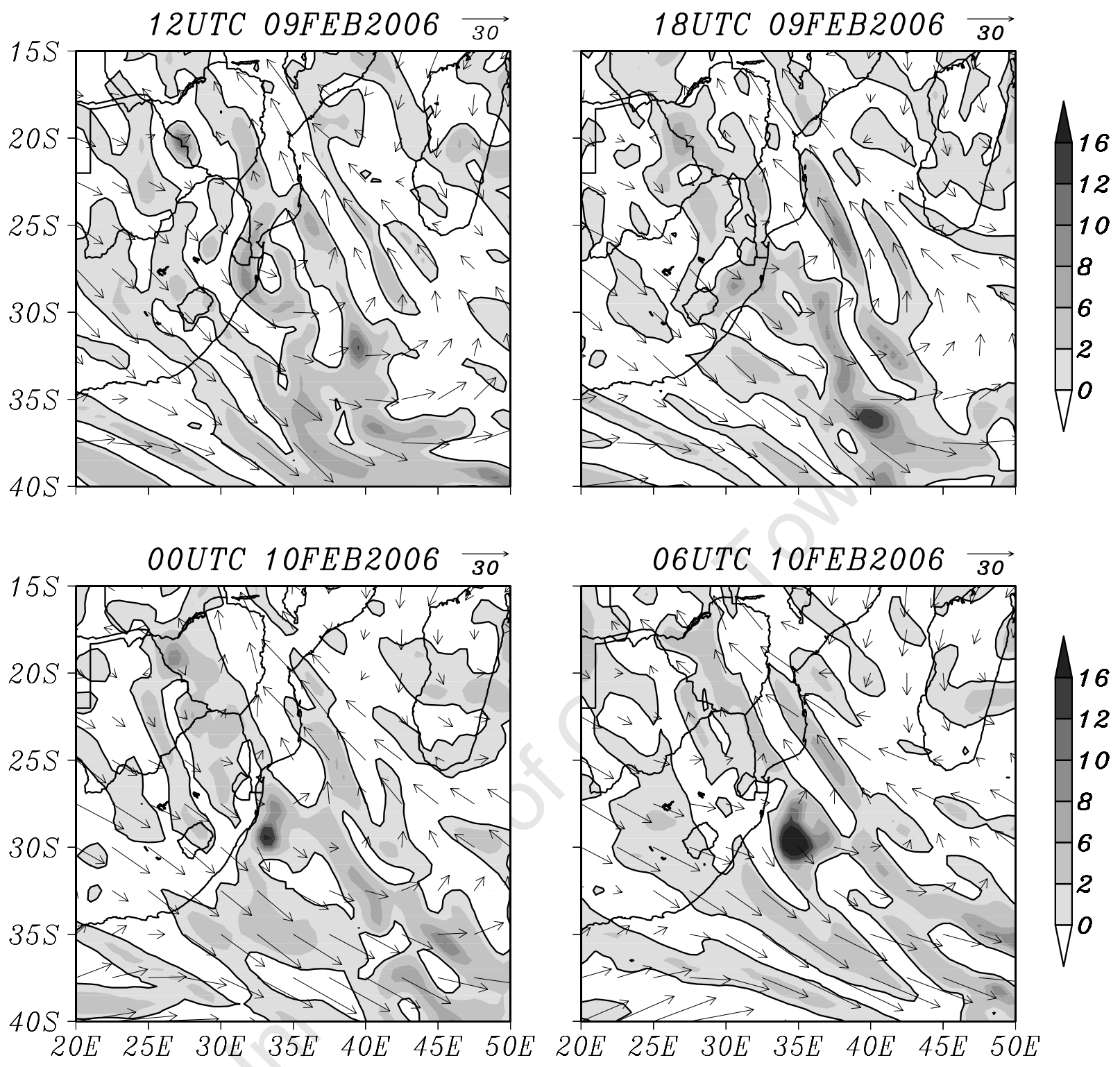

Figure A7.7: Divergence (shaded, $10^{-5} \mathrm{~s}^{-1}$ ) and vector winds $\left(\mathrm{m}_{\mathrm{s}} \mathrm{s}^{-1}\right)$ at $200 \mathrm{hPa}$. 

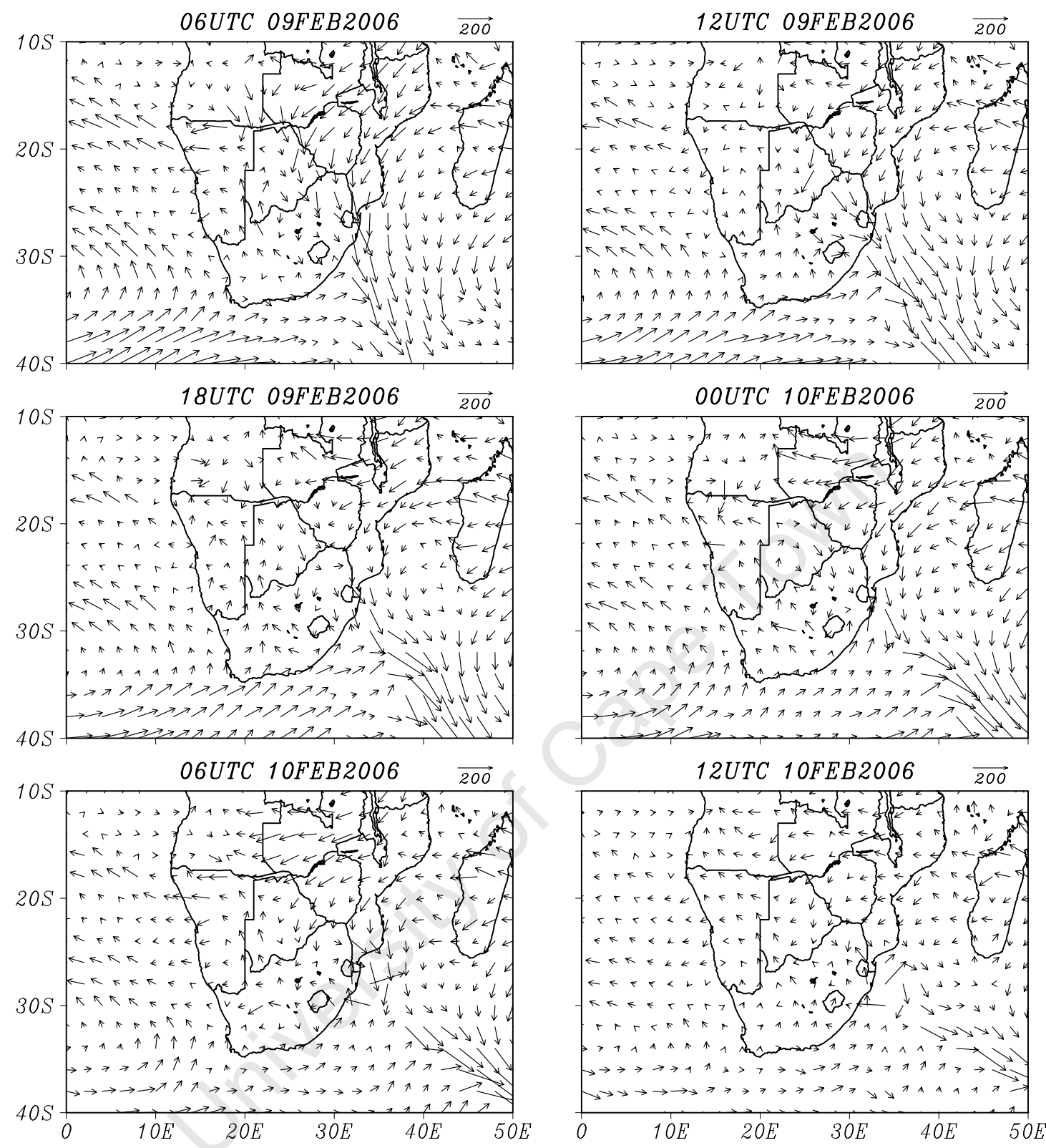

Figure A7.8: Moisture flux (vector arrows; units are g. $\mathrm{kg}^{-1} \mathrm{~m} . \mathrm{s}^{-1}$ ) at $850 \mathrm{hPa}$. 

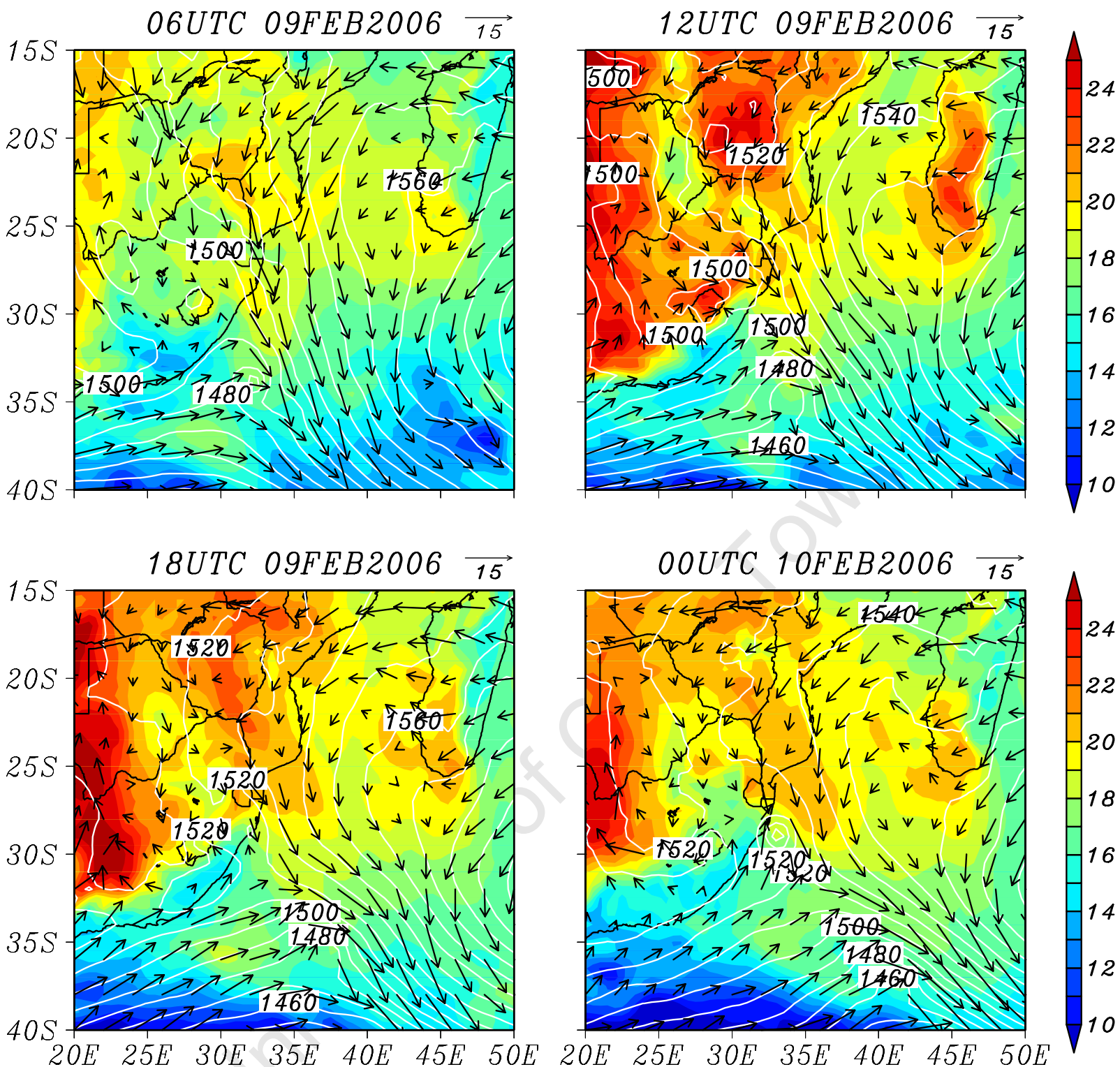

Figure A7.9: Temperature (shaded; ${ }^{\circ} \mathrm{C}$ ), geopotential height (contours; $\mathrm{m}$ ) and wind vectors $\left(\mathrm{m}^{-1} \mathrm{~s}^{-1}\right)$ at $850 \mathrm{hPa}$. 

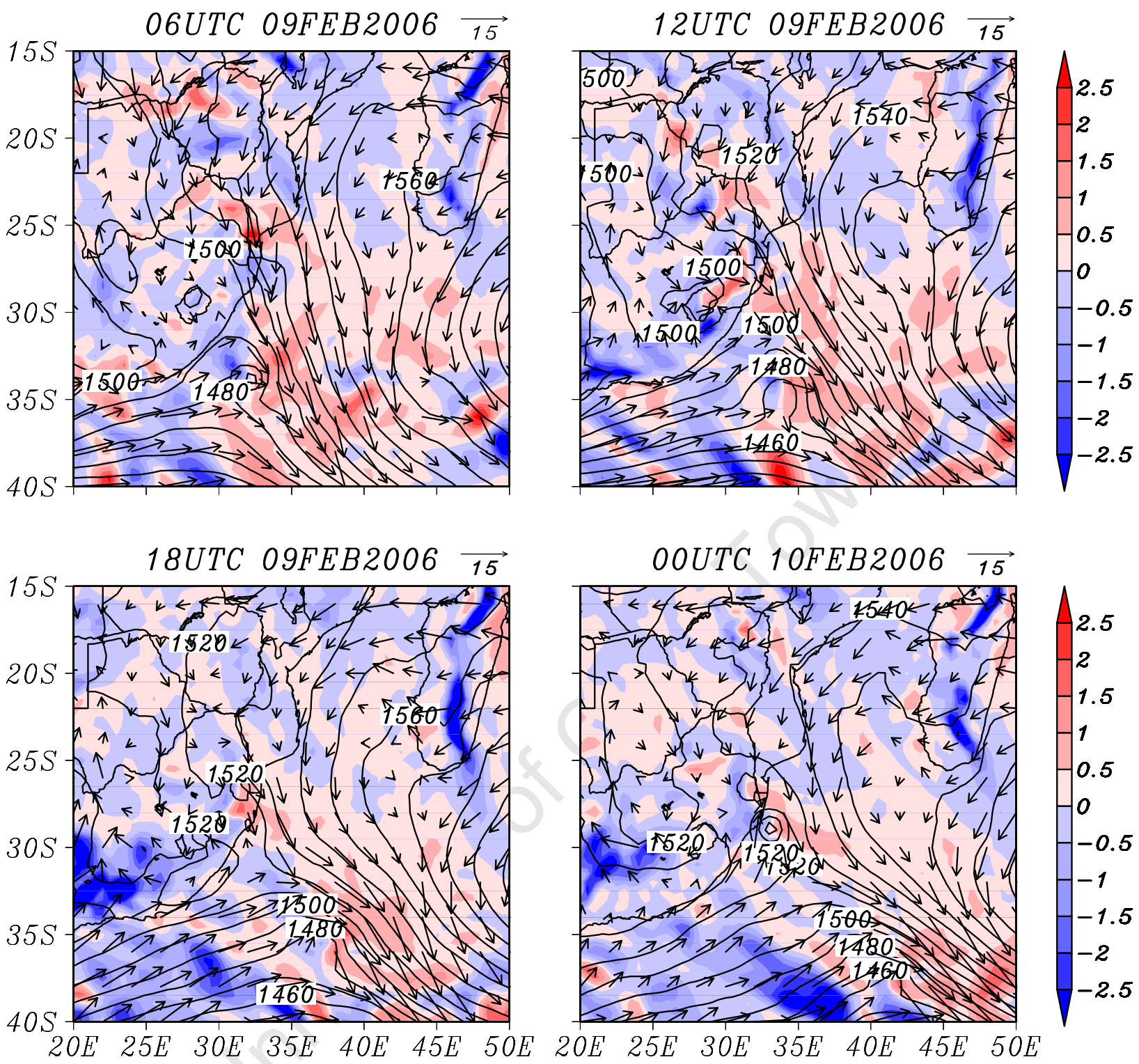

Figure A7.10: Temperature advection (shaded; $\mathrm{K} \mathrm{s}^{-1}$ ), geopotential height (contours; $\mathrm{m}$ ) and wind vectors $\left(\mathrm{m} . \mathrm{s}^{-1}\right)$ at $850 \mathrm{hPa}$. 

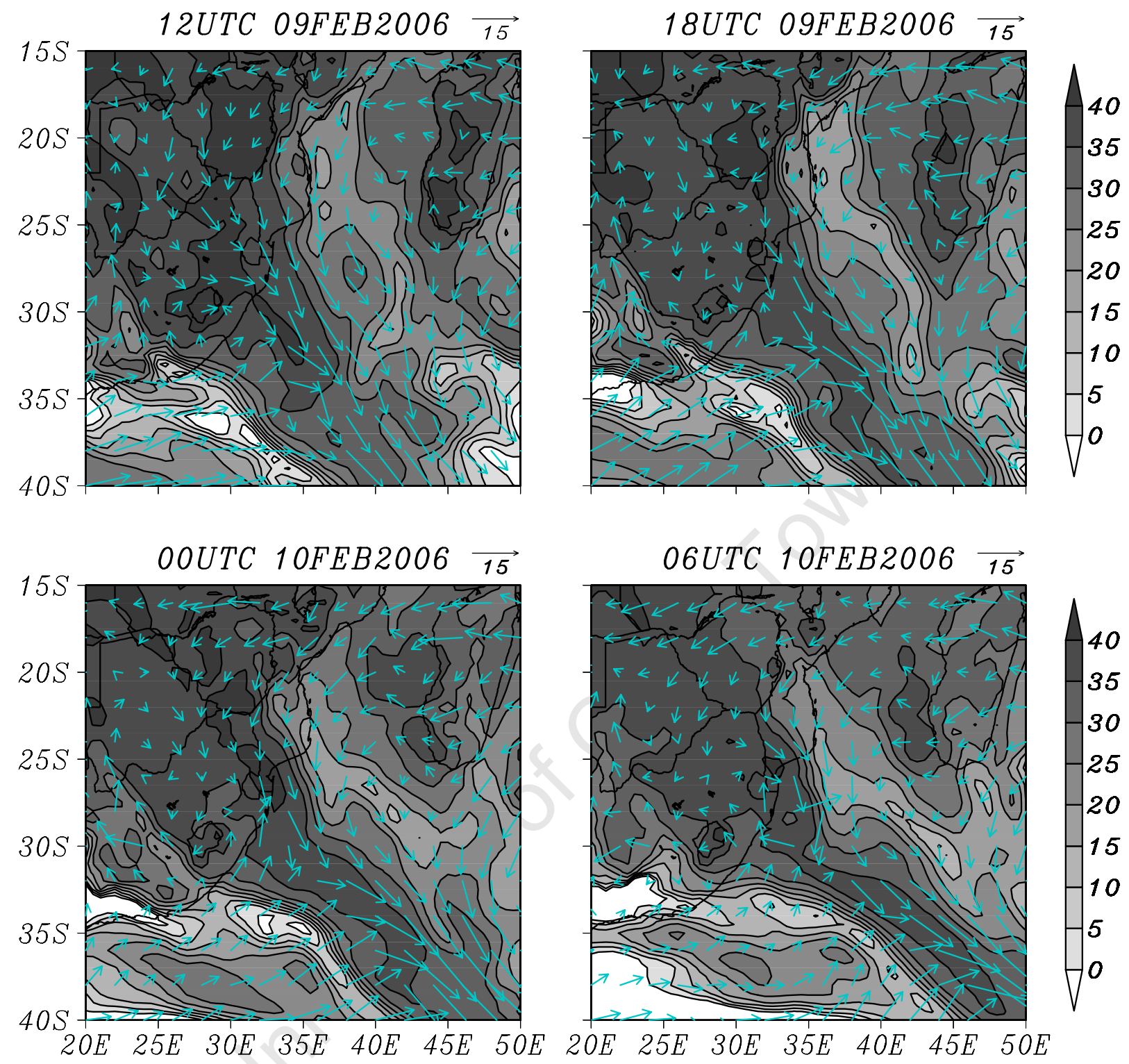

Figure A7.11: The $K$-Index (shaded) and vector winds $\left(\mathrm{m}^{-\mathrm{s}^{-1}}\right)$ at $850 \mathrm{hPa}$. 

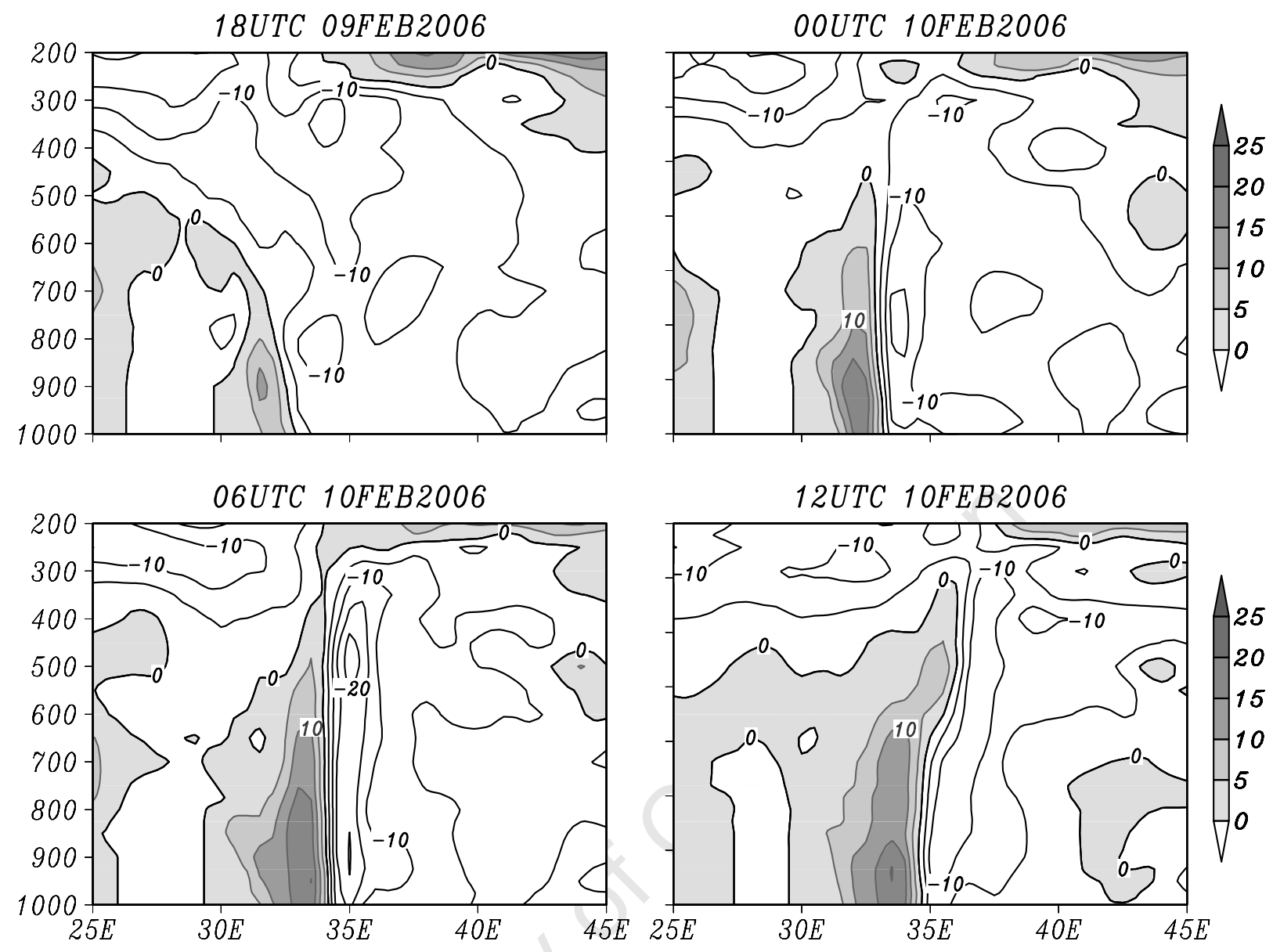

Figure A7.12: Meridional wind speed along 29 ${ }^{\circ}$ S (see Fig. 7.38 for location). Positive shaded values indicate equatorward moving air, while negative contoured values indicate poleward moving air. 